\title{
Desarrollo del esqueleto larvario y musculatura asociada en el género Batrachyla Bell 1843 \\ (Anura: Neobatrachia) y sus relaciones filogenéticas interespecíficas
}

Autor: Lic. Leandro Alcalde.

Director: Dr. Néstor G. Basso.

Institución: Facultad de Ciencias Naturales y Museo - Universidad Nacional de La Plata.

Año: 2007. 


\title{
DEDICATORIA Y AGRADECIMIENTOS
}

\author{
"siéntate ante los hechos como un niño pequeño, \\ disponte a abandonar cualquier idea preconcebida, \\ sigue a la naturaleza dondequiera \\ y a cualesquiera abismos a los que te lleve, \\ o no aprenderás nada". \\ Thomas Henry Huxley
}

A mis padres por incentivar mi curiosidad. A mi madre en especial, por darme la posibilidad.

A mi hijo Luan, que floreció en la última etapa del trabajo y lo colmó todo con su belleza.

A mi mujer, Gabriela, por su apoyo en todo momento, amor y compañía.

A Cata y los Pochos.

A mi director Néstor G. Basso por haberme iniciado, orientado y acompañado en esta etapa.

A mis compañeros del área de sistemática del ILPLA.

A quienes me han acompañado en diferentes campañas y momentos: G. Spinelli, J. D. Williams, S. D. Rosset.

A diversas personas por la facilitación de parte del material, consejo y toma de fotografías, como C. Úbeda, B. Blotto, R. Herrera.

A G. Carrizo y J. D. Williams por la atención durante el estudio de las colecciones a su cargo.

A las autoridades de Parques Nacionales por los permisos correspondientes.

A Pedro y los muchachos que me alegraron el último tramo de este trabajo y demostraron que lo más importante es dar lo mejor de sí en la lucha por una meta aunque luego, ésta no se logre. 


\section{INDICE}

RESUMEN. 8-11

ABSTRACT.

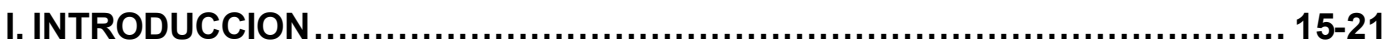

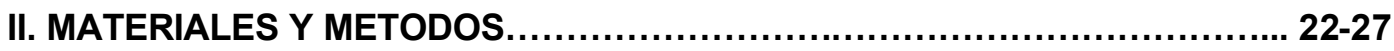

II.1. Obtención del material de estudio.............................................22

II.2. Determinación de especies y estadios larvarios ..........................22-23

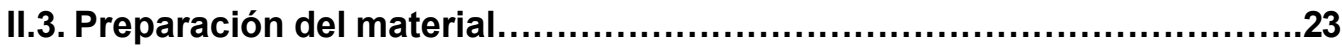

II.4. Observación y descripción del material....................................23-24

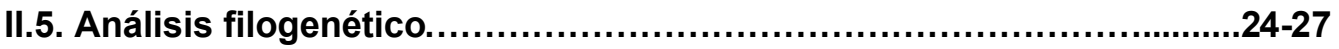

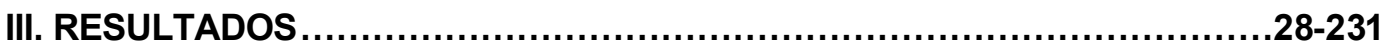

III.1. Desarrollo del condrocráneo en Batrachyla taeniata .....................28-45

III.1.1. Neurocráneo: Región etmoidal y cartílagos nasales..............28-30

III.1.2. Neurocráneo: Región fronto-orbitaria..................................34

III.1.3. Neurocráneo: Región ótico-occipital..............................34-37

III.1.4. Arco mandibular........................................................37-39

III.1.5. Aparato hiobranquial .................................................39-41

III.2. Desarrollo del osteocráneo en B. taeniata..................................46-53

III.2.1. Neurocráneo: Región nasoetmoidal.....................................46

III.2.2. Neurocráneo: Región fronto-orbitaria.........................................46-47

III.2.3. Neurocráneo: Región ótico-occipital.................................47-48

III.2.4. Paladar................................................................ $48-49$

III.2.5. Mandíbula.............................................................

III.2.6. Alostosis de las crestas neurales asociadas al arco maxilar.....50-53

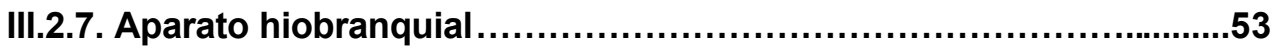

III.3. Desarrollo de la musculatura craneana en $B$. taeniata....................54-75

III.3.1. Musculatura mandibular...............................................54-57

III.3.2. Musculatura hioidea ............................................61-64

III.3.3. Musculatura branquial.................................................64-68

III.3.4. Musculatura hipobranquial..........................................68-70

III.3.5. Musculatura ocular.....................................................74-75

III.4. Desarrollo del esqueleto axial postcraneana en B. taeniata................76-83

III.5. Desarrollo de la musculatura axial postcraneana de $B$. taeniata.........84-91

III.6. Desarrollo del esqueleto apendicular anterior en B. taeniata...........92-101

III.6.1. Cintura escapular y esternón.......................................92-94 
III.6.2. Estilopodio........................................................94-95

III.6.3. Zeugopodio.......................................................95-96

III.6.4. Autopodio............................................................96-98

III.7. Desarrollo de la musculatura apendicular anterior en B. taeniata...102-126

III.7.1. Músculos asociados a la cintura escapular y estilopodio.......102-108

III.7.2. Músculos asociados al zeugopodio..................................108-110

III.7.3. Músculos asociados al autopodio.................................115-126

III.8. Desarrollo del esqueleto apendicular posterior en $B$. taeniata........127-135

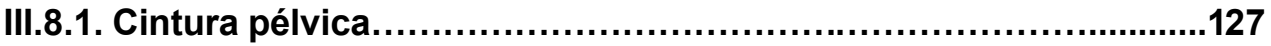

III.8.2. Estilopodio.......................................................127-128

III.8.3. Zeugopodio................................................................ 128

III.8.4. Autopodio..........................................................128-130

III.9. Desarrollo de la musculatura apendicular posterior en B. taeniata.136-153

III.9.1. Músculos asociados a la cintura pélvica y estilopodio.........136-139

III.9.2. Músculos asociados al zeugopodio...............................139-140

III.9.3. Músculos asociados al autopodio.................................143-153

III.10. Descripción y codificación de los caracteres..........................154-225

III.10.1. Caracteres de cráneo y musculatura craneana..................154-183

III.10.1.1. Condrocráneo. Neurocráneo..................................154-158

III.10.1.2. Condrocráneo. Arco mandibular ...........................158-159

III.10.1.3. Condrocráneo. Aparato hiobranquial.......................159-163

III.10.1.4. Osteocráneo. Neurocráneo y arco mandibular............163-175

III.10.1.5. Musculatura mandibular....................................175-178

III.10.1.6. Musculatura hioidea............................................178-179

III.10.1.7. Musculatura branquial....................................179-183

III.10.2. Caracteres de musculatura axial postcraneana .................183-184

III.10.3. Caracteres de esqueleto y musculatura del miembro anterior 185-196

III.10.3.1. Cintura y esternón.........................................185-189

III.10.3.2. Autopodio...............................................189- 196

III.10.4. Caracteres de esqueleto y musculatura del miembro posterior 196-204

III.10.4.1. Estilopodio...............................................196-198

III.10.4.2. Zeugopodio...................................................198-201

III.10.4.3. Autopodio..................................................201-204 
III.10.5. Caracteres de morfología externa del adulto .204-209

III.10.6. Caracteres de morfología externa de la larva. .209-214

III.10.7. Caracteres de la cavidad bucofaríngea de la lana. .214-216

III.10.8. Caracteres de cariología. 216-217

III.10.9. Caracteres de biología reproductiva. 217-219

III.10.10. Caracteres descartados 219-225

III.10.10.1. Caracteres insuficientemente conocidos 219-220

III.10.10.2. Caracteres merísticos influenciados por el error de medición 220-221

III.10.10.3. Caracteres de codificación subjetiva. 221-222

III.10.10.4. Caracteres no informativos. $.222-224$

III.10.10.5. Teratologías. .224

III.10.10.6. Caracteres dependientes. $.224-225$

III.11. Análisis de relaciones filogenéticas .226-231

III.11.1. Análisis con los caracteres igualmente pesados...................226

III.11.2. Análisis sin pesos implicados .......................................226

III.11.3. La monofília de Batrachyla y los clados que lo integran....226-230

III.11.4. Relación de Batrachyla + Hylorina con los grupos externos .230-231

IV. DISCUSION 232-260

IV. 1. Condrocraneo. 232-234

IV. 2. Osteocraneo. $.234-243$

IV. 3. Musculatura craneana 243-245

IV. 4. Esqueleto axial postcraneano. .245-252

IV. 5. Musculatura axial postcraneana. .252-254

IV. 6. Esqueleto y musculatura apendicular anterior .255-257

IV.7. Esqueleto y musculatura apendicular posterior. $.257-258$

IV. 8. Relaciones Filogenéticas 258-260

V. CONCLUSIONES. 261-263 


\section{INDICE DE TABLAS, FIGURAS Y APENDICES}

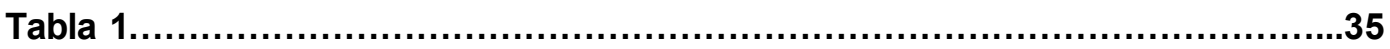

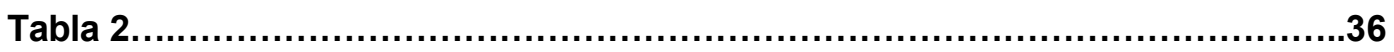

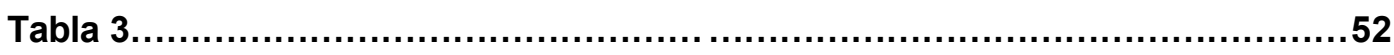

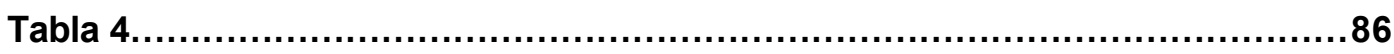

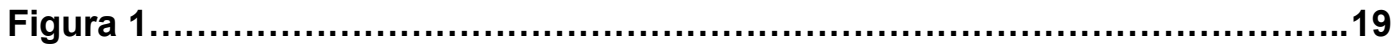

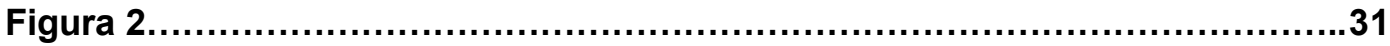

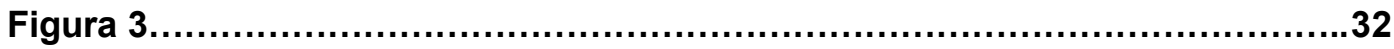

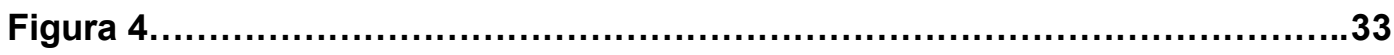

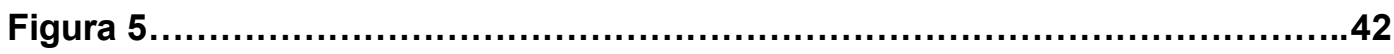

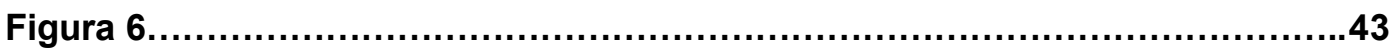

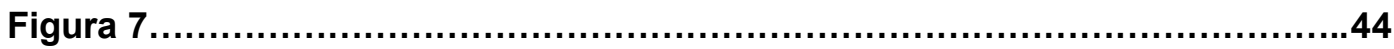

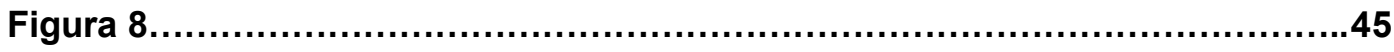

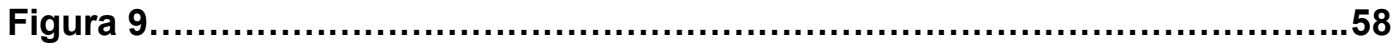

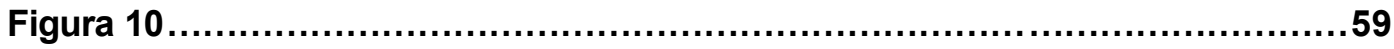

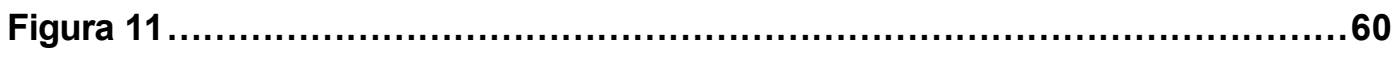

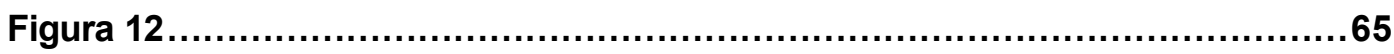

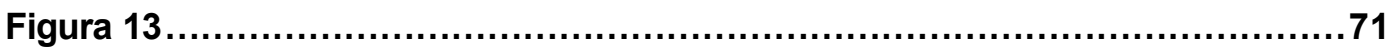

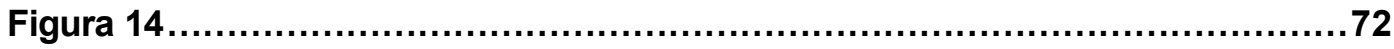

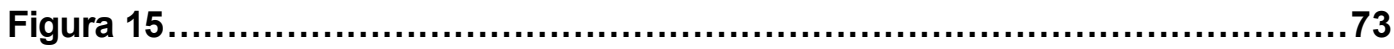

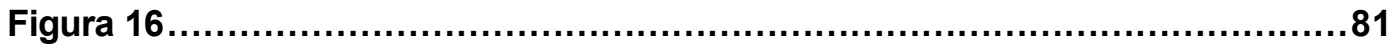

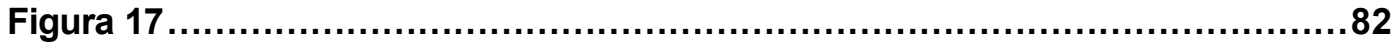

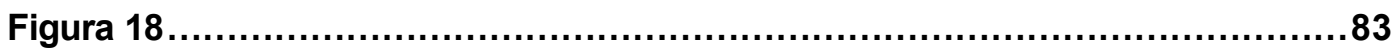

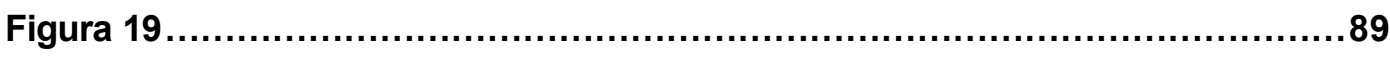

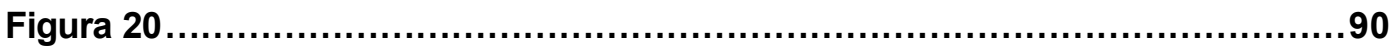

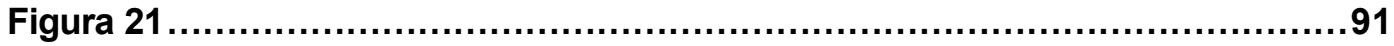

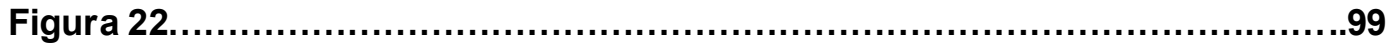

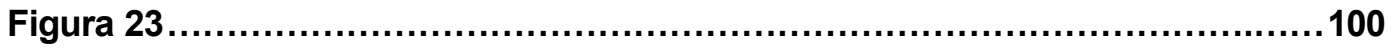

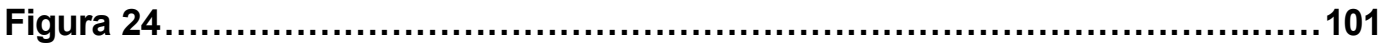

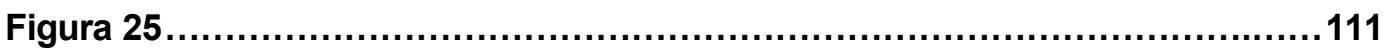

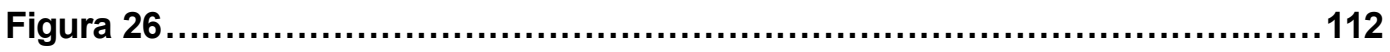

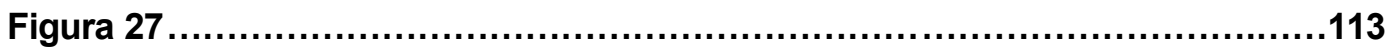

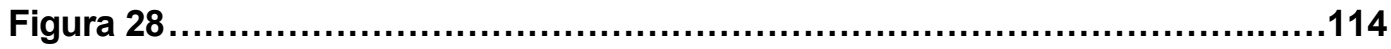

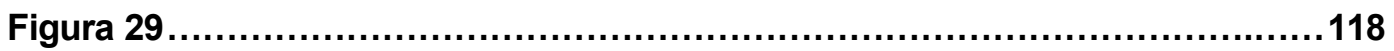




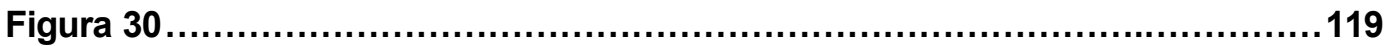

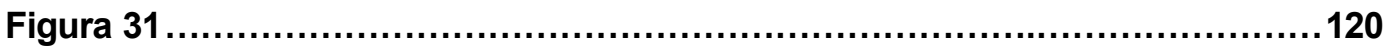

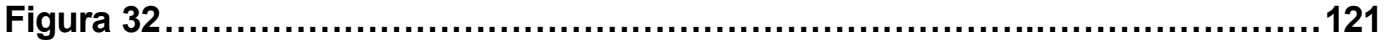

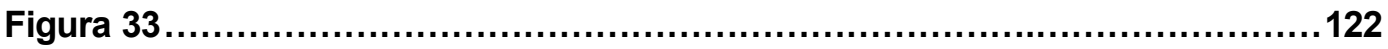

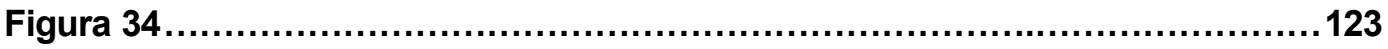

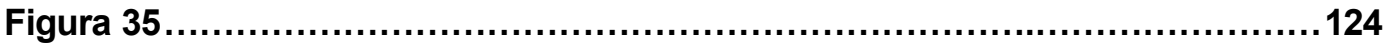

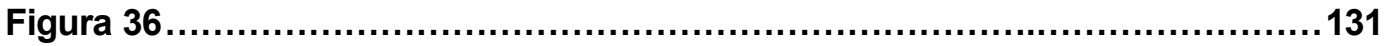

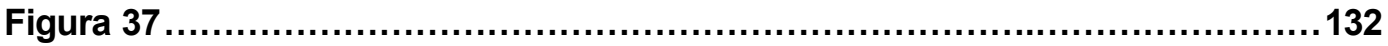

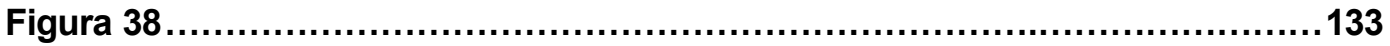

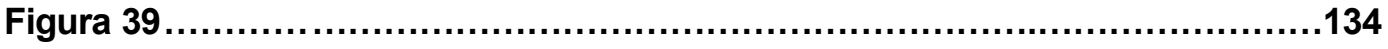

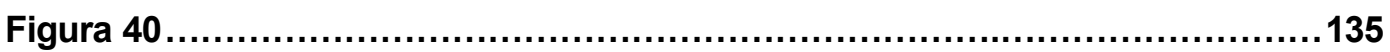

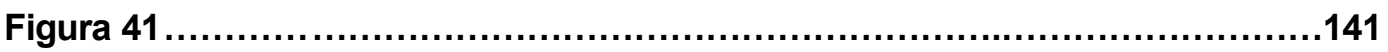

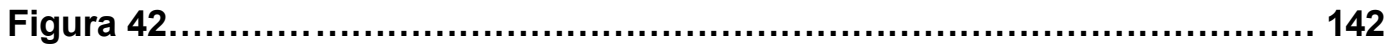

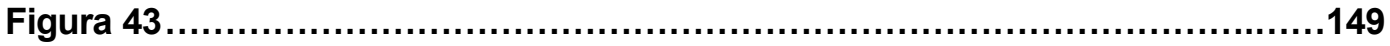

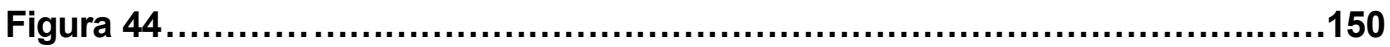

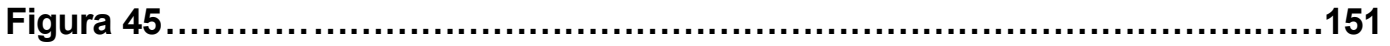

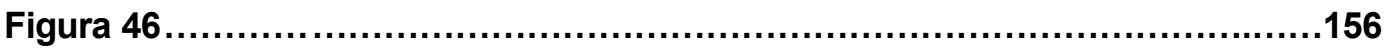

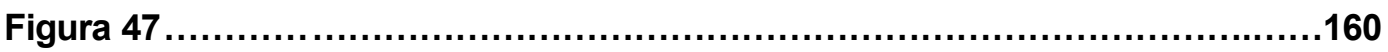

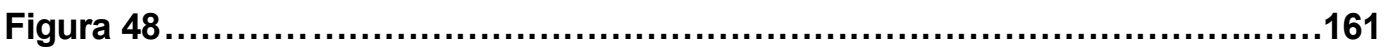

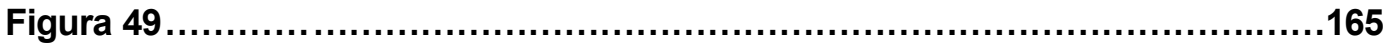

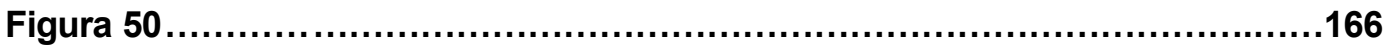

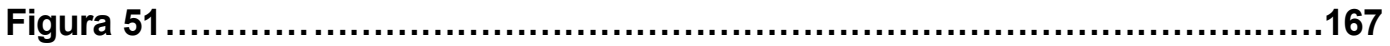

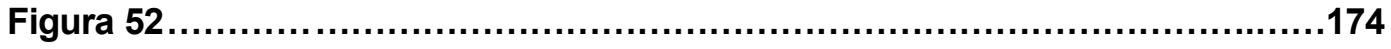

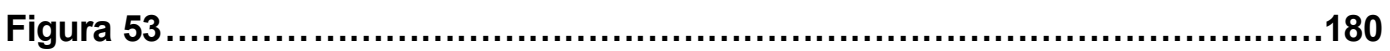

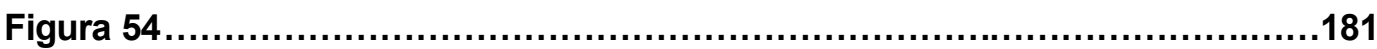

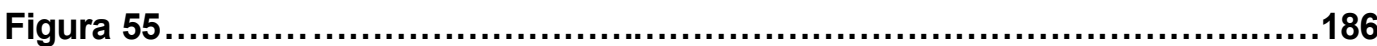

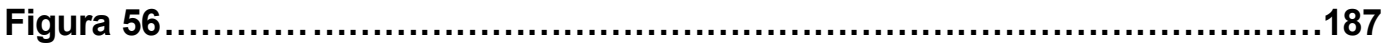

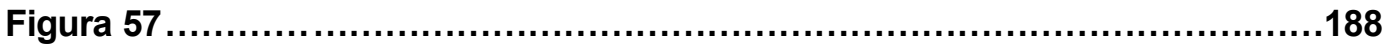

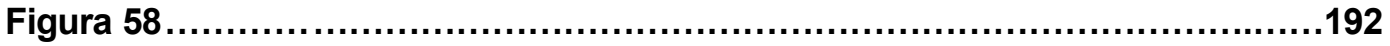

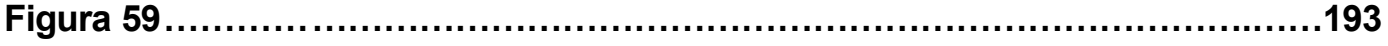

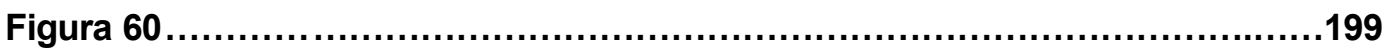

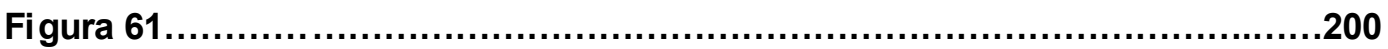

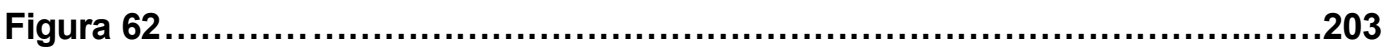

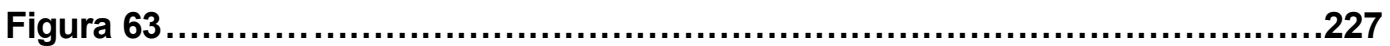

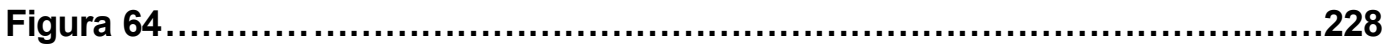




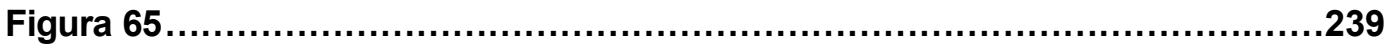

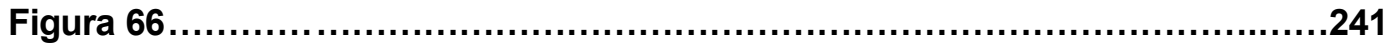

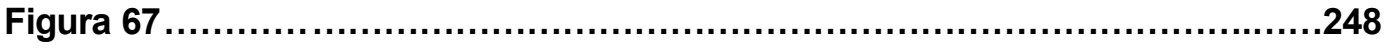

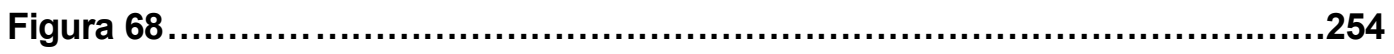

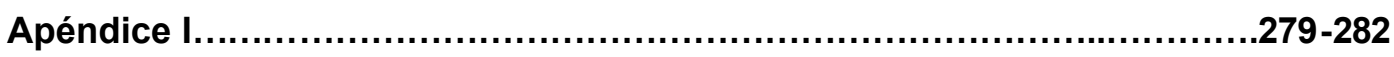

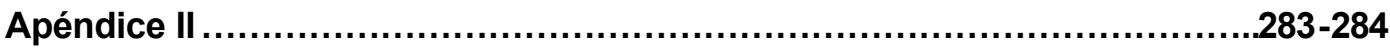

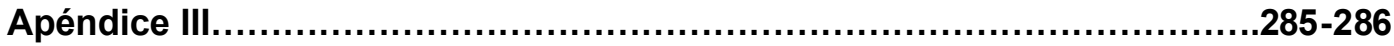

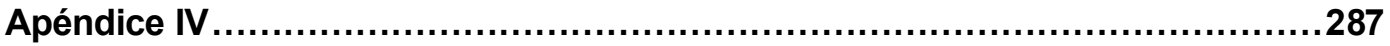

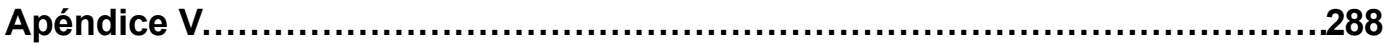

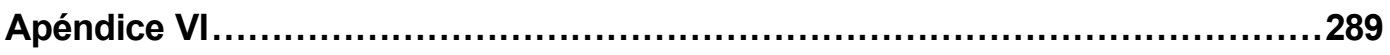

Apéndice VII...................................................................290

Apéndice VIII..........................................................................291 
RESUMEN. El presente trabajo comprende dos objetivos. El primero está referido al desarrollo, desde larva hasta adulto, del esqueleto y los músculos en las especies del género Batrachyla. El segundo es realizar un análisis cladístico del género.

Batrachyla es un género neotropical de Anuros Neobatracios compuesto por cinco especies distribuidas por los bosques argentinos y chilenos del género Nothofagus. Historicamente ha sido clasificado dentro de "Leptodactylidae", en la subfamilia "Telmatobiinae", pero actualmente se conoce que ambas entidades no son monofileticas, sin existir acuerdo en como se distribuyen taxonomicamente los clados que integran esos agrupamientos.

Se trabajo con larvas de tres especies (la larva de Batrachyla fitzroya y $B$. nibaldoi permanecen desconocidas) y adultos todas las especies del género. Al ser $B$. taeniata la especie con que más material se dispuso, la base de las observaciones y descripciones fue realizada sobre esta especie y luego se realizaron comparaciones con las restantes.

El material para análisis ostológico y condrológico se preparó según técnicas convencionales de doble tinción y diafanización. El material destinado al análisis miológico se preparó según esas técnicas evitando el paso final de diafanización.

Para el análisis cladístico se emplearon 7 grupos externos que corresponden a las especies Alsodes gargola, Atelognathus patagonicus, Ceratophrys ornata, Chacophrys pierottii, Eupsophus calcaratus, Hylorina sylvatica y Pleurodema borellii (empleada para enraizar). Los 110 caracteres (72 de morfología del adulto, 33 de morfología larvaria, 2 de cariología y 3 de biología reproductiva) se analizaron con el programa TNT. Se realizaron dos análisis, uno con caracteres igualmente pesados y otro con pesos implicados.

El condrocráneo de Batrachyla spp. presenta el patrón descrito para larvas exotroficas, microfagas, bentónicas y de charca. Su metamorfosis también sigue los patrones descritos en la literatura para otras especies de anuros. El condrocráneo aporto diversos caracteres, muchos de los cuales resultaron en sinapomorfias de grupos.

Respecto del análisis osteológico los aspectos más relevantes fueron: 1) presencia de osificaciones parahioideas en diversos especimenes metamórficos de Batrachyla taeniata, las cuales no fueron observadas en los ejemplares adultos, 2) presencia de un centro de osificación ubicado en la región posterior de la cápsula ótica interpretado como correspondiente a un opistótico reducido, el cual es rapidamente incorporado al centro del hueso exoccipital, y 3 ) presencia de dos centros para el 
hueso escamoso, uno correspondiente a la rama ventral, y otro a las ramas ótica y anterior. El primero de ellos fue interpretado como el escamoso de los otros tetrápodos, el segundo se interpreto como tabular. Del mismo modo se discute el problema de los diversos centros que se han reportado para el hueso pterigoides, sugiriendo que el centro correspondiente a la rama zigomática representa el ectopterigoides de los restantes tetrápodos, mientras que el centro de la rama posterior corresponde al endopterigoides.

Respecto de la musculatura craneana se registraron 7 músculos oculares (larva y adulto), 10 (larva) y 7 (adulto) músculos mandibulares, 8 (larva) y 2 (adulto) músculos hioideos, 13 (larva) y 9 (adulto) músculos branquiales, y 3 (larva) y 4 (adulto) músculos hipobranquiales. Se discute la homología entre los $\mathrm{mm}$. rectus cervicis, rectus abdominis y sternohyoideus en el contexto de la confusión que existe en la literatura respecto de los mismos.

Los aspectos más sobresalientes derivados del análisis del desarrollo del esqueleto axial postcraneano son referidos a la formación de los cuerpos vertebrales (tipo de osificación y cantidad de centros intervinientes). Al respecto se concluye que: 1) las vertébras de los anuros estudiados no pasan en su osificación por un molde cartilaginoso, con lo cual deben ser consideradas de naturaleza alostósica, y 2) en la formación del cuerpo vertebral de los anuros intervienen hasta cuatro centros de osificación, dos ventrolaterales y dos dorsolaterales respecto de la notocorda.

Finalmente, se discute si el hipocordo es una neoformación o una estructura modificada de otras persistentes. Se concluye que la hipótesis más plausible es que el hipocordo corresponde a cuerpos postsacros fusionados.

La musculatura axial de las larvas estudiadas esta compuesta por una serie de miomeros cuyo número es constante en el tronco (9) y variable en la región caudal (16-33). De estos miomeros se diferencian los músculos epiaxiales del adulto. En el adulto se reconocen 32 músculos axiales, la mayoría de los cuales conservan rasgos metámericos. Se reporta un elemento axial previamente desconocido al cual he denominado $\mathrm{m}$. transveroesophagicus. Este músculo se origina en el proceso transverso III e inserta en la región lateral del esófago, justo por detrás de la posición de la laringe.

Se identificaron 84 músculos asociados al esqueleto apendicular anterior, uno de ellos previamente desconocido para anuros, al cual he denominado $\mathrm{m}$. rhomboideus superior. Este músculo se origina en el área dorsal de la supraescápula e inserta en una fascia sobre el m. longissimus dorsi. Los músculos son evidentes bajo 
lupa a partir del estadio 40 (musculatura del estilopodio y zeugopodio) y 42 (músculos del autopodio), a excepción de los $\mathrm{mm}$. interphalangeales que culminan su desarrollo al estadio 45.

Se identificaron 79 músculos asociados al esqueleto apendicular posterior. Estos son diferenciables bajo lupa a partir del estadio 38 (musculatura del estilopodio y zeugopodio) y 41 (músculos del autopodio), a excepción de los mm. interphalangeales, los $\mathrm{mm}$. asociados al prehallux y los $\mathrm{mm}$. extensores breves medius que se diferencian a estadios posteriores.

Como resultado del análisis filogenético se obtuvo que: 1) Batrachyla es monofilético pero incluye a Hylorina en su composición, 2) el género hermano al clado Batrachyla + Hylorina es Atelognathus, y 3) Ceratophrys y Chacophrys forman un clado muy bien soportado que se ubica por fuera del clado compuesto por Alsodes + (Atelognathus + (Batrachyla + Hylorina)).

Las sinapomorfias que sostienen el clado Batrachyla + Hylorina son: 1) unión sindesmotica entre el ceratobranquial II y la placa hipobranquial, 2) posición transversal del eje mayor de la cresta dentigera del vomer respecto del eje axial, 3) proyección anterior del hueso cuadrado presente, 4) m. subarcualis rectus II-IV inserto en el primer ceratobranquial, 5) tubéculo óseo en la cara medial del metacarpo II presente, 6) $\mathrm{m}$. adductor longus ausente, 7) las fibras del $\mathrm{m}$. extensor cruralis brevis ocupan solo los $2 / 3$ proximales del zeugopodio y rematan distalmente en un largo tendón que deja expuestos al tercio distal de la tibia-fíbula y al m. tibialis anticus brevis, y 8) tubo proctodeal reducido o ausente.

Dentro de Batrachyla, se reconocen dos clados: el clado taeniata que incluye a B. nibaldoi, B. taeniata e Hylorina sylvatica, y el clado leptopus que incluye a $B$. antartandica, B. fitzroya y B. leptopus.

Las sinapomorfias del clado taeniata son cuatro: 1) proceso lateral de los cuernos trabeculares ventralizado, 2) extremo de la falange dístal del digíto $V$ supera el nivel de la mitad de la segunda falange del digíto IV pero sin alcanzar la base de la falange dístal de dicho digíto, 3) cabeza central del $\mathrm{m}$. interphalangealis digiti $\mathrm{V}$ del miembro posterior presente y 4) factor de tamaño ovárico $>10$.

Las sinapomorfias del clado leptopus son:1) cóndilos occipitales separados por una distancia claramente mayor al ancho condilar, 2) dilatación en T de las falanges distales con ancho igual o mayor al ancho de la base de la falange distal, 3) cabeza central del $\mathrm{m}$. interphalangealis IV delmiembro anterior ausente, 4) $\mathrm{m}$. interphalangealis III del miembro posterior representado solo por la cabeza lateral, 5) 
m. interphalangealis IV del miembro posterior con cabeza medial menos desarrollada que la lateral, 6) m. interphalangealis distalis IV del miembro posterior compuesto solo por la cabeza lateral, y 7) granulación glandular dorsal del adulto presente.

Dentro del clado taeniata, Batrachyla taeniata y B. nibaldoi forman un clado soportado por dos sinapomorfias: 1) límite posterior del xifiesternón del adulto úbicado entre los miómeros $4^{\circ}$ y $5^{\circ}$ del $\mathrm{m}$. rectus abdominis, y 2 ) canto rostral bien marcado.

Dentro del clado leptopus, $B$. fitzroya y $B$. leptopus forman un clado cuya unica sinapomorfia es: hocico del adulto redondeado en vista lateral. 
ABSTRACT. The present work comprises two objectives. The first one is referred to the development, from larva to adult, of the skeleton and the muscles in the species of the genus Batrachyla. The second is to carry on a cladistic analysis of the genus.

Batrachyla is a neotropical genus of neobatrachians anurans compound by five species that distributes in the Nothofagus forests from Argentina and Chile.

Traditionally, Batrachyla has been classified into "Leptodactylidae", within the subfamily "Telmatobiinae", but nowadays it is known that both entities are non monophyletic without agreenment about the taxonomic distribution of both groups.

Tadpoles of only three of its species (the tadpoles of Batrachyla fitzroya and $B$. nibaldoi remain unknown) and adults of all of them were studied. The basis of the observations and descriptions was on $B$. taeniata, because it is the best represented in the studied material, and then comparisons with the other species were carried out.

The specimens were double stained and cleared for chondrologic and osteologic studies following conventinal techniques. The specimens for miological observation were prepared according to these techniques but stopping the process previous to the clearing step.

Seven external groups corresponding to the species Alsodes gargola, Atelognathus patagonicus, Ceratophrys ornata, Chacophrys pierottii, Eupsophus calcaratus, Hylorina sylvatica y Pleurodema borellii (employed for rooting) were used for the cladistic analysis. The 110 characters (72 of adult morphology, 33 of larval morphology, 2 of cariology, and 3 of reproduction biology) were analyzed using the program TNT. Two analyses were carried out, one with equally weighted characters and the other using implied weighting.

The chondrocranium of Batrachyla spp. follows the pattern described for other exotrophic, microphagic, and benthic pond type tadpoles. The metamorphosis of the condrocranium also follows the patterns described in the literature for other anuran species. A lot of chondrocranial characters were employed in the cladistic analysis and some of them were recovered as sinapomorphic states for several groups.

With respect to the osteological analysis, the most relevant aspects were: 1) parahyoid ossifications were observed in sevaral metamorphic specimens of Batrachyla taeniata, but not in the adults, 2) presence of one ossification center placed in the posterior wall of the otic capsule that was interpreted as a reduced opistotic. It center is fastly fused to the exoccipital, 3) presence of two ossification centers for the squamosal, one corresponding to the ventral arm, and the other to the otic and anterior arms. The first one was interpreted as the squamosal of other tetrapods, and the 
second one as a tabular, and 4) presence of two ossifications centers corresponding to the pterygoid, one center (zygomatic arm) corresponding to the ectopterygoid of other tatrapods, and the other center (center of posterior and medial arms) represents at least the endopterygoid.

In spite that several pterygoid ossifications centers were not observed here, the problem of the literature reports about the various pterygoid centers is also discussed. With respect to the cranial muscles, the following muscles were registered: 7 ocular muscles (tadpole and adult), 10 (tadpole) and 7(adult) mandibular muscles, 8 (tadpole) and 2 (adult) hyoid muscles, 13 (tadpole) y 9 (adult) branchial muscles, and 3 (tadpole) and 4 (adult) hypobranchial muscles. The homology among the $\mathrm{mm}$. rectus cervicis, rectus abdominis and sternohyoideus is discussed in the context of some literature mistakes about them.

The most relevant aspects of the postcranial axial development are about the vertebral body formation (mode of ossification and number of centers implicated). The conclusions are: 1) the vertebral ossification in the studied anurans occurs without a cartilage fase and should be considered of alostosic nature, 2) each anuran vertebra ossifies from four ossifications centers, two dorsolateral and two ventrolateral to the notochord. Finally, the homology of the hypochord is discussed concluying that the most plausible hypothesis is that the hypochord represents a serie of fused postsacral vertebral bodies.

There are nine troncal and a variable number (16-33) of axial myomeres that represent the axial muscles of the sudied tadpoles. The epaxial muscles of the adult diferentiates from this larval myomeres. There are 32 axial muscles in the adults, most of them with a metameric pattern. A previously uncknown axial muscles is first reported here. It was named $\mathrm{m}$. transversoesophagicus, have origin in the transverse process III and inserts in the lateral sides of the oesophagus, just behind the larinx.

Batrachyla posses 84 muscles associated to the anterior apendicular skeleton, one of these muscles was previously unknown for other anurans. It was named $\mathrm{m}$. rhomboideus superior, originates in the dorsal area of the suprascapular cartilage and inserts in a fascia over the $\mathrm{m}$. longissimus dorsi .

The muscles are evident under stereomicroscope since stage 40 (stylopodial and zeugopodial muscles) and 42 (autopodial muscles), exception of the $\mathrm{mm}$. interphalangeales who ends the development at stage 45.

Batrachyla posses 79 muscles associated to the posterior apendicular skeleton. They are evident under stereomicroscope since stage 38 (stylopodial and zeugopodial 
muscles) and 41 (autopodial muscles), exception made of the $\mathrm{mm}$. interphalangeales, the $\mathrm{mm}$. associated to the prehallux and the $\mathrm{mm}$. extensores breves medius that develop later.

The following are the most relevant hypothesis of the cladistic analysis: 1) Batrachyla is monophyletic but includes Hylorina in its composition, 2) the sister genus of the clade Batrachyla + Hylorina is Atelognathus, and 3) Ceratophrys and Chacophrys are a well supported clade placed out side of the clade compound by Alsodes + (Atelognathus + (Batrachyla + Hylorina) $)$.

The synapomorphies that support the clade Batrachyla + Hylorina are: 1) syndesmotic connection between ceratobranchial II and the hypobranchial plate, 2) the longest axis of the dentigerous process of the vomer is transversl to the axial axis, 3) anterior projection of the quadrate present, 4) $\mathrm{m}$. subarcualis rectus II-IV inserts on first ceratobranchial, 5) bone tubercle on the medial side of the metacarpal II present, 6) $\mathrm{m}$. adductor longus absent, 7 ) the fibers of the m. extensor cruralis brevis run only on the proximal $2 / 3$ of the zeugopod and are distally represented by a long tendon that does not cover the distal third of the tibia-fibula, y 8 ) proctodeal tube reduced or absent.

There are two clades within Batrachyla: the taeniata (B. nibaldoi, B. taeniata, Hylorina sylvatica) and the leptopus clade (B. antartandica, B. fitzroya, B. leptopus).

The sinapomorphies of the taeniata clade are: 1) lateral process of the trabecular horns ventralized, 2) distal end of the second phalanx (digit V) does not reach the base of the distal phalanx of digit IV, 3) central head of $\mathrm{m}$. interphalangealis digiti $\mathrm{V}$ (foot) present, and 4) ovary size factor $>10$.

The synapomorphies of the leptopus clade are:1) occipital condiles separated by a distancy clearly bigger than the condilar width, 2) T arms of the distal phalanx equal or widher than the base of the phalanx, 3) central head of $m$. interphalangealis IV (foot) absent, 4) $\mathrm{m}$. interphalangealis III (foot) formed only by the lateral head, 5) $\mathrm{m}$. interphalangealis IV (foot) with medial head smaller than the lateral one, 6) $\mathrm{m}$. interphalangealis distalis IV (foot) compound only by lateral head, and 7) dorsal glandular granulation of the adult present.

Within the taeniata clade, Batrachyla taeniata and B. nibaldoi form a clade supported by two synapomorphies: 1) posterior limit of the adult xiphisternon placed between the myomeres $4^{\circ}$ and $5^{\circ}$ of the m. rectus abdominis, and 2) well marked canthus rostralis.

Within the leptopus clade, Batrachyla fitzroya and B. leptopus form a clade supported by only one synapomorphy: snout of the adult rounded in lateral view. 


\section{INTRODUCCIÓN}

Los anfibios vivientes agrupados en tres ordenes, Caudata (salamandras y tritones), Gymnophiopna (cecilias o apodos) y Anura (ranas y sapos), integran los Lissamphibia (Duellman \& Trueb, 1986). La monofília de Lissamphibia fue discutida por los primeros investigadores que trabajaron en la sistemática del grupo, pero actualmente existe un amplío aunque no mayoritario consenso acerca de que este grupo constituye un grupo natural soportado por caracteres tanto morfológicos como moleculares (Zardoya \& Meyer, 2001). Los tres ordenes que lo integran cuentan con representantes fósiles que datan del periodo Jurásico (190-160 m.a), momento desde el cual ya se observa el plan de organización característico para cada grupo, lo que indica una divergencia temprana dentro de Lissamphibia (Zardoya \& Meyer, 2001).

Los anuros pueden considerarse un grupo diverso donde se reconocen alrededor de 4800 especies agrupadas en al menos 26 familias (Frost, 2004) pero muy homogéneo, dado que a pesar de la existencia de diversos tipos adaptativos (fosorial, trepador, acuático, etc.), en todos se verifica la presencia de un plan estructural que se interpreta en asociación a la capacidad saltatorial, donde los rasgos más sobresalientes son la ausencia de cola, un importante acortamiento de la columna vertebral y el alargamiento de los miembros posteriores. Reig (1958), basado en la presencia-ausencia de costillas libres y teniendo en cuenta el tipo vertebral, propuso la partición de Anura en dos grandes grupos: los Archaeobatrachia (considerados primitivos) y los Neobatrachia (considerados derivados). Con el advenimiento de la sistemática filogénetica se puso a prueba la monofília de ambos grupos hasta que actualmente la mayoría de los a utores considera que Archaeobatrachia es parafilético respecto de Neobatrachia, siendo estos últimos un grupo monofilético (Darst \& Cannatella, 2004). Dentro de los anuros neobatracios se encuentran dos grandes grupos soportados por caracteres osteológicos y miológicos, los Hyloidea (anteriormente denominados Bufonoidea) y los Ranoidea (Ford \& Cannatella, 1993). Estudios realizados sobre caracteres morfológicos indican que los Hyloidea son paráfileticos respecto a Ranoidea (Ford, 1989), sin embargo recientes filogenias elaboradas a partir de análisis moleculares indican la monofília reciproca de ambos grupos (Darst \& Cannatella, 2004).

La tradicional familia "Leptodactylidae" es un agrupamiento no monofiletico (Cannatella, 1985; Ford \& Cannatella, 1993) de anuros neobatracios que hasta recientemente se lo consideró compuesto por 5 subfamilias, 49 géneros y más de 
1100 especies (Frost, 2004), pero actualmente se encuentra dividido en diversas grupos monofileticos (Frost et al., 2006, Basso et al., en revisión) que se hallan ampliamente diversificados a lo largo de toda la región neotropical. Historicamente, diversos autores han sugerido que dentro de "Leptodactylidae", la subfamilia "Telmatobiinae" constituye un grupo basal (Laurent, 1979; Lynch, 1978). El primero en considerar a los telmatobínos fue Fitzinger (1843), quien empleó el nombre Telmatobii para agrupar las especies de Telmatobius dentro de "Leptodactylidae".

Posteriormente, Miranda - Ribeiro (1926) utilizó el nombre Telmatobiidae para agrupar a 2 géneros de ranas acuáticas Caudiverbera y Pseudis, este último considerado actualmente dentro de la familia Hylidae. Finalmente, Vellard (1951) consideró "Telmatobiinae" como subfamilia dentro de "Leptodactylidae" y agrupó en ella a Batrachophrynus y Telmatobius. A partir de entonces la composición de "Telmatobiinae" fue siempre controvertida.

Lynch (1971) propuso la definición más inclusiva de los "Telmatobiinae", considerándola compuesta por un género fósil y 24 vivientes arreglados en 5 tribus: Neoprocoela †, Batrachophrynus, Caudiverbera, Telmatobius y Telmatobufo (Telmatobiini); Batrachyla, Eusophus, Hylorina y Thoropa (Alsodini); Odontophrynus y Proceratophrys (Odontophrynini); Crossodactylodes, Cycloramphusy Zachaenus (Gripiscyni); Amblyphrynus, Eleutherodactylus, Euparkerella, Holoaden, Hylactophryne, Ischnocnema, Niceforonia, Sminthillus, Syrrhophus y Tomodactylus (Eleutherodactylini); y Scythrophrys (sin designación de tribu).

Posteriormente la tribu Alsodini fue dividida en 2 nuevas tribus por Lynch (1973): Alsodini ( Eupsophus -incluyendo Alsodes-e Hylorina) y Batrachylini (Batrachyla y Thoropa).

En 1975, Heyer analizó las relaciones dentro de "Leptodactylidae" y propuso una definición menos inclusiva de "Telmatobiinae", con los siguientes cambios respecto de Lynch (1971): 1) la tribu Eleutherodactylini de Lynch es considerada como un grupo informal, los Eleutherodactylines, 2) parte de las tribus Gripyscini y Alsodini (Thoropa) de Lynch, más el género Scythrophrys pasan a otro grupo informal, los Grypiscines, y 3) la tribu Odontophrynini de Lynch es pasada al grupo de los Ceratophrynes. Entonces, según Heyer (1975), los telmatobínos integran los siguientes géneros: Batrachophrynus, Batrachyla, Caudiverbera, Eupsophus (incluyendo Alsodes), Hylorina, Insuetophrynus, Telmatobius y Telmatobufo.

En 1978, Lynch proporcionó una definición más acotada de los "Telmatobiinae", coincidiendo parcialmente con Heyer (1975), pero proponiendo los 
siguientes cambios: 1) reconoce 2 nuevos géneros (Atelognathus y Somuncuria) cuyas especies habían sido previamente consideradas dentro de Batrachophrynusy Telmatobius respectivamente, 2) insinuó la inclusión de Limnomedusa dentro de "Telmatobiinae" (antes considerada en Leptodactylinae), y 3) reagrupa los géneros de "Telmatobiinae" en 3 tribus: Batrachylini (Batrachyla y Thoropa), Calyptocephalellini (Caudiverbera y Telmatobufo) y Telmatobiini (Alsodes, Atelognathus, Batrachophrynus, Eupsophus, Hylorina, Insuetophrynus, Limnomedusa, Somuncuria yTelmatobius). A estos 13 géneros los denomina colectivamente con el nombre informal de telmatobínos inferiores.

Autores posteriores siguen indistintamente a uno $u$ otro de los esquemas básicos y en parte antagónicos propuestos por Lynch $(1971,1978)$ y Heyer (1975). En 1986, Laurent otorgó identidad taxonómica a los grupos informales de Heyer (1975) incluyendo dentro de "Telmatobiinae" a los Alsodini y Telmatobiini de Lynch (1971).

Más recientemente, han salido publicadas tres filogénias basadas sobre datos moleculares en las cuales se plantean cambios radicales para diversos grupos y en particular para la tradicional familia "Leptodactylidae" (Frost et al., 2006; Grant et al., 2006, Basso et al., en revisión). A continuación se reseñaran los cambios hipotetizados por esos autores para los géneros que historicamente se han planteado como relacionados a Batrachyla.

Frost et al. (2006) recuperan un clado inclusivo denominado Chthonobatrachia, en el cual incluyen un clado con categoría de familia (Ceratophryidae) que a su vez se divide en dos subfamilias (Ceratophryninae y Telmatobiinae). Atelognathus, Batrachyla, Ceratophrys, Chacophrys y Lepidobatrachus integran Ceratophryninae, mientras que Telmatobiinae se integra solo por Telmatobius. Según Frost et al. (2006), el grupo hermano de los Ceratophryidae es un clado de nombre Hesticobatrachia en el cúal úbican a la familia Cyclorampidae. Los Cycloramphidae estan integrados por 12 géneros: Alsodes, Crossodactylodes, Cyclorhamphus, Eupsophus, Hylorina, Limnomedusa, Macrogenioglottus, Odontophrynus, Proceratophrys, Rhinoderma, Thoropa y Zachaenus.

Grant et al. (2006) también recuperan el clado denominado Chthonobatrachia e incluyen en el a la familia Ceratophryidae, y presentan identica composición para los Cycloramphidae. Sin embargo, a diferencia del trabajo de Frost et al (2006), incluyen tres subfamilias dentro de Ceratophryidae en vez de dos (Batrachylinae, Ceratophryninae y Telmatobiinae), dado que separan a Atelognathus y Batrachyla de los Ceratophryninae y los incluyen en la subfamilia Batrachylinae. 
Basso et al. (en revisión) ubican a Batrachyla en Alsodidae. Esta familia incluye dos clados, los Alsodinae (Alsodes y Eupsophus) y los Batrachylinae (Atelognathus, Batrachyla e Hylorina).

Sin considerar a los géneros Ceratophrys, Chacophrys y Lepidobatrachus, el género Batrachyla y la mayoría de los géneros australes que se hallan relacionados con ella (Alsodes, Atelognathus, Eupsophus, Hylorina e Insuetophrynus) constituyen un grupo poco diverso, rico en endemismos (Formas, 1979), y con un alto grado de especialización ecológica (Diaz \& Veloso, 1979) en relación a los modos de reproducción y a los tipos larvarios (Formas, 1981). Sus especies se distribuyen a lo largo de la Cordillera de los Andes desde Ecuador hasta los bosques templados de Hayas australes del género Nothofagus y la estepa patagónica en Argentina y Chile (Cei, 1980).

El género Batrachyla está integrado por 5 especies vivientes (Figura 1), de tamaño mediano (3-4 cm de longitud promedio), adaptadas a depositar los huevos en la tierra húmeda cerca del agua, mientras que las larvas desarrollan en charcas temporarias (Basso, 1994; Cei, 1980; Formas, 1997). Sus especies están distribuidas a ambos lados de la Cordillera de los Andes, asociadas a los bosques templados y australes del género Nothofagus (Cei, 1980). Batrachyla antartandica Barrio, 1967, B. leptopus Bell, 1843 y B. taeniata (Girard, 1854) se distribuyen ampliamente en Chile y Argentina, mientras que Batrachyla fitzroya Basso, 1994 es endémica de la Isla Grande, Lago Menéndez, P. N. Los Alerces, Chubút (Argentina) y Batrachyla nibaldoi Formas, 1997 se restringe a las regiones de Aysen y de Los Lagos (Chile) (Cei, 1980; Basso, 1994; Díaz-Páez \& Carreño, 2002; Formas, 1997; Pincheira-Donoso \& DíazPáez, 2003).

El estudio sistemá tico del género Batrachyla ha sido abordado desde disciplinas tales como anatomía ósea, bioacústica, bioquímica, cariología, desarrollo larvario, ecología reproductiva, genética y morfología externa de adultos y larvas (Barrio \& Rinaldi de Chieri, 1971; Basso, 1994; Brieva Vasquez, 1988; Busse, 1971; Capurro, 1958; Cei \& Capurro, 1958; Diaz Perez, 1984; Diaz \& Veloso, 1979; Formas, 1971, 1976, 1997; Formas \& Brieva, 2000; Guzmán Poo, 1970; Jorquera \& Molinari, 1979; Lavilla, 1988; Lynch, 1971; Mulsow Flores, 1984; Úbeda, 1998; Vallejos Vallejos, 1994). Existen numerosas contradicciones en consonancia con la mencionada profusión de estudios, por ejemplo acerca de la presencia o ausencia del hueso cuadradoyugal, en cuanto al tipo de amplexo y la cantidad media de huevos por puesta (Basso, 1994; Cei, 1980; Formas, 1997; Lynch, 1971; Vallejos Vallejos, 1994). 

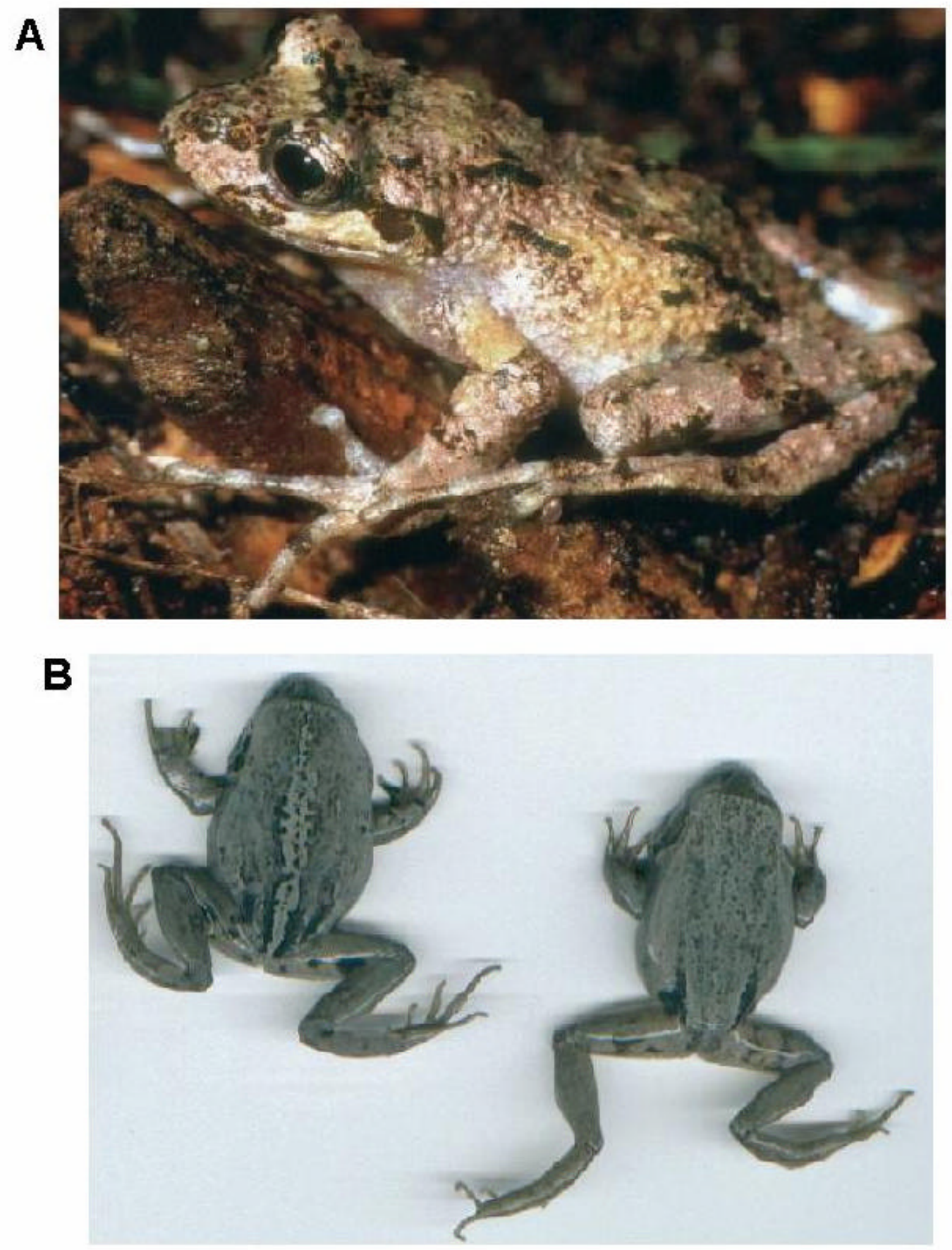

Figura 1. Adulto de Batrachyla leptopus fotografiado en su ambiente natural (A) y dos ejemplares macho de Batrachyla nibaldoi (B) como ejemplo de los dos tipos morfológicos que presentan las especies de Batrachyla. Nótese la piel rugosa y los extremos de los dígitos dilatados en (A) y la piel lisa y los extremos de los dígitos no dilatados en (B). 
La existencia de interpretaciones contradictorias y/ o de variabilidad en los caracteres se refleja en los resultados de los análisis filogenéticos realizados por Basso (1994), Brieva Vasquez (1988) y Vallejos Vallejos (1994). Si bien estos autores coinciden en que Batrachyla es un grupo monofilético, no hay acuerdo en cuanto a que sinapomorfías sostienen la monofília del género. Según el análisis de Basso (1994), Batrachyla está sostenido por 3 sinapomorfías: falanges terminales en forma de "T", cuadradoyugal fuertemente reducido y cóndilos occipitales separados por una distancia mayor que el ancho condilar. Para Vallejos Vallejos (1994) el número de sinapomorfías son 5: ausencia de cuadradoyugal, sobreposición parcial entre maxilar y pterigoides, nasales pequeños, presencia de callosidades nupciales y primer dígito de la mano más corto que el segundo. Finalmente, Brieva Vasquez (1988) postuló 10 sinapomorfías procedentes de la morfología externa y la cavidad oral de las larvas. Finalmente, dos de las tres últimas filogenias basadas sobre datos moleculares que se han publicado recientemente (Frost et al., 2006; Grant et al., 2006) recuperan la monofilia de Batrachyla. Basso et al. (en revisión) tambien recupera a Batrachyla como grupo monofiletico, aunque en varios de sus análisis Hylorina queda anidada en su composición.

Los cambios en la secuencia de desarrollo resultan en aspectos fundamentales de la evolución de muchos linajes de vertebrados (Alberch, 1980; Hall, 1984). El conocimiento de estas secuencias es de sumo interés tanto en el análisis de la ontogenia como en el de la evolución morfológica. En el caso de los anfibios anuros, los cambios estructurales a lo largo de la ontogenia son particularmente importantes a causa que éstos poseen un ciclo de vida bifásico en el cual existe una larva y una forma adulta. La selección natural opera en ambas etapas del ciclo y en términos de adaptación, no puede afirmarse que una etapa sea más importante que la restante. De hecho existen hipótesis acerca de si existen tendencias de pérdida de una etapa a favor de la otra (Altig \& Mc Diarmid, 1999). A pesar de no existir evidencias que avalen una importancia mayor acerca de las formas adultas respecto de las larvas, existen condicionamientos históricos que han llevado a basar la sistemática de los anuros, casi en su totalidad, sobre caracteres de las formas adultas. A partir de los estudios de Edgewgorth (1920), De Jongh (1968), Orton (1957), Sedra (1951), Sokol (1975, 1981), Starret $(1968,1973)$ y Wassersug (1980), paulatinamente se ha ido promoviendo el conocimiento y la importancia de las larvas para elaborar la sistemática del grupo. A pesar del escaso conocimiento acerca de la ontogenia y las características larvarias de la morfología externa e interna, las larvas de anuros han sido fuente de información 
para análisis cladísticos a nivel genérico (Larson \& de Sá, 1998) y de categorías superiores (Haas, 1996, 2003).

La existencia de numerosos caracteres considerados primitivos resalta la necesidad de avanzar en un conocimiento sólido acerca de las relaciones evolutivas internas de los telmatobínos como aporte inicial a la resolución de las relaciones dentro de la familia "Leptodactylidae". En ese sentido, esta tesis pretende avanzar en ese conocimiento, estudiando al género Batrachyla a partir de caracteres que han sido utilizados con anterioridad por otros autores (Basso, 1994; Brieva Vasquez, 1988; Lynch, 1971; Vallejos Vallejos, 1994) y aportando caracteres originales provenientes fundamentalmente de la morfología del esqueleto a lo largo del desarrollo larvario. El estudio del desarrollo en un contexto evolutivo, se robusteció durante la última década en forma de una nueva disciplina conocida como "evo-devo" (del ingles evolutiondevelopment), la cual sintetiza la biología del desarrollo y la biología evolutiva dando interesantes frutos en la comprensión de la historia evolutiva. Esta historia pasó a ser interpretada a partir de cambios en el desarrollo de los organismos más que de cambios en la estructura de los organismos adultos (Raff, 2000). El presente trabajo de tesis doctoral se enmarca en ese contexto y presenta los siguientes objetivos: 1) describir y comparar la morfología del esqueleto en larvas del género Batrachyla a lo largo de su desarrollo, 2) obtener caracteres que permitan proponer hipótesis que reflejen la historia filogenética del género, y 3) contrastar la/s hipótesis obtenida/s con aquellas relaciones propuestas por otros autores (Brieva Vasquez, 1988; Basso, 1994; Vallejos Vallejos, 1994) sobre la base de otras fuentes de caracteres. 


\section{MATERIALES Y MÉTODOS}

II. 1. Obtención del material de estudio. Los ejemplares estudiados provienen de 2 vías diferentes: material existente en las colecciones de anfibios del Museo de La Plata (MLP) y del Museo Argentino de Ciencias Naturales "Bernardino Rivadavia" (MACN) y material capturado específicamente para el desarrollo de este proyecto (actualmente depositado en el MLP). La cantidad de ejemplares, datos de colección, identidad especifica, estadio (para larvas), sexo (para adultos) y fin para el que fue empleado se especifican en el Apéndice I.

Las larvas capturadas específicamente para este trabajo, procedentes de las localidades Circuito Chico y Puerto Blest (Río Negro, Argentina), y Glaciar Exploradores y Bahía Murta (XI Región, Chile) (Apéndice I), se fijaron a campo con solución de formaldehido al $10 \%$ estabilizado con carbonato de calcio a fin de evitar la acción ácida en la descalcificación de los centros de osificación. En el caso de no estar representados todos los estadios de desarrollo en el momento de la captura en el campo, se procedió a llevar al laboratorio un lote de larvas para su crianza (ver determinación del material). Las larvas procedentes de las localidades Lago Queñi (Neuquén, Argentina), Villa Amengual y Pucatrihue (X y XI Región, Chile) (Apéndice I) se fijaron con alcohol $70 \%$.

II. 2. Determinación de especies y estadios larvarios. Los estadios se clasificaron según la tabla de desarrollo normal propuesta por Gosner (1960). Esta tabla agrupa los estadios en 4 períodos de desarrollo: desarrol lo de la yema del miembro posterior (estadios 26 - 30), diferenciación de los dígitos del pie (estadios 31 -41), clímax metamórfico (estadios $42-46$ ) y postmetamórfosis. Cuando algunos ejemplares presentaron características de 2 o 3 estadios sucesivos se procedió a ubicar el material de acuerdo a sus características más avanzadas.

La determinación del material se realizó considerando descripciones originales (Barrio, 1967a; Basso, 1994; Formas, 1976, 1997) y literatura adicional (Cei, 1962a, 1980; Lavilla, 1988; Úbeda, 1998) y en el caso de las larvas, cuando fue necesario, mediante la crianza de algunos especímenes hasta su metamorfosis. La misma se efectuó a temperatura ambiente que osciló entre los 20 y 25 grados centígrados. Los recipientes de crianza eran de 3 litros de capacidad, 5 centímetros de profundidad, con una densidad de 10 larvas por litro. El agua se oxigenó continuamente con aireadores para acuario y las larvas fueron alimentadas diariamente "ad libitum" con alimento en 
escamas para peces. El nivel de agua se mantuvo constante mediante el agregado de agua declorinada cada vez que la evaporación hacía descender el nivel máximo de cada recipiente. Los recipientes contaron con vegetación flotante (Azzola sp.) con el fin de permitir la salida de las larvas a medida que culminaban la metamorfosis.

II. 3. Preparación del material. El material fue teñido y diafanizado para la observación de hueso y cartílago según la técnica de tinción diferencial de Taylor \& Van Dyke (1985) con ligeras modificaciones respecto a la diafanización. Esta técnica deja el material con sus huesos teñidos de rojo por efecto de la Alizarina, los cartílagos teñidos de azul por el colorante Azul de Alcian y los tejidos blandos completamente diáfanos por acción de Tripsina o de Hidróxido de Potasio. En el caso de la observación de musculatura, el proceso fue interrumpido previo a la diafanización y el material se diseccionó bajo microscopio estereoscópico. A fin de marcar mejor los paquetes musculares, el material fue deshidrat ado por inmersión en alcohol etílico a concentración creciente $\left(70^{\circ}, 96^{\circ}\right.$ y $\left.100^{\circ}\right)$, por el espacio de 48 horas en cada concentración.

Para la observación de la papilación bucofaríngea y de las estructuras del disco oral bajo microscopio electrónico de barrido se seleccionó una larva de cada una de las siguientes especies: Batrachyla antartandica (estadio 30, población de Puerto Murta, ver Apéndice I), B. leptopus (estadio 35, población de Villa Amengual, ver Apéndice I), B. taeniata (estadio 35, población de Circuito Chico, ver Apéndice I) e Hylorina sylvatica (estadio 33, población de Circuito Chico, ver Apéndice II). El protocolo fue el siguiente: 1) deshidratación en serie de etanol (30\%: 3 baños de 15 minutos; 50\%: una semana; 70\%: 3 baños de 15 minutos; 100\%: 15 minutos antes de el punto crítico), 2) disección del renacuajo (según Wassersug, 1980), 3) punto crítico en Dióxido de Carbono usando Acetato de Amilo como liquído intermediario, 4) montaje en cinta de Carbono doble faz, 5) Baño con capa de $400 \AA$ de espesor de Oro y Paladio empleando el modelo "Ion Sputter Fine Coat JFC-1100" (Jeol System), 6) observación con un Jsm-T100 microscopio electrónico de barrido a 5-15 kV, y 7) toma de fotos empleando una cámara llford.

II. 4. Observación y descripción de I material. Las observaciones se realizaron bajo un microscopio estereoscópico Zeiss Jena 30-G720. Las mediciones tomadas a las larvas fueron realizadas con un microscopio estereoscópico Reitcher Wien 235461 equipado con gradilla para medición (precisión $0,01 \mathrm{~mm}$ ). Las mediciones tomadas a 
ejemplares adultos fueron realizadas con calibre digital (precisión 0,03 mm). Las ilustraciones se realizaron utilizando una cámara clara acoplada al microscopio estereoscópico Zeiss.

A continuación se presenta la terminología empleada en la descripción de las estructuras, según los distintos autores, citados entre parentesis: condrocráneo (Cannatella, 1999), osteología axial de cráneo y postcráneo (Trueb, 1973), autopodio anterior (Fabrezi \& Alberch, 1996), autopodio posterior (Fabrezi, 1993) musculatura mandibular (Haas, 2001), musculatura branquial y hioidea de larvas (Haas, 2003), musculatura branquial e hioidea de adultos y musculatura ocular (Duellman \& Trueb, 1986), musculatura apendicular (Andersen, 1978; Duellman \& Trueb, 1986; Dunlap, 1960; Noble, 1922), musculatura axial (Duellman \& Trueb, 1986).

A fin de decidir acerca de la existencia de un centro de osificación, se consideró como criterio general que éste debe estar teñido de rojo por el colorante Alizarina. Se empleó un segundo criterio en una parte del material donde, quizás por razones de fijación (alcohol 70\%) o largo tiempo de conservación (6-9 años), los centros de osificación no presentaron tinción alguna. El mismo consistió en detectar las autostosis como áreas Azul de Alcian negativas rodeadas de zonas Azul de Alcian positivas y, en el caso de las alostosis por contrastar contra un fondo Azul de Alcian positivo.

En la obtención de las secuencias de condrificación y osificación de cada especie se siguieron los siguientes pasos: 1) observación del material de cada población de cada especie por separado y determinación de sus secuencias de desarrollo, 2) comparación interpoblacional de las secuencias y elaboración de una secuencia de condrificación y osificación generalizada para cada especie.

Se consideró que un elemento cartilaginoso, muscular u óseo presentó desarrollo heterocrónico cuando el mismo, al comparar especies, puede aparecer en distintos periodos de desarrollo (ver determinación de los estadios larvarios).

II. 5. Análisis filogenético. El análisis cladístico se realizó siguiendo los postulados de la sistemática filogenética, utilizando el programa TNT (Goloboff et al., 2003). Para la elección de los grupos externos utilizados en el análisis de parsimonia se tomaron en cuenta los análisis cladísticos propuestos por Basso (1994), Basso \& Cannatella (2001) y Frost et al (2006) los cuales corresponden a especies de los géneros Alsodes (Alsodes gargola), Atelognathus (A. patagonicus), Ceratophrys (C. ornata), Chacophrys (Ch. pierottii), Eupsophus (E. calcaratus) e Hylorina (H. sylvatica) 
(Apéndice II). Pleurodema (P. borelli) fue empleado para enraizar el árbol (Apéndice II). En el grupo interno se incluyeron las 5 especies que componen Batrachyla. Del análisis morfológico comparado entre las especies del grupo interno y los grupos externos, más los caracteres tomados de la revisión bibliografica, se obtuvieron 110 caracteres (85 binarios y 25 multiestado), de los cuales 6 fuerón polimórficos. La mayoría de ellos resultan ser caracteres originales y otros se verificaron a partir de propuestas existentes en la literatura. No se hicieron hipótesis ad hoc acerca de los caracteres multiestado. Del total de caracteres, 72 proceden de la morfología del adulto, 33 de la morfología larvaria, 2 de cariología y 3 de biología reproductiva. La matriz de caracteres se muestra en el Apéndice IV. Adicionalmente se describieron 14 caracteres que, por distintas razones no fueron considerados para el análisis (ver sección III.10.10). La procedencia de los caracteres morfológicos larvarios es según se detalla: condrocráneo (neurocráneo: 6 caracteres, arco mandibular: 2 caracteres, aparato hiobranquial: 5 caracteres); osteocráneo (neurocráneo: 1 caracter); musculatura mandibular (5 caracteres); musculatura branquial (4 caracteres); morfología externa (7 caracteres); papilación bucofaríngea (3 caracteres). La procedencia de los caracteres de morfología adulta es según se detalla: osteocráneo (19 caracteres); musculatura mandibular ( 2 caracteres); musculatura hioidea (4 caracteres); musculatura axial postcraneana (3 caracteres); esqueleto apendicular anterior (13 caracteres); musculatura apendicular anterior ( 7 caracteres); esqueleto apendicular posterior (2 caracteres); muscul atura apendicular posterior (11 caracteres); morfología externa (11 caracteres).

Todos los caracteres (salvo casos particulares con que no se contó con material, e g., larvas de Eupsophus calcaratus, papilación bucofaríngea de algunas especies, caracteres cariológicos y de biología reproductiva) fueron revisados personalmente por el autor. En esas excepciones, la codificación se realizó teniendo en cuenta la bibliografía existente que se detalla oportunamente en la descripción de cada caracter. Cada vez que se haga mención a los caracteres en la sección resultados y discusión se notaran entre paréntesis indicando el numero de caracter seguido por el estado que presenta (e g., 75.2 indica caracter 75 , estado 2 ).

Para el análisis se comenzó con una búsqueda heurística mediante el método de secuencia de adición conocido como arboles de Wagner (Farris, 1970). Este método, que va conectando los terminales uno por uno hasta obtener un árbol, no permite obtener de entrada los arboles más parsimoniosos, pero suele emplearse como punto de partida del análisis, para luego emplear métodos de permutación de 
ramas. El método de permutación de ramas que se empleó fue el "tree bisection and reconnection" (TBR). EI TBR es un método de permutación exhaustivo que trabaja cortando subclados y pegándolos en las diferentes posiciones posibles del cladograma, re-enraizando el árbol cada vez, y en cada ronda va guardando las topologías más parsimoniosas. Para la búsqueda de arboles de Wagner y las rondas de TBR se empleó la opción "traditional search" del programa TNT, empleando para cada caso las opciones "default" del programa. Este proceso se realizó tanto empleando el método de los pesos implicados como sin el, a fin de comparar los resultados, entre un análisis en que no se castiga a los caracteres homoplásicos (sin pesos implicados) y uno en que si se lo hace. Los pesos implicados (ver Goloboff, 1993) son un método de pesado de caracteres a posteriori teniendo en cuenta el ajuste entre estos y el árbol. El método emplea una función que da más peso a un caracter cuando menos pasos extras da éste en el árbol. Luego del análisis, son seleccionados los arboles que minimizan el valor de la función. Éste método, a diferencia del método de pesado sucesivo de Farris (Farris, 1970), es in dependiente de los arboles que se obtienen inicialmente en análisis. Para el análisis empleando pesos implicados se seleccionó el valor de constante dado por defecto en el programa $(\mathrm{K}=3.0000)$.

Para los casos en que fue necesario calcular un arbol de consenso, éste se calculó como consenso estricto. Este método construye un único árbol donde se incluyen solo los grupos que estan presentes en todos los arboles de mínima longitud.

Para calcular el soporte de los grupos se emplearon tres métodos de análisis: Bootstraping (Felsenstein, 1985), Jackknifing (Farris et al., 1996) y soporte de Bremer (Bremer, 1988; 1994). El Bootstraping es un procedimiento estadístico no paramétrico que permite conocer si la topología obtenida no puede ser producto del azar. Para ello se producen numerosas replicas de la matriz original, donde en cada replica se eliminan caracteres al azar y se los reemplaza por los caracteres que no fueron eliminados, preservando el numero total de caracteres por cada replica. Luego de cada replica el método guarda los arboles más cortos y luego del proceso se obtiene un árbol de consenso por mayoría donde se expresan los clados encontrados en el $50 \%$ de las replicas, con el valor de porcentaje para cada uno de ellos. Se considero que un clado esta bi en soportado cuando presenta un valor de Bootstrap de 70 o más (según Hillis \& Bull, 1993). Este método se calculó sobre el arbol obtenido mediante pesos implicados usando la opción Standard Bootstrap del programa, empleando frecuencias absolutas. El Jackknifing es un procedimiento similar al Bootstraping pero 
que realiza un número determinado de pseudoreplicas de la matriz original eliminando al azar siempre el mismo número fijo de caracteres. Cada pseudoreplica de la matriz es analizada y finalmente se obtiene un árbol de consenso por mayoría donde se incluyen los clados que se repiten al menos en el $50 \%$ de los arboles obtenidos. A diferencia del Bootstraping, no se reemplazan los caracteres eliminados en cada una de las matrices pseudoreplicadas. Este método se calculó sobre el arbol obtenido mediante pesos implicados usando la opción "relative frequencies" para el Jackknifing del programa. Se calcularon con varios valores de corte para ver a que valores colapsan los diferentes clados. Finalmente el soporte de Bremer indica el numero de pasos necesarios para que un clado desaparezca del árbol, entonces los clados soportados con menos sinapomorfías tendrán un valor de Bremer bajo con relación a aquellos clados bien soportados. El soporte de Bremer se empleó solo para el árbol de consenso estricto obtenido a partir del análisis sin aplicar pesos implicados, donde adicionalmente se examinaron los arboles subóptimos para probar la estabilidad de los clados hallados en los arboles fundamentales

Los índices de consistencia (IC, Kluge \& Farris, 1969) y de retención (IR, Farris, 1989, 1990) para los arboles de menor longitud fueron calculados para examinar los niveles de incongruencia de los caracteres. Ambos índices toman valores entre cero y uno, y se considera que valores más cercanos al uno indican bajo nivel de homoplásia. Para el cálculo de ambos índices se empleó el archivo stats.run llamado desde la línea de comandos del programa TNT. Por último, la polaridad de los caracteres se analizó a posteriori según el criterio del grupo externo 


\section{RESULTADOS}

\section{III.1. Desarrollo del condrocráneo en Batrachyla taeniata.}

La secuencia de aparición de estructuras del condrocráneo se presenta en la Tabla 1. A los fines de establecer comparaciones, las secuencias de osificación de Batrachyla antartandica y B. leptopus se encuentran en los Apéndices VII y VIII respectivamente. En la larva, el condrocráneo es sub-cuadrangular (Ancho Máximo / Largo Total = 0,94 - 0,97, $n=5$, estadios 32 - 33). El ancho máximo ocurre al nivel posterior del arco subocular.

\section{III.1.1. Neurocráneo: Región etmoidal y cartílagos nasales (Figs. 2-4 y 6).}

El cartílago suprarrostral cumple funciones de maxila, constituye el sostén interno para

el suprarrostrodonte del pico corneo y recibe la inserción de parte de los $\mathrm{mm}$. levatorae mandibulae. Los cuerpos se ubican medial y frontalmente mientras que las alas se ubican lateral y posteriormente a ellos. El área proximal de cada cuerpo es más angosta comparada con la dístal y se proyecta lateralmente para efectuar la sindesmósis con el ala. A ese nivel, el ala proyecta un corto proceso anterior dorsal donde articulan los cuernos trabeculares. El proceso posterior dorsal del ala esta bien desarrollado. Los adrostrales están representados por una masa de tejido conectivo denso ubicado dorsal y caudal al proceso posterior dorsal. La presencia de conexiones cartilaginosas proximales y distales entre cuerpo y ala del cartílago suprarrostral varía intrapoblacionalmente en forma independiente al estadio (Tabla 2).

Los cuernos trabeculares son estructuras pares que divergen anteriormente desde la placa etmóidea. Su longitud representa el $14-17 \%$ de la longitud total del neurocráneo. Presentan sus extremos levemente dilatados y expandidos en sentido anterior y lateral. En el punto de unión de ambos cuernos se determina un espacio cóncavo amplio (la mayoría de los casos) o un profundo surco ubicado por delante del septo nasal en el suelo nasal en formación (estadio 31, 2 de 5 ejemplares; estadio 33, 8 de 12 ejemplares).

A nivel dístal, el espacio medio entre los cuernos trabeculares es equivalente al ancho de un cuerno trabecular en su extremo (Ancho Espacio Medio / Ancho Cuerno = 0,6 $0-8, n=5)$. En

la mayoría de los especímenes, el proceso lateral de los cuernos trabeculares no es visible en vista dorsal a causa de que se halla ventralizádo, sin embargo, en dos ejemplares (estadios 33 y 34 ) éste fue visible en vista dorsal. 
La placa etmóidea es cuadrangular y sostiene lateralmente al esbozo de la lamina orbitonasal. El esbozo del septo nasal se proyecta anteriormente desde el margen anterior de la placa etmoidea. A cada lado del septo nasal abren los foramenes olfatorios.

El techo craneano está compuesto por un delgado techo anterior que cierra la fontanela frontoparietal anteriormente y se ubica dorsal a los foramenes olfatorios.

Previo al estadio 38, aparecen las primeras estructuras nasales: el proceso anteorbitario de la lámina orbitonasal y el septo nasal. El primero es un muñón de cartílago que se proyecta lateral y anteriormente desde la pila etmóidea. El segundo es un crecimiento cartilaginoso anterodorsal a la placa etmóidea, formado en la pared anterior de la caja craneana, entre los foramenes olfatorios.

Al progresar el desarrollo, el septo nasal se proyecta cranealmente en forma medio dorsal a los cuernos trabeculares (fig. 1. 1-2).

En el desarrollo de los cartílagos nasales, la placa etmóidea, el septo nasal, la lamina orbitonasal, el techo anterior y el techo nasal son las únicas estructuras nasales que aparecen antes del inicio de la metamorfosis. Ya al estadio 38 se aprecia el septo nasal extendido hasta la base de los cuernos trabeculares. Del mismo modo a partir de ese estadio se expande la lamina orbitonasal. Entre los extremos libres de la lamina orbitonasal y el techo nasal existe una banda de tejido conectivo denso sobre la que, al estadio 41, se diferencian los siguientes cartílagos nasales: cartílago alar, cartílago oblicuo, cresta intermedia, cresta subnasal y proceso prenasal superior. El suelo nas al se forma sobre los restos de los cuernos trabeculares regresionados (estadio 42) más la adición de nuevo cartílago en la región media y lateral a estos. Durante la metamorfosis el cartílago suprarrostral regresiona en sentido distal-proximal hasta desaparecer, primero lo hacen los cuerpos y luego las alas (estadios 41-42).

Las cápsulas nasales son estructuras complejas compuestas por numerosos cartílagos, cuyo desarrollo larvario ya fue descrito. La estructura adulta de las mismas se alcanza al estadio 46. Ambas cápsulas están separadas medialmente por el septo nasal que es la única estructura impar de las mismas. Este se proyecta desde la placa etmóidea hasta el tercio anterior de las cápsulas nasales, rematando anteriormente en un ápice agudo. El septo apoya sobre el suelo nasal, recorriéndolo por su superficie medio dorsal. El techo de las cápsulas nasales esta formado por el techo nasal que se proyecta desde el dorso de cada lamina orbitonasal, formando una medialuna cuya cara convexa es lateral, ubicado ligeramente anterior y ventral a los nasales. Del extremo anterior del techo nasal se proyecta posteriormente el cartílago oblicuo y 
ventralmente el cartílago alar, la cresta intermedia y el proceso prenasal inferior. El cartílago oblicuo forma un semicirculo abierto anteriormente y corre lateral al techo nasal limitando posteriormente la abertura de las narinas. Del extremo posterior del cartílago oblicuo se proyecta el plano terminal, una comisura cartilaginosa que establece el contacto entre éste y la lamina orbitonasal. El cartílago alar es un elemento redondeado que se proyecta ventral y posteriormente desde el extremo anterior del techo nasal hacia la abertura de la narina.

El proceso prenasal inferior es una proyección dorsal del extremo anterior del suelo nasal, mientras que el proceso prenasal superior se proyecta ventralmente a partir del extremo anterior del cartílago oblicuo en el punto donde este converge con el techo nasal. Ambos procesos prenasales tienen sus extremos libres embebidos en el premaxilar. La lamina orbitonasal está bien desarrollada formando una pared vertical, ligeramente cóncava anteriormente, que constituye la pared posterior de la cápsula nasal. La lámina orbitonasal se proyecta anteriormente mediante el proceso maxilar anterior, el cual queda embebido en la pars fascialis del maxilar. La cresta subnasal, que también se halla embebida en la pars fascialis del maxilar, se continúa anteriormente con el margen anteroventral del cartílago oblicuo, y posteriormente con el tercio posterior del suelo nasal.

Figura 2. Neurocráneo y arco mandibular de Batrachyla taeniata al estadio 35 de Gosner (1960) en vistas ventral (A), dorsal (B) y lateral (C). Las zonas oscuras representan fenestraciones, las punteadas son cartílago y las regiones sin puntear son hueso. Escala $1 \mathrm{~mm}$. Referencias: aoc: arco occipital, as: ala suprarrostral, aso: arco subocular, ccca: comisura cuadrado craneana anterior, cco: comisura cuadrado orbitaria, ci: cartílago inrarrostral, cm: cartílago de Meckel, co: cáps ula ótica, cs: cuerpo suprarrostral, ct: cuerno trabecular, ex: exoccicpital, fc: foramen carotídeo, fcp: foramen craneopalatino, ffp: fenestra frontoparietal, fh: fenestra hipofisaria, fom: foramen oculomotor, fop: foramen óptico, fov: fenestra oval, fp: frontoparietal, fpo: foramen proótico, fps: foramen perilinfático superior, fy: foramen yugular, Ion: lamina orbitonasal, pacp: proceso anterolateral de la cresta parótica, pan: pila antótica, par: proceso articular, pas : proceso ascendente, pce : proceso c uadrado etmoidal, pe: placa etmoidea, pe-ppo: pilares etmoideo y preóptico, pf: paraesfenoides, plc:proceso lateral de los cuernos, pm: proceso muscular, pme: pilar metóptico, pp: proceso pseudopterigoideo, pr: proceso retroarticular, op: opérculo, s n: septo nasal, ta: techo anterior, ts: techo sinótico, ttm: tenia tecti marginal. VER PAGINA SIGUIENTE 


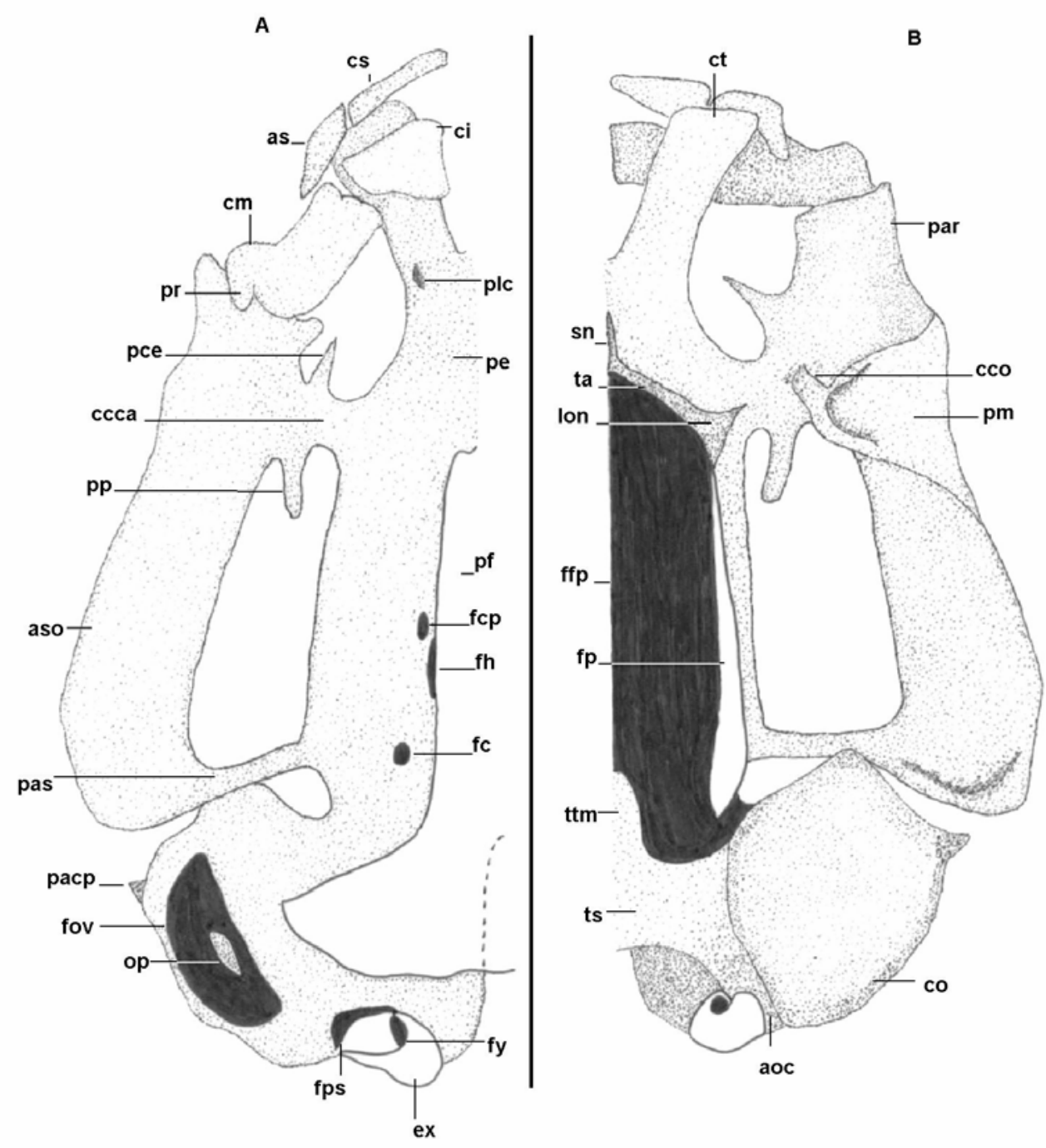

c

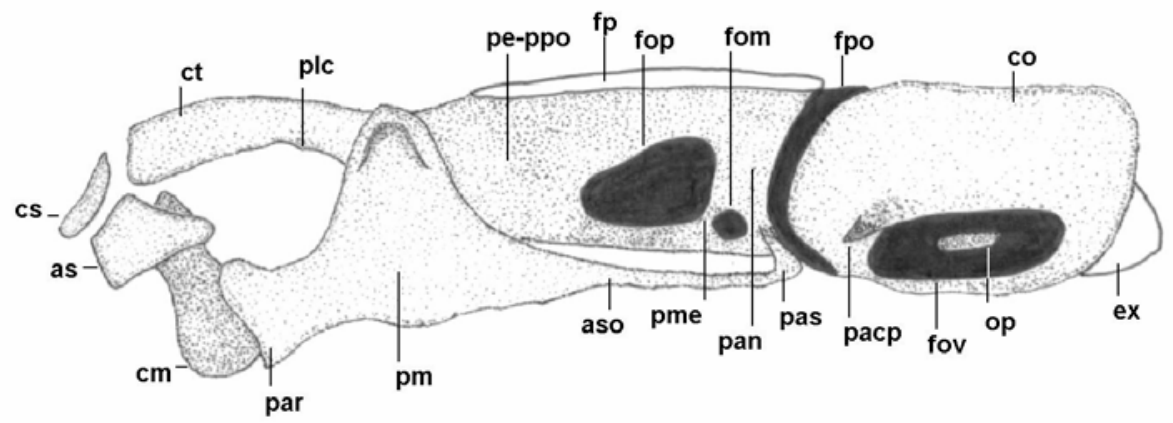




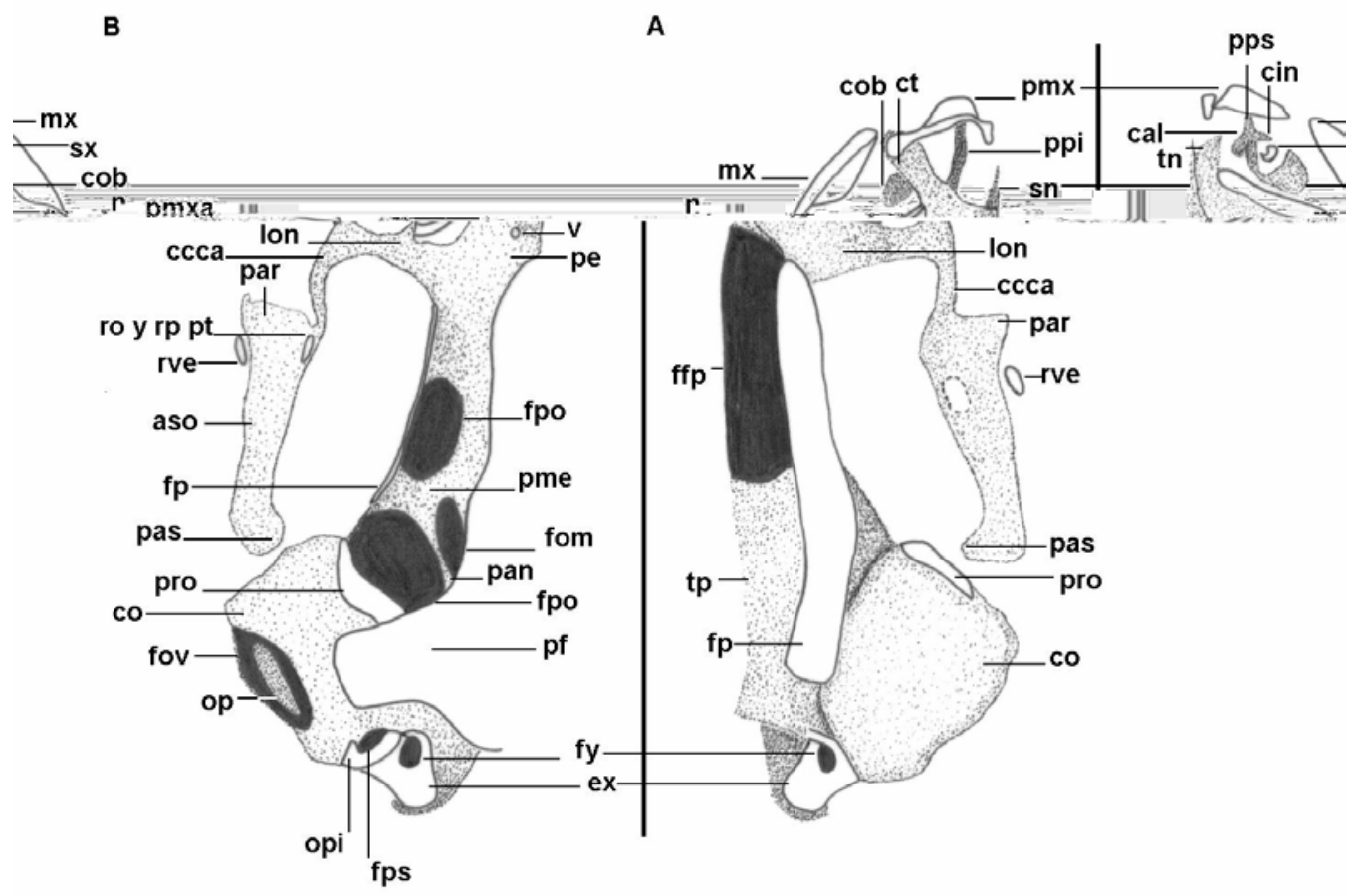

C

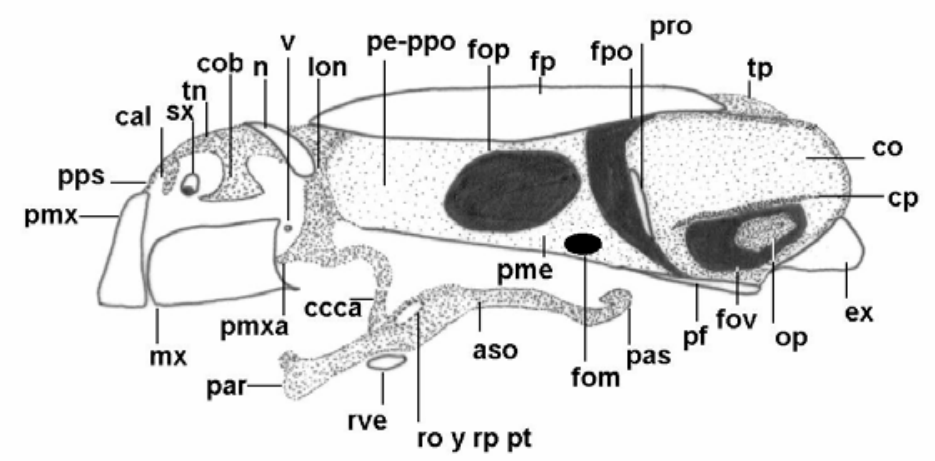

Figura 3. Neurocráneo y arco mandibular de Batrachyla taeniata al estadio 43 de Gosner (1960) en vistas ventral (A), dorsal (B) y lateral (C). Las zonas oscuras representan fenestraciones, las punteadas son cartílago y las regiones sin puntear son hueso. Escala $1 \mathrm{~mm}$. Referencias: cal: cartílago alar, cin: cresta intermedia, cob: cartílago oblicuo, cp: cresta parótica, mx: maxilar, $\mathbf{n}$ : nasal, opi: opistótico, pmx: premaxilar, pmxa: proceso maxilar anterior, ppi: proceso prenasal inferior, pps: proceso prenasal superior, pro: prótico, ro y rp pt: ramas ótica y posterior del pterigoides, rve : rama ventral del escamoso, sx: septomaxilar, tn: techo nasal, tp: techo parietal, v: vomer. El resto de las referencias como en la figura 1. 

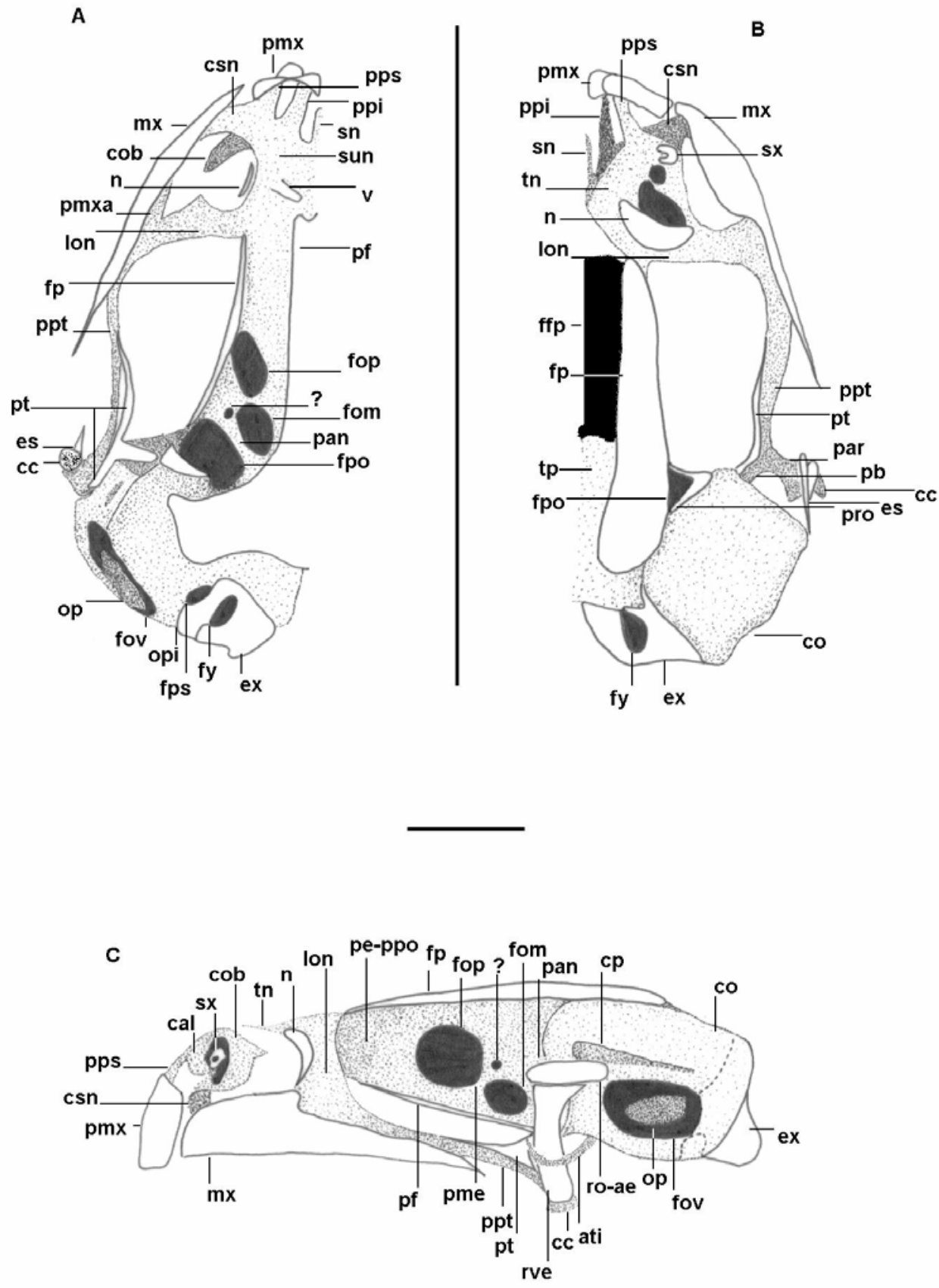

Figura 4. Neurocraneo y arco mandibular de Batrachyla taeniata al estadio 46 de Gosner (1960) en vistas ventral (A), dorsal (B) y lateral (C). Las zonas oscuras representan fenestraciones, las punteadas son cartílago y las regiones sin puntear son hueso. Escala $1 \mathrm{~mm}$. Referencias: ati: anillo timpánico, cc: cartílago cuadrado, csn: cresta subnasal, es: escamoso, pb: proceso basal, ppt: proceso pterigoideo, pt pterigoides, ro-a e : ramas ótica y anterior del escamoso, sun: suelo nasal. El resto de las referencias como en la figuras 1 y 2 . 


\section{III.1.2. Neurocráneo: Región fronto-orbitaria (Figs. 2-4).}

El cartílago orbitario está compuesto por los pilares etmóideo, proótico, metóptico y antótico. Los foramenes óptico, oculomotor y proótico se encuentran presentes. El foramen proótico se halla abierto dorsalmente a causa de la ausencia de taenia tecti marginal a ese nivel.

La condrificación del piso craneano procede desde la periferia hacia el centro y recién se cierra completamente al estadio 36. Durante el proceso de condrificación aparecen primero los foramenes carotídeos y luego los foramenes craneopalatinos.

Los foramenes carotídeos son de posición caudal y lateral respecto a los cráneopalatinos.

El techo del cráneo está compuesto por la porción anterior de la taenia tecti marginal y la taenia tecti transversa. La porción anterior de la taenia tecti marginal está representada por el área dorsal al cartílago orbitario que limita lateralmente a la fontanela frontoparietal. La taenia tecti transversa es una barra de cartílago que divide la fontanela frontoparietal en dos: la fontanela parietal por detrás y la frontal por delante.

\section{III.1.3. Neurocráneo: Región ótico-occipital (Figs. 2-4).}

Las cápsulas óticas poseen aspecto ovoide en vista dorsal (Ancho Cápsula Ótica / Largo Cápsula Ótica $=0,66-0,75, n=5$ ) y representan el $31-35 \%$ de la longitud total del neurocráneo. La copula anterior de las mismas no se solapa dorsalmente con el proceso ascendente del palatocuadrado (o apenas tapa su margen posterior). La cresta parótica guarda escaso desarrollo lateral y presenta un breve proceso anterolateral que se proyecta en sentido lateral más que anterior. La presencia de proceso posterolateral varía intrapoblacionalmente en forma independiente a los estadios (Tabla 2).

La pared medial de la cápsula ótica presenta 3 foramenes. El foramen endolinfático es el más pequeño y se ubica ventral al techo sinótico. El foramen acústico es el mayor de todos y se ubica dorsal a la placa basal. El foramen perilinfático inferior se ubica caudal al foramen acústico. El foramen perilinfático superior abre en la pared posterior de la cápsula ótica, enfrentado al foramen yugular.

La ventana oval es amplia y en ella se observa un cartílago opercular pequeño a partir del estadio 34 pero presente en todos los ejemplares solo a partir del estadio 37. 


\begin{tabular}{|c|c|c|c|c|}
\hline Estadio & Cráneo & Axial & $\mathbf{A A}$ & $\mathbf{A P}$ \\
\hline $29(\mathrm{~N}=2)$ & $\begin{array}{l}\text { AH-AO-CCO-Cl-CM-CS } \\
\text { CT-FC-LO-P-PA-PIE-PL } \\
\text { PLE-PPR-SN-TS }\end{array}$ & AN +VIII & & \\
\hline $31(\mathrm{~N}=5)$ & PM-FCO-PACP-PPS & AN IX-PT HII & & $F$ \\
\hline $32(\mathrm{~N}=1)$ & TTMA & & & TF \\
\hline $33(\mathrm{~N}=2)$ & TTM-TE & & & \\
\hline $34(\mathrm{~N}=8)$ & FCP-O-PPC & AN X-PT III & $\mathrm{H}-\mathrm{RU}$ & $\mathrm{CP}$ \\
\hline $35(\mathrm{~N}=13)$ & & $\overline{\mathrm{ZP}}$ & CE & TFr \\
\hline $36(\mathrm{~N}=16)$ & TTT & $\mathrm{HP}$ & $\begin{array}{l}\mathrm{MC}(\mathrm{D} \text { IV-V) } \\
\mathrm{F} 1-2 \text { (D IV-V) }\end{array}$ & MT(D IV-V) \\
\hline $37 \mathrm{~N}=12)$ & & & $\begin{array}{l}\text { EP-MC(D II-III) } \\
\text { CD II, III y IV-V } \\
\text { E Y-R-R'-U-U ' }\end{array}$ & $\begin{array}{l}\text { MT(D HIII) } \\
\text { F1(D IV) } \\
\text { F3 (D IV) } \\
\text { F 2(D III y V) }\end{array}$ \\
\hline $38(\mathrm{~N}=9)$ & TN-TTMP & & $\begin{array}{l}\text { F1-2(D IF III) } \\
\text { F3(D IV-V)-PX }\end{array}$ & $\begin{array}{l}\text { TDHIII } \\
\text { E Y-BPH }\end{array}$ \\
\hline $39(\mathrm{~N}=1)$ & & PT IV-IX & & \\
\hline $40(N=5)$ & AT-Cl & & & \\
\hline $41(\mathrm{~N}=25)$ & CO-CA-PPS-CS-CIN & AN II & & \\
\hline $43(\mathrm{~N}=24)$ & $\mathrm{PPI}$ & & OM-E & $\mathrm{DP}$ \\
\hline $46(\mathrm{~N}=2)$ & CR-COL & & & \\
\hline PM & & & EPE-X & \\
\hline
\end{tabular}

TABLA 1. Secuencia de condrificación de Batrachyla taeniata. A los estadios $42(\mathrm{~N}=7)$ y 44 $(\mathrm{N}=4)$ no se registraron novedades. Referencias: $\mathbf{A A}$ : apendicular anterior, $\mathbf{A H}$ : Aparato hiobranquial, AN: arco neural, AO: arco occipital, AP: apendicular posterior, AT: aritenoides, BPH: basal del prehallux, CA: cartílago alar, CE: cintura escapular, CCO: comisura cuadradoorbitaria, CD: carpianos distales, CI: comisura intramandibular, CIM: cresta intermedia, CM: cartílago de Meckel, CO: cartílago oblicuo, COL: columella, CP: cintura pélvica, CR: cricoides, CS: cartílago suprarrostral, CSU: cresta subnasal, CT: cuernos trabeculares, DP: distales del prehallux, E: esternón, EP: epicoracoides, EPE: epiesternón, EY: elemento Y, F: fémur, F(D): falange (digíto), FC: foramenes carotídeos, FCO: foramenes cápsula ótica, FCP: forámen craneopalatino, H: húmero, HP: hipocordo, I: infrarrostral, LO: lamina orbitonasal, MC: metacarpianos, MT: metatarsianos, O: opérculo, OM: omoesternón, P: palatocuadrado, PA: pila antótica, PACP: proceso anterolateral de la cresta parótica, PIE: pila etmóidea, PL: proceso lateral de los cuernos trabeculares, PLE: placa etmóidea, PM: pila metóptica, PP: proceso pseudopterigoideo, PPC: proceso posterolateral de la cresta parótica, PPI: proceso prenasal inferior, PPR: pila preóptica, PPS: proceso prenasal superior, PT: proceso transverso, PX: prepollex, R-R': radial-radial', RU: radio-ulna, SN: septo nasal, TE: techo etmóideo, TF: tibia-fíbula, TFr: tibial-fibular, TN: techo nasal, TS: techo sinótico, TTM: taenia tecti medial, TTMA: taenia tecti marginal anterior, TTMP: taenia tecti marginal posterior, TTT: taenia tecti transversal, U-U': ulnar-ulnar', X: xifiesternón, ZP: zigapofisis. 


\begin{tabular}{|c|c|c|c|c|c|c|c|}
\hline \multirow[t]{2}{*}{$E(N)$} & \multicolumn{2}{|l|}{ CS } & \multirow[t]{2}{*}{ PPL } & \multirow[t]{2}{*}{ PFPP } & \multicolumn{2}{|c|}{ APA } & \multirow[t]{2}{*}{ PCA } \\
\hline & UP & UD & & & $A$ & $\mathbf{R}$ & \\
\hline $29(2)$ & - & - & - & 1 & 1 & 1 & - \\
\hline $31(5)$ & 2 & 1 & - & - & 5 & - & 1 \\
\hline $32(2)$ & - & - & - & - & 2 & - & - \\
\hline $33(12)$ & 1 & - & 1 & 7 & 8 & 4 & 6 \\
\hline $34(2)$ & - & - & 1 & - & 2 & - & - \\
\hline $35(15)$ & - & 2 & - & 8 & 12 & 3 & 3 \\
\hline $36(8)$ & 1 & 1 & - & 8 & 7 & 1 & 4 \\
\hline $37(5)$ & - & - & - & 2 & 3 & 2 & 3 \\
\hline $38(5)$ & 1 & 1 & 2 & 5 & 5 & - & 2 \\
\hline $39(2)$ & - & - & - & 2 & 2 & - & 1 \\
\hline $40(8)$ & - & 3 & 1 & 6 & 6 & 2 & 1 \\
\hline $41(26)$ & 1 & 1 & 7 & - & - & 28 & 1 \\
\hline AA & I (2) & $\mathbf{I}(2) \mathbf{D}(2)$ & I (3) D (3) & - & - & & - \\
\hline
\end{tabular}

TABLA 2. Detalle de la variación observada para determinadas estructuras del condrocráneo en las larvas de Batrachyla taeniata. Referencias: A: agudo, AA: asimetrias, APA: ángulo proceso ascendente, CS: cartílago suprarrostral, D: lado derecho, E: estadio, I: lado izquierdo, PCA: precencia de copula anterior, PFPP: precensia de fosa posterolateral del palatocuadrado, PPL: precencia de proceso posterolateral de la cápsula ótica, R: recto, UD: unión dístal, US: union próximal.

La notocorda penetra la placa basal hasta el nivel de la región proximal del proceso anterolateral de la cresta parótica.

El techo craneano a nivel ótico está compuesto por el dorso de las cápsulas óticas, la porción posterior de la taenia tecti marginal, el techo sinótico y la taenia tecti medial. La segunda continua caudalmente a la porción anterior de la taenia tecti marginal (borde dorsal del cartílago orbitario) hasta contactar el techo sinótico, cerrando dorsalmente el foramen proótico y limitando lateralmente a las fontanelas parietales. El techo sinótico es robusto y se ubica entre las cápsulas óticas. La taenia tecti medial es una proyección anterior del techo sinótico que divide la fontanela parietal en una parietal izquierda y otra derecha. Al estadio 40 ya se observa un techo 
parietal producto de la proliferación de cartílago entre el techo sinótico, la taenia tecti transversal y las cápsulas óticas.

\section{III.1.4. Arco mandibular (Figs. 2-4 y 8).}

La parte ventral del arco mandibular se compone por dos pares de cartílagos: el cartílago de Meckel de posición lateral y el cartílago infrarrostral de posición medial. En vistas dorsal y ventral, el cartílago de Meckel posee forma de "C" con la concavidad hacia delante. En el extremo medial y anterior del mismo existen dos procesos, el proceso dorsomedial y el proceso ventromedial. El proceso ventromedial delimita una cavidad amplia para recibir al cóndilo articular del cartílago infrarrostral. El proceso dorsomedial no presenta cavidad, está levemente más proyectado que el proceso ventromedial y recibe la inserción del $\mathrm{m}$. levatorae mandibulae longus superficialis. En el área dorsal del cartílago de Meckel insertan los mm. levator mandibulae articularisy levator mandibulae internus.

El extremo lateral del cartílago de Meckel se proyecta caudalmente constituyendo el proceso retroarticular, corto y romo, el cual recibe la inserción de tres músculos hioideos que actúan como abductores (hyoangularis lateralis, quadratoangularis, suspensorioangularis).

El componente dorsal del arco mandibular está representado por el cartílago palatocuadrado. Éste corre paralelo al piso del cráneo y cumple las funciones de suspensión al neurocráneo y de origen de numerosos músculos mandibulares, hioideos y branquiales. En sentido cráneo - caudal, las estructuras que lo componen son el proceso articular, proceso cuadrado etmóidal, proceso muscular, comisura cuadrado orbitaria, comisura cuadrado craneana anterior, proceso pseudopterigoideo, arco subocular y proceso ascendente. El proceso ótico larvario está ausente.

En la región del proceso articular ocurre la articulación con el cartílago de Meckel. Su extremo anterior posee: 1) una concavidad amplia que recibe la superficie posterior convexa del cartílago de Meckel, y 2) un pequeño surco articular donde calza el proceso retroarticular del cartílago de Meckel.

El proceso muscular es una proyección dorsal del margen lateral del palatocuadrado que se ubica en la región etmóidea justo por detrás del proceso articular. Este proceso presenta una ligera curvatura en sentido medial y anterior y extremo dístal redondeado. Su cara externa constituye una superficie de origen e inserción para ciertos músculos hioideos (orbitohyoideus, suspensorioangularis, suspensoriohyoideus). Ventral al proceso muscular, existe una ligaera concavidad, la 
fosa hiocuadrada, para articular con el ceratohial. Esta fosa emite un proceso lateral visible en vista dorsal.

La comisura cuadrado-craneana anterior constituye una conexión cartilaginosa entre el palatocuadrado y la región etmóidea del neurocráneo. Corre casi vertical entre la placa etmóidea y el palatocuadrado. El proceso pseudopterigoideo es una proyección de su margen caudal hacia la fenestra subocular. Este proceso tiene un ancho en su base equivalente al de la comisura cuadrado craneana anterior y se extiende caudalmente hasta alcanzar el nivel del extremo caudal del proceso muscular.

La comisura cuadrado orbitaria es la conexión cartilaginosa que corre en forma oblicua entre el extremo dístal del proceso muscular y el margen anterior de la comisura cuadrado craneana anterior. Representa la condrificación del ligamento tectum superior. Inmediatamente delante del punto de unión entre comisura cuadrado orbitaria y comisura cuadrado craneana anterior se proyecta el proceso cuadrado etmóidal. Este proceso recibe al ligamento cuadrado etmóidal desde el proceso lateral de los cuernos trabeculares.

El arco subocular presenta sus márgenes lateral y medial sin irregularidades ni proyecciones. En el arco subocular de muchos ejemplares de diferentes estadios se observo una fosa al origen de los $\mathrm{mm}$. levatorae mandibulae longus. La presencia de esta fosa varío intrapoblacionalmente en forma independiente al estadio (Tabla 2).

El proceso ascendente se forma a partir del extremo caudal del arco subocular, el cual se curva medialmente y une con la pila antótica. La unión del proceso ascendente ocurre justo por detrás del foramen oculomotor y es de tipo intermedia (sensu Sokol, 1981). En la mayoría de los especímenes estudiados, el proceso ascendente contacta a la pila antótica formando un ángulo agudo respecto de las trabeculas, sin embargo en otros ejemplares ambas estructuras determinaron un ángulo recto. El tipo de ángulo entre trabeculas y proceso ascendente varío intrapoblacionalmente en forma independiente al estadio (Tabla 2). El palatocuadrado se proyecta caudalmente hacia la cresta parótica, sin contactarla.

La metamorfosis del arco mandibular comienza en algunos ejemplares entre los estadios 40 y 41 . Durante este proceso se observa lo siguiente: 1) se establece una comisura intramandibular cartilaginosa, 2) se alargan la comisura cuadrado craneana anterior (constituyendo el proceso pterigoideo del adulto), el cartílago de Meckel y el cartílago infrarrostral, 3) se reabsorben la comisura cuadrado orbitaria, el proceso ascendente, el proceso muscular, el proceso cuadrado etmóidal y el proceso 
pseudopterigoideo. Finalmente el palatocuadrado del adulto queda restringido a una porción vertical ubicada anterior y lateral respecto de la cápsula ótica. El palatocuadrado del adulto contacta la cápsula ótica mediante el proceso basal y el proceso ótico. El proceso basal es evidente desde el estadio 46, corre aplicado lateralmente a la rama ótica del pterigoides y contacta con la cara anteroventral de la cápsula ótica mediante una unión sindesmótica. El proceso ótico contacta sincondróticamente con la cresta parótica y aparece postmetamorficamente. Finalmente el palatocuadrado remata ventralmente en una superficie articular para la mandíbula, y se proyecta anteriormente como proceso pterigoideo, hasta continuarse con el extremo ventral posterior de la lamina orbitonasal.

\section{III.1.5. Aparato hiobranquial (Fig. 7).}

Los ceratohiales constituyen los elementos del aparato hipobranquial que tienen posición más anterior. Se disponen perpendiculares al eje axial del cráneo, poseen una serie de procesos y se relacionan con todos los músculos hioideos y una parte de los músculos branquiales. Sus procesos son el proceso anterohial, proceso anterohial lateral, proceso articular (cóndilo) y proceso posterohial. El extremo distal del proceso anterohial lateral no alcanza el nivel del extremo distal del proceso anterohial. A causa del buen desarrollo que presenta el cóndilo articular, una porción de éste es visible en vista ventral. Los procesos anterohial y posterohial presentan aproximadamente el mismo tamaño.

Los ceratohiales se reúnen medialmente a través de una pars reuniens de cartílago difuso Azul de Alcian positivo. Anteriormente a la pars reuniens, ubicada sobre el ligamento interhioideo que une los procesos anterohiales, se ubica una copula anterior pequeña y esférica. La presencia de copula anterior varío intrapoblacionalmente en forma independiente al estadio (Tabla 2).

La copula posterior es hexagonal y se encuentra en continuidad cartilaginosa con la pars reuniens. El proceso urobranquial es rectangular, de una longitud equivalente a la copula posterior. Se proyecta ventral y caudalmente desde la copula posterior y su extremo libre recibe al $\mathrm{m}$. subarcualis obliquus II.

Los hipobranquiales están separados medialmente y en su margen lateral presentan tres carillas de articulación para los ceratobranquiales II, III y IV respectivamente. El seno posterior hipobranquial es en forma de "U".

El ceratobanquial I está unido sincondróticamente al hipobranquial. Los restantes ceratobranquiales se unen al hipobranquial mediante sindesmósis. 
Los radios branquiales faltan en la cara anterior del segundo ceratobranquial y en la posterior del tercero. El ceratobranquial I presenta un proceso anterior branquial proyectado hacia el ceratohial. Los ceratobranquiales II y III presentan procesos branquiales sin formar puente branquial. La comisura proximal está ausente y una comisura dístal reúne a todos los ceratobranquiales.

Las espículas I a III son delgadas, presentan el extremo dístal no bífido y se unen a los respectivos ceratobranquiales mediante sincondrósis. La cuarta espícula es más robusta, no posee dilatación ni foramen dístal y se une sincondróticamente al ceratobranquial IV.

La metamorfosis del aparato hiobranquial se inicia a los estadios 41-42 con la desaparición de la espícula IV y la ligera erosión de los procesos del ceratohial y de los ceratobranquiales. La regresión de los ceratobranquiales y espículas ocurre en sentido distal-proximal y proximal - distal, y desde los elementos más caudales hacia los anteriores. Al estadio 43, el ceratohial se halla bastante estilizado (pierde primero el proceso anterohial lateral y luego el posterohial) y en proceso de alargarse posteriormente para formar los cuernos hioideos del adulto. Los hipobranquiales aun están separados medialmente pero el área correspondiente a la articulación con los ceratobranquiales II y III se remodela. Culminando ese proceso, el margen posterior de los hipobranquiales permanece formando el proceso posteromedial del cuerpo hioideo del adulto, mientras que la base del ceratobranquial I queda como proceso posterolateral del hioides adulto. Al estadio 44, no se observan grandes cambios respecto del estadio 43, pudiendo conservarse aun restos de los ceratobranquiales en algunos ejemplares, ya sin relación entre ellos ni con el hipobranquial. El proceso anterolateral aparece como una pequeña condensación cartilaginosa, redondeada, ubicada lateral a la copula II, medial al ceratohial y anterior a la base del ceratobranquial I (proceso posterolateral del adulto). Al estadio 46 el hioides presenta las características generales que presentan los adultos. La formación del cuerpo ocurre entre los estadios 43 y 44 . El mismo se forma por la fusión de los hipobranquiales, la pars reuniens y la copula posterior de la larva, lo cual queda evidenciado en los ejemplares postmetamórficos por una línea de sutura, en forma de “T”, ligeramente negativa al Azul de Alcian. El proceso posteromedial es homólogo al extremo posterior del hipobranquial, presenta su diáfisis osificada autostósicamente y su extremo libre en "T". Los procesos posterolateral y anterolateral se forman entre los estadios 43 y 44 . El primero es estilizado, agudo, angosto en toda su extensión y de extremo bífido. El proceso anterolateral se proyecta desde el cuerpo hioideo por detrás 
de la base de los cuernos, presenta base angosta y extremo dístal bífido. Los cuernos hioideos son homólogos a los ceratohiales de la larva y se hallan en continuidad cartilaginosa con el piso de las cápsulas óticas. La columela surge al estadio 46 , en el lugar exacto que ocupara en el adulto. El proceso anteromedial es notorio en el adulto pero no pudo resolverse su origen. Aparentemente sería una recondensación del proceso anterohial del ceratohial.

La laringe se compone inicialmente por los cartílagos aritenoides, los cuales semejan dos pequeñas valvas triangulares, concavas medialmente y lateralmente convexas, ubicadas por detrás del seno posterior hipobranquial y del último par de espículas. El cartílago cricoides aparece al estadio 46, a partir de un esbozo par ubicado ventral a cada lado de los aritenoides. En principio no se nota claramente su estructura adulta dado que es par y carece de los procesos esofágico y lateral. En cambio, el aritenoides muestra desde su aparición (estadio 40) su forma adulta, restando crecer en tamaño.

La laringe del adulto se ubica entre los procesos posteromediales del hioides, posición que se aprecia desde la diferenciación de éstos a los estadios 43 - 44. La estructura adulta de la laringe presenta el par de aritenoides ubicados dorsales al cricoides. Este último formado por la fusión media de ambos esbozos larvarios. La estructura de los primeros no varía de lo descrito para la larva. El cricoides forma un anillo completo, ubicado ventral a los aritenoides, acompañando toda la base de estos y compuesto por dos procesos, uno impar posterior (proceso esofágico) y uno par (proceso lateral). El proceso esofágico es en realidad una prominencia medio ventral del extremo posterior del anillo. El proceso lateral se proyecta lateralmente en sentido posterior hasta alcanzar el nivel del margen posterior del cartílago cricoides. Es un proceso delgado y bífido, compuesto por dos ramas, una principal y una lateral que a su vez rematan en extremos bífidos. Ambas sostienen una membrana posterior a la laringe. Las 2 cuerdas vocales recorren verticalmente el espacio que hay entre el ápice dorsal de los aritenoides, al nivel de la abertura de la glotis, y el proceso esofágico del cricoides. A mitad de su recorrido, cada cuerda se une lateralmente, mediante un ligamento, con el cartílago cricoides, al nivel de la base de sus procesos laterales. 

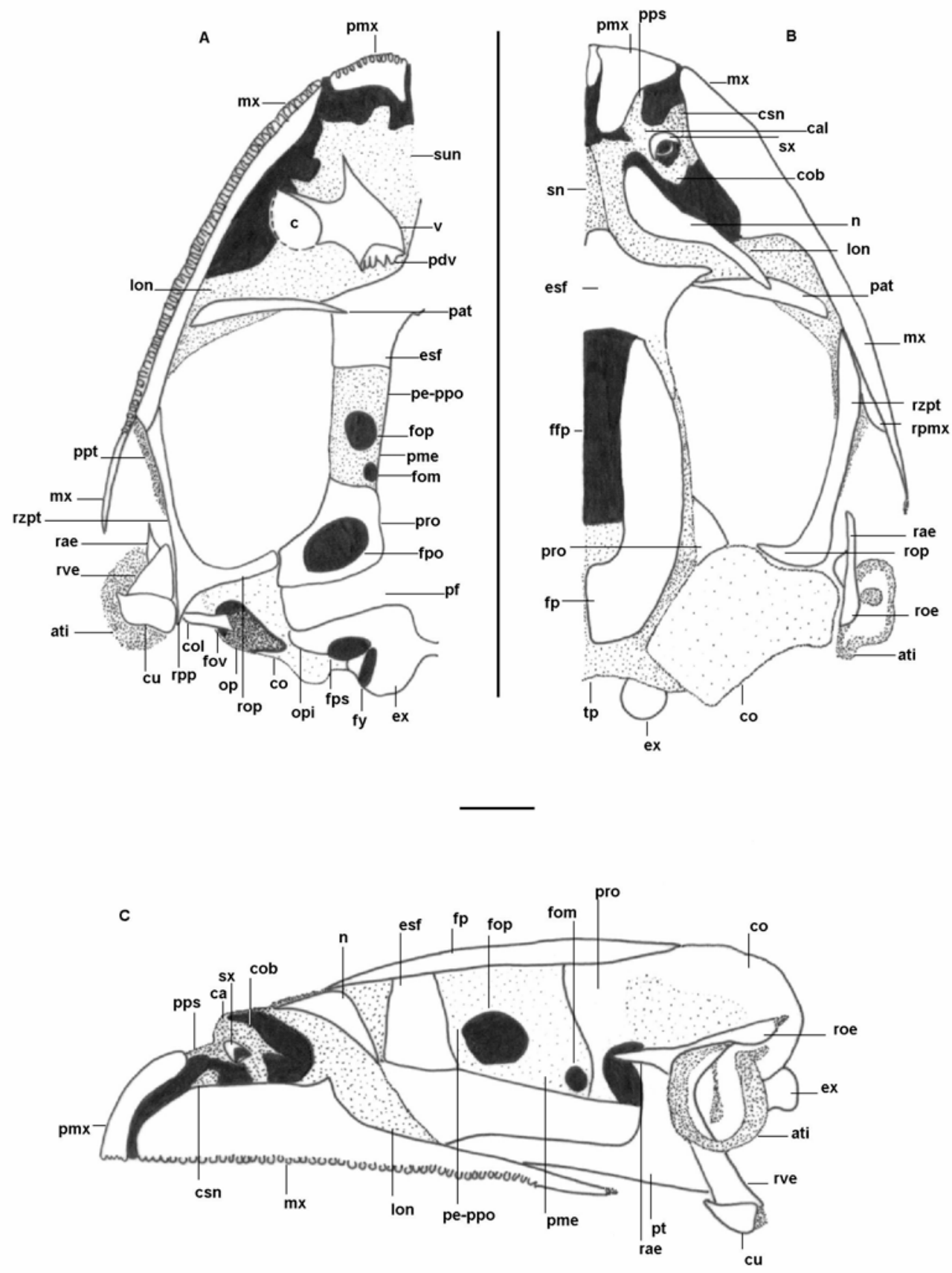

Figura 5. Neurocraneo y arco mandibular de del adulto de Batrachyla taeniata en vistas ventral (A), dorsal (B) y lateral (C). Las zonas oscuras representan fenestraciones, las punteadas son cartílago y las regiones sin puntear son hueso. Escala $1 \mathrm{~mm}$. Referencias: col: columela, $\mathbf{c u}$ : cuadrado, esf: esfenoetmoides, pat: palatino, pdv: proceso dentigero del vomer, rae: rama anterior del escamoso, roe : rama ótica del escamoso, rop: rama ótica del pterigoides, rpmx: reborde pterigoideo del maxilar, rpp: rama posterior del pterigoides, rve : rama ventral del escamoso, rzpt: rama zigomática del pterigoides. El resto de las referencias como en la figuras 1,2 y 3 . 

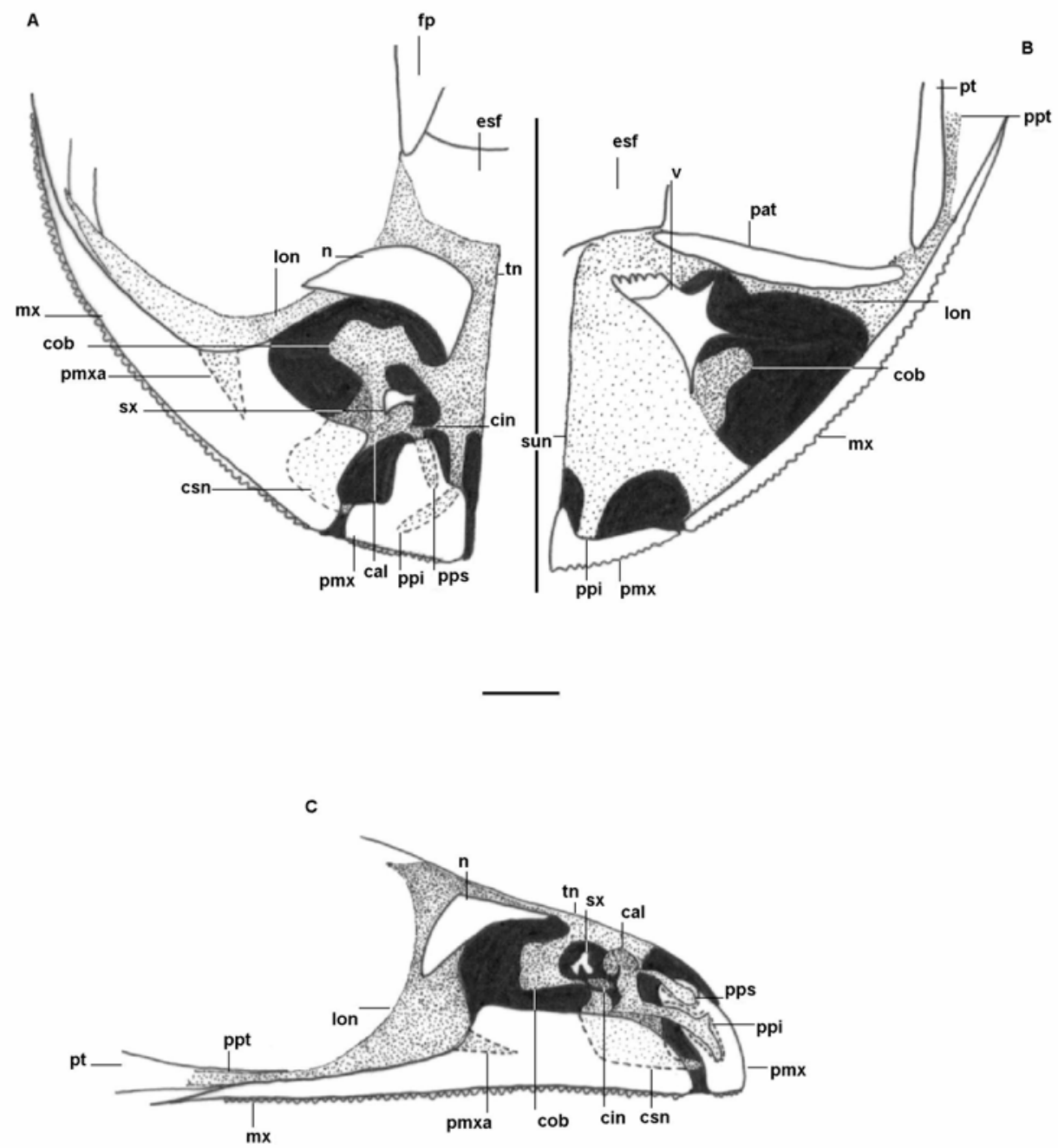

Figura 6. Detalle de la región nasal del adulto de Batrachyla taeniata en vistas dorsal (A), ventral (B) y lateral (C). Las zonas oscuras representan fenestraciones, las punteadas son cartílago y las regiones sin puntear son hueso. Escala $1 \mathrm{~mm}$. Referencias como en figuras 1-4. 

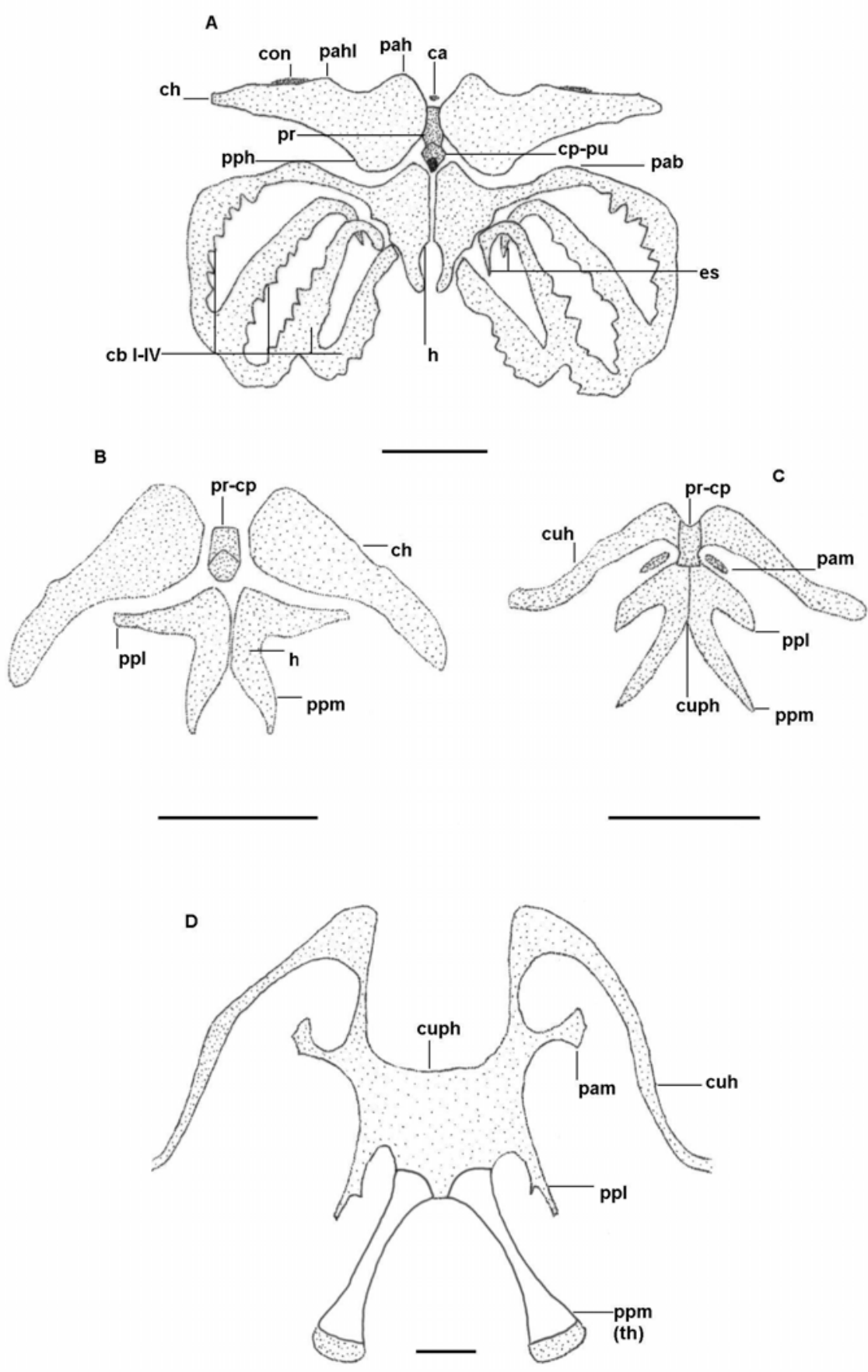

Figura 7. Vista ventral del aparato hiobranquial de Batrachyla taeniata a los es tadios 35 (A), 43 (B), 44 (C) y 46 (D). Escala $1 \mathrm{~mm}$. Referencias: ca: copula anterior, cb I- IV: ceratobranquiales I-IV, ch: ceratohial, con: cóndilo articular, cp-pu: pars reuniens y proceso urobranquial, cuh: cuerno hioideo, cuph: cuerpo hioideo, es: espículas, h: hipobranquial, pab: proceso anterior branquial, pah: proceso anterohial, pahl: proceso anterolateral hioides, pam: proceso anteromedial, pph: proceso posterohial, ppl: proceso posterolateral, ppm: proceso posteromedial, th: tirohial. 

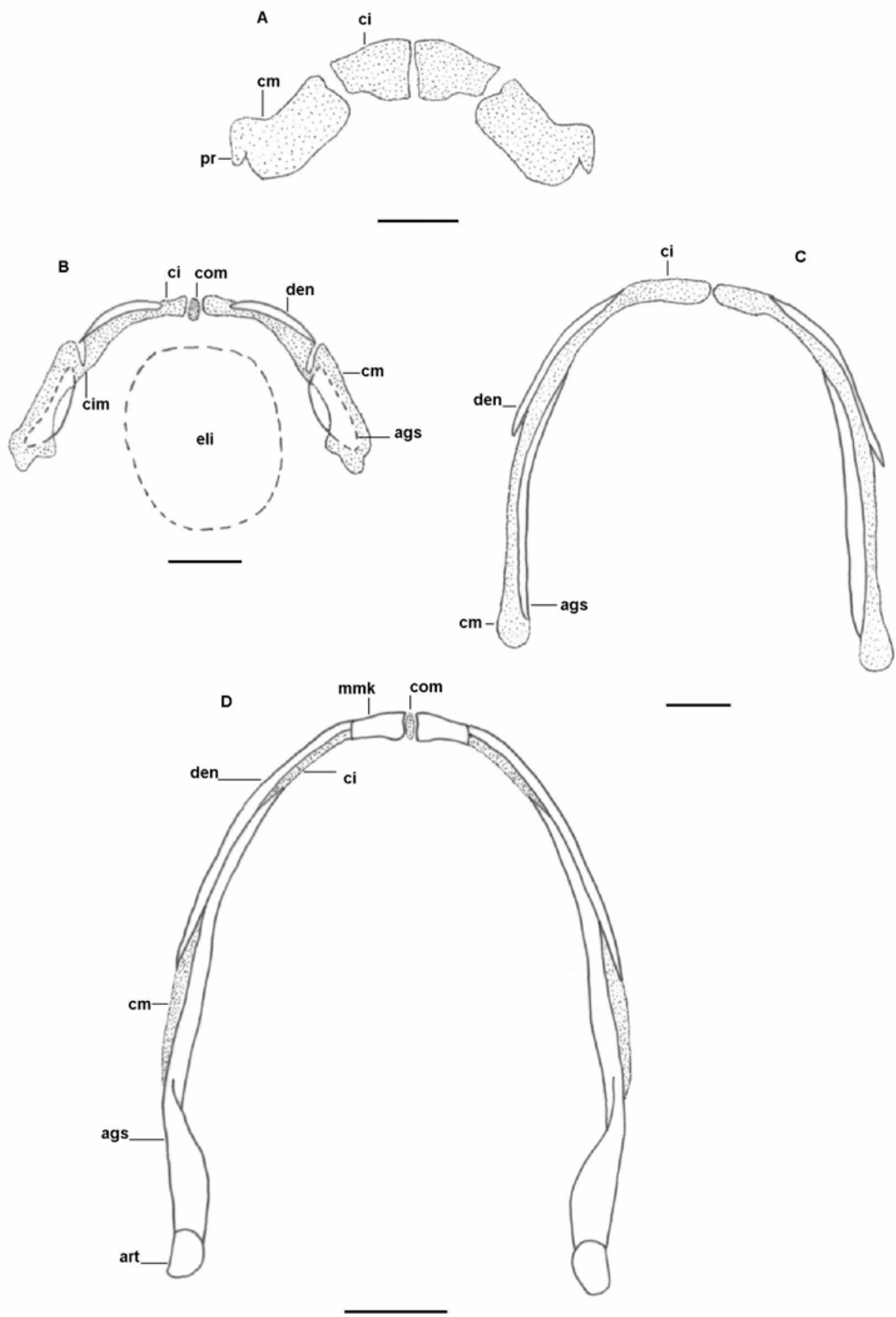

Figura 8. Porción ventral del arco mandibular de Batrachyla taeniata a los estadios 35 (A), 43 (B), 46 (C) y adulto (D). (A), (B) y (C) en vista ventral, (D) en vista dorsal. Escala $1 \mathrm{~mm}$. Referencias: ags: anguloesplenial, art: articular, ci: cartílago inrarrostral, cim : comisura intramandibular, cmp: cartílago de Meckel, com: copula mandibular, den: dentario, eli: esbozo lingual, pr: proceos retroarticular. 


\section{III.2. Desarrollo del osteocráneo en Batrachyla taeniata (Figs. 3-5, 7 y 8).}

La secuencia de osificación se presenta en la Tabla 3. A los fines de establecer comparaciones, las secuencias de osificación de Batrachyla antartandica y $B$. leptopus se encuentran en los Apéndices VII y VIII respectivamente.

\section{III.2.1. Región Naso-etmoidal (Figs. 3-5).}

- Nasal. Alostosis par, que aparece en el estadio 43 y recién se lo ve en todos los ejemplares a partir del estadio 44. Cada nasal se forma a partir de un único centro de osificación, que ya desde un comienzo muestra forma de medialuna, ubicado dorsal al techo nasal y anterior a la lamina orbitonasal, en la misma posición que tendrá en el adulto. En el adulto compone el techo del cráneo a nivel de la región naso-etmoidal. Se ubica por delante del extremo anterior del frontoparietal y medial a la pars fascialis del maxilar. Su forma es de medialuna, se ubica ligeramente oblicuo al eje axial y presenta su extremo anteromedial (pars medialis) dilatado respecto al extremo posterolateral (pars lateralis) que es aguzado. No presenta puntos de contacto con ningún otro hueso, y tamp oco contactan entre si en la línea media dejando descubiertos al septo nasal y a gran parte del techo nasal.

- Septomaxilar. Alostosis par, que aparece en el estadio 42 y recién se lo ve en todos los ejemplares a partir del estadio 44. Cada septomaxilar se forma a partir de un único centro de osificación, que desde un comienzo muestra su compleja forma definitiva. Se ubica dentro de la cápsula nasal, posterior y ventral al cartílago alar; anterior, ventral y dorsal al cartílago oblicuo, el cual que lo rodea como un anillo. Presenta forma irregular, anular, con la cara anterior y dorsal dilatada respecto del resto de la circunferencia. Se le reconocen tres procesos mediales, uno medio dorsal (el mas desarrollado), uno posteroventral y otro anteroventral. Se ubica subparalelo al eje axial y esta atravesado en su espacio medio por la cresta intermedia. En el adulto conserva la misma forma, posición y relaciones que las descritas para su desarrollo.

\section{III.2.2. Región Fronto-orbitaria (Figs. 3-5).}

- Esfenoetmoides. Autostosis impar que osifica postmetamorficamente a nivel ventral sobre la base del cráneo al nivel del tercio anterior de las trabeculas, lateral al cartílago orbitario por delante del foramen optico, anterior a la caja craneana al nivel de la pila etmoidea y base del septo nasal, y dorsal en el 
techo etmóideo. Aparentemente se forma a partir de un único centro de osificación difuso.

Cierra dorsalmente al paraesfenoides y anterolateralmente a la caja craneana. El esfenoetmoides puede expandirse, mediante osificación o calcificación, hacia la región posterior de la cápsula nasal, a nivel del septo nasal y laminas orbitonasales.

- Frontoparietal. Alostosis par, que aparece en el estadio 35. Cada frontoparietal se forma a partir de un único centro de osificación laminar y rectangular, ubicado en el margen de la fontanela frontoparietal dorsalmente al cartílago orbitario, entre la cápsula otica y el foramen óptico. En el adulto se ubican en el margen de la fontanela frontoparietal, limitandola lateralmente a lo largo de toda su extensión, abarcando las regiones fronto-orbitaria y óticooccipital. Los frontoparietales derecho e izquierdo no contactan en la línea media en ningún punto de su extensión. El espesor del espacio medio entre los frontoparietales es mayormente homogeneo y equivalente al espesor del frontoparietal. Sin embargo, en algunos ejemplares pudo reconocerse una dilatación ubicada a nivel del tercio anterior del techo parietal. El techo parietal se encuentra calcificado a nivel posterior y esto no debe ser confundido con un contacto posterior de los frontoparietales derecho e izquierdo, que se curvan medialmente a este nivel, pero sin establecer contacto ni fusión.

\section{III.2.3. Región Otico-occipital (Figs. 3-5).}

- Columela. Autostóosis par que osifica postmetamorficamente aparentemente a partir de un centro de osificación. Se ubica en la cavidad del oído medio, medial al tímpano, lateral a la cápsula ótica y posterior al escamoso. Tiene forma de varilla, proximalmente ensanchada y distalmente aguzada, siendo cartilaginosa en su ápice. Su base cierra la ventana oval por delante del opérculo.

- Exoccipital. Autostosis par que osifica a partir de un único centro de osificación ubicado en el arco occipital. Es el segundo hueso del cráneo que aparece, aunque notorio desde el estadio 35 , recién está en todos los ejemplares observados a partir del estadio 36. Al estadio 42 es evidente la formación del oto-occipital por invasión de la pared posteroventral de la cápsula ótica. 
En el adulto abarca todo el arco occipital y la placa basal a cada lado de la fenestra basicraneana, se extiende por la pared posterior de la cápsula auditiva donde delimita los foramenes perilinfaticos inferior y superior (ver opistótico), e incluso en la porción posterior del techo parietal (techo sinótico). Anteriormente esta separado del proótico por una zona calcificada del techo y el piso de la cápsula auditiva. Contacta con el extremo posterior de los frontoparietales al nivel del techo sinótico. A nivel medio ventral del arco occipital constituye los cóndilos occipitales (que permanecen cartilaginosos en el punto de contacto con la primera vértebra) y delimita al foramen yugular.

- Opistótico. En algunos ejemplares (estadio 41) se reconoce una separación entre el centro de osificación del exocci pital ubicado en el arco occipital y la osificación de la pared posteroventral de la cápsula ótica (opistótico) ubicada rodeando a los foramenes perilinfaticos. En el adulto, aunque sin contactar con el proótico, ambos centros forman el oto-occipital. El centro del opistótico se fusiona inmediatamente con el centro del exoccipital y a causa de ello su presencia pasa inadvertida en la mayoría de los ejemplares. En consecuencia, el centro de osificación independiente al del arco occipital, ubicado medial en la pared posterior y ventral de la cápsula ótica es interpretado aquí, por su posición, como hueso opistótico.

Sobre el techo de la cápsula ótica al nivel del proótico y del oto-occipital corre la arteria occipital, simplemente apoyada, sin existir surco nicanal en el hueso.

- Proótico. Autostosis par que osifica en el estadio 40. Es un centro de osificación redondeado y laminar ubicado en la pared anterior y ventral de la cápsula auditiva, a nivel medial de la misma. Hasta el estadio 46 permanece restringido a la pared anterior de la cápsula auditiva. En el adulto, en cambio, abarca la pared anterior de la cápsula auditiva, el piso del cráneo al nivel de la pila antótica (constituyendo el margen posterior de los foramenes metóptico y óptico), la taenia tecti marginal y la pila antótica, delimitando en consecuencia al foramen proótico. También establece contacto con los frontoparietales dorsalmente, con las alas del paraesfenoides ventralmente y con la rama ótica del pterigoides por los laterales. No forma parte del oto-occipital del adulto.

\section{III.2.4. Paladar (Figs. 3-5).}

- Palatino. Alostosis par formada a partir de un único centro de osificación que desde su aparición al estadio 46 muestra la estructura y posición que tendrá en 
el adulto, restando solo crecer en extensión. Se ubica ventral en el cráneo, exactamente en el límite entre la cavidad nasal y la región fronto-orbitaria. En el adulto es un hueso delgado orientado perpendicular al eje axial, dispuesto ligeramente oblicuo, con su región medial ubicada más dorsal respecto de su región lateral. Medialmente se apoya en el esfenoetmoides en el punto en que termina la cavidad encefalica y comienza la cavidad nasal. Lateralmente es libre, no contacta al maxilar.

- Paraesfenoides. Alostosis impar formada a partir de un único centro de osificación masivo que desde el comienzo de su desarrollo ya muestra las porciones correspondientes a alas y rostro esfenoidal. Osifica al estadio 34, en la base del cráneo a nivel de las regiones fronto-orbitaria (rostro) y óticooccipital (alas). La estructura adulta, que se alcanza al estadio 46, muestra las alas, de forma rectangular, ocupando practicamente todo el piso de las cápsulas óticas sobrepasando lateralmente el extremo medial de la rama ótica del pterigoides. El rostro pr esenta forma rectangular y se orienta axialmente desde su extremo anterior, ubicado ligeramente por detrás del nivel de los palatinos, hasta su extremo posterior que ocupa a modo de muñón la mitad anterior de la fenestra basicraneana. El extremo anterior del rostro es irregular.

- Vómer. Alostosis par formada a partir de un único centro de osificación, pequeño y redondo, ubicado ventral al piso de la cavidad nasal, lateralmente a la región proximal del septo nasal. El vómer aparece al estadio 43 pero finalmen te esta en todos los ejemplares observados recién a partir del estadio 46. En este estadio se reconoce su estructura adulta, formada por un cuerpo irregular, del cual se proyectan los procesos anterior, lateral (precoanal), posterior (postcoanal) y dentígero. El proceso dentígero (cresta) es la porción con mayor espesor del hueso y sostiene tanto proyecciones oseas denticulares (3-4) como dientes pedicelados (3-4).

\section{III.2.5. Mandíbula (Figs. 3-5 y 8).}

- Anguloesplenial. Alostosis par formada a partir de un único centro de osificación que aparece al estadio 43 pero recién es notorio en todos los ejemplares a partir del estadio 44. En el desarrollo presenta la misma ubicación que en el adulto, en la cara lateral del cartílago de Meckel al nivel de su mitad anterior. En el adulto se extiende por la cara medial y ventral de la mitad posterior del cartílago de Meckel, y en su extremo más posterior reviste ventral, 
lateral y medialmente a la porción articular del cartílago de Meckel. No presenta contacto con el dentario. En el tercio posterior de la mandíbula, al nivel dorsal, forma el proceso coronoideo.

- Articular. Autostosis par formada en el extremo posterior del cartílago de Meckel. Aparece postmetamorficamente. En el adulto se encuentra rodeado ventral, lateral y medialmente por el anguloesplenial y su extremo más dístal permanece cartilaginoso.

- Dentario. Alostosis par formada a partir de un único centro de osificación que aparece al estadio 43 pero recién es notorio en todos los ejemplares a partir del estadio 44. En el desarrollo presenta la misma ubicación que en el adulto, en la cara medial y ventral del cartílago de Meckel, al nivel de su mitad posterior. En el adulto reviste lateralmente la mitad anterior del cartílago de Meckel, por el cual queda separado de la porción más anterior del anguloesplenial. No contacta anteriormente con el mentomeckeliano.

- Mentomeckeliano. Autostosis par formada a partir de un único centro de osificación ubicado en el cartílago de Meckel en las inmediaciones de la sínfisis mandibu lar, justo por delante del extremo anterior del dentario. Aparece en el estadio 46. En el adulto presenta forma rectangular y las porciones derecha e izquierda no contactan medialmente entre si, quedando separadas por una sínfisis mandibular sindesmótica que puede presentar copula mandibular en algunos ejemplares. Tampoco contacta posteriormente con el dentario.

\section{III.2.6. Alostosis de las crestas neurales asociadas al arco maxilar (Figs. 3-5).}

- Cuadradoyugal. A lo largo del desarrollo y en particular en la larga muestra analizada de ejemplares metamórficos, no he observado centros de osificación que puedan asimilarse al cuadradoyugal. No obstante ello, en todos los especímenes adultos analizados existe un proceso anterior, suturado al hueso cuadrado, que suel e ser interpretado como hueso cuadradoyugal reducido (ver Basso, 1994). En este trabajo de tesis la proyección anterior del cuadrado, al no haber sido observado su centro de osificación, no es interpretada como hueso cuadradoyugal.

- Escamoso. Alostosis par formada a partir de dos centros de osificación, uno correspondiente a la rama ventral y otro centro común para las ramas ótica y anterior. El centro de la rama ventral aparece primero al estadio 43, pero recién esta presente en todos los ejemplares al estadio 44 , mientras que el centro 
restante aparece al estadio 46. Ambos centros presentan desde su aparición la estructura definitiva, sin embargo el centro de la rama ventral aparece en la región fronto-orbitaria, en el margen anterior del proceso muscular en regresión, y migra posteriormente acompañando la metamorfosis del palatocuadrado, hasta ubicarse en la región ótica hacia el estadio 46. Ya en el adulto, muestra la estructura triradiada típica, donde la rama ventral está ubicada verticalmente, lateral al margen anterior de la cápsula ótica y es la de mayor desarrollo. Su extremo dorsal se proyecta hacia atrás constituyendo la rama ótica y hacia delante formando la rama anterior. Las ramas ótica y anterior son subiguales. La rama ótica se solapa dorsalmente a la cresta parótica y junto con la rama ventral forman la muesca ótica para sostén del anillo timpánico y de la membrana timpánica.

- Maxilar. Alostosis par que aparece al estadio 43 a partir de un único centro de osificación correspondiente a la pars fascialis. En estadios posteriores el hueso va tomando su forma adulta por crecimiento en longitud hacia caudal. Al estadio 46 los dientes y la estructura adulta ya son evidentes. El maxilar recién se encuentra en todos los especímenes observados a partir del estadio 44 . En el adulto la pars fascialis se ubica entre la cresta subnasal y el margen anterior de la lamina orbitonasal y se proyecta posteriormente rematando en un ápice agudo y libre. Salvo en su extremo más posterior, sostiene 42 dientes a lo largo de toda su longitud. Contacta anteriormente con el premaxilar.

- Premaxilar. Alostosis par que se forma a partir de un único centro de osificación correspondiente al proceso alar. Este centro es notorio a partir del estadio 42, pero se halla presente en todos los ejemplares solo a partir del estadio 43. El proceso prenasal inferior queda embebido rapidamente en el proceso alar del premaxilar. En estadios posteriores se forman los restantes dos procesos por crecimiento a partir del proceso alar. Al estadio 46 ya es evidente la estructura adulta aunque no están muy definidos los dientes. En el adulto, el proceso alar acompaña la forma anterior de la cavidad nasal, siendo cóncavo posteriormente y convexo en su cara anterior. Dorsalmente alcanza el nivel del proceso prenasal superior y ventralmente remata en el borde de la quijada con el proceso dentígero que sostiene 13 dientes. Del proceso dentígero y hacia caudal se proyecta el proceso palatino de forma triangular. El premaxilar contacta solo con el maxilar mediante un ligero solapamiento de su extremo posterior. 


\begin{tabular}{|c|c|c|c|c|}
\hline Estadio & Cráneo & Axial & AA & AP \\
\hline $34(\mathrm{~N}=8)$ & Paraesfenoides & & & \\
\hline $35(\mathrm{~N}=13)$ & $\begin{array}{l}\text { 1.Exoccipital } \\
\text { 2.Frontoparietal }\end{array}$ & $\begin{array}{l}\text { AN IX } \\
\text { C HVIII } \\
\text { PT I-III }\end{array}$ & $\begin{array}{l}\text { Escápula } \\
\text { Húmero } \\
\text { Radio-ulna }\end{array}$ & $\begin{array}{l}\text { Fémur } \\
\text { Tibia-fíbula } \\
\text { Ileon } \\
\text { Tibial-fibular }\end{array}$ \\
\hline $38(\mathrm{~N}=9)$ & & $\begin{array}{l}\text { PT IV } \\
\text { Hipocordo }\end{array}$ & $\begin{array}{l}\text { Coracoides } \\
\text { Clavícula } \\
\text { Cleitro } \\
\text { MC (D II-V } \\
\text { FP (D IV-V) }\end{array}$ & $\begin{array}{l}\text { MT (D III-V) } \\
\text { FP (D IV-V) }\end{array}$ \\
\hline $40(N=5)$ & Proótico & & & \\
\hline 41(N=25) & Opistótico & C IX & $\begin{array}{l}\text { Falanges } \\
\text { restantes }\end{array}$ & $\begin{array}{l}\text { MT (D I-II) } \\
\text { Falanges } \\
\text { restantes }\end{array}$ \\
\hline $42(N=7)$ & $\begin{array}{l}\text { 1.Premaxilar } \\
\text { 2. Septomaxilar }\end{array}$ & & & \\
\hline 43(N=35) & $\begin{array}{l}\text { 1. Dentario } \\
\text { 2. Maxilar } \\
\text { 3. Nasal } \\
\text { 4. Vomer } \\
\text { 5. Anguloesplenial } \\
\text { 6. Escamoso (rv) } \\
\text { 7. Pterigoides }\end{array}$ & $\begin{array}{l}\text { PT V-IX } \\
\text { AN XI }\end{array}$ & & Isquion \\
\hline $46(N=5)$ & $\begin{array}{l}\text { 1.Tirohial } \\
\text { 2.Escamoso (ro-ra) } \\
\text { 3.Mentomeckeliano } \\
\text { 4.Palatino }\end{array}$ & & & \\
\hline PM & $\begin{array}{l}\text { Articular } \\
\text { Cuadrado } \\
\text { Columela } \\
\text { Esfenoetmoides } \\
\end{array}$ & & $\begin{array}{l}\text { Carpianos } \\
\text { Prepollex } \\
\text { Esternón }\end{array}$ & $\begin{array}{l}\text { Tarsianos } \\
\text { Prehallux }\end{array}$ \\
\hline
\end{tabular}

TABLA 3. Secuencia de osificación de Batrachyla taeniata. En negrita se indican las autostosis. A los estadios $29(\mathrm{~N}=2), 32(\mathrm{~N}=1), 33(\mathrm{~N}=2), 36(\mathrm{~N}=16), 37(\mathrm{~N}=12), 39$ $(\mathrm{N}=1)$ y $44(\mathrm{~N}=4)$ no se registraron novedades. Referencias: $A \mathrm{~A}$ : apendicular anterior, AN: arcos neurales, AP: apendicular posterior, C: cuerpos vertebrales, FP: falanges proximales, MC: metacarpianos, MT: metatarsianos, PT: procesos transversos, ra: rama anterior, ro: rama ótica, rv: rama ventral.

- Pterigoides. Alostosis par que aparece al estadio 43 representado por el centro de osificación correspondiente a sus ramas ótica y posterior, las cuales estarán presentes en todos los ejemplares recién a partir del estadio 44 . El centro de las ramas ótica y posterior aparece en la región fronto-orbitaria, en la cara ventral de la comisura cuadrado craneana anterior (proceso pterigoideo en 
formación), medialmente al centro de la rama ventral del escamoso. Migra posteriormente acompañando la metamorfosis del palatocuadrado, hasta ubicarse en la región ótica hacia el estadio 46. Inicialmente se ubica horizontal y al migrar posteriormente se verticaliza, acompañando la verticalización del palatocuadrado. La rama zigomática fue observada al estadio 46 y no se pudo determinar si osifica a partir de un centro de osificación independiente o si es un crecimiento óseo de las restantes ramas (en material de comparación correspondiente a Pleurodema spp. sí se pudo verificar la presencia de un centro independiente). La aparición de la rama zigomática permite el reconocimiento de las ramas ótica y posterior, dado que estas quedan ubicadas dorsal y ventral al punto de contacto con la rama zigomática. La estructura adulta del pterigoides es trirradiada y su posición es medial al escamoso. Las ramas ótica y posterior son ligeramente subiguales. La rama posterior del pterigoides es subparalela a la del escamoso, aunque ligeramente más anterior y solo contactando a aquella mediante el cuadrado. La rama ótica se dirige hacia la cápsula ótica a la cual contacta a nivel del proótico. La rama zigomática se dirige anteriormente aplicada al proceso pterigoideo del palatocuadrado y se encuentra solapada medialmente con el extremo posterior libre del maxilar, aunque sin establecer contacto.

\section{III.2.7. Aparato hiobranquial (Fig. 7).}

- Parahioideo. Calcificaciones de la pars reuniens, hipobranquiales y ceratohiales, asimilables a los huesos parahioideos han sido identificados a lo largo del proceso metamórfico en 6 ejemplares del estadio 43 y en uno del estadio 44 (también en $B$. leptopus al estadio 43). Las mismas no fueron observadas en estadios posteriores ni en el estado adulto.

- Tirohial. Autostosis par que osifica sobre los procesos posteromediales del cuerpo hioideo al estadio 46. La osificación comienza en el punto medio del proceso posteromedial y crece hacia los extremos. En el adulto todo el proceso posteromedial, a excepción de su extremo dístal se encuentra osificado. 
III.3. Desarrollo de la musculatura craneana en Batrachyla taeniata (Figs. 9-15).

\section{III.3.1. Musculatura mandibular (Figs. 9-14).}

La larva de Batrachyla taeniata presenta 10 músculos mandibulares inervados por el nervio craneano trigémino (V): levator mandibulae articularis, $I . m$. externus profundus, I. m. externus superficialis, I. m. internus, I. m. lateralis, I. m. longus profundus, I. $m$. longus superficialis, intermandibularis, mandibulolabialis superior y submentalis.

Todos los músculos mandibulares de la larva se encuentran desde el primer estadio observado (31) a excepción del m. submentalis que aparece tardíamente en el desarrollo. A continuación se presentan las características generales de cada uno y los aspectos de su metamorfosis.

- Levator mandibulae articularis. Músculo par originado en el proceso articular del palatocuadrado cerca de la base del proceso muscular. Inserta en el área dorsal del cartílago de Meckel medial a la inserción del m. levator mandibulae internus. Es interno a la rama mandibular del nervio trigémino. Al estadio 46 ya presenta sus características adultas definitivas. Durante la metamorfosis, como los restantes músculos elevadores, migra en sentido posterior acompañando las transformaciones del arco mandibular y sus fibras pasan a correr dorsal y ventralmente en vez de axialmente. Con la aparición del hueso escamoso desplaza su origen a ese elemento.

- Levator mandibulae externus profundus. Músculo par originado en el margen anterior y medial del proceso muscular del palatocuadrado. Inserta en la cara lateral del ala del cartílago suprarrostral mediante un tendón común con el $\mathrm{m}$. levator mandibulae longus profundus. Es interno a la rama mandibular del nervio trigémino. Al estadio 42, a causa de la regresión del cartílago suprarrostral, se junta con el $\mathrm{m}$. levator mandibulae externus superficialis y desplazan su inserción hacia el cartílago de Meckel. Al finalizar la metamorfosis, ambos mm. levatorae mandibulae externus son indistinguibles entre si y desplazan su origen al escamoso y anillo timpánico.

- Levator mandibulae externus superficialis. Músculo par originado en el proceso muscular del palatocuadrado junto con el m. levator mandibulae externus profundus. Inserta en el ligamento mandibulo-suprarostrale en las adyacencias del proceso posterodorsal del ala del cartílago suprarrostral. Está representado por un pequeño haz de fibras. Es interno a la rama mandibular 
del nervio trigémino. Al estadio 42, a causa de la regresión del cartílago suprarrostral, se junta con el $\mathrm{m}$. levator mandibulae externus superficialis y desplazan su inserción hacia el cartílago de Meckel. Al final izar la metamorfosis, ambos $\mathrm{mm}$. levatorae mandibulae son indistinguibles entre si y desplazan su origen al escamoso y anillo timpánico.

- Levator mandibulae internus. Músculo par originado en la región ventral de la copula anterior de la cápsula ótica y del proceso ascendente. Inserta por medio de un largo y delgado tendón en el área dorsolateral del cartílago de Meckel. Es interno a la rama mandibular del nervio trigémino. Al estadio 42, a causa de la reabsorción del proceso ascendente, desplaza su origen hacia la pared anterior de la cápsula ótica. Al finalizar la metamorfosis presenta inserción en el cartílago orbitaio al nivel de la pila antótica.

- Levator mandibulae lateralis. Músculo par, formado por un delgado paquete de fibras que corren oblicuamente desde su origen, en el extremo anterolateral del proceso articular del palatocuadrado, hasta su inserción. Inserta en el ligamento mandibulo-suprarostrale en las adyacencias del proceso posterior dorsal del ala del cartílago suprarrostral. Es interno a la rama mandibular del nervio trigémino. Al estadio 42 desplaza su inserción al cartílago de Meckel.

- Levator mandibulae longus profundus. Músculo par originado en el margen lateral del arco subocular del palatocuadrado y en la porción más externa de la fosa articular del mismo. No se solapa ventralmente con el $\mathrm{m}$. levator mandibulae longus superficialis. Inserta en la cara lateral del ala del cartílago suprarrostral mediante un tendón común con el $\mathrm{m}$. levator mandibulae externus profundus. Es interno a la rama mandibular del nervio trigémino. Al estadio 42 desplaza su inserción hacia el cartílago de Meckel. Al estadio 44 se junta con el $\mathrm{m}$. levator mandibulae longus superficialis y desplazan su origen hacia la cápsula ótica.

- Levator mandibulae longus superficialis. Músculo par originado en la fosa articular ubicada en el extremo posterior del arco subocular y en la zona lateral del proceso ascendente. Inserta en el proceso dorsomedial del cartílago de Meckel. Es interno a la rama mandibular del nervio trigémino. Al estadio 44 se junta con el m. levator mandibulae longus superficialis y desplazan su origen hacia la cápsula ótica.

- Intermandibularis. Músculo impar originado en la superficie ventromedial del cartílago de Meckel. Inserta medialmente sobre si mismo en una aponeurosis 
media. Durante la metamorfosis crece en sentido anteroposterior acompañando el alargamiento del cartílago de Meckel. Al estadio 44, a pesar del importante alargamiento del cartílago de Meckel, aun se restringe al tercio anterior entre ambas hemi mandíbulas. Con la osificación de las alostosis mandibulares pasa a tener origen en ellas, aun cuando conserva parte de su inserción en el cartílago de Meckel. Al finalizar la metamorfosis constituye el m. intermandibularis del adulto y se halla por delante del $\mathrm{m}$. interhyoideus y por detrás y debajo del m. submentalis.

- Mandibulolabialis inferior. Músculo par originado en la superficie ventromedial del cartílago de Meckel en las adyacencias del origen del m. intermandibularis. Presenta inserción en el área mental del disco oral. Se reabsorbe durante la metamorfosis hasta su desaparición total al estadio 43.

- Submentalis. Se observo por primera vez al estadio 38. Es un músculo impar que se origina en la superficie medio ventral del cartílago infrarrostral. Presenta inserción sobre si mismo mediante una aponeurosis media. Al estadio 42 presenta un mayor desarrollo pero recién entra en contacto con el intermandibularis al estadio 43, momento en que ambos músculos se encuentran ocupando la mitad anterior del espacio entre ambas hemimandíbulas. Hacia el estadio 46 se diferencia en una pars anterior y una pars posterior, ambas con origen en el cartílago infrarrostral. Estas se mantendrán en el estado adulto, la pars posterior tapando las fibras más anteriores del $\mathrm{m}$. intermandibularis, y la pars anterior restringida a las adyacencias de la sínfisis mandibular.

Los adultos de Batrachyla taeniata presentan 7 músculos mandibulares: Levator mandibulae articularis, levator mandibulae externus, levator mandibulae internus, levator mandibulae lateralis, levator mandibulae longus, intermandibularis y submentalis. A continuación se dan las características generales de cada uno de ellos:

- Levator mandibulae articularis. Músculo par, homólogo al m. levator mandibulae articularis de la larva. Visible en vista profunda por debajo del $\mathrm{m}$. levator mandibulae lateralis. Se origina en la rama ventral del escamoso, por encima del origen del $\mathrm{m}$. levator mandibulae lateralis. Inserta en la superficie medial del proceso coronoideo de la mandíbula, detrás del $\mathrm{m}$. levator mandibulae longus. 
- Levator mandibulae externus Músculo par, homólogo a los mm. levatorae mandibulae externus superficialis y profundus de la larva. Visible en vista superficial por delante del $\mathrm{m}$. levator mandibulae lateralis. Se origina en el margen anterior de la rama ventral del escamoso y área ventral anterior del anillo timpánico. Inserta lateralmente al proceso coronoideo de la mandíbula, en el cartílago de Meckel y parte del anguloesplenial.

- Levator mandibulae internus. Músculo par, homólogo al m. levator mandibulae internus de la larva. Solo su origen es visible en vista superficial. Se origina en la región dorsal de la pila antótica y margen lateral de los frontoparietales justo por delante de la cápsula ótica. Inserta bien posterior en la mandíbula, en la cara medial del cartílago de Meckel mediante un largo tendón.

- Levator mandibulae lateralis. Músculo par homólogo al m. levator mandibulae lateralis de la larva. Es visible en vista superficial entre los $\mathrm{mm}$. depressor mandibulae (pars timpanica) y levator mandibulae externus. Se origina en el proceso articular del palatocuadrado y parte ventral de la rama ótica del escamoso. Inserta en la cara lateral del cartílago de Meckel por detrás del m. levator mandibulae externus.

- Levator mandibulae longus. Músculo par, homólogo a los mm. levatorae mandibulae longus profundus y superficialis de la larva. Su origen es visible en vista superficial entre los $\mathrm{mm}$. levator mandibulae internus, depressor mandibulae (pars timpanica) y rhomboideus anterior. Se origina en el área dorsal anterior de la cápsula ótica e inserta en la cara medial al cartílago de Meckel por delante del $\mathrm{m}$. levator mandibulae articularis.

- Intermandibularis. Músculo impar homólogo al m. intermandibularis de la larva. Sus fibras son perpendiculares al eje axial, se originan en el anguloesplenial por detrás y debajo del $\mathrm{m}$. submentalis y por delante del $\mathrm{m}$. interhyoideus. Ambas insertan sobre si mismas en una aponeurosis media.

- Intermaxilaris. Ausente.

- Submentalis. Músculo impar compuesto por dos partes, la pars anterior y la pars posterior, ambas homologas a las descritas para el $\mathrm{m}$. submentalis de la larva. La primera se origina en las adyacencias de la sínfisis mandibular. La segunda se origina en el extremo anterior del anguloesplenial y presenta fibras marcadamente oblicuas al eje axial. Ambas insertan sobre si mismas en una aponeurosis media. 
A

B

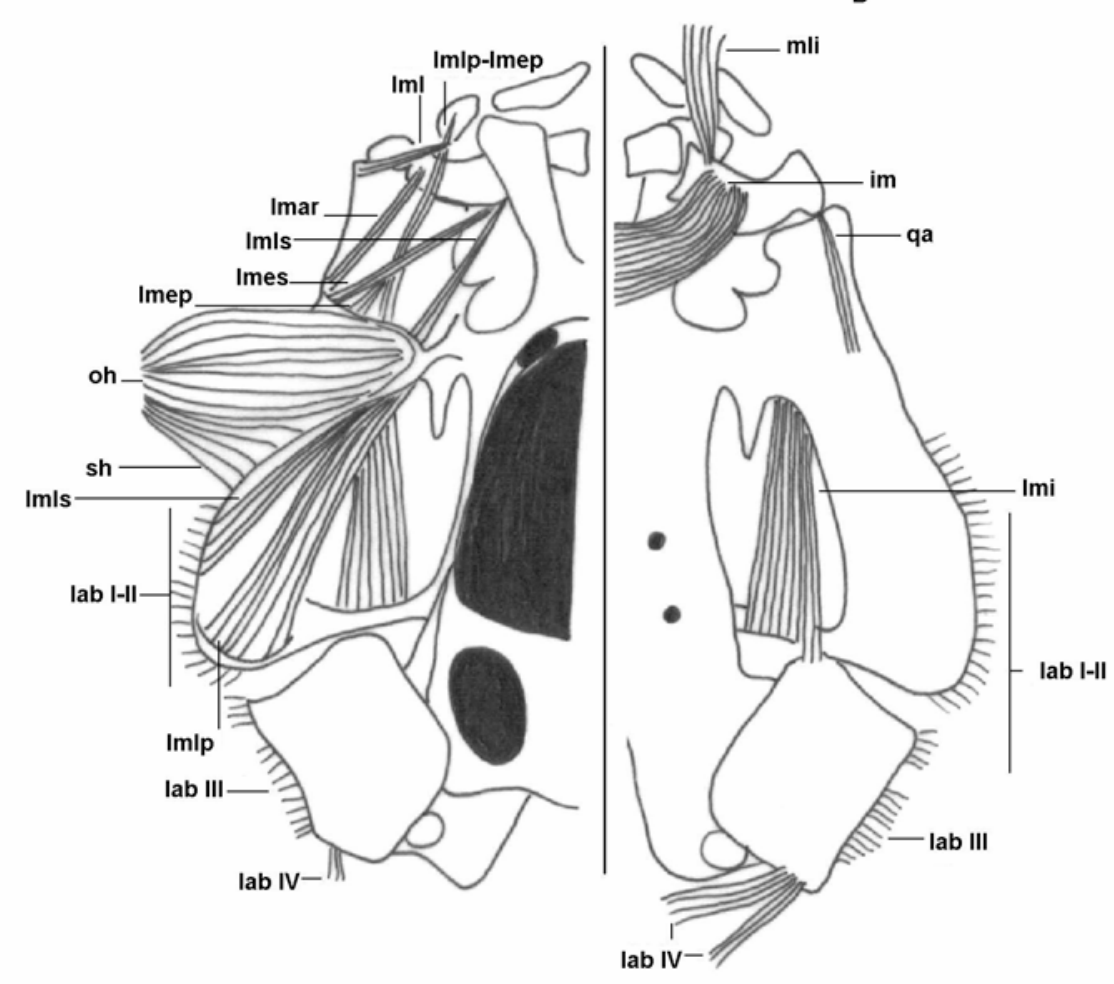

C

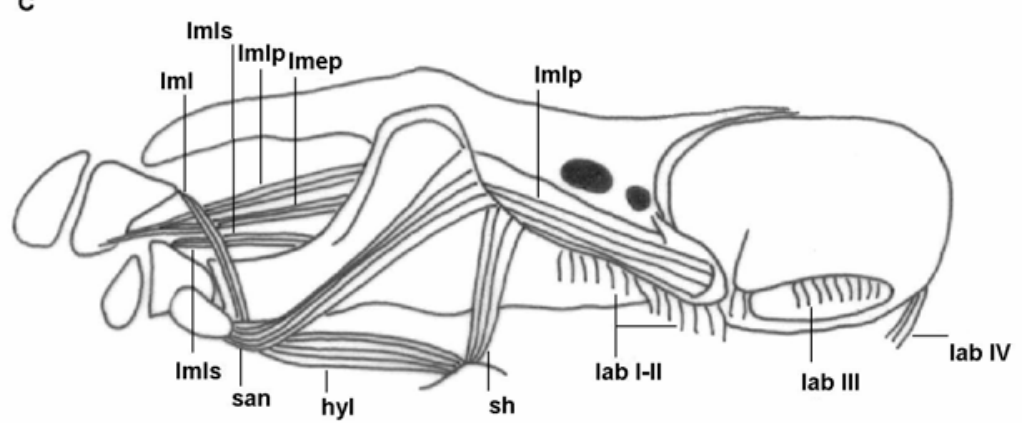

Figura 9. Musculatura mandibular, hioidea y branquial asociada al neurocráneo y arco mandibular de Batrachyla taeniata al estadio 35 de Gosner (1960) en vistas dorsal (A), ventral(B) y lateral (C). En (C) los $\mathrm{mm}$. levator mandibulae externus superficialis y orbitohyoideus feuron removidos. Las zonas oscuras representan fenestraciones. Escala $1 \mathrm{~mm}$. Referencias: hyl : hyoangularis lateralis, im: intermandibularis, Iab I-IV: levatorae arcuum branchialium I-IV, Imar: levator mandibulae articularis, Imep: I. m. externus profundus, Imes: I. m. e. superficialis, Imi: I. m. internus, ImI: I. m. lateralis, ImIp: I. m. longus profundus, Imls: I. m. I. superficialis, mli: mandibulolabialis, oh: orbitohyoideus, qh: quadratoangularis, san: suspensorioangularis, sh: suspensoriohioideus. 
A

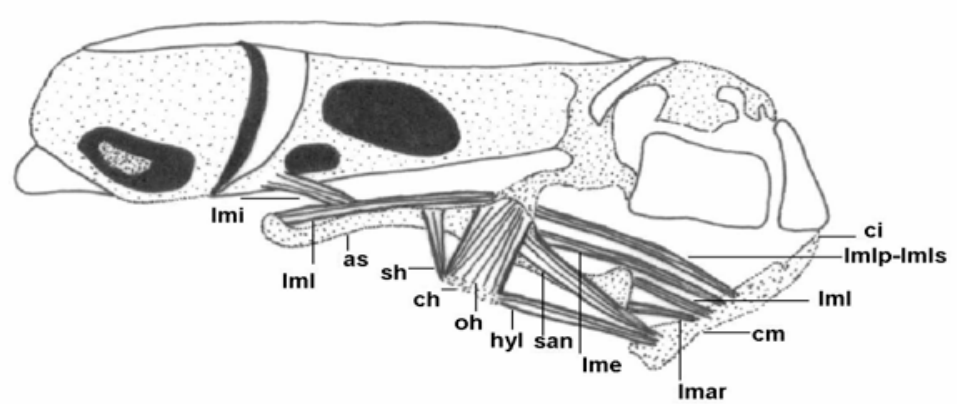

B

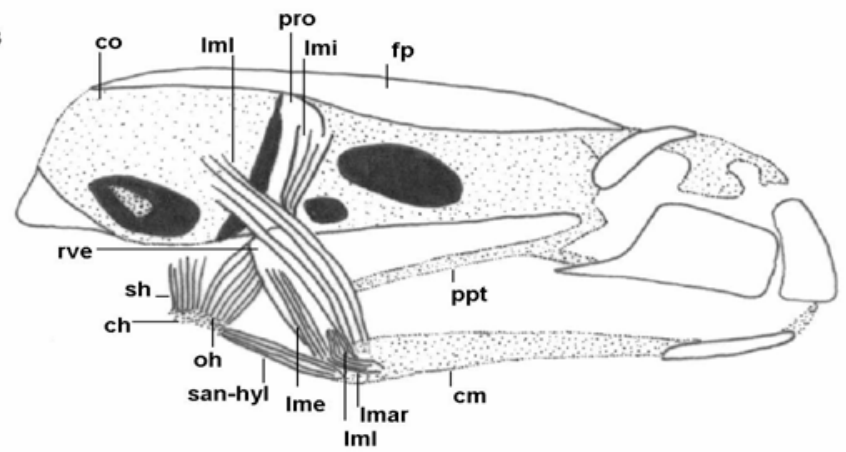

c

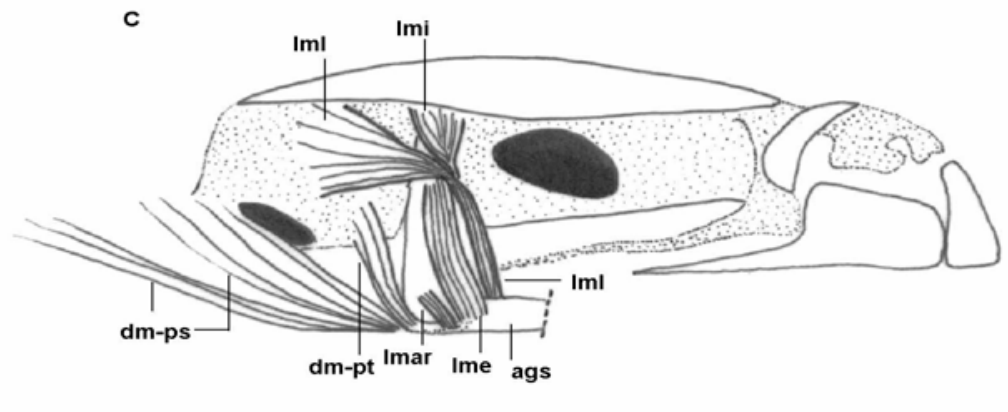

Figura 10. Vista lateral de la musculatura mandibular e hioidea asociada al neurocráneo y arco mandibular de Batrachyla taeniata a los estadios 43 (A), 44 (B) y 46 (C) de Gosner (1960). Las zonas oscuras representan fenestraciones, el punteado cartílago y las regiones sin puntear hueso. Escala $1 \mathrm{~mm}$. Referencias: ags : anguloesplenial, ch: ceratohial, ci: cartílago infrarrostral, cm: cartílago de Meckel, co: cápsula ótica, dm-ps: depresor mandibulae- pars scapularis, dm-pt: depresor mandibulae- pars timpanica, fp: frontoparietal, Ime: levator mandibulae externus, Iml: I. m. longus, ppt: proceso pterigoideo, pro: proático, rve : rama ventral del escamoso. El resto de las referencias como en la figura 8. 


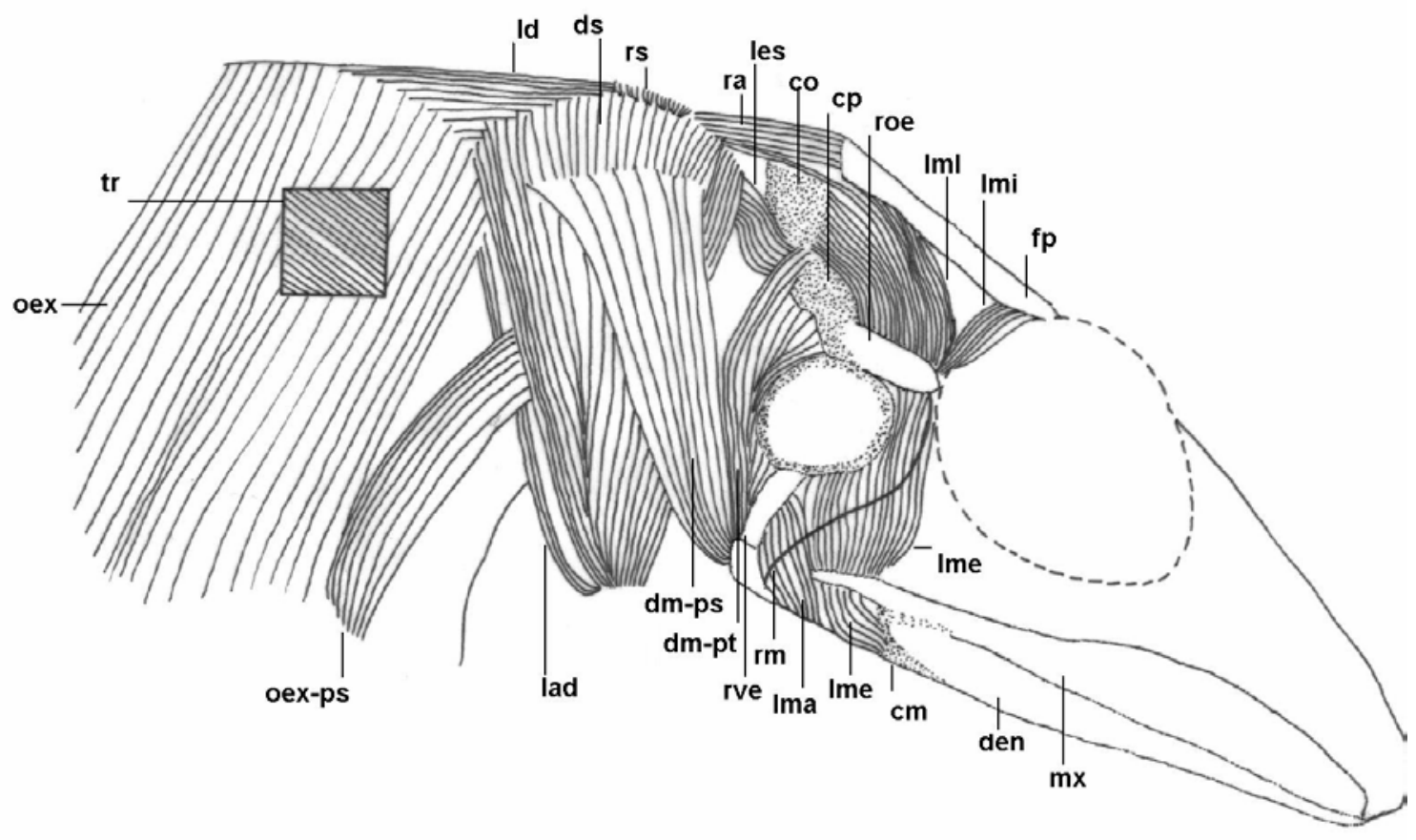

Figura 11. Vista lateral de la musculatura de la musculatura craneana y parte de la musculatura apendicular anterior y axial postcraneana en un adulto de Batrachyla taeniata. Escala $5 \mathrm{~mm}$.

Referencias: c p: cresta parótica, den: dentario, ds: dorsalis scapulae, lad: latissimus dorsi, Id: longissimus dorsi, les: levator scapulae, mx: maxilar, oex: obliquus externus, oex-ps: obliquus externus - pars scapularis, ra: rhomboideus anterior, $\mathbf{r m}$ : rama mandibular del nervio trigémino, roe: rama ótica escamoso, rs: rhomboideus superior, tr: transversus. El resto de las referencias como en la figura 9. 


\section{III.3.2. Musculatura hioidea (Figs. 9-14).}

La larva de Batrachyla taeniata presenta 8 músculos hioideos inervados por el nervio facial (VII): diaphragmatopraecordialis, hyoangularis lateralis, interhyoideus, interhyoideus posterior, orbitohyoideus, quadratoangularis, suspensorioangularis, suspensoriohyoideus. El m. hyoangularis medialis falta en esta especie. Todos los músculos hioideos se hallan presentes desde los primeros estadios observados. A continuación se presentan las características larvarias y el cambio metamórfico de cada músculo.

- Diaphragmatopraecordialis. Músculo par compuesto por una delgada capa de fibras que se prolongan desde el extremo medial del $\mathrm{m}$. interhyoideus posterior hacia el peritoneo faríngeo lateralmente al origen del $\mathrm{m}$. rectus cervicis, en continuidad con las fibras del m. diaphragmatobranchialis. Durante la metamorfosis, a partir de los estadios 42-43 aumenta la cantidad de fibras formando una capa más compacta pero con iguales características que en estadios previos. Durante los estadios 45-46 queda, aparentemente incorporado, a la porción más caudal del m. interhyoideus de la larva para formar el m. interhyoideus del adulto.

- Hyoangularislateralis. Músculo par, originado en la cara anterior del cóndilo articular del ceratohial e inserto en el proceso retroarticular del cartílago de Meckel. Sus fibras corren casi paralelas al eje axial y en ningún tramo de su recorrido entre el origen y la inserción tapan al $\mathrm{m}$. quadratoangularis. El cambio metamórfico comienza entre los estadios 42 y 43 . Al estadio 44 se encuentra reducido en tamaño, sus fibras dispuestas verticalmente, forma un conjunto indistinguible respecto de los $\mathrm{mm}$. quadratoangularis y suspensorioangularis, pero aún muestra las mismas relaciones topográficas respecto al resto del condrocráneo. Al completarse la metamórfosis (estadio 46) se encuentra formando parte del $\mathrm{m}$. depressor mandibulae junto con los restantes músculos hioideos (excepto el interhyoideus, interhyoideus posterior y diaphragmatopraecordialis).

- Interhyoideus. Músculo impar, ubicado perpendicular al eje axial cubriendo ventralmente casi toda la extensión de los ceratohiales. Se origina en el extremo distal y ventral de cada ceratohial. Inserta sobre si mismo mediante una aponeurosis media. Actúa antagónicamente al m. orbitohyoideus, sus contracciones hacen descender el piso de la cavidad bucofaríngea. A partir del estadio 42 comienza a notarse su cambio metamórfico, a través del cual se 
observa un ensanchamiento en sentido anteroposterior y un acortamiento lateromedial. Acompaña la metamorfosis de los ceratohiales siempre conservando su origen en el extremo distal de los mismos. Al estadio 44 aun se halla separado del intermandibularis. Al finalizar la metamorfosis (estadio 46) presenta sus características adultas definitivas y pasa a formar parte de la poderosa musculatura del piso de la boca, por detrás del $\mathrm{m}$. intermandibularis.

- Interhyoideus posterior. Músculo par compuesto por pocas fibras, dispuestas Irregularmente sobre la pared ventral de la cámara peribranquial formando un arco a nivel de los ceratobranquiales I y III. Medialmente, las fibras divergen, unas insertan en el m. interhyoideus, otras en el pericardio anterior, y las restantes se continuan posteriormente con el $\mathrm{m}$. diaphragmatopaecordialis. La relación de algunas fibras del $\mathrm{m}$. interhyoideus posterior con el $\mathrm{m}$. interhyoideus puede faltar en muchos especimenes en forma independiente al estadio de desarrollo. Durante la metamorfosis, a partir de los estadios 42-43 aumenta la cantidad de fibras formando una capa más compacta pero con iguales características que en estadios previos. Durante los estadios 45-46 queda aparentemente incorporado a la porción más caudal del $\mathrm{m}$. interhyoideus de la larva para formar el $\mathrm{m}$. interhyoideus del adulto.

- Orbitohyoideus. Poderoso músculo par que actúa antagónicamente al m. interhyoideus e interviene en la elevación del piso de la cavidad bucofaríngea. Presenta origen en todo el margen externo del proceso muscular del palatocuadrado y se inserta en el extremo distal del ceratohial. Se reduce continuamente durante la metamorfosis, a part ir del estadio 42 , acompañando la reducción y migración en sentido caudal del proceso muscular. Al final de la metamorfosis se encuentra integrado en una masa muscular común junto a los restantes músculos hioideos (menos el interhyoideus, interhyoideus posterior y diaphragmatopraecordialis) formando el $\mathrm{m}$. depressor mandibulae.

- Quadratoangularis. Músculo par originado en la cara ventral del proceso articular del palatocuadrado anteriormente a la fosa hiocuadrada. Presenta inserción en el proceso retroarticul ar del cartílago de Meckel, junto a los mm. hyoangularis lateralis y suspensorioangularis. Este músculo corre medialmente al $\mathrm{m}$. hyoangularis lateralis y es visible en toda su extensión. Se reduce durante el cambio metamórfico, a partir de los estadios 42 y 43 . Al final de la metamorfosis se encuentra integrado en una masa muscular común junto a los 
restantes músculos hioideos (menos el interhyoideus, interhyoideus posterior y diaphragmatopraecordialis) formando el $\mathrm{m}$. depressor mandibulae.

- Suspensorioangularis. Músculo par originado en la mitad inferior de la cara externa y posterior del proceso muscular. Presenta inserción en el proceso retroarticular del cartílago de Meckel. Se reduce durante el cambio metamórfico, a partir de los estadios 42 y 43 . Al final de la metamorfosis se encuentra integrado en una masa muscular común junto a los restantes músculos hioideos (menos el interhyoideus, interhyoideus posterior y diaphragmatopraecordialis) formando el $\mathrm{m}$. depressor mandibulae.

- Suspensoriohyoideus. Músculo par, representado por una delgada capa de fibras que se proyectan casi verticalmente desde su origen en la parte inferior del margen posterior externo del proceso muscular y margen anterior del arco subocular hasta su inserción en el extremo distal del ceratohial. Caudalmente está casi en continuidad con el origen del m. levator arcuum branchialium I y anteriorlmente está enmascarado por el m. orbitohyoideus. Se reduce durante el cambio metamórfico, a partir de los estadios 42 y 43 . Al final de la metamorfosis se encuentra integrado en una masa muscular común junto a los restantes músculos hioideos (menos el interhyoideus, interhyoideus posterior y diaphragmatopraecordialis) formando el $\mathrm{m}$. depressor mandibulae.

Los adultos de Batrachyla taeniata presentan 2 músculos hioideos: el depressor mandibulae y el interhyoideus. A continuación se dan las características generales de cada uno de ellos:

- Depressor mandibulae. Homólogo a los mm. hyoangularis lateralis, orbitohyoideus, quadratoangularis, suspensorioangularis y suspensoriohyoideus de la larva. Se encarga de la abducción de la boca y actúa antagónico al conjunto de $\mathrm{mm}$. levatorae mandibulae. Se divide en dos partes, la pars scapularis y la pars timpanica. La primera se origina sobre el $\mathrm{m}$. dorsalis scapulae y el tejido conectivo que existe entre el cráneo y la supraescápula. La segunda lo hace en el borde posterolateral de la cápsula ótica y margen posterior del anillo timpánico Ambas insertan en el área posterior del cartílago de Meckel y del anguloesplenial.

- Interhyoideus. Es un elemento impar, homólogo a los mm. interhyoideus, interhyoideus posteriory diapragmatopraecordialis de la larva. Sus fibras son ligeramente oblicuas al eje axial y caudales a las de la pars profunda del $\mathrm{m}$. 
intermandibularis. Representa el décimo más caudal de la masa muscular del piso de la boca. Su origen es en el extremo de los cuernos hioideos justo antes de su unión con las cápsulas óticas. Inserta medialmente sobre si mismo en una aponeurosis media. En los machos esta hipertrofiado integrando la estructura del saco vocal.

\section{III.3.3. Musculatura branquial (Figs. 13-15).}

La larva de Batrachyla taeniata presenta 13 músculos branquiales inervados por los nervios glosofaríngeo (IX) y vago (X): constrictor branchiales II, III y IV, constrictor laryngis, diaphragmatobranchialis, dilatator laryngis, levatorae arcuum branchialium I, II, III y IV, subarcualis obliquus II, subarcualis rectus I, subarcualis rectus II-IV. Los $\mathrm{mm}$. constrictor branchialis I, subarcualis obliquus IV, transversus ventralis IV y tympanopharyngeus faltan en esta especie. A continuación se presentan las características generales de cada uno y los aspectos de su metamorfosis.

- Constrictor branchiales II, III y IV. Inervados por el nervio vago. Se trata de músculos muy delgados, pares, notorios al menos desde el estadio 31. Presentan origen en la región proximal de los ceratobranquiales II (constrictor branchialis II) y III (constrictor branchiales III y IV). Insertan en la comisura terminal de los ceratobranquiales I y II (constrictor branchiales II y III) y II- II (constrictor branchialis IV). A partir del estadio 42 se reducen, acompañando la reabsorción de los ceratobranquiales, hasta su desaparición total al estadio 43.

- Constrictor laryngis. Inervado por el nervio vago. Es notorio a partir del estadio 33 formando un anillo rodeando lateralmente a la laringe. Durante la metamorfosis, estadios 45-46, aumenta de tamaño y se divide en dos partes que representan los $\mathrm{m}$. sphincter anterior y sphincter posterior del adulto.

- Dilatator laryngis Inervado por el nervio vago. Músculo par, notorio al menos desde el estadio 31. Tiene origen en la pared posteroventral de la cápsula ótica, junto al $\mathrm{m}$. levator arcuum branchialium IV, mediante un ligamento. Inserta en el m. constrictor laryngis. Durante el fin de la metamorfosis, estadios 45-46, aumenta de tamaño desplazando su origen hacia la cara dorsal del extremo distal del proceso posteromedial del hioides, y su inserción hacia el cartílago aritenoides. Durante este proceso se divide en dos partes, que representan los $\mathrm{mm}$. dilatator laryngis e hyolaryngeus del adulto. 


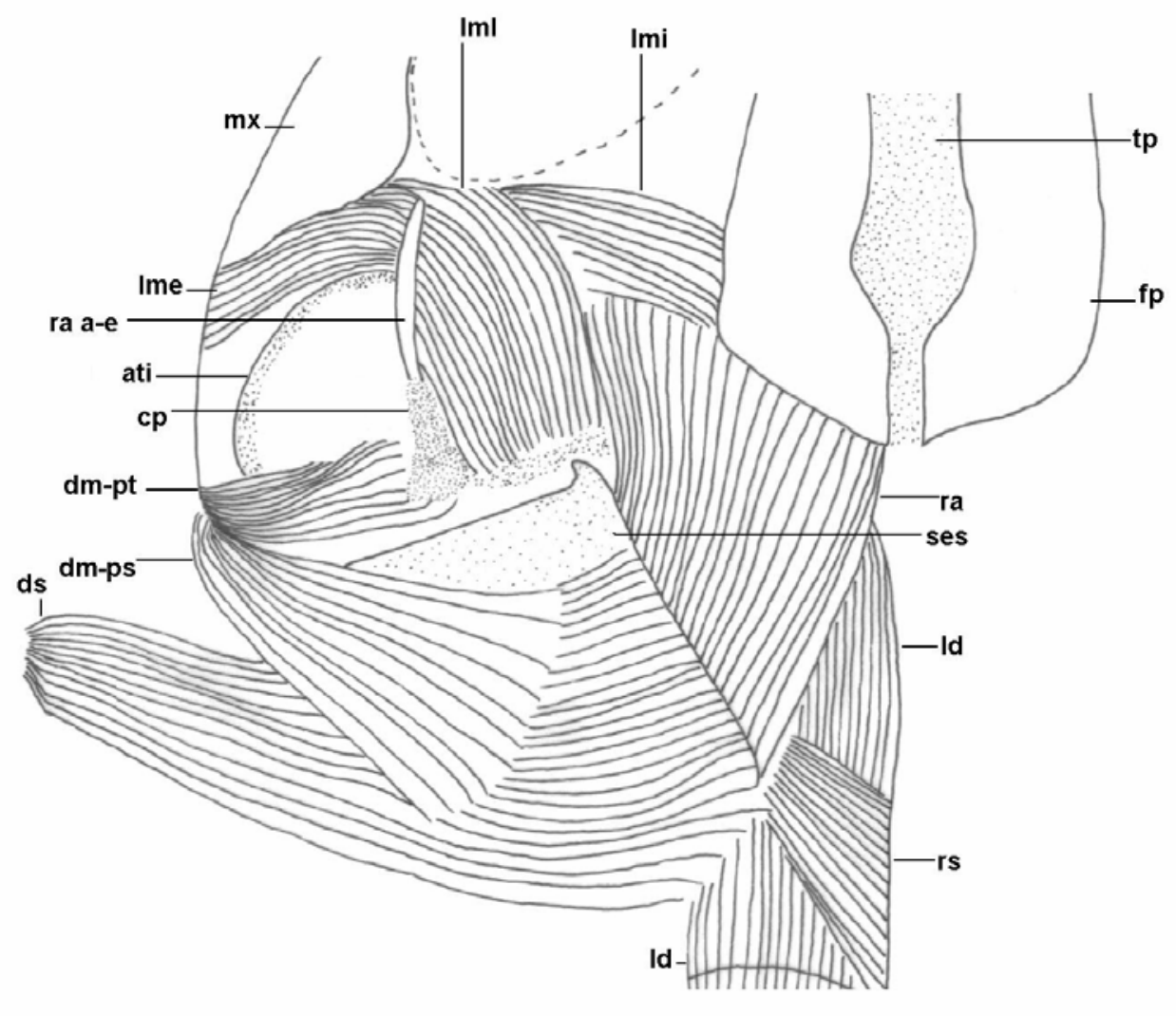

Figura 12. Vista dorsal de la mitad derecha de la musculatura craneana y parte de la musculatura apendicular anterior y axial postcraneana en un adulto de Batrachyla taeniata. Escala $5 \mathrm{~mm}$. Referencias: ati: anillo timpánico, ro-a e: ramas ótica y anterior del escamoso, ses: supraescápula, tp: techo parietal. El resto de las referencias como en las figuras 9 y 10. 
- Diaphragmatobranchialis. Inervado por el nervio vago. Músculo par, notorio al menos desde el estadio 31. Se origina en el peritoneo faríngeo, lateralmente al origen del m. rectus cervicis. Inserta en el extremo distal del ceratobranquial III. A partir del estadio 41, acompañando la emergencia de los miembros anteriores, desplaza su origen hacia el margen anterior del cartílago procoracoideo anterior. Al estadio 43 aún mantiene su inserción en los restos del ceratobranchial III y muestra mayor desarrollo en volumen. Al finalizar la metamorfosis desplazó su inserción al proceso posterolateral del cuerpo hioideo y pasa a ser el m. omohyoideus del adulto.

- Levator arcuum branchialium I. Inervado por el nervio glosofaríngeo. Músculo par notorio al menos desde el estadio 31. Se origina en el margen anterolateral del arco subocular. Inserta en el área distal del ceratobranquial I. Se modifica a partir de los estadios 42-43 acompañando la remodelación de los arcos viscerales. Al finalizar la metamorfosis desplaza su origen hacia el piso de la cápsula ótica y su inserción hacia el hioides. En el adulto constituye el m. petrohyoideus I.

- Levator arcuum branchialium II. Inervado por el nervio vago. Músculo par, notorio al menos desde el estadio 31. Se origina en el margen posterior del arco subocular y proceso anterolateral de la cresta parótica larvaria. Inserta en la comisura terminal de los ceratobranquiales I y II. Se modifica a partir de los estadios 42-43 acompañando la remodelación de los arcos viscerales. Al finalizar la metamorfosis desplaza su origen hacia el piso de la cápsula ótica y su inserción hacia el hioides. En el adulto constituye el $\mathrm{m}$. petrohyoideus II.

- Levator arcuum branchialium III. Inervado por el nervio vago. Músculo par, notorio al menos desde el estadio 31. Se origina en la pared lateral de I a cápsula ótica. Inserta en la comisura terminal de los ceratobranquiales III y IV. Se modifica a partir de los estadios 42-43 acompañando la remodelación de los arcos viscerales. Al finalizar la metamorfosis desplaza su origen hacia el piso de la cápsula ótica y su inserción hacia el hioides. En el adulto constituye el m. petrohyoideus III.

- Levator arcuum branchialium IV. Inervado por el nervio vago. Músculo par, notorio al menos desde el estadio 31. Se origina en la pared posteroventral de la cápsula ótica junto con el $\mathrm{m}$. dilatator laryngis. Inserta en la cara posterior del ceratobranquial IV. Se modifica a partir de los estadios 42-43 acompañando la remodelación de los arcos viscerales. Al finalizar la metamorfosis desplaza su 
origen hacia el piso de la cápsula ótica y su inserción hacia el hioides. En el adulto constituye el $\mathrm{m}$. petrohyoideus IV.

- Subarcualis obliquus II. Inervado por el nervio vago. Músculo par, notorio al menos desde el estadio 31. Está compuesto por una sola cabeza, originada en el tejido conectivo ubicado entre las bases de los ceratobranquiales II y III e insertá en el proceso urobranquial. Sin embargo, en algunos individuos se observo la presencia de dos cabezas separadas por un espacio menor a la longitud total del músculo, incluso en situación de asimetria bilateral. Se reduce durante la metamorfosis hasta su desaparición total al estadio 44.

- Subarcualis rectusI. Inervado por el nervio glosofaríngeo. Músculo par, notorio al menos desde el estadio 31. Se compone por tres cabezas. La cabeza dorsal se origina en al área proximal del ceratobranquial I, las dos ventrales lo hacen en los ceratobranquiales II y III. Todas insertan en la pared posterolateral del ceratohial. Se reduce durante la metamorfosis hasta su desaparición total al estadio 45.

- Subarcualis rectus II-IV. Inervado por el nervio vago. Músculo par, notorio al menos desde el estadio 31. Se origina en el ceratobranquial IV e inserta en el ceratobranquial I. Se reduce durante la metamorfosis hasta su desaparición total al estadio 45.

Los adultos de Batrachyla taeniata presentan 9 músculos branquiales: constrictor laryngis, dilatator laryngis, hyolaryngeus, omohyoideus, petrohyoideus I -IV, sphincter anterior y sphincter posterior. A continuación se dan las características generales de cada uno de ellos:

- Dilatator laryngis. Músculo par homólogo al m. dilatator laryngis de la larva. Se origina en la región dorsolateral del extremo distal del proceso posteromedial del hioides. Inserta en el margen dorsolateral del cartílago aritenoi des.

- Hyolaryngeus. Músculo par que se origina a partir del m. dilatator laryngis de la larva. Es visible al retirar el m. dilatator laryngis. Se origina en el proceso posteromedial del hioides, medialmente al m. dilatator laryngis. Inserta en la región anterior del cartílago aritenoides.

- Omohyoideus. Músculo par visible en vista profunda al retirar el m. interhyoideus. Es homólogo al m. diaphragmatobranchialis de la larva. Se 
origina en el margen anterior y proximal de la escápula e inserta en el proceso posterolateral del hioides.

- Petrohyoideus I - IV. Músculos pares, homólogos a los mm. levatorae arcuum branchialium I - IV de la larva. Se originan en el piso de la cápsula ótica y región posterior y medial del anillo timpánico, tapados por los mm. cucularis, opercularisy levator scapularis superior. El m. petrohyoideus I es el más anterior y voluminoso. Inserta en todo el margen lateral del hioides entre los procesos anterolateral y posterolateral. El m. petrohyoideus II inserta en la región proximal y lateral del proceso posteromedial del hioides. El m. petrohyoideous III inserta en la región lateral y distal del proceso posteromedial del hioides. El m. petrohyoideus IV inserta mayormente en la cara distal del proceso posterolateral del hioides pero algunas fibras insertan también en la cara posterior del cartílago cricoides.

- Sphincter anterior. Músculo par, originado a partir del m. constrictor laryngis de la larva. Se origina en la región anterior de los cartílagos aritenoides e inserta en el extremo posterior de los mismos. Esta ubicado medial y anterior al m. sphincter posterior y se encuentra mayormente oculto por el m. dilatator laryngis.

- Sphincter posterior. Músculo par, originado a partir del m. constrictor laryngis de la larva. Se origina en el extremo anterior de los cartílagos aritenoides e inserta en el extremo posterior de los mismos. Esta ubicado lateral y posteriormente al $\mathrm{m}$. sphincter anterior y se encuentra mayormente oculto por el m. dilatator laryngis.

\section{III.3.4. Musculatura hipobranquial (Figs. 13 y 14).}

La larva de Batrachyla taeniata presenta 3 músculos hipobranquiales inervados por el nervio espinal II (hipogloso): genioglossus, geniohyoideus y rectus cervicis. A continuación se presentan las características generales de cada uno y los aspectos de su metamorfosis.

- Genioglossus. Músculo impar formado en el esbozo lingual. Este esbozo es notorio al menos desde el estadio 31. Se ubica entre los procesos anterohiales del ceratohial. Al estadio 38 pasa a tener relación con el m. geniohyoideus.

- Geniohyoideus. Músculo par, notorio al menos desde el estadio 31. Se origina en el hipobranquial a la altura de los ceratobranquiales III y IV. Inserta en la superficie medioventral del cartílago infrarrostral. Al estadio 38 , su porción más 
anterior, comienza a desdoblarse en una pars medialis y una pars lateralis. Las fibras más mediales y profundas de la pars medialis toman contacto con el esbozo lingual dando origen a lo que será el $\mathrm{m}$. hyoglossus del adulto. Al estadio 44, la relación con el esbozo lingual es más notoria y ambas partes, medialis y lateralis, están bien definidas. Al finalizar la metamorfosis muestra las características adultas definitivas y desplaza su inserción hacia el margen anterior de la laringe ( geniohyoideus pars medialis) y proceso posteromedial del hioides (geniohyoideuspars lateralis y hyoglossus).

- Rectus cervicis. Músculo par, que se origina en el peritoneo faríngeo e inserta en forma variable, mediante una o dos cabezas (varia poblacionalmente), en el tejido conectivo entre las bases de los ceratobranquiales III y IV. Durante la metamorfosis, aumenta continuamente su desarrollo en volumen. Al estadio 41 desplaza su origen hacia la cintura escapular. Al estadio 44 desplaza su inserción a la base del proceso posteromedial del cuerpo hioideo en formación. Al finalizar la metamorfosis muestra sus características adultas definitivas y pasa a llamarse m. sternohyoideus.

Los adultos de Batrachyla taeniata presentan 4 músculos hipobranquiales. A continuación se dan las características generales de cada uno de ellos.

- Geniohyoideus. Músculo par, notorio al menos desde el estadio 31. Es visible en vista profunda al retirar los $\mathrm{mm}$. intermandibularis, submentalis e interhyoideus. Está compuesto por una pars medialis y una pars lateralis homologas a las respectivas del $\mathrm{m}$. geniohyoideus de las larvas metamorficas. La pars medialis se origina en las caras anterior de la laringe y posterior del cuerpo hioideo. La pars lateralis en el proceso posterolateral del hioides y margen lateral del cuerpo hioideo. Ambas insertan en las adyacencias de la sínfisis mandibular.

- Genioglossus. Músculo impar intrínseco de la lengua. Se distinguen una pars basalis ubicada dorsalmente al $\mathrm{m}$. submentalis y una pars medialisque se proyecta libremente a partir de é sta en sentido caudal y dorsal. La región más posterior de la pars medialis establece contacto con las fibras más anteriores del m. hyoglossus.

- Hyoglossus. Músculo par que deriva de la capa de fibras mediales más profundas de la pars medialis del m. geniohyoideus de la larva. Es visible en vista profunda al retirar los mm. geniohyoideus, interhyoideus e 
intermandibularis. Se origina en el proceso posteromedial del hioides y cara posterior del cuerpo hioideo. Inserta en la misma lengua donde pasa a tener relación con las fibras posteriores del m. genioglossus.

- Sternohyoideus. Músculo par visible en vista profunda al retirar el m. interhyoideus y la mayoría de los músculos ventrales de la cintura escapular. Es homólogo al $\mathrm{m}$. rectus cervicis de la larva. Sus fibras mediales se originan en el dorso del esternón y las más laterales en el m. rectus abdominis. Inserta en la superficie ventrolateral del cuerpo hioideo entre las bases de los procesos anterolateral y posterolateral del mismo.

Figura 13. Vista ventral de la musculatura craneana asociada al aparato hiobranquial y porción ventral del arco mandibular de Batrachyla taeniata a los estadios 35(A) , 43 (B) , 44 (C) y 46 (D) de Gosner (1960). Del lado derecho en la region de la cestilla branquial en A), (B) y (C) se representa la musculatura superficial asociada al peritoneo faringeo de la camara branquial (región delimitada por linea discontinua). En (D), del lado derecho se representa la musculatura superficial, y del izquierdo se expone la musculatura profund a.Las regiones punteadas son cartílago y las no punteadas hueso. Escala $1 \mathrm{~mm}$. Referencias: ags : anguloesplenial, $\mathbf{c b}$ : ceratobranquiales I-IV, $\mathbf{c h}$ : ceratohial, ci: cartílago infrarrostral, $\mathbf{c m}$ : cartílago de Meckel, cuh: cuerno hioideo, den: dentario, dfb: diaphragmatobranchialis, dfp: diaphragmatopraecordialis, dl: dilatator laringis, esl: esbozo lingual, gh: geniohyoideus, ghl: geniohyoideus lateralis, ghm: geniohyoideus medialis, h: hipobranquial, hyl: hyoangularis lateralis, ih: interhyoideus, ihp: interhyoi deus posterior, im: intermandibularis, im-pp: intermandibularis - pars profunda, im-ps: intermandibularis - pars superficialis, lab: levatorae arcuum branchialium HIV, mli: mandibulolabialis inferior, mmk: mentomeckeliano, oh: orbitohyoideus, omh: omohyoideus, par: proceso articular, ph I: petrohyoideus I, ppm: proceso posteromedial, qa: quadratoangularis, rc: rectus cervicis, sao: subarcualis obliquus, sar I: subarcualis rectus I, sar II-IV: subarcualis rectus II-IV, s m: submentalis, sth: sternohyoideus. Ver pagina siguiente 


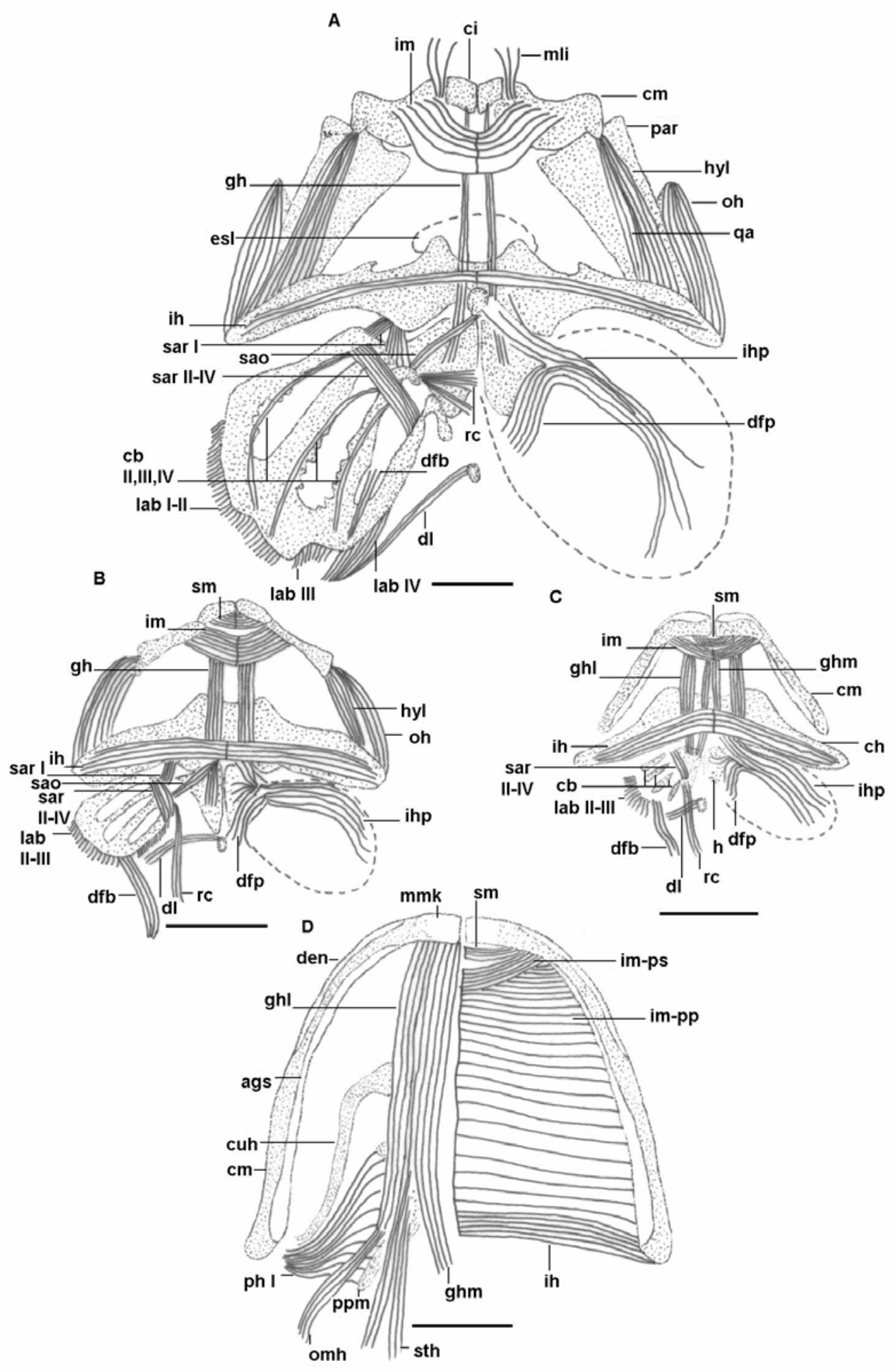



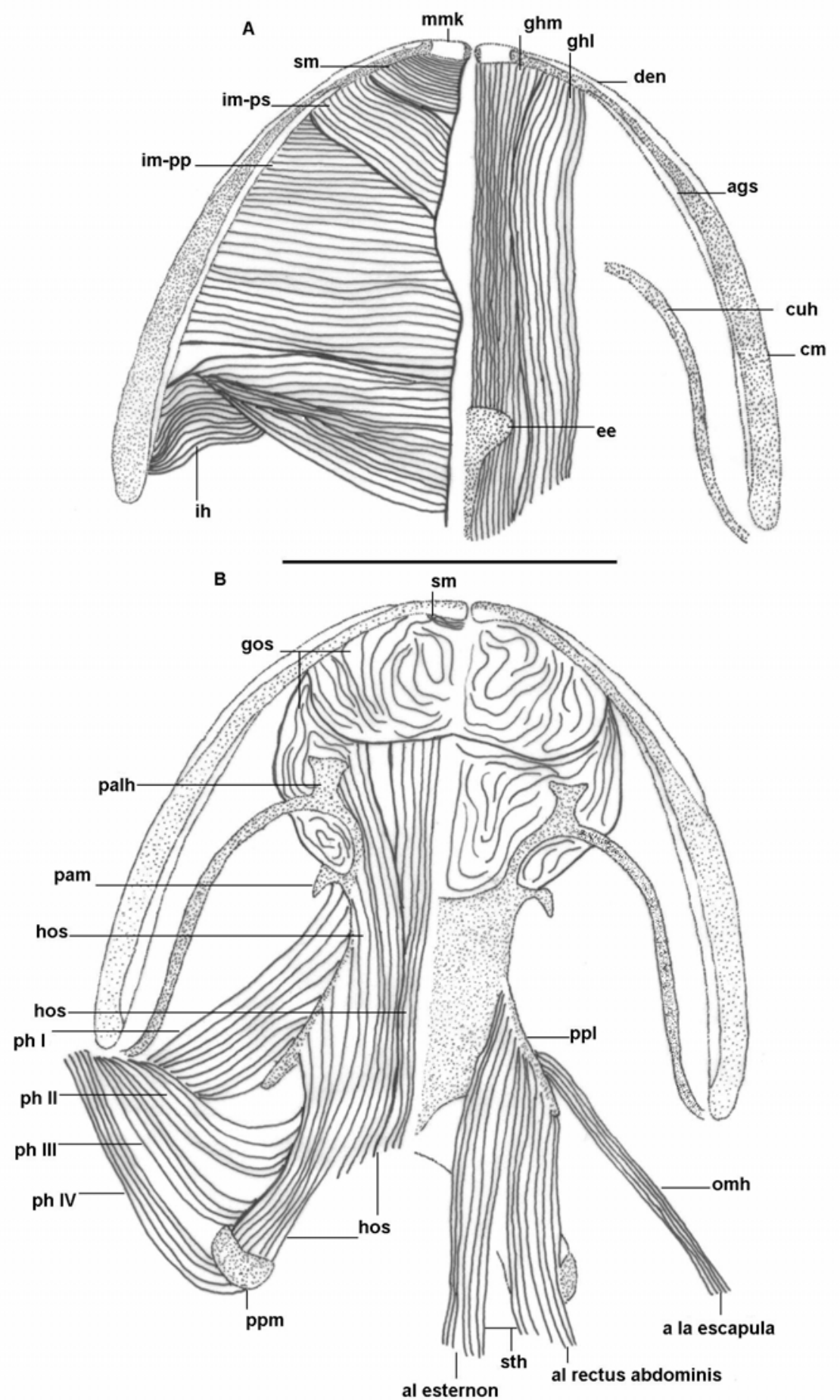

Figura 14. Vista ventral de la musculatura craneana asociada al aparato hiobranquial y porción ventral del arco mandibular de adultos de Batrachyla taeniata. En (A) se muestra la capa de músculos más superficial (lado izquierdo) y la más superficial de las 2 capas intermedias (lado derecho). En (B) se muestra la capa más profunda de las 2 capas intermedias (lado izquierdo) y la capa de músculos más profunda (lado derecho). Las regiones punteadas son cartílago y las no punteadas hueso. Escala $5 \mathrm{~mm}$. Referencias: es: epiesternón, gos: genioglossus, hos : hyoglossus, palh: proceso anterolateral del hioides, pam: proceso anteromedial del hioides, ph I-IV: petrohyoideus I-IV, ppl: proceso posterolateral del hioides, ppm: proceso posteromedial del hioides. El resto de las referencias como en la figura 12. 

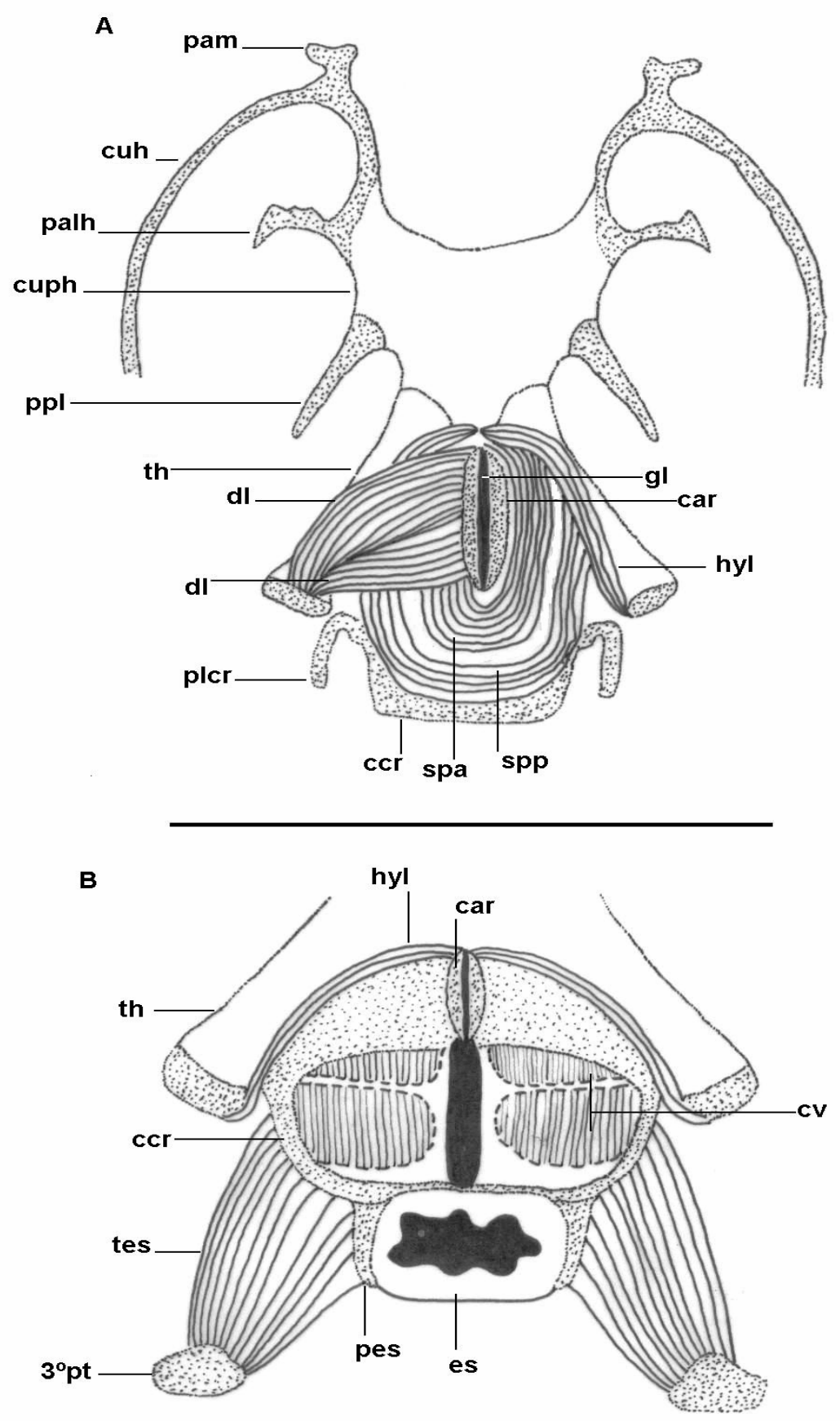

Figura 15. Vista ventral (A) y posteroventral (B) de la musculatura asociada al aparato laringeo de adultos de Batrachyla taeniata. En (A) se muestra la capa de músculos superficial (lado izquierdo) y la profunda (lado derecho). Las regiones punteadas son cartílago y las no punteadas hueso. Escala $5 \mathrm{~mm}$.

Referencias: car: cartílago aritenoides, ccr: cartílago cricoideo, cuph: cuerpo hioideo (calcificado), cv: cuerdas vocales, dl: dilatator laringis, es: esofago, gl: glotis, hyl : hyolaringeus, pes: proceso esofágico, plcr: proceso lateral del cricoides, pt: proceso transverso, spa: sphincter anterior, spp: sphincter posterior, tes: transversoesophagicus, th: tirohial. El resto de las referencias como en la figura 13. 


\section{III.3.5. Musculatura ocular (sin Fig.).}

Las larvas y adultos de Batrachyla taeniata presentan 7 músculos asociados al globo ocular inervados por los nervios craneanos III, IV y VI: levator bulbi, obliquus inferior, obliquus superior, rectus anterior, rectus inferior, rectus posterior y rectus superior. A continuación se presentan las características generales de cada uno para la larva y el adulto y los aspectos de su metamorfosis.

- Levator bulbi. Aparece en larvas durante la crisis metamórfica. Su aparición esta ligada al proceso de posteriorización del palatocuadrado y su musculatura asociada. Cuando este fenomeno sucede se desarrollan unas fibras muy laxas por debajo del globo ocular. De este modo esta capa de músculos separa el globo ocular del techo de la cavidad bucal. Se trata en realidad de musculatura mandibular dado que sus fibras estan inervadas por el nervio trigémino. En los adultos mantiene la misma disposición que en las larvas aunque con una mayor cantidad de fibras.

- Obliquus inferior. Inervado por el nervio III (oculomotor). Se lo observa desde estadios tempranos (30-31 de Gosner). Tanto en larvas como adultos presenta el mismo origen e inserción. En larvas es un haz homogeneo de fibras, mientras que en los adultos es considerablemente más ancho a nivel de la inserción, presentando entonces forma de abanico. Presenta origen en la región del cartílago orbitario correspondiente a la pila etmoidea, a nivel cercano a la confluencia entre ésta con las trabeculas y la comisura cuadrado craneana anterior. Inserta en el globo ocular a nivel ventral anterior del mismo.

- Obliquus superior. Inervado por el nervio IV (troclear). Se lo observa desde estadios tempranos (30-31 de Gosner). Tanto en larvas como adultos presenta el mismo origen e inserción. En larvas es un haz homogeneo de fibras, mientras que en los adultos es considerablemente más ancho a nivel de la inserción, presentando entonces forma de abanico. Presenta origen en la región del cartílago orbitario correspondiente a la pila etmoidea, a nivel cercano a la confluencia entre ésta con la lamina orbitonasal y el techo etmoideo. Inserta en el globo ocular a nivel dorsal anterior del mismo.

- Rectus anterior. Inervado por el nervio III (oculomotor). Se lo observa desde estadios tempranos (30-31 de Gosner). Tanto en larvas como adultos presenta el mismo origen e inserción. En larvas es un haz homogeneo de fibras, mientras que en los adultos es considerablemente más ancho a nivel de la inserción, 
presentando entonces forma de abanico. En los adultos resulta más dificil identificar a cada uno de los cuatro músculos rectos porque cada uno confluye con los restantes formando una especie de copa alrededor de toda la superficie medial del globo ocular. Presenta origen en la región del cartílago orbitario correspondiente a la pila metoptica. Inserta en el globo ocular a nivel ventral y anterior del mismo.

- Rectus inferior. Inervado por el nervio VI (abducente). Tanto en larvas como adultos presenta el mismo origen e inserción. En larvas es un haz homogeneo de fibras, mientras que en los adultos es considerablemente más ancho a nivel de la inserción, presentando entonces forma de abanico. Presenta origen en la región del cartílago orbitario correspondiente a la pila metoptica. Inserta en el globo ocular a nivel ventral e inferior del mismo.

- Rectus posterior. Inervado por el nervio III (oculomotor). Tanto en larvas como adultos presenta el mismo origen e inserción. En larvas es un haz homogeneo de fibras, mientras que en los adultos es considerablemente más ancho a nivel de la inserción, presentando entonces forma de abanico. Presenta origen en la región del cartílago orbitario correspondiente a la base de la pila antotica. Inserta en el globo ocular a nivel ventral y posterior del mismo.

- Rectus superior. Inervado por el nervio III (oculomotor). Tanto en larvas como adultos presenta el mismo origen e inserción. En larvas es un haz homogeneo de fibras, mientras que en los adultos es considerablemente más ancho a nivel de la inserción, presentando entonces forma de abanico. Presenta origen en la región del cartílago orbitario correspondiente a la pila metoptica. En adultos y en larvas desde el estadio 42 sus fibras más dorsales toman inserción también en el margen lateral de los frontoparietales. Inserta en el globo ocular a nivel ventral y superior del mismo.

- Retractor bulbi. Ausente tanto en larvas como adultos. Para ver características de este elemento ver Duellman \& Trueb (1986). 


\section{III.4. Desarrollo del esqueleto axial postcraneano en Batrachyla taeniata (Figs.} 16-18).

El esqueleto axial postcraneano de los adultos de Batrachyla taeniata está compuesto por 11 vertebras: 8 presacras, una sacra y dos postsacras. Todas ellas, con excepción de la primer vertebra o atlas y de las dos postsacras, sostienen procesos transversos que se proyectan lateralmente desde los arcos neurales. Las dos vertebras postsacras estan representadas solo por sus arcos neurales, e integran, junto al hipocordo, el urostilo. La secuencia de condrificación y de osificación de las estructuras axiales se muestra en las Tablas 1 y 3.

A continuación se detallara la estructura adulta y luego el desarrollo de cada una de las estructuras mencionadas.

- Vertebras presacras. Salvo la primera, que articula anteriormente con los cóndilos occipitales todas estan articuladas entre si mediante proyecciones anteriores y posteriores de los arcos neurales: las prezigapofisis y postzigapofisis. La primera solo presenta postzigapofisis y la articulación con los cóndilos occipitales se realiza mediante sendas concavidades ubicadas cada una en la cara anterior de los arcos neurales. Todas presentan cuerpos procelicos. Con excepción de la primera vertebra, los arcos neurales de las presacras II-VIII se proyectan lateralmente formando los proce sos transversos. Los cuerpos de las presacras son subiguales en tamaño, en cambio el arco neural de la primer vertebra está mas desarrollado que los arcos neurales de las restantes. Los procesos transversos de las presacras difieren en longitud y espesor. En orden decreciente de longitud y espesor, los procesos transversos se ordenan de la siguiente manera: II - III - I - (IV - VII). Si bien todos ellos son transversos al eje axial, existe algun tipo de desviación que hace que no sean exactamente perpendiculares al eje. De este modo, los procesos transversos I y II presentan una desviación anteroventral, los procesos transversos III - V se desvian posterodorsalmente, mientras que los procesos transversos VI y VII lo hacen anterodorsalmente. El extremo distal de todos los procesos transversos permanece cartilaginoso. En el punto de encuentro mediodorsal, los arcos neurales derecho e izquierdo de las cuatro primeras presacras se expanden dorsalmente formando una pequeña espina neural. Vistas en vista lateral todas las espinas neurales alcanzan la misma altura, pero no presentan la misma longitud. En orden decreciente de longitud, se ordenan de la siguiente manera: II, I, III y IV. 
- Vertebra sacra. Los arcos neurales sacros presentan prezigapofisis para articular con las postzigapofisis de la presacra VIII, pero carecen de postzigapofisis. El tamaño de los arcos neurales de la vertebra sacra es equivalente al de los arcos neurales de las vertebras presacras II - VIII. Las diapófisis sacras presentan el mismo grado de desarrollo en longitud y espesor que los procresos transversos de la vertebra presacra III (procesos transversos II), estan ligeramente dirigidos en sentido posteroventral y su extremo distal permanece cartilaginoso. Las diapófisis sacras articulan sindesmoticamente con el extremo anterior de cada ileon, a los cuales se solapan dorsalmente. La vertebra sacra carece de espina neural y su cuerpo no es tipicamente procelico a causa de la falta de la prominencia media posterior. En reemplazo de la prominencia medio posterior existen dos pequeños cóndilos posteriores al cuerpo, ubicadas ventrales a las bases de los arcos, mediante los cuales la vertebra sacra articula con el urostilo.

- Urostilo. El urostilo es una estructura formada por la unión de los arcos neurales de dos vertebras postsacras reducidas, más el hipocordo. El urostilo articula anteriormente con los dos cóndilos de la vertebra sacra (articulación bicondilar) mediante la porción correspondiente al hipocordo, para lo cual presenta dos cavidades. El extremo posterior del urostilo alcanza la cintura pélvica a nivel de la únion de ileon e isquion.

- Desarrollo larvario de los arcos neurales. Los arcos neurales son inicialmente cartilaginosos y según su grado de desarrollo y orden de aparición, pudo establecerse que condrifican en sentido anteroposterior, con modificaciones. Al estadio 29, de los 8 arcos presacros, los más desarrollados son los arcos II - IV, evidenciando que el desarrollo no procede exactamente en sentido anteroposterior, sino que mas bien procedemás velozmente en esos arcos. Los primeros 8 arcos presacros condrifican en estadios previos al 29, luego aparece el arco sacro (estadio 31), mientras que los ultimos en aparecer son los arcos postsacros I y II (estadios 34 y 41-42 respectivamente). segundo arco neural postsacro crece posteriormente a partir del primero, y recien es bien distinguible cuando, sobre el mismo bloque de cartílago cada uno de ellos osifica de centros independientes. Los arcos neurales I - X osifican autostósicamente hacia el estadio 35. Su osificación procede en sentido anteroposterior, a partir de un centro de osificación por arco, ubicado a media altura de los mismos en lo que sera el punto donde se proyectan lateralmente 
los procesos transversos. Los arcos I - X osifican casi en forma simultánea al estadio 35, aunque la existencia de variación dentro del estadio permite reconocer un claro sentido anteroposterior en el proceso de osificación. Los arcos postsacros osifican de la misma manera que los presacros, aunque el arco XI lo hace en estadios más avanzados (estadio 43). Una vez iniciada la osificación de cada arco neural, ésta procede en sentido dorsal y ventral abarcando rapidamente las apófisis articulares (notorias simultaneamente al estadio 35) y expandiendose lateralmente por los procesos transversos. Las espinas neurales, en las vertebras que estan presentes, se forman por una expansión medio dorsal de los arcos neurales derecho e izquierdo a nivel de punto de contacto dorsal. El encuentro medio dorsal de los arcos neurales comienza al estadio 36 en las vertebras presacras IV -VII. Al estadio 37 ya se observa la fusión mediodorsal del VIII par de arcos, al estadio 38 la de los pares I-III, y al estadio 39 la del IX par. La existencia de variación permitio reconocer que la fusión mediodorsal de los arcos ocurre primero en la vertebra IV, procede posteriormente hasta la VIII presacra, seguido por los arcos sacro y primer presacro. Siempre el último en fusionarse es el par X (estadio 43).

- Desarrollo larvario de los procesos transversos. Los procesos transversos, al igual que las zigapofisis, se forman como crecimientos laterales de la parte lateral, de cada arco neural. Primero aparecen secuencialmente los tres primeros procesos transversos, luego lo hace el IV, seguido la diapófisis sacra y finalmente los presacros $\mathrm{V}$ - VIII, estos últimos en forma simultanea. La osificación de los procesos transversos procede desde el arco neural, es decir en sentido proximo -distal, hasta alcanzar casi el extremo distal del proceso, el cual permanecera cartilaginoso. En ningun ejemplar se observaron esbozos independientes que puedan interpretarse como la presencia de costillas reducidas y fusionadas al extremo distal del proceso transverso. La secuencia de osificación de los procesos transversos repite la observada en su condrificación y comienza al estadio 35 con la osificación de los arcos neurales I- III.

- Desarrollo larvario de los cuerpos vertebrales. Los cuerpos vertebrales se originan a partir de dos pares de centros de osificación, uno dorsolateral ubicado en la base de cada arco neural y otro par de posición ventrolateral, respecto de la notocorda. Los centros osifican alostósicamente siguiendo un sentido anteroposterior. En dos ejemplares al estadio 35 es notoria la 
existencia de núcleos cartilaginosos pares en el punto en que se osificaran los centrpos dorsolaterales, al nivel de las vertebras II-VI. Sin embargo estos desaparecen previo a la osificación alostosica de los mismos. En principio, cada par de centros dorsolaterales es supranotocordal, pero rapidamente ambos centros simetricos se fusionan en la linea media y proceden a crecer ventralmente a cada lado de la notocorda, para finalmente encontrarse con el par de centros lateroventrales a la notocorda, cerrandola y conformando la estructura anular del cuerpo vertebral. La secuencia en que se fusionan los centros dorsolaterales pares de cada vertebra y se expanden ventralmente no sigue exactamente un sentido anteroposterior. Por ejemplo, en algunos ejemplares del estadio 35 , los centros de las vertebras III y IV estan formando el anillo alrededor de la notocorda, mientras que los centros derecho e izquierdo de las vertebras I y II estan fusionados solo a nivel mediodorsal, y los centros derecho e izquierdo de las restantes vertebras aun no establecieron ningun contacto entre si. Al estadio 37 , algunos ejemplares presentan el primer par de cuerpos aun abiertos medioventralmente, los cuerpos II a IV ya estan constituidos, y los centros derecho e izquierdo de las vertebras V - VIII aun no establecieron contacto entre si, restando osificar el centro sacro. Otros ejemplares, tambien al estadio 37 , ya muestran los cuerpos I - V totalmente formados, mientras que los centros VI - VIII aun son pares, restando osificar el centro sacro.

Resumiendo, el desarrollo de los cuerpos vertebrales es más avanzado en las vertebras relacionadas a la cintura escapular, progresando de ellos tanto en sentido posterior como anterior, siendo los de desarrollo más lento los centros de la presacra VIII y de la vertebra sacra, que al estadio 46 aun estan abiertos medioventralmente.

- Desarrollo larvario del urostilo. El desarrollo del urostilo comienza al condrificar los arcos neurales de las dos vertebras postsacras (vertebras X y $\mathrm{XI}$ ). Esos arcos neurales osifican del mismo modo que los restantes arcos neurales, aunque están reducidos en tamaño, carecen de apofisis articulares y de procesos transversos. La osificación de los arcos neurales postsacros es al estadio $35(\mathrm{X})$ y $43(\mathrm{XI})$.

El hipocordo es una estructura subcordal e impar que condrifica al estadio 36 ocupando el espacio entre la base del ileon y la parte posterior de los arcos neurales sacros. La osificación autostósica del hipocordo (estadio 38) procede 
en sentidos anterior y posterior a partir de un unico centro de osificación ubicado en su punto medio. La autostosis del hipocordo presenta forma acanalada, ubicada en el margen ventral de la notocorda, semejando en aspecto a la porción ventral de los cuerpos vertebrales.

A los estadios 43-44, se produce la fusión de los centros de osificación de los dos arcos neurales postsacros entre si, dejando un amplio foramen entre ellos. El hipocordo ya esta practicamente todo osificado al estadio 43, y la fusión de los arcos postsacros con el hipocordo ocurre al estadio 46. Al estadio 44 se esboza la articulación bicondilar entre el primer arco neural postsacro y la vertebra sacra, aun previo a que las vertebras postsacras se fusionen al hipocordo. 
A
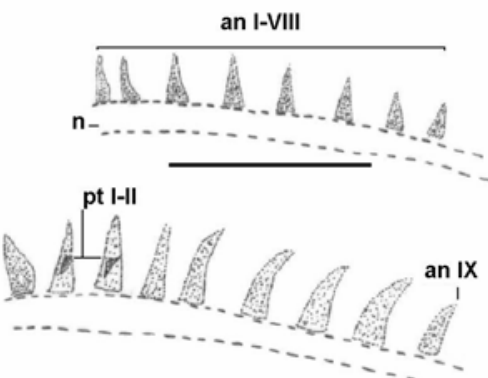

C
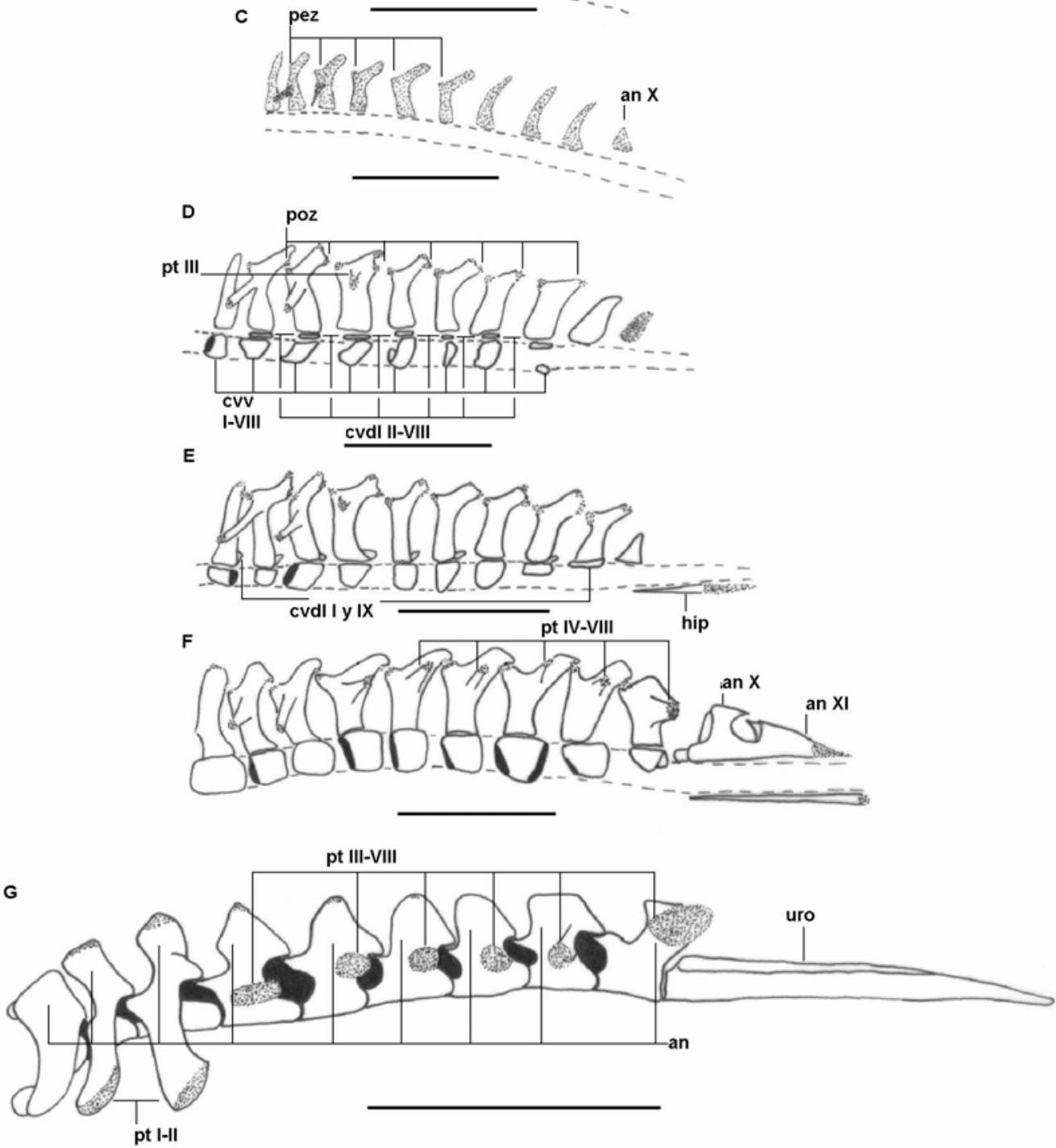

Figura 16. Vista lateral del esqueleto axial postcraneano de Batrachyla taeniata a los estadios 29 (A), 31 (B), 34 (C), 35 (D), 38 (E), 43 (F), y adulto (G). Las regiones punteadas son cartílago y las no punteadas hueso. Escala $1 \mathrm{~mm}$. Referencias: an: arcos neurales, cvdl: centros vertebrales dorsolaterales, cvvl: centros vertebrales ventrolaterales, hip: hipocordo, n: notocorda, pez: prezigoapofisis, poz: postzigoapofisis, pt: procesos transversos, uro: urostilo. 

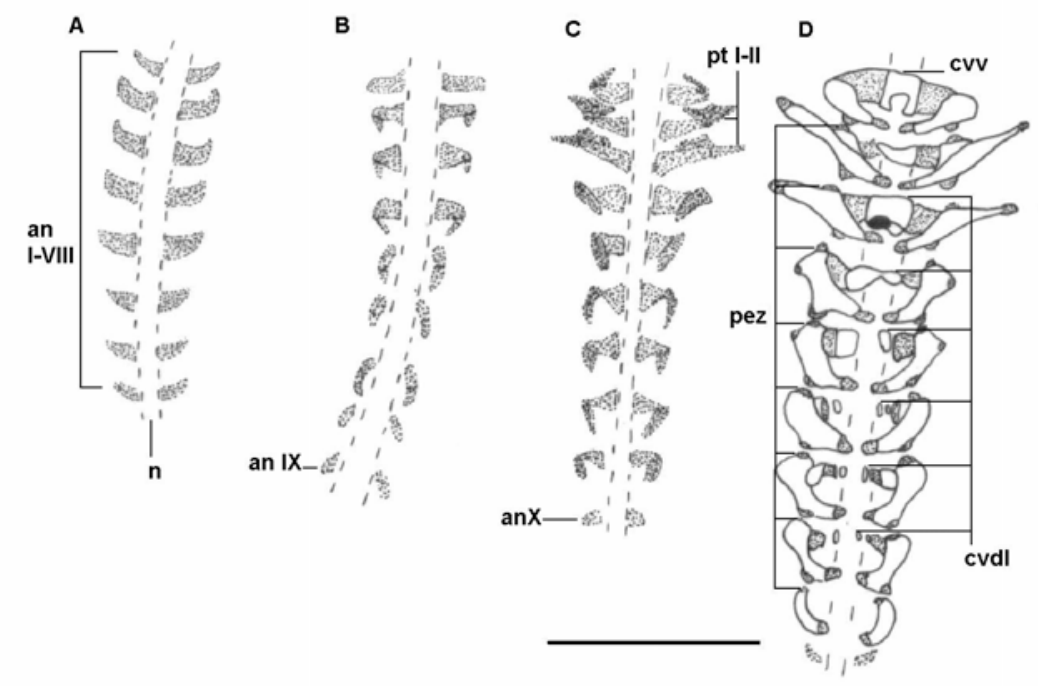

E

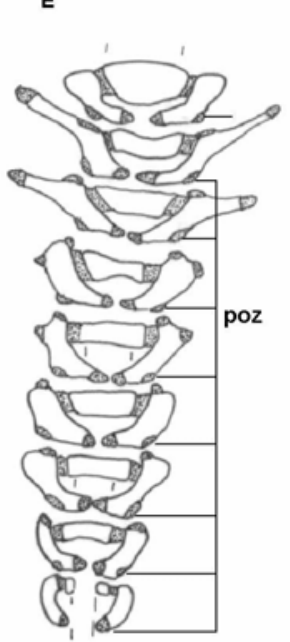

$\mathbf{F}$
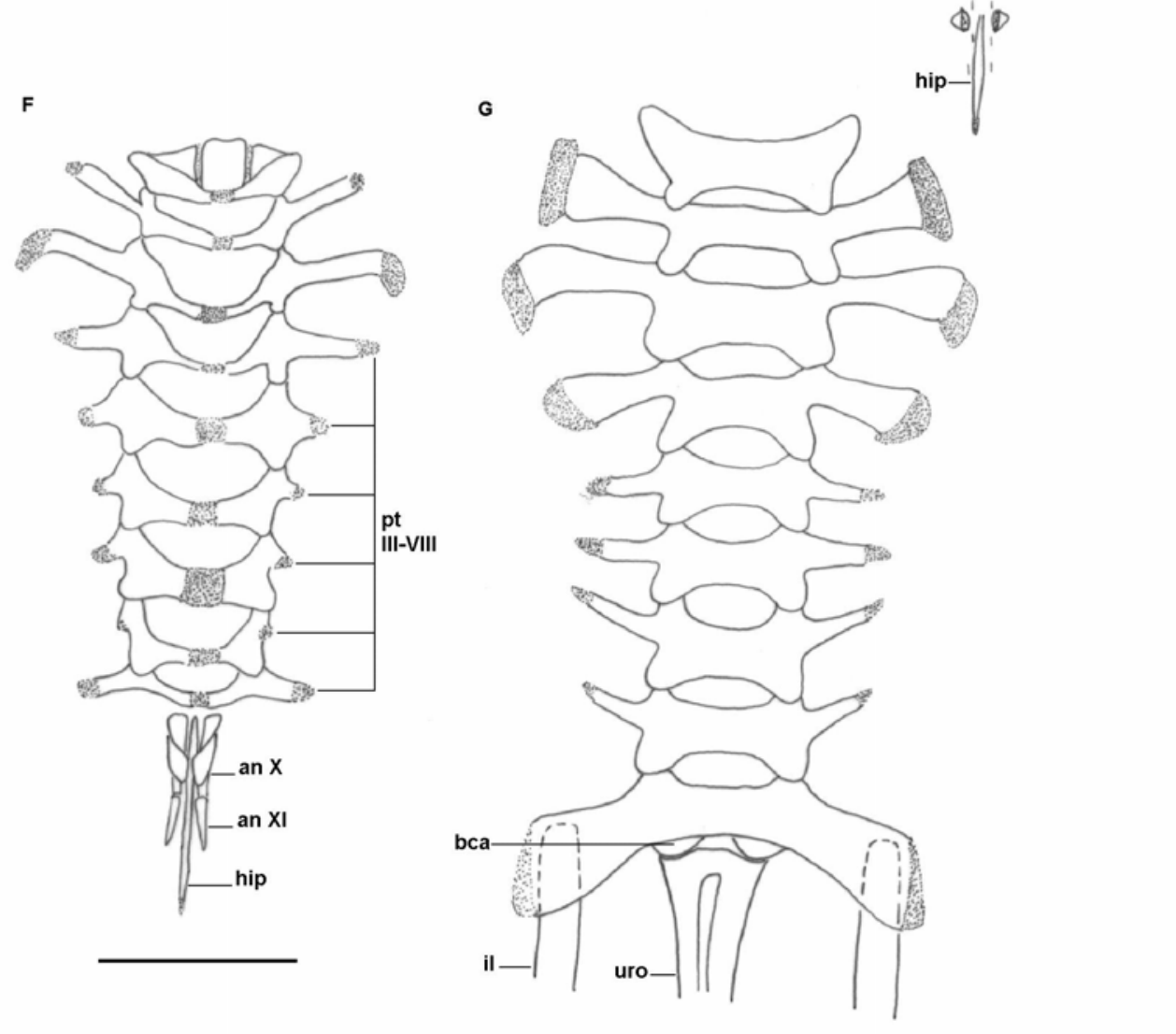

Figura 17. Vista dorsal del esqueleto axial postcraneano de Batrachyla taeniata a los estadios 29 (A) , 31 (B), 34 (C) , 35 (D) , 38 (E) , 43 (F), y adulto (G) . Las regiones punteadas son cartílago y las no punteadas hueso. Escala $1 \mathrm{~mm}$. Referencias: bca: articulación bicondilar, cvv: centro vertebral ventral, il: ileon. El resto de las referencias como en la figura 15. 


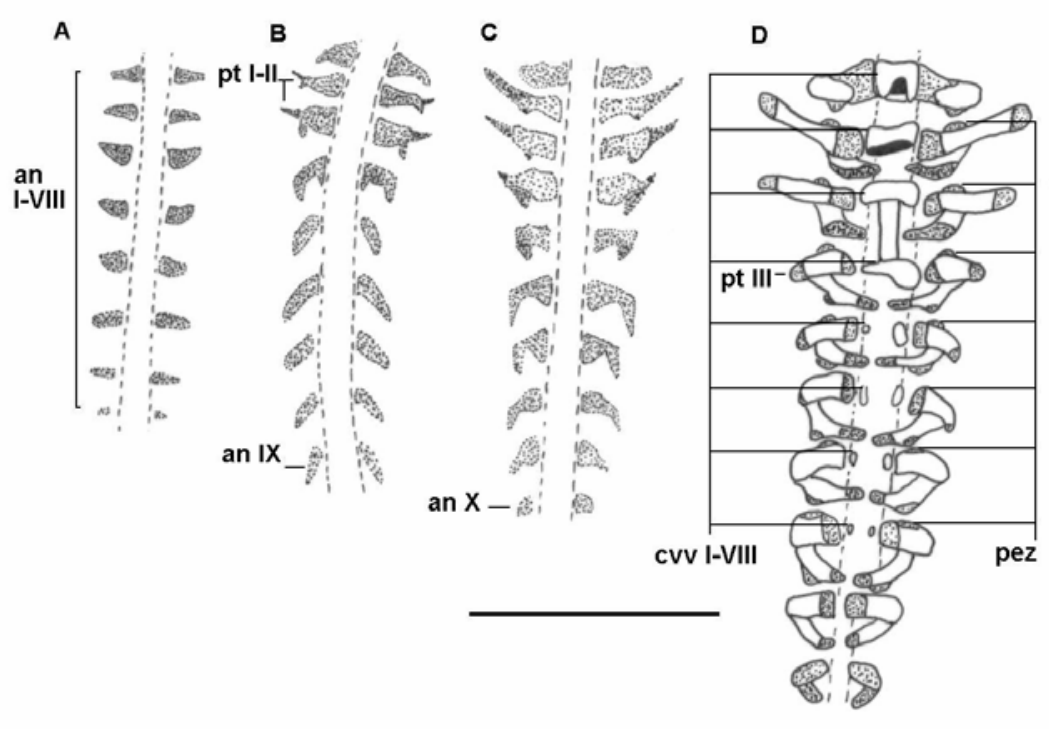

E

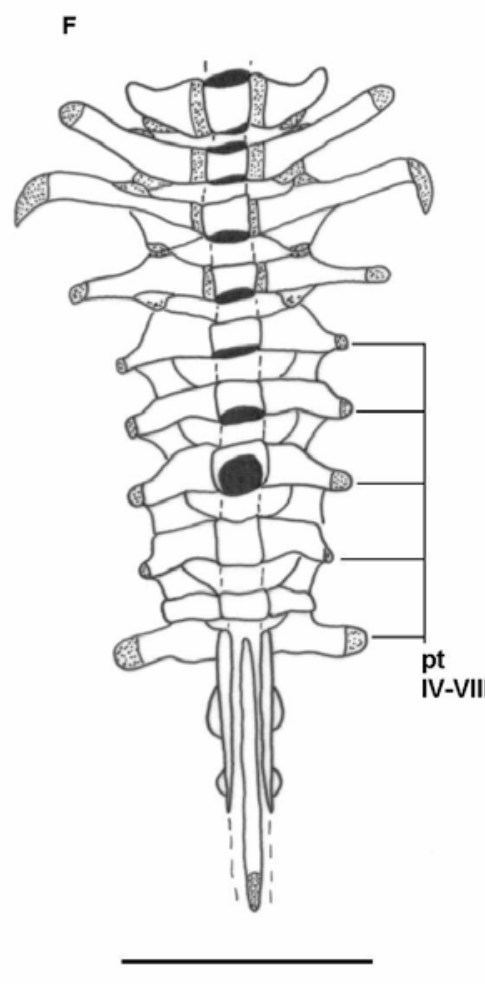

G
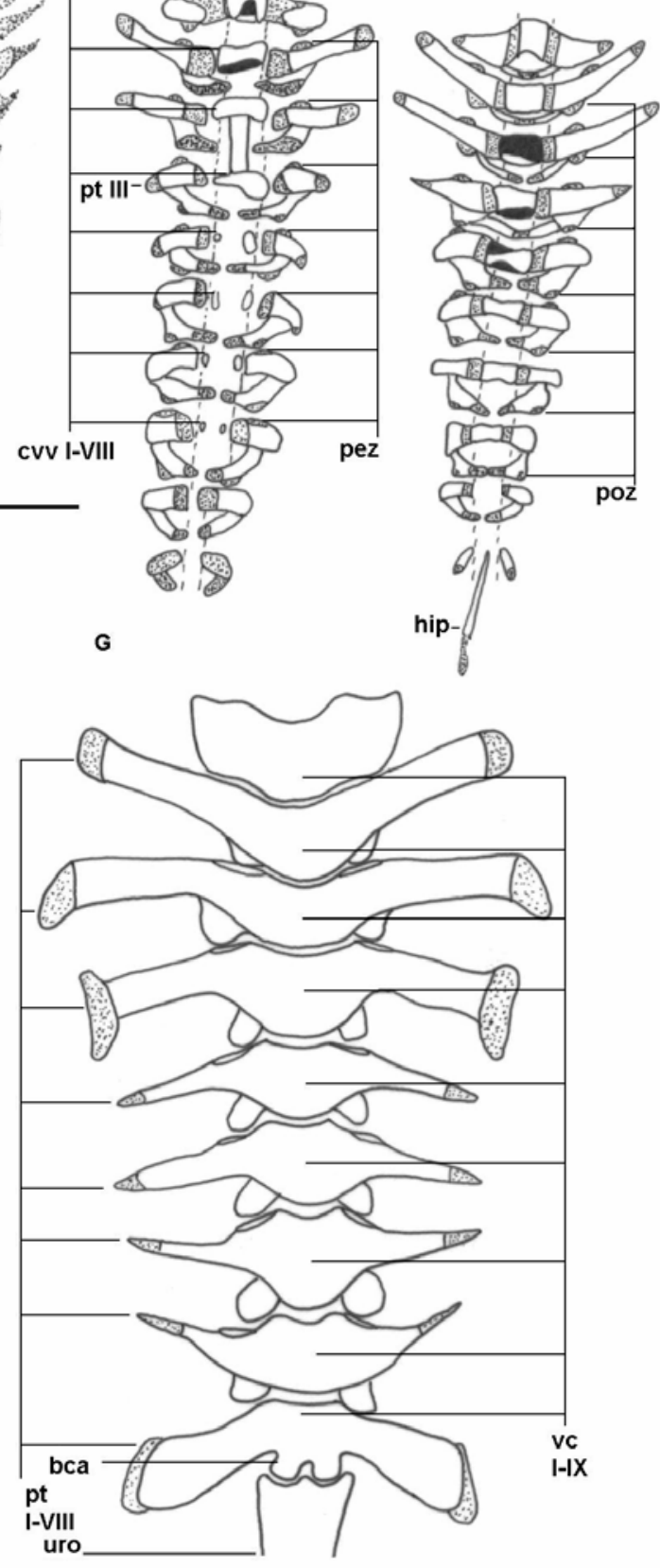

Figura 18. Vista ventral del esqueleto axial postcraneano de Batrachyla taeniata a los estadios 29 (A), 31 (B), 34 (C), 35 (D), 38 (E), 43 (F), y adulto (G). Las regiones punteadas son cartílago y las no punteadas hueso. Escala $1 \mathrm{~mm}$. Referencias: vc: cuerpo vertebral. El resto de las referencias como en las figuras 15 y 16. 


\section{III.5. Desarrollo de la musculatura axial postcraneana de Batrachyla taeniata} (Figs. 15 y 19-21).

En la larva, la musculatura axial postcraneana está ordenada en miómeros consecutivos, separados por mioseptos en forma de $V$ con vértice anterior. Los miómeros ubicados en la región del tronco son los que se encuentran por delante del miembro posterior y son constantes en numero, en cambio los que integran la región caudal se pres entan en número variable (Tabla 4). El extremo de la cola suele tener los miómeros mal definidos o incluso inexistentes. Al inicio de la metamorfosis (estadio 43 en adelante), los mayores cambios tienen que ver con la reabsorción de los miómeros caudales. Al final de la misma se diferencian los músculos epiaxiales y parte de los músculos hipoaxiales del adulto (obliquus externus y transversus). Una gran parte de la musculatura axial adulta conserva rasgos metamericos (longissimus dorsi, intercrurales, rectus abdominis, etc.) y otros pasan a componer la musculatura extrínseca de los miembros y serán tratadas en los capítulos respectivos. El único músculo axial postcraneano que aparece en estadios larvarios tempranos es el $\mathrm{m}$. rectus abdominis.

A continuación se presentan las características y el desarrollo de los músculos epiaxiales del adulto.

- Coccygeoiliacus. Músculo par notorio macroscopicamente desde el estadio 46. Se diferencia a partir de los últimos dos miómeros del tronco de la larva. En el adulto presenta origen en la mitad posterior del urostilo e inserta en el tercio anterior del ilion y extremo distal de la apófisis sacra. Sus fibras mas anteriroes y mediales se solapan ventralmente con las más posteriores del $\mathrm{m}$. coccygeosacralis.

- Coccygeosacralis. Músculo par notorio macroscopicamente desde el estadio 46. Se diferencia a partir de los miómeros anteúltimo y antepenúltimo del tronco de la larva. En el adulto presenta origen en la mitad anterior del urostilo e inserta en los dos tercios proximales de la apófisis sacra. Sus fibras más posteriores corren debajo de las más anteriores del m. coccygeoiliacus.

- Ileolumbaris. Músculo par notorio macroscopicamente desde el estadio 46. Se diferencia a partir de la región más lateral de los 4-5 miómeros anteriores a la vértebra sacra de la larva. En el adulto es un músculo superficial y segmentario que corre lateral al $\mathrm{m}$. longisimus dorsi desde el extremo distal de la apófisis sacra mediante un tendón, hasta el extremo distal del proceso transverso III. Carece de metameria a nivel de sus 3 ultimos segmentos. 
- Intercrurales (=interespinales). Son 9 músculos pares, metamericos que se diferencian junto a los $\mathrm{mm}$. intertransversarius a partir del estadio 41 , aunque recién forman una unidad discreta al estadio 46. Cada uno deriva de un miómero del tronco de la larva. En el adulto son visibles al retirar el $\mathrm{m}$. longisimus dorsi y se ubican intercalados entre el dorso de vértebras contiguas a excepción del más anterior que se encuentra entre el margen posterior del frontoparietal y la primer vértebra.

- Intertransversarius. Son 7 músculos pares, metamericos, que se diferencian junto con los mm. intertcrurales a partir del estadio 41 , aunque recién forman una unidad discreta al estadio 46. En el adulto se ubican lateralmente a los $\mathrm{mm}$. intercrurales intercalados entre los procesos transversos por debajo del $\mathrm{m}$. longisimus dorsi. El m. intertransversarius I se ubica entre los procesos transversos I y II. El m. intertransversarius II se ubica entre los procesos transversos II y III y está compuesto por dos haces de fibras, uno medial y otro lateral. El haz lateral une el extremo posterior del proceso transverso II con el anterior del III y es visible sin necesidad de retirar el $\mathrm{m}$. longissimus dorsi. El m. intertransversarius III está entre las procesos transversos III y IV. EI m. intertransversarius IV está entre los procesos transversos IV y V. El m. intertransversarius $\mathrm{V}$ se ubica entre los procesos transversos $\mathrm{V}$ y $\mathrm{VI}$. El $\mathrm{m}$. intertransversarius $\mathrm{VI}$ corre entre los procesos transversos $\mathrm{VI}$ y $\mathrm{VII}$, y el $\mathrm{m}$. intertransversarius VII entre el proceso transverso VII y el proceso transverso VIII (sacro).

- Intertransversarius capitis superior. Es evidente a partir del estadio 44 y representa la parte dorsal del más anterior de los mm. intertransversarius. En el adulto se origina en el proceso transverso I e inserta en la región posteromedial dorsal de la cápsula ótica.

- Intertransversarius capitis inferior. Es evidente a partir del estadio 39 y representa la parte ventral del más anterior de los mm. intertransversarius. En el adulto se origina en el proceso transverso I e inserta en la región posterolateral ventral de la cápsula ótica.

- Longissimus dorsi . Músculo par y metamerico (excepto al nivel de las 3 primeras vertebras) compusto por 6 segmentos que se diferencian al estadio 46. En el adulto ocupa toda la región superficial y medial del dorso del tronco. Se origina ligamentosamente en el tercio anterior del urostilo por encima del $\mathrm{m}$. 


\begin{tabular}{|c|c|c|c|}
\hline Estadio (N) & MTo & MTr & MC \\
\hline $31(1)$ & 40 & \multirow[t]{13}{*}{9} & 31 \\
\hline $32(2)$ & $36-39$ & & $27-30$ \\
\hline $33(2)$ & $36-38$ & & $27-29$ \\
\hline $34(2)$ & $33-38$ & & $24-29$ \\
\hline $35(3)$ & $27-38-40$ & & $16-27-31$ \\
\hline $36(1)$ & 36 & & 27 \\
\hline $38(1)$ & 38 & & 29 \\
\hline $40(1)$ & 35 & & 26 \\
\hline $41(7)$ & $38-42$ & & $29-32$ \\
\hline $42(6)$ & $32-42$ & & $23-33$ \\
\hline $43(11)$ & $26-42$ & & $27-33$ \\
\hline $44(3)$ & $11-29$ & & $8-20$ \\
\hline Jv (4) & 9 & & - \\
\hline
\end{tabular}

TABLA 4. Detalle de la cantidad de miómeros totales (MTo), del tronco (MTr) y de la cola (MC), que componen la musculatura axial postcraneana de las larvas de Batrachyla taeniata a diferentes estadios de desarrollo.

coxxygeosacralis e inserta en la región posterior del frontoparietal y posteromedial dorsal de la cápsula ótica.

- Transversoesophagicus. Músculo par que se diferencia al estadio 44. Se origina en el proceso transverso III e inserta en el área dorsal del esófago inmediatamente posterior a la laringe. Este músculo ha sido llamado diafragma por otros autores (Pickering et al., 2004).

- Sphincter. Músculo impar notorio desde el estadio 44. No se pudo establecer a partir de que miómero axial se diferencia. En el adulto forma un esfínter en la cloaca. Es visible dorsalmente por detrás del origen del m. coccygeoiliacus. En el adulto está compuesto por dos haces de fibras, uno anterior y otro posterior respecto del trayecto del $\mathrm{m}$. pyriformis. Las fibras de ambas porciones de este músculo se disponen anularmente formando un esfinter tubular. Las fibras más internas se disponen oblicuamente y corren de dorsal a ventral y de anterior a posterior hasta converger en la cara posterior del isquion donde insertan junto al origen del m. gracilis minor. 
A continuación se presentan las características y el desarrollo de los músculos hipoaxiales del adulto.

- Obliquus externus. Este músculo pudo ser individualizado claramente a partir del estadio 43, en los que ya muestra las características adultas, pero con poco desarrollo. Se difeencia sobre la pared lateral de la cavidad abdominal. En el adulto se trata de un músculo par que forma una capa continua de fibras orientadas en forma oblicua, cuyos extremos anteriores son dorsales y los caudales ventrales. Se origina de una fascia que lo separa de los músculos epiaxiales coccygeoiliacus, iliolumbaris y longisimus dorsi. Ventralmente sus fibras insertan en una fascia que lo separa del m. rectus abdominis. Las fibras más anteriores del $\mathrm{m}$. obliquus externus se separan postmetamorficamente de sus inmediatas posteriores para formar el $\mathrm{m}$. obliquus externus pars scapularis del adulto (ver músculos asociados a la cintura escapular, capitulo III.6).

- Rectus abdominis. Músculo metamerico presente al menos a partir del estadio 31. Se diferencia en la región del vientre de la cavidad abdominal. En la larva está compuesto por dos bridas laterales de 5 segmentos pares (a veces 6) que se separan medialmente por un amplio espacio medio desprovisto de fibras. En cada brida se reconocen una pars medialis y una pars lateralis. La primera se extiende desde la región ventral de la sínfisis media de la cintura pélvica hasta la pared posterior y ventral del septo transverso. La segunda es discontinua al nivel de los paquetes musculares III y IV sin alcanzar al septo transverso.

Con la emergencia de los miembros anteriores la musculatura asociada a estos se torna más diferenciada y es posible distinguir haces laxos de fibras del rectus abdominis ubicados en posición lateral a las fibras del primer paquete de este músculo. Estas fibras pasan a tener inserción en el húmero y son las que dan origen al $\mathrm{m}$. pectoralis abdominalis .

Hacia el fin de la metamorfosis, con la condrificación del esternón, el m. rectus abdominis modifica su inserción. Entonces, sus fibras anteriores más mediales pasan a tener inserción sobre la superficie dorsal del omoesternón y se continúan anteriormente con las fibras mediales del $\mathrm{m}$. sternohyoideus. Sus fibras más laterales pasan a tener continuidad con las fibras más laterales del m. sternohyoideus. 
- Transversus. Este músculo pudo ser individualizado claramente a partir del estadio 43 , en los que ya muestra las características adultas, pero con poco desarrollo. Se trata de un músculo par, que forma una capa por debajo de las fibras del $\mathrm{m}$. obliquus externus. Sus fibras también se disponen en forma oblicua pero a diferencia de las del $\mathrm{m}$. obliquus externus presentan sus extremos caudales ubicados dorsalmente y los anteriores son ventrales. Se origina de la misma fascia dorsal descrita en ocasión del $\mathrm{m}$. obliquus externus e inserta también en la fascia ventral que lo separa del m. rectus abdominis, e incluso sus fibras más anteriores llegan a tener inserción dorsalmente al omoesternón por debajo de los músculos del grupo pectoralis. 
A

$\mathrm{mt}$

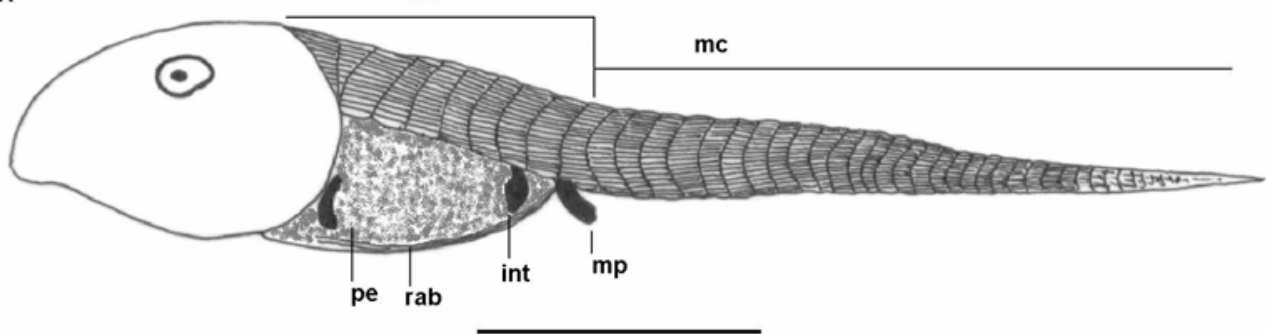

B

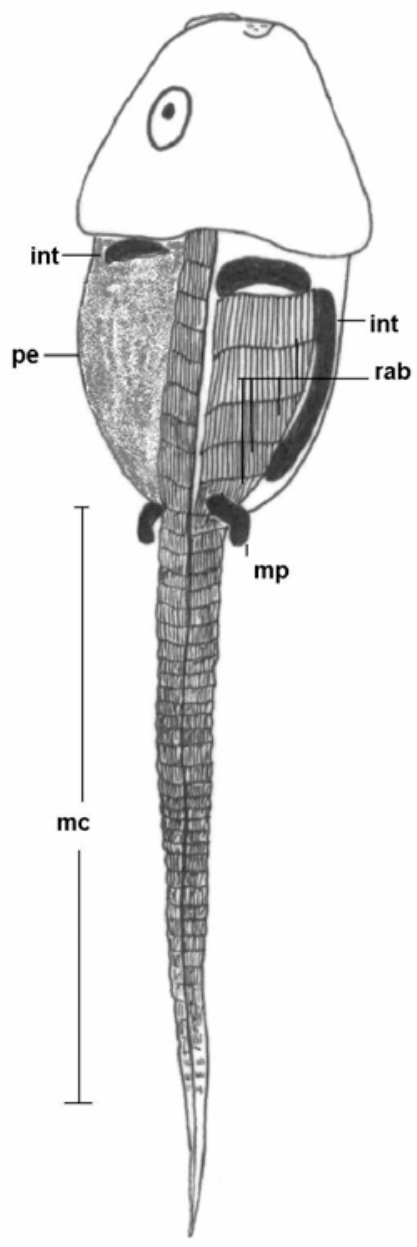

Figura 19. Vistas lateral(A) y dorsal-ventral (B) de la musculatura axial postcraneana de la larva de Batrachyla taeniata al estadio 34. En (B) del lado izquierdo se muestra una vista dorsal y del derecho la vista ventral. Escala $5 \mathrm{~mm}$. Referencias: int: intestino, mc: miómeros caudales, mp: miembro posterior, mt: miómeros caudales, pe: peritoneo, rab: rectus abdominis. 


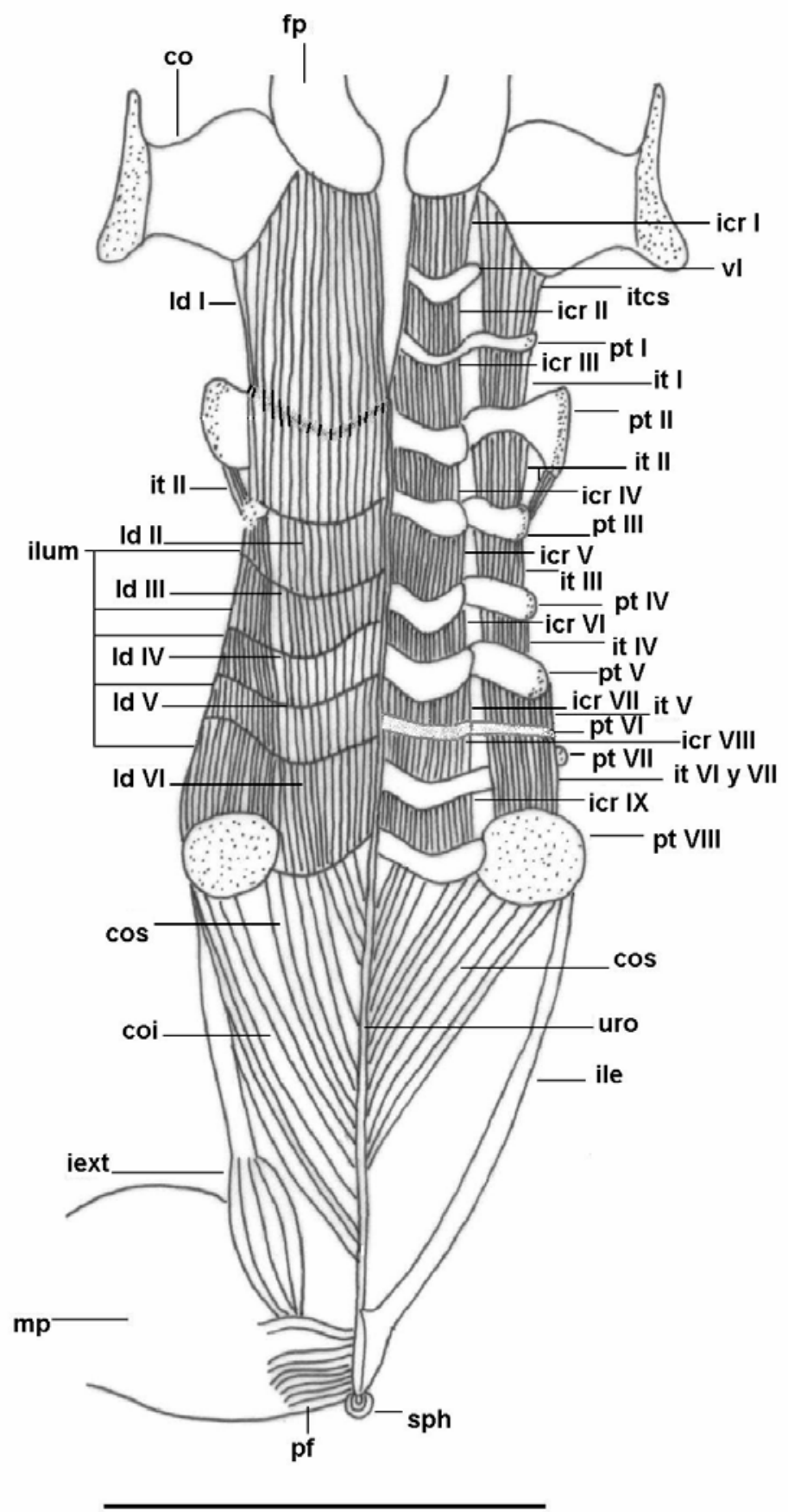

Figura 20. Vista dorsal superficial (lado izquierdo) y profunda (lado derecho) de la musculatura axial postcraneana del adulto de Batrachyla taeniata. Las regiones punteadas son cartílago y las no punteadas hueso. Escala 5mm. Referencias: co: cápsula ótica, coi: coccygeoiliacus, cos: coccygeosacralis, fp: frontoparietal, icr I-IX: intercrurales HIX, iext: iliacus externus, ile: ileon, ilum: ileolumbaris, it: intertransversarius I-VII, itcs : intertransversarius capitis superior, Id I-VI: longissimus dorsii I-VI, mp: miembro posterior, pf: pyriformis, pt I-VIII: procesos transversos I- VIII, uro: urostilo, vl: primer presacra. 


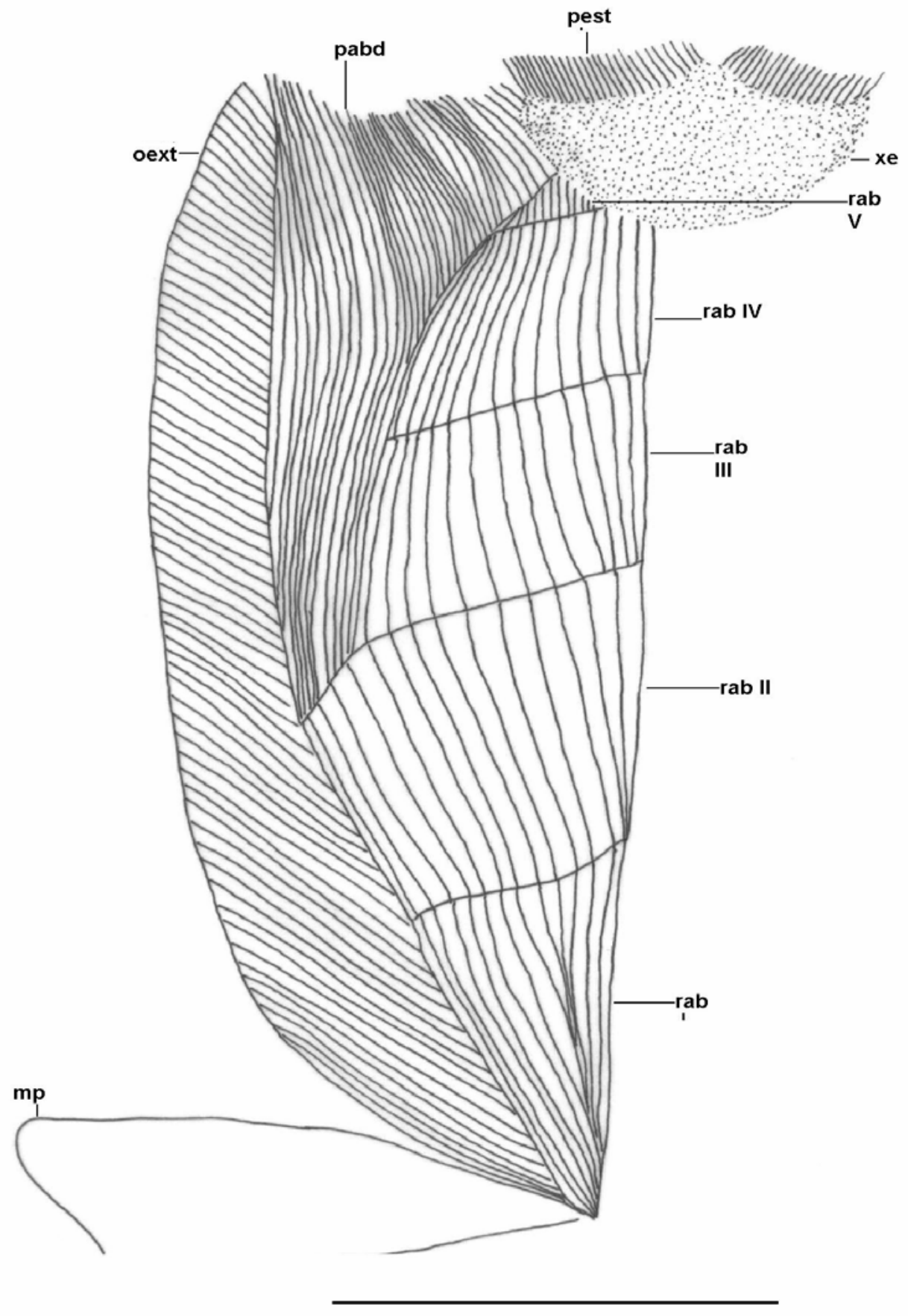

Figura 21. Vista ventral superficial del adulto de Batrachyla taeniata. Escala $5 \mathrm{~mm}$. Referencias: mp: miembro posterior, oext obliquus externus, pabd: pectoralis abdominalis, pest: pectoralis sternalis, rab I-V: rectus abdominis miómeros $\mathrm{HV}$, xe: xifiesternón. 


\section{III.6. Desarrollo del esqueleto apendicular anterior en Batrachyla taeniata (Figs}

22-24).

Las secuencias de condrificación y de osificación del esqueleto apendicular anterior de Batrachyla taeniata se muestran en las Tablas 2 y 3 respectivamente.

III.6.1. Cintura escapular y esternón (Figs. 22-23). La cintura escapular es arcifera. A continuación se describe el desarrollo larvario y la estructura adulta de cada una de sus partes.

- Cartílagos epicoracoideos. Condrifican luego de que lo haga el resto de los esbozos cartilaginosos de la cintura escapular al estadio 37 y a partir del estadio 38 comienzan su expansión medial. En los adultos observados, el epicoracoideo izquierdo se solapa ventralmente al derecho, en cambio el solapamiento durante el desarrollo fue variable $(D / I=40 \%-l / D=60 \%)$. En el adulto pueden estar en su mayor parte calcificados.

- Cartílagos procoracoideos. Condrifican al estadio 35 en conjunto con la mayoría de los esbozos cartilaginosos de la cintura escapular, salvo los cartílagos epicoracoideos, formando parte del primordio de cada hemi cintura. En los adultos, los anteriores se encuentran bastante calcificado y anteriormente revestidos por las clavículas, mientras que los posteriores se encuentran osificados autostósicamente como huesos coracoides.

- Clavícula. Alostosis de origen par formada a partir de un único centro de osificación ubicado anteriormente al margen anterior del cartílago procoracoideo anterior, sin contactarlo. Osifica al estadio 38 junto a la mayoría de los huesos de la cintura escapular, excepto la escápula. Al estadio 44 ya muestra la posición y forma adulta, aunque aun no contacta con la escápula. En el adulto se solapa anterior, ventral y dorsalmente al margen anterior del cartílago procoracoideo anterior. Las claviculas derecha e izquierda no contactan medialmente. Presenta en vista dorsal un tamaño ligeramente menor al del coracoides, contacta lateralmente con la escápula y medialmente contacta el cartílago epicoracoideo.

- Cleitro. Alostosis de origen par formada a partir de un único centro de osificación ubicado anteriormente al margen anterior de la supraescápula. Osifica al estadio 38 junto a la mayoria de los huesos de la cintura escapular, excepto la escápula. Primero se forma la rama anterior y luego la base (estadio 46). La rama posterior osifica postmetamorficamente. 
En el adulto ocupa practicamente la mitad de la superficie de la supraescápula. Tiene forma de "U", es decir que consta de una porción basal o cuerpo y dos porciones ascendentes, la anterior (mayor) y la posterior (menor). El cuerpo se ubica en el tercio proximal de la supraescápula, mientras que las porciones ascendentes anterior y posterior ocupan el margen anterior y la mitad proximal del margen posterior de la supraescápula respectivamente. La porción anterior constituye todo el margen anterior de la supraescápula, mientras que la porción posterior es submarginal, es decir que queda una porción de supraescápula posterior a ella.

- Coracoides. Autostosis par que osifica al estadio 38 junto a la mayoría de los huesos de la cintura escapular, excepto la escápula. Osifica igual que la escápula, siguiendo el mismo mecanismo que los huesos largos de los miembros. Osifica sobre el cartílago procoracoideo posterior, que aparece al estadio 35. Al estadio 44 esta totalmente osificado, aunque aun le reste establecer el contacto lateral con la escápula.

En el adulto, el coracoides compone el margen posterior de la cavidad glenoidea. Visto en vista dorsal es ligeramente mayor que la clavícula. Contacta lateralmente con la escápula y se continúa medialmente con el cartílago epicoracoideo. Los coracoides derecho e izquierdo no contactan medialmente entre sí.

- Escápula. Es una autostosis par que osifica al estadio 35 del mismo modo en que lo hacen los huesos largos de los miembros. Osifica sobre el cartílago escapular simultáneamente a su condrificación al estadio 35. Se encuentra totalmente osificada al estadio 44.

En el adulto se ubica verticalmente, lateral al esqueleto axial y contacta dorsalmente con la supraescápula y ventralmente con el coracoides y la clavícula. La porción más angosta de la escápula es ventral y presenta dos ramas que, junto con el coracoides delimitan a la cavidad glenoidea. La rama posterior articula con el coracoides y la rama anterior (pars acromialis) articula con la clavícula. La porción de cavidad glenoidea cerrada por la escápula es la anterior y lateral. La escápula proyecta posteriormente un proceso corto y romo desde el margen anterior de la cavidad glenoidea.

- Supraescápula. Condrifica junto al resto de los esbozos cartilaginosos de la cintura escapular al estadio 35 . En el adulto permanece cartilaginosa, a lo 
sumo calcificada y se encuentra revestida anterior, proximal y posteriormente por el cleitro.

- Esternón. El esternón y omoesternón aparecen al estadio 43, el primero a partir de un esbozo par y el segundo de uno impar. A partir de la variación dentro del estadio 43 se determinó que el esternón aparece despues que el omoesternón. Entre los estadios 43 y 46 hay una relativa estásis respecto del desarrollo esternal. Al estadio 46 se diferencia, separado del esbozo par del esternón, un xifiesternón redondeado, que lo remata distalmente. E epiesternón se diferencia postmetamorficamente.

En el adulto el aparato esternal es completo, se halla compuesto por cuatro porciones, dos anteriores a la cintura (omoesternón y epiesternón), y dos posteriores a ella (esternón y xifiesternón).

El omoesternón presenta forma rectangular, se encuentra pesadamente calcificado y remata anteriormente en un epiesternón cartilaginoso, pequeño y redondeado. El epiesternón se separa del omoesternón por una ligera constricción. El omoesternón se solapa posteriormente con el margen medial anterior de los cartílagos epicoracoideos.

El esternón tambien se asimila a una forma rectangular aunque de vertices redondeados y no angulosos, que en vista dorsal, dobla en ancho al omoesternón. El xifiesternón es bilobado y se proyecta posteriormente al esternón, del cual se lo diferencia por permanecer el primero cartilaginoso y el segundo encontrarse pesadamente calcificado.

El esternón se solapa posteriormente con el margen medial posterior de los cartílagos epicoracoideos.

III. 6.2. Estilopodio (Figs. 23-24). En el desarrollo, el húmero aparece como estructura cartilaginosa al estadio 34 , simultaneamente con el esbozo cartilaginoso del zeugopodio. Osifica autostósicamente a partir de un centro ubicado en el área central de la diáfisis (estadio 35). Conforme la osificación avanza hacia las epífisis, se alcanza la osificación total al estadio 43, momento en el que son distinguibles las crestas para inserción muscular.

El húmero del adulto presenta las tres crestas para inserción muscular bien desarrolladas (medial, dorsal y ventral), asi como las epífisis para articular con la cavidad glenoidea y para articular con el zeugopodio. 
La cresta mas desarrollada es la medial. Observando al húmero en vista dorsal, estando éste en posición, la cresta medial se proyecta desde la epífisis proximal hasta la mitad del hueso. Las restantes crestas presentan menor desarrollo que la cresta medial y estan restringidas a la mitad distal (cresta ventral) y cuarto distal (cresta dorsal) del húmero. Si bien la cresta ventral presenta la misma extensión que la cresta medial, esta última es mucho más ancha que la primera.

Lateral a la epífisis distal del húmero hay un moderado epicóndilo lateral para inserción muscular.

III.6.3. Zeugopodio (Figs. 23-24). En el desarrollo, el zeugopodio aparece como estructura cartilaginosa, a partir de un esbozo para cada elemento del mismo, al estadio 34, simultaneamente con el esbozo cartilaginoso del estilopodio: Un estadio despues comienza a osificar autostósicamente a partir de un centro ubicado en cada diáfisis, la osificación avanza hacia las epífisis, alcanzando la osificación total al estadio 43. La fusión a nivel de las epífisis ocurre luego de iniciada la osificación, comenzando por la epífisis proximal y continuando por la distal. La fusión media de ambos elementos comienza luego del inicio de la osificación a partir de dos puntos de contacto, ubicados proximal y distal a los centros de osificación diafisiarios. La fusión total se alcanza en algunos ejemplares cuando ambos elementos se encuentran practicamente totalmente osificados, al estadio 43 , aunque a ese estadio aun es posible advertir pequeños espacios entre ambos elementos.

En el adulto, si bien el radio y la ulna se encuentran fusionados en la linea media a lo largo de toda su longitud, es posible distinguir cada elemento y se reconoce que ambos son subiguales en espesor y longitud. La fusión media de a mbos elementos deja un area acanalada que ocupa los dos tercios distales tanto en vista dorsal como ventral. Sin embargo la fusión es imperceptible a nivel del tercio proximal. La ulna proyecta proximalmente un proceso para inserción muscular (olecranón).

Proximalmente existe una superficie articular, formada equitativamente por las epífisis proximales del radio y la ulna, con la cual el zeugopodio articula con la epífisis distal del húmero. El margen lateral de dicha articulación está formado por la cara medial del olécranon y el resto de la misma, que remata proximalmente al zeugopodio, por la tibia. Distalmente, la tibia presenta una superficie articular para la prominencia proximal del tibial, mientras que la ulna presenta una prominencia para articular con la superficie articular concava proximal del ulnar. 


\section{III.6.4. Autopodio (Figs. 23-24).}

Basipodio. En el desarrollo, los carpianos son notorios como estructuras Azul de Alcian positivas desde el estadio 37. El radial tiene origen doble a partir de dos esbozos cartilaginosos ubicados distales al radio, que se fusionan hacia el estadio 38. Esos elementos son denominados radial y radial' (homología incierta). El ulnar tambien se forma a partir de dos esbozos cartilaginosos, el ulnar y el ulnar' (intermedio) que aparecen al estadio 37 y se fusionan hacia el estadio 38.

El elemento $Y$ tambien tiene origen doble, sus dos esbozos aparecen al estadio 37 y se fusionan hacia los estadios 40-41. Los restantes carpianos corresponden a la serie distal, tambien aparecen al estadio 37 , el correspondiente al carpiano distal IIIV se forma a partir de dos esbozos cartilaginosos, uno lateral ubicado en la base de los metacarpianos IV y V, a su vez el de mayor tamaño; y otro esbozo medial en la base del metacarpiano III, el más pequeño. La fusión de ellos ocurre hacia los estadios 40-41. Los carpianos osifican postmetamorficamente.

En el adulto, el basipodio se halla osificado y se compone de 4 elementos: el radial (proximal medial), el fibular (proximal lateral), el carpiano distal II (distal medial) y el carpiano distal III-V (distal lateral). Además existe un elemento ubicado medialmente al carpiano distal II y basalmente al prepollex, el elemento Y. El carpiano distal IIFV articula proximalmente mediante sendas cavidades con las superficies articulares lateral y distal del tibial y distal del ulnar. En tanto que el carpiano distal II articula proximalmente con una carilla articular medio distal del elemento $\mathrm{Y}$, distalmente con el metacarpiano II y medialmente con el segmento basal del prepollex Tibial y fibular presentan una articulación entre si mediante una prominencia lateral del tibial y una cavidad medial del fibular.

El elemento $Y$ articula proximalmente, mediante una cavidad, con una prominencia articular medio distal del tibial, mediodistalmente lo hace con el carpiano distal II, lateralmente con el carpiano distal IIF V, y medialmente con el segmento basal del prepollex.

Metapodio y acropodio. Al estadio 35 ya es evidente el arco digital con el esbozo de los dígitos, pero los elementos de los mismos aun no son distinguibles. Al estadio 36 se observa el inicio de la segmentacion dentro de los esbozos de cada digito, siendo más avanzada en el dígito IV. 
La condrificación y osificación de los elementos de los dígitos ocurre en sentido proximal distal dentro de cada dígito, comenzando por los metacarpianos y rematando en la última serie de falanges. Sin embargo, los dígitos que más rapido desarrollan sus elementos son los más largos, en esta secuencia: IV-VIIIII.

La osificación autostósica de las falanges y metacarpianos comienza por las diáfisis y procede hacia ambas epífisis, alcanzando la osificación total al estadio 44. Al formarse, las falanges de la última serie muestran forma triangular, pero rapidamente alcanzan la forma de $\mathrm{T}$.

En el adulto, el metapodio esta compuesto por cuatro metacarpianos correspondientes a los digitos II-V. El metacarpiano II articula proximalmente con el carpiano distal II y medialmente con el segmento basal del prepollex, mientras que los restantes metacarpianos lo hacen con el carpiano distal III-V. La superficie articular proximal de los cuatro metacarpiano esta compuesta por cavidades que reciben prominencias articulares de los carpianos distales. En cambio las superficies articulares distales de los metacarpianos son ligeramente convexas y articulan con las cavidades articulares proximales de la primer serie de falanges. El metacarpiano II, en su cara dorsomedial, y el metacarpiano $\mathrm{V}$, en su cara dorso lateral, sostienen sendos tuberculos óseos. El tuberculo óseo del metacarpiano I es triangular, curvado distalmente y absolutamente mas desarrollado que el respectivo del metacarpiano V. Los metacarpianos no presentan III y IV no presentan carillas de articulación entre si. En cambio, el metacarpiano II articula con el metacarpiano III a nivel proximal y lo mismo sucede entre los metacarpiano IV y V.

Las falanges proximales repiten el patron articular descrito para los metacarpiano (cavidades proximales y saliencias distales). En cambio, la superficie distal de las falanges de la serie media y la superficie proximal de las respectivas falanges distales se relacionan mediante superficies articulares planas. La serie de falanges distales remata en forma de $\mathrm{T}$.

La formula de falanges es 2-2-3-3. No existen elementos intercalares, ni óseos ni cartilaginosos, entre las falanges.

- Prepollex. El prepollexaparece al estadio 38 representado por sus dos segmentos y su osificación comienza postmetamorficamente, aunque es posible encontrar individuos adultos que aun no lo presentan enteramente osificado. 
El prepollex del adulto está compuesto por 2 segmentos, el basal y el distal. El segmento basal es irregularmente redondeado, tan largo como ancho, y articula proximalmente con el elemento $\mathrm{Y}, \mathrm{y}$ con los margenes mediales del carpiano distal II y del metacarpiano II. El segmento distal es alargado, curvo medialmente, cuatro veces más largo que ancho, y osificado casi en su totalidad salvo su apice distal que permanece cartilaginoso. La articulación entre ambos segmentos es mediante una saliencia distal del segmento proximal y una cavidad proximal del segmento distal. 
A

B
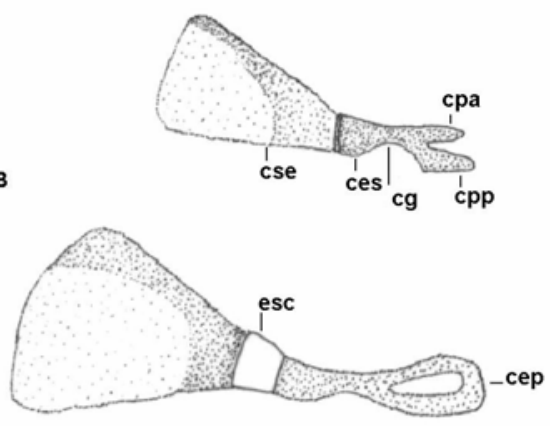

C

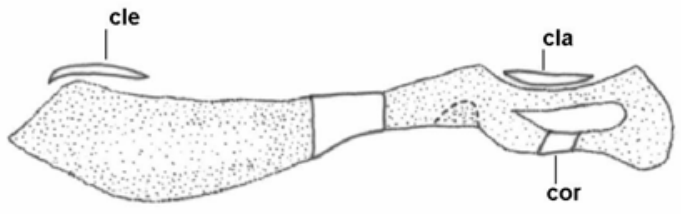

D

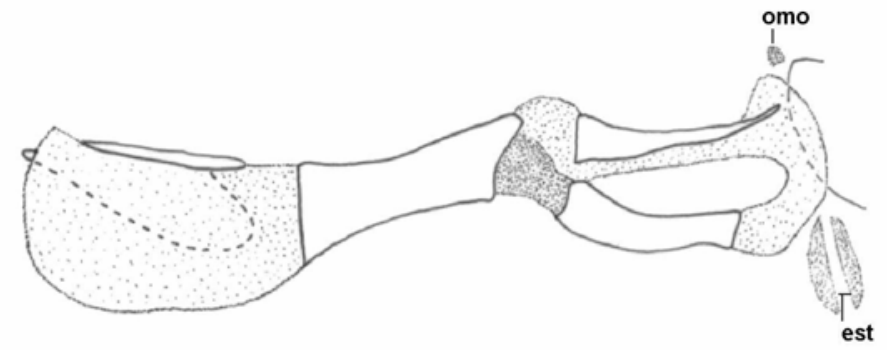

E

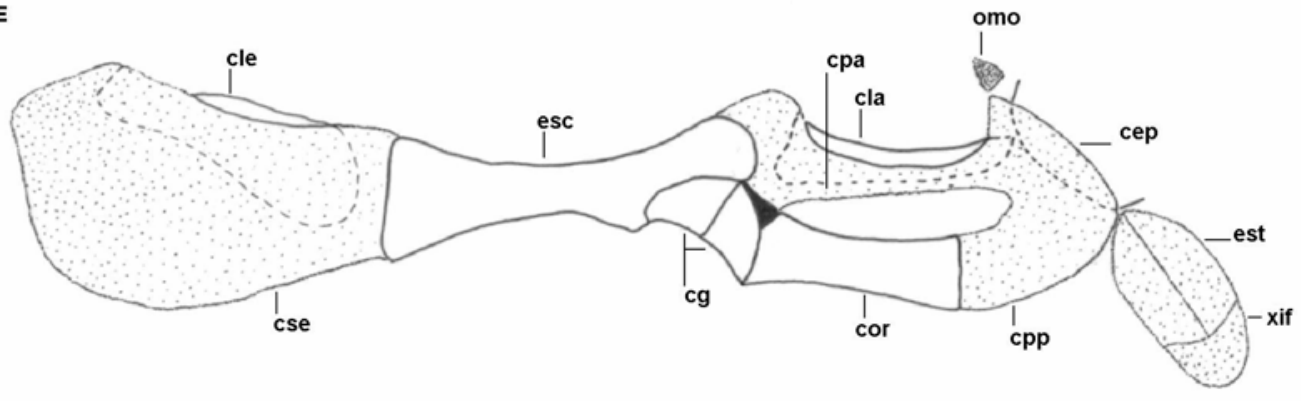

Figura 22. Vista ventral de las hemicinturas escapulares derechas de Batrachyla taeniata a los estadios 35 (A), 37 (B) , 38 (C) , 43 (D) y 46 (E). Las regiones punteadas son cartílago y las no punteadas hueso. Escala $1 \mathrm{~mm}$. Referencias: cep: cartílago epicoracoideo, ces: cartílago escapular, cg: cavidad glenoidea, cla: clavícula, cle : cleitro, cor: coracoides, cpa: cartílago procoracoideo anterior, cpp: cartílago procoracoideo posterior, cse: cartílago supraescapular, esc: escápula, est: esternón, omo: omoesternón, xif : xifiesternón. 

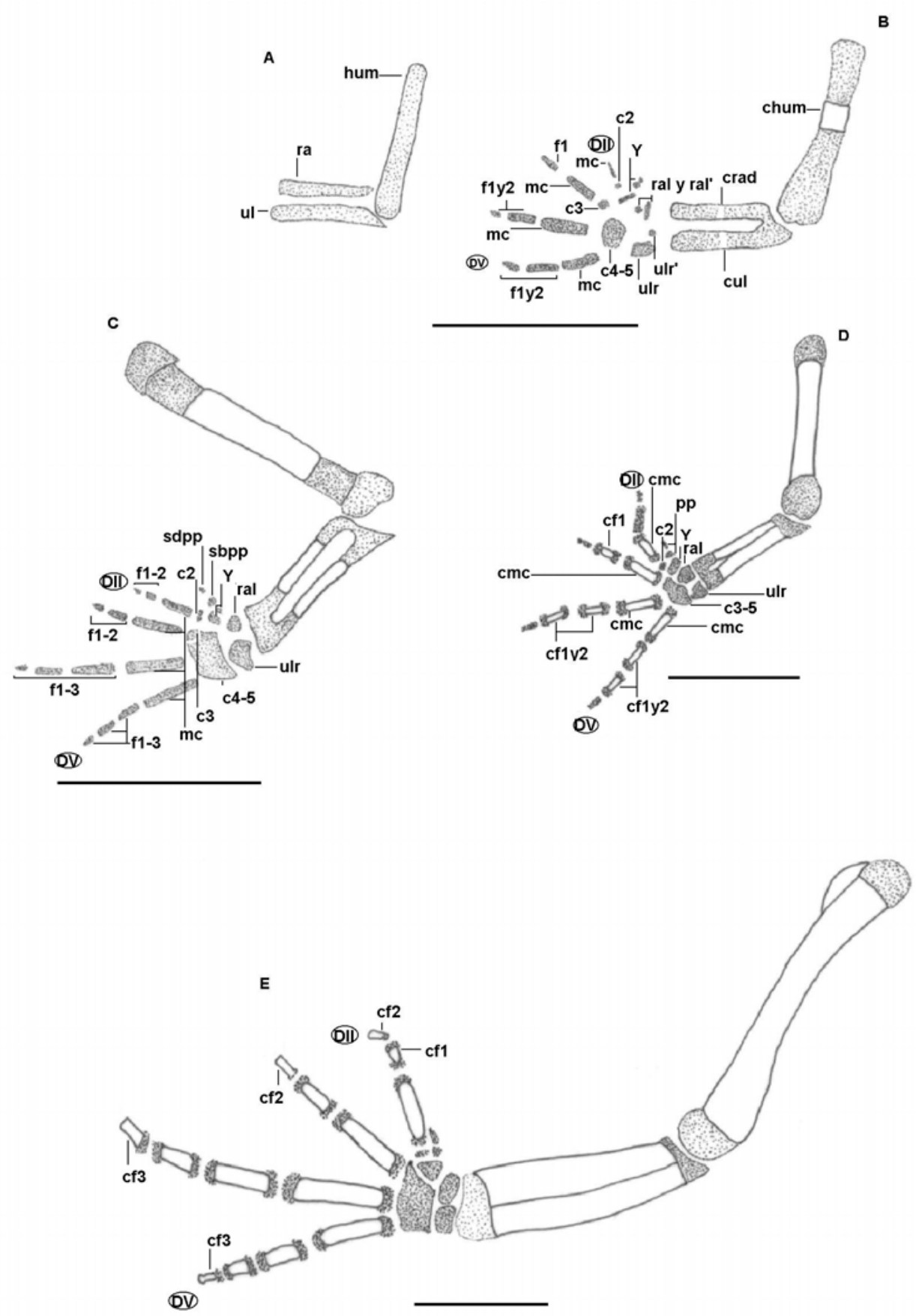

Figura 23. Miembro anterior derecho en posición a traves de diferentes estadios de Gosner (1960) de Batrachyla taeniata: estadios 35 (A), 37 (B), 38 (C), 43 (D), y 46 (E). Las zonas punteadas indican cartílago y las zonas sin puntear representan hueso. Escala $1 \mathrm{~mm}$. Referencias: c2: carpiano II, c3: carpiano III, c4-5: carpiano IV-V, c3-5: carpiano III-V, cf. centro de las falanges, cmc: centro de los metacarpianos, chum: centro del húmero, crad: centro del radio, cul : centro de la ulna, DII-V: digitos II al $\mathrm{V}$, f: falanges, hum: húmero, mc: metacarpianos, pp: prepollex, ra: radio, ral: radial, ral': radial prima, sbpp: segmento basal del prepollex, sdpp: segmento distal del prepollex, ul: ulna, ulr: ulnar, ulr': ulnar prima (intermedio), Y: elemento $\mathrm{Y}$. 

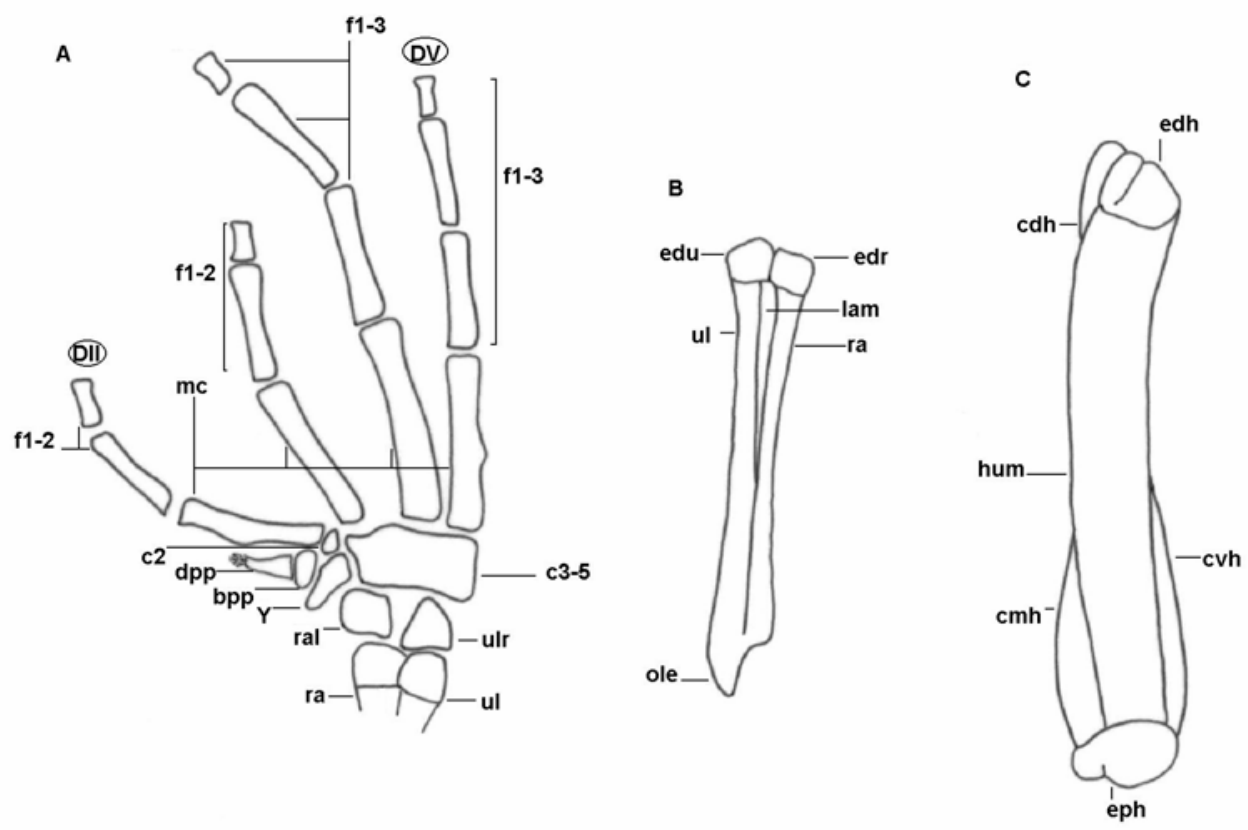

D

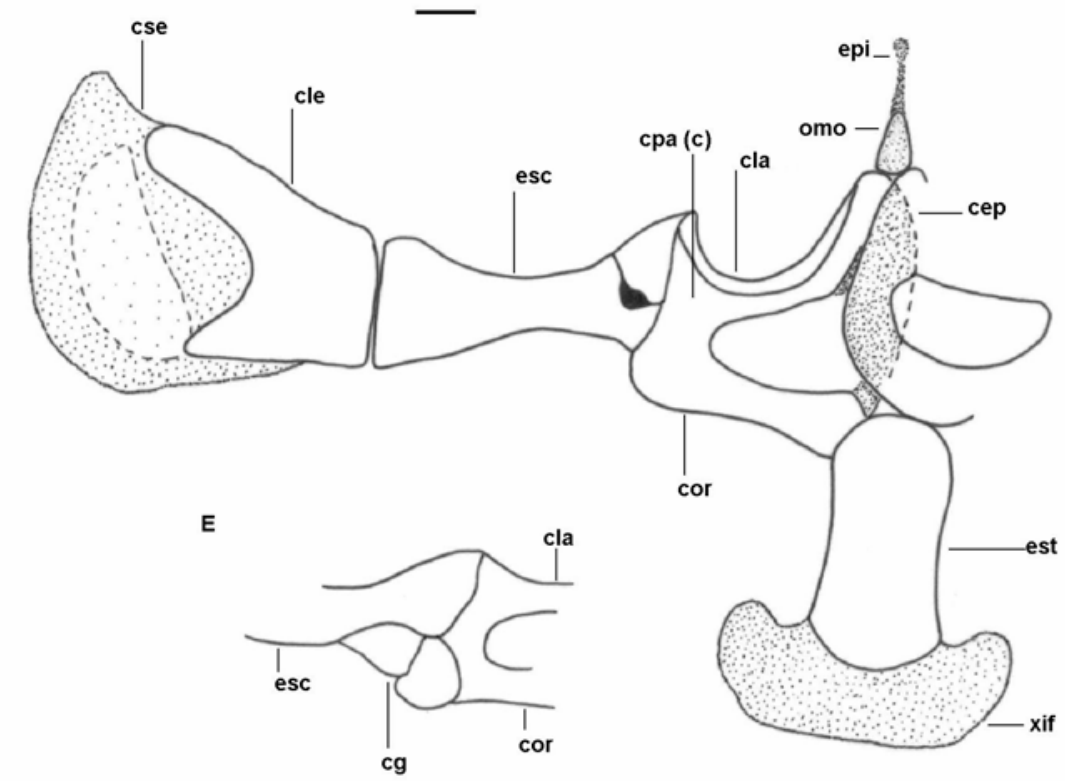

Figura 24. Diferentes segmentos del esqueleto apendicular anterior del adulto de Batrachyla taeniata: vista ventral del autopodio izquierdo (A), vista dorsal del zeugopodio izquierdo (B), vista ventromedial del estilopodio izquierdo (C), vista ventral de la hemicintura escapular derecha (D), y detalle de la cavidad glenoidea (E) . Las zonas punteadas indican cartílago y las zonas sin puntear representan hueso. Escala $1 \mathrm{~mm}$. Referencias: $\mathbf{c d h}$ : cresta dorsal del húmero, $\mathbf{c m h}$ : cresta medial del húmero, $\mathbf{c v h}$ : cresta ventral del húmero, edh: epífisis distal del húmero, edr: epífisis distal del radio, edu: epífisis distal de la ulna, eph: epífisis proximal húmero, epr: epífisis proximal del radio, epu: epífisis proximal de la ulna, lam : lamina osea media, ole: olécranon. El resto de las referencias como en las figuras 21 y 22. 


\section{III.7. Desarrollo de la musculatura apendicular anterior en Batrachyla taeniata} (Figs. 25-35).

III.7.1. Músculos asociados a la cintura escapular y estilopodio (Figs 25-28). Se consideraron como músculos pectorales aquellos que presentan su inserción, su origen, o ambos en la cintura escapular. De acuerdo a sí se insertan u originan en la cara dorsal (medial) o en la ventral (lateral) de la cintura, se reconocieron dos categorías de músculos, los dorsales y los ventrales. Los músculos ventrales son visibles en vistas ventral y lateral. Los elementos dorsales, dependiendo de su posición, son visibles mayormente en vista medial, aunque algunos también lo son en vista dorsal y lateral. A continuación se exponen las características generales para cada músculo considerando su origen, inserción y relaciones topográficas con otros elementos a lo largo del desarrollo desde larva hasta adulto.

\section{Músculos ventrales.}

- Coracobraquialis brevis. Músculo intrínseco, notorio a partir del estadio 37 formando una masa común junto a los mm. coracobraquiales longus. A partir del estadio 42 se separa de estos y ya toma sus características adultas. En el adulto es evidente en vista profunda al remover los $\mathrm{mm}$. pectoralis abdominalis, pectoralis sternalis y pectoralis epicoracoideus. Se origina en la cara anterior del cora coides e inserta en la cara posterior de la cresta deltoidea (ventral) del húmero, en su región proximal.

- Coracobraquialis longus profundus. Músculo intrínseco que es notorio a partir del estadio 37 formando una masa común junto a los mm. coracobraquialis brevis y coracobraquialis longus superficialis. A partir del estadio 42 se separa del $\mathrm{m}$. coracobraquialis brevis, pero la separación del m. coracobraquialis longus superficialis ocurre postmetamorficamente. En el adulto es notorio en vista profunda al remover los $\mathrm{mm}$. pectoralis abdominalis, pectoralis sternalis y pectoralis epicoracoideus. Se origina fundamentalmente en el margen posterior y proximal del coracoides, pero algunas fibras lo hacen en el margen posterolateral del cartílago epicoracoideo. Inser ta en la cara posterior de la cresta deltoidea (ventral) del húmero, justo en su mitad.

- Coracobraquialis longus superficialis. Músculo intrínseco que es notorio a partir del estadio 37 formando una masa común junto a los $\mathrm{mm}$. coracobraquialis brevis y coracobraquialis longus profundus. A partir del 
estadio 42 se separa del m. coracobraquialis brevis, pero la separación del m. coracobraquialis longus profundus ocurre postmetamorficamente. En el adulto es visible en vista profunda al remover los $\mathrm{mm}$. pectoralis abdominalis, pectoralis sternalis y pectoralis epicoracoideus. Se origina fundamentalmente en el margen posterior y proximal del coracoides, pero algunas fibras lo hacen en el margen posterolateral del cartílago epicoracoideo y en la base del esternón. In serta en la cara posterior de la cresta deltoidea (ventral) del húmero, justo en su tercio medio.

- Coracoradialis. Músculo intrínseco que es notorio a partir del estadio 37 formando una masa común con el $\mathrm{m}$. pectoralis epicoracoideus. A partir del estadio 39 es evidente el largo tendón característico de este músculo. Al estadio 44 se separa del $\mathrm{m}$. pectoralis epicoracoideus y muestra las características del adulto. En el adulto, sus dos tercios posteriores son evidentes en vista profunda al remover el $\mathrm{m}$. pectoralis epicoracoideus. Su tercio anterior es notorio en vista superficial ubicado entre los $\mathrm{mm}$. deltoideus episternalis y pectoralis epicoracoideus. Se origina en todo el margen lateral del cartílago epicoracoideo. Inserta en la cabeza proximal del zeugopodio mediante un largo y fuente tendón que recorre el húmero por detrás de la cresta deltoidea (ventral) oculto por los $\mathrm{mm}$. pectoralis abdominalis, pectoralis sternalis y pectoralis epicoracoideus.

- Deltoideus clavicularis. Músculo intrínseco que se diferencia al estadio 37. En el adulto es visible parcialmente en vista superficial, ubicado anterior y dorsal al m. deltoideus episternalis, ventral al $\mathrm{m}$. deltoideus scapularis. Se origina en la cara anterior y distal de la clavícula cerca de la fosa glenoidea. Inserta, junto al m. deltoideus scapularis, en la región proximal y anterior de la cresta deltoidea (ventral) del húmero.

- Deltoideus episternalis. Músculo intrínseco que se diferencia al finalizar la metamorfosis a partir del m. deltoideus clavicularisal desarrollarse la porción anterior del esternón. En el adulto es visible en vista superficial por delante de los mm. coracoradialis y pectoralis epicoracoideus. Se origina en el margen lateral del extremo redondeado del omoesternón. Inserta en la cara anterior y distal de la cresta deltoidea (ventral) del húmero.

- Deltoideus scapularis. Músculo intrínseco que se diferencia al estadio 37 . Es evidente anterior a los $\mathrm{mm}$. deltoideus episternalis y deltoideus clavicularis. En 
el adulto se origina en la cara anterior y proximal de la escápula cerca de la fosa glenoidea.

Inserta en la cara anterior, región medio distal de la cresta deltoidea (ventral) del húmero.

- Depressor mandibulae. Sus características fueron descritas en relación a la musculatura hioidea (ver m. depressor mandibulae, capitulo III.5).

- Dorsalis scapulae. Músculo extrínseco que se diferencia al estadio 37. A Partir del estadio 42 sus fibras más posteriores desplazan su origen a una fascia sobre el $\mathrm{m}$. longisimus dorsi. Es un músculo superficial. En el adulto se origina mayormente en el cleitro y la región de la supraescápula dorsal a este elemento. Sus fibras más posteriores se originan en una fascia sobre el $\mathrm{m}$. longisimus dorsii. Inserta en la región proximal del húmero, tapado por el complejo de los mm. deltoideus.

- Pectoralis abdominalis. Músculo extrínseco que se diferencia al estadio 37 como un haz de fibras que se desprende lateralmente del $\mathrm{m}$. rectus abdominis. Durante la metamorfosis aumenta su desarrollo hasta que al estadio 44 está extendido hast a el tercer miómero del $\mathrm{m}$. rectus abdominis incluso solapado con parte del mm. obliquus externus a ese nivel. En el adulto es evidente en vista superficial por detrás del $\mathrm{m}$. pectoralis sternalis. Sus fibras más laterales se originan en el $\mathrm{m}$. obliquus externus a la altura del segundo miómero del m. rectus abdominis. Sus fibras más mediales, la mayoría, se originan en los miómeros tercero, cuarto y quinto del $\mathrm{m}$. rectus abdominis. Inserta en la cara posterior de la cresta deltoidea (ventral) del húmero mediante una aponeurosis tendinosa común con los $\mathrm{mm}$. pectoralis sternalisy pectoralis epicoracoideus.

- Pectoralis epicoracoideus. Músculo par e intrínseco que forma una masa muscular común con el m. coracoradialis desde su diferenciación (estadio 37) hasta el estadio 44, momento en que ambos elementos se distinguen uno del otro. Es evidente en vista superficial entre los $\mathrm{mm}$. pectoralis sternalis, coracoradialis y deltoideus episternalis. Se origina en el margen lateral de los tres cuartos posteriores del cartílago epicoracoideo. Inserta en la cara posterior de la cresta deltoidea (ventral) del húmero mediante una aponeurosis tendinosa común con los $\mathrm{mm}$. pectoralis sternalisy pectoralis epicoracoideus.

- Pectoralis sternalis. Músculo par e intrínseco que se diferencia al estadio 37 en relación al $\mathrm{m}$. rectus abdominis. Hasta la condrificación del esternón y xifiesternón se origina en II área medio ventral del abdomen, en el mismo sitio 
donde se formaran dichos elementos. Es evidente en vista superficial entre los $\mathrm{mm}$. pectoralis epicoracoideus y pectoralis abdominalis. Se origina en el área ventral, proximal y lateral del mesoesternón y xifiesternón. Inserta en la cara posterior de la cresta deltoidea (ventral) del húmero mediante una aponeurosis tendinosa común con los mm. pectoralis sternalisy pectoralis epicoracoideus.

- Omohyoideus. Sus caracteristicas fueron descritas con relación a la musculatura branquial (ver m. diaphragmatobranchialis, capitulo III.5).

\section{Músculos dorsales.}

- Anconeus. Al estadio 39 se pudo observar a este músculo como entidad separada. A ese estadio presenta dos masas de fibras, una correspondiente a la cabeza dorsal, y otra a las cabezas ventral y lateral. Al estadio 41 es posible diferenciar la cabeza ventral de la lateral lograndose la composición adulta de tres cabezas. A partir de este estadio avanza la diferenciación de las mismas asemejandose paulatinamente a la estructura adulta, la que se logra previo al fin del proceso metamórfico. En el adulto corre superficialmente por las 4 caras del húmero. Presenta tres cabezas, la dorsal (profunda), la medial y la lateral. La cabeza lateral es la más larga, se origina en el borde posterior de la escápula y borde superior de la cavidad glenoidea, y corre mayormente por la cara dorsal del húmero. La cabeza lateral desprende de su origen a un pequeño haz de fibras que cruza dorsalmente a la epífisis proximal del húmero para insertar proximalmente en la superficie proximal del mismo hueso. Este pequeño haz corre entre las cabezas dorsal y medial del músculo. La cabeza medial se origina en la superficie medio proximal del húmero, en la cara anterior de la cresta. La cabeza dorsal se origina en la superficie dorsolateral del húmero. Todas se unen distalmente, aproximadamente a la mitad del húmero, formando el cuerpo del músculo. Insertan mediante una aponeurosis sobre el olécranon.

- Cucularis. Músculo extrínseco que se diferencia al estadio 37. Tanto en larvas como adultos conecta la escápula con la región ótica del cráneo. Desde su diferenciación presenta la misma inserción que en el adulto (margen anterior y proximal de la escápula), pero el origen es diferente al comparar larvas y adultos. En la larva se origina en la región posterior y ventral de la cápsula ótica junto al $\mathrm{m}$. levator arcuum branchialium IV, pero durante la metamorfosis desplaza su origen hacia la cresta parótica y el anillo timánico. Su tercio 
anterior es visible en vista profunda al retirar la pars timpanica del m. depressor mandibulae.

- Interscapularis. Músculo intrínseco que se diferencia al estadio 42. Tanto en la larva como en el adulto corre entre el límite proximal de la escápula y el límite proximal de la supraescápula.

- Latisimus dorsi. Músculo extrínseco que desde su diferenciación al estadio 37 muestra el mismo origen e inserción que en el adulto. Desde el estadio 42 es visible en vista superficial por detrás del $\mathrm{m}$. dorsalis scapulae. Presenta dos vientres, el anterior y el posterior. Ambos se originan en la región proximal de la escápula. El posterior es el más desarrollado e inserta en el extremo distal del proceso transverso III tapado por los mm. obliquus externus y transversus. E vientre anterior, de menor tamaño, inserta en el proceso transverso II oculto por el m. dorsalis scapulae.

- Levator scapulae inferior. Músculo extrínseco que desde su diferenciación al estadio 37 muestra las mismas características que en el adulto. Su extremo anterior corre por debajo de la pars timpanica del $\mathrm{m}$. depressor mandibulae. Se origina en la región medio ventral del cleitro. Inserta en la zona posterior, ventral y lateral de la cápsula ótica, oculto por el m. levator scapulae superior.

- Levator scapulae superior. Músculo extrínseco que se diferencia al estadio 37. Desde su diferenciación presenta el mismo origen e inserción que en el adulto. Se origina en la región anterodorsal del cleitro junto al m. opercularis. Inserta en el piso posterior de la cápsula ótica.

- Obliquus externus pars scapularis. Músculo extrínseco que se diferencia postmetamorficamente a partir del $\mathrm{m}$. obliquus externus. Es evidente en vista superficial por detrás del m. latisimus dorsii. Inserta en el margen posterior y ventral de la supraescápula justo en el límite con la escápula.

- Opercularis. Músculo extrínseco que se diferencia postmetamorficamente a partir del m. levator scapulae superior. Corre profundo y en intima relación con el m. levator scapulae superior, siendo distinguibles entre sí sólo en el punto de su inserción. Se origina junto con el $\mathrm{m}$. levator scapulae superior en el extremo anterior y dorsal del cleitro y la supraescápula. Inserta en el cartílago opercular.

- Rhomboideus anterior. Músculo extrínseco que se diferencia al estadio 37 a partir del primer miómero axial. En general muestra las mismas características durante todo el desarrollo, pero se hace bien conspicuo desde el estadio 41. En el adulto es evidente en vista superficial entre los $\mathrm{mm}$. longisimus dorsii, levator 
mandibulae internus, levator mandibulae longus y levator scapulae superior. Se origina en el margen anterior y dorsal de la supraescápula. Inserta en una fascia dorsal a los $\mathrm{mm}$. levator mandibulae internus y levator mandibulae longus, en la parte dorsal de la cápsula ótica y extremo posterior de los frontoparietales. En los machos, el espacio medio entre sus partes izquierda y derecha determina un triangulo cuyo vértice se encuentra en el punto medio de la fusión posterior de ambos huesos frontoparietales. En las hembras, en cambio, el espacio medio entre ambas partes del músculo es rectangular.

- Rhomboideus posterior. Músculo extrínseco que se diferencia al estadio 37 a partir de fibras laterales del tercer y cuarto miómeros axiales. Desde su diferenciación presenta las mismas características que en el adulto. Se origina en el extremo distal del proceso transverso III e inserta en la cara medial de la supraescápula, cerca de su margen dorsal. Este músculo y el m. serratus superior corren en intima asociación, comparten el mismo origen y la misma inserción. La distinción entre ambos músculos, aunque dificultosa, es posible recién desde el estadio 42.

- Rhomboideus superior (nuevo término). Músculo extrínseco que se diferencia partir de las fibras laterales de los primeros dos miómeros axiales. Es visible, desde el estadio estadio 41, como un haz compacto de fibras asociado al borde dorsal de la supraescápula. Recién toma sus características adultas al estadio 44. Es visible en vista superficial por encima del $\mathrm{m}$. longisimus dorsii. En el adulto se origina en la superficie ventral del margen anterior y dorsal de la supraescápula, algo ventral al origen del $\mathrm{m}$. rhomboideus anterior. Inserta en una aponeurosis sobre el $\mathrm{m}$. longisimus dorsii.

- Serratus inferior. Músculo extrínseco que se diferencia al estadio 37 a partir del segundo y tercer miómero axial. Presenta el mismo origen e inserción a lo largo de todo el desarrollo. Está oculto totalmente por la supraescápula y tiene una tendencia a formar dos vientres que se originan en el proceso transverso II e insertan en la base de la rama ascendente anterior del cleitro.

- Serratus medius. Músculo extrínseco que se origina al estadio 37 a partir de los miómeros axiales segundo y tercero. Muestra las mismas características a lo largo de todo el desarrollo. Está tapado totalmente por la supraescápula, se origina en el proceso transverso II e inserta en el margen dorsomedial de la supraescápula junto a los mm. serratus superior y rhomboideus posterior. 
- Serratus superior. Músculo extrínseco que se diferencia al estadio 37 a partir de fibras laterales del tercer y cuarto miómeros axiales. Desde su diferenciación presenta las mismas características que en el adulto (ver m. rhomboideus posterior).

- Sternohyoideus. Sus características fueron descritas en relación a la musculatura hipobranquial (ver m. rectus cervicis, capitulo III.5).

III.7.2. Músculos asociados al zeugopodio (Figs. 27-28). Se consideraron en esta categoría aquellos músculos que recorren el zeugopodio independientemente de si presentan inserción u origen en él. A continuación se exponen las características generales para cada músculo considerando su origen, inserción y relaciones topográficas con otros elementos a lo largo del desarrollo desde larva hasta adulto.

Aspectos del desarrollo larval. Previo al estadio 40, desde la aparición de la yema del miembro posterior y durante todo el período de diferenciación de los digitos resulta imposible identificar bajo lupa a los músculos del zeugopodio y autopodio. Esto es posible solo desde el estadio 40 para los músculos asociados al zeugopodio, mientras que los músculos del autopodio se diferencian individualmente recien hacia el estadio 42. A este estadio es reconocible la mayoría de ellos con rasgos estructurales practicamente identicos a los del adulto, presentando un mayor desarrollo relativo los músculos de la palma respecto de los elementos dorsales.

Los $\mathrm{mm}$. interphalangealis digiti IV e interphalangealis digiti $\mathrm{V}$ presentan una masa muscular única para cada uno, la cual ocupa la posición de las cabezas respectivas que se observan al estado adulto. Esta masa se dividira recien hacia el estadio 45.

Como exepción de la musculatura del zeugopodio, el m. flexor antibrachii lateralis profundus se diferencia tardiamente recien a los estadios 43-44, mientras que el $\mathrm{m}$. flexor carpi ulnaris lo hace al estadio 45.

\section{Músculos ventrales.}

- Flexor antibrachii lateralis profundus. En la larva es el último de los músculos de la cara ventral del zeugopodio en diferenciarse. Se diferencia del m. flexor antibrachii lateralis superficialis a los estadios 43-44, momento a partir del cual ya muestra sus rasgos adultos. En el adulto estaría representado por la porción de fibras cortas proximales del m. flexor antibrachii lateralis 
superficialis, las cuales insertan en la cara lateral, región proximal de la porción ulnar del radio-ulna.

- Flexor antibrachii lateralis superficialis. En el adulto se compone por una sola cabeza que se origina en el epicóndilo lateral del húmero. Es un músculo que corre por el lado ulnar del zeugopodio. Inserta en la cara ventral del carpiano distal III-V.

- Flexor antibrachii medialis. Músculo profundo de la cara medial del zeugopodio que corre tapado por el $\mathrm{m}$. flexor carpi ulnaris. En el adulto presenta origen, mediante un grueso tendón, en el epicóndilo medial del húmero. Inserta mayormente en el lado radial del radio-ulna, pero algunas fibras insertan medialmente en las capas profundas del $\mathrm{m}$. flexor carpi radialis.

- Flexor carpi radialis. Se trata de un músculo superficial que en el adulto presenta un amplio origen detrás del epicóndilo medial, en la región media del húmero. Inserta en el carpiano distal III-V. Está muy desarrollado en los machos, en los cuales presenta hasta 3 capas. La presencia de diferentes capas se logra luego de finalizada la metamorfosis.

- Flexor carpi ulnaris. Es notorio en la larva a partir del estadio 45, momento desde el cual es posible diferenciarlo, aunque con dificultad, del m. flexor carpi radialis. En el adulto se origina en el cóndilo medial del húmero mediante un tendón e inserta en el carpiano distal III-V. Corre por la cara externa del m. flexor carpi radialis, e incluso algunas de sus fibras convergen distalmente con este elemento y lateralmente con las del $\mathrm{m}$. palmaris longus, con el que comparten una aponeurosis.

- Palmaris longus. Es notorio en la larva a partir del estadio 41. La diferenciación total de la masa de este músculo con la del m. ulnocarpalis ocurre en el estadio 42. Se trata de un músculo superficial, que en el adulto se origina en el epicóndilo medial del húmero e inserta penetrando la aponeurosis palmar.

- Palmaris profundus. Músculo superficial que se origina en el borde ulnar del radio-ulna. Corre oblicuamente hacia su inserción en el dorso de la aponeurosis palmar.

- Ulnocarpalis. Presente desde el estadio 42. En estadios previos (40-41) no es diferenciable del $\mathrm{m}$. palmaris longus a nivel del origen de ambos. Corre profundo al m. palmaris longus. Se origina en el tercio dístal de la ulna insertando en el ulnar mediante un grueso tendón. 


\section{Músculos dorsales.}

- Abductor indicis longus. Se trata de un músculo superficial que en el adulto corre medialmente al $\mathrm{m}$. extensor digitorum commu nis longus y lateralmente al m. extensor carpi radialis. Presenta origen doble en la mitad distal de la cara lateral del radio-ulna (origen profundo) y en el epicóndilo lateral del húmero (origen superficial), junto al m. extensor digitorum communis longus. Cruza el zeugopodio de lateral a medial y de proximal a distal hasta su inserción en el m. extensor indicis brevis superficialis . La diferenciación en dos capas es clara recien al estadio 45.

- Epicondylocubitalis. Es un músculo profundo que en el adulto está originado en el epicóndilo lateral del húmero. Inserta en el borde dorsal de la porción radial del radio-ulna a lo largo de casi toda su longitud, mayormente a nivel distal.

- Epitrochleocubitalis. Es un músculo profundo que en el adulto presenta origen en el epicóndilo medial del húmero. Inserta en el borde dorsal de la porción ulnar del radio-ulna a lo largo de casi toda su longitud.

- Extensor carpi radialis. Es un músculo superficial que en el adulto presenta dos sitios de origen, mediante dos cabezas, la distal y la superior. La cabeza superior se origina en la cresta lateral, distalmente en el húmero. La cabeza distal lo hace en el epicóndilo lateral del húmero. Ambas corren separadas casi en toda la longitud del músculo y se unen distalmente cruzando el radio-ulna de medial a lateral y de proximal a distal, insertando en el área dorsal del carpiano distal III-V.

- Extensor carpi ulnaris. Se trata de un músculo superficial de la cara lateral del zeugopodio que en el adulto está ubicado entre los $\mathrm{mm}$. palmaris longus y extensor digitorum communis longus. Se origina en el epicóndilo lateral del húmero e inserta en la superficie externa del carpiano distal III- $\mathrm{V}$ y en la base del metacarpiano $\mathrm{V}$.

- Extensor digitorum communis longus. Es un músculo superficial que corre por el borde lateral del zeugopodio. En el adulto se origina en el epicóndilo lateral del húmero. Inserta por un lado en la aponeurosis dorsal de la mano, en la base de los músculos extensores de los dígitos IV y $\mathrm{V}$, y por otro mediante un tendón en el m. abductor brevis digiti V. 

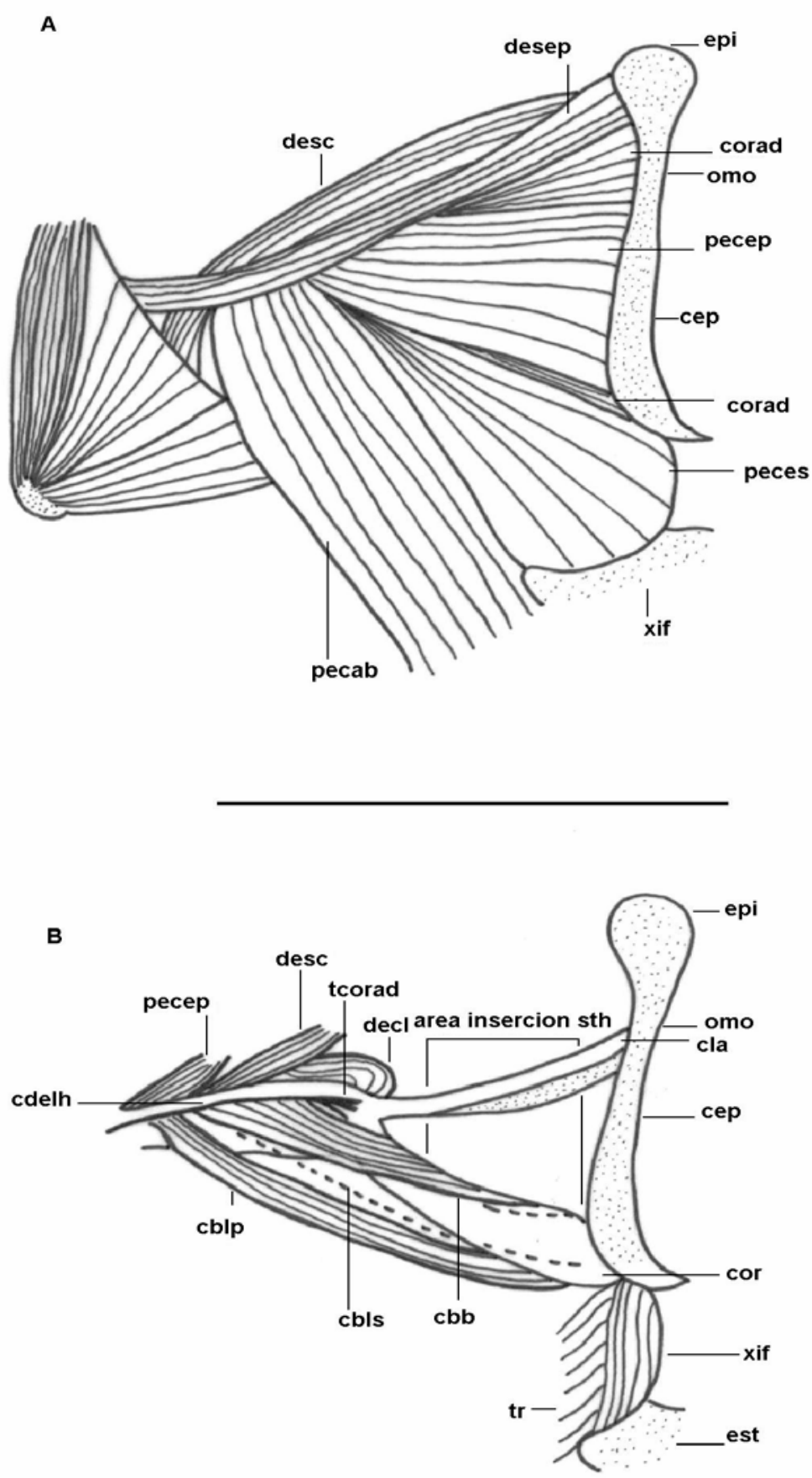

Figura 25. Hemicinturas pectorales de adultos de Batrachyla taeniata en vista ventral derecha mostrando la musculatura superficial (A) y profunda (B). Escala $5 \mathrm{~mm}$. Referencias: cbb: coracobraquialis brevis, cblp: coracobraquialis longus profundus, cbls: coracobraquialis longus superficialis, cdlh: cresta deltoidea del húmero (ventral), corad: coracoradialis, decl: deltoideus clavicularis, desc: deltoideus scapularis, desep: deltoideus epiesternalis, epi: epiesternón, pecab: pectoralis abdominalis, pecep: pectoralis epicoracoideus, peces: pectoralis sternalis, sth : sternohyoideus, tcorad: tendón del coracoradialis, tr: transversus. El resto de las referencias como en la figura 21. 


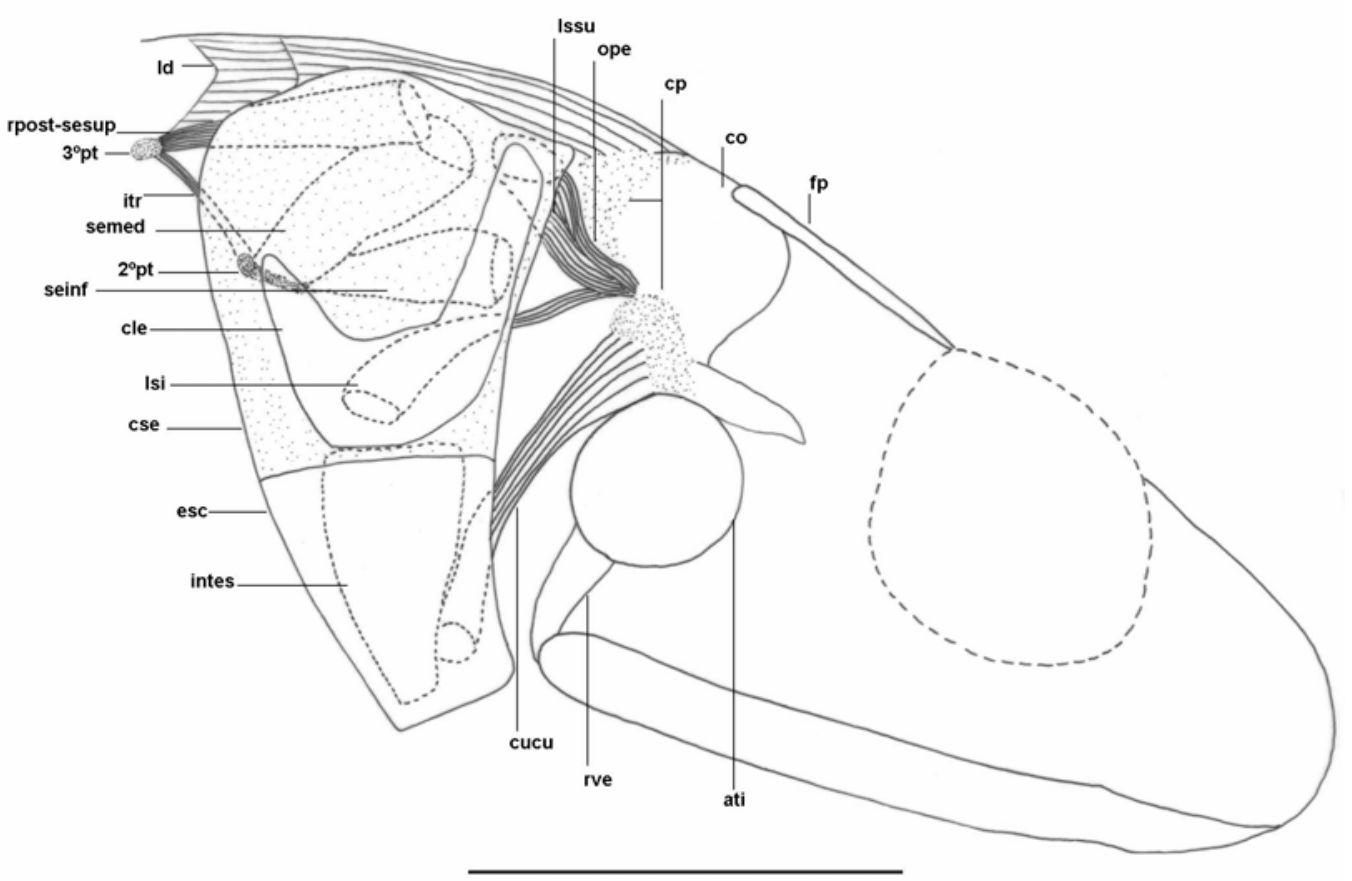

Figura 26. Vista lateral de la musculatura dorsal (medial) de la cintura escapular en vista lateral derecha del adulto de Batrachyla taeniata . Los músculos que insertan medialmente a la supraescápula y escápula se indican en parte por un trazado discontinuo. Escala $5 \mathrm{~mm}$. Referencias: ati: anillo timpánico, cle : cleitro, co: cápsula ótica, cp: cresta parótica, cse: cartílago supraescapular, cucu: cucularis, esc: escápula, fp: frontoparietal, intes: interscapularis, Isi: levator scapulae inferior, Issu: levator scapulae superior, itr. intertransversarius, Id: longissimus dorsi, ope: opercularis, pt procesos transversos $2^{\circ}$ y $3^{\circ}$, rpost -sesup: rhomboideus posterior-serratus superior, rve : rama ventral del escamoso, seinf: serratus inferior, semed: serratus medius. 
A
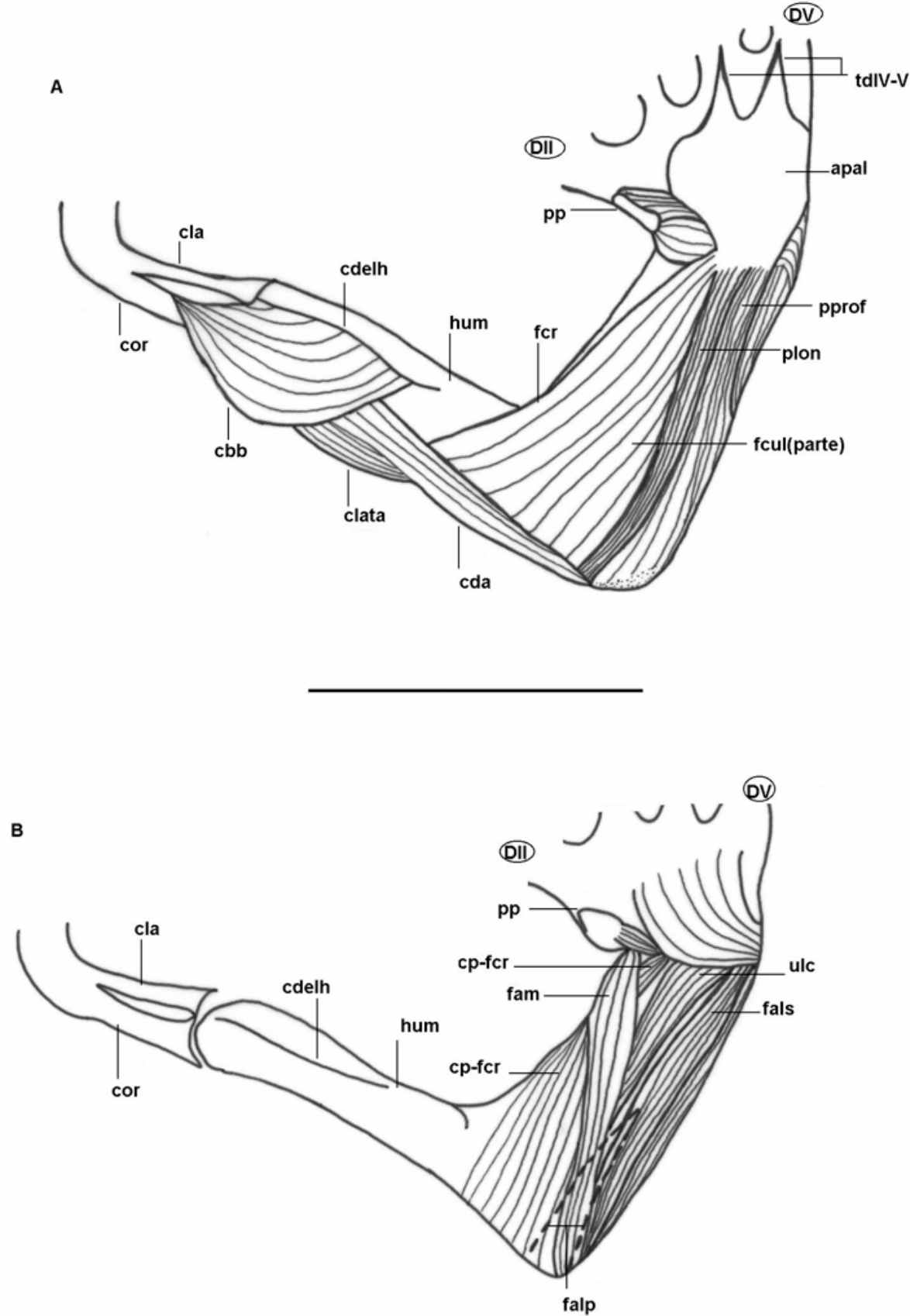

Figura 27. Vista ventral de la musculatura asociada al estilopodio y zeugopodio del miembro anterior en el adulto de Batrachyla taeniata. En (A) vista superficial y en (B) vista profunda. Escala $5 \mathrm{~mm}$. Referencias: apal: aponeurosis palmaris, cbb: coracobraquialis brevis, cda: cabezadorsal del anconeus, cdelhp: cresta deltoidea del húmero (ventral), cla: clavícula, clata: cabeza lateral del anconeus , cor: coracoides, cp-fcr: capa profunda del flexor carpi radialis, D II-V: digítos II al V, falp: flexor antebrachii lateralis profundus, fals: flexor antebrachii lateralis superficialis, fam : flexor antebrachi medialis, fcr: flexor carpi radialis, fcul: flexor carpi ulnaris, hum: húmero, plon: palmaris longus, pp: prepollex, pprof: palmaris profundus, td Iv-V: tendo digiti IV-V, ulc: ulnocarpalis. 


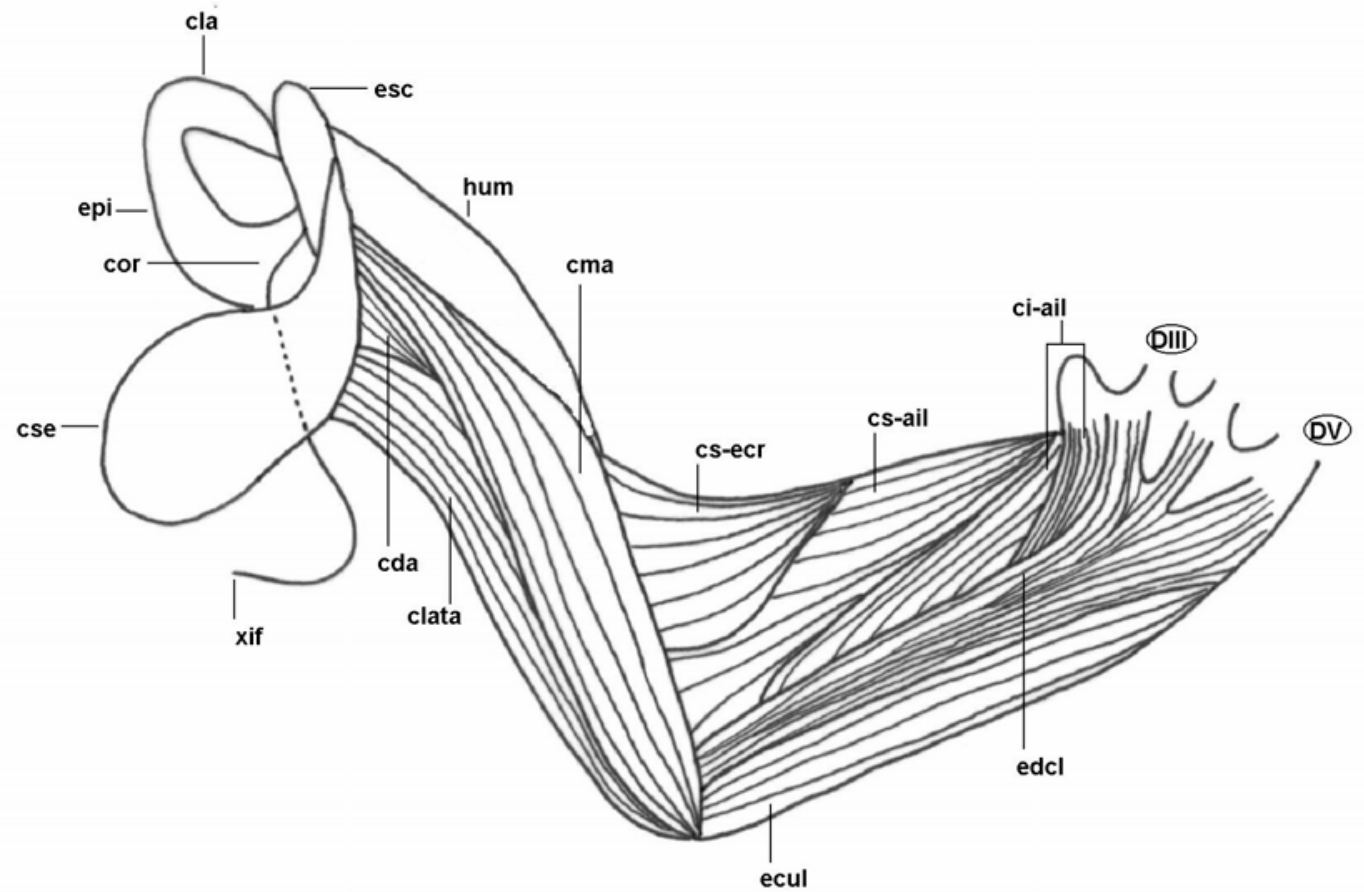

Figura 28. Vista dorsal de la musculatura asociada al estilopodio y zeugopodio del miembro anterior en el adulto de Batrachyla taeniata . Escala $5 \mathrm{~mm}$. Referencias: ci-ail: cabeza inferior (profunda) del abductor indicis longus, cma: cabeza medial del anconeus, cse: cartílago supraescapular, cs-ecr: cabeza superior del extensor carpi radialis, ecul: epicondilocubitalis, edcl: extensor digitorum communis longus, epi : epicoracoides, esc : escápula, xif : xifiesternón. El resto de las referencias como en la figura 26. 
III.7.3. Músculos asociados al autopodio (Figs. 27-35). Se consideraron en esta categoría aquellos músculos que recorren el autopodio independientemente de sí presentan inserción u origen en él. A continuación se exponen una breve reseña general del desarrollo larvario de este grupo de músculos y luego se desarrollan los rasgos especificos para cada músculo considerando su origen, inserción y relaciones topográficas con otros elementos para el estado adulto.

\section{Músculos ventrales.}

- Abductor pollicis. Se origina en el extremo distal de la ulna mediante un corto y ancho tendón. Inserta principalmente en la cara medio dorsal del segmento basal y primer elemento del prepollex, sin embargo unas pocas fibras insertan accesoriamente en la cara medio ventral del metacarpiano del dígito II.

- Abductor primus digiti V. Se origina a partir del extremo lateral de la aponeurosis palmaris en el margen lateral del carpiano distal III-V. Inserta lateralmente en la región proximal del metacarpiano $\mathrm{V}$.

- Abductor secundus digiti V. Se origina en la ulna y el ulnar e inserta en la región proximal y lateral del metacarpiano $\mathrm{V}$.

- Adductor pollicis. Se origina en la cara medial del carpiano distal III-V e inserta en la superficie lateroventral del segmento distal del prepollex.

- Adductor propius digiti V. Se origina en el carpiano distal III-V, al nivel del metacarpiano III. Inserta en la superficie medioventral del metacarpiano V.

- Aponeurosis palmaris. Es una capa gruesa que cubre la palma y avanza sobre la base de los dígitos II-V. Recibe las inserciones de los mm. palmaris longus y palmaris profundus (en la cara dorsal).

- Caput profundum. Es un músculo fusiforme originado mediante un corto tendón en el margen distal del carpiano distal III-V. Inserta mediante un fuerte tendón, el tendo superficialis digiti III, en la superficie ventral de la última falange del dígito III. A su vez, este músculo recibe un tendón desde el margen distal de la aponeurosis palmaris.

- Intercarpalis. Se origina en la cara medial del ulnar. Inserta en la superficie medio ventral proximal del carpiano distal III-V.

- Flexor indicis superficialis propius. Es el elemento más voluminoso del dígito II en una vista ventral. Se origina en el borde medial del carpiano distal III-V, e inserta en la cara ventral de la última falange mediante un largo tendón. 
- Flexor ossis metacarpi digiti III. Se origina mediante un ancho tendón en la superficie ventral del carpiano distal III-V. Inserta en la superficie ventrolateral del metacarpiano III.

- Flexor ossis metacarpi digiti IV. Se origina mediante un importante tendón en la cara distal lateral del carpiano distal III-V. Inserta ventrolateralmente en el metacarpiano IV.

- Flexor teres digiti III. Es un músculo angosto, que presenta origen en la superficie medioventral del metacarpiano III, dorsal al origen del m. transversus metacarpi I. Inserta mediante un tendón corto en la falange proximal.

- Flexor teres digiti IV. Se origina en la superficie ventral del metacarpiano IV, dorsalmente al origen del m. transversus metacarpi II. Inserta por un corto tendón en la superficie proximal de la falange proximal del dígito IV.

- Flexor teres digiti V. Se origina en la cara ventral del metacarpiano V. Inserta mediante un tendón angosto en la región proximal de la falange proximal del dígito $\mathrm{V}$.

- Flexor teres indicis. Es un músculo angosto que corre profundo y lateral al $\mathrm{m}$. flexor superficialis indicis propius. Se origina en el carpiano distal III-V e inserta vía un corto tendón en la superficie proximal de la falange proximal del dígito II.

- Interphalangealis digiti IV. Esta compuesto por tres haces de fibras, totalmente separados uno del otro, originados en las caras ventral, medial y lateral de la falange proximal del dígito IV. Cada uno inserta mediante un tendón en la superficie proximal de la segunda falange de ese dígito.

- Interphalangealis digiti $\mathbf{V}$. Se origina en la falange proximal del dígito $\mathrm{V}$ mediante 3 puntos de orígen separados (lateral, central y medial). Cada uno inserta en la segunda falange del dígito $\mathrm{V}$ mediante un tendón. El central tapa ligeramente al medial y es el mayor.

- Lumbricalis brevis digiti III. Se origina del margen distal del carpiano distal IIF $\mathrm{V}$ mediante un angosto tendón profundo al $\mathrm{m}$. caput profundum Es un músculo grueso que inserta mediante un importante tendón en la base de la falange proximal del dígito III.

- Lumbricalis brevis digiti IV. Esta compuesto por dos vientres completamente separados, el medial y el lateral, uno a cada lado del tendo superficialis digiti IV. Ambos se originan mediante tendones a partir del borde distal de la aponeurosis palmaris. Cada uno inserta mediante un corto tendón en la falange proximal del dígito IV. 
- Lumbricalis brevis digiti V. Presenta triple origen, mediante tres tendones en el carpiano distal III-V, el borde medial del tendo superficialis digiti $\mathrm{V}$, y el extremo distal y lateral de la aponeurosis palmaris. Cada uno de ellos inserta mediante cortos tendones proximalmente en la falange proximal del dígito $\mathrm{V}$.

- Lumbricalis brevis indicis. Es un músculo fusiforme que corre profundo y medial al $\mathrm{m}$. flexor indicis superficialis proprius. Se origina mediante un breve tendón en la cara medial del carpiano distal III-V. Inserta en la zona proximal, cara ventral, de la falange proximal mediante un corto tendón.

- Lumbricalis longus digiti IV. Se origina en el margen distal de la aponeurosis palmaris. Esta asociado al tendo superficialis digiti IV y se continua mediante dicho tendón hasta insertar en la falange distal del dígito IV.

- Lumbricalis longus digiti V. Se origina en la aponeurosis palmaris lateralmente al punto en que se forma el tendo superficialis digiti $\mathrm{V}$ y a partir del área dorsal de dicho tendón. Se continua anteriormente con el tendo superficialis digiti $\mathrm{V}$ hasta su inserción en la ultima falange del dígito $\mathrm{V}$.

- Opponens digiti V. Se origina en el carpiano distal III-V e inserta en la articulación entre el metacarpiano y la falange proximal del dígito $\mathrm{V}$.

- Opponens indicis. Es el más profundo del dígito II. Se origina de la superficie medial del carpiano distal III-V e inserta medioventralmente en el metacarpiano II.

- Tendines superficiales. El tendo superficialis digiti II es el tendón mediante el cual inserta en la falange distal el $\mathrm{m}$. flexor indicis superficialis propius. El tendo superficialis digiti III se forma a partir del extremo distal del m. caput profundum. El tendo superficialis digiti IV se forma a partir de la aponeurosis palmaris e inserta en la última falange del dígito IV. El tendo superficialis digiti $\checkmark$ se forma a partir de la aponeurosis palmaris e inserta en la última falange del dígito $\mathrm{V}$.

- Transversus metacarpi I. Se origina en la región proximal, cara medial, del metacarpiano III. Inserta en todo el margen lateral del metacarpiano II.

- Transversus metacarpi II. Se origina en la región proximal, cara medioventral, del metacarpiano IV. Inserta en los dos tercios distales del margen lateral del metacarpiano III.

- Transversus metacarpi III. Se origina en la región proximal, cara medial, del metacarpiano V. Inserta en el margen lateroventral del metacarpiano IV. 


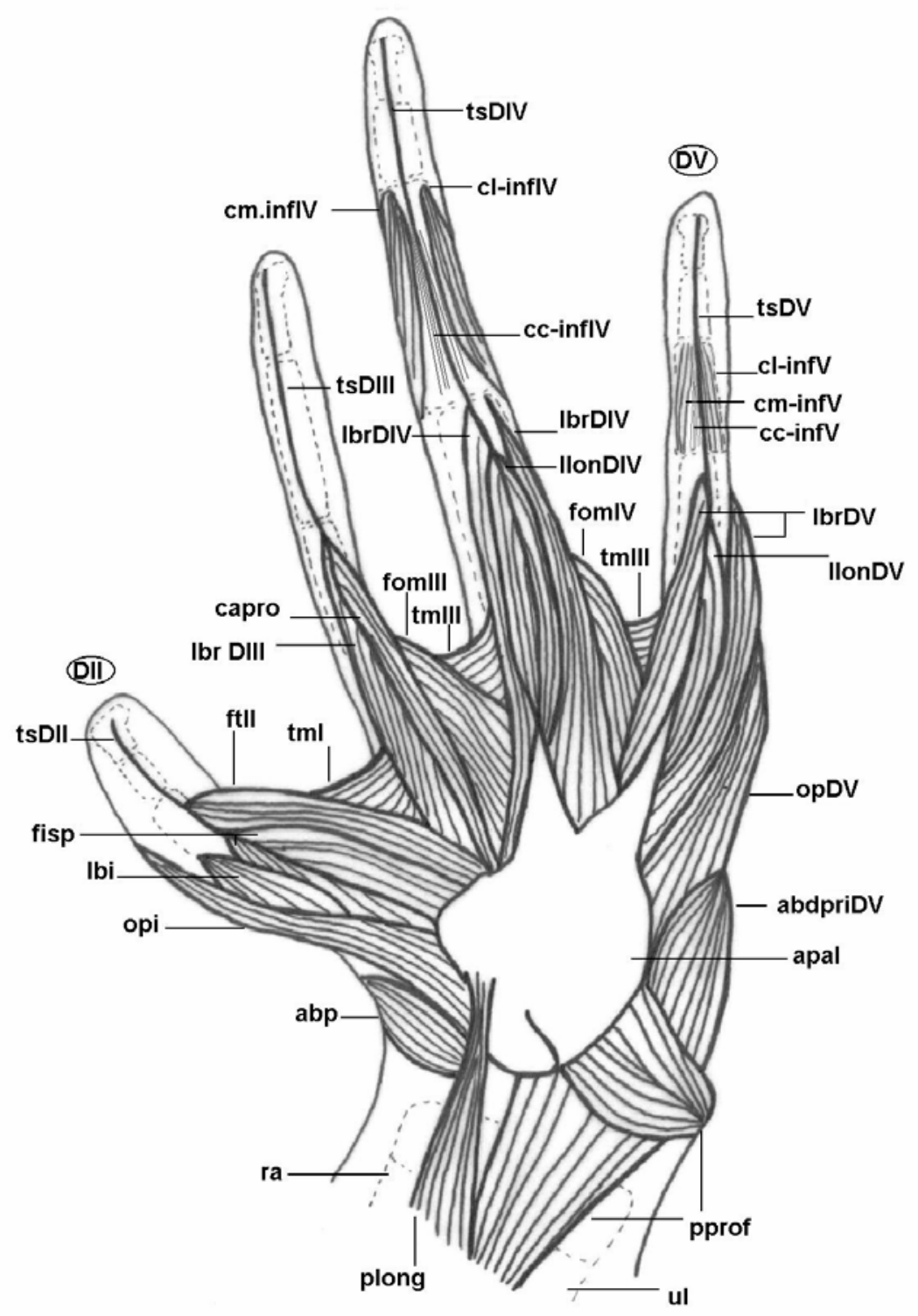

Figura 29. Vista ventral de la musculatura superficial asociada al autopodio del miembro anterior en el adulto de Batrachyla taeniata. Escala 5mm. Referencias: abdpri: abductor primus, abp: abductor pollicis, apal: aponeurosis palmaris, capro: caput profundus, cc-inf: cabeza cental del interphalangealis, cl-inf: cabeza lateral del interphalangealis, cm-inf: cabeza medial del interphalangealis, D II-V: digítos II al V, fisp: flexor indicis superficialis propius, fom : flexor ossis metacarpi, ft: flexor teres, lbr: lumbricalis brevis, Ibi : lumbricalis brevis indicis, Iblon: lumbricalis longus, op: opponens, opi : opponens indicis, plong: palmaris longus, pprof : palmaris profundus, ra: radio, tm: transversus metacarpi, ts: tendo superficialis, ul: ulna. 


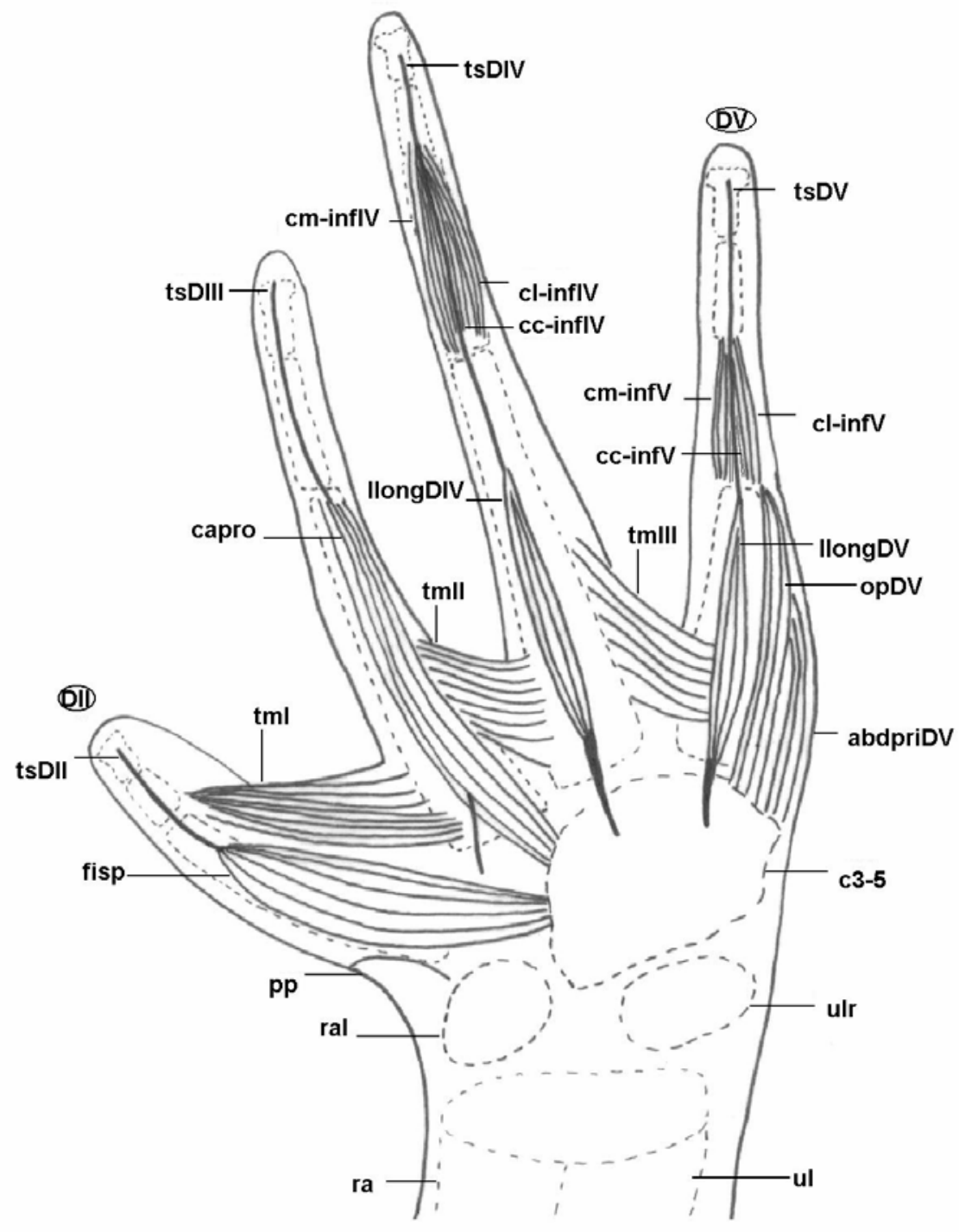

Figur a 30. Vista ventral de la segunda capa (capa media superficial) de musculatura asociada al autopodio del miembro anterior en el adulto de Batrachyla taeniata. Escala $5 \mathrm{~mm}$. Referencias: c 3-5: carpiano III-V5, pp: prepollex, ral: radial, ulr: ulnar. El resto de las referencias como en la figura 28. 


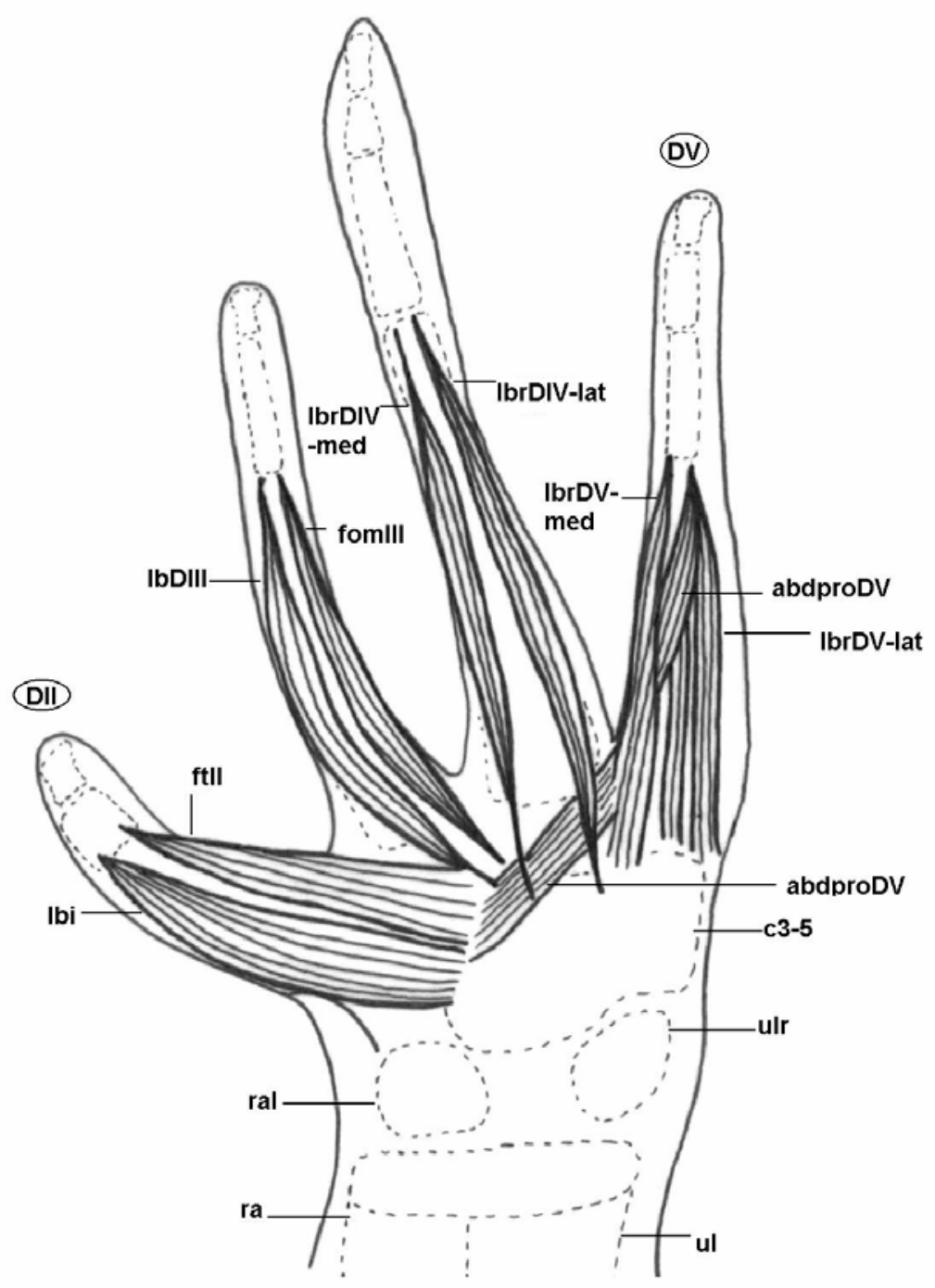

Figura 31. Vista ventral de la tercer capa (capa media profunda) de musculatura asociada al autopodio del miembro anterior en el adulto de Batrachyla taeniata. Escala $5 \mathrm{~mm}$. Referencias: abdpro: abductor propius, Ibr - lat: cabeza lateral del/umbricalis brevis, Ibr - med: cabeza medial del /umbricalis brevis. El resto de las referencias como en las figuras 28 y 29. 


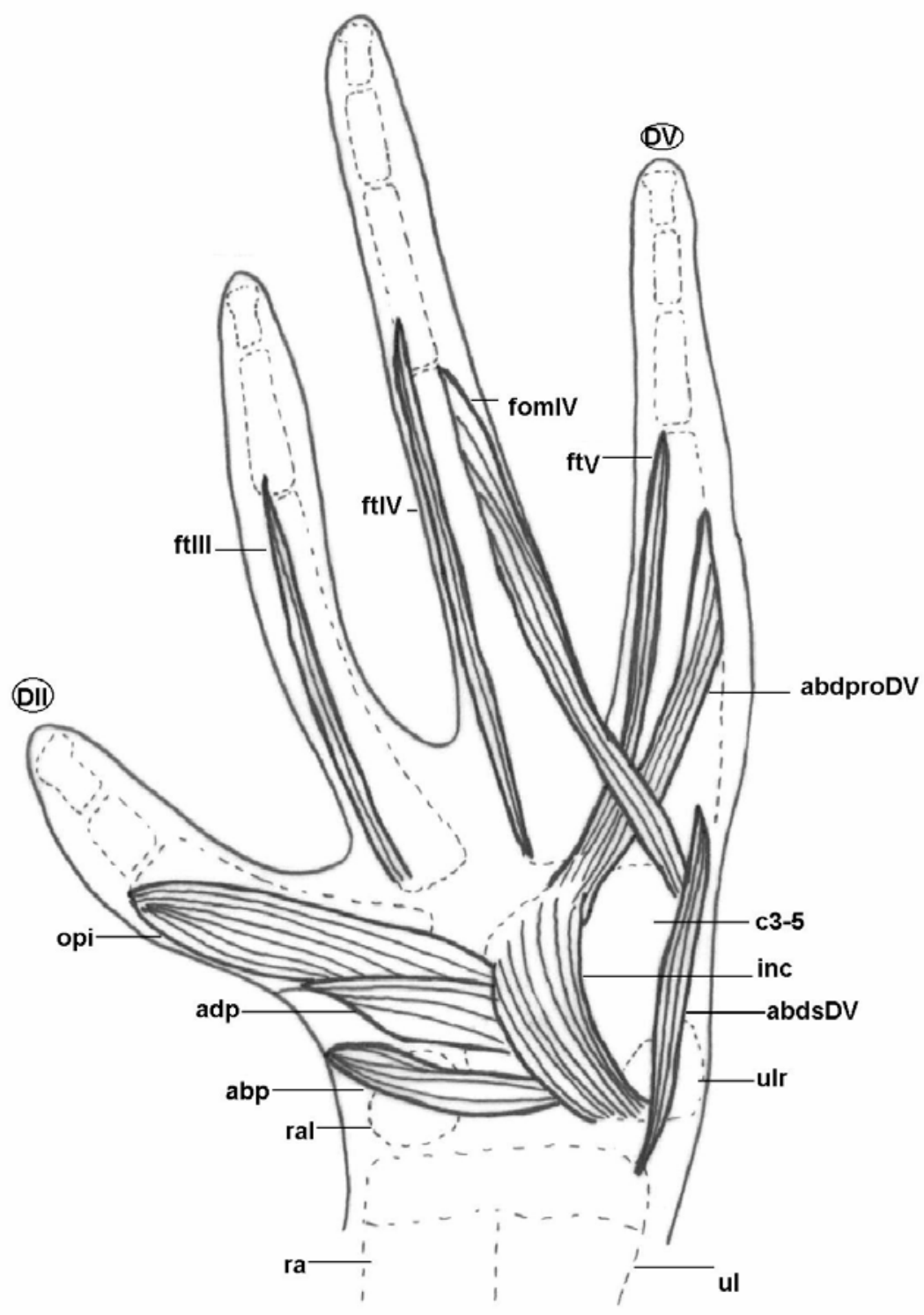

Figura 32. Vista ventral de la cuarta capa (capa profunda) de musculatura asociada al autopodi o del miembro anterior del adulto de Batrachyla taeniata. Escala $5 \mathrm{~mm}$. Referencias: abds : abductor secundus, adp: adductor pollicis. El resto de las referencias como en las figuras 28,29 y 30. 


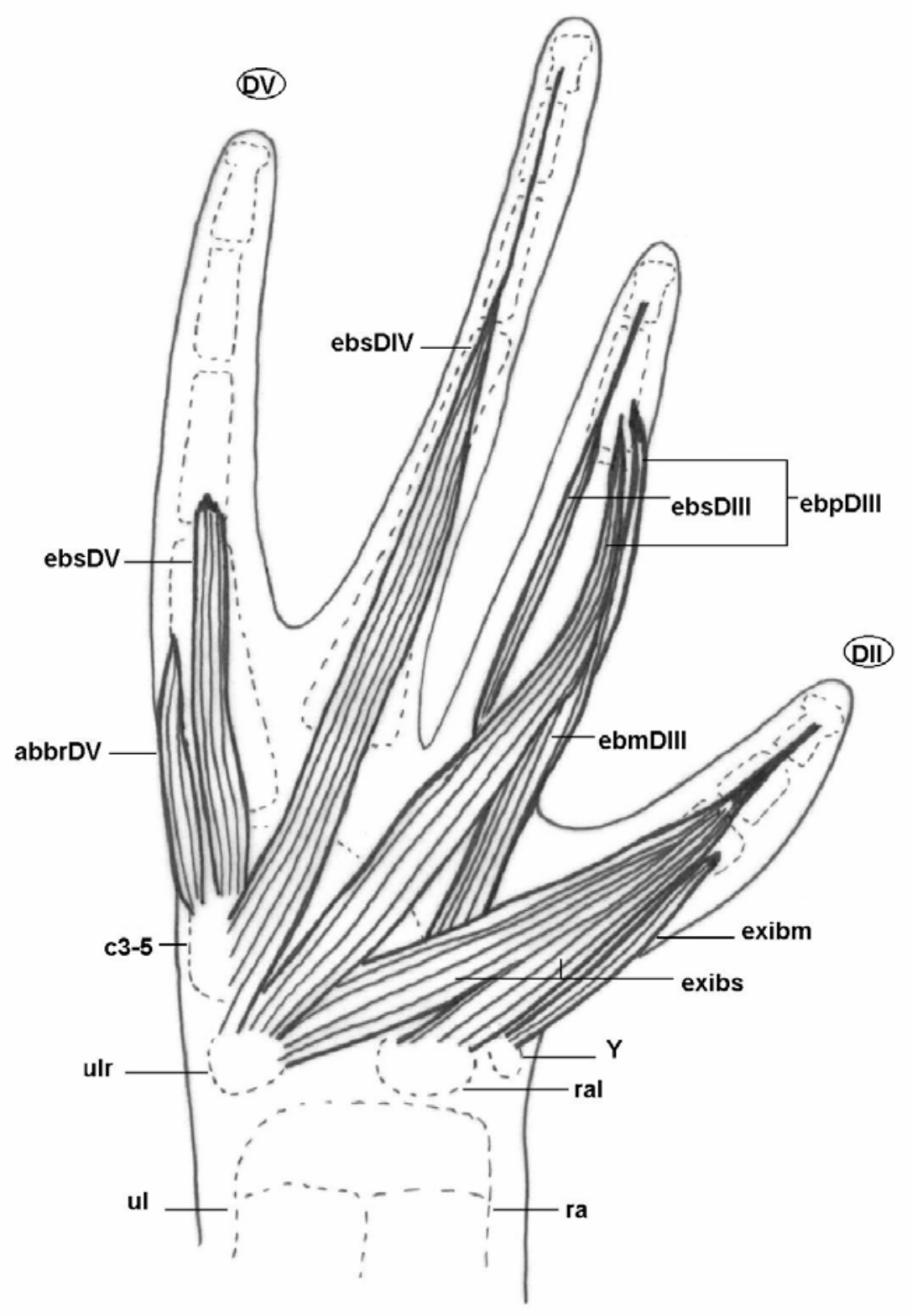

Figura 33. Vista dorsal de la musculatura superficial asociada al autopodio del miembro anterior del adulto de Batrachyla taeniata . Escala $5 \mathrm{~mm}$. Referencias: abbr: abductor brevis, ebm : extensor brevis medius, ebp: extensor brevis profundus, ebs : extensor brevis superficialis, exibm: extensor indicis brevis medius, exibs: extensor indicis brevis superficialis, Y: elemento Y, D II-V: digítos II al V. El resto de las referencias como en la figura 29. 


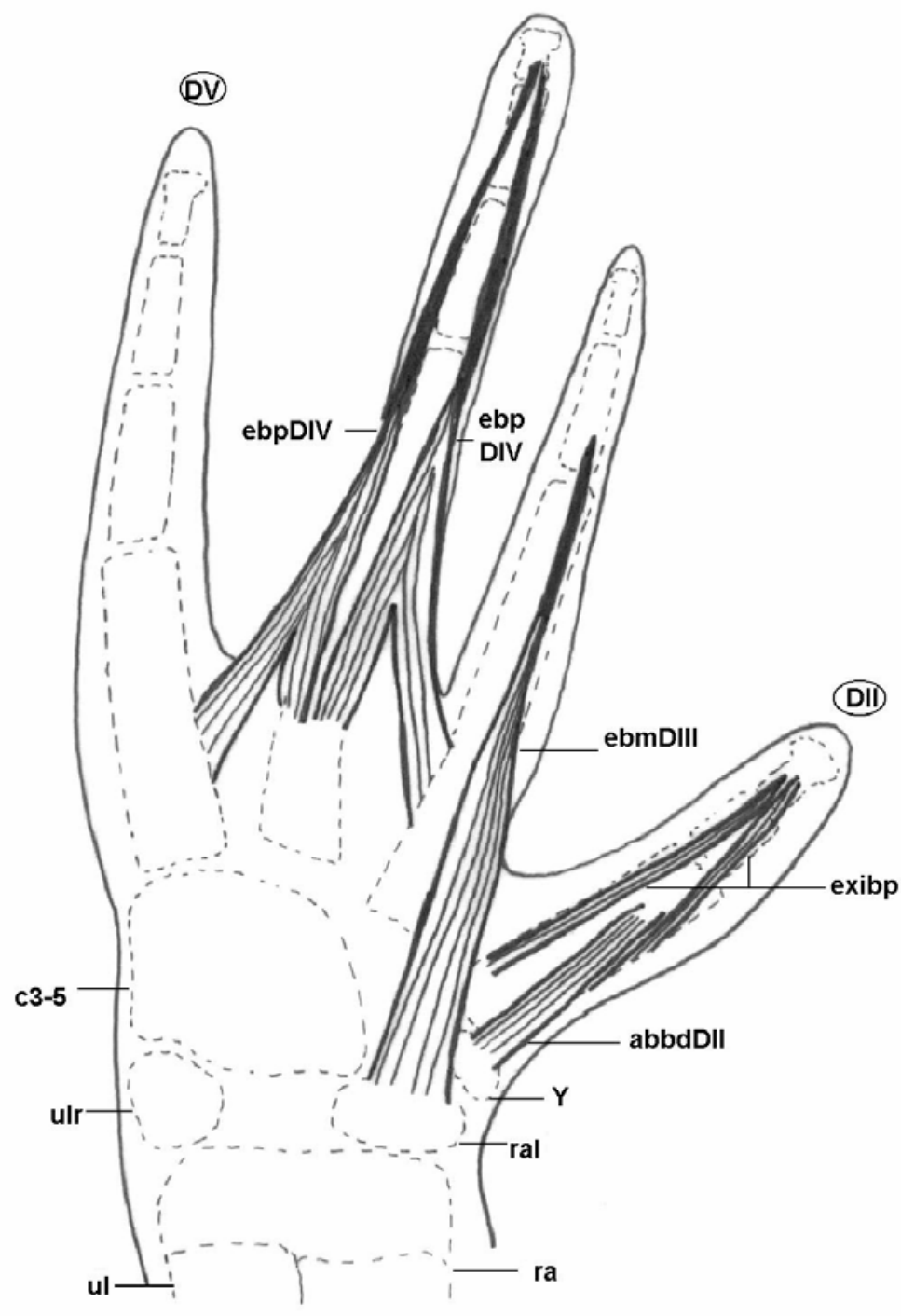

Figura 34. Vista dorsal de la capa media de la musculatura asociada al autopodio del miembro anterior del adulto de Batrachyla taeniata. Escala $5 \mathrm{~mm}$. Referencias: abbd: abductor indicis brevis dorsalis, exibp: extensor indicis brevis profundi. El resto de las referencias como en las figuras 29 y 32 . 


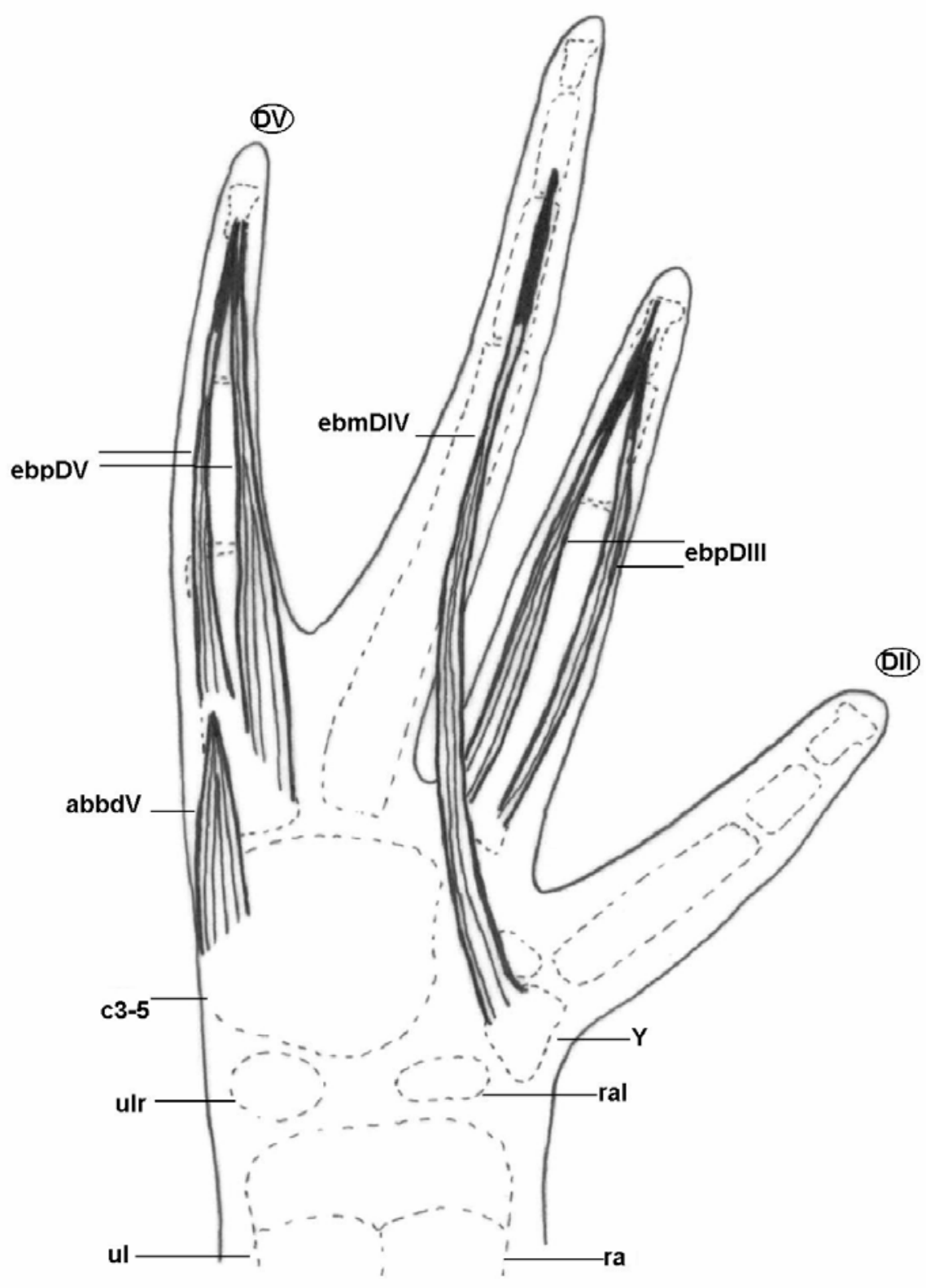

Figura 35. Vista dorsal de la musculatura profunda asociada al autopodio del miembro anterior del adulto de Batrachyla taeniata. Escala $5 \mathrm{~mm}$. Referencias como en las figuras 29, 32 y 33. 


\section{Músculos dorsales.}

- Abductor brevis digiti $\boldsymbol{V}$. Se origina en el carpiano III-V. Inserta lateralmente al metacarpiano $\mathrm{V}$ mediante un tendón.

- Abductor indicis brevis dorsalis. Se origina en el elemento " $Y$ " e inserta en el metacarpiano II.

- Abductor indicis longus. Presenta doble origen, por un lado en el epicóndilo lateral del húmero, por otro en la mitad distal del radio-ulna. Inserta en el m. extensor indicis brevis medius mediante un tendón.

- Extensores breves distales. Ausentes.

- Extensor brevis medius digiti III. Se origina en el elemento "Y" y el radial. Inserta mediante un ancho tendón en la segunda falange del dígito III. Algunas de sus fibras pueden insertar en el tendón del m. extensor brevis superficialis digiti III. Corre medial al m. extensor brevis superficialis digiti III.

- Extensor brevis medius digiti IV. Se origina en el elemento "Y", profundo al m. extensor brevis medius digiti II. Inserta mediante un importante tendón entre las dos primeras falanges del dígito IV. Corre adyacente al lado medial del $\mathrm{m}$. extensor brevis superficialis digiti IV.

- Extensores breves profundi digiti III. Son dos haces de fibras que se originan en el metacarpiano III e insertan mediante dos tendones en el dorso de la ultima falange de ese dígito.

- Extensores breves profundi digiti IV. Son cuatro haces. Del lado medial hay dos haces, uno con origen en la superficie dorsomedial del metacarpiano IV, y otro en la superficie dorsolateral del metacarpo III. Ambos convergen distalmente en un tendón que pasa dorsolateralmente por el dígito IV e inserta en la falange distal de dicho dígito.

Del lado lateral están los dos haces restantes, uno a partir de la cara dorsolateral del metacarpiano IV, y otro de la cara dorsomedial del metacarpiano V. Ambos convergen en un largo tendón que recorre el dígito IV dorsolateralmente e inserta en el dorso de la falange distal de dicho dígito.

- Extensores breves profundi digiti V. Son dos elementos originados en el dorso del metacarpiano V. Insertan mediante dos largos tendones a cada lado de la falange distal del dígito $V$. Puede haber un tercer haz, pequeño, originado en la superficie dorsolateral del metacarpiano IV e inserto en el tendón medial. 
- Extensor brevis superficialis digiti III. Se origina en el ulnar y corre en sentido medio distal hacia su inserción, mediante un ancho tendón, en el dorso de la falange dístal del dígito III.

- Extensor brevis superficialis digiti IV. Presenta dos orígenes, uno en el ulnar y otro en el carpiano distal III-V. Ambos convergen en un ancho tendón que inserta en el dorso de la falange dístal del dígito IV.

- Extensor brevis superficialis digiti V. Se origina del dorso del carpiano III-V. Inserta proximalmente en el dorso de la falange proximal del dígito $\mathrm{V}$.

- Extensor indicis brevis medius. No se distingue del abductor indicis brevis superficialis.

- Extensores indicis brevis profundi. Son dos elementos originados en el dorso del metacarpiano II. Insertan en la falange distal de ese dígito mediante sendos largos tendones.

- Extensor indicis brevis superficialis. Presenta doble origen, en el ulnar y radial. El haz que se origina en el radial podría representar al $\mathrm{m}$. extensor indicis brevis medius de Andersen (1978) dado que este último no es distinguible del $\mathrm{m}$. abductor indicis brevis superficialis. Insertan mediante un tendón común en el dorso de la falange dístal del dígito II. 


\section{III.8. Desarrollo del esqueleto apendicular posterior en Batrachyla taeniata (Figs.} 36-40).

Las secuencias de condrificación y de osificación del esqueleto apendicular posterior de Batrachyla taeniata se muestran en las tablas 2 y 3 respectivamente.

III.8.1. Cintura pélvica (Figs 36-38). En el desarrollo, el esbozo cartilaginoso de la cintura aparece estadio 34. En algunos ejemplares (estadios 41-42) ambas hemicinturas contactan en la linea media a nivel de la cápsula acetabular, siendo más nitido el contacto al estadio 43. Los ileones se disponen oblicuamente al eje axial, con su extremo libre anterior ubicado dorsal respecto de la cápsula acetabular. En el comienzo de su desarrollo, el extremo anterior de los ileones no alcanza el nivel posterior de la primer vertebra postsacra, mientras que hacia los estadios $41-42$ ya se ubica entre ésta y la vertebra sacra.

El ileon osifica autostósicamente en algunos ejemplares al estadio 35, a partir de su tercio medio, desde donde procede hacia anterior y posterior. Al estadio 43 ya se encuentra casí totalmente osificado. El isquion osifica al estadio 43 a partir de un centro ubicado dorsolateralmente en la cápsula acetabular.

En el adulto, acetábulo y púbis estan ligeramente calcificados. Isquion formando las regiones posterodorsal, posterior y posteroventral de la cápsula acetabular, donde se proyecta dorsalmente a nivel dorsal posterior de la misma. Púbis calcificado, ubicado entre el extremo ventral y posterior del ileon y el extremo anterior y ventral del isquion. lleon cerrando anteriormente la cápsula acetabular y proyectado proximalmente hasta solaparse con su extremo anterior cartilaginoso con la superficie ventral de los procesos transversos sacros. En posición dorsal a cada rama del ileon existe una cresta para inserción muscular, no muy marcada, que ocupa aproximadamente la mitad proximal del hueso. Entre la cresta dorsal y la cavidad acetabular existe una prominencia ilíaca dorsal, corta y redondeada.

III.8.2. Estilopodio (Figs. 39-40). En el desarrollo, el fémur aparece como esbozo cartilaginoso al estadio 31, prácticamente en simultáneo con el zeugopodio. Su osificación autostosica comienza partir de un centro de la diáfisis que procede hacia las epífisis (estadio 35). La osificación total se alcanza al estadio 43. La cresta lateral se diferencia postmetamorficamente.

En el adulto, el fémur del adulto presenta una cresta lateral para inserción muscular y dos epífisis articulares, una para la cavidad acetabular y otra para el zeugopodio. 
Observando al fémur en vista dorsal, estando éste articulado a la cintura, la cresta lateral se ubica en la cara posterior, en su tercio proximal, apenas separada de la epífisis articular. Los cóndilos laterales no son prominentes.

III.8.3. Zeugopodio (Figs. 39-40). En el desarrollo, radio y ulna aparecen, al estadio 31 , como esbozos cartilaginosos totalmente separados. Al estadio 35 comienza su osificación autostosica a partir de un centro ubicado en cada diáfisis. Al estadio $37 \mathrm{se}$ fusionan a nivel de las epífisis. La osificación procede de la diáfisis hacia las epífisis. La osificación total se alcanza al estadio 43. La fusión de radio y ulna comienza luego del inicio de la osificación mediante dos puntos de contacto proximal y distal al centro de osificación diafisiario. Al estadio 43, ambos elementos se hallan practicamente fusionados, pudiendo aun estar ligeramente separados a nivel medio.

En el adulto, tibia y fíbula se encuentran fusionados en la linea media a lo largo de toda su longitud. A pesar de estar fusionados es posible distinguir cada elemento y se reconoce que ambos son subiguales en tamaño y longitud. La fusión media de ambos elementos deja un area acanalada que ocupa el tercio distal y el tercio proximal, tanto en vista dorsal como ventral, aunque la fusión es casí imperceptible a nivel del tercio medio.

Proximalmente, ambas epífisis de la tibia-fíbula forman una superficie articular, aproximadamente plana, formada equitativamente por la tibia y la fíbula, con la cual el zeugopodio articula con la epífisis distal del fémur. Distalmente, la tibia presenta una prominencia que articula con una cavidad proximal del tibial, mientras que el extremo distal de la fíbula presenta una cavidad que articula con una prominencia proximal del fibular.

\section{III.8.4. Autopodio (Figs. 39-40).}

Basipodio. El tibial y fibular aparecen como esbozos cartilaginosos separados, alargados proximodistalmente al estadio 35 y rapidamente comienzan su osificación en algunos especimenes, al estadio 36 , del mismo modo que lo hacen los restantes huesos largos del miembro. La fusión a nivel de las epífisis es evidente al estadio 37.

Al estadio 38 son evidentes los 2 elementos tarsianos que al fusionarse (estadios 41-42) conformaran el tarsiano distal II-III. También al estadio 38 se reconocen el tarsiano distal I y el elemento Y. Los tarsianos osifican postmetamorficamente.

En el adulto, los elementos del basipodio se hallan totalmente osificados. Los elementos proximales, el tibial y fibular, son alargados, no fusionados en la 
linea media, pero fusionados en ambas epífisis. Tibial y fibular son subiguales y su longitud corresponde aproximadamente a la mitad de la del zeugopodio. El extremo distal común del tibial y fibular articula a nivel del tibial con la cara proximal del elemento $\mathrm{Y}$, y las respectivas de los tarsianos distales I y IFIII. EI extremo distal común del tibial y fibular articula a nivel del radial con los extremos proximales de los metatarsianos IV y V, aunque separado por un amplio espacio.

El elemento $Y$ representa la serie de tarsianos centrales y además de articular con el tibial, articula medio distalmente con el segmento basal del prehallux, distalmente con la base del metatarsiano I, y medio lateralmente con la cara medial del tarsiano distal I.

El tarsiano distal I es un elemento esférico que articula medio proximalmente con el elemento $\mathrm{Y}$, medio distalmente con el metatarsiano I, distalmente con el metatarsiano II, y lateralmente con el tarsiano distal If III.

El tarsiano distal IF III es un elemento rectangular, ubicado en las bases de los metatarsianos II (porción más medial) y III (toda la base).

Metapodio y acropodio. Al estadio 34 ya es evidente el arco digital con el esbozo de los dígitos, pero los elementos de los mismos aun no son distinguibles como núcleos cartilaginosos. En algunos ejemplares al estadio 35, se observa el inicio de la segmentacion dentro de los esbozos de cada digito, donde se reconocen tres esbozos (metatarsiano y falanges I y II) en el dígito IV, no siendo distuinguibles los de los otros digitos.

La condrificación y osificación de los elementos de los dígitos ocurre en sentido proximal distal dentro de cada dígito, comenzando por los metatarsianos y rematando en la última serie de falanges. Sin embargo, los dígitos que mas rapido desarrollan sus elementos son los dígidos más largos, en esta secuencia: IV-V-IIIIII.

La osificación autostosica de las falanges y metatarsianos comienza por las diáfisis y procede hacia las epífisis, alcanzando a estar practicamente totalmente osificadas al estadio 44. Desde el inicio de su condrificación, las falanges de la última serie muestran forma triangular, pero rapidamente alcanzan la forma de $\mathrm{T}$.

En el adulto el metapodio esta compuesto por cinco metatarsianos correspondientes a los digitos $\mathrm{HV}$. El metatarsiano I articula con el segmento basal del prehallux, con el elemento $\mathrm{Y}$ y con el tarsianos distal I. 
metatarsiano II articula con el tarsiano distal I y con la porción medial del tarsiano distal IF III. El metatarsiano III articula con el tarsiano distal II-III y los restantes metatarsianos articulan con el extremo del fibular (metatarsianos IV y V). La superficie articular proximal de los cinco metatarsianos es aproximadamente plana. En cambio las superficies articulares distales de los metatarsiano son ligeramente convexas y articulan con las respectivas cavidades articulares proximales de la primer serie de falanges. El metatarsiano I presenta un tubérculo óseo en su cara medial. En los restantes metatarsianos no hay tuberculos óseos ni carillas de articulacion intermetatarsianas en ningun metatarsiano. Las falanges proximales presentan cavidades proximales y saliencias distales para articulacion. En cambio, las carillas distales de las falanges de la serie media y la superficie proximal de las respectivas falanges distales se relacionan mediante superficies articulares planas. La serie de falanges distales remata libremente en forma de $\mathrm{T}$.

La formula de falanges es 2-2-3-4-3. No existen elementos intercalares, ni óseos ni cartilaginosos, entre las falanges.

- Prehallux. Al estadio 38 aperece el segmento basal del prehallux, mientras que el segmento distal es el último elemento del autopodio en aparecer (estadio 43).

El prehallux del adulto esta compuesto por 3 segmentos, el basal y dos distales. El segmento basal es irregularmente redondeado, igual de largo que ancho, esta totalmente osificado y articula proximalmente con el elemento $\mathrm{Y}$ y distalmente con el metatarsiano I. El primer segmento distal es alargado, curvo medialmente, más largo que ancho, osificado solo en la base, siendo su mayor superficie cartilaginosa. Las carillas articulares de ambos segmentos son aproximadamente planas. A nivel distal del primer segmento distal existe un segundo segmento dístal, cartilaginoso y pequeño, de forma ligeramente triangular. 
A

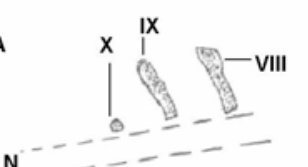

N

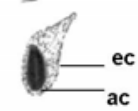

B

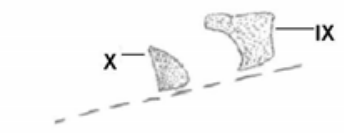

$\mathbf{N}$

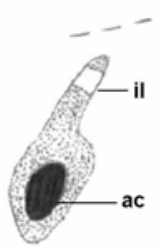

C

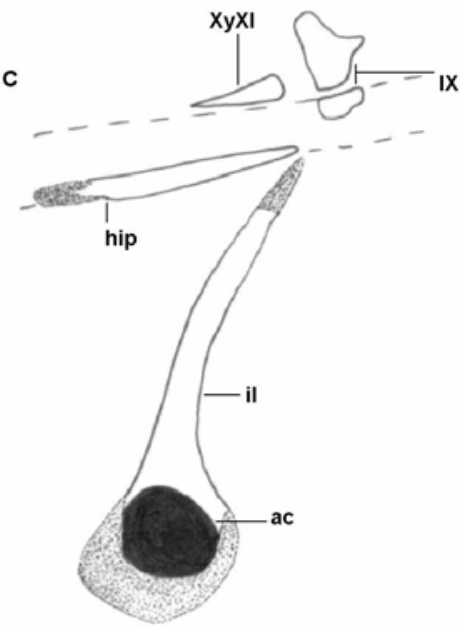

西

Figura 36. Vista lateral de la región posterior del esqueleto axial postcraneano y de la cintura pélvica a diferentes estadios de Gosner (1960) de Batrachyla taeniata Estadios 35 (A), 37 (B), 42 (C), 46 (D) y adulto (E). El área oscura representa el acetábulo. El punteado es cartílago y el área sin puntear es hueso. Escala $1 \mathrm{~mm}$. Referencias: VIII: presacra VIII, IX: vertébra sacra, X: primer postsacra, XI: segunda postsacra, ac: acetábulo, cpub: cartílago púbico, e c: esbozo cartilaginoso, hip: hipocordo, il: ileon, isq: isquion, $\mathbf{n}$ : notocorda, uro: urostilo. 
A

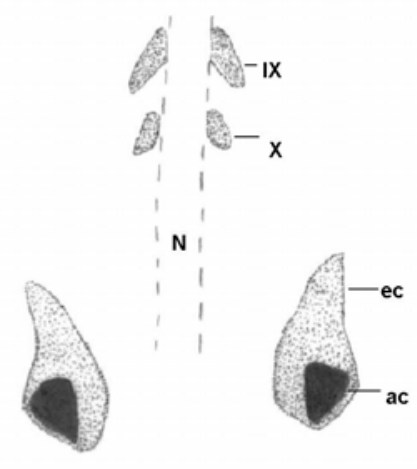

B

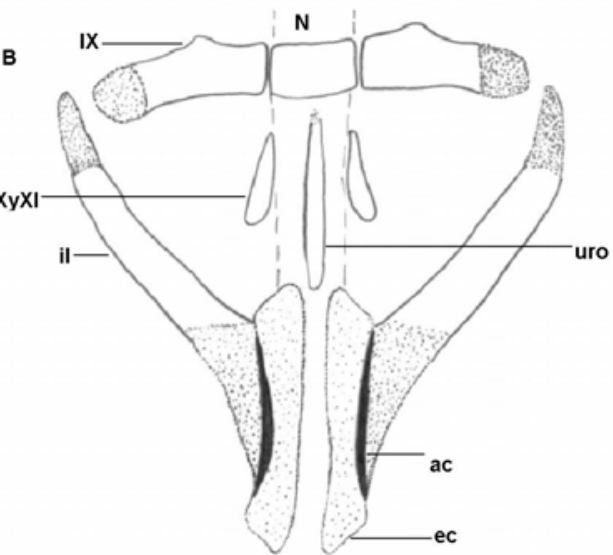

c
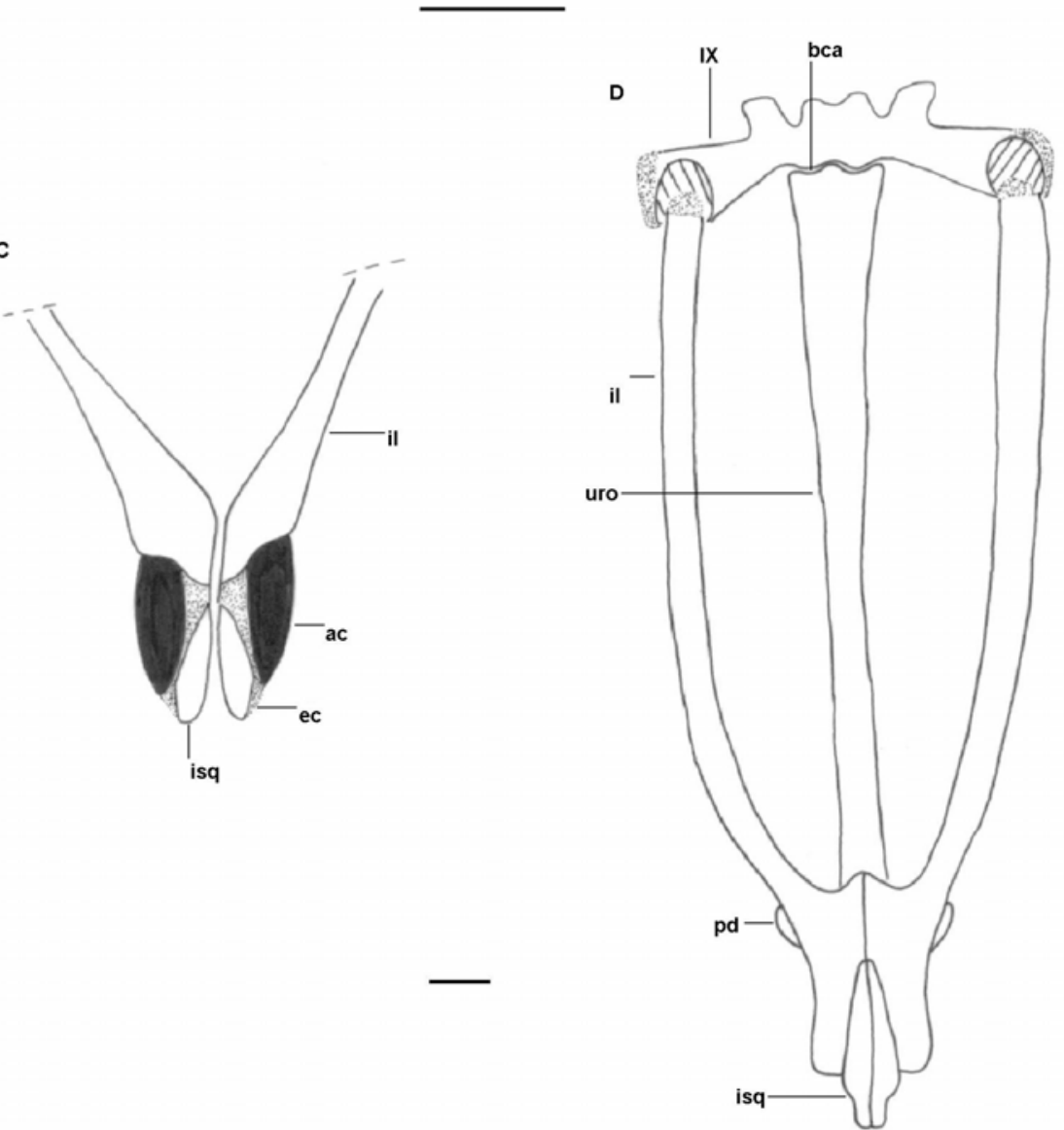

Figura 37. Vista ventral de la región posterior del esqueleto axial postcraneano y de la cintura pélvica a diferentes estadios de Gosner (1960) de Batrachyla taeniata Estadios 36 (A), 42 (B), 43 (C) y adulto (D). El área oscura representa el acetábulo. El punteado es cartílago y el área sin puntear es hueso. El área rayada indica la zona de contacto entre ileon y proceso transverso sacro. Escala $1 \mathrm{~mm}$. Referencias: bca: articulación bicondilar, pd: prominencia dorsal. El resto de las referencias como en la figura 35 . 


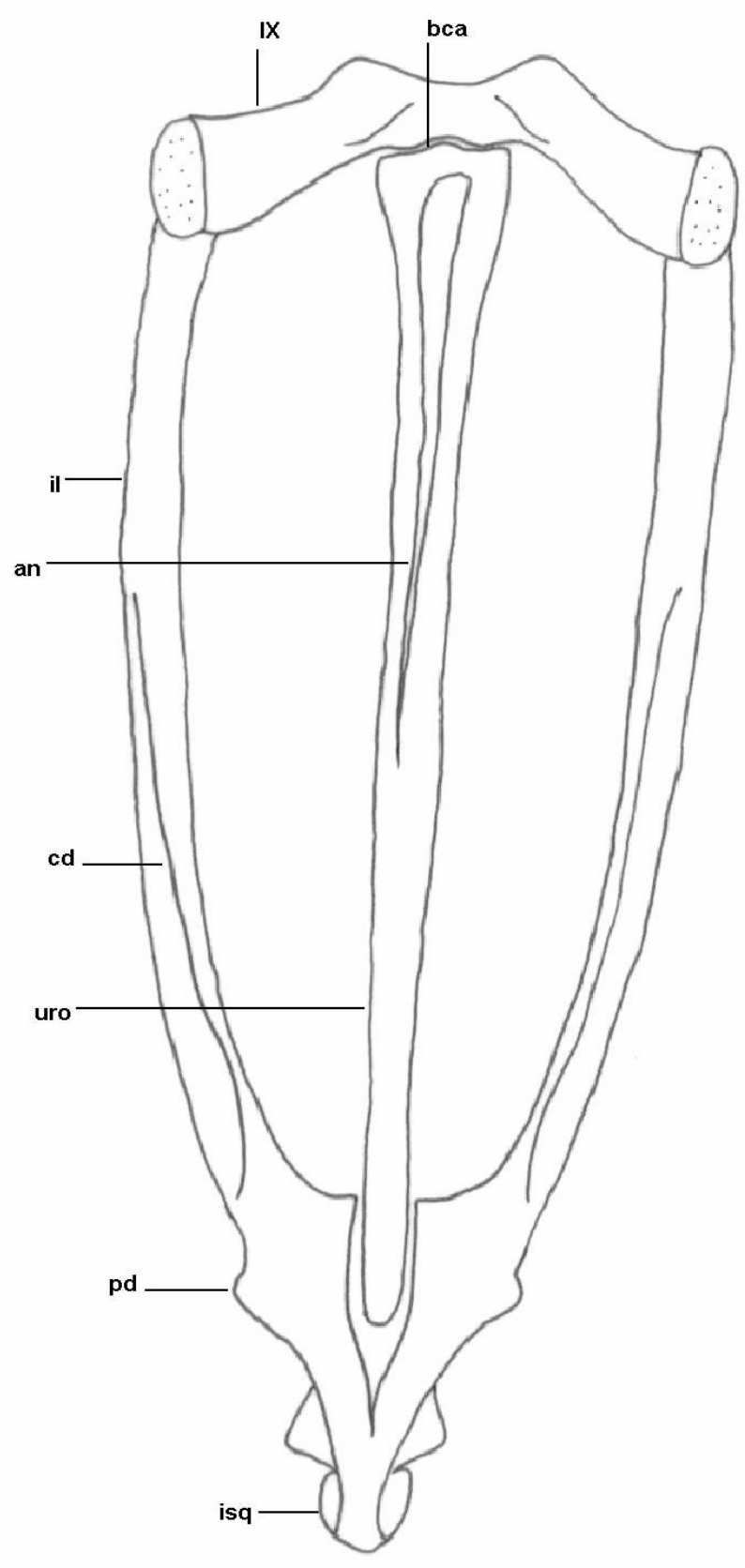

Figura 38. Vista dorsal de la región sacra y de la cintura pélvica en el adulto de Batrachyla taeniata. El punteado es cartílago y el área sin puntear es hueso. Escala $5 \mathrm{~mm}$. Referencias: an: arcos neurales postsacros, cd: cresta dorsal del ileon. El resto de las referencias como en las figuras 35 y 36. 


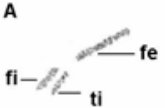

B

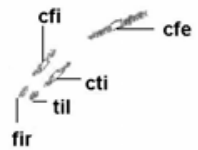

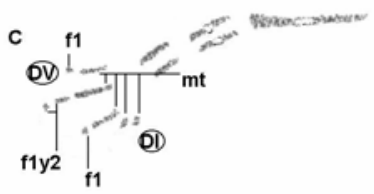
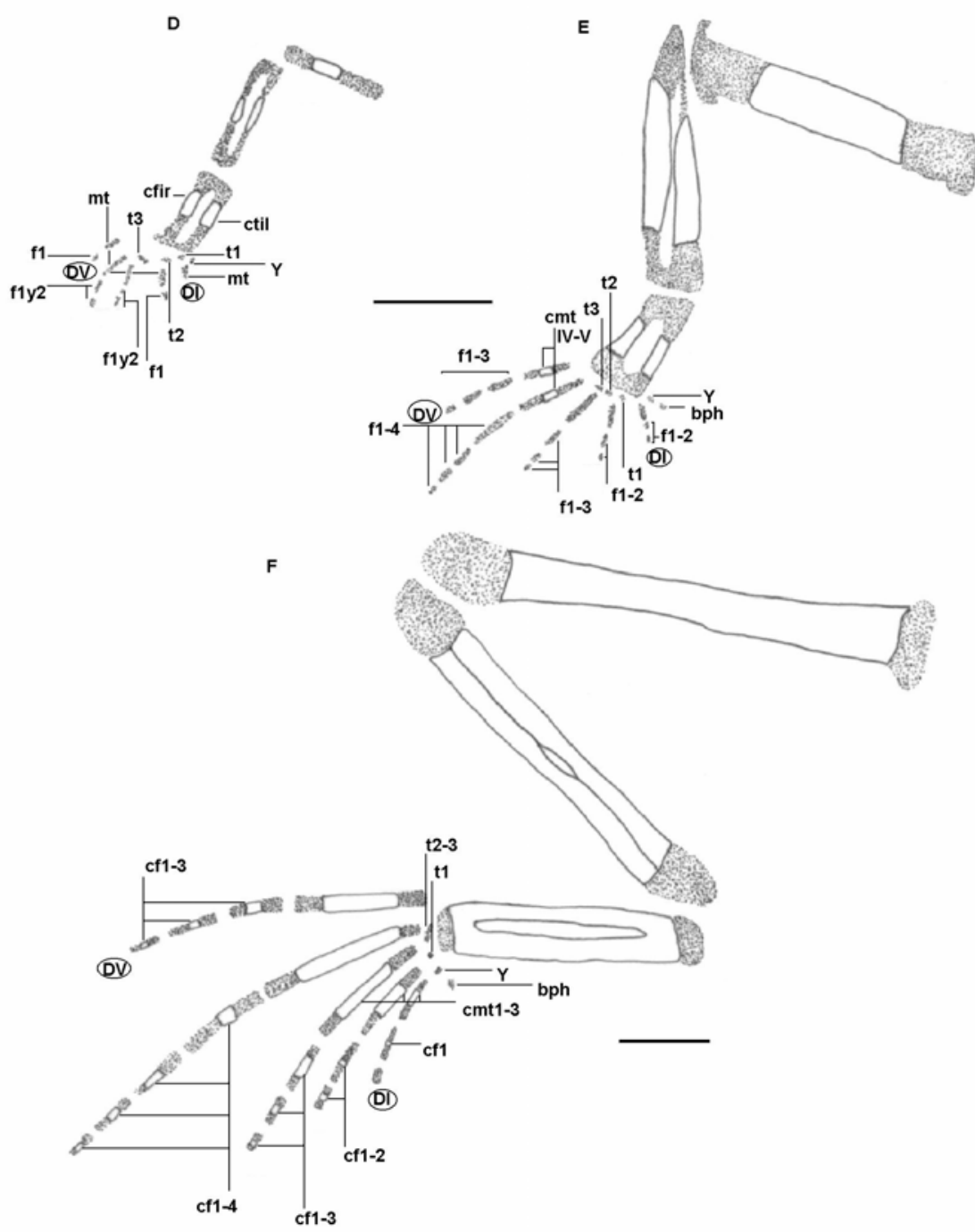

Figura 39. Miembro posterior derecho en posición a traves de diferentes estadios de Gosner (1960) de Batrachyla taeniata: estadios 31 (A), 35 (B), 36 (C), 37 (D), 38 (E) y 42 (F). Las zonas punteadas indican cartílago y las zonas sin puntear representan hueso. Escala $1 \mathrm{~mm}$. Referencias: bph: basal del prehallux, cf: centros de las falanges, cfe: centro del fémur, cfi: centro de la fíbula, cfir: centro del fibular, cmt: centros de los metatarsianos, cti: centro de la tibia, ctir: centro del tibial, DI-V: digitos I al V, f: falanges, fe: fémur, fi: fíbula, fir : fibular, ti: tibia, tir: tibial, $\mathbf{m t}$ : metatarsianos, $\mathbf{t} 1$ : tarsiano I, t $\mathbf{2}$ : tarsiano II, $\mathbf{t} 3$ : tarsiano III, t 2-3: tarsiano II- III, Y: elemento Y. 


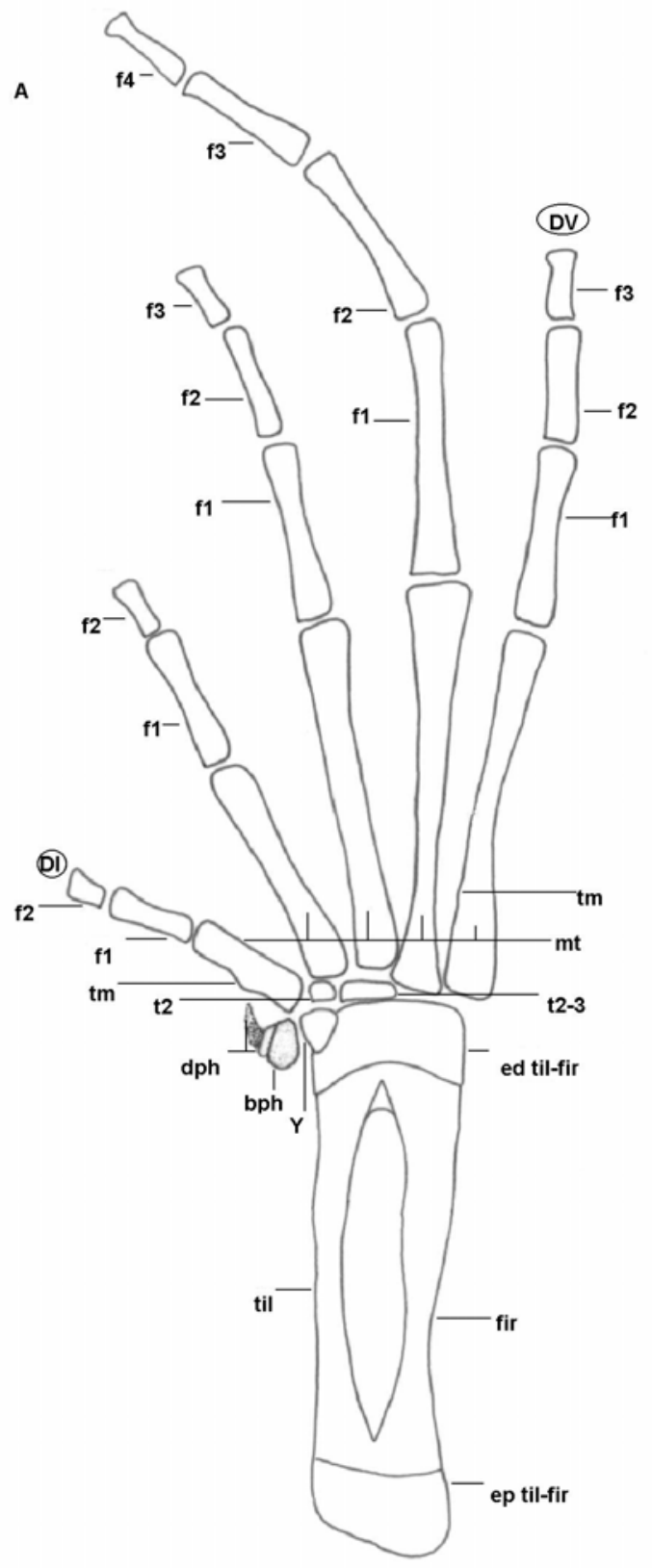

B

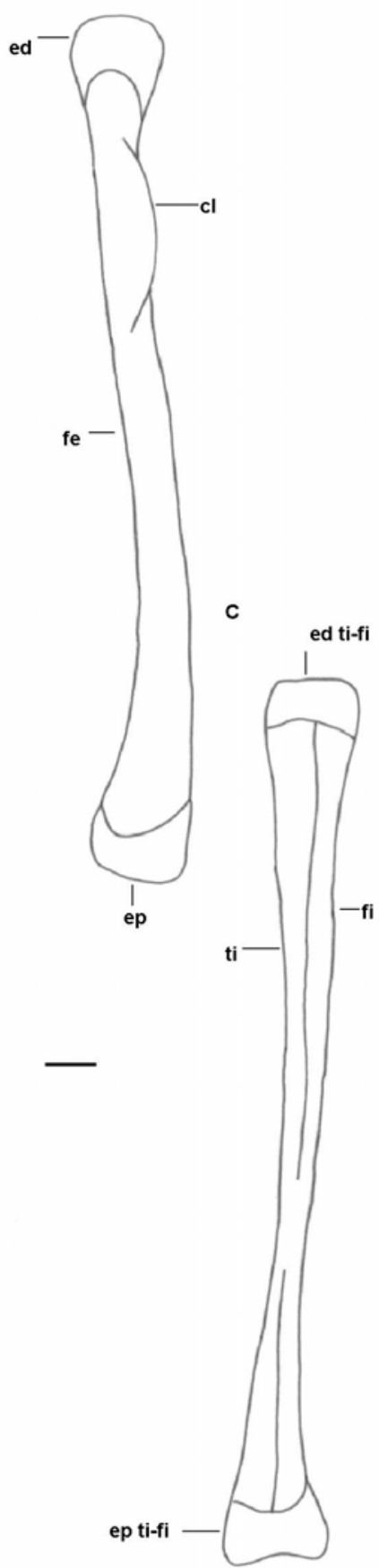

Figura 40. Diferentes segmentos del esqueleto apendicular posterior del adulto de Batrachyla taeniata: vista ventral del autopodio izquierdo (A), vista ventral del estilopodio izquierdo (B) y vista ventral del zeugopodio izquierdo (C). Las zonas punteadas indican cartílago y las zonas sin puntear representan hueso. Escala $1 \mathrm{~mm}$. Referencias: cl: cresta lateral del fémur, ed: epífisis distal, ep: epífisis proximal, dph: segmentos distales del prehallux , tm: tubeculo medial. El resto de las referencias como en la figura 38. 


\section{III.9. Desarrollo de la musculatura apendicular posterior en Batrachyla taeniata} (Figs. 41-45).

\section{III.9.1. Músculos asociados a la cintura pélvica y estilopodio (Figs. 41-42). Se} consideraron en esta categoría aquellos que presentan su inserción u origen en dicha cintura, o recorren casi toda la extensión del estilopodio. A continuación se exponen las características generales para cada músculo considerando su origen, inserción y relaciones topográficas con otros elementos a lo largo del desarrollo desde larva hasta adulto.

Aspectos del desarrollo larval. Previo al estadio 38, desde la aparición de la yema del miembro posterior y durante todo el período de diferenciación de los digitos resulta imposible identificar bajo lupa a los músculos del miembro posterior. Esto es posible solo desde el estadio 38 para los músculos asociados a estilopodio y zeugopodio (a excepción de los mm. obturatores y el m. gracilis minor que se diferencian al estadio 42). Los músculos del autopodio se diferencian individualmente recien hacia el estadio 41. A este estadio es reconocible la mayoría de ellos con rasgos estructurales practicamente identicos a los del adulto, presentando un mayor desarrollo relativo los músculos de la planta respecto de los elementos dorsales.

Los músculos interphalangeales y los asociados al prehalluxson los últimos en diferenciarse. Los mm. interphalangeale de los digitos III, Iv y $\mathrm{V}$ aparecen al estadio 42 como una masa única de fibras ubicada en la superficie medio ventral de la primer falange del digito respectivo. En el estadio 45 se produce la división de la masa única y es posible reconocer las cabezas típicas del estado adulto. A su vez, el m. interphalangealis distalis digiti IV aparece directamente al estadio 45 mostrando la estructura típica del adulto. Los músculos asociados al prehallux son notorios a partir del estadio 45.

Por último, en la superficie dorsal de los digitos I a IV no es posible distinguir entre los m. extensores brevis superficialis y extensores brevis medius de cada dígito recien hasta culminada la metamorfosis.

\section{Músculos ventrales.}

- Abdominal crenator. Ausente.

- Adductor longus. Ausente.

- Adductor magnus. En el adulto es un músculo intrínseco, largo y proximalmente superficial, pero distalmente profundo al $\mathrm{m}$. sartorius que se origina en la porción púbica del cóccix. La cabeza dorsal se origina mediante 
un tendón dorsal a la cabeza anterior del $\mathrm{m}$. semitendinosus y corre dorsal a ésta hasta su inserción en los 2/3 distales de la cara dorsoposterior del fémur. La cabeza dorsal recibe a la cabeza accesoria que se deprende del vientre anterior del m. semitendinosus. Su cabeza dorsal inserta en la porción distal del fémur, en su cara dorsal. Su cabeza ventral inserta en la porción distal del fémur, en su cara ventral.

- Cruralis. En el adulto es un músculo intrínseco, largo y superficial que se origina mayormente en la región ilíaca del cóccix mediante un tendón fuerte y parcialmente en la epífisis proximal del fémur. Inserta junto al m. glutaeus magnus en la aponeurosis que cubre la epífisis distal del fémur y la proximal de la tibia-fíbula. Cerca de su inserción, sus fibras se diferencian poco de las del m. glutaeus magnus. Carece de cabeza accesoria.

- Gracilis major. En el adulto es un músculo intrínseco, largo y superficial que se origina mediante un tendón corto en la región isquiádica del cóccix. Sus fibras forman un tendón que converge con el tendón del m. gracilis minor, ambos tendones corren, dorsalmente a los de los $\mathrm{mm}$. sartorius y semitendinosus, hacia su inserción en la epífisis proximal de la tibiafíbula.

- Gracilis minor. Notorio desde el estadio 42 del desarrollo larval. Se diferencia de la región posterior del $\mathrm{m}$. gracilis major. En los últimos estadios de la metamórfisis aumenta considerablemente su volumen. En el adulto es un músculo intrínseco, largo y superficial que se origina mediante un tendón corto en la región isquiádica del cóccix. Sus fibras más centrales, ocupan el tercio posterior del músculo, se disponen en forma difusa y tienen inserción proximal en el tegumento. Sus fibras más externas, son más compactas y forman un tendón que converge con el del m. gracilis major.

- Iliacusinternus. En el adulto es un músculo intrínseco, corto, profundo al origen y la inserción, superficial en su tramo medio. Se origina mediante en la superficie interna del ileon, inmediatamente anterior al cóccix. Inserta en el tercio medio del fémur, en su cara dorsal, debajo de los $\mathrm{mm}$. cruralis y glutaeus magnus.

- Obturator externus. Diferenciable desde el estadio 42 del desarrollo larval. En el adulto es un músculo intrínseco, corto y profundo a los $\mathrm{mm}$. adductor longus y adductor magnus que se origina entre la región pubica y la isquiádica del cóccix, posteriormente al origen del m. pectineus. Inserta en cara ventral del fémur en su región proximal. 
- Obturator internus. Diferenciable desde el estadio 42 del desarrollo larval. . En el adulto es un músculo intrínseco, corto y profundo que en el adulto se origina en la región pubica del coccis e inserta en la epífisis proximal del fémur.

- Pectineus. En el adulto se trata de un músculo intrínseco, corto y profundo al m. adductor magnus (cabeza ventral). En el adulto se origina en la porción ilíaca del cóccix dorsal al origen del $\mathrm{m}$. sartorius. Inserta en el tercio proximal del fémur en su cara ventral

- Quadratus femoris. En el adulto se trata de un músculo intrínseco, corto y profundo que corre tapado por la cabeza dorsal del $\mathrm{m}$. adductor magnus y su origen es posterior al del m. obturator externus. Inserta en la cara ventral del fémur en su tercio proximal muy cerca de la cabeza articular y por detrás del $\mathrm{m}$. obturator externus.

- Sartorius. En el adulto es un músculo intrínseco, largo y superficial que se origina entre la porción ilíaca y la púbica del cóccix. Inserta mediante un tendón junto al tendón del $\mathrm{m}$. semitendinosus en la epífisis proximal de la tibia-fíbula. Ambos tendones corren ventralmente a los tendones de los $\mathrm{mm}$. gracilis major y gracilis minor.

- Semitendinosus. En el adulto es un músculo intrínseco, largo y profundo al m. adductor magnus que se origina mediante un tendón largo en la porción isquiádica del cóccix. Inserta mediante un tendón junto al tendón del m. sartorius o en la epífisis proximal de la tibiafíbula. Ambos tendones corren ventralmente a los tendones de los $\mathrm{mm}$. gracilis major y gracilis minor.

- Tensor fasciae latae. Se diferencia de la masa de fibras del músculo cruralis. En el adulto se trata de un músculo intrínseco, corto y superficial que se origina en el m. cruralis. Inserta en el tercio proximal del ilion, en la cara ventral, bajo el origen del m. iliacusexternus.

\section{Músculos dorsales.}

- Iliacus externus. En el adulto es un músculo intrínseco y corto que ocupa el tercio proximal del ileon. Se origina en el tercio proximal del ileon, en su cara dorsal. Sus fibras cruzan el ileon en dirección anterior-posterior y medial-lateral, pasan ventralmente al tendón proximal del $\mathrm{m}$. ileofibularis por debajo de los $\mathrm{mm}$. pyriformis e ileofemoralis y se insertan, mediante un tendón, en las adyacencias de la epífisis proximal del fémur, en su cara posterior. 
- Gemellus. En el adulto es un músculo intrínseco, corto y visible en vista profunda al retirar el m. semimembranosus. Se origina en la región isquiádica del cóccix. Inserta en la porción proximal del fémur, en las adyacencias de la epífisis proximal en su cara posterior.

- Glutaeusmagnus. En los últimos estadios de la metamórfisis aumenta considerablemente su volumen. En el adulto es un músculo intrínseco, largo y superficial que se origina en la cara posterior y lateral del ilion. Inserta junto al m. cruralis en la aponeurosis que cubre la epífisis distal del fémur y la proximal de la tibia-fíbula.

- Ileo-femoralis. En el adulto es un músculo intrinseco y profundo que está oculto en todo su trayecto es oculto por el m. ileofibularis. Se origina en el tendón del m. ileofibularis. Inserta en la cara posterior del fémur aproximadamente en su mitad, por detrás del m. iliacus internus.

- Ileo-fibularis En el adulto es un músculo intrínseco, largo y parcialmente visible en vista superficial entre los mm. glutaeus magnus y semimembranosus. Se origina mediante un tendón largo entre las regiones pubica e ilíaca del cóccix. Inserta mediante un largo tendón en la epífisis proximal de la tibiafíbula.

- Pelvocutaneous. Ausente.

- Pulmonum proprius. Ausente.

- Pyriformis. En el adulto es un músculo intrínseco, corto, proximalmente superficial y distalmente profundo a los $\mathrm{mm}$. ileo-fibularis y semimembranosus. Se origina en la región isquiádica dorsal del cóccix. Inserta en el tercio proximal del fémur, en su cara posterior, por detrás del m. ileofemoralis y por delante del m. gemellus.

- Semimembranosus. En el adulto es un músculo intrínseco, largo y superficial que se origina en la porción isquiádica del cóccix. Inserta mediante un tendón en la epífisis proximal de la tibia-fíbula.

III.9.2. Músculos asociados al zeugopodio (Figs. 41-42). Se consideraron en esta categoría aquellos músculos que recorren el zeugopodio independientemente de si presentan inserción u origen en él. A continuación se exponen las características generales para cada músculo considerando su origen, inserción y relaciones topográficas con otros elementos a lo largo del desarrollo desde larva hasta adulto. 


\section{Músculos ventrales.}

- Extensor cruralis brevis. En el adulto es un músculo largo y superficial que se origina mediante un tendón en la aponeurosis distal de los mm. cruralis y glutaeus magnus, medialmente al tendón del m. tibialis anticus longus. Inserta en los dos tercios proximales de la tibia-fíbula, en su cara anterior y ventral.

- Plantaris longus. En el adulto es un músculo largo y superficial que se origina en la cara posterior de la articulación entre estilopodio y zeugopodio. Su corto y fuerte tendón de origen se relaciona por un lado con la aponeurosis distal de los mm. cruralisy glutaeus magnus, y por otro con el complejo de tendones dístales de los mm. gracilis major, gracilis minor, sartorius y semitendinosus. Inserta mediante el tendón de Aquiles en la aponeurosis plantar.

- Tibialis anticus brevis. En el adulto es un músculo corto y superficial que se origina en el tercio distal de la tibia-fíbula a partir de la región distal del $\mathrm{m}$. extensor cruralis brevis. Inserta en el tibial junto al tendón medial del m. tibialis anticus longus

- Tibialis anticus longus. En el adulto es un músculo largo y superficial que se origina mediante un corto tendón en la aponeurosis distal de los $\mathrm{mm}$. cruralis y glutaeus magnus. Inserta mediante dos tendones, uno medial, en la epífisis proximal del tibial, y otro lateral en la epífisis proximal del fibular.

- Tibialis posticus Al estadio 45 permanece aún totalmente expuesta la tibiafíbula entre los mm. tibialis posticus y extensor cruralis brevis. En el adulto es un músculo largo y superficial que se origina a lo largo de toda la superficie medio ventral de la tibia-fíbula. Inserta en el tibial al lado del tendón medial del m. tibialis anticus longus, mediante un tendón que recorre medialmente la epífisis distal de la tibia-fíbula.

\section{Músculos dorsales.}

- Peroneus. En el adulto es un músculo largo y superficial que se origina en la aponeurosis distal de los mm. cruralis y glutaeus magnus mediante un tendón corto. Inserta lateroventralmente en la epífisis distal de la tibia-fíbula formando una aponeurosis que se prolonga mediante un tendón hacia la epífisis proximal del fibular.

- Plantaris longus. Sus características ya fueron dadas con relación a los músculos ventrales del zeugopodio. 


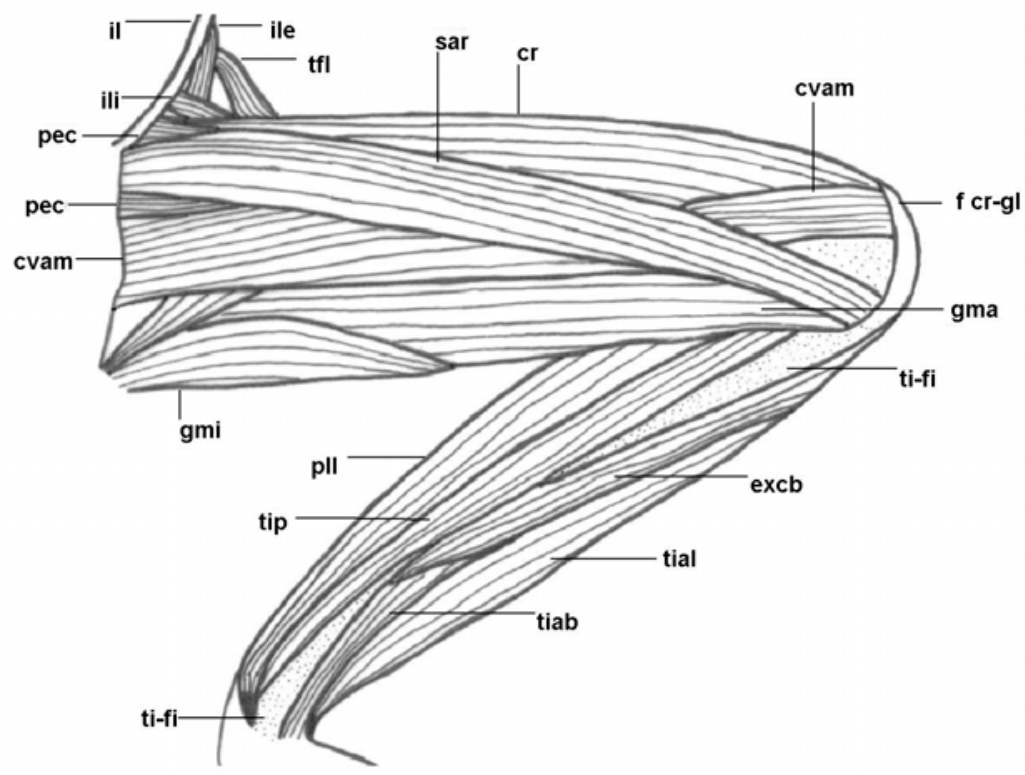

B

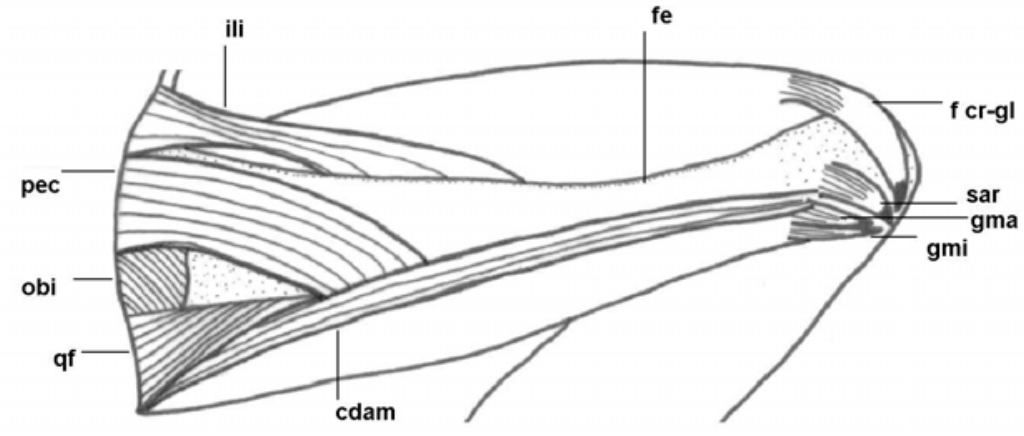

Figura 41. Vista ventral de la musculatura asociada al estilopodio y zeugopodio del miembro posterior en el adulto de Batrachyla taeniata. En (A) vista superficial y en (B) vista profunda. Escala $5 \mathrm{~mm}$. Referencias: cdam: cabeza dorsal del adductor magnus, cr: cruralis, cvam: cabeza ventral del adductor magnus, excb: extensor cruralis brevis, fcr -gl: fascia de los músculos cruralis y glutaeus, fe: fémur, gma: gracilis major, gmi: gracilis minor, il: ileon, ile: iliacus externus, ili: iliacus internus, obi: obturator internus, pec: pectineus, pll: plantaris longus, qf: quadratus femoris, sar: sartorius, tfl: tensor fasciae latae, tiab: tibialis anticus brevis, tial: tibialis anticus longus, ti-fi: tibia-fíbula, tip : tibialis posticus . 
A

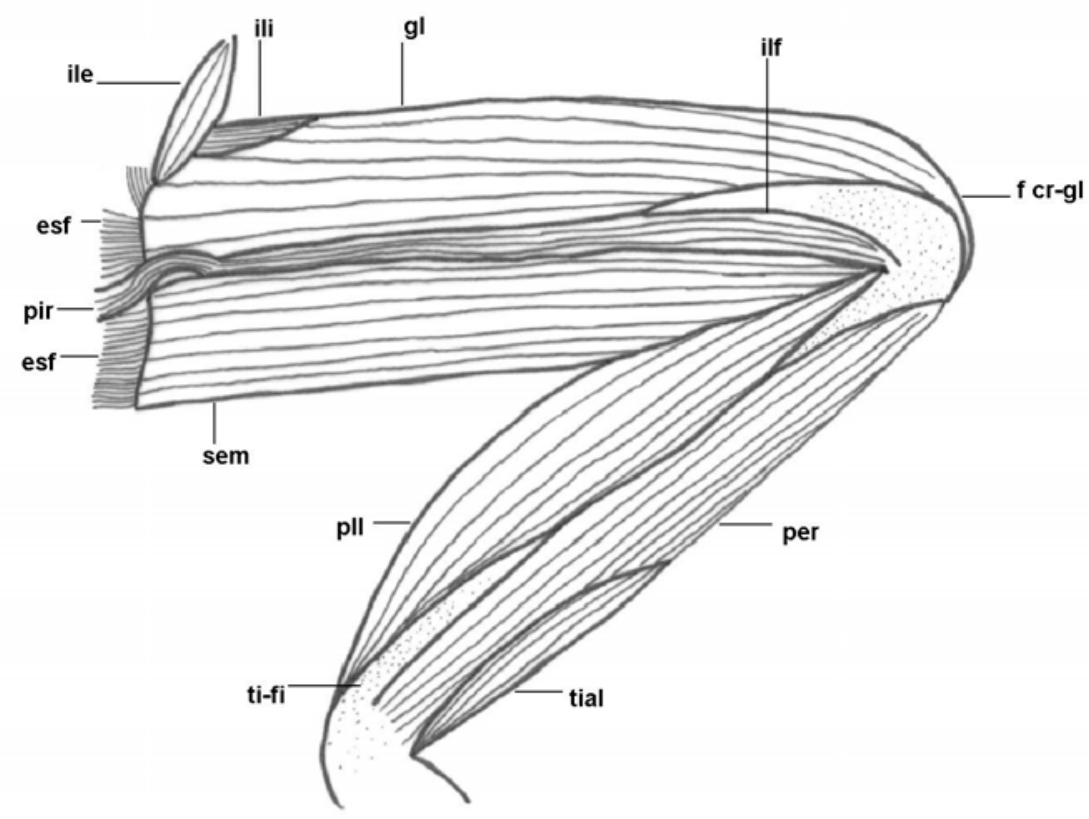

B

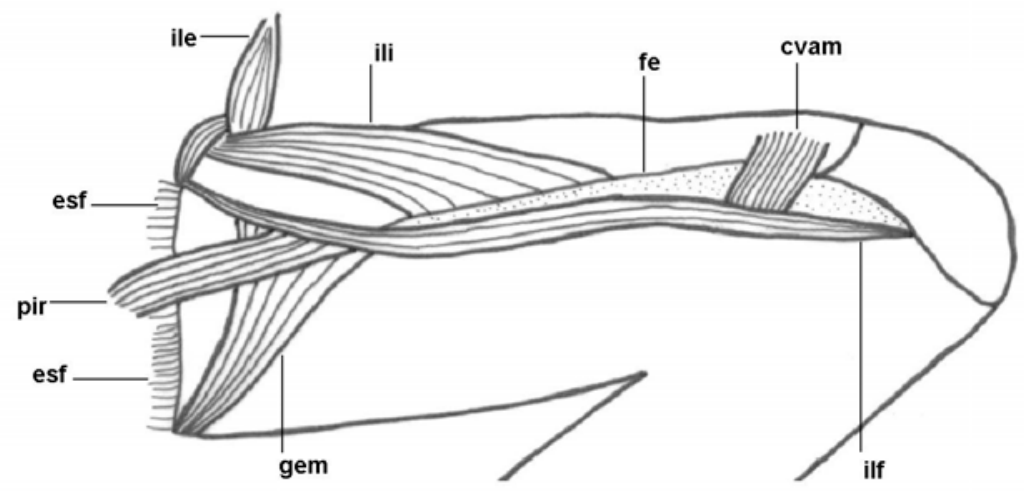

Figura 42. Vista dorsal de la musculatura asociada al estilopodio y zeugopodio del miembro posterior en el adulto de Batrachyla taeniata. En (A) vista superficial y en (B) vista profunda. Escala 5mm. Referencias: esf: sphincter, gem: gemellus, gl: glutaeus, ilf: ileofibularis, per: peroneus, sem: semimembranosus. El resto de las referencias como en la figura 40. 
III.9.3. Músculos asociados al autopodio (Figs. 43-45). Se consideraron en esta categoría aquellos músculos que recorren el autopodio independientemente de sí presentan inserción u origen en él. A continuación se exponen una breve reseña general del desarrollo larvario de este grupo de músculos y luego se desarrollan los rasgos especificos para cada músculo considerando su origen, inserción y relaciones topográficas con otros elementos para el estado adulto.

\section{Músculos ventrales del tarso.}

- Aponeurosis plantaris. Representa la continuación distal del tendón del m. plantaris longus. Su cara dorsal es continua con los mm. plantaris profundusy transversus plantae. En su extremo distal, del lado lateral, rodea al tendón del m. flexor digitorum brevis superficialis. De la región lateral y distal se originan diversos músculos asociados al metapodio y acropodio. De ella se originan los tendines superficiales del prehalluxy de los dígitos I, II y III, el de este último también formado a partir del tendón distal del m. flexor digitorum brevis superficialis.

- Flexor digitorum brevis superficialis. Se origina en la mitad lateral del ligamento del $\mathrm{m}$. plantaris longus dorsalmente a la aponeurosis plantaris. Distalmente forma un tendón que penetra la aponeurosis plantaris al nivel de la base de los dígitos IV y $\mathrm{V}$, continuándose en los tendines superficiales de dichos dígitos y colaborando en la formación del tendo superficialis digiti III.

- Intertarsalis. Se origina a lo largo de los dos tercios proximales del tibial en su cara lateral y también en el borde medial del fibular. Inserta mediante un tendón que nace en el centro del músculo y se engruesa distalmente hasta alcanzar la superficie ventral del segmento basal del prehallux.

- Plantaris profundus. Se origina en el borde medial del ligamento del m. plantaris longus, ventral al $\mathrm{m}$. tarsalis posticus y medial al $\mathrm{m}$. flexor digitorum brevis superficialis. Inserta en la superficie dorsal de la aponeurosis plantaris a la altura de los dos tercios a tres cuartos dístales del tibial-fibular, extendiéndose hasta el nivel de la base de los dígitos I a IV.

- Tarsalis posticus. Se origina en el borde medial del ligamento del m. plantaris longus, dorsal al m. plantaris profundus. Inserta a lo largo de los tres cuartos dístales del tibial en su cara ventral, dístal a la epífisis. 
- Transversus plantae distalis. Se origina a lo largo del extremo dístal lateral del fibular. Inserta en la aponeurosis plantaris, lateral al m. transversus plantae distalis, a la altura del dígito IV.

- Transversus plantae proximalis. Se origina a lo largo del extremo distal del fibular, por debajo del elemento dístal. Inserta en la superficie medio dorsal de la aponeurosis plantaris a la altura del extremo distal del tibial.

\section{Músculos dorsales del tarso.}

- Abductor brevis dorsalis digiti V. Se origina a lo largo de toda la extensión del fibular lateralmente al origen del grupo de los $\mathrm{mm}$. extensores breves superficiales. Inserta en la cara dorsal del tercio proximal del metatarsiano $\mathrm{V}$, flanqueado lateralmente por el $\mathrm{m}$. abductor brevis plantaris digiti $\mathrm{Vy}$ medialmente por el $\mathrm{m}$. extensor brevis profundi digiti $\mathrm{V}$.

- Extensor digitorum communis longus. Se origina mediante un tendón delgado, junto al tendón del m. tarsalis anticus, distal y lateral en la tibiafíbula. Inserta tendinosamente en el dorso del $\mathrm{m}$. extensor brevis medius digiti $\mathrm{IV}$, a la altura del primer tercio del metatarso y en los músculos respectivos de los dígitos II y III.

- Tarsalis anticus. Se origina distal en la tibia-fíbula, en su cara lateral, mediante un tendón corto junto al tendón del m. extensor digitorum communis longus. Inserta a lo largo de la mitad distal del tibial, en su cara dorsal. Distalmente corre oculto por el m. extensor brevis superficialis hallucis

\section{Músculos ventrales de los metatarsos-falanges.}

- Abductor brevis plantaris hallucis. Se origina a lo largo del margen medio ventral de la aponeurosis plantaris al nivel de los tres cuartos distales del tarso. Inserta en la superficie plantar, cara medial, del metatarso I mediante un largo tendón.

- Abductor praehallucis. Se origina mediante dos cabezas en la aponeurosis plantaris y en el m. plantaris profundus. La cabeza dorsal es más grande y se origina en el borde ventromedial de la aponeurosis plantaris, en su tercio distal, medial al $\mathrm{m}$. abductor brevis plantaris hallucis. La cabeza ventral es más pequeña y se origina en el borde dorsomedial de la aponeurosis plantaris y en el m. plantaris profundusa lo largo de la mitad distal de la cabeza dorsal. Ambas insertan juntas en el prehallux dándole al músculo un aspecto triangular 
en sus segmentos medio y distal. Corre debajo de la mitad distal del $\mathrm{m}$. abductor brevis plantaris hallucis.

- Abductor propius digiti IV. Se origina semitendinosamente en el borde medio dorsal de la base del metatarsiano IV. Inserta en borde lateral del mismo metatarsiano a lo largo de su mitad a dos tercios proximales. Corre dorsal al $\mathrm{m}$. flexor ossis metatarsi IV y es cubierto dorsalmente por los $\mathrm{mm}$. extensores breves digiti IV.

- Contrahente digiti l Se origina mediante en el tarsiano II. Inserta en la articulación entre metatarsiano y primer falange del digito I.

- Flexor ossis metatarsi digiti II. Se origina mediante un tendón ancho y grueso compartido con los $\mathrm{mm}$. flexores ossei metatarsi III y IV, en el extremo distal del tibial, en su cara ventral. Inserta en la superficie ventrolateral del metatarsiano II.

- Flexor ossis metatarsi digiti III. Se origina mediante un tendón ancho y grueso compartido con los mm. flexores ossei metatarsi III y IV, en el extremo distal del tibial, en su cara ventral. Inserta en la superficie ventrolateral del metatarsiano III.

- Flexor ossis metatarsi digiti IV. Se origina mediante un tendón ancho y grueso compartido con los mm. flexores ossei metatarsi III y IV, en el extremo distal del tibial, en su cara ventral. Inserta en la superficie ventrolateral del metatarsiano IV.

- Flexor teres digiti II. Se origina en el borde ventromedial del metatarsiano II, ventralmente al $\mathrm{m}$. transversus metatarsi I. Inserta en la base de la falange proximal del dígito II, en su cara ventral.

- Flexor teres digiti III. Se origina en el borde ventromedial del metatarsiano III. Inserta en la base de la falange proximal del dígito III, en su cara ventral.

- Flexor teres digiti IV. Se origina en el borde ventromedial del metatarso IV. Inserta en la base de la falange proximal del dígito IV, en su cara ventral.

- Flexor teres digiti $\boldsymbol{V}$. Se origina en el borde ventromedial del metatarso V. Inserta en la base de la falange proximal del dígito $\mathrm{V}$, en su cara ventral.

- Interphalangealis digiti III. Se origina mediante dos cabezas en la base de la falange proximal del dígito III, en su cara ventral. Inserta por un alargado tendón en la mitad basal de la superficie ventral de la segunda falange. La cabeza medial presenta menor desarrollo. 
- Interphalangealis digiti IV. Se origina mediante dos cabezas, no tan marcadas como en el $\mathrm{m}$. interphalangealis digiti III, en la base de la falange proximal del dígito IV, en su cara ventral. Inserta por un largo tendón en la mitad basal de la superficie ventral de la segunda falange del mismo dígito.

- Interphalangealis digiti $\boldsymbol{V}$. Se origina mediante dos cabezas, no tan marcadas como en el $\mathrm{m}$. interphalangealis digiti III, en la base de la falange proximal del dígito $\mathrm{V}$, en su cara ventral. Inserta por un largo tendón en la mitad basal de la superficie ventral de la segunda falange del mismo dígito.

- Interphalangealis distalis digiti IV. Esta representado por un haz doble de fibras, medial y lateral, que recorre la superficie ventral de las falanges II (origen) y III (inserción) del digito IV.

- Lumbricalis brevis digiti II. Se origina en parte en la aponeurosis plantaris, lateral a la base del tendo superficialis digiti I. Inserta en la superficie ventral de la unión metatarso-falange del digito II. Al nivel proximal es recorrido medioventralmente por el tendo superficialis digiti II y al retirar dicho tendón queda un surco en el músculo.

- Lumbricalis brevis digiti III. Se origina en parte en la superficie dorsal de la aponeurosis plantaris lateral al origen del tendo superficialis digiti Ily dorsal al $\mathrm{m}$. lumbricalis longus digiti III. Algunas fibras se originan mediante un corto tendón en el margen distal del $\mathrm{m}$. transversus plantaris proximalis, lateral al $\mathrm{m}$. lumbricalis brevis digiti II. Inserta ventral en la articulación metatarso-falange del dígito III, medialmente al $\mathrm{m}$. Iumbricalis longus digiti III.

- Lumbricalis brevis digiti IV. Compuesto por una sola cabeza, la medial. Esta se origina enteramente en la aponeurosis plantaris en el origen del $\mathrm{m}$. lumbricalis longus digiti III mediante un largo y delgado tendón. Inserta en la superficie ventral de la articulación metatarso-falange del dígito IV. Recorre ventralmente el metatarso IV medialmente al $\mathrm{m}$. lumbricalis longissimus digiti IV.

- Lumbricalis brevis digiti $\boldsymbol{V}$. Compuesto por dos cabezas, medial y lateral. La medial se origina distalmente en la aponeurosis plantaris, entre la base del metatarsiano $\mathrm{V}$ y la epífisis distal del fibular, medialmente al origen del $\mathrm{m}$. lumbricalis longus digiti IV. La cabeza lateral se origina en un corto tendón junto a la cabeza medial, pero lateral a ésta. El origen de ambas se relaciona con el extremo dístal del m. flexor digitorum brevis superficialis. La cabeza medial inserta en el borde ventromedial de la articulación entre metatarso y falange del 
dígito V. La cabeza lateral inserta en el margen ventrolateral de la articulación entre metatarso y falange del dígito $\mathrm{V}$.

- Lumbricalis brevis hallucis. Se origina en el borde dorsomedial de la aponeurosis plantaris lateralmente al prehallux. Inserta ventral a la unión metatarso falange del dígito $\mathrm{I}$.

- Lumbricalis longissimus digiti IV. Se origina dorsomedialmente a la base del tendo superficialis digiti IV. Recorre ventralmente el metatarso IV lateralmente al mencionado tendón e inserta mediante un largo tendón en la superficie ventral de la base de la tercer falange del dígito IV.

- Lumbricalis longus digiti III. Se origina en la región dorsal y distal de la aponeurosis plantaris entre los tendines superficiales de los dígitos II y III, y en el extremo distal del m. transversus plantae distalis. Inserta mediante un tendón alargado en la base de la falange proximal del dígito III, cara ventral. El tendo superficialis digiti III corre sobre la región lateral del músculo y al retirar el tendón queda un surco en la superficie ventral y dístal del músculo.

- Lumbricalis longus digiti IV. Se origina en la superficie dorsolateral del tendo superficialis digiti IV, en el extremo distal del m. flexor digitorum brevis superficialis, lateral al m. lumbricalis longissimus digiti IV. Inserta mediante un tendón alargado en la superficie ventral de la articulación entre las falanges I y II del dígito IV.

- Lumbricalis longus digiti $\boldsymbol{V}$. Se origina en la cara dorsal del tendo superficialis digiti $V$, mediante un tendón. Inserta en la articulación entre las falanges I y II del dígito V. Este músculo es fusiforme y corre a lo largo de la cara ventral del metatarsiano $\mathrm{V}$, dorsalmente al tendo superficialis digiti $\mathrm{V}$, ventralmente a la cabeza medial del $\mathrm{m}$. lumbricalis brevis digiti $\mathrm{V}, \mathrm{y}$ medialmente a la cabeza lateral de ese mismo músculo.

- Opponens hallucis. Se origina en la superficie ventral del tarsiano II, medial al origen del $\mathrm{m}$. contrahentis digiti I. Inserta a lo largo del borde medio ventral del metatarsiano I. Corre medial al $\mathrm{m}$. contrahentis digiti I y esta oculto en vista ventral por el $\mathrm{m}$. lumbricalis brevis digiti $\mathrm{I}$.

- Tendines superficiales. Recorren ventralmente cada digito desde su base hasta la base de la falange distal. Los del prehallux, dígitos I, II y III se originan de la región medial y distal de la aponeurosis plantaris. El del dígito III se forma a partir del tendón distal del $\mathrm{m}$. flexor digitorum brevis superficialis y de la 
aponeurosis plantaris. Los de los dígitos IV y $\mathrm{V}$ se originan enteramente a partir de este tendón.

- Transversus metatarsi I. Se origina en el margen ventrolateral del metatarso I, en sus dos tercios medios, lateralmente a la inserción del m. opponens hallucis. Inserta en el borde medio ventral del metatarso II, en su tercio o mitad proximal, medialmente al origen del $\mathrm{m}$. transversus metatarsi II.

- Transversus metatarsi II. Se origina en el margen ventrolateral del metatarso II, en sus dos tercios o mitad proximal. Inserta en el borde medio ventral del metatarso III, en su mitad proximal.

- Transversus metatarsi III. Se origina en el margen ventrolateral del metatarso III, en su mitad proximal. Inserta en el tercio proximal del metatarso IV.

- Transversus metatarsi IV. Se origina en el margen ventrolateral del tercio proximal del metatarso IV, y en parte con el m. transversus metatarsi III. Inserta en la superficie ventral del metatarsiano $\mathrm{V}$, en su tercio proximal.

\section{Músculos dorsales de los metatarsos-falanges.}

- Abductor brevis dorsalis halluccis. Se origina en la superficie dorsal y dorsomedial del segmento basal prehalluxy en la mitad proximal del segmento distal (parte osea) del mismo. Inserta a lo largo de toda la superficie dorso medial del metatarso I.

- Extensores breves profundi halluccis. Se originan en la superficie dorsal del central y en la cara dorsomedial del metatarso I (cabeza medial) y en la superficie lateral del metatarso I, en su mitad proximal (cabeza lateral). Inserta cada una mediante un largo y delgado tendón en la base de la falange distal del dígito I.

- Extensores breves profundi digiti II. Se originan en el margen lateral del metatarso I (cabeza medial), o en el borde lateral del metatarso II, en su mitad proximal (cabeza lateral). La cabeza medial inserta mediante un corto tendón en la base de la falange proximal del dígito II. La cabeza lateral inserta por un largo tendón en la superficie dorsolateral de la falange distal del dígito II.

- Extensores breves profundi digiti III. Se originan en el borde lateral del metatarso II (cabeza medial), o en el borde lateral del metatarso III en su mitad proximal (cabeza lateral). Insertan en la superficie dorsomedial (cabeza medial) o dorsolateral (cabeza lateral) de la falange distal mediante un largo tendón. 


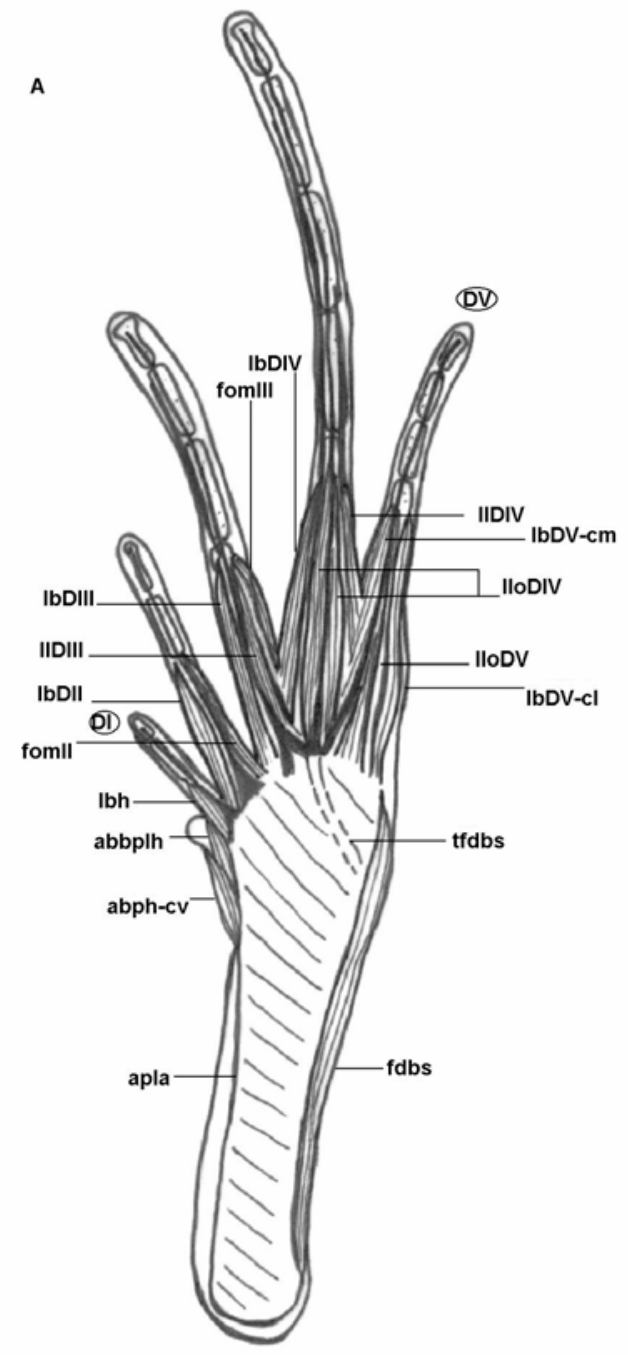

B

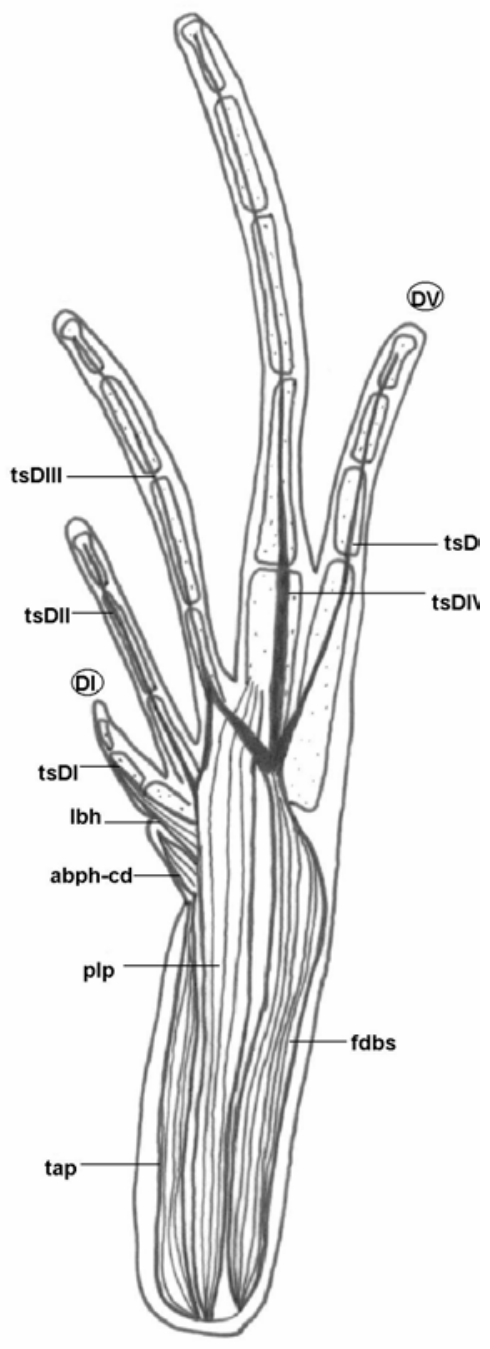

Figura 43. Vista ventral de la musculatura asociada al autopodio del miembro posterior en el adulto de Batrachyla taeniata. En (A) vista superficial y en (B) vista de la capa media superficial. Escala 5mm. Referencias: abbplh: abductor brevis plantaris hallucis, abph-c d: cabeza dorsal del abductor praehallucis, abph-cv: cabeza ventral del abductor praehallucis, apla: aponeurosis plantaris, fdbs: flexor digitorum brevis superficialis, fom: flexor ossis metatarsi, Ib-cl: cabeza lateral del lumbricalis brevis, Ib-cm: cabeza medial del/umbricalis brevis II: Iumbricalis longus, Ilo: lumbricalis longissimus, plp: plantaris profundus, tap: tarsalis posticus, tfdbs : tendón del flexor digitorum brevis superficialis, ts: tendones superficiales. 

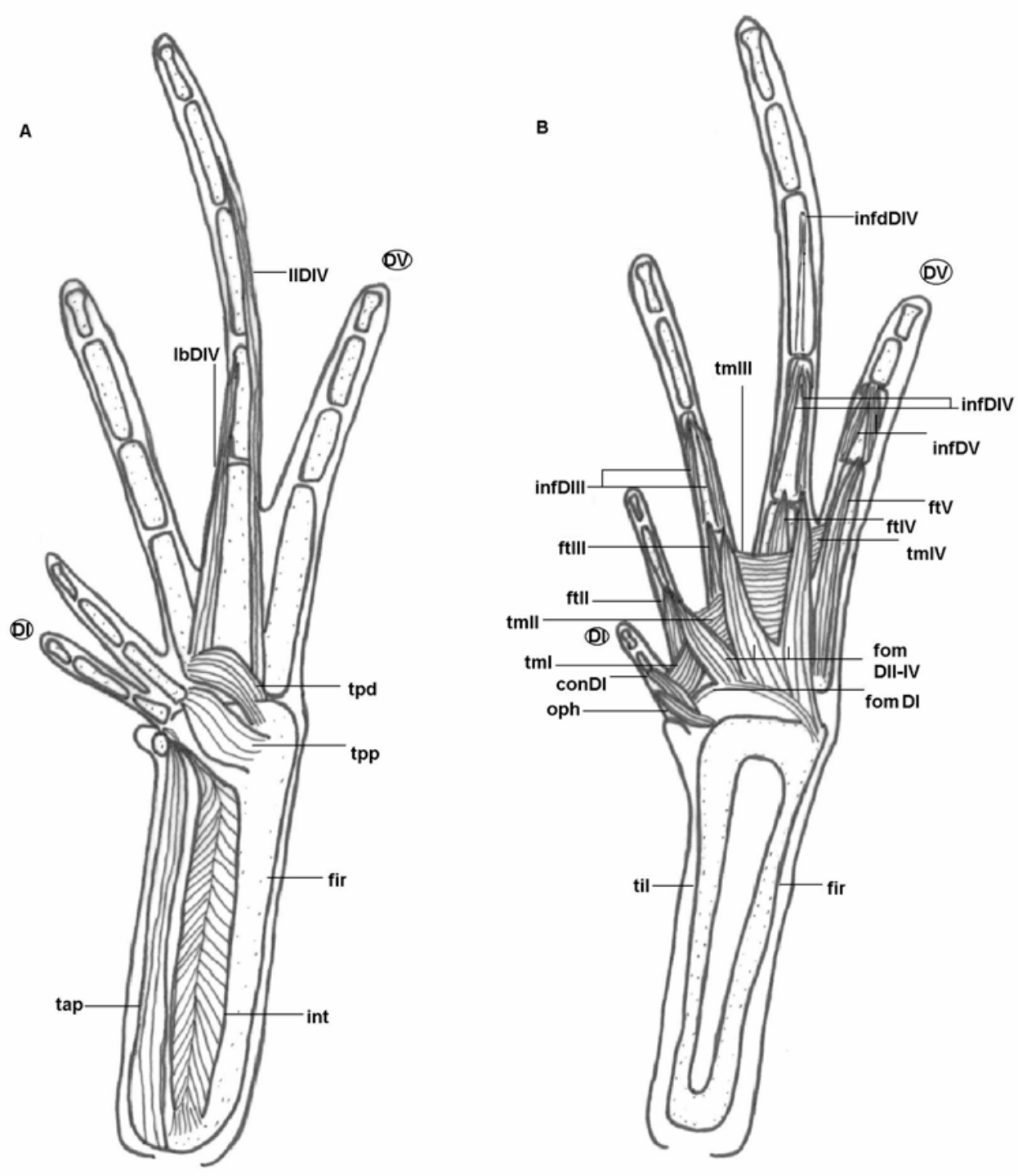

Figura 44. Vista ventral de la musculatura asociada al autopodio del miembro posterior en el adulto de Batrachyla taeniata. En (A) vista de la capa media profunda y en (B) vista de la capa profunda. Escala 5mm. Referencias: con : contrahente, fir: fibular, ft: flexor teres, inf: interphalangealis, infd: interphalangealis distalis, int: intertarsalis, oph: opponens hallucis, til: tibial, tm: transversus metatarsi, tpd: transversus plantae distalis, tpp : transversus plantae proximalis. El resto de las referencias como en la figura 42. 

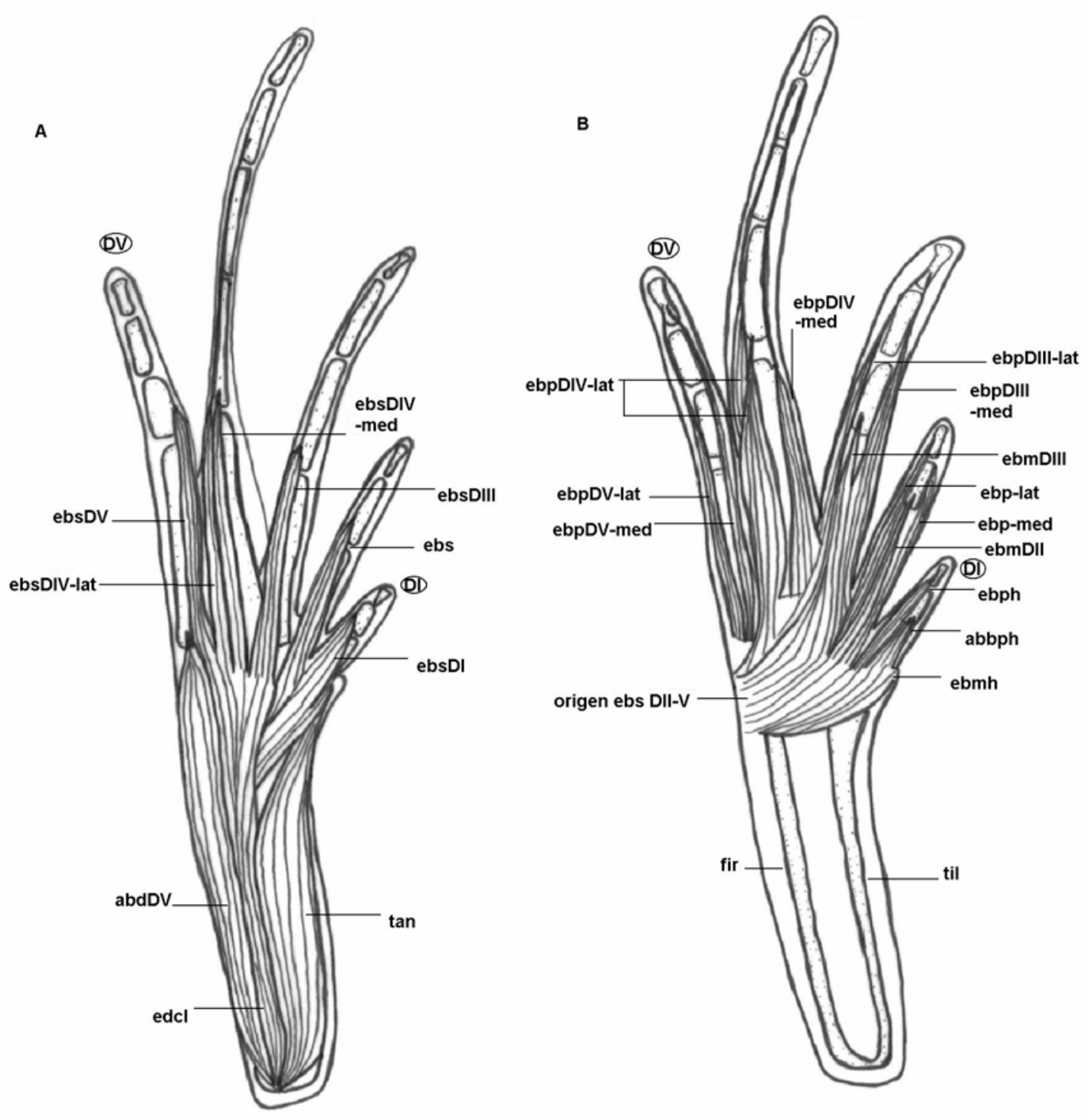

Figura 45. Vista dorsal de la musculatura asociada al autopodio del miembro posterior en el adulto de Batrachyla taeniata. En (A) vista superficial y en (B) vista profunda. Escala $5 \mathrm{~mm}$. Referencias: abbph: abductor brevis plantaris hallucis, abd: abductor brevis dorsalis, ebm : extensor brevis medius, ebmh: extensor brevis medius hallucis, ebph: extensor brevis profundi hallucis, ebp-lat: cabeza lateral del extensor brevis profundi, ebp-med: cabeza medial del extensor brevis profundi, ebs -lat: cabeza lateral del extensor brevis superficialis, ebs -med: cabeza medial del extensor brevis superficialis, edcl: extensor digitorum communis longus, fir: fibular, tan: tarsalis anticus, til: tibial. 
- Extensores breves profundi digiti IV. Se originan mediante un tendón en la extremidad distal del tibial (cabeza medial), o mediante dos cabezas en el margen dorsolateral del metatarso IV y borde medial del metatarso $\mathrm{V}$ (cabeza lateral). Cada una presenta doble inserción en la unión metatarso falange y en la falange distal del dígito IV, en este último caso mediante un largo tendón (cabeza medial), o en la superficie lateral de la falange distal (cabe za lateral).

- Extensores breves profundi digiti $\boldsymbol{V}$. Ambas cabezas (medial y lateral) se originan en el borde dorsal del metatarso V. Cada una inserta en la falange distal por un largo y delgado tendón.

- Extensores breves superficiales digiti IV. Son dos músculos. Ambos se originan en la superficie dorsomedial del fibular al nivel distal, distalmente al origen del m. extensor brevis superficialis digiti III. El músculo medial inserta mediante un tendón en la base de la falange proximal del dígito IV. El elemento lateral inserta por un largo tendón en la superficie dorsal de la segunda falange del dígito IV. Ambos corren por la superficie dorsolateral del dígito IV.

- Extensor brevis medius digiti II. Esta representado por la cabeza lateral solamente. Se origina en la epífisis distal común del tibial y fibular. El elemento lateral se junta con el m. extensor brevis superficialis digiti II e inserta por tendones en la unión metatarso falange del dígito II.

- Extensor brevis medius digiti III. Se origina en la epífisis distal común del tibial y fibular. Se une con el $\mathrm{m}$. extensor brevis superficialis digiti III y forma dos tendones que insertan en la región proximal de la primer falange del dígito III.

- Extensor brevis medius digiti. Se origina en la epífisis distal común del tibial y fibular. Inserta mediante u delgado tendón en el m. extensor brevis superficialis digiti IV (cabeza medial).

- Extensor brevis medius hallucis. Se origina en la epífisis distal común del tibial y fibular. Inserta junto al tendón medial del $\mathrm{m}$. extensor brevis superficialis hallucis en el metatarso I y el prehallux. Esta oculto por el m. extensor brevis superficialis hallucis.

- Extensor brevis superficialis digiti II. Se origina en el borde dorsomedial de la epífisis distal del fibular, distal al origen del m. extensor brevis superficialis hallucis, junto al m. extensor brevis superficialis digiti III, del cual es indiferenciable proximalmente. Se distinguen uno del otro al nivel proximal de 
los metatarsos. Inserta mediante un largo y delgado tendón en la falange proximal del dígito II.

- Extensor brevis superficialis digiti III. Se origina en el borde dorsomedial de la epífisis distal del fibular, distal al origen del m. extensor brevis superficialis hallucis, junto al m. extensor brevis superficialis digiti III, del cual es indiferenciable proximalmente. Inserta mediante un largo y delgado tendón en la falange proximal del dígito III.

- Extensor brevis superficialis digiti $V$. Se origina en la superficie dorsal del fibular, en el tercio distal del hueso, lateralmente al origen del m. extensor brevis superficialis digiti I. Inserta por un delgado tendón en la superficie dorsal de la base de la falange proximal del dígito $\mathrm{V}$.

- Extensor brevis superficialis hallucis. Se origina en el borde dorsomedial de la epífisis distal del fibular proximal al origen de los $\mathrm{mm}$. extensores breves superficiales II y III. Inserta medialmente en la superficie dorsal del metatarso I con una aponeurosis hacia el prehallux, y lateralmente en la articulación metatarso-falange del dígito I. 


\section{III.10. Descripción y codificación de los caracteres.}

\section{III.10.1. Caracteres de cráneo y musculatura craneana.}

\section{III.10.1.1 Condrocráneo. Neurocráneo.}

Caracter 0. Forma del neurocráneo. De acuerdo a que figura geometrica se asimila el neurocráneo larvario en vista dorsal se reconocen dos estados de caracter: subtriangular con el ancho maximo al nivel del arco subocular del palatocuadrado ligeramente por delante del proceso ascendente (0), y sub-cuadrangular con el ancho al nivel del proceso articular del palatocuadrado ligeramente menor al ancho máximo al nivel del proceso ascendente (1). Atelognathus patagonicus, Batrachyla antartandica, B. leptopus, B. taeniata, Chacophrys pierottii (según Wild, 1999), Eupsophus calcaratus (según Vera Candioti et al. 2005, si bien no fue especificado en el texto se codifico teniendo en cuenta la figura 2A de dicho trabajo) Hylorina sylvatica y Pleurodema borelli presentan el estado (0). Alsodes gargola y Ceratophrys ornata presentan el estado (1). No se pudo asignar el estado de caracter para Batrachyla fitzroya y B. nibaldoi por carecer de larvas de esas especies, con lo cual se entraron a la matriz como datos faltantes (?).

Comentarios: La determinación de los estados debe hacerse con larvas tipicas (estadios 31-38).

\section{Caracter 1. Longitud de los cuernos trabeculares (Fig. 46). Los cuernos} trabeculares constituyen proyecciones de la placa etmoidea que se dirigen anteriormente hasta establecer una articulación con el cartílago suprarrostral (Cannatella, 1999). Se han descrito diversos caracteres relativos a la morfología y morfometría de los cuernos trabeculares (e.g., longitud relativa, tipo de articulación con el suprarrostral, etc). Ver Larson \& de Sá (1998), Haas (2003) y Pugéner et al. (2003) para más detalle. Con relación al caracter longitud relativa, los cuernos trabeculares pueden ser proporcionalmente cortos o largos respecto de la longitud total del neurocráneo. Teniendo en cuenta esas proporciones se reconocen tres estados de caracter (modificado de Larsón \& de Sá, 1998): cuernos largos, proporción mayor al $12 \%(0)$, cuernos cortos, proporción entre 6 y $11 \%$ (1), y cuernos extremadamente cortos, proporción menor de 6 (2). Alsodes gargola, Atelognathus patagonicus, Batrachyla antartandica, B. leptopus, B. taeniata, Chacophrys pierottii (calculado a partir de los esquemas a escala dados por Wild, 1999), Hylorina sylvatica y 
Pleurodema borelli presentan el estado (0). Eupsophus calcaratus (según Vera

Candioti et al. 2005) presenta el estado (1). Ceratophrys ornata presenta el estado (2). No se pudo asignar el estado de caracter para Batrachyla fitzroya y B. nibaldoi por carecer de larvas de esas especies, con lo cual se entraron a la matriz como datos faltantes (?).

Comentarios: La determinación de los estados debe hacerse con larvas tipicas (estadios 31-38).

Caracter 2. Posición del proceso lateral de los cuernos trabeculares (Fig. 46). El proceso lateral de los cuernos trabeculares es una proyección cartilaginosa de los mismos que recibe al ligamento cuadrado et moidal desde el margen anterior de la comisura cuadrado craneana anterior (Cannatella, 1999). De acuerdo a si este proceso es o no visible en vista dorsal del neurocraneo se reconocen dos estados de caracter: proceso lateral no visible en vista dorsal porque se halla ventralizado (0), y visible a causa de hallarse lateralizado (1). Batrachyla taeniata, Eupsophus calcaratus (según Vera Candioti et al. 2005, si bien no fue especificado en el texto se codifico teniendo en cuenta la figura 2A de dicho trabajo), Ceratophrys ornata e Hylorina sylvatica presentan el estado (0). Alsodes gargola, Atelognathus patagonicus, Batrachyla antartandica, B. leptopus, Chacophrys pierottii (según Wild, 1999) y Pleurodema borelli se codificaron (1). No se pudo asignar el estado de caracter para Batrachyla fitzroya y $B$. nibaldoi por carecer de larvas de esas especies, con lo cual se entraron a la matriz como datos faltantes (?).

Comentarios: La determinación de los estados debe hacerse con larvas tipicas (estadios 31-38).

Caracter 3. Dilatación del extremo distal de los cuernos trabeculares (Fig. 46). Se reconocen dos estados de carácter: el espacio medio a nivel distal entre ambos cuernos es igual o mayor al ancho del cuerno a ese nivel (0), y el espacio medio a nivel distal entre ambos cuernos no es mayor al ancho del cuerno a ese nivel (1). Alsodes gargola, Atelognathus patagonicus, Batrachyla antartandica, B. leptopus, Chacophrys pierottii (según Wild, 1999), Eupsophus calcaratus, Hylorina sylvatica y Pleurodema borelli presentan el estado (0). B. taeniata presenta el estado (1). No se pudo asignar el estado de caracter para Batrachyla fitzroya y B. nibaldoi por carecer de larvas de esas especies, con lo cual se entraron a la matriz como datos faltantes (?). Ceratophrys ornata presenta cuernos extremadamente cortos (caracter 2.2) y uniformemente anchos, tanto que el espacio medio distal es menor al ancho del 
A

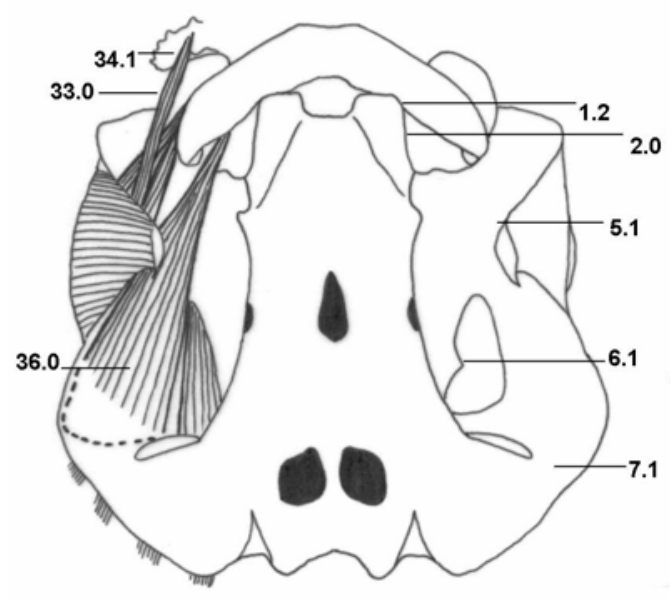

c

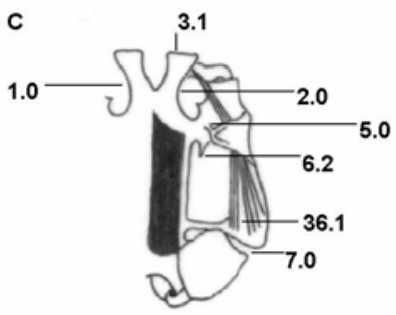

E

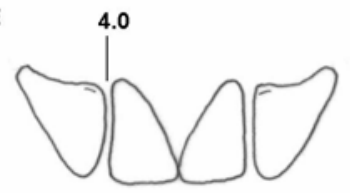

G

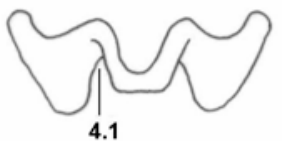

B
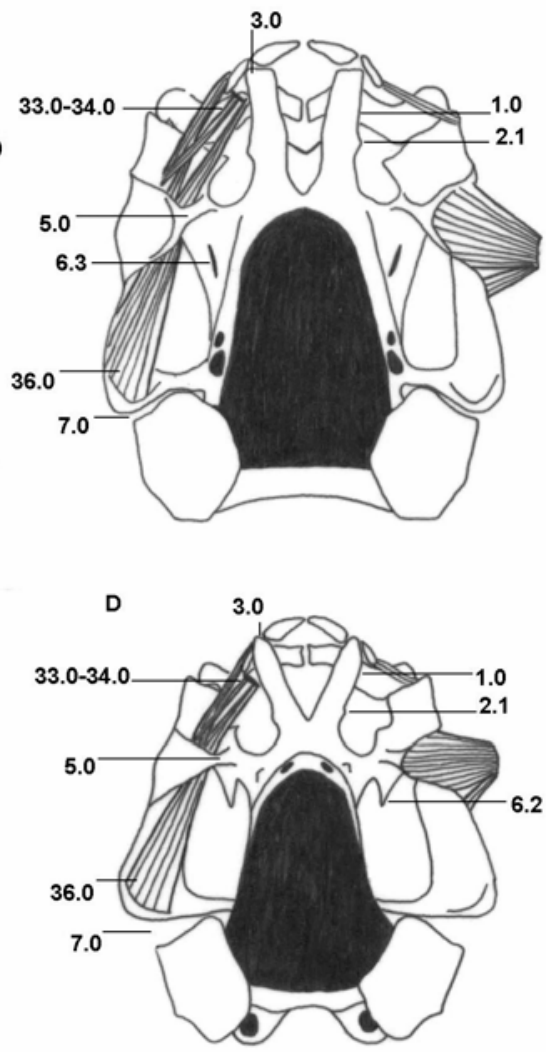

$\mathbf{F}$

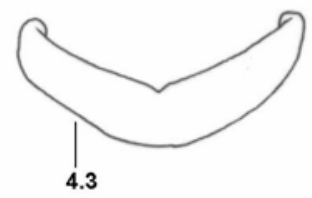

H

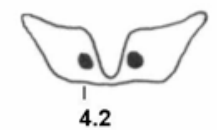

Figura 46. Estados de los caracteres 1-7 y 33, 34 y 36 esquematizados en craneos de larvas de algunas de las diferentes especies analizadas. (A) Vista dorsal del neurocráneo, arco mandibular y musculatura mandibular asociada en Ceratophrys ornata al estadio 31. (B) Vista dorsal del neurocráneo, arco mandibular y musculatura mandibular asociada en Alsodes gargola al estadio 32. (C) Vista dorsal derecha del neurocráneo, arco mandibular y musculatura mandibular asociada en Batrachyla taeniata al estadio 35. (D) Vista dorsal del neurocráneo, arco mandibular y musculatura mandibular asociada en Batrachyla leptopus al estadio 35. (E) - (H) Vistas frontales del cartílago suprarrostral de Alsodes gargola Ceratophrys ornata, Eupsophus calcaratus (redibujado de Vera Candioti et al., 2004) y Pleurodema borelli respectivamente. Esquemas sin escala. 
cuerno a pesar que no existe dilatación distal en los mismos. Entonces se considero el caracter inaplicable para esta especie y fue entrado a la matriz como (-).

Comentarios: La determinación de los estados debe hacerse con larvas tipicas (estadios 31-38).

Caracter 4. Tipo de unión entre alas y cuerpo del cartílago suprarrostral (Fig. 46). El cartílago suprarrostal es una estuctura que forma la mandibula superior en larvas de anuros que normalmente está compuesta por dos cartílagos mediales (cuerpos) y dos laterales (alas). Su origen es a partir del extremo anterior de los cuernos trabeculares formando parte de las estructuras anteriores del neurocráneo que derivan de las crestas neurales. Se han descrito divesos caracteres relativos al cartílago suprarrostral (ver Larsón \& de Sá, 1998, Haas, 2003 y Pugéner et al., 2003 para una descripción de los mismos). De acuerdo al modo en que las alas se unen con los cuerpos se reconocen cuatro estados de caracter (modificado de Larsón \& de Sá, 1998 y Haas, 2003): unión sindesmótica (0), unión sincondrótica proximal (1), uniones sincondróticas proximal y distal (2), y unión sincondrótica total (3). El estado (0) lo presentan Alsodes gargola, Atelognathus patagonicus, Batrachyla antartandica, B. leptopus, B. taeniata, e Hylorina sylvatica. Eupsophus calcaratus (según Vera Candioti et al. 2005, si bien no fue especificado en el texto se codificó teniendo en cuenta la figura 2B de dicho trabajo) presenta el estado (1). Chacophrys pierottii (según Wild, 1999) y Pleurodema borelli presentan el estado (2). El estado (3) lo presenta Ceratophrys ornata. No se pudo asignar el estado de caracter para Batrachyla fitzroya y B. nibaldoi por carecer de larvas de esas especies, con lo cual se entraron a la matriz como datos faltantes (?). Comentarios: La determinación de los estados debe hacerse con larvas tipicas (estadios 31-38).

Caracter 5. Comisura cuadrado-orbitaria (Fig. 46). El margen libre dorsal del proceso muscular del palatocuadrado puede o no establecer una conexión sincondrotica con la comisura cuadrado craneana anterior mediante la condrificación del ligamento tectum que pasa a fomar la comisura cuadrado orbitaria (Haas, 2003). De acuerdo a la presencia o no de dicha comisura se reconocen dos estados de caracter (modificado de Haas, 2003): ligamento tectum condrificado totalmente (comisura presente) (0), o sin condrificar (comisura ausente) (1). El estado (0) lo presentan Alsodes gargola, Atelognathus patagonicus, Batrachyla antartandica, $B$. leptopus, B. taeniata, Chacophrys pierottii (según Wild, 1999), Hylorina sylvatica y Pleurodema borelli. Ceratophrys ornata y Eupsophus calcaratus (según Vera Candioti et al. 2005, si bien no fue especificado en el texto se codificó teniendo en cuenta la 
figura 2A de dicho trabajo) presentan el estado (1). No se pudo asignar el estado de caracter para Batrachyla fitzroya y B. nibaldoi por carecer de larvas de esas especies, con lo cual se entraron a la matriz como datos faltantes (?).

Comentarios: La determinación de los estados debe hacerse con larvas tipicas (estadios 31-38).

\section{III.10.1.2. Condrocráneo. Arco mandibular.}

Caracter 6. Proceso pseudopterigoideo (Fig. 46). El proceso pseudopterigoideo es una proyección posterior de la comisura cuadrado craneana anterior presente solo en determinados grupos de anuros. De acuerdo a su grado de desarrollo se reconocen tres estados de caracter (modificado de Haas, 2003): ausente (0), corto con una longitud no mayor al doble de su base (1), largo con una longitud mayor al doble de su base, y libre de la base del cráneo (2), y largo pero fusionado a lo largo de su margen medial con la base del cráneo (3). Pleurodema borelli presenta el estado (0). Ceratophrys ornata, Chacophrys pierottii (según Wild, 1999) y Eupsophus calcaratus (según Vera Candioti et al. 2005) presentan el estado (1). Atelognathus patagonicus, Batrachyla antartandica, B. leptopus, B. taeniata, e Hylorina sylvatica poseen el estado (2). Alsodes gargola muestra el estado (3). No se pudo asignar el estado de caracter para Batrachyla fitzroya y B. nibaldoi por carecer de larvas de esas especies, con lo cual se entraron a la matriz como datos faltantes (?).

Comentarios: La determinación de los estados debe hacerse con larvas tipicas (estadios 31-38). El proceso pseudopterigoideo de Ceratophrys ornata fue considerado ausente para otras especies del género (Wild, 1997; Vera Candioti, 2005) e incluso paa la especie aquí estudiada (Haas, 2003), dado que se halla posteriorizado por el gran desarrollo de la comisura cuadrado craneana anterior.

Caracter 7. Proceso ótico larvario (Fig. 46). El proceso ótico larvario es producto de la condrificación del ligamento ótico que une el proceso anterior de la cresta parótica larvaria con el margen posterolateral del palatocuadrado (Haas, 2003). De acuerdo a la precencia o no de dicho proceso se reconocen dos estados de caracter: ausente (0), y presente (1). Alsodes gargola, Atelognathus patagonicus, Batrachyla antartandica, $B$. leptopus, B. taeniata, Eupsophus calcaratus (según Vera Candioti et al. 2005) e Hylorina sylvatica y Pleurodema borelli presentan el estado (0). Ceratophrys ornata y Chacophrys pierottii (según Wild, 1999) presentan el estado (1). No se pudo asignar el 
estado de caracter para Batrachyla fitzroya y B. nibaldoi por carecer de larvas de esas especies, con lo cual se entraron a la matriz como datos faltantes (?).

Comentarios: La determinación de los estados debe hacerse con larvas tipicas (estadios 31-38).

\section{III.10.1.3. Condrocráneo. Aparato hiobranquial.}

\section{Caracter 8. Unión del ceratobranquial II y la placa hipobranquial (Fig. 48). El} ceratobranquial I de larvas de anuros siempre se une sincondroticamente con la placa hipobranquial, excepto en Ascaphus y en Discoglossidae en los cuales esta articulado (Haas, 2003). En cambio, los restantes ceratobranquiales pueden presentar dos tipos de unión con la placa hipobranquial: sindesmótica y sincondrótica, las que fueron codificadas (0) y (1) respectivamente. Batrachyla antartandica, B. leptopus, B. taeniata, Ceratophrys ornata, Eupsophus calcaratus (según Vera Candioti et al. 2005, si bien no fue especificado en el texto se codifico teniendo en cuenta la figura $2 \mathrm{E}$ de dicho trabajo), e Hylorina sylvatica presentan el estado (0). En Alsodes gargola, Atelognathus patagonicus, Chacophrys pierottii (según Wild, 1999) y Pleurodema borelli la unión es sincondrotica (1). No se pudo asignar el estado de caracter para Batrachyla fitzroya y $B$. nibaldoi por carecer de larvas de esas especies, con lo cual se entraron a la matriz como datos faltantes (?).

Comentarios: La determinación de los estados debe hacerse con larvas tipicas (estadios 31-38).

Es común que uniones sindesmoticas muy intimas debido a la proximidad entre el ceratobranquial y la placa hipobranquial tomen ligeramente el azul de Alcian (e.g., algunos especimenes de Hylorina sylvatica de Puerto Murta, Chile). Esos casos fueron codificados como uniones sindesmoticas (0).

Caracter 9. Unión del ceratobranquial III y la placa hipobranquial (Fig. 48). Para detalle de la codificación ver el caracter anterior. Atelognathus patagonicus, Batrachyla antartandica, B. leptopus, B. taeniata, Ceratophrys ornata, Eupsophus calcaratus (según Vera Candioti et al. 2005, si bien no fue especificado en el texto se codifico teniendo en cuenta la figura 2E de dicho trabajo), Hylorina sylvatica y Pleurodema borelli presentan estado (0). En Alsodes gargola y Chacophrys pierottii (según Wild, 1999) se observa el estado (1). No se pudo asignar el estado de caracter para Batrachyla fitzroya y $B$. nibaldoi por carecer de larvas de esas especies, con lo cual se entraron a la matriz como datos faltantes (?). 

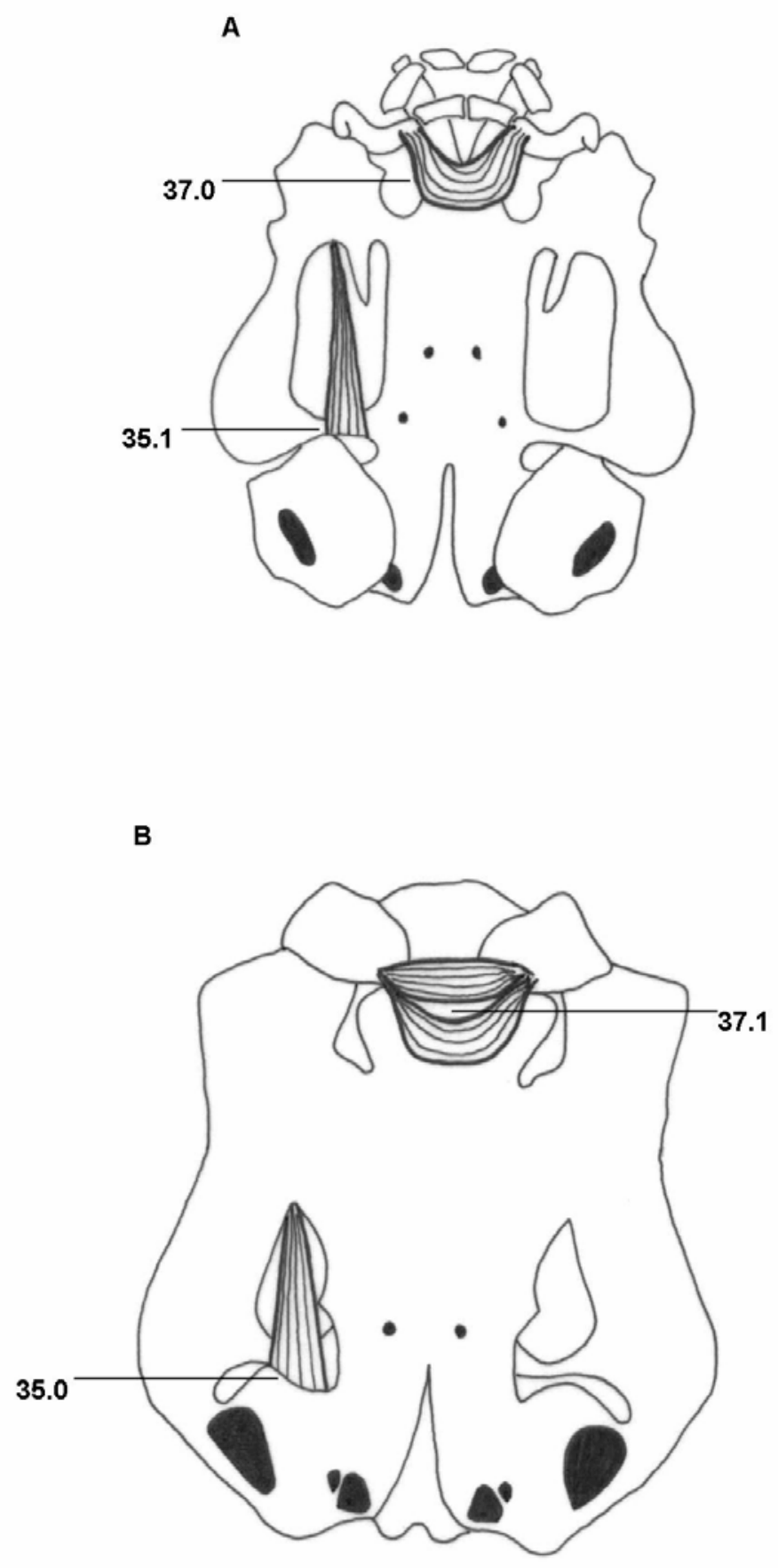

Figura 47. Estados de los caracteres 35 y 37 esquematizados en una vista ventral de cráneos de larvas de Batrachyla leptopus al estadio 31 (A) y de Ceratophrys ornata al estadio 31 (B). Esquemas sin escala. 


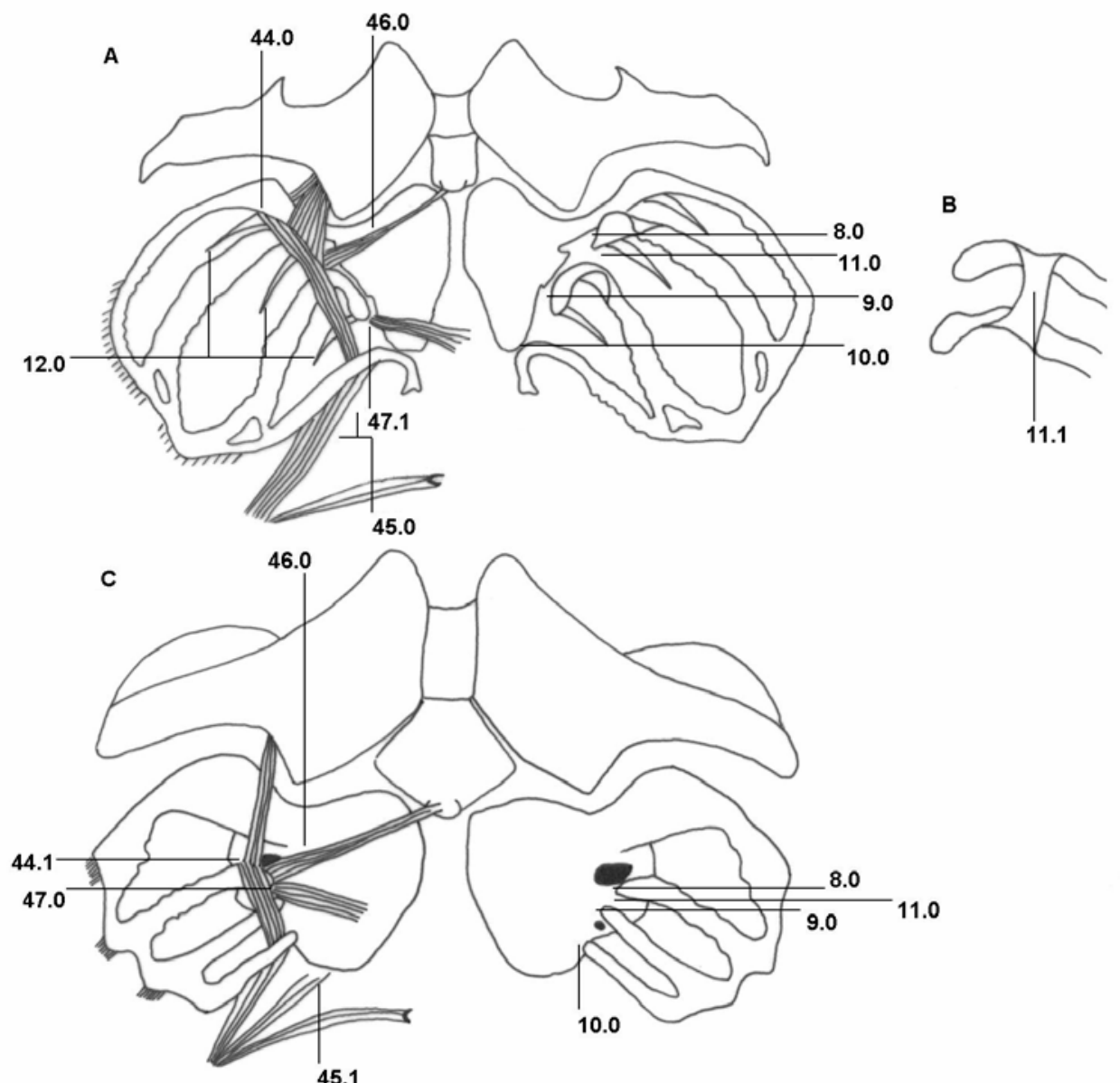

45.1

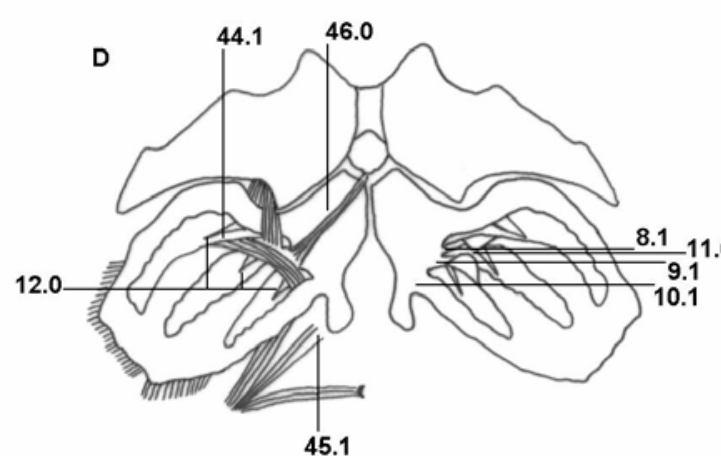

E

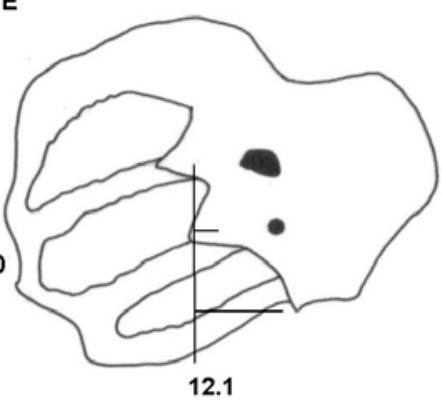

Figura 48. Estados de los caracteres 8-12 y 44-47 esquematizádos en los aparatos hiobranquiales de larvas de algunas de las diferentes especies analizadas. (A) Vista ventral del aparato hiobranquial y musculatura branquial asociada en Batrachyla leptopus al estadio 31. (B) Vista dorsal en detalle del puente branquial de Pleurodema borelli. (C) Vista ventral aparato hiobranquial y musculatura branquial asociada en Ceratophrys ornata al estadio 31. (D) Vista ventral aparato hiobranquial y musculatura branquial asociada en Alsodes gargola al estadio 32. (E) Detalle en vista dorsal de la placa hipobranquial izquierda y los ceratobranquiales Ceratophrys ornata al estadio 31. Esquemas sin escala. 
Comentarios: La determinación de los estados debe hacerse con larvas tipicas (estadios 31-38).

Caracter 10. Unión del ceratobranquial IV y la placa hipobranquial (Fig. 48). Para detalle de la codificación ver el caracter 9. Batrachyla antartandica, B. leptopus, $B$. taeniata, Ceratophrys ornata, Eupsophus calcaratus (según Vera Candioti et al. 2005, si bien no fue especificado en el texto se codifico teniendo en cuenta la figura $2 \mathrm{E}$ de dicho trabajo), Hylorina sylvatica y Pleurodema borelli presentan el estado (0). Alsodes gargola, Atelognathus patagonicus y Chacophrys pierottii (según Wild, 1999) poseen el estado (1). No se pudo asignar el estado de caracter para Batrachyla fitzroya y $B$. nibaldoi por carecer de larvas de esas especies, con lo cual se entraron a la matriz como datos faltantes (?).

Comentarios: La determinación de los estados debe hacerse con larvas tipicas (estadios 31-38).

Caracter 11. Puente branquial (Fig. 48). Los ceratobranquiales II y III presentan cada uno un proceso branquial proximal que en algunos grupos pueden fusionarse formando un puente branquial (Haas, 2003). De acuerdo a la presencia o no de puente se reconocen dos estados de caracter (según Larsón \& de Sá, 1998 y Haas, 2003): puente ausente, conexión ligamentosa entre los procesos branquiales (0), y puente presente (1). Alsodes gargola, Atelognathus patagonicus, Batrachyla antartandica, $B$. leptopus, B. taeniata, Ceratophrys ornata, Eupsophus calcaratus (según Vera Candioti et al. 2005, si bien no fue especificado en el texto se codificó teniendo en cuenta la figura 2E de dicho trabajo), e Hylorina sylvatica presentan el estado (0). Chacophrys pierottii (según Wild, 1999) y Pleurodema borelli presentan el estado (1). No se pudo asignar el estado de caracter para Batrachyla fitzroya y B. nibaldoi por carecer de larvas de esas especies, con lo cual se entraron a la matriz como datos faltantes (?). Comentarios: La determinación de los estados debe hacerse con larvas tipicas (estadios 31-38). Haas (2003) consideró que C. ornata presenta proceso branquial cerrado. No he observado este estado en ninguno de los 5 ejemplares observados (estadios 31 hasta 39).

Caracter 12. Espículas (Fig. 48). De acuerdo a la fusión o no de las espículas con la placa hipobranquial se reconocen dos estados: espículas libres (0), o espículas fusionadas a la placa (1). Alsodes gargola, Atelognathus patagonicus, Batrachyla antartandica, B. leptopus, B. taeniata, Eupsophus calcaratus (según Vera Candioti et al. 2005), Hylorina sylvatica y Pleurodema borelli presentan el estado (0). Ceratophrys ornata y Chacophrys pierottii (según esquemas dados por Wild, 1999) presentan el 
estado (1). No se pudo asignar el estado de caracter para Batrachyla fitzroya y $B$. nibaldoi por carecer de larvas de esas especies, con lo cual se entraron a la matriz como datos faltantes (?).

Comentarios: La determinación de los estados debe hacerse con larvas tipicas (estadios 31-38). Autores previos que han trabajado con diversas especies de Ceratophrys (Wild, 1997; Haas, 2003; Vera Candioti, 2005) y con Chacophrys pierottii (Wild, 1999) han interpretado que las espículas de estos grupos se han perdido. En las larvas de $C$. ornata aquí examinadas y en los esquemas dados por los autores mencionados es evidente la existencia una proyecciòn triangular al nivel donde normalmente aticulan las espículas. Adicionalmente tambien se verifica la presencia de dos foramenes, uno en la base de cada una de las dos proyecciones triangulares más anteriores. Por lo expuesto he considerado que en estos grupos las espículas no se hallan reducidas si no que estan muy bien desarolladas, pero fusionadas a la placa hipobranquial.

\section{III.10.1.4. Osteocráneo. Neurocráneo arco mandibular.}

\section{Caracter 13. Tiempo de aparición de los huesos paraesfenoides, frontoparietal y}

exoccipital. En la mayoría de las especies de anuros para los que se conoce la secuencia de osificación craneana, el paraesfenoides, frontoparietal y exoccipital son los primeros elementos óseos en osificar durante el desarrollo (Trueb, 1985), generalmente antes del climax metamórfico. De acuerdo al momento en que aparecen los centros de dichos huesos se reconocen dos estados de caracter: aparición antes del climax metamórfico (0), o aparición durante el climax metamórfico, o postmetamorficamente (1). Alsodes gargola, Atelognathus patagonicus, Batrachyla antartandica, B. leptopus, B. taeniata, Ceratophrys ornata, Chacophrys pierottii (según Wild, 1999), Hylorina sylvatica y Pleurodema borelli presentan el estado (0). Eupsophus calcaratus presenta el estado (1) (según Vera Candioti et al., 2005). No se pudo asignar el estado de caracter para Batrachyla fitzroya y B. nibaldoi por carecer de larvas de esas especies, con lo cual se entraron a la matriz como datos faltantes (?). Caracter 14. Posición de los dientes vomerianos (Fig. 49). Vallejos Vallejos (1994) describió tres estados para la posición de la cresta dentigera del vomer respecto del eje axial: recta (Batrachyla taeniata), ligeramente oblicua (B. leptopus) y bien oblicua (B. antartandica). Dado que no he observado la variación reportada por Vallejos Vallejos (1994) en el material estudiado para la presente tesis, y considerando que la 
misma autora no empleó el caracter para su análisis filogenético de Batrachyla he optado por reconocer dos estados de caracter de acuerdo a la posición del eje mayor de la cresta dentigera del vomer respecto del eje axial: transversal (0), y oblicua (1). Batrachyla spp., e Hylorina sylvatica presentan el estado (0). Alsodes gargola, Atelognathus patagonicus, Ceratophrys ornata, Chacophrys pierottii, Eupsophus calcaratus y Pleurodema borelli presentan el estado (1).

Comentarios: Basso (1994) empleó la posición de la cresta dentigera del vomer respecto del límite posterior de las coanas (con 3 estados de caracter) en su análisis del género Batrachyla. He descartado del presente análisis a la posición de la cresta dentigera del vomer respecto del límite posterior de las coanas por los siguientes motivos: 1) en muchos casos el caracter es susceptible de codificarse erroneamente debido a su dependencia con el angulo de observación, y 2) cuando se verifica el patron oblicuo de la cresta (Alsodes gargola, Atelognathus patagonicus, Eupsophus calcaratus, Pleurodema borelli) es muy dificil codificar el caracter en cuanto a la posición respecto del borde posterior de las coanas, a causa de la extensión y variabilidad en longitud de la cresta dentigera.

Caracter 15. Morfología del extremo medial del palatino (Fig. 49). Lynch (1978), en su descripción del género Atelognathus citó la existencia de un proceso anteromedial al palatino, el cual se encuentra en todas las especies de ese género estudiadas en su trabajo. Aquí se empleará tal caracter, para el cual se reconocen dos estados: extremo medial del palatino simple a causa de la ausencia de un proceso anterior (0), y extremo medial bífido a causa de la presencia de proceso anterior (1). Alsodes gargola, Batrachyla spp., Ceratophrys ornata, Chacophrys pierottii, Eupsophus calcaratus, Hylorina sylvatica y Pleurodema borelli presentan el estado (0). Atelognathus patagonicus presenta el estado (1).

Caracter 16. Separación de los cóndilos occipitales (Fig. 49). Heyer (1975) y Lynch $(1971,1978)$ describen este caracter y lo aplican al estudio sistemático de la familia Leptodactylidae. Posteriormente, Basso (1994) lo modificó para su análisis de las relacion es interespecíficas del género Batrachyla. Según Basso (1994) se reconocen 2 estados: cóndilos separados medialmente por una distancia claramente mayor al ancho condilar (0), y separados por una distancia menor o igual (1). Batrachyla antartandica, B. fitzroya, B. leptopus y Eupsophus calcaratus presentan el estado (0). Alsodes gargola, Atelognathus patagonicus, B. nibaldoi, B. taeniata, Ceratophrys ornata, Chacophrys pierottii, Hylorina sylvatica y Pleurodema borellipresentan el estado (1). 

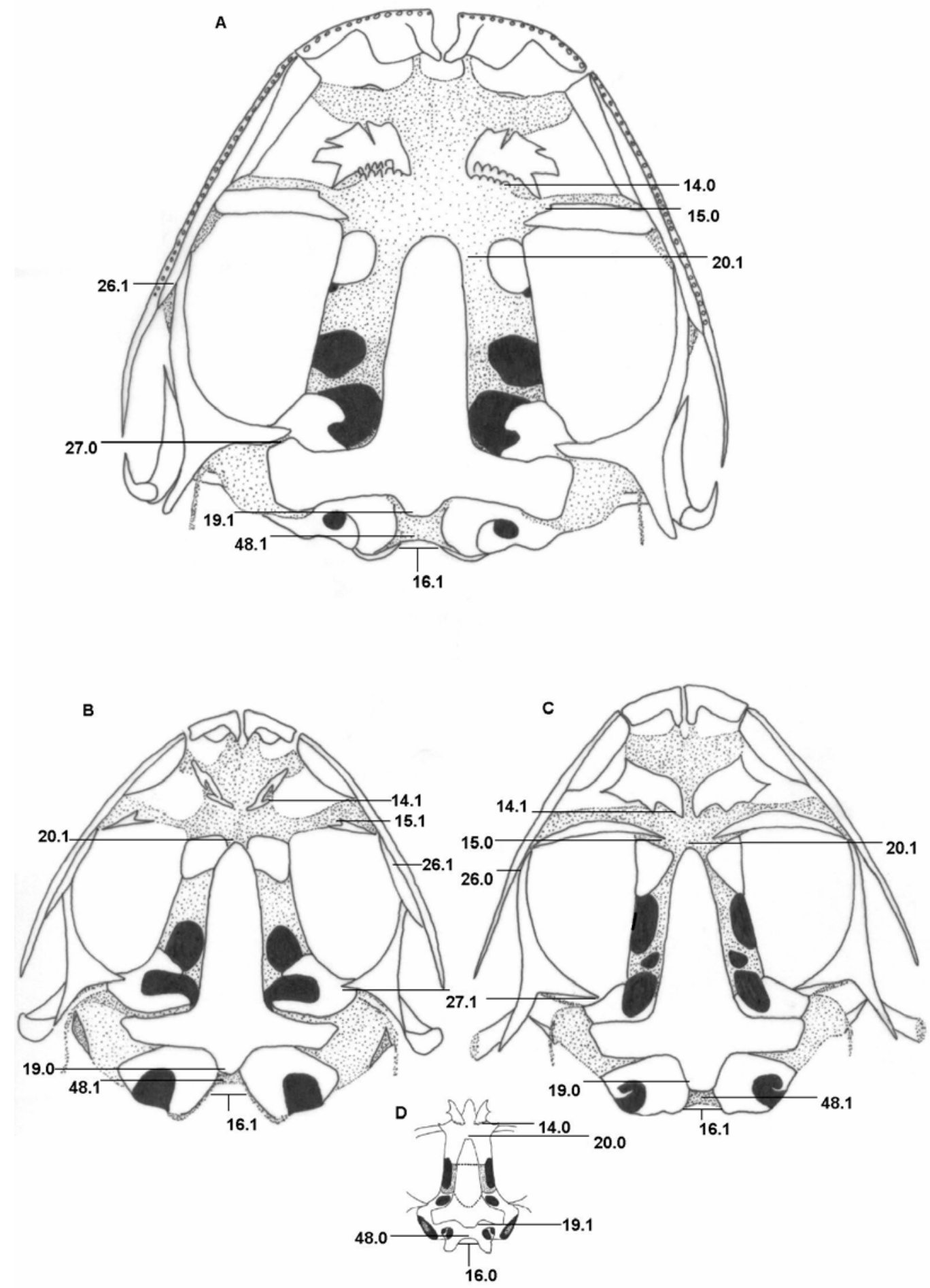

Figura 49. Estados de los caracteres 14 16, 19-20, 26-27 y 48 esquematizados cráneos de adultos de algunas de las diferentes especies analizadas. (A) Vista ventral del cráneo de Hylorina sylvatica (B) Vista ventral del cráneo de Atelognathus patagonicus. (C) Vista ventral del cráneo de Pleurodema borelli. (D) Vista ventral de la caja cráneana de Batrachyla leptopus. Esquemas sin escala. 

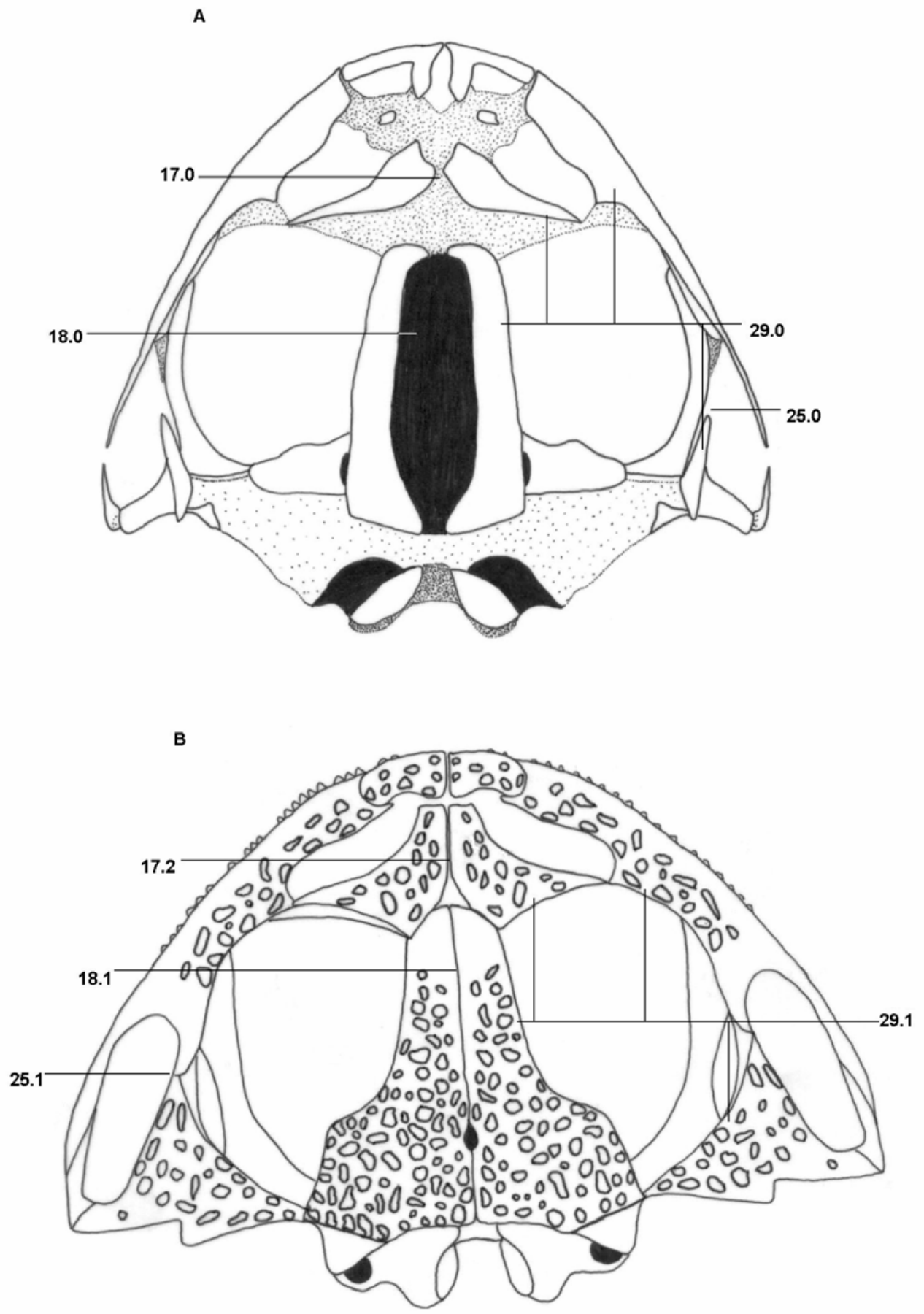

Figura 50. Estados de los caracteres 17-18, 25 y 29 esquematizados cráneos de adultos de algunas de las diferentes especies analizadas. (A) Vista dorsal del cráneo de Hylorina sylvatica. (B) Vista dorsal del cráneo de Chacophrys pierottii. Esquemas sin escala. 

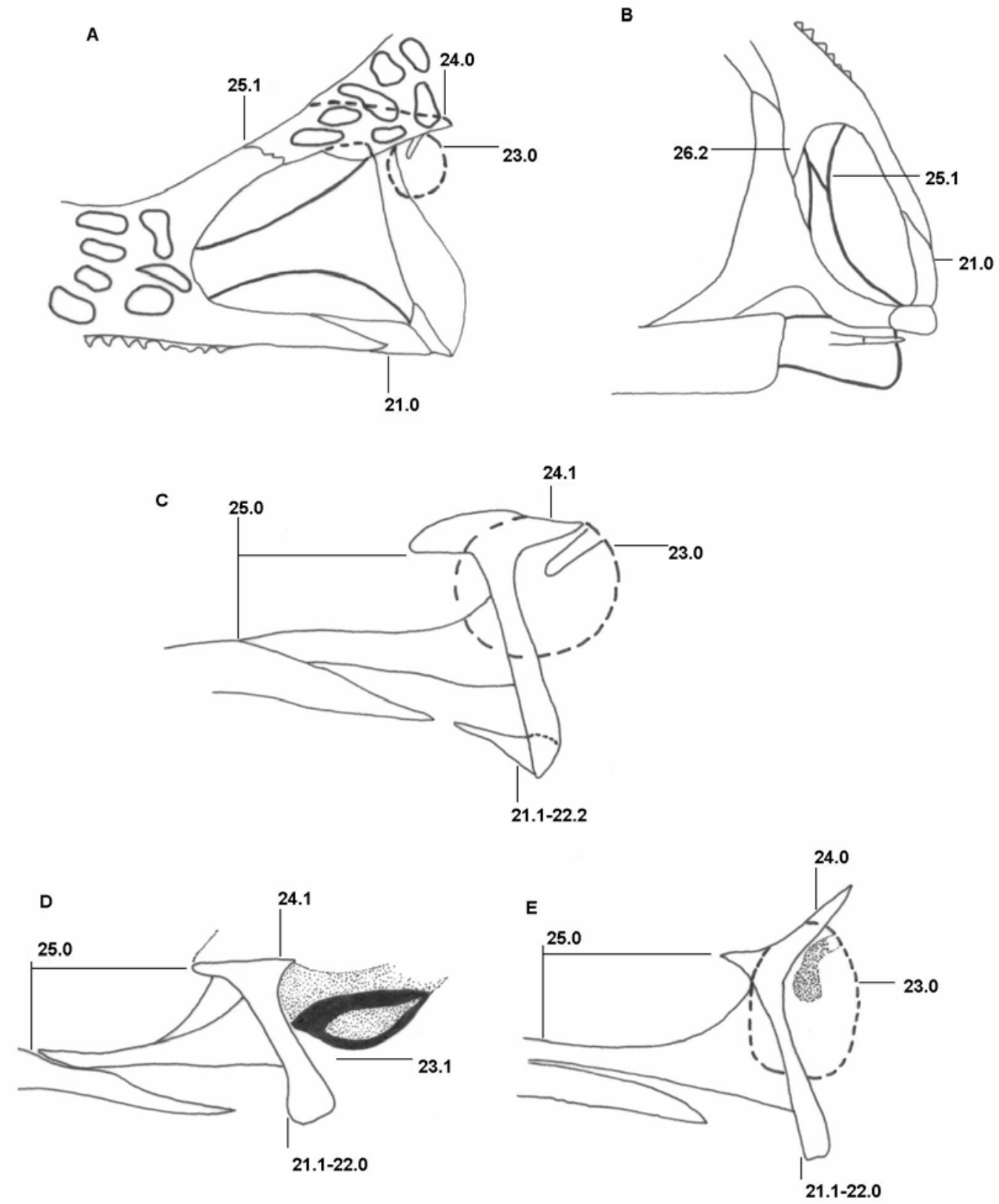

Figura 51. Detalle de la región ótica en algunas de las especies analizadas mostrando los estados de los caracteres 21 al 26. (A) Vista lateral en Chacophrys pierottii. (B) Vista ventral en Chacophrys pierottii. (C) Vista lateral en Hylorina sylvatica. (D) Vista lateral en Atelognathus patagonicus. (E) Vista lateral en Pleurodema borellii. Esquemas sin escala. 
Comentarios: En trabajos previos sobre la base de las especies Batrachyla antartandica, B. fitzroya, B. leptopus y B. taeniata (Basso, 1994), B. leptopus y B. taeniata (Heyer, 1975), y B. nibaldoi (Formas, 1997) se consideró que el género Batrachyla se caracteriza por presentar cóndilos occipitales separados medialmente por una distancia claramente mayor al ancho condilar (estado 0 del presente trabajo).

Caracter 17. Grado de desarrollo de los nasales (Fig. 50). Este caracter fué descrito por Lynch (1978) y empleádo por Vallejos Vallejos (1994) en su análisis de las relaciones del género Batrachyla. A partir del material analizádo para este trabajo, reconozco tres estados de caracter: nasales bien desarrollados al punto de estar el izquierdo y el derecho practicamente en contacto a lo largo de toda la linea media dorsal, dejando solo expuesto al septo nasal (0), situación intermedia donde el izquierdo y el derecho están casi en contacto al nivel anterior, posteriormente estan bien separados (1), y nasales ampliamente separados el derecho del izquierdo a lo largo de toda la linea media dorsal, dejando expuestos al septo nasal y a la porción medial del techo nasal (2). El estado (0) lo presentan Ceratophrys ornata y

Chacophrys pierottii. El estado (1) lo presenta Atelognathus patagonicus. El estado (2) lo presentan Alsodes gargola, Batrachyla spp., Eupsophus calcaratus, Hylorina sylvatica y Pleurodema borelli.

Caracter 18. Fontanela frontoparietal (Fig. 50). De acuerdo al grado de exposición de la fontanela frontoparietal con relación al desarrollo de los frontoparietales, Heyer (1975) reconoció dos estados de caracter: fontanela expuesta y no expuesta. Todas las especies empleadas para el presente trabajo muestran fontanela expuesta en diferente grado. Por tal motivo hé decidido considerar dos estados de caracter: 0 ) ancho de la fontanela frontoparietal en vista dorsal heterogéneo, con variaciones de espesor, siempre estando bien separados ambos frontoparietales, y (1) fontanela frontoparietal sumamente reducida y homogénea a lo largo de toda su longitud, lo que determina que los frontoparietales derecho e izquierdo esten practicamente en contacto en la linea media. Alsodes gargola, Atelognathus patagonicus, Batrachyla spp, Eupsophus calcaratus, Hylorina sylvatica y Pleurodema borelli presentan el estado (0). Ceratophrys ornata y Chacophrys pierottii presentan el estado (1). Comentarios: Vallejos Vallejos (1994) analizó osteologicamente a tres de las cinco especies de Batrachyla y reportó para ellas cuatro patrones de exposición de la fontanela frontoparietal en relación al desarrollo de los frontoparietales (patrones denominados A, B, C y D). De ellos, Batrachyla antartandica y B. leptopus presentan sólo el patrón $A$, mientras que en $B$. taeniatapueden hallarse los cuatro patrones. 
Todos esos patrones caen en lo considerado estado (0) del presente trabajo. Lynch (1978) argumentó contra este caracter señalando que el grado de exposición de la fontanela frontoparietal es un fenómeno que varía con la edad y el sexo de los individuos. Yo también pienso que la variación con la edad es un fenómeno susceptible de ocurrir (la he observado en los ejemplares analizados de Chacophrys pierottii, no asi la relacionada al sexo y quizas a la edad se deban los diferentes patrones observados por Vallejos Vallejos (1994). De todas maneras, para codificar el caracter he considerado que, salvo Chacophrys, las especies analizadas que presentan el estado (0) nunca alcanzan al envejecer el estado (1). En Chacophrys si se observa un paulatino cerramiento de la fontanella en los especimenes de mayor tamaño (presumiblemente mayor edad), pero esta especie há sido codificada considerando el estado final del caracter.

Caracter 19. Proceso posterior del paraesfenoides (Fig. 49). En todas las especies estudiadas se observó la presencia de un proceso posterior del paraesfenoides, que se ubica al nivel de la región occipital, creciendo hacia atrás desde el punto medio en que se encuentran ambas alas del hueso. De acuerdo a la longitud relativa de ese proceso se reconocen dos estados de caracter: proceso largo (igual o mayor a la mitad de la longitud máxima de cualquiera de las alas del paraesfenoides) (0), o proceso corto (menor a la mitad de la longitud maxima de cualquiera de las alas del paraesfenoides) (1). El estado (0) lo presentan Atelognathus patagonicus, Eupsophus calcaratus y Pleurodema borelli. El estado (1) lo presentan Alsodes gargola, Batrachyla spp., Ceratophrys ornata, Chacophrys pierottiie Hylorina sylvatica. Caracter 20. Esfenoetmoides (Fig. 49). El esfenoetmoides es una autostosis, usualmente impar, que cierra lateral, ventral y anteriormente la caja craneana. De acuerdo a si las porciones derecha e izquierda son continuas o discontinuas ventralmente se reconocen dos estados de caracter: porción derecha e izquierda continuas medioventralmente (condición impar) (0), o porciones izquierda y derecha discontinuas medioventralmente (condición par). El estado (0) lo presentan Alsodes gargola, Batrachyla spp. Ceratophrys ornata, y Eupsophus calcaratus. El estado (1) lo presentan Atelognathus patagonicus, Chacophrys pierottii, Hylorina sylvatica y Pleurodema borelli.

Caracter 21. Desarrollo del hueso cuadradoyugal (Fig. 51). El arco maxilar de los anuros es incompleto debido a la perdida de hueso yugal (Trueb, 1973). Adicionalmente, en diversos grupos dentro del orden, existe una tendencia a la reduccion y pérdida del hueso cuadradoyugal. El grado de reduccion de este elemento 
ha sido empleado en dilucidar las relaciones dentro de Leptodactylidae (Heyer, 1975) y en la reconstrucción filogénetica del género Batrachyla (Basso, 1994; Vallejos Vallejos, 1994). Sin embargo, teniendo en cuenta los trabajos mencionados, existen evidentes divergencias de interpretación respecto de aquellos taxa en los cuales el hueso cuadradoyugal esta muy reducido (e.g., Batrachyla spp.). En particular, los taxa en los que se lo considera o muy reducido o ausente son las especies de Batrachyla e Hylorina sylvatica. Heyer (1975) consideró que el hueso cuadradoyugal está ausente en Batrachyla spp. e Hylorina, mientras que Vallejos vallejos (1994) lo consideró ausente en Batrachyla spp. y presente para Hylorina. No obstante ello, las tres especies de Batrachyla estudiadas por Vallejos Valllejos (1994) muestran la misma proyección anterior del hueso cuadrado que fue interpretada para Hylorina por Lavilla \& Lobo (1992) como hueso cuadradoyugal fuertemente reducido y fusionado al cuadrado. Del mismo modo, Basso (1994), consideró que Batrachyla spp. presenta hueso cuadradoyugal fuertemente reducido, aunque diferenciando la situación de Batrachyla respecto de Hylorina, género que lo tendria no tan reducido.

Teniendo en cuenta las diferentes interpretaciones mencionadas, creo conveniente que el mejor criterio para determinar la presencia de hueso cuadradoyugal sería observar la existencia o no de un centro de osificación independiente para el hueso. E centro del hueso cuadradoyugal no ha sido observado en las secuencias de desarrollo de Hylorina y Batrachyla empleadas para el presente trabajo. Por lo tanto queda pensar que el cuadradoyugal aparece postmetamorficamente o bien, como ya han sugerido otros autores sería un crecimiento anterior del hueso cuadrado. En los ejemplares adultos existe una sutura, a veces no muy clara, entre el hueso cuadrado y la proyeccion anterior del mismo (¿cuadradoyugal?) en las especies de Hylorina y Batrachyla. Por lo expuesto, hasta que no se disponga de amplías secuencias postmetamorficas, he optado por considerar ausente al hueso cuadrado yugal en esas especies. En consecuencia se ha codificado de la siguiente manera: cuadradoyugal presente, bien desarrollado y en contacto óseo con el maxilar (0), cuadradoyugal ausente (1). Alsodes gargola, Ceratophrys ornata, Chacophrys pierottii, y Eupsophus calcaratus presentan el estado (0). Atelognathus patagonicus, Batrachyla spp., Hylorina sylvatica y Pleurodema borelli presentan el estado (1).

Caracter 22. Proyección anterior del cuadrado (Fig. 51). En relación al caracter anterior se reconoce que las especies que carecen de hueso cuadradoyugal pueden o no presentar una proyección anterior del cuadrado. De acuerdo a si está presente o no dicha proyección se reconocen 2 estados: proceso anterior del cuadrado ausente (0), 
proceso presente pero separado del maxilar por un espacio mayor a la longitud de dicho proceso (1), y proceso presente y separado del maxilar por un espacio menor a la longitud de dicho proceso (2). Atelognathus patagonicusy Pleurodema borelli presentan el estado (0). Batrachyla spp. presenta el estado (1). Hylorina sylvatica presenta el estado (2). Alsodes gargola, Ceratophrys ornata, Chacophrys pierottiiy Eupsophus calcaratus presentan hueso cuadradoyugal bien desarollado y fueron ingresados a la matriz como datos inaplicables (-).

Caracter 23. Grado de desarrollo del aparato auditivo (Fig. 51). A nivel esqueletico, se considera que el aparato auditivo está reducido cuando no posee ni columela ni anillo timpánico. Entonces se reconocen dos estados de caracter: aparato completo (0), y aparato reducido (1). Batrachyla spp., Ceratophrys ornata, Chacophrys pierottii, Eupsophus calcaratus, Hylorina sylvatica y Pleurodema borellipresentan el estado (0). Alsodes gargola y Atelognathus patagonicus presentan el estado (1).

Caracter 24. Grado de desarrollo relativo de la rama ótica del escamoso (Fig. 51). Se reconocen 2 estados de caracter: rama ótica mayor que la rama anterior (0), y rama ótica menor o igual que la rama anterior (1). Chacophrys pierottii y Pleurodema borelli presentan el estado (0). Alsodes gargola, Atelognathus patagonicus, Batrachyla spp., Ceratophrys ornata, Eupsophus calcaratus e Hylorina sylvatica presentan el estado (1).

Comentarios: Lynch (1978) consideró que la mayoría de sus "telmatobinos inferiores" poseen la rama ótica del escamoso dirigida medialmente, a excepción de Batrachyla y Thoropa. Mis observaciones coinciden con las de Lynch (1978) solo para Alsodes gargola, pero discrepo en cuanto a Atelognathus, Eupsophus e Hylorina, géneros en los que observe a la rama ótica siempre recta, támpoco coincido respecto de Batrachyla donde algunos especimenes muestran una proyección medial atenuada de la rama ótica. Al tratarse de un fenómeno evidentemente variable y dada la imposibilidad de conocer por el momento los límites y las causas de tal variación, he decidido excluir del análisis el caracter presencia-ausencia de proyección medial de la rama ótica del escamoso.

Lynch (1978) reconoce a su vez grados de desarrollo de la rama ótica pero no especifica relativos a que con lo cual mi codificación del caracter, asi como su distribución en los géneros analizados difieren respecto de la de aquel autor.

Caracter 25. Contacto entre la rama anterior del escamoso y el maxilar (Figs. 5051). Se econocen 2 estados: contacto ausente (0) y contacto presente (1). Alsodes gargola, Atelognathus patagonicus, Batrachyla spp., Eupsophus calcaratus, Hylorina 
sylvatica y Pleurodema borelli presentan el estado (0). Ceratophrys ornata y Chacophrys pierotti presentan el estado (1).

Caracter 26. Reborde pterigoideo del maxilar (Figs. 49,51). Se reconocen tres estados de caracter: reborde ausente (0), reborde presente a modo de repisa (1), y reborde muy desarrollado proyectandose hacia atrás formando el proceso pterigoideo del maxilar (2). Eupsophus calcaratus y Pleurodema borelli presentan el estado (0). Alsodes gargola, Atelognathus patagonicus, Batrachyla spp., e Hylorina sylvatica presentan el estado (1). Ceratophrys ornata y Chacophrys pierottii presentan el estado (2).

Comentarios: Lynch (1978) consideró que dentro de sus telmatobinos inferiores, Caudiverbera y Telmatobufo presentan un amplio reborde pterigoideo, Batrachyla, Eupsophus y Thoropa presentan proceso pterigoideo, mientras que en los restantes géneros el maxilar no muestra proyección alguna hacia el pterigoides.

La sobreposición entre el maxilar y la rama zigomatica del pterigoides fué descrita por Lynch (1978) y empleada por Vallejos Vallejos (1994) en su análisis de las relaciones del género Batrachyla. Sobre la base de aquellos autores, pero con modificaciones, se reconocen 2 estados de caracter: la sobreposición entre maxilar y rama zigomatica del pterigoides es completa y sobrepasa anteriormente el nivel de la mitad de la orbita hasta alcanzar los palatinos (Alsodes gargola, Atelognathus patagonicus, Batrachyla spp., Ceratophrys ornata, Chacophrys pierottii, e Hylorina sylvatica) y sobreposición incompleta sobrepasando el nivel de la mitad de la orbita pero sin alcanzar los palatinos (Eupsophus calcaratus y Pleurodema borelli). En consecuencia el caracter "sobreposición entre el maxilar y la rama zigomatica del pterigoides" presenta los mismos estados para las especies aquí consideradas que el estado "reborde pterigoideo", por tal razón he considerado soló a uno de ellos, en este caso, al reborde pterigoideo.

\section{Caracter 27. Contacto entre la rama media del pterigoides y las alas del} paraesfenoides (Fig. 49). Según Lynch (1978), se reconocen dos estados de caracter: contacto presente (0), y contacto ausente (1). Alsodes gargola, Ceratophrys ornata, Chacophrys pierottii, Eupsophus calcaratus, e Hylorina sylvatica presentan el estado (0). Atelognathus patagonicus, Batrachylaspp., y Pleurodema borelli presentan el estado (1).

Comentarios: Lynch (1978) considero que, dentro de sus telmatobinos inferiores, la rama media del pterigoides y las alas del paraesfenoides contactan solo en Batrachophrynus, Caudiverbera, Eupsophus, Hylorina y Telmatobufo. Mis 
observaciones coinciden respecto de Alsodes gargola (Lynch menciona el contacto entre rama media del pterigoides y ala del paraesfenoides en su descripción del cráneo de Alsodes gargola, pero en su descripción de los caracteres considera que esa especie no presenta contacto entre ambos elementos) e Hylorina, pero difieren en cuanto a Eupsophus (Lynch no estudio E. calcaratus, la especie que he empleado en el presente trabajo). Sin embargo, respecto de Hylorina, Lavilla \& Lobo (1992) consideraron ausencia de contacto entre rama media del pterigoides y ala del paraesfenoides. Dadas las discrepancias expuestas, la asignación de los estados para las distintas especies analizadas será sobre la base de mis observaciones.

Caracter 28. Grado de osificación medioventral del oto-occipital (Fig. 49). El otooccipital es una autostosis que presenta doble origen, estando formada en parte por el opistótico y en parte por el exoccipital. En la región medioventral y más posterior del oto-occipital, que corresponde enteramente al exoccipital, he observado dos condiciones, que ya han sido empleadas en otros análisis (e.g., Faivovich, 2002), y cada una de ellas corresponde a un estado de caracter: 0) exoccipitales derecho e izquierdo continuos medioventralmente (condición impar), o 1) exoccipitales derecho e izquierdo separados por cartílago (condición par). Alsodes gargola, Batrachyla antartandica y $B$. leptopus presentan el estado (0). Atelognathus patagonicus, Batrachyla fitzroya, B. nibaldoi, Chacophrys pierottii, Eupsophus calcaratus, Hylorina sylvatica y Pleurodema borellipresentan el estado (1). Batrachyla taeniata y Ceratophrys ornata presentan ambas condiciones y se las codificó considerando el polimorfismo como ambigüedad $(0,1)$.

Caracter 29. Exostosis (Fig. 50). De acuerdo a la existencia de una osificación masiva de la dermis particularmente aquella asociada a los huesos de la boveda craneana se reconocen dos estados: expstosis ausentes (0), y presentes (1). Alsodes gargola, Atelognathus patagonicus, Batrachyla spp., Hylorina sylvatica, Eupsophus calcaratus y Pleurodema borelli presentan el estado (0). Ceratophrys ornata y Chacophrys pierottii presentan el estado (1).

Caracter 30. Contacto entre anguloesplenial y mentomeckeliano (Fig. 52). De acuerdo a la presencia o no de contacto óseo entre los huesos anguloesplenial y mentomeckeliano se reconocen 2 estados: contacto ausente (0), y contacto presente (1). Alsodes gargola, Atelognathus patagonicus, Batrachyla spp., Hylorina sylvatica, Eupsophus calcaratus y Pleurodema borelli presentan el estado (0). Ceratophrys ornata y Chacophrys pierottii presentan el estado (1). 


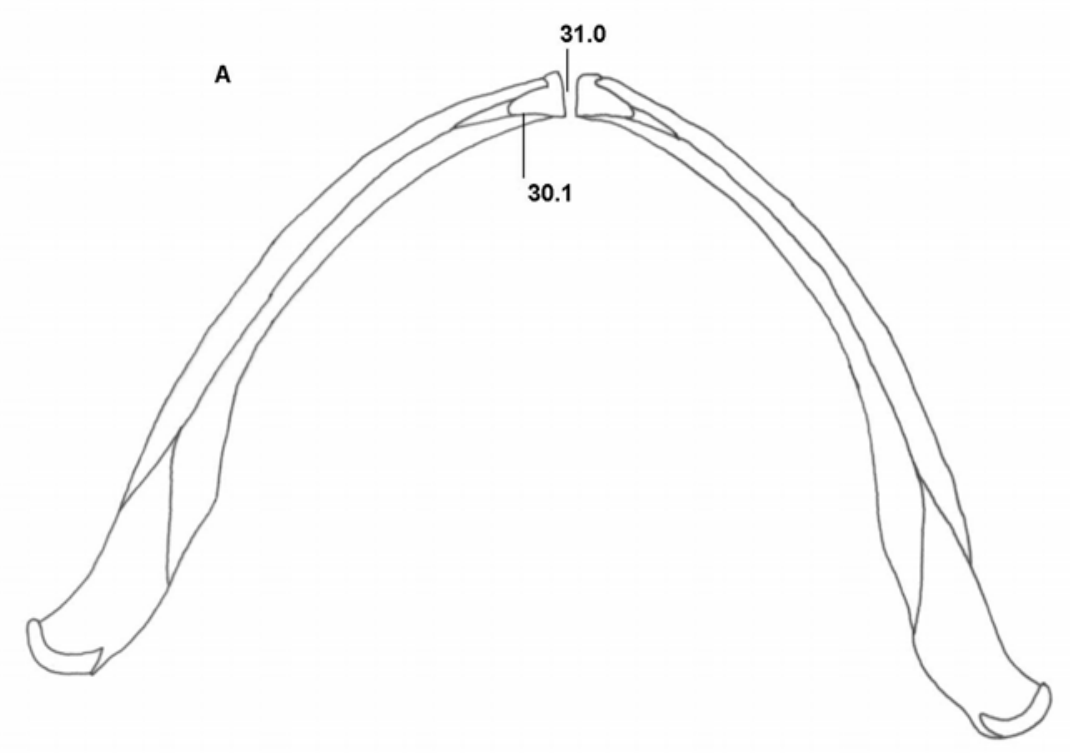

B

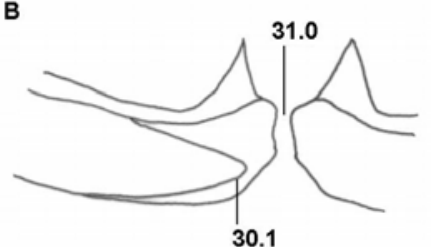

C
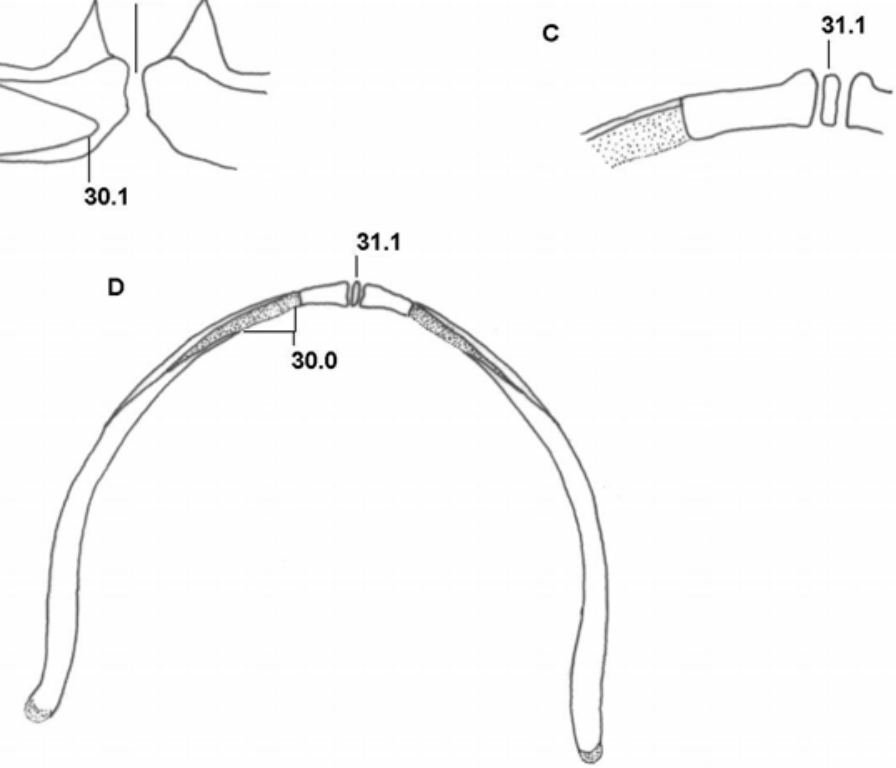

E

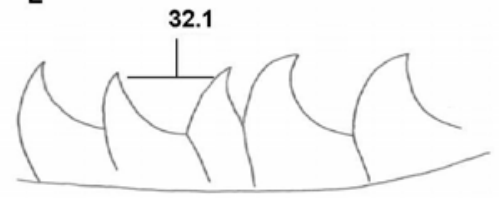

F

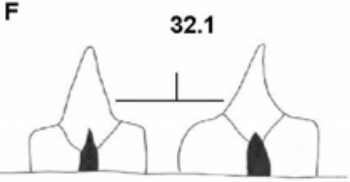

G

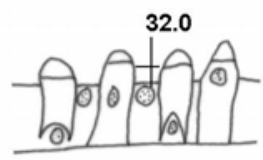

Figura 52. Estados de los caracteres 30-31 y 32 esquematizados en mandíbulas y dientes de adultos de cuatro de las especies analizadas. (A) Vista dorsal de la mandíbula en Chacophrys pierottii. (B) Detalle en vista frontal de la porción anterior de la mandíbula en Ch. Pierottii. (C) Detalle en vista frontal de la porción anterior de la mandíbula en Pleurodema borellii. (D) Vista dorsal de la mandíbula en P. borellii. (E) Vista lateral de dientes maxilares en Ceratophrys ornata. (F) Vista lingual de dientes maxilares en C. ornata. (G) Vista lingual de dientes maxilares en Hylorina sylvatica. Esquemas sin escala. 
Comentarios: Adicionalmente, las dos especies que presentan contacto presente, poseen procesos dentigeros del mentomeckeliano bien desarrollados.

Caracter 31. Comisura intramandibular del adulto (Fig. 52). De acuerdo al tipo de comisura intramandibular se reconocen 2 estados de caracter: comisura sindesmótica (0), y comisura sindesmótica con una cópula mandibular osificada (1). Alsodes gargola, Atelognathus patagonicus, Batrachyla spp., Ceratophrys ornata, Chacophrys pierottii, Hylorina sylvatica y Eupsophus calcaratus presentan el estado (0).

Pleurodema borelli pesenta el estado (1).

Caracter 32. Dientes (Fig. 52). De acuerdo a la presencia o ausencia de la condición pedicelada en los dientes se observan dos estados: dientes con condición pedicelada (0), dientes no pedicelados (1). Alsodes gargola, Atelognathus patagonicus, Batrachyla spp., Hylorina sylvatica, Eupsophus calcaratus y Pleurodema borelli presentan el estado (0). Ceratophrys ornata y Chacophrys pierottii presentan el estado (1). Comentarios: Atelognathus patagonicus presenta reducción en el número de dientes, pero en los pocos dientes que presenta se observa la condición pedicelada.

\section{III.10.1.5. Musculatura mandibular.}

Caracter 33. Músculo levator mandibulae externus superficialis (Fig. 46). El m. I. $m$. externus superficialis está compuesto por un delicado haz de fibras que se desprende del m. I. m. longus profundus, diferenciandose ambos al nivel de la inserción, independientemente del trayecto de la rama mandibularis del nervio trigémino (Haas, 2001). De acuerdo a la presencia o ausencia de dicho músculo se reconocen dos estados de caracter (modificado de Haas, 2003): músculo presente (0), y músculo ausente (1). Alsodes gargola, Atelognathus patagonicus, Batrachyla antartandica, B. leptopus, B. taeniata, Ceratophrys ornata, Hylorina sylvatica y Pleurodema borelli presentan el estado (0). Eupsophus calcaratus presenta el estado (1) (según Vera Candioti et al., 2005). No se pudo asignar el estado de caracter para Batrachyla fitzroya, B. nibaldoi y Chacophrys pierottii por carecer de larvas de esas especies, con lo cual se entraron a la matriz como datos faltantes (?).

Comentarios: La determinación de los estados debe hacerse con larvas tipicas (estadios 31-38).

Caracter 34. Insercion del m. levator mandibulae externus superficialis (Fig. 46). De acuerdo al sitio donde inserta el $\mathrm{m}$. levator mandibulae externus superficialis se reconocen dos estados: inserción en el ligamento mandibulo suprarrostral (0), o en el 
disco oral (1). Alsodes gargola, Atelognathus patagonicus, Batrachyla antartandica, $B$. leptopus, B. taeniata, Hylorina sylvatica y Pleurodema borelli presentan el estado (0). Ceratophrys ornata presenta el estado (1). No se pudo asignar el estado de caracter para Batrachyla fitzroya, B. nibaldoi y Chacophrys pierottii por carecer de larvas de esas especies, con lo cual se entraron a la matriz como datos faltantes (?). Eupsophus calcaratus carece de dicho músculo y se ingreso a la matriz como dato inaplicable (-). Comentarios: La determinación de los estados debe hacerse con larvas tipicas (estadios 31-38).

Caracter 35. Origen del m. levator mandibulae internus en la larva (Fig. 46). El sitio de origen de este músculo puede ser dorsal al proceso ascendente (condición plesiomorfica, "alta", compartida con Caudata, presente solo en Ascaphus) o a nivel ventral de la cápsula ótica y proceso ascendente (“condición baja” presente en el resto de los anuros) (Haas, 2003). De acuerdo a la variación respecto de la condición "baja" se reconocen dos estados: anteroventral en la cápsula ótica y ventral al proceso ascendente (0), o ventral al proceso ascendente solamente (1). Alsodes gargola, Ceratophrys ornata y Pleurodema borelli presentan el estado (0). Atelognathus patagonicus, Batrachyla antartandica, B. leptopus, B. taeniata, Eupsophus calcaratus (según Vera Candioti et al., 2005) e Hylorina sylvatica presentan el estado (1). No se pudo asignar el estado de caracter para Batrachyla fitzroya, B. nibaldoi y Chacophrys pierottii por carecer de larvas de esas especies, con lo cual se entraron a la matriz como datos faltantes (?).

Comentarios: La determinación de los estados debe hacerse con larvas tipicas (estadios 31-38).

Caracter 36. Grado de solapamiento de los $\mathrm{mm}$. levatorae mandibulae longus superficialis et profundus en la larva (Fig. 46). Ambos músculos se encuentran presentes en la mayoría de los anuros (en Ascaphus, Pipidae y Caudata existe un único $\mathrm{m}$. l. $\mathrm{m}$. longus) y presentan origen en la cara dorsal a nivel posterolateral del arco subocular del palatocuadrado (Haas, 2001, 2003). En este contexto se reconocieron dos estados de caracter (según Haas, 2003): el origen del m. levator mandibulae longus superficialis está solapado dorsalmente al del m. levator mandibulae longus profundus dejando expuestas solo las fibras más laterales de este último (0), o no existe solapamiento (1). Alsodes gargola, Atelognathus patagonicus, Batrachyla antartandica, B. leptopus, Ceratophrys ornata, Eupsophus calcaratus (según Vera Candioti et al., 2005), Hylorina sylvatica y Pleurodema borelli presentan el estado (0). Batrachyla taeniata presenta el estado (1). No se pudo asignar el estado de 
caracter para Batrachyla fitzroya, B. nibaldoi y Chacophrys pierottii por carecer de larvas de esas especies, con lo cual se entraron a la matriz como datos faltantes (?). Comentarios: La determinación de los estados debe hacerse con larvas tipicas (estadios 31-38). La condición descrita aquí para Batrachyla taeniata fue descita por Haas (2003) para Xenopus laevis y Microhylidae.

Caracter 37. Composición del m. intermandibularisde la larva (Fig. 47). De acuerdo a si este músculo se compone por uno o dos vientres se reconocen dos estados: músculo formado por un solo vientre (0), y músculo compuesto por un vientre anterior y otro posterior (1). Alsodes gargola, Atelognathus patagonicus, Batrachyla antartandica, B. leptopus, B. taeniata, Hylorina sylvatica y Pleurodema borelli presentan el estado (0). Ceratophrys ornata presenta el estado (1). No se pudo asignar el estado de caracter para Batrachyla fitzroya, B. nibaldoi y Chacophrys pierottii por carecer de larvas de esas especies, con lo cual se entraron a la matriz como datos faltantes (?).

Comentarios: La determinación de los estados debe hacerse con larvas tipicas (estadios 31-38).

\section{Caracter 38. Cantidad de capas que componen el $\mathrm{m}$. intermandibularis en el} adulto (Fig. 53). La variación relativa al $\mathrm{m}$. intemandibularis ha sido estudiada por diversos autores para diferentes familias de anuros (Tyler, 1972; Manzano \& Lavilla, 1995; Tyler \& Duellman, 1995; Burton, 1998; Palavecino, 2000; Haas, 2001). En esas descripciones se observa que el $\mathrm{m}$. intermandibularis puede estar formado por una o dos capas. Entonces, teniendo en cuenta ello se reconocen dos estados de caracter: m. intermandibularis compuesto por dos capas, una capa superficial restringida al tercio anterior del espacio entre las hemimandíbulas (elemento apical de algunos autores), cuyas fibras corren oblicuamente en sentido anteroposterior; y una capa profunda, cuyas fibras corren transversalmente ocupando todo el espacio entre las hemimandíbulas por detrás del $\mathrm{m}$. submentalis (0); $\mathrm{m}$. intermandibularis sin porción anterior o apical, formado solo por la capa profunda (1). Alsodes gargola, Atelognathus patagonicus, Batrachyla spp., Chacophrys pierottii, Eupsophus calcaratus e Hylorina sylvatica presentan el estado (0). Ceratophrys ornata y Pleurodema borelli presentan el estado (1).

\section{Caracter 39. Fascia entre los $\mathrm{mm}$. intermandibularis y submentalis del adulto}

(Fig. 53). De acuerdo a la presencia o ausencia de una fascia entre los nombrados músculos se reconocen dos estados: fascia ausente (0) y fascia presente (1). Alsodes gargola, Atelognathus patagonicus, Batrachyla spp., Eupsophus calcaratus, Hylorina 
sylvatica y Pleurodema borellipresentan el estado (0). Ceratophrys ornata y

Chacophrys pierottii presentan el estado (1).

\section{III.10.1.6. Musculatura hioidea.}

Caracter 40. Grado de separación de la pars scapularis y la pars timpanica del m. depressor mandibulae (Fig. 54). La validez del m. depressor mandibulae como fuente de caracteres para estudios sistemáticos a diversos niveles fue negada (Lynch, 1971) o afirmada (Limeses, 1965; Starrett, 1968; Heyer, 1975; Lynch, 1993) por diversos autores. En la mayoría de los trabajos mencionados los caracteres más empleados en relación a este músculo son relativos a las variaciones en el punto de origen del mismo. En el trabajo de Limeses (1965) se discuten pero no se formalizan los caracteres empleados en la presente tesis (caracteres 41-44) referidos al $\mathrm{m}$. depressor mandibulae. Sobre la base de los taxa empleados para la presente tesis hé podido identificar cuatro caracteres relativos al $\mathrm{m}$. depressor mandibulae (caracteres 41-44). Este músculo presenta dos porciones, la anterior (pars timpanica de Limeses, 1965) y la posterior (pars scapularis de Limeses, 1965). De acuerdo al grado de separación entre ambas al nivel del origen del músculo se reconocen 2 estados: pars scapularis y pars timpanica no separadas o separadas por una muesca no mayor al $50 \%$ de la altura de la pars timpanica (0), o ambas porciones separadas por una muesca mayor al $50 \%$ de la altura de la pars timpanica (1). El estado (0) lo presentan Atelognathus patagonicus, Ceratophrys ornata, Chacophrys pierottii, Eupsophus calcaratus y Pleurodema borelli. El estado (1) se encuentra en Alsodes gargola, Batrachyla spp., e Hylorina sylvatica.

Caracter 41. Tamaño relativo de las porciones del $\mathbf{m}$. depressor mandibula e (Fig. 54). Se reconocen dos estados: pars timpanica mayor que la pars scapularis (0), o viceversa (1). El estado (0) se encuentra en Atelognathus patagonicus, Batrachyla antartandica, B. fitzroya, B. leptopus y Ceratophrys ornata. El estado (1) se encuentra en Alsodes gargola, B. nibaldoi, B. taeniata, Chacophrys pierottii, Eupsophus calcaratus, Hylorina sylvatica y Pleurodema borelli.

\section{Caracter 42. Grado de desarrollo de la pars timpanica del m. depressor} mandibulae (Fig. 54). De acuerdo a si las fibras de la pars timpanica superan en altura al nivel de la cresta parótica e insertan en una fascia sobre el $\mathrm{m}$. levator mandibulae longus se reconocen dos estados de caracter: el haz de fibras más posterior de la pars timpanica inserta por encima del nivel de la cresta parótica (0), o 
su inserción no supera dicho nivel (1). El estado (0) lo presentan Atelognathus patagonicus, Batrachyla spp., Ceratophrys ornata, Chacophrys pierottii, Eupsophus calcaratus y Pleurodema borelli. El estado (1) lo presentan Alsodes gargola e Hylorina sylvatica.

Caracter 43. Inserción de la pars scapularisdel m. depressor mandibulae (Fig. 54). Se reconocen dos estados de caracter: pars scapularis inserta mediante una amplia fascia sobre el $\mathrm{m}$. dorsalis scapulae (0) o, inserta sobre el margen anterior de la supraescápula, no desarrollando la fascia sobre el $\mathrm{m}$. dorsalis scapulae (1). El estado (0) lo presentan Alsodes gargola, Batrachyla spp., Ceratophrys ornata, Chacophrys pierottii, Eupsophus calcaratus, Hylorina sylvatica y Pleurodema borelli. El estado (1) lo presenta Atelognathus patagonicus.

\section{III.10.1.7. Musculatura branquial.}

Caracter 44. Inserción del m. subarcualis rectus II-IV (Fig. 48). El m. subarcualis rectus II-IV es un músculo compuesto por los mm. subarcuales recti II, III y IV de otros Lissamphibia. Está representado por una banda de fibras que recorre la región proximal de los ceratobranquiales desde su origen en el ceratobranquial IV hasta la inserción, que según los taxa ocurre en el primer o segundo ceratobranquial. El sitio de inserción del m. subarcualis rectus II-IV fue empleado y descrito en detalle por Haas (2003). Entonces de acuerdo al sitio de inserción de este músculo se reconocen dos estados de caracter: inserción en la superficie proximal del ceratobranquial I (0), o del ceratobranquial II (1). Batrachyla antartandica, B. leptopus, B. taeniata, e Hylorina sylvatica presentan el estado (0). Alsodes gargola, Atelognathus patagonicus, Ceratophrys ornata, Eupsophus calcaratus (según Vera Candioti et al. 2005) y Pleurodema borelli presentan el estado (1). No se pudo asignar el estado de caracter para Batrachyla fitzroya, B. nibaldoi y Chacophrys pierottii por carecer de larvas de esas especies, con lo cual se entraron a la matriz como datos faltantes (?).

Comentarios: La determinación de los estados debe hacerse con larvas tipicas (estadios 31-38).

Caracter 45. Músculo tympanopharyngeus (Fig. 48). El m. tympanopharyngeus es un elemento derivado del $\mathrm{m}$. levator arcuum branchialium IV (Haas, 1997), resultando ambos muchas veces indistinguibles al nivel de su origen en la región posteroventral de la cápsula ótica. Independientemente del grado de separación que se verifique respecto del $\mathrm{m}$. levator arcuum branchialium IV, el m. tympanopharyngeus siempre 
A

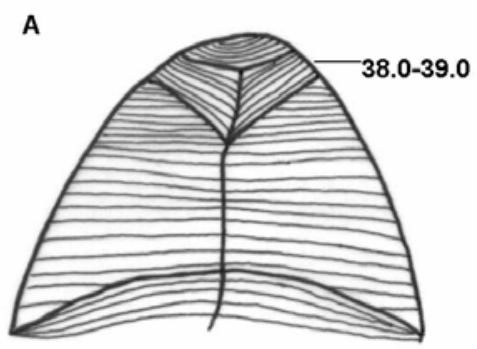

B

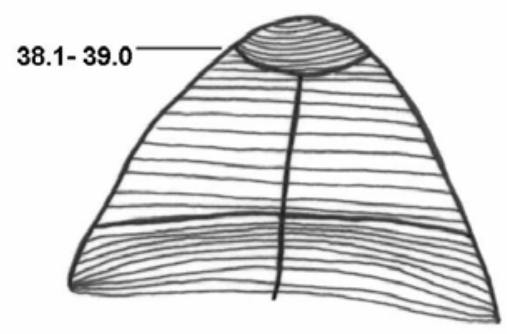

c
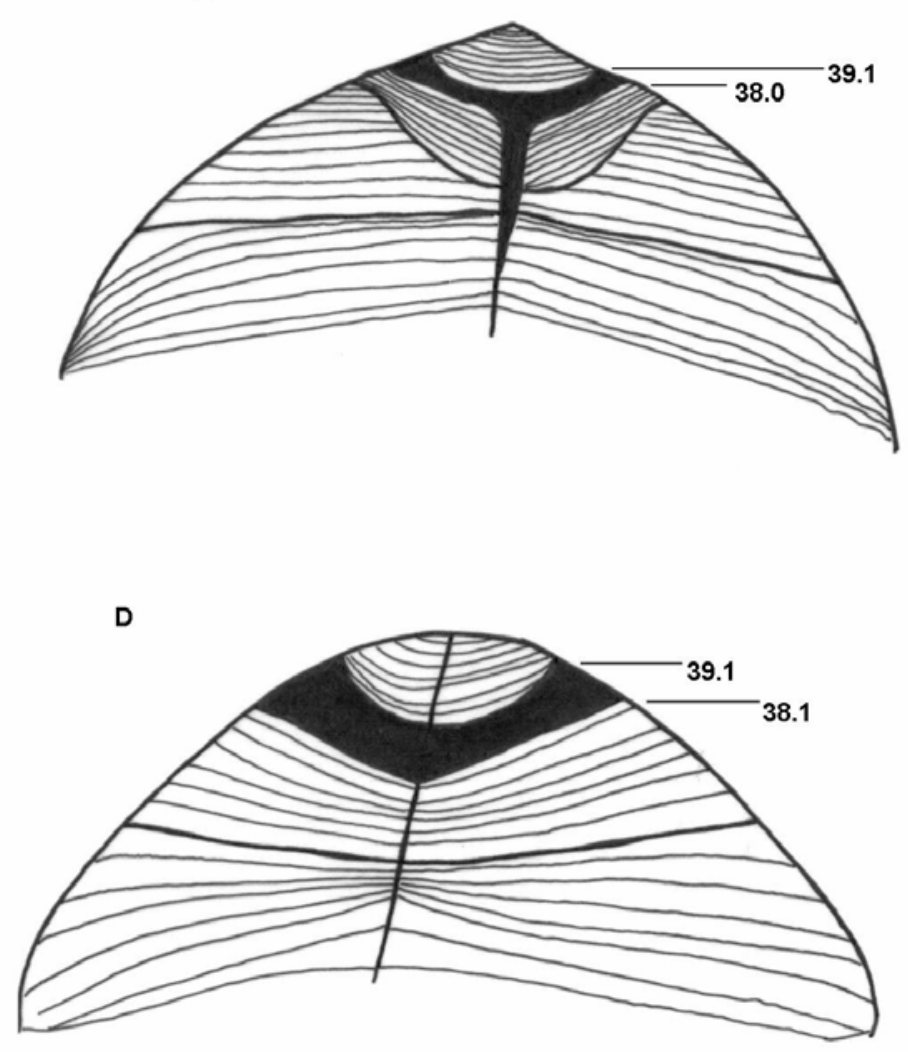

Figura 53. Estados de los caracteres 38 y 39 esquematizados en la musculatura del piso de la boca en adultos de cuatro de las especies analizadas. (A) Hylorina sylvatica, (B) Pleurodema borellii, (C) Chacophrys pierottii y (D) Ceratophrys ornata. Esquemas sin escala. 
A

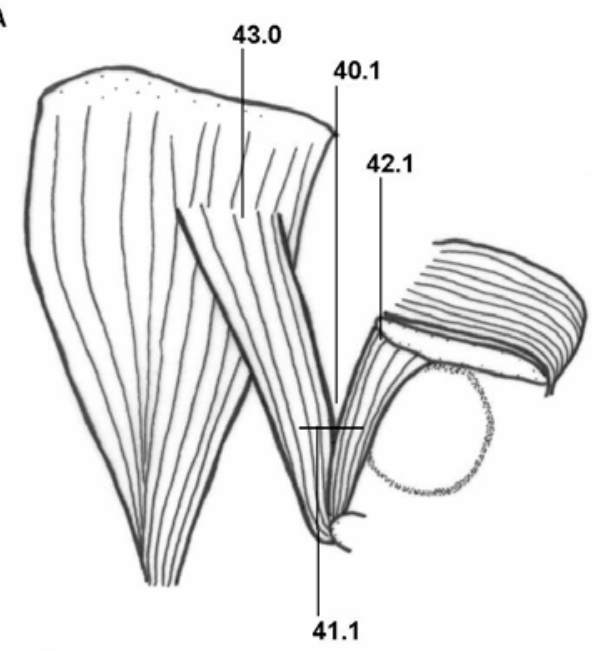

B

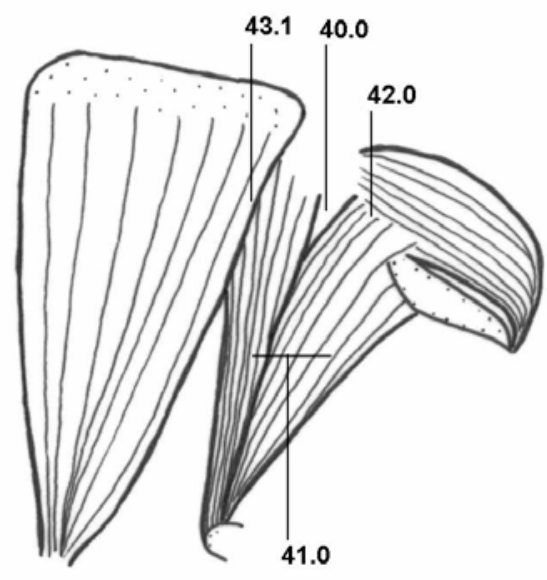

c

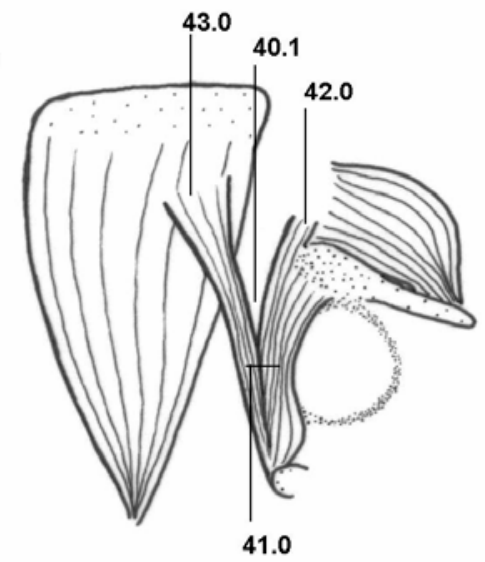

D

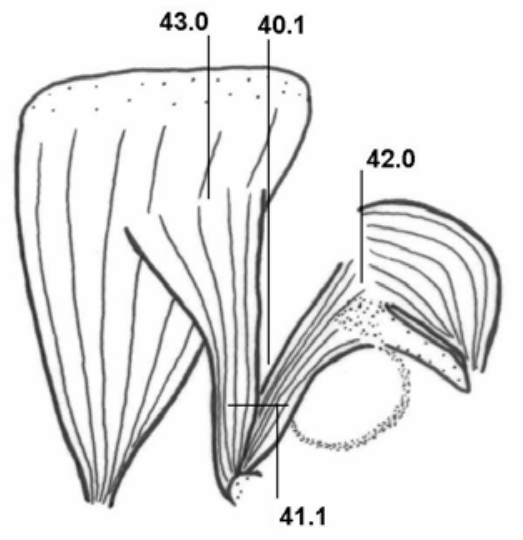

Figura 54. Estados de los caracteres 40 al 42 esquematizados en vista lateral de la musculatura asociada a la escápula y región ótica del cráneo en adultos de cuatro de las especies analizadas. (A) Hylorina sylvatica, (B) Atelognathus patagonicus, (C) Batrachyla leptopus y (D) Batrachyla taeniata. Esquemas sin escala. 
inserta en la región posterolateral del pericardio. La presencia-ausencia de este músculo fue empleada por Haas (2003). Entonces de acuerdo a ello, es posible distinguir dos estados de caracter: ausente (0), y presente (1). Atelognathus patagonicus, Batrachyla antartandica, B. leptopus, B. taeniata, Eupsophus calcaratus e Hylorina sylvatica presentan el estado (0). Alsodes gargola, Ceratophrys ornata, y Pleurodema borelli presentan el estado (1). No se pudo asignar el estado de caracter para Batrachyla fitzroya, B. nibaldoi y Chacophrys pierottii por carecer de larvas de esas especies, con lo cual se entraron a la matriz como datos faltantes (?).

Comentarios: La determinación de los estados debe hacerse con larvas tipicas (estadios 31-38). Vera Candioti et al. (2005) reportó al m. tympanopharyngeus para Eupsophus calcaratus, sin embargo según la información presentada en la tabla 2 y esquematizada en la figura $3 \mathrm{C}$ de ese mismo trabajo se trata en realidad de $\mathrm{m}$. levator arcuum branchialium IV. Para considerar la presencia de $\mathrm{m}$. tympanopharyngeus debe verificarse la existencia de inserción en el pericardio, independientemente del grado de separación que presenten sus fibras de las del m. levator arcuum branchialium IV (ver Haas, 2003). Por lo tanto el m. tympanopharyngeus descrito por Vera candioti et al. (2005) para la larva de E. calcaratus debe considerarse como m. levator arcuum branchialium IV.

Caracter 46. Músculo subarcualis obliquus II (Fig. 48). De acuerdo a la presencia o ausencia de dicho músculo se reconocen dos estados de caracter: músculo presente (0), músculo ausente (1). Alsodes gargola, Atelognathus patagonicus, Batrachyla antartandica, B. leptopus, B. taeniata, Ceratophrys ornata, Hylorina sylvatica y Pleurodema borelli presentan el estado (0). Eupsophus calcaratus presenta el estado (1) (según Vera Candioti et al., 2005). No se pudo asignar el estado de caracter para Batrachyla fitzroya, B. nibaldoi y Chacophrys pierottii por carecer de larvas de esas especies, con lo cual se entraron a la matriz como datos faltantes (?).

Comentarios: La determinación de los estados debe hacerse con larvas tipicas (estadios 31-38).

Caracter 47. Inserción del $\mathrm{m}$. rectus cervicis (Fig. 48). El m. rectus cervicis se origina en la pared posterior del peritonéo faríngeo y de acuerdo al sitio de su inserción se reconocen dos estados de caracter (modificado de Haas, 2003): inserción en la región proximal de los ceratobranquiales II y III (0), o III y IV (1). Alsodes gargola, Ceratophrys ornata, Eupsophus calcaratus (según Vera Candioti et al., 2005) y Pleurodema borelli presentan el estado (0). Atelognathus patagonicus, Batrachyla antartandica, B. leptopus, B. taeniata, e Hylorina sylvatica presentan el e stado (1). No 
se pudo asignar el estado de caracter para Batrachyla fitzroya, B. nibaldoi y

Chacophrys pierottii por carecer de larvas de esas especies, con lo cual se entraron a la matriz como datos faltantes (?).

Comentarios: La determinación de los estados debe hacerse con larvas tipicas (estadios 31-38). El caracter se codifico independientemente del número de cabezas que pueda presentar este músculo (caracter que varía a nivel poblacional, e g., Batrachyla taeniata).

El estado para Eupsophus calcaratus fue asignado según la descripción realizada por Vera Candioti et al. (2005). Según la tabla 2 de ese trabajo, el m. rectus cervicis de $E$. calcaratus se origina en el ceratobranquial II, pero según la figura $3 \mathrm{C}$ del mismo trabajo se originaria en el ceratobranquial III. Aun considerando esas contradicciones, ambas sitios de inserción son compatibles con el estado (0) descrito en el presente trabajo, dado que en ninguno de los dos casos se menciona el origen posterior al tercer ceratobranquial.

\section{III.10.2. Caracteres de musculatura axial postcraneana.}

Caracter 48. Músculo obliquus externus pars scapularis (Fig. 55). El m. obliquus externus pars scapularis se diferencia postmetamorficamente a partir del $\mathrm{m}$. obliquus externus. Es evidente por detrás del vientre posterior del $\mathrm{m}$. latisimus dorsii e inserta en el margen posterior y ventral de la supraescápula en las inmediaciones del límite con la escápula. Se reconocen tres estados de caracter: músculo poco desarrollado, compuesto por fibras en su tercio proximal y formado por un ligamento en su inserción (0), músculo bien desarrollado, compuesto totalmente por fibras musculares e insertó en un pequeño área posterior a la escápula (1), y músculo hipertrofiado, también totalmente compuesto por fibras musculares pero con un amplío área de inserción en la cara posterior de la escápula (2).

El estado (0) lo presenta Pleurodema borelli. El estado (1) lo presentan Alsodes gargola, Atelognathus patagonicus, Batrachyla spp., Chacophrys pierottii, Eupsophus calcaratus, e Hylorina sylvatica. El estado (2) lo presenta Ceratophrys ornata.

Caracter 49. Desarrollo relativo del $\mathrm{m}$. obliquus externusrespecto del $\mathrm{m}$. transversus en el adulto (s/ Fig.). Este caracter debe revisarse en vista lateral de la musculatura axial, efectuando un corte transversal con bisturi al nivel posterior de la cintura escapular. La pared lateral del cuerpo en anuros esta formada por dos capas musculares, una interna correspondiente al $\mathrm{m}$. transversus y otra externa 
correspondiente al $\mathrm{m}$. obliquus externus, siendo la primera, por lo general la capa de mayor desarrollo. Sobre la base del grado de desarrollo de una capa respecto de la otra es posible distinguir dos estados de caracter: $m$. transversus más desarrollado que el m. obliquus externus (0) y, ambos con el mismo espesor (1). Alsodes gargola, Batrachyla spp., Ceratophrys ornata y Pleurodema borelli presentan el estado (0). Atelognathus patagonicus, Chacophrys pierottii, Hylorina sylvatica y Eupsophus calcaratus presentan el estado (1).

\section{Caracter 50. Dimorfismo sexual en la inserción del músculo rhomboideus}

anterior (s/ Fig.). Este músculo inserta en una fascia sobre el músculo levator mandibulae longus y en la porción posterior de los frontoparietales. De acuerdo al área que abarcan sus fibras en la inserción se observó que en todos los ejemplares macho de Batrachyla taeniata, las fibras más mediales del músculo insertan prácticamente en todo el margen posterior de los frontoparietales determinando que el espacio medio entre las porciones derecha e izquierda de este músculo sea de forma triangular con vértice anterior. Sin embargo en las hembras de esa especie se observó otra configuración donde las fibras mediales de dicho músculo insertan en el borde posterolateral de los frontoparietales determinando que el espacio medio entre las porciones derecha e izquierda de este músculo sea sub-cuadrangular. En consecuencia el caracter se interpreto como dimorfico para $B$. taeniata. Esta condición de las hembras de $B$. taeniata se observo tanto en los machos como en las hembras de las especies Alsodes gargola, Atelognathus patagonicus, B. fitzroya, B. leptopus e Hylorina sylvatica, especies en las que el caracter no sería dimórfico.

Entonces se reconocen dos estados: 0) dimorfismo sexual en la inserción del $\mathrm{m}$. rhomboideus anterior ausente, y 1) dimorfismo presente. Alsodes gargola, Atelognathus patagonicus, B. fitzroya, B. leptopus, Ceratophrys ornata, e Hylorina sylvatica presentan el estado (0). B. taeniata presenta el estado (1) No se contó con ejemplares machos de Batrachyla antartandica, ni con hembras de Chacophrys pierottii, B. nibaldoi, Eupsophus calcaratus y Pleurodema borellide modo que esas especies fueron entradas a la matriz como faltantes (?).

Comentarios: En las hembras de Batrachyla antartandica se observó la condición mostrada por las hembras de B. taeniata. En B. nibaldoi, Eupsophus calcaratus, Chacophrys pierottii y Pleurodema borelli los únicos machos estudiados se corresponden con lo observado para los machos de B. taeniata. 


\section{III.10.3. Caracteres de esqueleto y musculatura del miembro anterior.}

\section{III.10.3.1. Cintura y esternón.}

\section{Caracter 51. Posición del límite posterior del xifiesternón en los machos adultos}

(Fig. 56). La porción posterior del xifiesternón de las especies estudiadas se halla expuesta ventralmente al $\mathrm{m}$. rectus abdominis. Dado el hecho que se observó dimorfismo sexual en el caracter para algunas especies (ver siguiente caracter), se optó por codificar solo a los machos con lo cual B. antartandica fue ingresada a la matriz como dato faltante (?). Entonces, sobre la base de la posición del extremo posterior del xifiesternón respecto de los mioseptos del $\mathrm{m}$. rectus abdominis, es posible reconocer tres estados de caracter: extremo posterior del xifiesternón ubicado al nivel del miosepto que separa los miómeros $3^{\circ}$ y $4^{\circ}(0)$, o $4^{\circ}$ y $5^{\circ}(1)$, o anterior al miosepto que separa los miómeros $4^{\circ}$ y $5^{\circ}(2)$.

El estado (0) se observó en Chacophrys pierottii. El estado (1) se observó en Alsodes gargola, Eupsophus calcaratus, Batrachyla nibaldoi, B. taeniata y Pleurodema borelli. El estado (2) se observó en Atelognathus patagonicus, B. fitzroya, B. leptopus e Hylorina sylvatica. Ceratophrys ornata presento los estados (0) y (1) y se ingreso a la matriz contemplando el polimorfismo como ambigüedad $(0,1)$.

\section{Caracter 52. Dimorfismo sexual en la posición del límite posterior del} xifiesternón (s/ Fig.). La posición del extremo posterior del xifiesternón respecto de los mioseptos del músculo rectus abdominis es constante para los machos y hembras de cada especie observada (ver caracter anterior), sin embargo se observo que en Alsodes gargola y Eupsophus calcaratus existen diferencias entre machos y hembras. En Alsodes gargola, la posición del límite posterior del xifiesternón varía entre machos (entre los miómeros $4^{\circ}$ y $5^{\circ}$ ) y hembras (entre los miómeros $5^{\circ}$ y $6^{\circ}$ ). En Eupsophus calcaratus, los machos lo presentan entre los miómeros $4^{\circ}$ y $5^{\circ}$, mientras que no se observaron hembras de esa especie. En ambos sexos de Atelognathus patagonicus, Batrachyla fitzroya, B. leptopus, B. taeniata, Ceratophrys ornata, e Hylorina sylvatica no existe dimorfismo sexual para este caracter.

No se contó con hembras de Batrachyla nibaldoi, Chacophrys pierottii, Eupsophus calcaratus y Pleurodema borelli, ni con machos de $B$. antartandica, entonces esas especies fueron ingresadas como datos faltantes (?). Entonces, se reconocen dos estados: dimorfismo ausente (0), o presente (1). Atelognathus patagonicus, Batrachyla fitzroya, B. leptopus, B. taeniata, Ceratophrys ornata e Hylorina sylvatica presentan el estado (0). Alsodes gargola presenta el estado (1). 

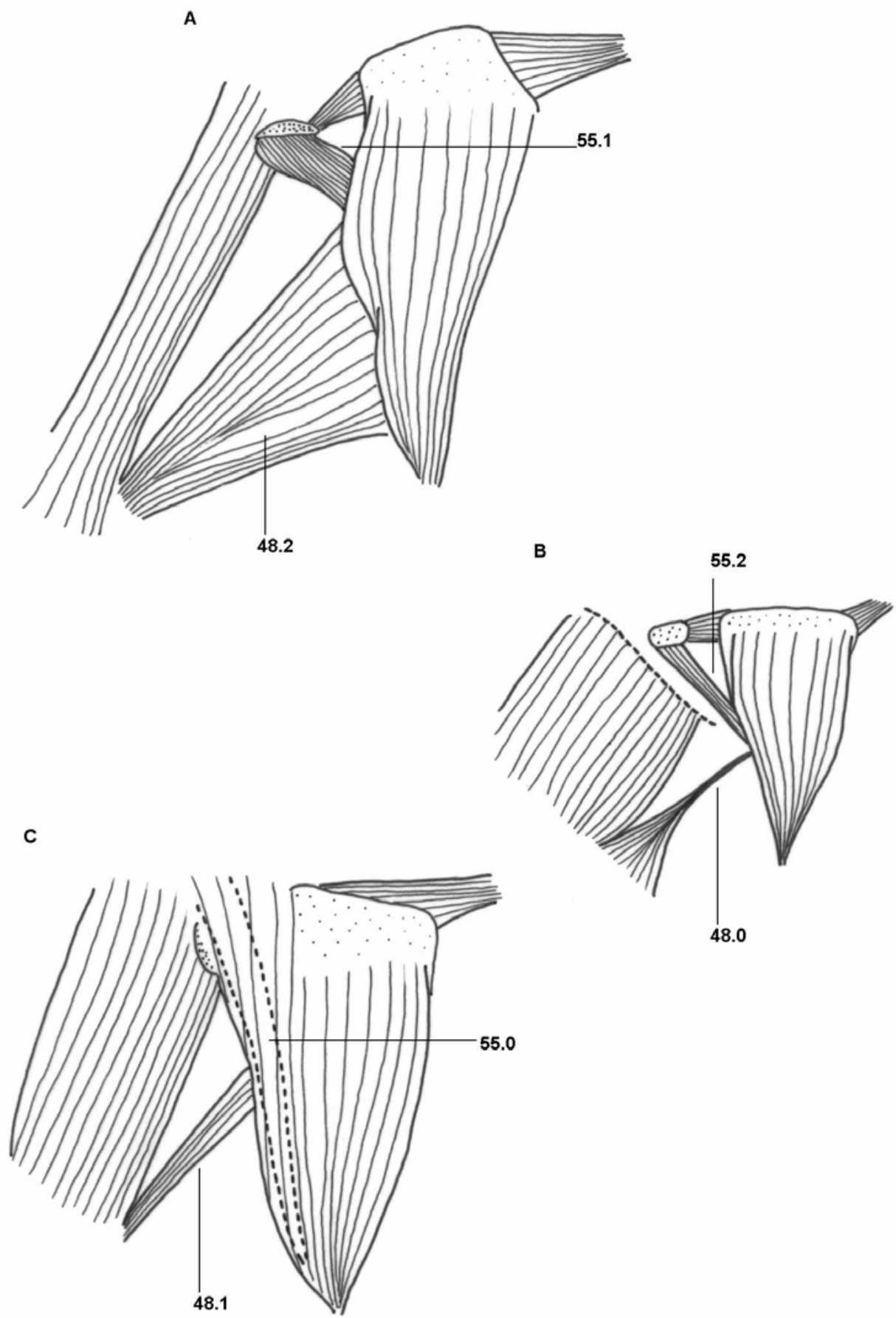

48.0

Figura 55. Estados de los caracteres 48 y 55 esquematizados en vista lateral de la musculatura asociada a la escápula y pared del cuerpo en adultos de tres de las especies analizadas. (A) Ceratophrys ornata, (B) Pleurodema borellii y (C) Alsodes gargola. Esquemas sin escala. 
A

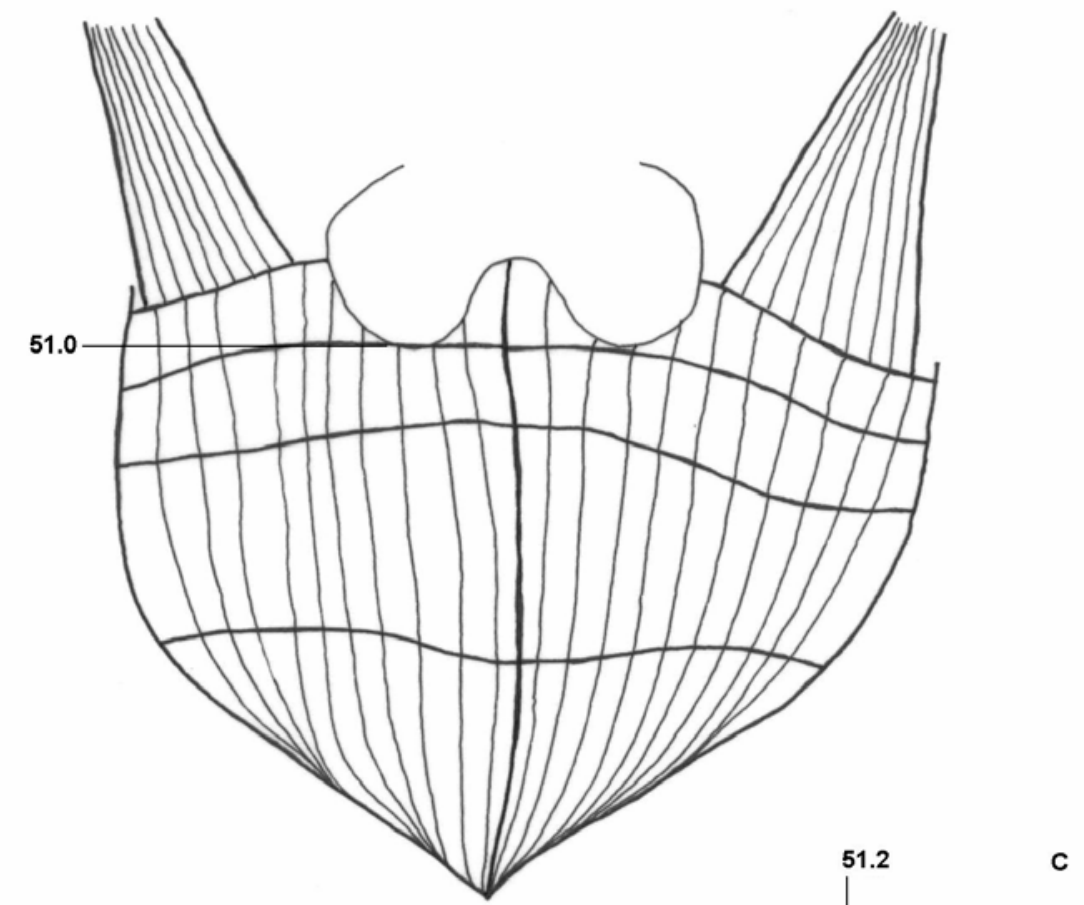

B

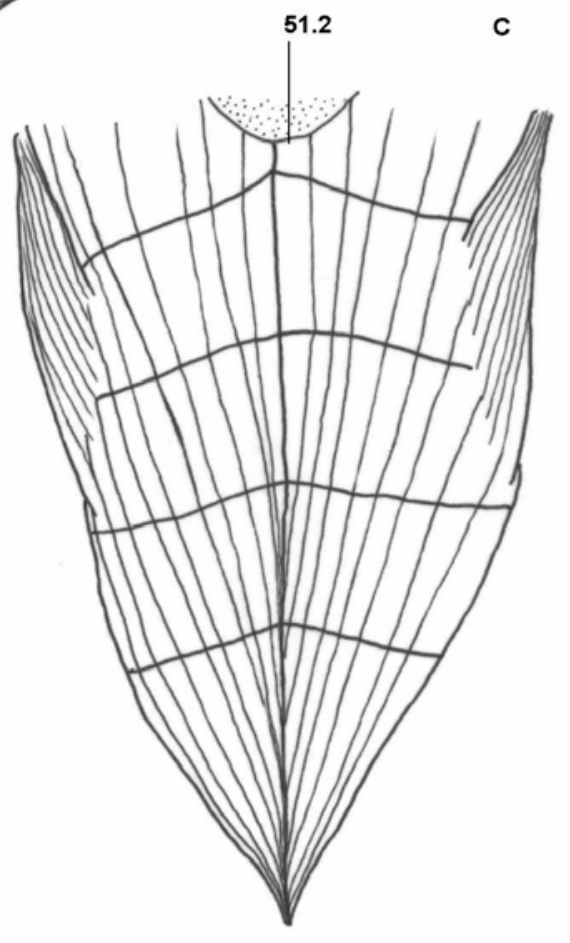

Figura 56. Estados del caracter 51 esquematizados en vista ventral de la musculatura hipoaxial en adultos de tres de las especies analizadas. (A) Chacophrys pierottii, (B) Batrachyla taeniata y (C) Atelognathus patagonicus. Esquemas sin escala. 

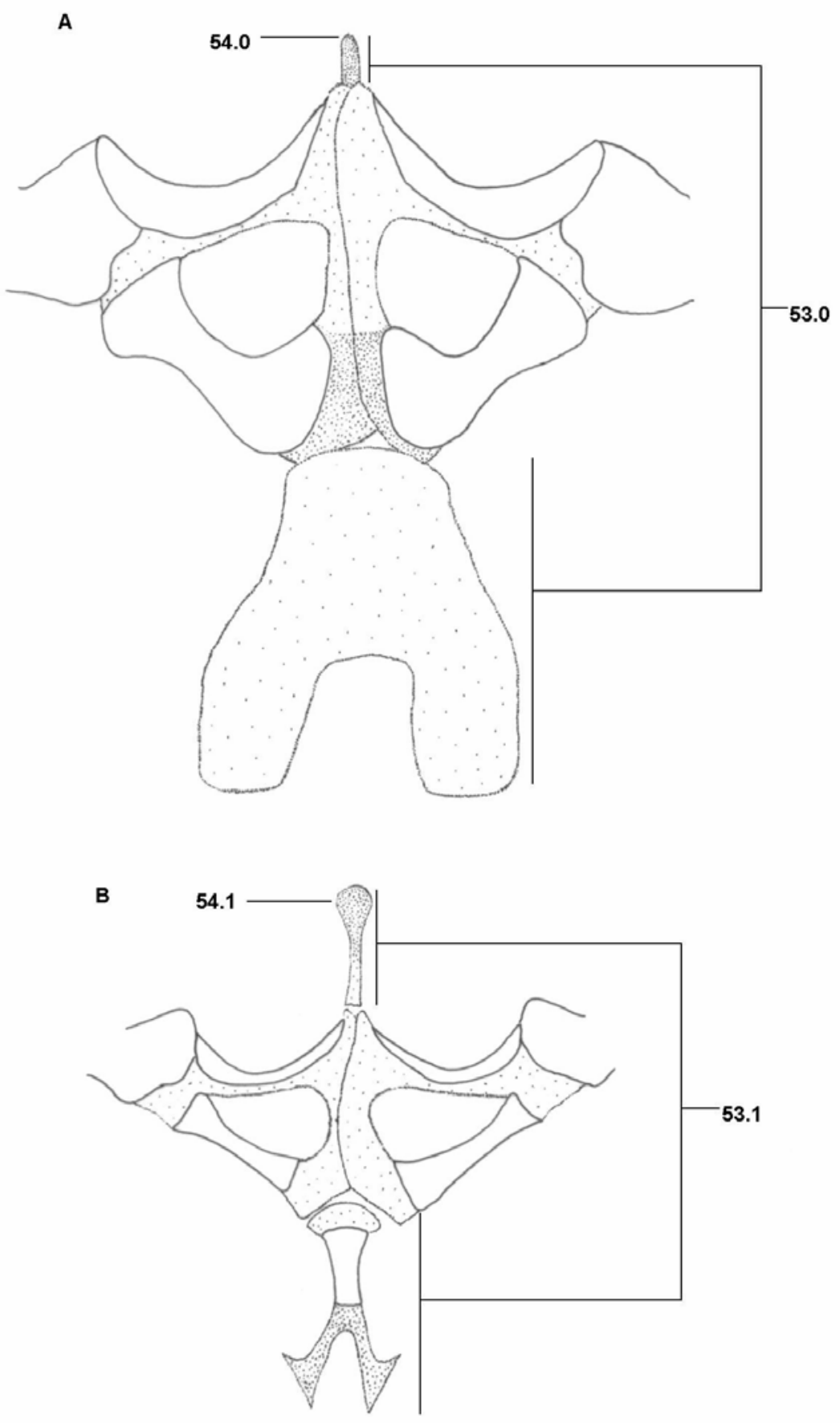

Figura 57. Estados de los caracteres 53 y 54 esquematizados en vista ventral de la cintura escapular de adultos de (A) Chacophrys pierottii y (B) Pleurodema borellii. Esquemas sin escala. 


\section{Caracter 53. Tamaño relativo del epiesternón respecto del conjunto esternón-} xifiesternón (Fig. 57). De acuerdo a la longitud relativa de ambas porciones esternales hé definido dos estados de caracter: epiesternón corto (su longitud no supera la mitad de la longitud del conjunto esternón-xifiestenón) (0), o largo (su longitud iguala o supera la mitad del conjunto esternón-xifiestenón) (1). El estado (0) lo presentan Alsodes gargola, Ceratophrys ornata y Chacophrys pierottii. El estado (1) lo presentan Atelognathus patagonicus, Batrachyla spp., Eupsophus calcaratus, Hylorina sylvatica y Pleurodema borelli.

Caracter 54. Morfología del extremo distal del epiesternón (Fig. 57). De acuerdo a la morfología que presenta el extremo distal del epiesternón se reconocen dos estados de caracter: dilatado (con o sin escotadura) (0), o ahuzado no dilatado (1). El estado (0) lo presentan Alsodes gargola, Batrachyla spp., Eupsophus calcaratus, Hylorina sylvatica y Pleurodema borelli. El estado (1) lo presenta Atelognathus patagonicus, Ceratophrys ornata y Chacophrys pierottii.

Caracter 55. Porción posterior del m. latissimus dorsi (Fig. 55). El m. latisimus dorsi presenta dos vientres, el anterior y el posterior. Ambos se originan en la región proximal de la escápula. El vientre anterior inserta en el extremo distal del proceso transverso II y siempre se halla oculto por el m. dorsalis scapulae y la supraescápula. En cambio el vientre posterior, que es el más desarrollado, inserta en el extremo distal del proceso transverso III. Sobre la base del grado de exposición de la inserción del vientre posterior se reconocen tres estados de caracter: vientre posterior totalmente oculto en vista lateral por la supraescápula y el m. dorsalis scapulae (0), tercio distal del vientre posterior expuesto por detrás de la supraescápula y del m. dorsalis scapulae (1) y, mitad distal del vientre posterior expuesta por detrás de la supraescápula y del m. dorsalis scapulae (2). Alsodes gargola presenta el estado (0). Ceratophrys ornata presenta el estado (1). Atelognathus patagonicus, Batrachyla spp., Chacophrys pierottii, Eupsophus calcaratus, Hylorina sylvatica y Pleurodema borelli presentan el estado (2).

\section{III.10.3.2. Autopodio.}

\section{Caracter 56. Sesamoideo en la aponeurosis palmarisen la base de los tendo} digiti III, IV y V (Fig. 58). Pueden reconocerse dos estados de caracter: ausencia de hueso sesamoideo en la aponeurosis palmaris en la base de los tendo digiti III, IV y V (0) y, presencia de un hueso sesamoideo de forma rectangular en ese lugar. Alsodes 
gargola, Atelognathus patagonicus, Batrachyla spp., Ceratophrys ornata, Chacophrys pierottii, Eupsophus calcaratus e Hylorina sylvatica presentan el estado (0).

Pleurodema borelli presenta el estado (1).

Comentarios: Burton (1998) describió la musculatura de la mano de diversas especies, entre ellas muchas de las analizadas para esta tesis (Atelognathus patagonicus, Batrachyla taeniata, Chacophrys pierottii e Hylorina sylvatica) y no describe la presencia de sesamoideo en Chacophrys y si la describe en otra de las especies de Atelognathus por el estudiadas (A. praebasalticus). He observado la ausencia de sesamoideo en ejemplares juveniles de Chacophrys, con lo cual para asegurarse una correcta codificación del carácter deben verificarse ejemplares adultos. Burton (1998) remarcó que los ejemplares de Chacophrys que el estudió eran juveniles.

Caracter 57. Número de segmentos del prepollex (Fig. 58). El prepollexes un elemento preaxial, autostosico o cartilaginoso, que no forma parte del arco digital y no sería homologo a los digitos (Shubin \& Alberch, 1986). Fue descrito para urodelos, anuros, diversos tetrapodos devónicos, temnospóndilos, algunos mamiferos (en este grupo se trata de sesamoideos) y está compuesto por un elemento basal y un número variado de segmentos distales (Fabrezi, 2001). De acuerdo a la cántidad de segmentos distales que lo componen se reconocen tres estados de caracter: uno (0), dos (1), y tres (2) segmentos distales. El estado (0) lo presentan Hylorina sylvatica y Chacophrys pierottii. El estado (1) se encuentra en Alsodes gargola, Atelognathus patagonicus, Batrachyla spp, y Ceratophrys ornata. El estado (2) se observa en Eupsophus calcaratus y Pleurodema borelli.

Comentarios: Lavilla \& Lobo (1992) reportaron que el prepollex de Hylorina sylvatica está formado por dos segmentos distales, siendo el más distal cartilaginoso. En el material de Hylorina sylvatica estudiado para esta tesis se reconoce un único elemento distal compuesto de cuatro núcleos de cartílago azul de Alcian positivo, de los cuales se considero que el más distal corresponde al segundo elemento distal reportado por Lavilla \& Lobo (1992). En consecuencia mi interpretación es que Hylorina sylvatica presenta un solo segmento distal compuesto por cuatro núcleos de cartílago azul de Alcian positivo rodeados de una matriz cartilaginosa azul de alcian negativa.

Caracter 58. Forma de la falange distal (Fig. 59). La forma de la falange distal ha sido ampliamente utilizada como caracter para la reconstrucción de las relaciones en anuros (Heyer, 1975, Lynch 1978). Fabrezi (1996) revisó y discutió los diferentes estados que presenta el caracter para diversas familias de anuros. Vallejos Vallejos (1994) y Basso (1994) han empleado el caracter para la reconstrucción de las 
relaciones del género Batrachyla. Para ello, este último autor consideró cualitativamente la presencia/ausencia de dilatación distal de la última falange formando una T, mientras que Vallejos Vallejos (1994) cuantificó el caracter considerando los valores que toma la relación longitud/ancho de la falange distal. En consecuencia, cada autor propone una codificación diferente para el mismo caracter: dilatación presente o ausente (Basso, 1994), y relación longitud/ancho de la falange distal mayor o menor a 0,5 mm (Vallejos Vallejos, 1994). La intención de Vallejos Vallejos (1994) de reflejar el grado de dilatación de la falange distal en forma de T resulta un buen intento de reflejar la variabilidad dentro de Batrachyla. Sin embargo, he optado por no considerar cuantitativamente el caracter por las siguientes razones: 1) al considerar cuantitativamente este caracter, Eupsophus calcaratus presenta una relación ancho/largo de la última falange equivalente a la observada en Batrachyla antartandica, mientras que Eupsophus no presenta falanges terminales en forma de $\mathrm{T}$, cosa que si ocurre en todas las especies de Batrachyla; y 2) la relación longitud/ancho de la falange distal de las especies de Batrachyla toma valores que oscilan entre 0,2 mm y 0,7mm (según datos de Vallejos Vallejos, 1994), valores muy susceptibles de ser influenciados por el método y el error de la medición. Entonces considere cualitativamente el caracter empleando la codificación de Basso (1994). Dado que la morfología de las falanges distales es igual en el miembro anterior y en el posterior, he optado por codificar este caracter teniendo en cuenta a la falange distal del dígito IV del miembro anterior. De esta manera, según la morfología de la falange distal reconozco dos estados: redondeada (0), y en T (1). Ceratophrys ornata, Chacophrys pierottii, Eupsophus calcaratus y Pleurodema borellipresentan el estado (0). Alsodes gargola, Atelognathus patagonicus, Batrachyla spp., e Hylorina sylvatica presentan el estado (1).

\section{Caracter 59. Relación de tamaño de la dilatación en T y la base de la falange}

distal (Fig. 59). Para detalle de la codificación ver caracter anterior. Se reconocen dos estados: 0) dilatación en T menor al ancho de la base de la falange distal, y 1) dilatación en T igual o mayor al ancho de la base de la falange distal. Alsodes gargola, Atelognathus patagonicus, Batrachyla nibaldoi, B. taeniata e Hylorina sylvatica presentan el estado (0). Batrachyla antartandica, B. fitzroya y $B$. leptopus presentan el estado (1). Ceratophrys ornata, Chacophrys pierottii, Eupsophus calcaratus y Pleurodema borelli carecen de dilatación distal en $\mathrm{T}$ y fueron entrados a la matriz como datos inaplicables (-). 
A

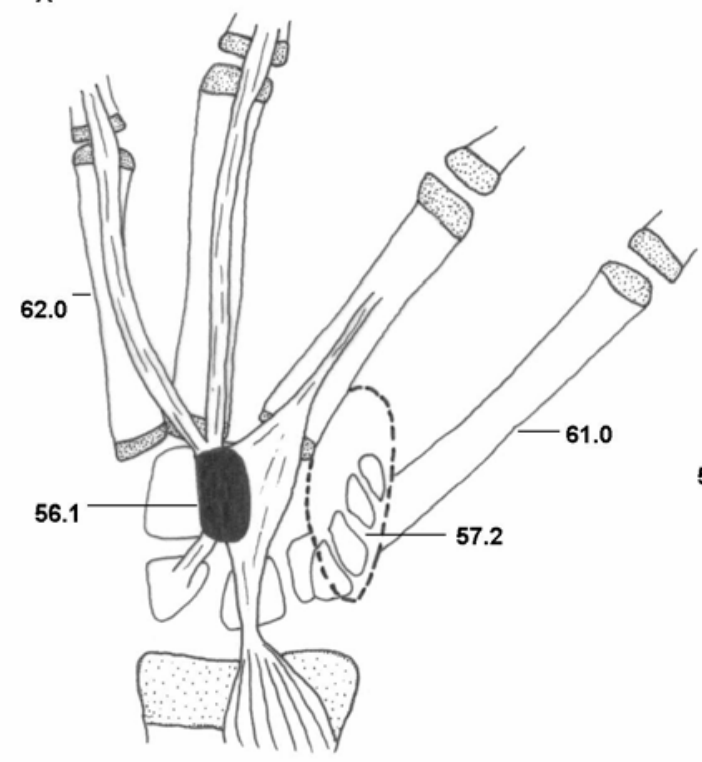

c

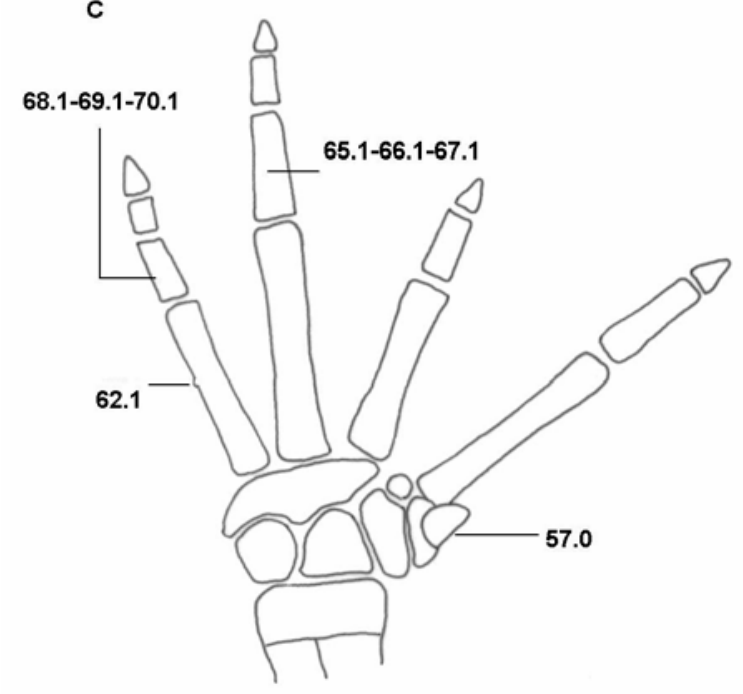

B

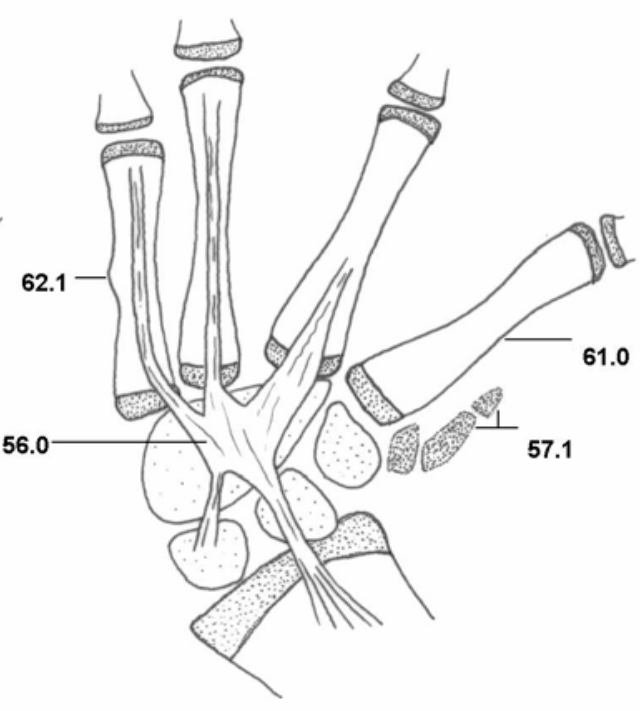

D

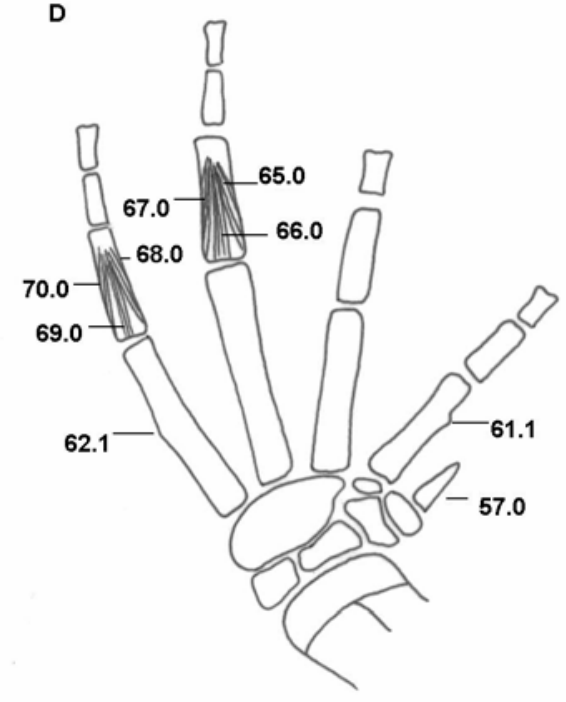

Figura 58. Estados de los caracteres 56-57, 61-62 y 65-70 esquematizados en vista ventral del autopodio del miembro anterior de 4 de las especies analizadas. (A) Pleurodema borellii, (B) Atelognathus patagonicus, (C) Chacophrys pierottiiy (D) Batrachyla taeniata. Esquemas sin escala. 
A

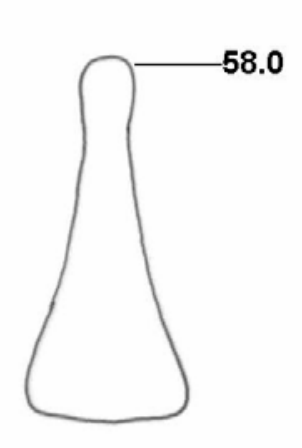

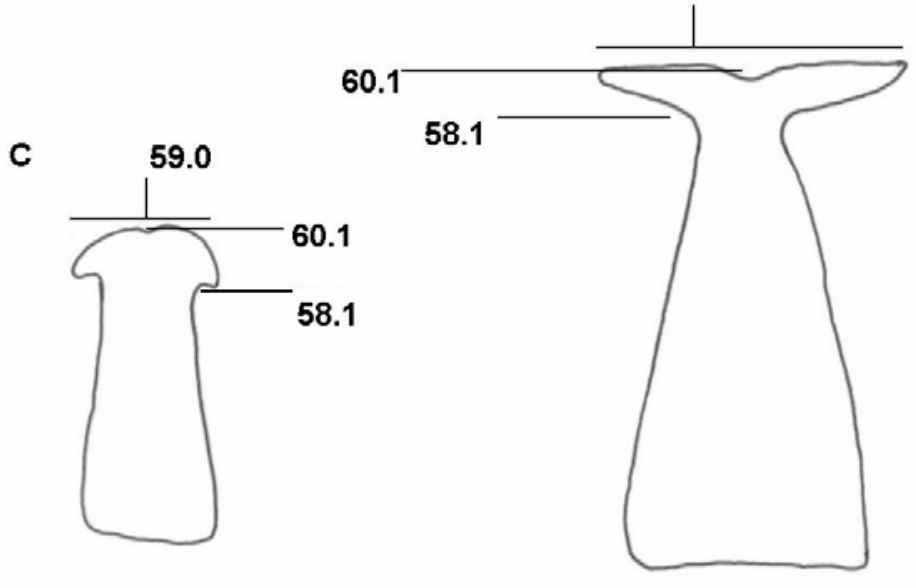

B

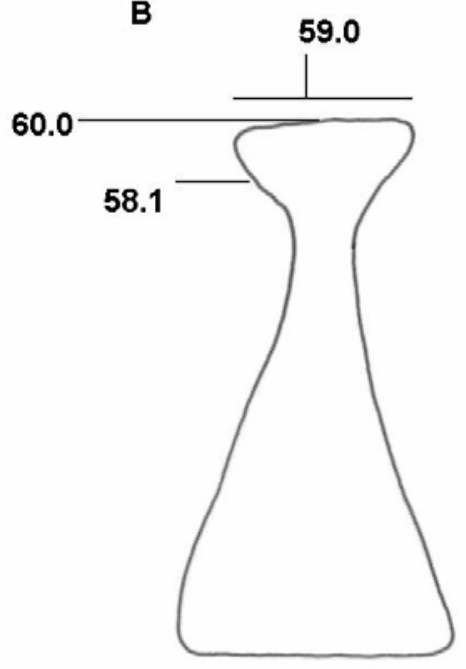

D

59.1

60.1

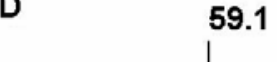

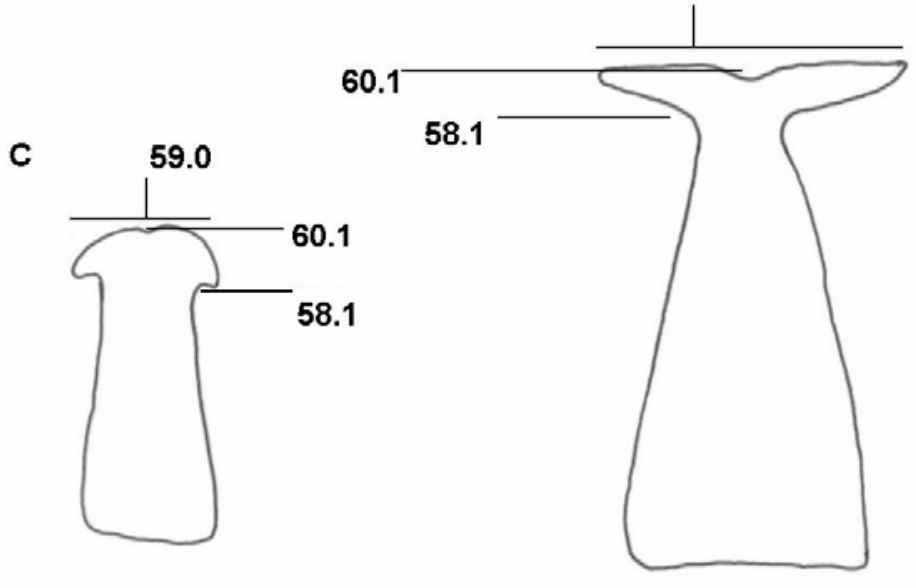

Figura 59. Estados de los caracteres 58 al 60 esquematizados en vista ventral de la falange distal del cuarto digito del miembro anterior en adultos de cuatro de las especies analizadas. (A) Pleurodema borellii, (B) Alsodes gargola, (C) Atelognathus patagonicus y (D) Batrachyla leptopus. Esquemas sin escala. 
Caracter 60. Escotadura distal entre los brazos de la dilatación en $\mathrm{T}$ de la falange distal (Fig. 59). Para detalle de la codificación ver caracter anterior. Se reconocen dos estados: 0) escotadura ausente, o 1) presente. Alsodes gargola presenta el estado (0). Atelognathus patagonicus, Batrachyla spp., e Hylorina sylvatica presentan el estado (1). Ceratophrys ornata, Chacophrys pierottii, Eupsophus calcaratus y Pleurodema borelli carecen de dilatación distal en T y fueron entrados a la matriz como datos inaplicables (-).

Comentarios: Para mayores detalles acerca de la escotadura distal entre ambos brazos de la T, ver el trabajo de Fabrezi (1996).

Caracter 61. Tubéculo óseo en la cara medial del metacarpiano II (Fig. 58). De acuerdo a la presencia o ausencia de un tubérculo óseo en la cara medial del metacarpiano II se reconocen dos estados de caracter: tubérculo ausente (0), o presente (1). El estado (0) lo presentan Alsodes gargola, Atelognathus patagonicus, $B$. fitzroya, Ceratophrys ornata, Chacophrys pierottii, Eupsophus calcaratus y Pleurodema borelli. El estado (1) lo presentan Batrachyla antartandica, B.leptopus, B. nibaldoi, B. taeniata e Hylorina sylvatica.

Caracter 62. Tubérculo óseo en la cara lateral del metacarpiano V (Fig. 58). La presencia de este tubérculo ha sidó propuesta por Basso (1991) como sinapomorfía para el grupo Batrachyla-Hylorina. De acuerdo a la presencia o ausencia de un tubérculo óseo en la cara lateral del metacarpiano $V$ se reconocen dos estados de caracter: tubérculo ausente (0), o presente (1). El estado (0) lo presentan Alsodes gargola, Eupsophus calcaratus y Pleurodema borelli. El estado (1) lo presentan Atelognathus patagonicus, Batrachyla spp., Ceratophrys ornata, Chacophrys pierottii, e Hylorina sylvatica.

Caracter 63. Longitud del dígito IV de la mano(s/ Fig.). Según la relación de longitud entre los dígitos IV y $\mathrm{V}$ de la mano se reconocen cinco estados de caracter (modificado de Basso, 1994, descritos como dígitos III y IV en ese trabajo): extremo de la falange distal del dígito $V$ alcanza el nivel de la base de la última falange del dígito IV (0), extremo de la falange distal del dígito $\mathrm{V}$ supera el nivel de la mitad de la segunda falange del dígito IV pero no alcanza el nivel de la base de la última falange de ese dígito (1), extremo de la falange distal del dígito $V$ no supera el nivel de la mitad de la segunda falange del dígito IV (2), extremo de la falange distal del dígito $\mathrm{V}$ alcanza la base de la segunda falange del dígito IV (3), o extremo de la falange distal del dígito $\mathrm{V}$ solo alcanza la mitad de la primer falange del dígito IV (4). 
El estado (0) lo presentan Alsodes gargola, Atelognathus patagonicus, Batrachyla antartandica y B. leptopus. El estado (1) lo presentan Batrachyla fitzroya, B. nibaldoi, B. taeniata, Eupsophus calcaratus e Hylorina sylvatica. El estado (2) lo presenta Pleurodema borelli. El estado (3) lo presenta Ceratophrys ornata. El estado (4) lo presenta Chacophrys pierottii.

Caracter 64. Longitud del dígitol II de la mano (s/ Fig.). Según la relación de longitud entre los dígitos II y III de la mano se reconocen cinco estados de caracter (modificado de Vallejos Vallejos, 1994, descritos como dígitos I y II en ese trabajo): extremo de la falange distal del segundo dígito no supera la mitad de la falange proximal del tercero (0), extremo de la falange distal del segundo dígito no alcanza la base de la falange distal del tercer digito pero supera la mitad de la falange proximal del mismo (1), extremo de la falange distal del segundo dígito alcanza la base de la falange distal del tercero (2), extremo de la falange distal del segundo dígito supera ligeramente la base de la falange distal del tercer dígito haciendo que ambos dígitos tengan practicamente la misma longitud (3), extremo de la falange distal del segundo dígito supera ampliamente la base de la falange distal del dígito III pero nunca supera el extremo de la misma haciendo que el segundo dígito sea más largo que el tercero (4), y extremo de la falange distal del segundo dígito supera ampliamente el extre mo de la falange distal del dígito III (5).

Batrachyla antartandica, B. fitzroya y B. leptopus presentan el estado (0). Hylorina sylvatica presenta el estado (1). Batrachyla nibaldoi y B. taeniata presentan el estado (2). Alsodes gargola y Atelognathus patagonicus presentan el estado (3). Eupsophus calcaratus y Pleurodema borelli presentan el estado (4). Ceratophrys ornata y Chacophrys pierottii presentan el estado (5).

Caracter 65. Cabeza medial del m. interphalangealis IV (Fig. 58). Como máximo se han registrado hasta tres cabezas componiendo el $\mathrm{m}$. interphalangealis IV, las cabezas medial, central y lateral, donde cada una de ellas puede faltar de acuerdo al taxon que se trate. Con relación a la presencia o ausencia de cabeza medial se reconocen dos estados de caracter: cabeza presente (0), o ausente (1). Alsodes gargola, Atelognathus patagonicus, Batrachyla spp., Ceratophrys ornata, Eupsophus calcaratus e Hylorina sylvatica presentan el estado (0). Chacophrys pierottii y Pleurodema borelli presentan el estado (1).

Caracter 66. Cabeza central del m. interphalangealis IV (Fig. 58). Para codificación ver caracter anterior. Se reconocen dos estados: cabeza central presente (0), o ausente (1). Alsodes gargola, Atelognathus patagonicus, Batrachyla nibaldoi, $B$. 
taeniata, Hylorina sylvatica y Pleurodema borelli presentan el estado (0). B. antartandica, B. fitzroya, B. leptopus, Ceratophrys ornata, Chacophrys pierottii y Eupsophus calcaratus presentan el estado (1).

Caracter 67. Cabeza lateral del m. interphalangealis IV (Fig. 58). Para codificación ver caracter 66. Se reconocen dos estados: cabeza lateral presente (0), o ausente (1). Alsodes gargola, Batrachyla spp., Ceratophrys ornata, Eupsophus calcaratus e Hylorina sylvatica presentan el estado (0). Atelognathus patagonicus, Chacophrys pierottii y Pleurodema borelli presentan el estado (1).

Comentarios: En Ceratophrys ornata se encuentra presente pero considerablemente reducida.

Caracter 68. Cabeza medial del m. interphalangealis V (Fig. 58). Como máximo se han registrado hasta tres cabezas componiendo el $\mathrm{m}$. interphalangealis $\mathrm{V}$, las cabezas medial, central y lateral, donde cada una de ellas puede faltar de acuerdo al taxon que se trate. Con relación a la presencia o ausencia de cabeza medial se reconocen dos estados de caracter: cabeza presente (0), o ausente (1). Alsodes gargola, Atelognathus patagonicus, Batrachyla spp. y Eupsophus calcaratus presentan el estado (0). Ceratophrys ornata, Chacophrys pierottii, Hylorina sylvatica y Pleurodema borelli presentan el estado (1).

Caracter 69. Cabeza central del m. interphalangealis V (Fig. 58). Para codificación ver caracter anterior. Se reconocen dos estados: cabeza central presente (0), o ausente (1). Alsodes gargola, Batrachyla taeniata, B. nibaldoi, Hylorina sylvatica y Pleurodema borelli presentan el estado (0). Atelognathus patagonicus, Batrachyla antartandica, B. fitzroya, B. leptopus, Ceratophrys ornata, Chacophrys pierottii y Eupsophus calcaratus presentan el estado (1).

Caracter 70. Cabeza lateral del $\mathrm{m}$. interphalangealis V (Fig. 58). Para codificación ver caracter 66. Se reconocen dos estados: cabeza lateral presente (0), o ausente (1). Alsodes gargola, Atelognathus patagonicus, Batrachyla spp., e Hylorina sylvatica presentan el estado (0). Ceratophrys ornata, Chacophrys pierottii, Eupsophus calcaratus y Pleurodema borellipresentan el estado (1).

III.10.4. Caracteres de esqueleto y musculatura del miembro posterior.

\section{III.10.4.1. Estilopodio.}


Caracter 71. Músculo adductor longus (Fig. 60). Sobre la base de la presenciaausencia de este músculo es posible distinguir dos estados de caracter (modificado de Heyer, 1975): m. adductor longus presente (0), y ausente (1). Alsodes gargola, Atelognathus patagonicus, Ceratophrys ornata y Pleurodema borelli presentan el estado (0). Batrachyla spp., Chacophrys pierottii, Eupsophus calcaratuse Hylorina sylvatica presentan el estado (1).

Comentarios: Según Heyer (1975) este caracter puede presentar variación intragenerica al punto de hallarse presente o ausente de acuerdo a la especie (e.g., Physalaemus). Ese sería el caso para el género Alsodes, donde Heyer (1975) reportó para $A$. nodosus el $\mathrm{m}$. adductor longus poco desarrollado con inserción en el $\mathrm{m}$. adductor magnus y estando totalmente cubierto por el $\mathrm{m}$. sartorius, mientras que en $A$. gargola (presente trabajo) el músculo esta bien desarrollado.

Limeses (1963) reportó la existencia de m. adductor longus en Chacophrys pierottii. No lo he observado en los dos especimenes diseccionados para la presente tesis y he optado por codificarlo ausente en esta especie.

Caracter 72. Inserción de la cabeza ventral del músculo adductor magnus (Fig. 60). La cabeza ventral del $\mathrm{m}$. adductor magnus inserta en las adyacencias de la epífisis distal del fémur, entre los sitios de inserción de los mú sculos cruralis (por delante) y sartorius (por detrás). Teniendo en cuenta ello, se distinguen dos estados de caracter: tercio distal de la inserción de la cabeza ventral del $\mathrm{m}$. adductor magnus visible en vista superficial sin necesidad de despejar a los $\mathrm{mm}$. sartorius y cruralis (0), y tercio distal de la inserción de la cabeza ventral del $\mathrm{m}$. adductor magnus no visible en vista superficial, oculta por los mm. sartorius y cruralis (1). Atelognathus patagonicus, Batrachyla spp., Ceratophrys ornata, Chacophrys pierottii, e Hylorina sylvatica presentan el estado (0). Eupsophus calcaratus y Pleurodema borelli presentan el estado (1). Alsodes gargola presenta ambos estados y se codificó (0-1).

Caracter 73. Músculo semitendinosus (Fig. 60). Se distinguen dos estados de caracter: $\mathrm{m}$. semitendinosus no visible superficialmente, a menos que se remuevan el m. gracilis major y la cabeza ventral del $\mathrm{m}$. adductor magnus (0), y m. semitendinosus visible superficialmente entre la cabeza ventral del $\mathrm{m}$. adductor magnus y el $\mathrm{m}$. gracilis major (1). Atelognathus patagonicus, Batrachyla spp., Ceratophrys ornata, Eupsophus calcaratus, Hylorina sylvatica y Pleurodema borelli presentan el estado (0). Alsodes gargola y Chacophrys pierottii presentan el estado (1).

Caracter 74. Desarrollo del m. pectineus con relación al m. iliacusinternus (Fig. 60). Se reconocen dos estados de caracter: $\mathrm{m}$. pectineus menor que el $\mathrm{m}$. iliacus 
internus (0), y m. pectineus igual de voluminoso que el $\mathrm{m}$. iliacus internus (1). Atelognathus patagonicus, Batrachyla spp., Ceratophrys ornata, Chacophrys pierottii, Eupsophus calcaratus, Hylorina sylvatica, Pleurodema borelli presentan el estado (0). Alsodes gargola presenta el estado (1).

\section{III.10.4.2. Zeugopodio.}

Caracter 75. Grado de exposición de la tibia-fíbula (Fig. 61). Dos músculos recorren la superficie medio ventral de la tibia-fíbula, el $\mathrm{m}$. extensor curalis brevis y el m. tibialis posticus. De acuerdo al grado en que las fibras mediales de ambos músculos insertan entre si se reconocen dos estados de caracter: las fibras mediales de ambos músculos insertan entre si impidiendo la exposición de la tibia-fíbula en su tercio medio (0), y las fibras mediales de ambos músculos no insertan entre si, dejando totalmente expuesta la tibia-fíbula que queda cubierta solo por una aponeurosis media a ambos músculos (1). Ceratophrys ornata, Chacophrys pierottii, Eupsophus calcaratus y Pleurodema borelli presentan el estado (0). Alsodes gargola, Atelognathus patagonicus, Batrachyla spp., e Hylorina sylvatica presentan el estado (1).

Caracter 76. Grado de desarrollo del m. extensor cruralis brevis (Fig. 61). El m. extensor cruralis brevis se origina mediante un tendón en la aponeurosis distal de los $\mathrm{mm}$. cruralis y glutaeus magnus e inserta en la cara anterior y ventral de la tibia-fíbula. De acuerdo a su grado de desarrollo es posible distinguir tres estados de caracter: las fibras de este músculo recorren $3 / 4$ de la longitud del zeugopodio y rematan en un corto tendón distal (0), las fibras de este músculo ocupan solo los $2 / 3$ proxi males del zeugopodio y rematan distalmente en un largo tendón que deja expuestos al tercio distal de la tibia-fíbula y al m. tibialis anticus brevis (1), y las fibras de este músculo recorren solo el tercio proximal del zeugopodio, siendo este músculo menos desarrollado que el m tibialis anticus brevis(2). Alsodes gargola, Atelognathus patagonicus, Eupsophus calcaratus y Pleurodema borellipesentan el estado (0). Batrachyla spp., e Hylorina sylvatica presentan el estado (1). Ceratophrys ornata y Chacophrys pierottiipresentan el estado (2).

Caracter 77. Músculo tibialis anticus brevis (Fig. 61). Este músculo se origina en el tercio distal de la tibia-fíbula a partir de la región distal del $\mathrm{m}$. extensor cruralis brevis, e inserta en el tibial. De acuerdo a si se diferencia o no del m. extensor cruralis brevis es posible reconocer dos estados de caracter: $\mathrm{m}$. tibialis anticus brevis bien desarrollado, claramente diferenciado del $\mathrm{m}$. extensor cruralis brevis, no visible o visible en distinto 
A

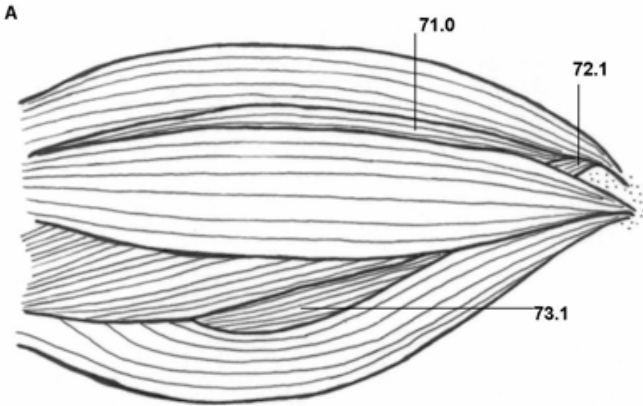

c

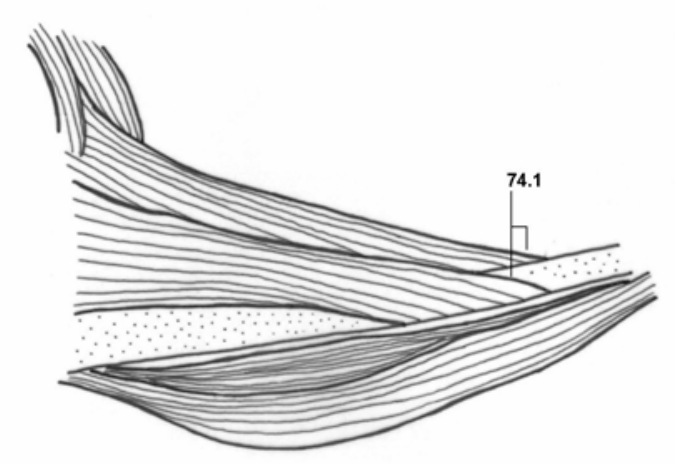

B
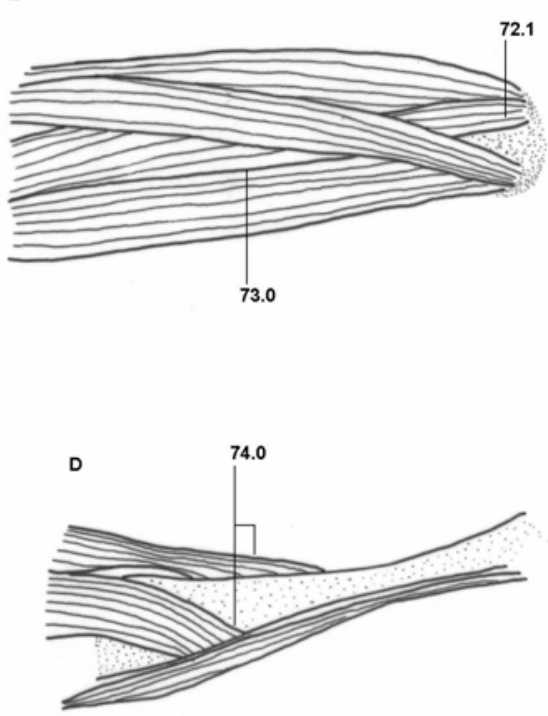

Figura 60. Estados de los caracteres 71 al 74 esquematizados en vista ventral de la musculatura del muslo de dos de las especies analizadas. (A) Vista superficial en Alsodes gargola, (B) Vista superficial en Batrachyla taeniata, (C) Vista profunda en Alsodes gargola y (D) Vista profunda en Batrachyla taeniata. Esquemas sin escala. 
A

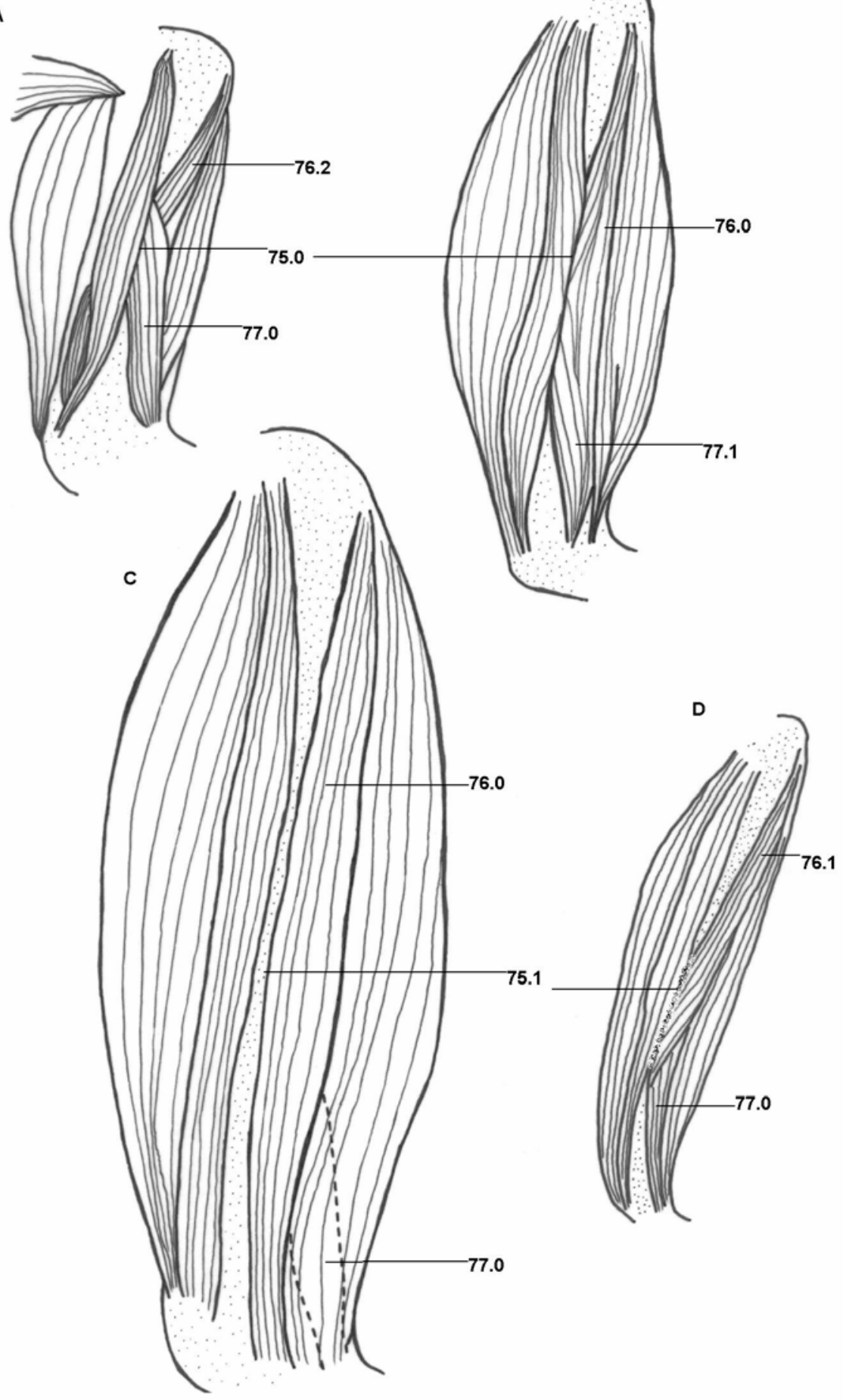

Figura 61. Estados de los caracteres 75 al 77 esquematizados en vista ventral de la musculatura del zeugopodio de cuatro de las especies analizadas. (A) Chacophrys pierottii, (B) Pleurodema borellii, (C) Alsodes gargola y (D) Batrachyla taeniata. Esquemas sin escala. 
grado entre los mm. tibialis anticus longus y extensor cruralis brevis (0), y m. tibialis anticus brevis no diferenciado del m. extensor cruralis brevis (1). Alsodes gargola, Atelognathus patagonicus, Batrachyla spp., Ceratophrys ornata, Chacophrys pierottii, e Hylorina sylvatica presentan el estado (0). Eupsophus calcaratus y Pleurodema borelli presentan el estado (1).

\section{III.10.4.3. Autopodio.}

\section{Caracter 78. Sesamoideo del tendón del $\mathrm{m}$. flexor digitorum brevis superficialis y} de la aponeurosis plantaris en la base de los tendo digiti IV y V (Fig. 62). De acuerdo a la presencia-ausencia de sesamoideos en la planta del pie se reconocen dos estados de caracter: sesamoideos ausentes (0), y al menos un sesamoideo presente (1). Alsodes gargola, Atelognathus patagonicus, Batrachyla spp., Ceratophrys ornata, Eupsophus calcaratus, e Hylorina sylvatica presentan el estado (0). Chacophrys pierottii y Pleurodema borelli presentan el estado (1).

Caracter 79. Desarrollo de las cabezas del m. interphalangealisIII (Fig. 62). De acuerdo a la cántidad de cabezas que presenta este músculo se reconocen 3 estados de caracter: dos cabezas (medial y lateral) bien desarrolladas (0), cabeza medial muy poco desarrollada respecto de la lateral (1) y una sola cabeza (lateral) (2). Alsodes gargola, Atelognathus patagonicus, Batrachyla nibaldoi, B. taeniata, Hylorina sylvatica y Pleurodema borelli presentan el estado (0). Ceratophrys ornata y Chacophrys pierottii presentan el estado (1). Batrachyla antartandica, B. fitzroya, B. leptopusy Eupsophus calcaratus presentan el estado (2).

Caracter 80. Desarrollo de las cabezas del m. interphalangealisIV (Fig. 62). El m. interphalangealis IV de los taxa examina dos siempre esta formado por dos cabezas, la medial y lateral, separadas en la línea media. De acuerdo al desarrollo relativo de ambas es posible reconocer 2 estados de caracter: ambas cabezas subiguales (0), y cabeza medial de menor tamaño que la lateral (1). Alsodes gargola, Atelognathus patagonicus, Batrachyla nibaldoi, B. taeniata, Ceratophrys ornata, Chacophrys pierottii, Eupsophus calcaratus, Hylorina sylvatica y Pleurodema borelli presentan el estado (0). Batrachyla antartandica, B. fitzroya y $B$. leptopus presentan el estado (1).

Comentarios: En todas las especies analizadas se observó la tendencia a invadir la región medio ventral de la falange por parte de las fibras mas mediales de la cabeza lateral, aunque ellas no representen una cabeza media diferenciada, la que debería claramente diferenciarse al origen. Solo en Eupsophus calcaratus la invasión del area 
medio ventral de la falnge por parte de la cabeza lateral es bien marcada y relativamente bien diferenciada de dicha cabeza.

Caracter 81. Número de cabezas del m. interphalangealis distalis IV (Fig. 62). De acuerdo al número de cabezas que componen el músculo se reconocen tres estados de caracter: músculo compuesto por dos cabezas (medial y lateral) (0), una sola cabeza (lateral) a causa de que la cabeza medial está muy reducida o ausente (1), y ambas cabezas ausentes (2). Alsodes gargola, Atelognathus patagonicus, Batrachyla nibaldoi, B. taeniata, Ceratophrys ornata, Eupsophus calcaratus, Hylorina sylvatica y Pleurodema borelli presentan el estado (0). Batrachyla antartandica, B. fitzroya y B. leptopus presentan el estado (1). Chacophrys pierottii presenta el estado (2). Comentarios: En algunos especimenes de Atelognathus patagonicus, Eupsophus calcaratus, e Hylorina sylvatica fue posible reconocer, dado su gran desarrollo, la fusión media de ambas cabezas. Por otro lado, si bien la mayoría de los especimenes de Batrachyla antartandica, B. fitzroya, B. leptopus carecieron de cabeza medial, en algunos está se observo sumamente reducida, y a veces presente solo en uno de los pies (indistintamente del lado izquierdo o del derecho).

\section{Caracter 82. Grado de desarrollo de los mm. flexor ossei metatarsi II y III (Fig.}

62). Se reconocen dos estados de caracter: 0) mm. flexores ossi metatarsi II y III con igual longitud que los respectivos $\mathrm{mm}$. flexores teretes, lo que se traduce en una inserción en el extremo distal de los respectivos metatarsos (0), y mm. flexores ossi metatarsi II y III reducidos, con menor longitud que los respectivos $\mathrm{mm}$. flexores teretes, lo que se traduce en una inserción que no sobrepasa los dos tercios distales de los respectivos metatarsos (1). Alsodes gargola, Batrachyla spp., Ceratophrys ornata, Chacophrys pierottii, Eupsophus calcaratus, Hylorina sylvatica y Pleurodema borelli presentan el estado (0). Atelognathus patagonicus presenta el estado (1).

Caracter 83. Número de segmentos distales del prehallux (Fig. 62). El prehallux es un elemento preaxial que no forma parte del arco digital y que por lo tanto no sería homologo a los digitos (Shubin \& Alberch, 1986). Fue descrito para urodelos, anuros, diversos tetrapodos devónicos, temnospondilos, algunos mamiferos (en este grupo no serían homologos al de los restantes por ser sesamoideos) y está compuesto por un elemento basal y un número variado de segmentos distales (Fabrezi, 2001). De acuerdo a la cántidad de segmentos distales que lo componen en los taxa examinados, se reconocen tres estados de caracter: uno (0), dos (1), y tres (2) segmentos distales. El estado (0) lo presentan Alsodes gargola, Ceratophrys ornata, Chacophrys pierottii y Eupsophus calcaratus. El estado (1) se encuentra en 


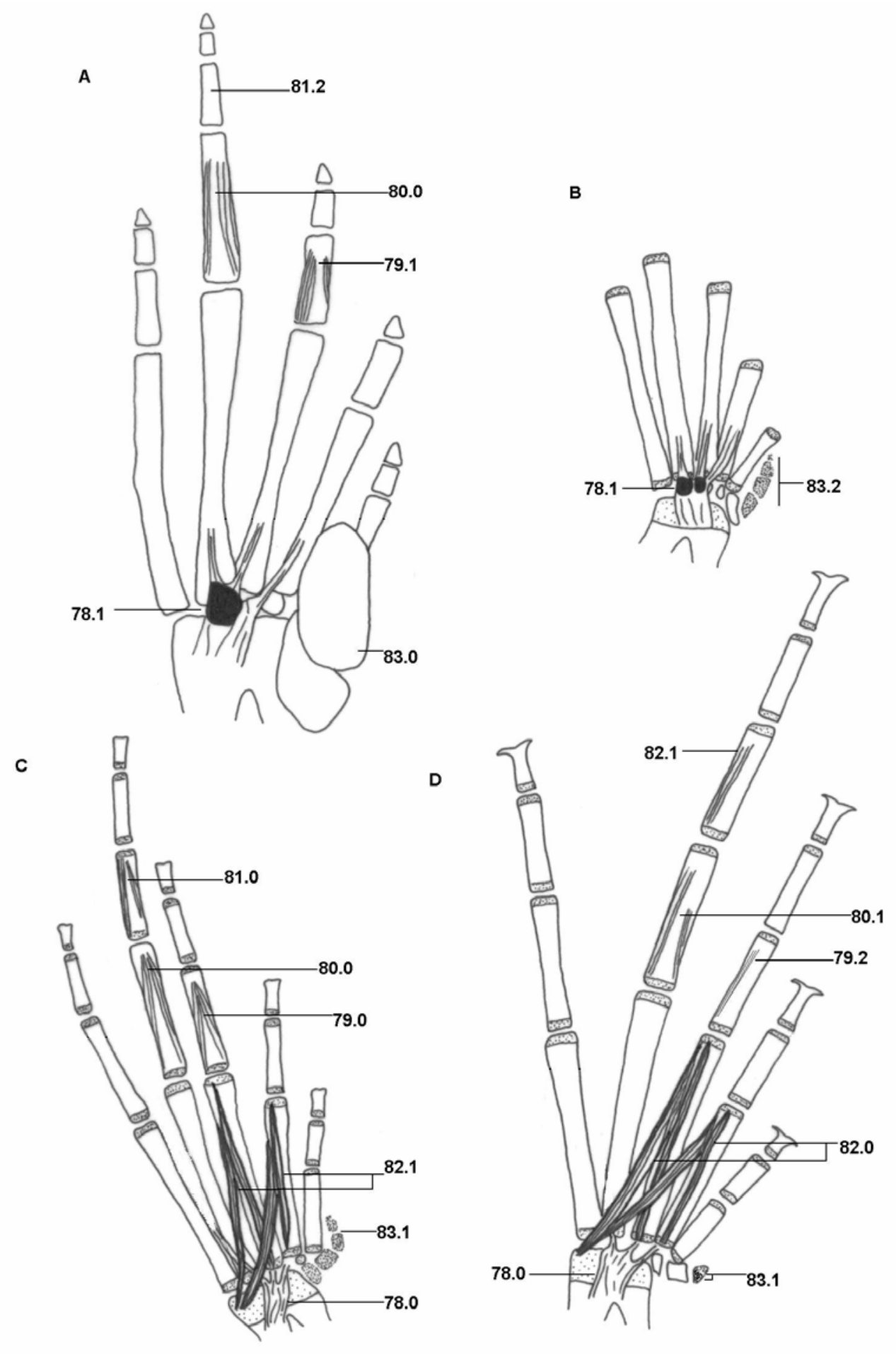

Figura 62. Estados de los caracteres 78 al 83 esquematizados en vista ventral del autopodio del miembro posterior de 4 de las especies analizadas. (A) Chacophrys pierottii, (B) Pleurodema borellii, (C) Atelognathus patagonicus y (D) Batrachyla antartandica. Esquemas sin escala. 
Atelognathus patagonicus, Batrachyla spp. e Hylorina sylvatica. El estado (2) se observa en Pleurodema borelli.

Comentarios: Lavilla \& Lobo (1992) reportaron que el prehallux de Hylorina sylvatica está formado por tres segmentos distales de cartílago mineralizado. En el material de adultos de Hylorina sylvatica estudiado para esta tesis se reconoce un único elemento distal alargado que representa la suma de los dos elementos distales observados en las larvas. Formas (1997) reportó la existencia de un elemento basal y uno distal para el prehallux de Batrachyla nibaldoi. Teniendo en cuenta la existencia de inconsistencias entre la figura 6E (se gráfica un solo elemento, el basal) y el texto (en la pagina 12 se indican dos elementos, presumiblemente el basal más otro distal) del trabajo de Formas (1997), más la comprobación de dos elementos distales (al igual que en las restantes especies de Batrachyla) en los especimenes por mi estudiados, he optado por codificar la especie Batrachyla nibaldoi con el estado (1).

\section{III.10.5. Caracteres de morfologia externa del adulto.}

Caracter 84. Forma del hocico en vista lateral (s/ Fig.). Basso (1994) propusó tres estados para este caracter: 0) redondeado, 1) oblicúo, y 2) trunco. (0). Alsodes gargola, Batrachyla fitzroya y $B$. leptopus presentan el estado (0). Atelognathus patagonicus, Batrachyla antartandica, B. nibaldoi, B. taeniata, Ceratophrys ornata, Hylorina sylvatica y Pleurodema borelli presentan el estado (1). Chacophrys pierottii y Eupsophus calcaratus presentan el estado (2).

Caracter 85. Longitud total (s/ Fig.). En su análisis del género Batrachyla, Basso (1994) dividio al caracter LT en dos estados: LT media mayor o menor a $35 \mathrm{~mm}$ y ubicó a $B$. antartandica y $B$. taeniata en la primera categoría y a $B$. fitzroya y $B$. leptopus dentro de la segunda. Los valores medios de LT dados por Vallejos Vallejos (1994) para B. antartandica, B. leptopus y B. taeniata coinciden en general con el recorte propuesto por Basso (1994) para las tres especies pero no lo hacen en el caso de los machos de B. taeniata. La LT media dada por Barrio (1967) y encontrada por mí en el presente trabajo para $B$. antartandica se aproxima, pero no coincide, a los valores dados por Basso (1994). Diaz Perez (1984) da valores medios para las hembras de $B$. antartandica, $B$. leptopus y $B$. taeniata que superan ampliamente el recorte de $35 \mathrm{~mm}$, siendo curiosamente $B$. leptopus la de mayor tamaño. Diaz Perez (1987) contradiciendo su trabajo anterior, da valores medios de LT para las hembras de $B$. taeniata que resultan muy inferiores al límite de $35 \mathrm{~mm}$ propuesto por Basso 
(1994). Otros autores (Cei, 1962; Grandison, 1962) dan valores de rango donde se observa que $B$. antartandica y $B$. taeniata son mayores a $B$. leptopus, pero no brindan los valores medios para esas especies. Dada las divergencias de los valores medios que se desprenden del análisis de la bibliografía más mis propios datos he decidido no expresar el carácter en término de valores máximos para cada especie (valores que en general son coincidentes con la LT de las hembras). Entonces, según lo expuesto, consideraré cinco estados de caracter: LT máxima menor de $40 \mathrm{~mm}$ (0), entre 40 y 50 $\mathrm{mm}$ (1), entre 50 y $60 \mathrm{~mm}$ (2), entre 60 y $70 \mathrm{~mm}$ (3), y mayor de $100 \mathrm{~mm}$ (4).

Batrachyla fitzroya y B. leptopuspresentan el estado (0). B. antartandica, B. nibaldoi y B. taeniata presentan el estado (1). Alsodes gargola (datos propios y según Cei, 1980), Chacophrys pierottii (datos propios y según Cei, 1980), Eupsophus calcaratus (datos propios y según Cei, 1980), y Pleurodema borelli (según Cei, 1980) presentan el estado (2). Hylorina sylvatica (según Barrio, 1967b) presenta el estado (3).

Ceratophrys ornata (datos propios y según Cei, 1980) presenta el estado (4).

Caracter 86. Forma de la pupila (s/ Fig.). Diversos autores han empleado la forma de la pupila como caracter en estudios sistemáticos de la familia "Leptodactylidae" (e.g., Heyer, 1975; Lynch, 1978) y al nivel ordinal (Haas, 2003). Según esos trabajos se reconocen dos estados de caracter: pupila vertical donde predomina el eje vertical sobre el horizontal (0), y pupila redondeada donde ningun eje de la misma, vertical u horizontal, son preponderantes (1). Hylorina sylvatica presenta el estado (0). Alsodes gargola, Atelognathus patagonicus, Batrachyla spp., Ceratophrys ornata, Chacophrys pierottii, Eupsophus calcaratus y Pleurodema borellipresentan el estado (1).

Caracter 87. Granulación glandular dorsal (s/ Fig.). De acuerdo a la presencia o ausencia de pequeñas, aunque conspicuas, prominencias glandulares en la piel del dorso se reconocen dos estados de caracter: granulación glandular ausente (0), o presente (1). Alsodes gargola, Atelognathus patagonicus, Batrachyla nibaldoi, B, taeniata, Eupsophus calcaratus, Hylorina sylvatica y Pleurodema borelli presentan el estado (0). Batrachyla antartandica, B. fitzroya, B. leptopus, Ceratophrys ornata y Chacophrys pierottii presentan el estado (1).

Caracte r 88. Grado de desarrollo del tubérculo metatarsiano externo (s/ Fig.). La presencia-ausencia de tuberculo metatarsiano externo fue empleado por diversos autores como caracter para resolver las relaciones dentro de Leptodactylidae (e.g., Heyer, 1975). Entonces se reconocen dos estados de caracter: tubérculo presente (0), y tubérculo ausente (1). Alsodes gargola, Atelognathus patagonicus, Batrachyla antartandica, B. fitzroya, B. leptopus, Eupsophus calcaratus, Hylorina sylvatica y 
Pleurodema borelli presentan el estado (0). Ceratophrys ornata y Chacophrys pierottii presentan el estado (1). B. nibaldoi y B. taeniata fueron polimorficas para el caracter y fueron codificadas $(0,1)$.

Comentarios: Hasta la descripción de Batrachyla nibaldoi (Formas, 1997), todas las especies de Batrachyla presentaban tubérculo metatarsiano externo reducido y por tal razón este caracter nunca fue empleado en la resolución de las relaciones internas del género realizadas por Basso (1994) y Vallejos Vallejos (1994). En el material de Batrachyla nibaldoi observado para el presente trabajo, he observado la siguiente variabilidad respecto de la presencia de tubérculo metatarsiano externo: tubérculo ausente ( 2 ejemplares macho, $\mathrm{N}=3$ ), tubérculo presente en el pie derecho, ausente en el izquierdo ( 1 ejemplar macho, $\mathrm{N}=3$ ). La misma clase de variación y la existencia de asimetria bilateral se observaó para $B$. taeniata.

Caracter 89. Grado de desarrollo del tuberculo metatarsiano interno (s/ Fig.). De acuerdo al desarrollo de dicho tuberculo se reconocen dos estados: tuberculo normal (0), e hipertrofiado (1). Alsodes gargola, Atelognathus patagonicus, Batrachyla spp., Eupsophus calcaratus, Hylorina sylvatica y Pleurodema borelli presentan el estado (0). Ceratophrys ornata y Chacophrys pierottii presentan el estado (1).

\section{Caracter 90. Queratinizaciones sexuales del dígito III de la mano de los machos}

(s/ Fig.). De acuerdo a la presencia-ausencia de queratinizaciones en el dorso del dígito III de la mano de los machos se reconocen dos estados de caracter: queratinizaciones presentes (0), o ausentes (1). Alsodes gargola, Atelognathus patagonicus, B. antartandica, B. leptopus, Batrachyla nibaldoi, B. taeniata y Eupsophus calcaratus presentan el estado (0). Ceratophrys ornata, Hylorina sylvatica y Pleurodema borelli presentan el estado (1). B. fitzroya y Chacophrys pierottii fueron entrados como datos faltantes (?) (ver comentarios).

Comentarios: Barrio (1967a) describió queratinizaciones en el dorso del segundo dígito (I según ese autor) de la mano de $B$. antartandica y no señaló que $B$. leptopus difiera de ella en ese sentido. Formas (1997), a pesar de haber contado con un espécimen macho de $B$. nibaldoi, no incluyó información acerca de las queratinizaciones de los dígitos de la mano para esta especie. De la misma manera, Basso (1994) tampoco incluyó esa información en su descripción de B. fitzroya. Vallejos Vallejos (1994) describió queratinizaciones en el dorso del prepollex y de los dígitos II y III (I y II según esa autora) para las especies $B$. antartandica, $B$. leptopus y $B$. taeniata, y remarcó su mayor desarrollo en la última especie nombrada. Ubeda (1998) señala para B. taeniata la presencia de queratinizaciones ("asperezas") sobre la cara interna 
de los dedos II y III (uno y dos de esa autora), pudiendo faltar las del dedo II en $B$. antartandica.

Los tres especimenes macho que estudié de $B$. nibaldoi presentaron queratinizaciones sexuales dorsales a los dígitos II y III. A pesar de haber contado con los especimenes macho de $B$. fitzroya estudiados por Basso (1994), las queratinizaciones sexuales no pudieron ser observadas a causa de su deterioro por la preservación.

Respecto de las queratinizaciones sexuales sobre el prepollexmencionadas por Vallejos Vallejos (1994), éstas fueron considerada para el presente trabajo como queratinizaciones del segundo dígito, dado que el prepollex no forma una estructura notoria a nivel morfológico externo, sino que forma un abultamiento lateral al dígito II, observaciones que coinciden con lo descritó por Cei (1960) y Grandison (1961) para esa especie.

Vallejos Vallejos (1994) mencionó que Hylorina pesenta la misma condición que las especies de Batrachyla, esto es queratinizaciones en los dígitos II y III (I y II de esa autora). Barrio (1967b) y Cei (1980) consideraron que Hylorina presenta queratinizaciones solo en el dígito II (primero de esos autores). Mis observaciones coinciden con las de Barrio (1967b) y Cei (1980).

Cei (1980) describió para Atelognathus patagonicus la presencia de queratinizaciones sobre los dígitos II y III (I y II según el autor).

\section{Caracter 91. Queratinizaciones sexuales de forma circular ubicadas} bilateralmente al nivel pectoral en los machos (s/ Fig.). Sobre la presenciaausencia de las mismas se reconocen dos estados de caracter: queratinizaciones ausentes (0), o presentes (1). Atelognathus patagonicus, Batrachyla spp., Ceratophrys ornata, Chacophrys pierottii, Eupsophus calcaratus, Hylorina sylvatica y Pleurodema borelli presentan el estado (0). Alsodes gargola presenta el estado (1).

Caracter 92. Grado de desarrollo de la membrana interdigital del pie (s/ Fig.). E grado de desarrollo de la membrana interdigital del pie fue empleado por diversos autores (e.g., Basso, 1994; Heyer, 1975) considerando diferentes estados de caracter de acuerdo a las características de los taxa empleados para el análisis. Para condificar el desarrollo de la membrana interdigital se pueden elegir al menos tres opciones: 1) considerar un estado para cada par de dígitos, resultando entonces cuatro caracteres, 2) considerar la membrana como una totalidad, teniendo entonces solo un caracter, y 3) plantear una solución intermedia contemplando solo un caracter definido sobre la base de la secuencia de reducción de la membrana, quese reduce primero en los dedos marginales y por último en los centrales. Elegir la primer opción implica darle 
mucho peso a una relación entre Alsodes y Atelognathus (ambas formas acúaticas con mucho desarrollo de la membrana). Elegir la opción dos resulta en una codificación dificil, dado las multiples variantes que se observaron en los taxa que presentan membrana presente pero reducida. Entonces he optado por la opción tres, donde defini tres estados de caracter para el desarrollo de la membrana entre los dígitos centrales (II y IV): membrana bien desarrollada (supera el tercio dístal de los dígitos al menos a modo de reborde cutaneo) (0), membrana reducida a la base (1), y membrana ausente (2). Alsodes gargola, Atelognathus patagonicus y Chacophrys pierottii presentan el estado (0). Batrachyla spp., Ceratophrys ornata e Hylorina sylvatica presentan el estado (1). Eupsophus calcaratus y Pleurodema borellifueron polimorficas y se codificaron considerando el polimorfismo como ambigüedad $(1,2)$. Comentarios: Formas (1997) describio para B. nibaldoi una membrana pequeña, delgada y translucida, y consideró a estas últimas dos características como diferenciales respecto de $B$. taeniata, aunque no aclaró entre que dígitos del pie de $B$. nibaldoi se desarrolla la membrana. Los tres especimenes macho que he observado de esa especie presentan membrana reducida ente los dígitos II- III y III-IV. Basso (1994) describió para B. fitzroya una membana reducida que está presente entre todos los dígitos del pie. He tenido oportunidad de estudiar el material empleado por Basso (1994), más dos especimenes adicionales y se observa la misma condición que en $B$. taeniata y $B$. nibaldoi. Las mismas consideraciones valen para las especies $B$. antartandica y B. leptopus para las cuales Barrio (1967a) indicó membrana reducida entre todos los dígitos del pie, situación presumiblemente observada también por Vallejos Vallejos (1994) para esas especies más B. taeniata (la autora no aclara entre que dígitos se halla la membrana). He observado gran parte del material estudiado por Barrio más una serie de ejemplares adicionales (ver Apéndice I) y no encontre membrana entre los dígitos I y II del pie.

A su vez, he observado que la membrana entre los dígitos II-III y II-IV está 100\% presente en los casos analizados, mientras que para el caso de los dígitos IV-V su presencia varía de la siguiente manera: en $B$. taeniata está presente en el $45 \%$ de los especimenes análizados (29 especimenes, 14 machos y 15 hembras, $N=64$ ) y en $B$. antartandica y $B$. leptopus se observaron porcentajes similares. La misma variación se observó en Hylorina sylvatica para la membrana entre los dígitos IV y V.

Para E. calcaratus y $P$. borelli puede verificarse en algunos especimenes una membrana extremadamente reducida entre los dígitos III y IV. Estas observaciones 
evidencian que la reducción de la membrana de las especies estudiadas opera desde los digitos perifericos hacia el centro.

Caracter 93. Manchado oscuro en el vientre (s/ Fig.). De acuerdo al patron de coloracion ventral del adulto se reconocen tres estados de caracter: vientre inmaculado (0), vientre claro con un fino punteado negro sin llegar a formar grandes manchas oscuras (1), vientre con grandes manchas oscuras irregulares y convergentes (2), y vientre con manchas oscuras circulares no convergentes, con o sin area clara central (3). Alsodes gargola, Ceratophrys ornata, Chacophrys pierottii, Hylorina sylvatica y Pleurodema borelli presentan el estado (0). B. fitzroya, B. leptopus presentan el estado (2). B. antartandica presenta el estado (3). Atelognathus patagonicus, Batrachyla nibaldoi y $B$. taeniata fueron polimorficas para el caracter y se codificaron $(0,1)$. Eupsophus calcaratus fue polimorfico para el caracter y se codifico $(0,1,2)$.

Caracter 94. Canto rostral (s/ Fig.). Basso (1994) propuso 2 estados de caracter: 0) curvo y 1) bien marcado. Alsodes gargola, Atelognathus patagonicus, Batrachyla antartandica, B. fitzroya, B. leptopus, Ceratophrys ornata, Chacophrys pierottii, Hylorina sylvatica y Pleurodema borelli presentan el estado (0). Batrachyla nibaldoi, $B$. taeniata y Eupsophus calcaratus presentan el estado (1).

\section{III.10.6. Caracteres de morfología externa de la larva.}

Caracter 95. Grado de desarrollo del tubo proctodeal (s/ Fig.). La literatura referida a las larvas de los taxa empleados en el análisis, má s mis propias observaciones indican que las especies Alsodes gargola (Lavilla, 1988; Pillado et al., 2000; presente trabajo), Atelognathus patagonicus (Gallardo, 1964; Cei, 1965, Lavilla, 1988; presente trabajo), Ceratophrys ornata, (según Fernandez \& Fernandez, 1921, más datos propios), Chacophrys pierottii (según Faivovich \& Carrizo, 1992), Eupsophus calcaratus (Formas, 1989; Vera Candioti et al., 2005) y Pleurodema borelli (Cei, 1980; Fabrezi \& Vera, 1997, presente trabajo) presentan tubo proctodeal bien desarrollado. La larva de Hylorina sylvatica presenta tubo reducido (Formas \& Pugin, 1978; Lavilla, 1988, presente trabajo), situación que no ha sido advertida por varios autores (e.g., Barrio, 1967b; Diaz Perez, 1984). Respecto de las especies Batrachyla antartandica, $B$. leptopus y $B$. taeniata la información es controvertida dado que en muchos trabajos no se ha considerado el grado de desarrollo del tubo proctodeal (Cei, 1962, 1980; Diaz Perez, 1984; Brieva Vasquez, 1988), pero en los trabajos en que si se le ha prestado 
atención a ese rasgo (Guzman Poo, 1970; Formas, 1976; Lavilla, 1988; Ubeda, 1998), los autores coinciden en señalar que en esas especies de Batrachyla existe una importante reducción del mismo (B. leptopus), su ausencia (B. taeniata), o la existencia de variación poblacional donde algunos especimenes lo tienen muy reducido y en otros se encuentra ausente (B. antartandica). Guzman Poo (1970) fue el primero en señalar que el tubo se encuentra reducido en $B$. taeniata, pero en realidad el tubo falta en la larva de esa especie. Ubeda (1998) fue la primera en observar la variación intraespecifica respecto de la presencia de tubo proctodeal en $B$. antartandica, variación que he observado en los especimenes empleados para esta tesis. Teniendo en cuen ta los antecedentes expuestos, he establecido tres estados de caracter: tubo proctodeal completamente desarrollado hasta alcanzar con su abertura el margen libre de la aleta ventral (0), tubo reducido no alcanzando su abertura el nivel del $50 \%$ de la altura de la aleta ventral (1), y tubo ausente con abertura en la base de la aleta sobre el límite posterior del cuerpo (2). Alsodes gargola, Atelognathus patagonicus, Ceratophrys ornata, Chacophrys pierottii, Eupsophus calcaratus y Pleurodema borelli presentan el estado (0). Batrachyla leptopus e Hylorina sylvatica presentan el estado (1). B. antartandica y $B$. taeniata presentan el estado (2). Este caracter no pudo codificarse para las especies Batrachyla fitzroya y B. nibaldoi dado que sus larvas aun no han sido descritas, con lo cual se entraron a la matriz como datos faltantes (?).

Caracter 96. Posición del tubo proctodeal y su abertura (s/ Fig.). La literatura existente resulta coincidente con mis observaciones acerca de que el tubo proctodeal y su abertura en las especies Alsodes gargola (Lavilla, 1988; Pillado et al., 2000; presente trabajo), Atelognathus patagonicus (Gallardo, 1964; Cei, 1965, Lavilla, 1988; presente trabajo), Batrachyla leptopus (Formas, 1976; Diaz Perez, 1984; Brieva Vasquez, 1988; Ubeda, 1998, presente trabajo) e Hylorina sylvatica (Formas \& Pugin, 1978; Diaz Perez, 1984; Lavilla, 1988; presente trabajo) son ambos dextrales respecto de la aleta ventral. Del mismo modo mis observaciones son coincidentes con lo descrito por Cei (1980) y Fabrezi \& Vera (1997) para Pleurodema borelli, especie que presenta tubo y abertura mediales respecto de la aleta ventral. Ceratophrys ornata, (según Fernandez \& Fernandez, 1921, más datos propios), Chacophrys pierottii (según Faivovich \& Carrizo, 1992) y Eupsophus calcaratus presentan la misma condición que Pleurodema borelli (Formas, 1989; Vera Candioti et al., 2005). Teniendo en cuenta ello he considerado dos estados de caracter: tubo y abertura dextrales (0), tubo y abertura mediales (1). Alsodes gargola, Atelognathus patagonicus, Batrachyla 
antartandica, B. leptopus, B. taeniata, e Hylorina sylvatica presentan el estado (0). Ceratophrys ornata, Chacophrys pierottii, Eupsophus calcaratus y Pleurodema borelli presentan el estado (1). Este caracter no pudo codificarse para las especies Batrachyla fitzroya y $B$. nibaldoi dado que sus larvas aun no han sido descritas, con lo cual se entraron a la matriz como datos faltantes (?).

Comentarios: La mayoría de los autores (Formas, 1976; Lavilla, 1988) que estudiaron la larva de $B$. antartandica no observaron la variación intraespecifica respecto de la presencia de tubo proctodeal que fuera señalada por primera vez por Ubeda (1998) y la cual he verificado en los especimenes estudiados para este trabajo de tesis. Entonces, mientras $B$. antartandica presenta desarrollo variable del tubo proctodeal (Ubeda, 1988, presente trabajo), B. taeniata siempre carece de tubo proctodeal y su abertura es siempre dextral (Cei, 1962, 1980; Guzman Poo, 1970; Formas, 1976; Diaz Perez, 1984; Brieva Vasquez, 1988; Lavilla, 1988; Ubeda, 1998, presente trabajo). Teniendo en cuenta que la variación de $B$. antartandica refleja la reducción desde un tubo dextral a una abertura dextral solamente, situación está que resulta típica de $B$. taeniata, he decidido considerar la condición de Batrachyla como tubo dextral, aunque el mismo pueda encontrarse ausente.

La información dada por Barrio (1967b) y repetida por Lynch (1971) acerca de que Hylorina sylvatica presenta tubo y abertura mediales resulta evidentemente errónea (ver observaciones en el caracter siguiente) y no se ha tenido en cuenta al momento de codificar el caracter. Del mismo modo tampoco se ha considerado al momento de la codificación la información dada por Lynch (1971) donde refiere que tanto el tubo como la abertura de Batrachyla spp. abren medialmente, interpretación que también repite Lavilla (1988) respecto de $B$. leptopus para la cual considera que posee abertura medial.

Caracter 97. Posición del espiráculo (s/ Fig.). Lavilla (1988) describió diferentes categorías y criterios para definir la posición del espiráculo. De la observación de los taxa empleados para el análisis más la información existente sobre ellos en la literatura (Lavilla, 1988, Ubeda, 1998; Pillado, et al., 2000; Vera Candioti et al., 2005) se desprende que todos presentan espiráculo siniestro ubicado en una de dos posiciones, lo que resulta en dos estados de caracter: espiráculo lateral (0), y espiráculo abdominal (1). Alsodes gargola, Batrachyla antartandica, B. leptopus, B. taeniata, Ceratophrys ornata, Chacophrys pierottii, (según Faivovich \& Carrizo, 1992), Eupsophus calcaratus, Hylorina sylvatica presentan el estado (0). Atelognathus patagonicus y Pleurodema borelli presentan el estado (1). Este caracter no pudo 
codificarse para las especies Batrachyla fitzroya y B. nibaldoi dado que sus larvas aun no han sido descritas, con lo cual se entraron a la matriz como datos faltantes (?). Comentarios: Diversos autores que han tratado las especies analizadas no han especificado la posición del espiráculo (e.g., Formas, 1976; Fomas \& Pugin, 1978; Cei, 1965, 1980; Brieva Vasquez, 1988). Formas (1989) consideró que la larva de Eupsophus calcaratus carece de tubo proctodeal presentando solo su abertura, aunque no especifico su posición. En ese sentido, para asignar el estado de esa especie, se siguió el trabajo de Vera Candioti et al., 2005. Para Pleurodema borelli (Cei, 1980) da posición lateral, mientras que los especimenes examinados por mi para el pesente trabajo presentaban espiráculo abdominal. Para codificar a esta especie me he basado en mis propias observaciones.

Caracter 98. Posición de las narinas (s/ Fig.). Lavilla (1988) describió dos posiciónes de las narinas en su análisis de la morfología larvaria de telmatobinos inferiores. Entonces se reconocen dos estados de caracter: narinas no elevadas (0), y narinas elevadas (1). Alsodes gargola, Batrachyla antartandica, B. leptopus, $B$. taeniata, Ceratophrys ornata, Eupsophus calcaratus (según Vera Candioti et al., 2005), Hylorina sylvatica y Pleurodema borelli presentan el estado (0). Atelognathus patagonicus presenta el estado (1). Éste caracter no pudo codificarse para las especies Batrachyla fitzroya y B. nibaldoi dado que sus larvas aun no han sido descritas, con lo cual se entraron a la matriz como datos faltantes (?). Faivovich \& Carrizo (1992) no tuvieron en cuenta este carácter en su descripción de la larva de Chacophrys pierottii, asi que esta especie se ingreso a la matriz como dato faltante (?). Caracter 99. Formula dentaria (s/ Fig.). A excepción de Eupsophus calcaratus, los restantes taxa analizados presentan una formula dentaria 2(2)/3(1). Esto ha sido descrito en la literatura para Alsodes gargola (Cei, 1980, Lavilla, 1988; Pillado et al., 2000; presente trabajo), Atelognathus patagonicus (Gallardo, 1964; Cei, 1965, presente trabajo), Batrachyla antartandica (Formas, 1976; Cei, 1980; Brieva Vasquez, 1988; Lavilla, 1988; Úbeda, 1998; presente trabajo), B. leptopus (Busse, 1971; Formas, 1976; Cei, 1980; Diaz Perez, 1984; Brieva Vasquez, 1988; Lavilla, 1988; Úbeda, 1998; presente trabajo), B. taeniata (Guzman Poo, 1970; Formas, 1976; Cei, 1980; Brieva Vasquez, 1988; Lavilla, 1988; Ubeda, 1998; presente trabajo) e Hylorina sylvatica (Formas \& Pugín, 1978; Diaz Perez, 1984; presente trabajo). Para Eupsophus calcaratus se ha descrito la ausencia total (Formas, 1989) o la reducción (Vera candioti et al., 2005) de los queratodontes del disco oral. Según este último trabajo la formula dentaria para Eupsophus calcaratus sería 2(2)/2 o 2(2)/2(1). 
Entonces se tendran en cuenta cuatro estados de caracter: 2(2)/3(1) (estado 0), 2(2)/2 (estado 1), 1/3(1) (estado 2), o mas de cinco hileras, interrumpidas o no, e irregulares a cada lado del rostrodonte (estado 3). Alsodes gargola, Atelognathus patagonicus, Batrachyla antartandica, B. leptopus, B. taeniata, Hylorina sylvatica y Pleurodema borelli presentan el estado (0). Eupsophus calcaratus presenta el estado (1).

Ceratophrys ornata (según Fernandez \& Fernandez, 1921, más datos propios) presenta el estado (3). Chacophrys pierottii (según Faivovich \& Carrizo, 1992) presenta dos estados $(0,2)$. Este caracter no pudo codificarse para las especies Batrachyla fitzroya y $B$. nibaldoi dado que sus larvas aun no han sido descritas, con lo cual se entraron a la matriz como datos faltantes (?).

Comentarios: Según Barrio (1967b) la larva de Hylorina sylvatica presenta una formula dentaria 2(2)/2(1), datos que son repetidos por Cei (1980) y Lynch (1971). Dadas mis observaciones y la información sobre esa especie (Formas \& Pugín, 1978; Diaz Perez, 1984) no se tendrá en cuenta la descripción de Barrio (1967b), que resulta evidentemente equivocada. Del mismo modo se ha descrito para Pleurodema borelli una formula dentaria 2(2)/3 (Cei, 1980; Fabrezi \& Vera, 1997), mientras que en el material que he observado de esa especie para la presente tesis encontre una formula dentaria 2(2)/3(1). Entonces, si bien no se descarta que $P$. borelli pueda presentar dos formulas dentarias dado que la interrupción en la primer hilera ventral es infima, esta especie fue codificada de acuerdo a mis observaciones.

Caracter 100. Papilas intramarginales mentales del disco oral (s/ Fig.). El disco oral de las larvas de todos los taxa analizádos presenta una única hilera de papilas marginales interrumpida en la región rostral y una constricción angular (Cei, 1965, 1980; Formas, 1976; Lavilla 1988; Ubeda, 1998; Echeverría et al., 2001; presente trabajo). De acuerdo a la presencia-ausencia de papilas intramarginales en el area mental se han determinado dos estados de caracter: papilas ausentes $(0)$, y papilas presentes (1). Atelognathus patagonicus, Batrachyla antartandica, B. leptopus, $B$. taeniata, Ceratophrys ornata (según Fernandez \& Fernandez, 1921, más datos propios), Chacophrys pierottii (según Faivovich \& Carrizo, 1992), Hylorina sylvatica, Eupsophus calcaratus (según Formas 1989 y Vera Candioti et al., 2005) y Pleurodema borelli presentan el estado (0). Alsodes gargola presenta el estado (1). Este caracter no pudo codificarse para las especies Batrachyla fitzroya y $B$. nibaldoi dado que sus larvas aun no han sido descritas, con lo cual se entraron a la matriz como datos faltantes (?). 
Comentarios. Barrio (1967b) indicó que el disco oral de la larva de Hylorina sylvatica presenta papilas solo en la region de los "corners. Lynch (1971) indico que las larvas de Batrachyla carecen de claro rostral y que tienen un disco oral en ventosa. No se han tenido en cuenta las observaciones de Barrio (1967b) y Lynch (1971) al momento de la codificación.

Caracter 101. Papilas intramarginales supra e infraangulares en el disco oral (s/ Fig.). De acuerdo a la presencia-ausencia de papilas intramarginales supra e infraangulares en la región angular del disco oral se han determinado dos estados de caracter: papilas ausentes (0), y papilas presentes (1). Ceratophrys ornata (según Fernandez \& Fernandez, 1921, más datos propios), Chacophrys pierottii (según Faivovich \& Carrizo, 1992), Eupsophus calcaratus (según Formas, 1989 y Vera Candioti et al., 2005) y Pleurodema borelli presentan el estado (0). Alsodes gargola, Atelognathus patagonicus, Batrachyla antartandica, B. leptopus, B. taeniata, e Hylorina sylvatica presentan el estado (1). Este caracter no pudo codificarse para las especies Batrachyla fitzroya y $B$. nibaldoi dado que sus larvas aun no han sido descritas, con lo cual se entraron a la matriz como datos faltantes (?).

Comentarios: Barrio (1967b) indicó que el disco oral de la larva de Hylorina sylvatica presenta papilas solo en la region de los "corners". Lynch (1971) indico que las larvas de Batrachyla carecen de claro rostral y que tienen un disco oral en ventosa. No se han tenido en cuenta las observaciones de Barrio (1967b) y Lynch (1971) al momento de la codificación.

\section{III.10.7. Caracteres de la cavidad bucofaringea de la larva.}

\section{Caracter 102. Papilas laterales a las papilas de la arena del techo de la cavidad} bucofaringea (s/ Fig.). De las especies terminales empleadas para el presente estudio, la papilación bucofaringea ha sido estudiada, empleando microscopia electronica de barrido, en Alsodes gargola (Echeverría et al. 2001), Atelognathus patagonicus (Wassersug \& Heyer, 1988), B. taeniata (Wassersug \& Heyer, 1988), Hylorina sylvatica (Wassersug \& Heyer, 1988) y Pleurodema borelli (Wassersug \& Heyer, 1988). La papilación bucofaringea de Batrachyla antartandica, B. leptopusy $B$. taeniata ha sido estudiada empleando microscopia optica por Brieva Vasquez (1988). Adicionalmente, he tenido oportunidad de preparar para su estudio bajo microscopia electronica de barrido, material de B. antartandica, B. leptopus, B. taeniatae Hylorina sylvatica. A partir de mis propias observaciones, más los datos procedentes de la 
información publicada (ver parrafo anterior), reconozco tres estados de caracter para las papilas laterales a las papilas de la arena del techo de la cavidad bucofaringea: papilas laterales ausentes $(0)$, laterales presentes en numero no mayor de cuatro 0 cinco (1), papilas laterales presentes en numero de diez o mayor (2). Alsodes gargola (según Echeverría et al., 2001) presenta el estado (0). Batrachyla antartandica, $B$. leptopus, B. taeniata y Pleurodema borelli (según Wassersug \& Heyer, 1988) presentan el estado (1). Hylorina sylvatica presenta el estado (2). La papilación bucofaríngea de Atelognathus patagonicus fue descrita por Wassersug \& Heyer (1988) pero el mal estado del ejemplar por ellos estudiado no permitió codificar a la especie, que fue entrada a la matriz como dato faltante (?). La papilación bucofaríngea de Batrachyla fitzroya, B. nibaldoi, Ceratophrys ornata, Chacophrys pierottii y Eupsophus calcaratus se desconoce hasta el momento y esas especies fueron ingresadas a la matriz como datos faltantes (?). El caracter fue tratado como multiestado, no ordenado y no aditivo.

Comentarios: Brieva Vasquez (1988) reportó el rango de variación para el número de papilas laterales de $B$. antartandica (16-26), B. leptopus (6-10) y B. taeniata (6). Sus valores no coinciden con los que he observado para el presente trabajo, y mis valores siquiera caen dentro del rango de variación por ella reportado. Al comparar las descripciónes de Wassersug \& Heyer (1988), Brieva Vasquez (1988) y la mía para el caso de $B$. taeniata, mis observaciones coinciden con las de Wassersug \& Heyer (1988). Teniendo en cuenta la contradicción he decidido codificar el caracter sobre la base de los datos obtenidos a partir de observaciones de microscopia electronica de barrido, por estar sustentados por una metodología más precisa.

\section{Caracter 103. Número de papilas largas de la arena del techo de la cavidad} bucofaringea (s/ Fig.). Brieva Vasquez (1988) consideró dos estados de caracter: pocas papilas (menos de 30 ) y muchas (más de 30). Dada la variación observada (entre 14 y 42 papilas) en los ejemplares por aquí estudiados considerare tres estados: 0) hasta 20 papilas, 1) entre 30 y 40, y 2) más de 40. Alsodes gargola (18, según Echeverría et al., 2001), Batrachyla leptopus (16), B. taeniata (18) y Pleurodema borelli (14, según Wassersug \& Heyer, 1988) presentan el estado (0). Hylorina sylvatica (33) presenta el estado (1). B. antartandica (42) presenta el estado (2). La papilación bucofaríngea de Atelognathus patagonicus fue descrita por Wassersug \& Heyer (1988) pero el mal estado del ejemplar por ellos estudiado no permitió codificar a la especie, que fue entrada a la matriz como dato faltante (?). La papilación bucofaríngea de Batrachyla fitzroya, B. nibaldoi, Ceratophrys ornata, Chacophrys pierottii y Eupsophus 
calcaratus se desconoce hasta el momento y esas especies fueron ingresadas a la matriz como datos faltantes (?). El caracter se consideró multiestado, no ordenado y no aditivo.

\section{Caracter 104. Desarrollo de la pustulación central de la arena del techo de la} cavidad bucofaringea (s/ Fig.). Se reconocen dos estados de caracter: 0) papilación baja, y 1) pustulas. Alsodes gargola (según Echeverria et al., 2001) presenta el estado (0). Batrachyla antartandica, B. leptopus, B. taeniata, Hylorina sylvatica y Pleurodema borelli (según Wassersug \& Heyer, 1988) presentan el estado (1). La papilación bucofaríngea de Atelognathus patagonicus fue descrita por Wassersug \& Heyer (1988) pero el mal estado del ejemplar por ellos estudiado no permitió codificar a la especie, que fue entrada a la matriz como dato faltante (?). La papilación bucofaríngea de Batrachyla fitzroya, B. nibaldoi, Ceratophrys ornata, Chacophrys pierottii y Eupsophus calcaratus se desconoce hasta el momento y esas especies fueron ingresadas a la matriz como datos faltantes (?).

\section{III.10.8. Caracteres de cariología.}

Caracter 105. Complemento diploide de cromosomas (s/ Fig.). De acuerdo al complemento diploide de cromosomas se reconocen tres estados de caracter: $2 n=30$ (estado 0), 2n=26 (estado 1), y 2n=22 (estado 2). E. calcaratus (según Formas, 1980) presenta el estado (0). Alsodes gárgola, Atelognathus patagonicus, Batrachyla antartandica, B. leptopus, B. taeniata, Ceratophrys ornata, Chacophrys pierottii, e Hylorina sylvatica (según Barrio, 1971 y Diaz \& Veloso, 1979) presentan el estado (1). Las especies de Pleurodema (según Heyer, 1975) presentan el estado 2. Este caracter no pudo codificarse para las especies Batrachyla fitzroya y $B$. nibaldoi dado que sus cariotipos aun nos se han realizado, con lo cual se entraron a la matriz como datos faltantes.

Caracter 106. Tamaño relativo de los cromosomas (s/ Fig.). Según los estudios de Barrio \& Rinaldi de Chieri $(1970,1971)$ acerca del cariotipo de integrantes de "Telmatobiinae" y Ceratophryidae se reconocen dos patrones de cariotipo: Patron 5 pares grandes y 8 pequeños (0), o patron seis pares grandes y 7 pequeños (1). Alsodes gargola, Atelognathus patagonicus, Batrachyla antartandica, B. leptopus y $B$. taeniata e Hylorina sylvatica presentan el estado (0). Ceratophrys ornata y Chacoprhys pierottii presentan el estado (1). Los c ariotipos de $B$. fitzroya y $B$. nibaldoi permanecen sin estudiar y el caracter para esas especies fue entrado a la matriz como dato faltante 
(?). El numero de cromosomas de Eupsophus calcaratus y Pleurodema borelli difiere al de las restantes especies analizadas y en consecuencia fueron entradas a la matriz como dato inaplicable (-).

\section{III.10.9. Caracteres de biología reproductiva.}

Tendencia a la terrestrialidad. Diferentes tendencias, tanto fisiológicas, como morfológicas y conductales, pueden ser vistas como componentes de la tendencia a la reproducción en tierra mostrada en distinto grado por algunos géneros de telmatobinos. Entre esos elementos se reconocen al menos los siguientes: sitio de puesta, cantidad de huevos de la puesta, tamaño de los huevos, sitio donde ocurre el desarrollo larvario y tipo de desarrollo larvario. A los fines del análisis, todos esos elementos pueden ser vistos como caracteres separados, o bien como parte de un conjunto que podría llamarse tendencia a la terrestrialidad, dentro del cual se reconocerian diferentes grados o estados de caracter. Para abordar este tema dentro del contexto del presente análisis, he escogido considerar cada uno de esos elementos por separado (a excepción del diámetro de huevos y el numero de huevos por puesta que se analizaran conjuntamente) y verificar su posible grado de asociación a posteriori, teniendo en cuenta su distribución en el/ los cladograma/s obtenido/s. Caracter 107. Sitio de puesta (s/ Fig.). De acuerdo a la información publicada respecto del sitio de puesta en los taxa analizados se reconocen tres estados de caracter: puesta en situación acúatica en sitios donde existe abundante agua (arroyos, charcas permanentes o semipermanentes) (0), puesta en cuevas construidas especialmente por los adultos donde existen pequeñas cantidades de agua (1), y puesta terrestre en suelos humedos (2). Alsodes gargola (según Gallardo, 1970), Atelognathus patagonicus (según Cei, 1965, 1980), Ceratophrys ornata, Hylorina sylvatica (según Barrio, 1967b) y Pleurodema borelli (según Cei, 1980) presentan el estado (0). Eupsophus calcaratus presenta el estado (1) (según Formas, 1989). Batrachyla antartandica, B. leptopus y B. taeniata presentan el estado (2) (según Cei \& Capurro, 1958; Barrio, 1967a; Busse, 1971; Formas 1976; Cei, 1980; Diaz Perez et al., 1987). Las puestas de B. fitzroya, B. nibaldoi y Chacophrys pierottii se desconocen y el caracter para esas especies fue entrado a la matriz como dato faltante (?). El caracter fue tratado como multiestado ordenado y no aditivo.

Comentarios: Lavilla (1988) consideró que $H$. sylvatica pone los huevos fuera del agua. Barrio (1967b) observó diversas puestas de la especie, las que siempre ocurren 
asociadas a las raices de juncaceas en las mismas charcas donde ocurre la fase larvaria, aunque este autor también menciona la posibilidad que los huevos queden ligeramente por fuera del agua (en la charca misma) y presenten un desarrollo intracapsular como en las especies de Batrachyla. Considero que la situación de Hylorina no es la misma de Batrachyla, donde los huevos siempre son puestos en tierra en sitios que posteriormente a la puesta se inundaran y hasta que ello ocurra siempre se pasa por un periodo de desarrollo intracapsular. Entonces, para asignar el estado de esta especie se tendran en cuenta las observaciones de Barrio (1967b).

Caracter 108. Factor de tamaño ovarico (s/ Fig.). El factor de tamaño ovarico (FOV) es un indice propuesto por Duellman \& Crump (1974) que permite comparar puestas de diferentes especies. Este indice tiene en cuenta el diámetro de los huevos en $\mathrm{mm}$ $\left(\mathrm{DH}\right.$, sin las membranas), la cantidad de los mismos $\left(\mathrm{N}^{\circ} \mathrm{H}\right)$ y la longitud total de las hembras en mm (LTH) según la formula: NoHxDH/LTH. El FOV para las especies analizadas se calculo teniendo en cuenta los valores de LT y DH (Barrio, 1967a,b; Formas 1976; Cei, 1980; Diaz Perez, 1987) y NoH (Cei \& Capurro, 1958; Barrio, 1967a, b; Fernandez \& Fernandez, 1921, Formas 1976; Cei, 1980; Diaz Perez et al., $1987)$ de la literatura.. Los datos referidos a huevos con me mbranas como los de Cei \& Capurro (1958) y Busse (1971) fueron exluidos. De esos datos solo se emplearon los valores máximos de cada variable para realizar el cálculo. Entonces a partir de los valores máximos de FOV obtenidos, se reconocen tres estados de caracter: FOV $<10$ (0), y FOV>10 (1). Batrachyla antatandica $(7,78)$, B. leptopus $(9,41)$ y Ceratophrys ornata $(8,4)$ presentan el estado $(0)$. B. taeniata $(22,33)$ e $H$. sylvatica $(15,5)$ presentan el estado (1).

El FOV de A. gargola, A. patagonicus, B. fitzroya, B. nibaldoi, Chacophrys pierottii, E. calcaratus y Pleurodema borelli no pudo ser calculado dada la ausencia de información de alguna o de todas las variables necesarias para el calculo y elc aracter para esas especies fue entrado a la matriz como dato faltante (?).

Comentarios: Diaz Perez et al. (1987) describió FOVs para B. taeniata que oscilaron entre 15,5 y 26,5 .

Caracter 109. Cuidado parental (s/ Fig.). Diversos autores han reportado la presencia de machos cerca de las puestas en las especies Batrachyla leptopus, $B$. taeniata y Eupsophus calcaratus (Busse, 1971, Formas, 1976, 1989). La presencia de machos cerca de las puestas ha sido considerado por algunos autores como una forma de cuidado parental (Ubeda \& Nuñez, 2006). Entonces, de acuerdo a la exist encia o no de cuidado parental, se reconocen dos estados de caracter: cuidado 
parental por parte de los machos sobre la puesta ausente (0), o presente (1). Alsodes gargola, Atelognathus patagonicus, Batrachyla antartandica, Ceratophrys ornata, Hylorina sylvatica y Pleurodema borelli presentan el estado (0). B. leptopus, B. taeniata y E. calcaratus presentan el estado (1).

Comentarios: Si bien el hecho que el cuidado parental nunca se ha observado en algunas especies, esto no significa que este no exista en ellas. De todos modos esas especies (A. gargola, A. patagonicus, B. antartandica, Ceratophrys ornata, $H$. sylvatica y $P$. borelli) fueron codificadas (0) dado que diversos autores han tenido oportunidad de observar sus puestas y nunca se reporto la existencia de cuidado parental sobre las mismas, con lo cual es altamente probable que este no exista en ellas. En cambio, las especies B. fitzroya, B. nibaldoi y Chacophrys pierottii no pudieron ser codificadas a causa de que su biología reproductiva permanece absolutamente desconocida y fueron entradas a la matriz como datos faltantes (?).

En el caso de los taxa analizados, coincide que el cuidado parental ocurre en las especies que ponen sus huevos en tierra, hecho que sugirie algun tipo de relacion entre ambas cuestiones, cosa que parece bastante razonable. Sin embargo, existe la posibilidad de que exista cuidado parental en caso de puestas acuaticas (e. g.: Leptodactylus ocellatus) (Cei, 1980), y por tal razon se han considerado ambos caracteres por separado.

\section{III.10.10. Caracteres descartados.}

\section{III.10.10.1. Caracteres insuficientemente conocidos.}

a. Amplexo. Según la información disponible en la literatura se reconocen dos tipos de amplexo para la muestra de especies empleada en el presente análisis: axilar y pélvico. Batrachyla taeniata (Lynch, 1971; Formas, 1976; Cei, 1980, Diaz Perez et al., 1987), e Hylorina sylvatica (Barrio, 1967b) presentan amplexo axilar.

El tipo de amplexo nos e ha descrito para las especies Alsodes gargola, Atelognathus patagonicus, Batrachyla fitzroya, B. nibaldoi y Eupsophus calcaratus.

La literatura referida al tipo de amplexo de las especies $B$. antartandica y $B$. leptopus resulta contradictoria. Algunos autores (Barrio 1967a; Cei, 1980) consideran que $B$. antartandica practica amplexo pélvico, mientras que según Formas (1976) y Úbeda (2000), el amplexo de esa especie es axilar. Del mismo modo, Barrio (1967a), Formas 
(1976) y Cei (1980) consideraron que el amplexo de B. leptopus es pélvico, mientras que para Busse (1971) sería axilar.

Dado que el amplexo se desconoce para muchos de los terminales empleados en el presente estudio y considerando la divergencia de opiniones respecto de $B$. antartandica y $B$. leptopus, más la imposibilidad de decidir entre ellas, he decidido descartar el caracter del análisis.

b. Ultraestructura del espermatozoide. Garrido et al. (1989) estudiaron la morfología de los espermatozoides de tres de las cinco especies de Batrachyla conocidas la fecha de publicación del trabajo. Allí brindan interesantes datos que podrían resultar en caracteres informativos para la resolución de las relaciones de los taxa aquí estudiados (e.g., presencia - ausencia de fibras auxiliares en la cola del espermatozoide. Lamentablemente esa información se desconoce para 7 de los 10 terminales empleados en el presente análisis y en consecuencia he optado por no incluir caracteres de morfología espermática.

\section{III.10.10.2. Caracteres merísticos influenciados por el error de medición.}

a. Diámetro ocular del adulto. Basso (1994) propusó 2 estados de caracter para cuatro de las cinco especies del género Batrachyla: diámetro ocular (DO) menor que la longitud del hocico (LH), o aproximadamente igual a la misma y atribuyó el primer estado a $B$. antartandica más $B$. fitzroya, mientras que el segundo se lo asignó a las especies B. leptopus y B. taeniata.

La literatura existente ofrece datos heterogeneos para B. leptopus y $B$. taeniata y no concuerdan con la codificación propuesta por Basso (1994): 1) en B. antartandica DO>LH (Barrio 1967a; Cei, 1980; Vallejos Vallejos, 1994); 2) en B. leptopus DO<LH (Cei, 1980) o DO>LH (Vallejos Vallejos, 1994); y 3) en B. taeniata DO>LH (Grandison, 1962, Vallejos Vallejos, 1994) o DO<LH (Cei, 1962). Formas (1997) da valores de DO>LH para B. nibaldoi. Atendiendo las divergencias mencionadas respecto de los estados que toma el caracter y de su distribución en las especies de Batrachyla, he decidido no considerar este caracter del análisis.

b. Distancia interocular. Basso (1994) empleó la proporción entre distancia interocular (DIO) y longitud del parpado superior (LPS) en su análisis del género Batrachyla y reconoció tres estados de caracter: DIO menor ( $B$. fitzroya), igual ( $B$. antartandica y $B$. taeniata) o mayor (B. leptopus) que LPS. La información sobre el caracter encontrada en la literatura (Barrio, 1967a; Cei, 1980) es bastante homogenea 
y coincidente con la codificación de Basso (1994) para las especies $B$. antartandica, $B$. leptopus y $B$. taeniata. Las únicas diferencias serían dadas por Cei (1962) quien considera para $B$. taeniata DIO<LPS, y por Barrio (1967a) quien no indica que $B$. leptopus difiera de $B$. antartandica para este caracter.

Dado que los autores mencionados no mencionan los grados de libertad en que sustentan los valores de proporción DIO/LPS, y dada la inexistencia de datos para $B$. nibaldoi, he optado por medir ambas variables en las cinco especies que componen el género y obtuve los siguientes rangos para la proporción DIO/LPS: $B$.antartandica $(\mathrm{n}=$ 24; rango=0,63-1), B. fitzroya $(n=2 ; r=0,88-0,96)$, B. leptopus $(n=69 ; r=0,49-1,08)$, B. nibaldoi $(n=3 ; r=0,88-0,96)$, B. taeniata $(n=60 ; r=0,57-1,08)$. De mis datos se desprende que en las cinco especies la variable DIO presenta un importante rango de variación a nivel intraespecifico. Batrachyla leptopus y $B$. taeniata muestran la mayor variación y contienen en su variación al rango de las restantes especies. Creo además que el rango de variación de la variable es producto de los valores bajos que toman ambas variables, en particular la variable LPS, lo cual puede estar muy influenciado por el error de medición. Dado lo expuesto he descartado el caracter del análisis.

\section{III.10.10.3. Caracteres de codificación subjetiva.}

\section{Longitud de los miembros posteriores respectode la relación articulación}

tibio tarsiana-ojo. Diversos autores han criticado el empleo de este carácter dado que el nivel que alcanzan los miembros posteriores al estirarlos hacia delante depende engran medida del estado del material y de la fuerza que se emplee en la tracción. Por tales motivos no he incluido el carácter en el análisis.

2. Prominencia de los ojos. El carácter se divide en 2 estados: 0) marcadamente prominentes, y 1) levemente prominentes. He hallado dificultoso establecer un límite claro entre ambas condiciones y he decidido excluir el caracter del análisis.

3. Morfología de los cromosomas. Barrio \& Rinaldi de Chieri (1971) estudiaron el cariotipo de la mayoría de los telmatobínos presentes en la República Argentina, entre ellos, incluyendo a ocho de los diez taxa empleados como terminales en el presente análisis. Algunos caracteres que se desprenden de dicha publicación fueron empleados en el análisis (e. g., complemento diplóide de cromosomas, constricción secundaria del sexto par) en tanto que se optó por dejar de lado aquellos referidos a la morfología de los cromosomas en relación con la posición del centrómero dado que si no se emplean técnicas para la identificación de 
cromosomas homólogos no sería posible establecer una comparación par por par de su morfología. Adicionalmente existe desacuerdo en torno a la morfología del par 10 de cromosomas de las especies de Batrachyla, donde para Diaz \& Veloso (1979) sería telocentrico, mientras que para Barrio \& Rinaldi de Chieri (1971) es metacentrico.

Según Barrio \& Rinaldi de Chieri $(1970,1971)$ de las especies estudiadas, las unicas que poseen una constricción secundaria en el par 6 son Batrachyla antartandica, $B$. leptopus y $B$. taeniata. Sin embargo, por no contar con información que asegure la homología del par 6 entre las distintas especies aquí analizadas se há optado por no emplear el carácter presencia ausencia de constricción secundaria en el sexto par.

\section{III.10.10.4. Caracteres no informativos.}

1. Contacto maxilar nasal. Heyer (1975) consideró para Hylorina sylvatica que los nasales contactan con la máxila o bien que ambos elementos están muy cerca entre sí. En cambio, consideró que Batrachyla leptopus y B. taeniata existe una gran separación entre ambos elementos. Lavilla \& Lobo (1992) revisaron la osteología de Hylorina sylvatica y no confirmaron muchos de los estados de caracter propuestos en los primeros estudios (Lynch, 1971; Heyer, 1975). A partir del material observado para la presente tesis no he podido verificar diferencias en el sentido de las propuestas por Heyer (1975) entre esas especies. Por el contrario, no he observado contacto entre el maxilar y el nasal en ninguno de los taxa empleados en el análisis. Por lo tanto he considerado al caracter como no informativo en el presente contexto y en consecuencia fue descartado del análisis.

2. Contacto medio entre los vomeres. Heyer (1975) consideró para Hylorina sylvatica que ambos vomeres contactan en la línea media, mientras que en Batrachyla leptopus y B. taeniata estarían separados. Lavilla \& Lobo (1992) consideraron que Hylorina presenta los vomeres separados. A partir de mis observaciones, coincido con estos últimos autores. Además no he observado contacto medio entre los vomeres en ninguno de los taxa empleados en el análisis. Entonces he considerado al caracter como no informativo en el presente contexto y en consecuencia fue descartado del análisis.

3. Relacion ancho ultima apofisis presacra / ancho apofisis sacra. Heyer (1975) reportó que Hylorina, Batrachyla leptopus y $B$. taeniata presentan los procesos 
transversos sacros y los de la última vértebra presacra aproximadamente del mismo ancho. Lavilla \& Lobo (1992) consideraron que la apofisis de la última presacra es más angosta que la apofisis sacra y aportaron una relación de 0,660,68 .

Las especies estudiadas para el presente trabajo muestran cierta variación en la relación donde se hace evidente que los estados subigual de Heyer (1975) y más angosta de Lavilla \& Lobo (1992) forman un gradiente difícil de recortar para su codificación. En consecuencia, en el contexto de la presente tesis he considerado que el caracter es no informativo y no lo he incluido en el análisis.

4. Longitud del proceso cultriforme del paraesfenoides. Lynch (1978) reportó que la longitud del proceso cultriforme es mucho más larga en Alsodes y Atelognathus (estudió entre otras a las mismas especies que se emplearon en esta tesis para esos géneros) respecto de Batrachyla, Eupsophus e Hylorina. No he observado diferencias en la longitud del proceso cultriforme que puedan ser expresadas en términos cualitativos relativos. He considerado el carácter no informativo para el presente estudio y en consecuencia excluidó del análisis.

5. Morfología del extremo distal del xifiesternón. Este caracter se consideró previamente en combinación con el grado de mineralización del esternón (ver Heyer 1975). En el contexto de los taxa analizados para el presente trabajo y considerando la variación observada respecto del grado de mineralización del esternón y de la morfología del extremo distal del xifiesternón he optado por descartar este caracter.

Comentarios: Lynch (1978) reportó una morfología del xifiesternón de Batrachyla leptopus que no coincide con la observada en el material empleado para está tesis, ni con las descripciones de otros autores que han trabajado con esa especie (Cei, 1980; Vallejos Vallejos, 1994). La descripción del xifiesternón de Atelognathus patagonicus dada por Lynch (1978) tampoco es coincidente con la morfología observada para esa especie en el presente trabajo. Según Cei (1980), el grado de escotadura distal varía geográficamente en las distintas poblaciones de Pleurodema borelli por el analizadas (ver esquemas en la figura 154 h-l, pp 363, de Cei, 1980). Si bien sus esquemas coinciden con lo que he observado para esa especie, en todos ellos se reconoce una escotadura importante.

6. Rostro del esfenoetmoides. Basso (1994) propuso 2 estados de caracter: 0) presente, y 1) ausente. Es polimórfico para todas las Batrachyla, presumiblemente en relación a la edad de los individuos., donde a veces se encuentra osificado 
sobre el septo nasal, otras veces no, incluso en ejemplares provenientes de la misma localidad.

\section{III.10.9.5. Teratologías.}

1. Estructura de la carilla de articulación posterior de las vértebras presacras. En toda la muestra estudiada de Alsodes gargola, Atelognathus patagonicus, Batrachyla spp., Eupsophus calcaratus, Pleurodema borelli y en la Hylorina sylvatica (CHINM 1870), el tipo de articulación entre vertebras presacras fue mediante un cóndilo articular grande, mediano y único (tipo procelico tipico). En cambio en un ejemplar de Hylorina sylvatica (MLP 2536) se observaron dos cóndilos pequeños, laterales producto del desdoblamiento del cóndilo grande (tipo bicondilar equivalente a la carilla de articulación posterior de la vertebra sacra).

\section{III.10.10.6. Caracteres dependientes.}

1. Ensanchamiento distal de los dedos de la mano. Basso (1994) propuso 2 estados de caracter: 0) ensanchamiento ausente, y 1) presente. Este caracter fue descartado del presente análisis por considerarse que está estechamente relacionado con el caracter 50 del presente estudio. Teniendo en cuenta la muestra de taxa estudiada, las especies Batrachyla antartandica, B. fitzroya y $B$. leptopus son las únicas de que presentan falanges distales con dilatación distal en T mayor o igual a la base de la falange distal y con escisión distal (caracter 49, estado 3), y a su vez son las únicas en presentar el extremo de los dedos ensanchado.

2. Tipo de desarrollo larvario. Las larvas de anuros practican diversos modos de desarrollo y de todos los tipos posibles existe una dicotomía básica en relación a la fuente nutricia. Entonces, sobre la base de esos dos tipos básicos de acuerdo a la fuente de alimentación para la larva se reconocen dos grandes clases: desarrollo exotrofico con alimentación activa microfaga o carnivora y desarrollo endotrofico. Las especies Alsodes gargola, Atelognathus patagonicus, Batrachyla antartandica, B. leptopus, B. taeniata, Chacophrys pierottii, Hylorina sylvatica y Pleurodema borelli son exotroficas microfagas y Ceratophrys ornata es exotrofico carnivoro (Cei \& Capurro, 1958; Barrio, 1967a, b; Busse, 1971; Formas 1976; Cei, 1980; Diaz 
Perez et al., 1987). Eupsophus calcaratus es endotrofico (Formas, 1989; Vera Candioti, et al., 2005).

Diversos caracteres larvarios presentan estados que reflejan el tipo de desarrollo larvario. Se ha optado por emplear a esos caracteres y pero excluir al tipo de desarrollo larvario del análisis. 


\section{III.11. Análisis de relaciones filogenéticas.}

\section{III.11.1. Análisis con los caracteres igualmente pesados.}

El análisis sin pesos implicados resultó en dos arboles de mínima longitud de 212 pasos (IR =0,63; IC=0,684). Las dos topologías obtenidas muestran conflicto solo en la posición de Batrachyla fitzroya (Fig. 62). Respecto de la posidón de Batrachyla fitzroya, ésta puede aparecer como hermana del clado $B$. antartandica $+B$. leptopus, o bien ser hermana de $B$. leptopus, quedando $B$. antartandica como hermana de estas. Este conflicto se refleja en el árbol de consenso estricto en la forma una politomia entre esas tres especies. Hylorina queda incluida dentro de Batrachyla, particularmente relacionada con el clado compuesto por Batrachyla nibaldoi y $B$. taeniata. El árbol de consenso estricto con los valores de soporte de Bremmer se muestra en la Figura 62.

\section{III.11.2. Análisis con pesos implicados.}

El análisis con pesos implicados resultó en un único árbol de mínima longitud, con la misma longitud e identicos valores de IR e IC que en el análisis sin pesos implicados. El único árbol obtenido presenta identica topología que los arboles obtenidos sin pesos implicados, pero con una única resolución para las especies Batrachyla antartandica, $B$. fitzroya y $B$. leptopus, donde las dos últimas forman un clado, teniendo como hermana a la primera. El árbol, con el número de pasos de cada nodo y los valores de boostrap y Jacknifing se muestran en la Figura 63. En dicha figura se ve que el clado de Batrachyla (incluyendo a Hylorina) es bien estable, colapsando recien a una probabilidad de 96 (Jacknifing).

\section{III.11.3. La monofilia de Batrachyla y de los clados que la integran.}

Ambos análisis coinciden en recuperar a Hylorina sylvatica anidada en Batrachyla, haciendo a este último género parafiletico (Bootstrap=96). Teniendo en cuenta el análisis con pesos implicados, Hylorina sylvatica también queda incluida en el clado (clado taeniata) junto a $B$. nibaldoi y $B$. taeniata, con un valor de Bootstrap bajo (Bootstrap=65). El valor de Bootstrap para el clado B. nibaldoi y B. taeniata es de 77. 
A

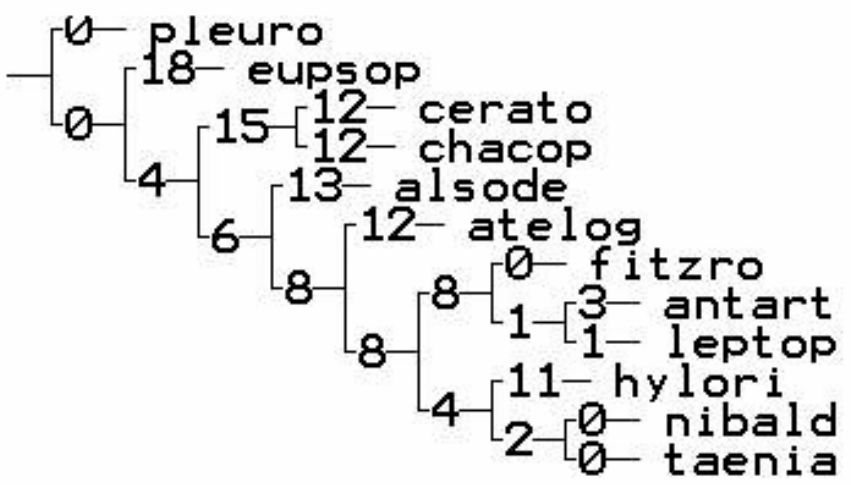

B

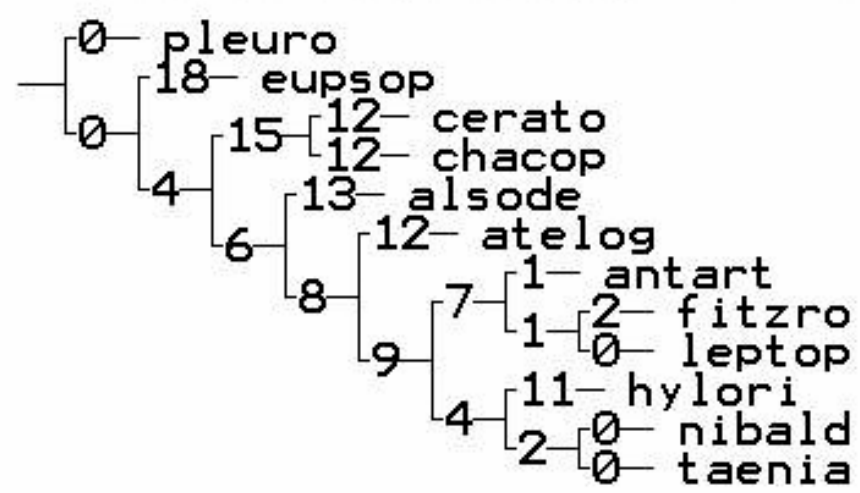

C

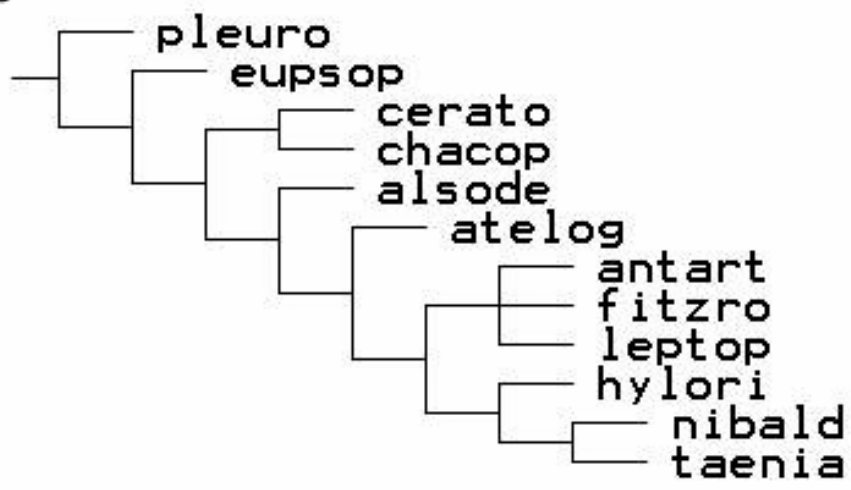

Figura 63. Topología de los dos árboles de mínima longitud obtenidos en los análisis con caracteres igualmente pesados indicando la longitud de cada rama ( $\mathbf{A}$ y $\mathbf{B}$ ) y el árbol de consenso estricto obtenido a partir de ambos (C). 


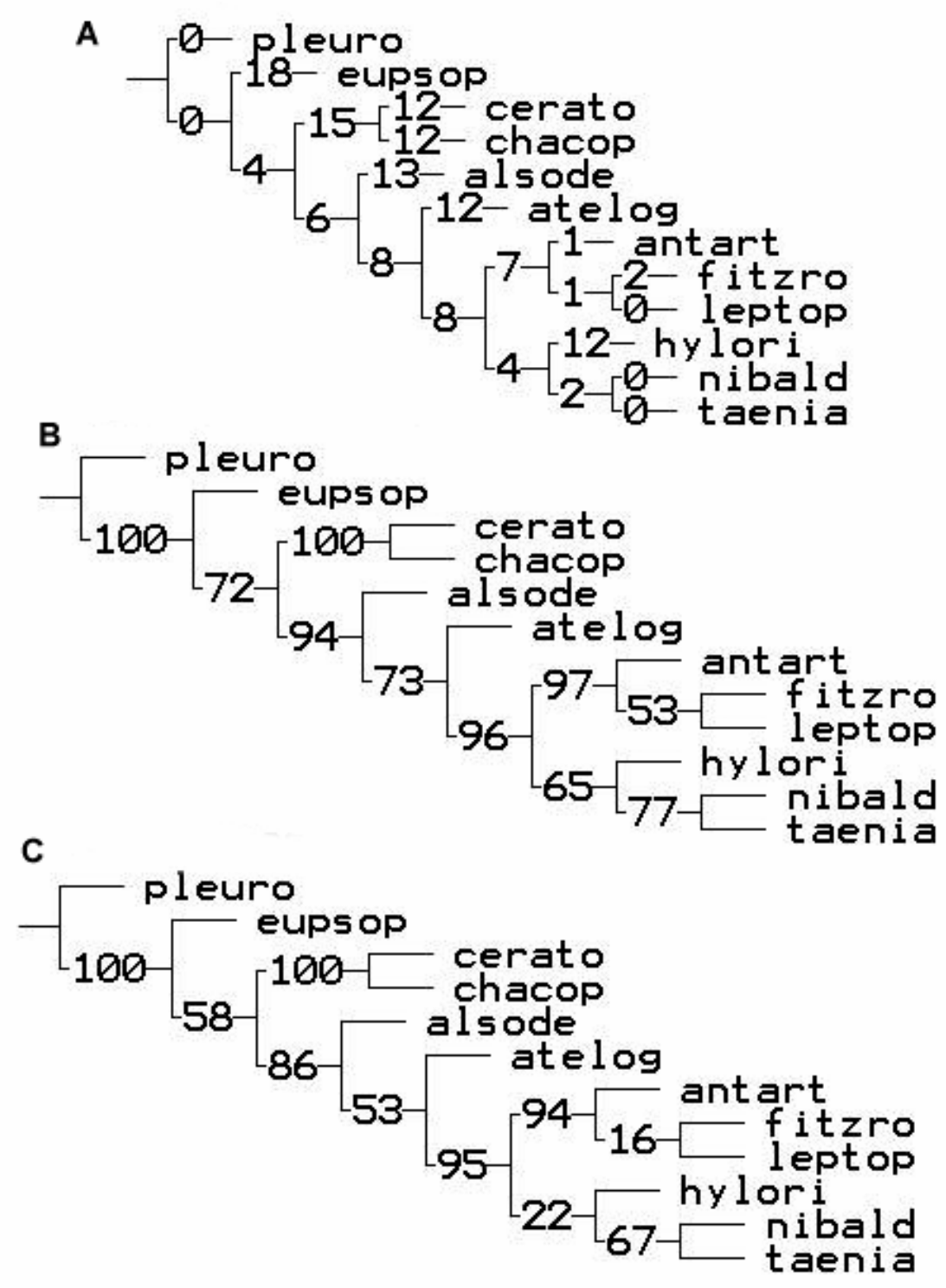

Figura 64. Único árbol obtenido en el análisis con pesos implicados indicando la longitud de cada rama (A) y los valores absolutos de Bootstrap (B) y relativos de Jackknifing (C). 
El otro clado dentro de Batrachyla (clado leptopus) incluye a $B$. antartandica, $B$. fitzroya y $B$. leptopus (Bootstrap=97), estas dos últimas asociadas entre si. Las sinapomorfias del clado compuesto por Batrachyla e Hylorina son las siguientes: 1) Unión sindesmotica entre el ceratobranquial II y la placa hipobranquial (8.0), 2) posición transversal del eje mayor de la cresta dentigera del vomer respecto del eje axial (14.0), 3) proyección anterior del hueso cuadrado presente (22.1), 4) m. subarcualis rectus II-IV inserto en el primer ceratobranquial (44.0), 5) tubéculo óseo en la cara medial del metacarpo II presente $(61.1), 6) \mathrm{m}$. adductor longus ausente (71.1), 7) las fibras del $m$. extensor cruralis brevis ocupan solo los 2/3 proximales del zeugopodio y rematan distalmente en un largo tendón que deja expuestos al tercio distal de la tibia-fíbula y al m. tibialis anticus brevis (76.1), y 8) tubo proctodeal reducido o ausente (95.1-2). A excepción de 8.0 (compartido con Ceratophrys ornata y Eupsophus calcaratus) y 71.1 (compartido con Chacophrys pierottii y Eupsophus calcaratus), las restantes seis sinapomorfias constituyen estados únicos para el clado Batrachyla + Hylorina.

Dentro de Batrachyla, el clado taeniata se halla soportado por cuatro sinapomorfias: 1) proceso lateral de los cuernos trabeculares ventralizado (2.0), 2) extremo de la falange dístal del digíto $V$ supera el nivel de la mitad de la segunda falange del digíto IV pero sin alcanzar la base de la falange dístal de dicho digíto (63.1), 3) cabeza central del $\mathrm{m}$. interphalangealis digiti $\mathrm{V}$ del miembro posterior presente (69.0) y 4) factor de tamaño ovárico > 10 (108.1).

Dentro del clado taeniata, Batrachyla taeniata y B. nibaldoi forman un clado soportado por dos sinapomorfias: 1) límite posterior del xifiesternón del adulto úbicado entre los miómeros $4^{\circ}$ y $5^{\circ}$ del $\mathrm{m}$. rectus abdominis (51.1, compartido con Alsodes gargola, Eupsophus calcaratus y Pleurodema borelli), y 2) canto rostral bien marcado (94.1, compartido con Eupsophus calcaratus).

Respecto del otro clado que compone Batrachyla, el clado leptopus, sus sinapomorfias son:1) cóndilos occipitales separad os por una distancia claramente mayor al ancho condilar (16.0, compartido con Eupsophus calcaratus), 2) dilatación en T de las falanges distales con ancho igual o mayor al ancho de la base de la falange distal (59.1), 3) cabeza central del m. interphalangealis IV delmiembro anterior ausente (66.1, compartido con Ceratophrys ornata, Chacophrys pierottii y Eupsophus calcaratus), 4) m. interphalangealis III del miembro posterior representado solo por la cabeza lateral (79.2, compartido con Eupsophus calcaratus), 5) m. interphalangealis IV del miembro posterior con cabeza medial menos desarrollada que la lateral $(80.1), 6)$ 
m. interphalangealis distalis IV del miembro posterior compuesto solo por la cabeza lateral (81.1), y 7) granulación glandular dorsal del adulto presente (87.1, compartido con Ceratophrys ornata y Chacophrys pierotti).

El clado (B. fitzroya + B. leptopus) no está bien soportado y presenta solo una sinapomorfia: hocico del adulto en vista lateral redondeado (85.0).

\section{III.11.4. Relación de Batrachyla + Hylorina con los grupos externos.}

En ambos análisis Atelognathus constituye el género hermano de Batrachyla (incluyendo Hylorina) con buen soporte (Bootstrap=73). Las ocho sinapomorfias que sostienen la relación son: 1) hueso cuadradoyugal ausente (21.1), 2) contacto entre la rama media del pterigoides y las alas del paraesfenoides ausente (27.1, reverso en Hylorina), 3) m. levator mandibulae internus de la larva con origen en el proceso ascendente solamente (35.1, compartido con Eupsophus calcaratus), 4) m. tympanopharyngeus ausente (45.0, compartido con E. calcaratus), 5) inserción del m. rectus cervicis entre los ceratobranquiales III y IV $(47.1), 6)$ límite posterior del xifiesternón ubicado anterior al miosepto que separa a los miómeros $4^{\circ}$ y $5^{\circ} \mathrm{del} \mathrm{m}$. rectus abdominis (51.2, reverso en $B$. nibaldoi y $B$. taeniata), 7) prehallux conformado por dos segmentos distales (83.1), y 8) LT máxima del adulto entre 40 y $50 \mathrm{~mm}$ (85.1, reverso en $B$. fitzroya y $B$. leptopus).

Finalmente, Alsodes aparece como hermano del clado (Atelognathus+ (Batrachyla+Hylorina)), con muy buen soporte (Bootstrap=94). Las seis sinapomorfias de éste clado son: 1) unión sindesmotica entre alas y cuerpo del cartílago suprarrostral (4.0), 2) extremo de las falanges ditales en forma de $\mathrm{T}$ (58.1), 3), cabeza lateral del $\mathrm{m}$. interphalangealis $\mathrm{V}$ presente (70.0), 4) las fibras mediales de los $\mathrm{m}$. extensor curalis brevis y tibialis posticus no insertan entre si, dejando totalmente expuesta la tibia-fíbula (75.1), 5) tubo proctodeal y su abertura con posición dextral (96.0), y 6) papilas intramarginales supra e infraangulares en el disco oral presentes (101.1). El clado (Ceratophrys + Chacophrys) es el grupo hermano de (Alsodes + (Atelognathus+ (Batrachyla+Hylorina))) con buen soporte (Bootstrap= 78). Las cuatro sinapomorfias que soportan este nodo son: 1) proceso posterior del hueso paraesfenoides corto (19.1, reverso en Atelognathus), 2) prepollex formado por dos segmentos distales (57.1, reverso en Chacophrys pierottii e Hylorina sylvatica), 3) tercio distal de la inserción de la cabeza ventral del $\mathrm{m}$. adductor magnus visible en vista superficial sin necesidad de despejar a los mm. sartorius y cruralis (72.0), y 4) $\mathrm{m}$. 
tibialis anticus brevis bien desarrollado, claramente diferenciado del m. extensor cruralis brevis, no visible o visible en distinto grado entre los $\mathrm{mm}$. tibialis anticus longus y extensor cruralis brevis (77.0).

Por fuera del clado ((Ceratophrys + Chacophrys $)+($ Alsodes + (Atelognathus + (Batrachyla+Hylorina))), se encuentra Eupsophus. A este nivel hay dos sinapomorfias: 1) comisura mandibular sin copula cartilaginosa (31.0) y 2) ausencia de sesamoideo en la aponeurosis palmaris sobre la base de los tendo digiti III, IV y $\mathrm{V}$ (56.1). Ceratophrys y Chacophrys constituyen un clado muy bien soportado (Bootstrap=100) por quince sinapomorfias: 1) proceso ótico larvario presente $(7.1), 2)$ espículas fusionadas a la placa hipobranquial (12.1), 3) ambos huesos nasales contactan medialmente entre si (17.0), 4) fontanela frontoparietal sumamente reduci da y homogénea a lo largo de toda su longitud, lo que determina que los frontoparietales derecho e izquierdo esten practicamente en contacto en la linea media (18.1), 5) contacto entre la rama anterior del escamoso y el maxilar presente (25.1), 6) exostosis presentes en diversas alostosis de la boveda craneana (29.1), 7) huesos anguloesplenial y mentomeckeliano en contacto óseo entre si (30.1), 8) dientes sin condición pedicelada (32.1), 9) fascia entre los mm. intermandibularis y submentalis del adulto presente $(39.1), 10$ ) extremo distal del epiesternón ahuzado, no dilatado (54.1), 11) las fibras del m. extensor cruralis brevis recorren solo el tercio proximal del zeugopodio, siendo este músculo menos desarrollado que el $\mathrm{m}$ tibialis anticus brevis (76.2), 12) cabeza medial del $\mathrm{m}$. interphalangealis III del pie muy poco desarrollada respecto de la lateral $(79.1), 13)$ granulación dorsal del adulto presente (87.1), 14) tuberculo metatarsiano externo ausente (88.1), y 15) tuberculo metatarsiano interno hipertrofiado (89.1). 


\section{DISCUSION}

\section{IV.1. Condrocraneo.}

El condrocráneo de las larvas de Batrachyla presenta la mayoría de los rasgos estructurales típicos descritos para las larvas microfagas (Vera Candioti, 2006). La mayoría de los géneros suele presentar un mismo tipo de larva y, no obstante ello, existen variaciones que en principio no están relacionadas a los morfotipos larvarios. A partir de esos caracteres se han reconstruido las relaciones filogenéticas, tanto al nivel genérico como familiar (Larson \& de Sá, 1998; Haas, 2003). Consistentemente con ello, el $12 \%$ de los caracteres empleados para el análisis filogenético en la presente tesis proceden del condrocráneo, en su gran mayoría de estructuras derivadas de las crestas neurales. Esta variabilidad de las estructuras derivadas de las crestas neurales ya se ha señalado en trabajos previos (Alcalde \& Rosset, 2003). La variabilidad de esas estructuras quizás tenga relación con los mecanismos de ventilación y alimentación. Entre ellas hay dos que merecen, a mi consideración, especial atención: la comisura cuadrado orbitaria y el proceso pseudopterigoideo. Esas dos estructuras no son comunes de observar en la mayoría de los grupos de anuros. El proceso pseudopterigoideo es una estructura que, dentro de los tetrápodos, resulta exclusiva de las larvas de anuros y cuya función, de tenerla, permanece desconocida. Ha sido descrito para especies de sólo 24 géneros, donde en 17 de ellos presenta el estado de caracter corto (sensu Haas, 2003) (Agalychnis, Alytes, Aplastodiscus, Ascaphus, Epipedobates, Eupsophus, Flectonotus, Limnonectes, Litoria, Lymnodinastes, Lysapsus, Phyllomedusa, Pleurodema, Pyxicephalus, Rhinoderma, Tomopterna) mientras que en los restantes presenta el estado largo (Alsodes, Caudiververa, Gastrotheca, Hyla, Limnomedusa, Odontophrynus, Pseudis, Telmatobius) (Reinbach, 1939; Lavilla, 1987, 1992; Fabrezi \& Lavilla, 1993; Haas, 1996, 2003; Formas \& Brieva, 2004; Vera Candioti et al., 2005; Alcalde \& Barg, 2006; Alcalde \& Blotto, 2006). A los géneros que presentan proceso pseudopterigoideo largo deben sumarse tres de los grupos estudiados para esta tesis (Atelognathus, Batrachyla e Hylorina) y también debe agregarse en el grupo de proceso pseudopterigoideo corto a Ceratophrys, el cual presenta una estructura que en este trabajo ha sido interpretada, a diferencia de otros autores (Wild, 1997; Vera Candioti, 2005), como un proceso pseudopterigoideo corto posteriorizado (ver descripción de caracteres). A su vez, algunos de los géneros que lo presentan largo, lo tienen además fusionado a la base del cráneo (Alsodes, Limnomedusa y Telmatobius) (Lavilla, 1992; Fabrezi \& Lavilla, 1993; Alcalde \& Blotto, 
2006). Si bien el análisis filogenético realizado no recupera al proceso pseudopterigoideo largo como sinapomorfia de ningún grupo (por la manera en que fue codificado), al mapear los estados de ese caracter en cualquiera de los cladogramas obtenidos, es evidente que esta condición estuvo presente en el ancestro del clado (Alsodes (Atelognathus (Batrachyla e Hylorina))). La fusión con la base del cráneo habría ocurrido secundariamente en Alsodes. Respecto de una probable función para este proceso he observado que el ligamento inferior del techo (el superior forma la comisura cuadrado orbitaria) inserta en ese proceso en las formas que lo tienen fusionado al piso del cráneo (Limnomedusa y Alsodes). Esto podría dar mayor estabilidad al proceso muscular, donde ocurre la inserción para el m. orbitohyoideus y la articulación con el ceratohial, lo que podría tener relación directa con el funcionamiento de la bomba faríngea.

Respecto de la comisura cuadrado orbitaria, su presencia ha sido descrita para 22 géneros de anuros, 4 de ellos con la condición alta (sensu Haas, 2003) (hyperolidos) y los restantes (Alsodes, Bufo, Caudiververa, Chacophrys, Dyscophus, Gastrotheca, Kaloula, Leptodactylus, Limnomedusa, Odontophrynus, Paradoxophyla, Pedostibes, Pelodytes, Peltophryne, Physalaemus, Pleurodema, Ptychadena y Telmatobius) (Reinbach, 1939; Lavilla, 1992; Fabrezi \& Lavilla, 1993; Fabrezi \& Vera, 1997; Wild, 1997; Haas, 2003; Alcalde \& Blotto, 2006). En el ejemplar de Caudiverbera que he analizado para esta tesis (ver Apéndice III) no se observa la presencia de comisura cuadrado orbitaria, sin embargo ésta fue reportada por Reinbach (1939) para ese género. La variación intraespecífica en la presencia de comisura cuadrado orbitaria fue descrita por Haas (2003) para Kaloula pulchra y probablemente esto sea lo que ocurra en Caudiverbera.

Durante la crisis metamórfica se observan profundas reestructuraciones de los arcos viscerales para originar la estructura adulta de los mismos, en tanto que los rasgos del neurocráneo permanecen mayormente inalterados durante este proceso. Mientras el cambio es abrupto para las estructuras del primer caso, las del segundo (salvo el caso de los cartílagos nasales) sufren un cambio gradual a lo largo de toda la fase larvaria). La mayoría de las estructuras neurocraneanas van apareciendo gradualmente en diferentes estadios larvarios y se mantienen hasta el adulto, en tanto que las estructuras de los arcos viscerales se pierden, fusionan o remodelan durante el cambio metamórfico. Estos aspectos han sido señalados por diversos investigadores (ver reseña en Cannatella, 1999) y se confirman en el presente trabajo. Respecto de los cambios profundos que ocurren en la crisis metamórfica para el 
aparato hiobranquial, es interesante discutir la homología entre diversas estructuras de la larva y las del adulto. Diversos autores han investigado el cambio metamó rfico del hiobranquium (de Beer, 1937; de Jongh, 1968; Wiens, 1989; Fabrezi \& Garcia, 1993; Wild, 1997, 1999; Haas, 1999). De esos pocos trabajos se destaca cierto patrón de desarrollo para algunas estructuras (cuernos hioideos, procesos posteromediales) pero también son notorias importantes diferencias relativas al origen del cuerpo hioideo, procesos posterolaterales y anterolaterales. En un trabajo anterior (Alcalde, 2005a) he investigado el desarrollo del hioides en Hypsiboas pulchellus y Leptodactylus ocellatus y reseñé los antecedentes del tema para discutir las homologías propuestas por los diversos autores. Las conclusiones de aquel trabajo son: 1) los procesos posteromediales corresponden al extremo posterior de la placa hipobranquial remodelada, 2) los procesos posterolaterales del hioides adulto corresponden fundamentalmente al ceratobranquial I recondensado, 3) los procesos anterolaterales no corresponderían a ninguna estructura larvaria, y desarrollan de una condensación cartilaginosa, 4) el proceso anterolateral corresponde al proceso anterohial del ceratohial recondensado, 5) los cuernos hioideos corresponden a los ceratohiales remodelados, y 6 ) el cuerpo hioideo deriva fundamentalmente de la placa hipobranquial. Las observaciones realizadas en las secuencias empleadas para la presente tesis son congruentes con las hipótesis de homología mencionadas.

\section{IV.2. Osteocraneo.}

El desarrollo del cráneo en anuros, así como el de vertebrados en general, se ha abordado mediante diferentes técnicas: técnicas de tinción y diafanización y técnicas histológicas, identificación y estudio de la expresión de genes reguladores, marcado de células, producción de organismos mutantes, estudio de condensaciones celulares (Hall \& Miyake, 2000; Hanken \& Gross, 2005). La información obtenida a partir de estas diferentes técnicas ha conducido a reformular el concepto de homología referido a ciertas estructuras. Por ejemplo, para los investigadores que trabajan con condensaciones celulares todos los elementos cartilaginosos u óseos que provienen de una misma condensación serian homólogos (Vickaryous \& Hall, 2006), mientras que los que trabajan con genes reguladores argumentan por la homología de estructuras que su desarrollo esta regulado por el mismo grupo de genes (Galis, 1999). Y a veces estos conceptos chocan con las hipótesis de homología producidas a partir de la morfología tradicional. Según Hall (1999), para salvar estas situaciones es necesario comprender la homología como un concepto naturalmente jerárquico, donde 
la información proveniente de diferentes enfoques debe integrarse. De este modo la comprensión genética del desarrollo, la paleontología y las técnicas modernas para el estudio de la ontogenia amplían el horizonte de comprensión para las distintas morfologías observadas mediante las técnicas tradicionales, sin anularlas. Como ejemplo de ello, se han propuesto interesantes hipótesis de homología para ciertos huesos complejos del cráneo de Gymnophiona, estudiando el desarrollo de larvas mediante el empleo de técnicas tradicionales (Mueller et al., 2005; Mueller, 2006).

Los anuros son un grupo monofilético (Trueb \& Cloutier, 1991) que junto a los Caudata y Gymnophiona constituyen los Lissamphibia, un clado cuyas relaciones con los restantes tetrápodos permanecen aun en controversia según los autores (Trueb \& Cloutier, 1991; Laurin \& Reisz, 1997). La osificación del cráneo de anuros se conoce para alrededor de 40 especies (Maglia \& Pugener, 1998; Perotti, 2001, Banbury \& Maglia, 2006). Muchas de esas descripciones poseen bajo nivel de resolución (Trueb, 1985; Wiens, 1989; Pugener \& Maglia, 1997) y también existe poco conocimiento acerca de la secuencia pura de osificación (Haas, 1999) y su variabilidad (Hanken \& Hall, 1988). Respecto de las secuencias de osificación craneana de anuros, en general, el inicio de la misma sigue un patrón bastante conservativo dentro del orden, donde los primeros elementos en osificar son el frontoparietal, el paraesfenoides y el exoccipital (Hanken \& Hall, 1988), mientras que los restantes elementos no muestran un patrón constante relativo a su aparición (Trueb, 1985). Todos estos aspectos han recibido relativa importancia en los trabajos específicos sobre el tema, pero otros aspectos del desarrollo craneano de anuros han pasado mayormente desapercibidos. Entre esos aspectos se destaca el caso de los huesos craneanos de origen complejo.

La existencia de más de un centro de osificación para ciertos huesos del cráneo ha sido reportada para todos los grandes grupos de tetrápodos (de Beer, 1937). El fenómeno de la existencia de más de un centro de osificación para ciertos huesos del cráneo de anuros ha sido reportado para diversas especies de diferentes grupos dentro del orden (de Sá, 1988; Wild, 1999) pero nunca se han planteado hipótesis de homología para cada centro de osificación respecto de los elementos óseos de otros tetrápodos, entre ellos los restantes Lissamphibia. La existencia de más de un centro de osificación para los huesos escamoso, esfenoetmoides, exoccipital, frontoparietal y pterigoides se ha reportado para Bombina variegata, Bufo arenarum, Caudiververa caudiververa, Ceratophrys cornuta, Chacophrys pierottii, Hypsiboas lanciformis, Leptodactylus chaquensis, Rana pipiens y Spea bombifrons 
(Reinbach, 1939; Kemp \& Hoyt, 1969; de Sá, 1988; Wiens, 1989; Wild, 1997, 1999; Perotti, 2001; Cihak et al., 2003).

Los únicos casos donde la nomenclatura ósea refleja el origen compuesto de determinados huesos son el frontoparietal, anguloesplenial y esfenoétmoides. $E$ frontoparietal de anuros es especial porque su formación a partir de dos centros de osificación, uno correspondiente al frontal y otro al parietal, esta muy bien documentada solo para el género Bombina (Hanken \& Hall, 1988; Cihak et al., 2003), no así para los restantes anuros, para los cuales la homología se ha extendido aunque en ellos el frontoparietal se origine a partir de solo un centro.

Para el caso del anguloesplenial, si bien su nombre refleja la homología con el angular y el esplenial de otros tetrápodos, no se ha descrito su desarrollo a partir de dos centros en ninguno de los géneros de anuros para los cuales se conoce el desarrollo del cráneo (ej., de Sá, 1988, Wiens, 1989; Perotti, 2001), con lo cual es muy probable que se trate de un solo elemento óseo expandido en área.

El esfenoétmoides es un elemento usualmente impar que cierra lateral, anterior y ventralmente la cavidad encefálica por delante del foramen óptico, y a veces suele extenderse hasta la región etmóidea por invasión del septo nasal y las laminas orbitonasales (Trueb, 1973). Este elemento es un hueso típico de los primeros tetrápodos, presente desde los crossopterigios ripidistios, y conservado en formas actuales solo en Lissamphibia (Duellman \& Trueb, 1986). Su osificación ocurre tardíamente en el desarrollo (Trueb, 1985) a partir de uno (Trueb et al. 2000), dos (Perotti, 2001) o más centros (de Beer, 1937). En general se trata de centros de osificación difusa que pueden osificar tanto autostosica como alostósicamente. Un desarrollo similar ocurre también en Gymnophiona (Mueller, 2006). En resumen, para el esfenoétmoides se ha formulado la hipótesis que representa la fusión de diversos huesos esfenoidales (orbitoesfenoides, basiesfenoides) y etmoidales (mesetmoides) (de Beer, 1937), situación que se refleja en su nombre.

No he observado osificación a partir de varios centros para esos tres huesos con lo cual no se discutirán aquí las homologías propuestas para los mismos.

Respecto de los huesos escamoso, exoccipital y pterigoides, teniendo en cuente la bibliografía existente, no existen antecedentes donde se propongan hipótesis de homología para los diferentes centros que los constituyen. Si bien no es objeto principal de esta tesis investigar la homología de los centros que componen esos tres huesos, es necesario darle debida trascendencia al tema de los huesos craneanos de origen complejo y proponer homologías para esos elementos (algunas fueron 
explícitamente formalizadas en la sección resultados: ver hueso opistótico). Esas homologías deberán ser probadas o rechazadas en futuros trabajos de investigación.

Respecto del opistótico, como los restantes elementos autostósicos de la cápsula ótica, presenta posición constante respecto de la cápsula entre los diferentes tetrápodos y en consecuencia resulta fáci Imente homologable entre ellos. Por tal razón, he formalizado directa y explícitamente en la sección resultados la homología entre el centro de osificación posterior de la cápsula ótica y el hueso opistótico (ver discusión en párrafos siguientes). En cambio, he preferido ser más cauto para proponer la homología de los distintos centros del escamoso y del pterigoides a causa de que el establecimiento de homología entre alostosis de la región temporal o de la bóveda craneana, para las cuales no existe un punt o fijo de referencia sobre los cuales se forman los centros de osificación, resulta más dificultosa.

El escamoso de anuros es una alostosis compuesta generalmente por tres ramas (ótica, ventral y anterior) (Trueb, 1973), que se halla presente incluso en las formas jurásicas del grupo (Estes \& Reig, 1973). El origen ontogenético del escamoso se ha descrito a partir de dos y hasta de tres centros de osificación, cada uno correspondiente a cada rama del hueso (Reinbach, 1939; Wiens, 1989; Wild, 1997, 1999; Perotti, 2001). Para proponer homologías entre cada centro de osificación del escamoso y los huesos de la región temporal de los restantes tetrápodos es necesario comparar el cráneo los anuros actuales con el cráneo de los Temnospondyli Dissorophoidea, grupo que es mayoritariamente aceptado como su ancestro (Trueb \& Cloutier, 1991). De la comparación surge que: 1) en el ancestro de anuros el escamoso no es trirradiado, y 2) la región temporal de los Dissorophoidea presenta un mayor numero de elementos óseos discretos respecto de anuros (ej., postorbital, supratemporal, tabular, etc) (ver Duellman \& Trueb, 1986). Entonces, esa diferencia en el numero de huesos entre los anuros y sus ancestros, sumado a la forma trirradiada del escamoso de anuros y al origen a partir de un centro de osificación para cada una de sus ramas conducen a buscar la homología de cada rama entre algunos de los huesos de la región temporal de los Dissorophoidea. En este grupo el escamoso contacta ventralmente con el cuadrado y el cuadradoyugal, anteroventralmente con el yugal, anterodorsalmente con el postorbital, y dorsalmente con el supratemporal y tabular. Estableciendo homologías por el criterio de posición y relación topográfica de los elementos la rama ventral del escamoso de anuros sería homologa al escamoso de los Dissorophoidea, mientras que la rama anterior correspondería al postorbital de estos últimos. El caso de la rama posterior es más conflictivo porque podría 
corresponder tanto al tabular como al supratemporal. Respecto de esta última posibilidad, Griffiths (1954) postuló que lo que el denomina elemento ótico de anuros es en realidad un supratemporal, aunque el elemento ótico de Griffiths (1954) no es la rama ótica del escamoso. Otra línea de evidencia surge por el lado de la muesca ótica. En los anfibios paleozoicos está constituida por el tabular y el escamoso (Duellman \& Trueb, 1986), mientras que en los anuros esta conformada por la rama ventral y ótica del escamoso (Trueb, 1973). Diversos autores han señalado la no homología de ambas muescas óticas en tanto estas se hallan conformadas por diferentes elementos (Milner, 1993). Sin embargo, si la rama ótica del escamoso de los anuros actuales representase al tabular (Figura 65), entonces no habría conflicto entre las muescas óticas de los anfibios paleozoicos y la de los anuros. De los restantes Lissamphibia, al menos los Gymnophiona forman el escamoso a partir de un solo centro (Mueller, 2006), aparentemente correspondiente a la rama ventral del escamoso de anuros.

El exoccipital de anuros es una autostosis que se ubica en el arco occipital del cráneo, forma los cóndilos occipitales y suele integrar el hueso oto-occipital por fusión con el proótico (Trueb, 1973). Respecto de su origen, la mayoría de los estudios refieren que el exoccipital se forma a partir de un único centro de osificación ubicado en el arco occipital (Trueb, 1985; Lavilla \& Fabrezi, 1987; Wiens, 1989; Haas, 1996; Wild, 1999; Trueb et al., 2000). Sin embargo, otros estudios describen la existencia de dos centros de osificación para el exoccipital (Kemp \& Hoyt, 1969; Wild, 1997). De esos dos centros, uno corresponde al centro del arco occipital descrito por la mayoría de los autores, mientras que el restante se encuentra en la pared ventromedial y posterior de la cápsula ótica. Este último ha sido interpretado como un segundo centro del exoccipital (Kemp \& Hoyt, 1969) o bien como un segundo centro del proótico (Wild, 1997). En el presente trabajo he observado el centro de osificación ubicado en la pared posteromedial y ventral de la cápsula ótica, tanto en las secuencias de Batrachyla como en ejemplares de Atelognathus nitoi y de Hypsiboas pulchellus empleados como material de comparación (Figura 66). En todos los casos ese centro aparece temporalmente más tarde que el centro del exoccipital ubicado en el arco occipital, y rápidamente ambos centros se fusionan. Esta situación ha dado lugar a que diversos autores interpreten ese centro posterior de la cápsula ótica como un centro accesorio del exoccipital (Kemp \& Hoyt, 1969). En cambio, al estar ubicado en la cápsula ótica ha sido interpretado por otros autores como un centro posterior del proótico (ej., Wild, 1997). Interpretar al centro posteromedial y ventral de la cápsula ótica como a uno de los huesos perióticos y no como parte del exoccipital es acertado, 

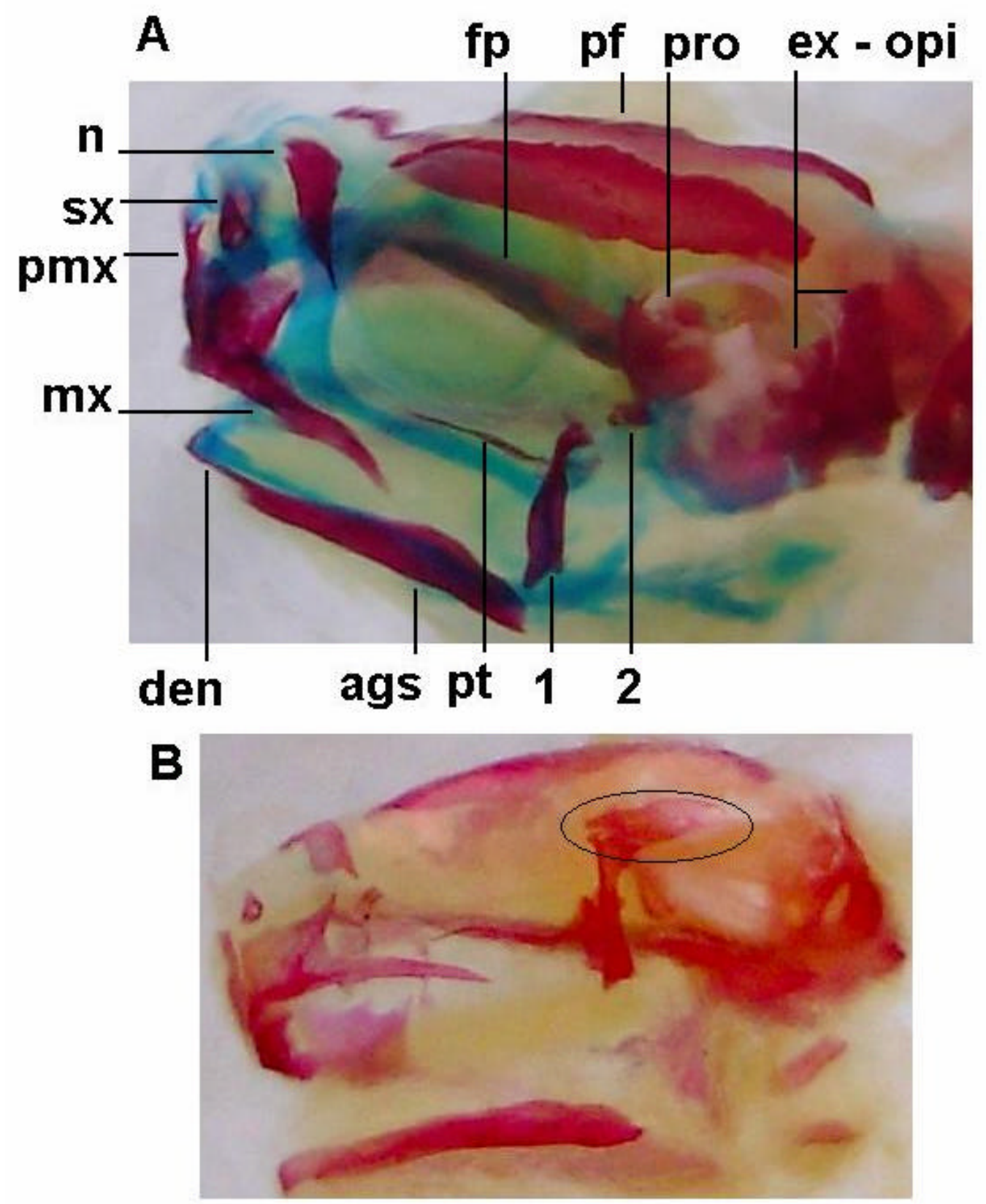

Figura 65. Vista lateral del neurocráneo y arco mandibular deBatrachyla antartandica en dos ejemplares al estadio 46 (Gosner, 1960), uno menos (A) y otro más avanzado (B). Escala 1 $\mathrm{mm}$. Referencias: 1: centro de la rama ventral del escamoso (probable escamoso de otros tetrápodos); 2: centro de las ramas ótica y anterior del escamoso (probable tabular de otros tetrápodos). El resto de las referencias como en las figuras 1, 2 y 3. 
pero en parte. Los tetrápodos poseen un número máximo de hasta tres elementos perióticos: el epiótico, el opistótico y el proótico (Goodrich, 1930). Ellos osifican en posición dorsal a dorsal posterior (epiótico), anterior y ventromedial (proótico) y posterior y ventromedial (opistótico) (de Beer, 1937). No obstante su constancia en el desarrollo y su posición relativa en la cápsula ótica, existen variaciones relativas a fusiones o perdidas de ellos. En mamíferos falta el epiótico y los dos restantes huesos óticos se fusionan formando el hueso petroso, mientras que en sauropsidos (salvo Testudines) el opistótico se encuentra fusionado al exoccipital mientras que el epiótico lo hace con el supraoccipital (Kardong, 1998). En tanto que para los Lissamphibia se ha descrito la presencia de opistótico y proótico para Gymnophiona y Caudata, y para Anura solo este último (Duellman \& Trueb, 1986). El opistótico de Caudata, descrito para la familia Proteidae (Eaton, 1959), suele estar fusionado al proótico y el exoccipital (Duellman y Trueb, 1986), mientras que su presencia en Gymnophiona es controvertida. Marcus et al. (1935) lo nombran como parte del "os basale", mientras que Mueller (2006) no ha podido identificar un centro correspondiente al opistótico en la conformación del os basale. Similarmente a lo que ocurre en algunos Caudata, el proótico de algunos anuros suele fusionarse a los exoccipitales formando el hueso ótooccipital (Trueb, 1973).

Considerando la evidencia recién mencionada y en tanto que los Lissamphibia constituyen un grupo monofilético (Zardoya \& Meyer, 2001; Haas, 2003), la ausencia de opistótico constituiría un rasgo derivado de los Anura y posiblemente de Gymnophiona, mientras que la presencia sería una plesiomorfía en Caudata. Sin embargo, como surge de la reinterpretación aquí realizada acerca del centro accesorio del exoccipital, el opistótico estaría presente en Anura, Caudata y los ancestros de Lissamphibia. Entonces su presencia constituye un rasgo plesiomórfico en Lissamphibia que se habría retenido en el clado de los Ba trachia (Caudata + Salientia) y secundariamente se habría perdido en Gymnophiona.

Finalmente, no obstante su presencia, debe reconocerse que el opistótico de anuros y caudados presenta reducción en área y tendencia a la fusión con el exoccipital. Respecto de esto último, en todos los anuros existe fusión de opistótico y exoccipital, mientras que en algunos grupos también se incluye en esta fusión al proótico formando lo que tradicionalmente se conoce como hueso ótooccipital.

El pterigoides, al igual que el escamoso es una alostosis trirradiada compuesta por tres ramas (zigomática, media y posterior) (Trueb, 1973), presente incluso en las formas jurásicas del grupo (Estes \& Reig, 1973). El origen ontogenético del pterigoides 

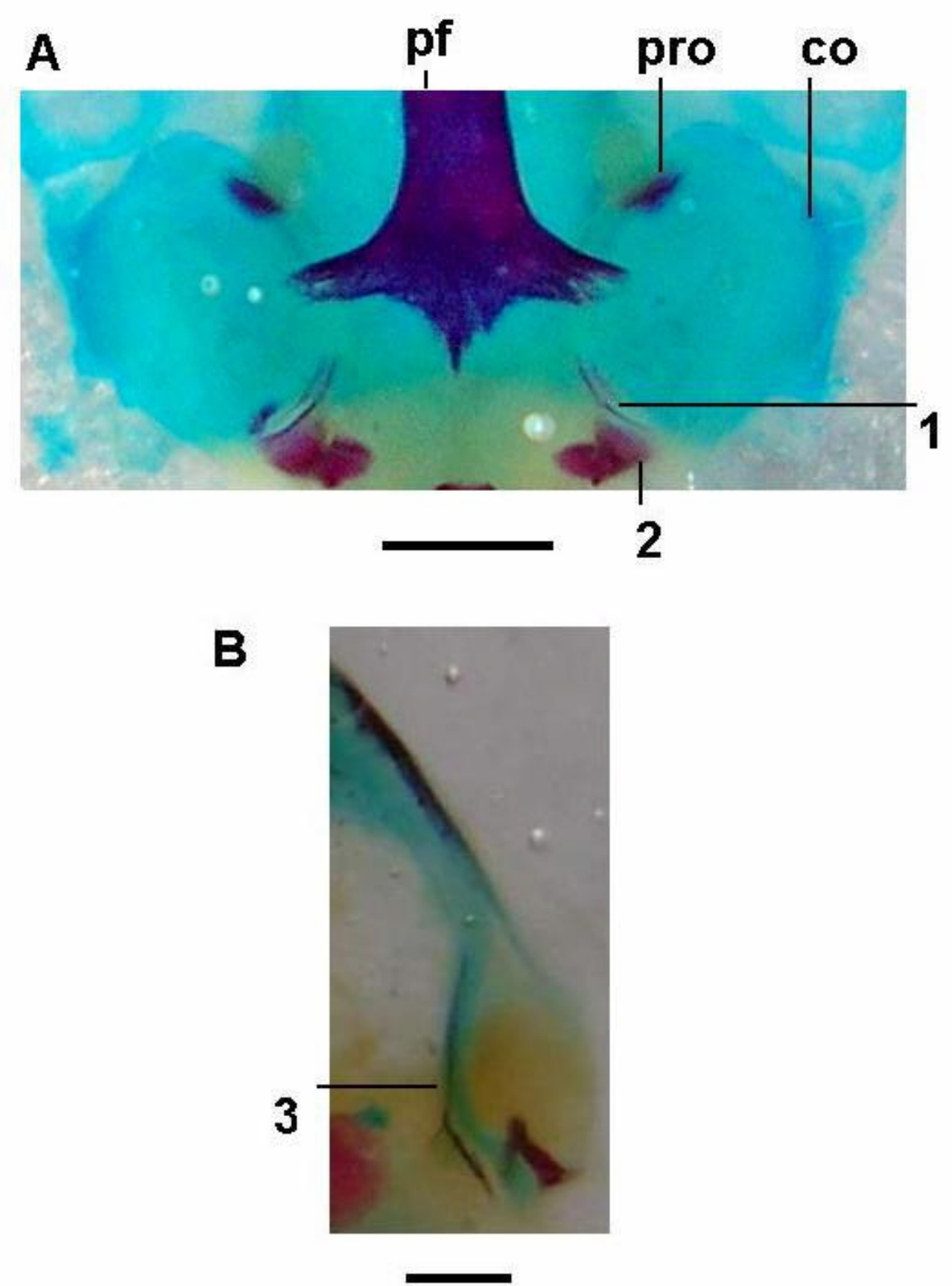

Figura 66. Vista ventral del n eurocráneo de Atelognathus nitoi (A) al estadio 38 de Gosner (1960) mostrando el centro de osificación de la pared posterior de la cápsula ótica correspondiente al hueso opistótico. En ( B) se muestra el neurocráneo de un ejemplar de Pleurodema thaul al estadio 46 donde se observa la osificación del pterigoides posteriormente a la fusión de los centos de cada rama. Escala 1 mm. Referencias: 1: centro del opistótico; 2: centro del exoccipital; 3: estructura trirradiada por fusión de ambos centros del pterigoides. El resto de las referencias como en las figuras 1 y 2. 
se ha descrito a partir de dos y hasta de tres centros de osificación, cada uno correspondiente a cada rama del hueso (Kemp \& Hoyt, 1969; de Sá, 1988; Perotti, 2001). Los anfibios paleozoicos presentaban un paladar primario bien osificado y amplío compuesto por vomer, palatinos, pterigoides (endopterigoides) y ectopterigoides (ver Duellman \& Trueb, 1986). En el clado de los Lissamphibia, los Gymnophiona presentan los cuatro elementos (Mueller, 2006), mientras que en Caudata y Anura presentan solo tres de esos elementos dada la falta de hueso ectopterigoides (Trueb, 1973, Duellman \& Trueb, 1986). En estos últimos dos grupos el pterigoides es trir radiado y la misma situación ocurre en los Temnospondyli Dissorophoidea donde existe un pterigoides trirradiado separado por importantes vacuidades interpterigoideas y ausencia de hueso ectopterigoides. En el material de Batrachyla no he observado la presencia de tres centros de osificación para el pterigoides, aunque como se expreso en la sección resultados, no puede descartarse que la rama zigomática de Batrachyla se forme independientemente a las restantes. Esto último sí lo he observado en parte del material usado para comparación, en particular en secuencias de Hypsiboas pulchellus, Leptodactylus ocellatus y Pleurodema thaul. En anuros, la rama zigomática del pterigoides se dirige anterolateralmente hacia el maxilar a partir del punto de unión de las ramas ótica y posterior (Trueb, 1973). Esta posición es la que clásicamente ocupa el hueso transverso o ectopterigoides de los restantes tetrápodos (Goodrich, 1930) y al presentar un centro de osificación separado debería ser interpretado como tal, al menos en los anuros, donde su origen independiente fue descrito para muchas de sus formas (Figura 66). Dada la estructura trirradiada del pterigoides de los Dissorophoidea cabe pensar que la fusión de ectopterigoides y pterigoides ha ocurrido tempranamente, incluso antes de la aparición de los Lissamphibia y posiblemente en relación a una reestructuración del paladar dada la presencia de vacuidades interpterigoideas. De este modo, de confirmarse su presencia en Caudata (la estructura trirradiada del pterigoides de los mismos parece sugerirla), la presencia de ectopterigoides sería una plesiomorfia de Lissamphibia, mientras que la fusión pterigoides - ectopterigoides sería un rasgo derivado de los Batrachia. La orientación de las ramas ótica y posterior del pterigoides de anuros recuerda la forma del pterigoides de la mayoría de los anfibios paleozoicos, aunque con mucho menor desarrollo debido a las vacuidades interpterigoideas. Restaría establecer, en un futuro, hipótesis de homología para las ramas ótica y posterior, de las cuales una es 
evidentemente el endopterigoides, para las cuales no he observado centros independientes en ninguna secuencia del material estudiado.

\section{IV.3. Musculatura craneana.}

Existen diversos trabajos relativos a la musculatura craneana de larvas (Haas \& Richards, 1998; Palavecino, 1999; Haas, 2003; Vera Candioti et al., 2004; Alcalde, 2005b) y adultos (Lynch, 1993; Tyler \& Duellman, 1995). El estudio del cambio metamórfico de esos músculos está bien abarcado para el caso de los músculos hioideos y mandibulares (Palavecino, 2000; Haas, 2001), no así para la musculatura asociada a los arcos branquiales. Las observaciones realizadas en el presente trabajo de tesis coinciden mayormente con las de los autores citados. Las discrepancias respecto de esos trabajos, mayormente relativos al desarrollo de la musculatura asociada a los arcos branquiales, se discutirán a continuación.

El m. rectus cervicis es un músculo asociado al aparato hiobranquial de la larva y forma parte de la musculatura hipobranquial, que se halla inervada por el nervio hipogloso (nervio espinal II). Esta musculatura esta muy desarrollada en peces, se ubica entre la cintura escapular y los arcos viscerales e interviene en los mecanismos de apertura de la boca y de ventilación de la cámara branquial (Kardong, 1998). En los tetrápodos se halla reducida y especializada en asociación al desarrollo de una lengua secundaria (musculatura lingual) y al desarrollo del miembro quiridio (musculatura apendicular). En larvas de anuros, el m. rectus cervicis suele ser considerado parte del grupo de músculos branquiales por diversos autores (Duellman \& Trueb, 1986; Haas \& Richards, 1998; Haas, 2003), entre los que me incluyo por aportes realizados previamente (Alcalde \& Barg, 2005). Sin embargo, el m. rectus cervicis no debe ser considerado parte de los músculos branquioméricos puesto que no deriva de somitómeros craneanos, sino que se origina a partir de somitos postcraneanos. Este origen se deduce de su inervación, dado que los músculos hipobranquiales reciben inervación del nervio hipogloso, mientras que la musculatura branquiomérica asociada a los arcos branquiales esta inervada por los nervios vago o glosofaríngeo (Kardong, 1998). Otro aspecto conflictivo respecto del $\mathrm{m}$. rectus cervicis es su homología. Comunmente es considerado como el miómero más anterior del m. rectus abdominis (Grandwell, 1972; Lynch, 1984, Lynch \& Harris, 1984; Haas, 1997; Manzano \& Perotti, 1999). De los trabajos de los autores recien citados se extraen las siguientes conclusiones respecto del $\mathrm{m}$. rectus abdominis: 1) se trata de un músculo con rasgos metaméricos, 2) está integrado por un número variable de miómeros, 3) su desarrollo y 
variabilidad en el adulto es causa de una remodelación en el proceso metamórfico más que de la conservación de diferencias existentes en el estad o larvario, y 4) tardíamente en el desarrollo desarrolla una porción anterior ( $m$. rectus cervicis), la cual pasa a estar asociada con la cintura escapular. Las observaciones realizadas en el material estudiado en esta tesis doctoral coinciden con lo observado por los autores mencionados a excepción de que el $\mathrm{m}$. rectus cervicis es una porción anterior del $\mathrm{m}$. rectus abdominis, la cual desarrollaría tardíamente en la fase larvaria. Manzano \& Perotti (1999) indican que el $\mathrm{m}$. rectus cervicis se forma a partir del miómero más anterior del m. rectus abdominis al estadio (Gosner, 1960) 34 (Gastrotheca gracilis), 37 (Phyllomedusa boliviana) o durante la crisis metamórfica (Hypsiboas andina, Scinax nasicus). Respecto de la aparición tardía, existe evidencia publicada (Alcalde, 2005b) que indica la presencia del $\mathrm{m}$. rectus cervicis desde estadios tempranos en diversas especies de Hypsiboas, Scinaxy Phyllomedusa, inclusive algunas de las estudiadas por Manzano \& Perotti (1999). Asimismo, contrariamente a lo señalado por Manzano \& Perotti (1999), el m. rectus cervicis de las especies analizadas en la presente tesis no se forma a partir del miómero más anterior del m. rectus abdominis, sino que está presente desde mucho antes que el $\mathrm{m}$. rectus abdominis alcanze la pared posterior de la cámara branquial. En todas las larvas para las cuales se conoce la musculatura asociada a los arcos branquiales (ver reseña en Cannatella, 1999), el m. rectus cervicis corre entre las bases de los ceratobranquiales (III, IV o ambos) y el peritoneo faríngeo. Lo mismo he observado en los ejemplares estudiados para la presente tesis, en los cuales es notorio que las fibras del $\mathrm{m}$. rectus abdominis nunca se extienden cranealmente más allá del septo transverso (límite posterior de la cámara branquial), punto en el que las fibras de ambos músculos coinciden topograficamente. $\boxminus \mathrm{m}$. diaphragmatobranchialis (branquiomerico) también coincide topográficamente, aunque en forma no tan clara, con el m. rectus abdominis a ese nivel. Respecto de la coincidencia topográfica de las fibras, es interesante notar en el único caso donde el $\mathrm{m}$. rectus abdominis se extiende anteriormente mas allá del septo transverso es en las larvas suctoras (Haas \& Richards, 1998) y adherentes (obs. pers.). En ambas clases de larva, los dos músculos se solapan a nivel de la camára branquial, sin que sus fibras establezcan relación, argumentando fuertemente a favor de la diferente identidad de ambos. Por último, el $\mathrm{m}$. rectus cervicis cambia su origen e inserción durante la crisis metamórfica dando origen al m. sternohyoideus del adulto, del cual sí es homólogo. Esto ocurre mediante un desplazamiento del origen desde el peritoneo faríngeo hacia la cintura escapular acompañándola en su migración caudal y 
desplazando su inserción de los ceratobranquiales (que se reabsorben) hacia el cuerpo hioideo del adulto. Finalmente, a partir de los lineamientos presentados en esta discusión se resaltan los siguientes aspectos: 1) debe considerarse como homólogos a los músculos rectus cervicis de la larva y sternohyoideus de los adultos, 2) las homologías entre los $\mathrm{mm}$. rectus abdominisy sternohyoideus en los adultos, o rectus abdominis y rectus cervicis de la larva parecen no ser tales aunque no puedan descartarse en forma concluyente, y por último, 3) en el caso que exista homología entre los $\mathrm{mm}$. rectus cervicis y rectus abdominis probablemente el primero se halla originado evolutivamente a partir del segundo.

\section{IV.4. Esqueleto axial postcraneano.}

Diversos aspectos del desarrollo larvario de las estructuras del esqueleto axial postcraneano han sido estudiados para las siguientes especies de anuros: Alytes obstetricians (Blanco \& Sanchiz, 2000), Bombina orientalis (Maglia \& Púgener, 1998; Blanco \& Sanchiz, 2000), Bufo calamita (Dunlap \& Sanchiz, 1996) y B. bufo (Dunlap \& Sanchiz, 1996; Blanco \& Sanchiz, 2000), Ceratophrys cornuta (Wild, 1997), Chacophrys pierottii (Wild, 1999), Dendrobates auratus (de Sá \& Hill, 1998), Discoglossus jeanneae (Blanco \& Sanchiz, 2000), D. sardus (Púgener \& Maglia, 1997), Epipedobates tricolor (de Sá \& Hill, 1998), Hamptophryne boliviana (de Sá \& Trueb, 1991), Hyla arborea (Blanco \& Sanchiz, 2000), Leptodactylus chaquensis (Perotti, 2001), Pelobates cultripes (Blanco \& Sanchiz, 2000), Pelodytes punctactus (Blanco \& Sanchiz, 2000), Pipa pipa (Trueb et al., 2000), Pyxicephalus adspersus (Haas, 1999), Rana spp. (Blanco \& Sanchiz, 2000), Rana pipiens (Kemp \& Hoyt, 1969), Spea bombifrons (Wiens, 1989), Spea multiplicata (Banbury \& Maglia, 2006), Xenopus laevis (Trueb \& Hanken, 1992; Blanco \& Sanchiz, 2000). Las 20 especies nombradas son un número proporcionalmente pequeño respecto de la cantidad de géneros y especies que componen el orden. Sin embargo, puede considerarse que esa muestra es sistemática y ecologicamente representativa de los mayores clados, tipos de desarrollo y modos ecológicos que se conocen para los anuros. A partir de este momento, cada vez que se nombre a esas especies en esta sección de la discusión se hará directa referencia al nombre de las mismas obviando reiterar la cita del trabajo correspondiente.

Teniendo en cuenta los trabajos mencionados puede establecerse que, como parece ser común a los restantes grupos de vertebrados, el desarrollo axial postcraneano de los anuros sigue una secuencia anteroposterior en diversos 
aspectos. Para el caso de los anuros se destacan los siguientes patrones: 1) la condrificación de los arcos neurales ocurre previo al inicio de la osificación de los cuerpos vertebrales; 2) la osificación de los arcos neurales precede ligeramente a la de los cuerpos vertebrales, ambas en estadios de Gosner (1960) correspondientes a la diferenciación de los dígitos; 3) cada hemiarco neural se forma por un centro autostósico ubicado al nivel donde se proyectan los procesos transversos; 4) los procesos transversos, espinas neurales y zigapofisis son parte del arco neural y su osificación ocurre por la expansión del centro del arco neural; 5) los únicos eventos del desarrollo axial postcraneano que parecen no seguir un patrón anteroposterior son el cierre dorsal de los arcos neurales, el crecimiento de los procesos transversos, y la fusión de los centros de osificación de los cuerpos vertebrales; 6) los cuerpos vertebrales son alostósicos; 7) el urostilo se forma por la fusión del hipocordo y de al menos dos arcos neurales postsacros; y 8) el proceso de osificación prosigue en algún grado luego de culminada metamorfosis.

No obstante el patrón común recientemente mencionado, al revisar la bibliografía mencionada al inicio de esta sección de la discusión, es notoria la existencia de controversias sobre varios aspectos del desarrollo larvario del esqueleto axial postcraneano. Si se descarta la existencia de errores de interpretación acerca del desarrollo de las estructuras, estas controversias señalan patrones que deberían ser abordados en un contexto filogenético, dada la información que podrían proveer. Sin embargo, esas cuestiones han pasado siempre desapercibidas en los trabajos específicos acerca del tema en cuestión. Esos temas controversiales son el tipo de osificación de los cuerpos vertebrales (osificación endocondral versus osificación de membrana), la cantidad de centros de osificación involucrados en la formación de los cuerpos vertebrales, y el desarrollo del urostilo teniendo en cuenta fundamentalmente la naturaleza del hipocordo.

Respecto del mecanismo por el cual osifican los cuerpos vertebrales, es conocido que en general para los tetrápodos, la osificación procede en manera endocondral, siendo una excepción los anuros y los teleósteos los cuales presentan una importante reducción del cartílago relativo a la formación de los cuerpos (Goodrich, 1930). De los trabajos en que se ha abordado de alguna manera este aspecto, en algunos de ellos no se indica nada al respecto (Kemp \& Hoyt, 1969; Wiens, 1989; Maglia \& Púgener, 1998; Haas, 1999), mientras que en la mayoría se señala un mecanismo endocondral para la formación de los cuerpos (de Sá \& Trueb, 
1991; Trueb \& Hanken, 1992; Púgener \& Maglia, 1997; Wild, 1997, 1999; de Sá \& Hill,1998, Trueb et al., 2000; Perotti, 2001).

Duellman \& Trueb (1986), basados en Wake (1970), reseñan el tipo de formación de los cuerpos vertebrales en el contexto de una revisión de los posibles caracteres que comparten los tres ordenes de anfibios actuales. Allí se indica que cada orden posee un patrón bastante diferente entre si donde en Caudata el cuerpo vertebral osifica a partir de cartílago intervertebral hipertrofiado (al nivel del tubo pericordal que rodea la notocorda) y de cartílago formado dentro de la notocorda. Para Gymnophiona indican una osificación mayormente membranosa del cuerpo vertebral con una pequeña contribución de hueso formado a partir del cartílago intervertebral. En tanto para anuros indican una osificación membranosa de los cuerpos vertebrales.

Las observaciones que he realizado en las secuencias estudiadas para la presente tesis doctoral correspondientes a los géneros Batrachyla, Ceratophrys, Hylorina, más secuencias analizadas como material de comparación correspondientes a Hypsiboas pulchellus y Leptodactylus ocellatus, muestran en todos los casos un mecanismo de osificación alostósico para los cuerpos vertebrales (Figura 67). En consecuencia, basado en mis observaciones, en las observaciones de Goodrich (1930) y en la reseña dada por Duellman \& Trueb (1986) considero que los cuerpos vertebrales de los anuros, a diferencia de lo que ocurre en los restantes Lissamphibia, osifican íntegramente en manera alostósica.

Para establecer los posibles motivos por los que diversos autores (ej., de Sá \& Trueb, 1991; Trueb \& Hanken, 1992; Púgener \& Maglia, 1997; Wild, 1997; Perotti, 2001) han interpretado que los cuerpos vertebrales osifican en manera autostósica, he comparado una secuencia de desarrollo de Leptodactylus ocellatus con los datos presentados por uno de esos autores (Perotti, 2001) para Leptodactylus chaquensis. De la comparación se desprende que Perotti (2001) y probablemente los restantes autores, habrian interpretado que la base cartilaginosa de los arcos neurales es el precursor de los centros dorsolaterales a la notocorda. Esos centros se forman aplicados a la base de los arcos neurales y es factible cometer un error de interpretación en ese sentido. Por otro lado, los autores que han indicado osificación autostósica de los cuerpos vertebrales no han observado a los centros de osificación ventrolaterales a la notocorda. Estos centros no están próximos a ninguna estructura cartilaginosa que de lugar a confusiones respecto de la naturaleza alotósica de su osificación. 

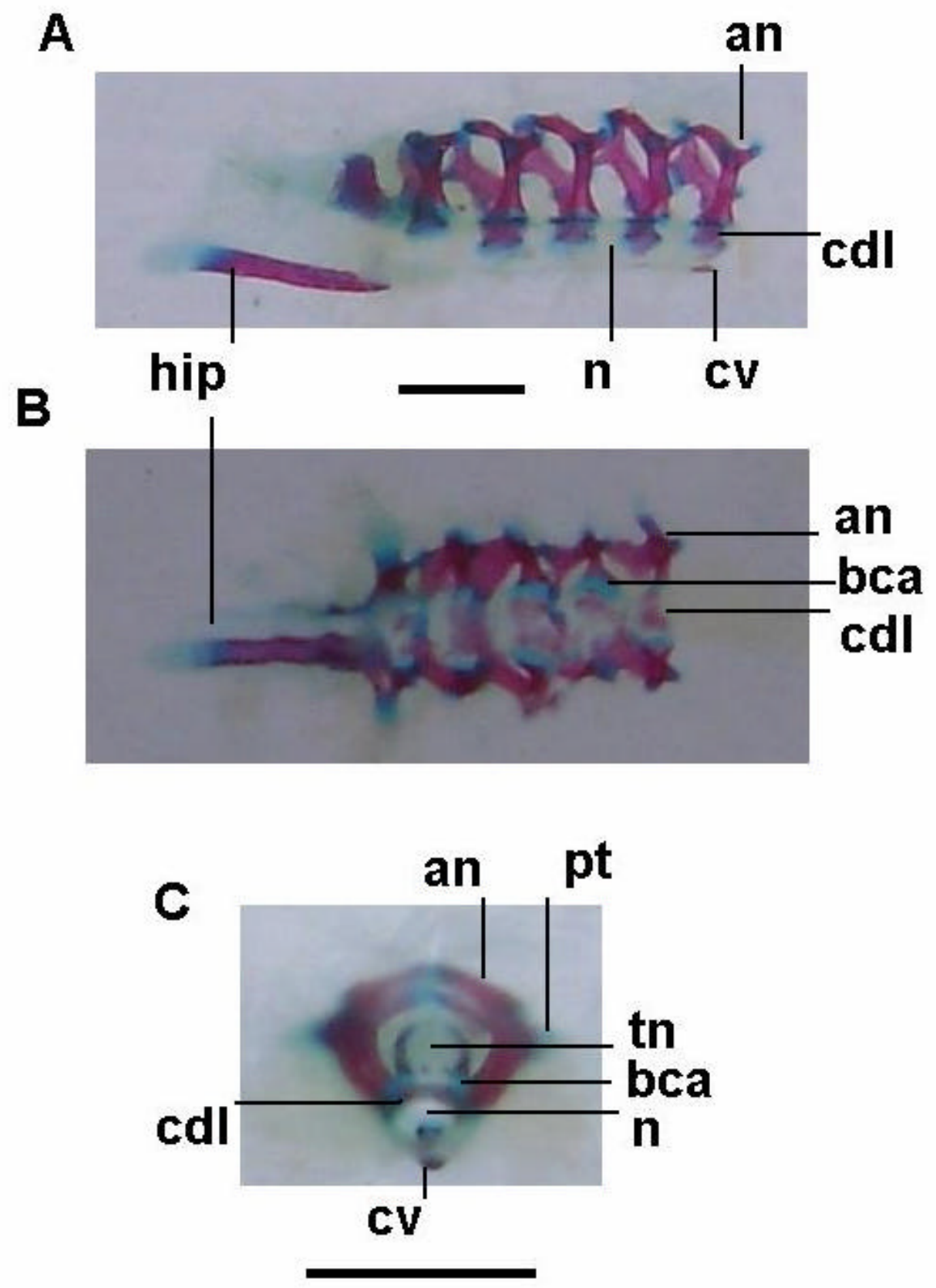

Figura 67. Vistas lateral (A, B) y frontal (C) del esqueleto axial postcráneano de una larva de Batrachyla taeniata al estadio 43 donde se observa la osificación de los distintos elementos. Escala $1 \mathrm{~mm}$. Referencias: an: arco neural; bca: base cartilaginosa del arco neural; cdl: centro de osificación de la vértebra de ubicación dorsolateral; cv: centro de osificación de la vértebra de ubicación ventral; hip: hipocordo; n: notocorda; pt: proceso transverso; tn: tubo neural. 
Otro de los puntos controversiales acerca del desarrollo de los cuerpos vertebrales es la cantidad de centros de osificación que componen cada cuerpo. Mookerjee (1936) distinguió dos categorías de desarrollo para la osificación de los cuerpos vertebrales: epicordal y peridordal. En la primera categoría, la osificación está restringida al área dorsal de la notocorda mientras que en la segunda, la osificación comienza en el área dorsal de la misma y rápidamente procede ventralmente hasta formar un anillo. Según Púgener et al. (2003) los géneros Ascaphus, Leptodactylus, Megophrys, Pyxicephalus, Rhinophrynusy Spea presentan, al igual que en Caudata, desarrollo pericordal. Del mismo modo indican que Alytes, Discoglossus, todos los pipidos, Hyla, Pelobates y Pelodytes presentan desarrollo epicordal. Independiente del mecani smo de formación de los cuerpos vertebrales (epicordal versus pericordal), los autores que han prestado atención a este tema, han descrito que cada cuerpo vertebral presenta origen a partir de dos centros de osificación dorsolaterales a la notocorda, ubicados en la base de los arcos neurales (Kempt \& Hoyt, 1969; Wiens, 1989; Wild, 1997, 1999; Perotti, 2001). Esto ha sido descrito para Ceratophrys cornuta, Chacophrys pietottii, Leptodactylus chaquensis, Rana pipiens y Spea bombifrons. La única excepción parecieran ser las observaciones de Banbury \& Maglia (2003) para Spea multiplicata, donde en el texto reportan la existencia de un par de centros laterales a la notocorda que primero crecen dorsalmente y luego ventralmente hasta rodearla por completo (pags. 11 y 12), mientras que en la figura $7 \mathrm{C}$ (pag., 11) ilustran claramente un par de centros de posición dorsolateral a la notocorda. La otra especie de Spea para la cual se ha descrito el desarrollo de los cuerpos vertebrales ( $S$. bombifrons, Wiens, 1989) presenta dos centros dorsolaterales. Este hecho sumado a la mencionada divergencia entre texto y figuras en el trabajo de Banbury \& Maglia (2006) conducen a considerar que $S$. multiplicata no se aparta de lo descrito para otros anuros. Haas (2003), describió que dos especies del género Litoria, así como también Leptopelis vermiculatus poseen un centro de osificación medioventral a la notocorda, accesorio a los dos centros dorsolaterales descritos para la mayoría de los anuros. El centro ventral descrito por Haas (2003), que no ha sido observado por los restantes autores, ha sido observado en las secuencias estudiadas para el presente trabajo de tesis (Figura 67). La única diferencia entre mis observaciones y las de Haas (2003) es la cantidad de centros ventrales. Yo he observado un par ventrolateral que rápidamente se fusiona entre si y es incorporado a los centros dorsolaterales que crecen ventralmente, mientras que Haas (2003) ha observado un único centro. Interpreto esas diferencias como debidas al momento de observación y no ha reales 
diferencias entre las especies. Entonces, generalizando, se puede asumir que los cuerpos vertebrales de los anuros se forman a partir de cuatro centros, un par ventrolateral y otro dorsolateral, donde en algunas especies el par ventrolateral parece no formarse como estructura independiente o bien ha pasado desapercibido para los diferentes autores (Perotti, 2001 no los describe para Leptodactylus chaquensis, mientras que he podido observarlos en secuencias de su especie hermana, $L$. ocellatus). Asumir el origen tetrápartito del cuerpo vertebral de los anuros es interesante para establecer comparaciones con los restantes Lissamphibia e incluso con los patrones observados para grupos de anfibios fósiles.

Según la reseña presentada en Duellman \& Trueb (1986), dos grandes tipos vertebrales se reconocen en los anfibios paleozoicos: el tipo "apsidospondilo" propio de los grupos de laberintodontes, y el tipo “lepospondilo" propio de los grupos de anfibios lepospondilos (ver Duellman \& Trueb, 1986 y Trueb \& Cloutier, 1991 para detalle de ambos grupos). Las vértebras del primer tipo poseen el cuerpo formado por dos grupos de osificación: el intercentro anteroventral (de origen par) y los pleurocentros posterodorsales a la notocorda. En tanto que las vértebras lepospondilas están compuestas por un cuerpo único, firmemente unido al arco neural y perforado centralmente para albergar a la notocorda persistente. A su vez, de acuerdo al predominio de un tipo de centro sobre el otro, reconocen al menos tres subtipos dentro de la vértebra apsidospondila: los tipos raquitomo (predomina el intercentro), embolomero (predomina el pleurocentro) y estereospondilo (solo intercentro).

El origen y la monofilia de Lissamphibia han sido y son aun profundamente estudiados desde diversas disciplinas (paleontología, genética, morfología de formas actuales) últimamente integradas en contextos filogenéticos. No obstante semejante esfuerzo de investigación no existe acuerdo absoluto acerca del tema. Hay autores que sostienen la monofilia de Lissamphibia a partir de un origen lepospondilo (Laurin \& Reisz, 1997; Laurin, 1998) y otros, la mayoría, sostienen la monofilia de los mismos a partir de un origen en los temnospondilos Dissorophoidea (Duellman \& Trueb, 1986; Trueb \& Cloutier, 1991). Y finalmente están los autores que aun sostienen que los Lissamphibia no son monofiléticos (Carroll et al., 1999), una idea común a los primeros investigadores en el tema pero que empezó a ser dejada de lado a partir de los 60' del pasado siglo (ver Szarski, 1962 y Parsons \& Williams, 1963). Desde el punto de vista de la paleontología, no existe registro de fósiles que vincule a los lepospondilos (no pasan del pérmico) y los primeros fósiles asimilables a Lissamphibia (Jurasico medio e 
inferior). Del mismo modo, los primeros fósiles de cada uno de los grupos de Lissamphibia indican que los planes estructurales de cada uno de estos grupos se habría establecido tempranamente y no muestran patrones morfológicos que los vinculen (Zardoya \& Meyer, 2001). En lo que hace a la estructura vertebral, los Lissamphibia comparten con los lepospondilos el hecho de tener una unión firme entre arco neural y cuerpo vertebral, mientras que solo en Caudata y Gymnophiona se observa, al igual que en lepospondilos, notocorda persistente en algún grado (Duellman \& Trueb, 1986).

Existe evidencia fósil de larvas de temnospondilos Dissorophoidea y de diferentes grupos de lepospondilos donde se aprecian ciertos rasgos del desarrollo axial postcraneano, entre ellos los centros de osificación que componen el cuerpo vertebral (Milner, 1988; Carroll et al., 1999). Los lepospondilos al igual que los Caudata y Gymnophiona no presentan varios centros de osificación para cada cuerpo vertebral, a diferencia de lo que sucede en los anuros y los temnospondilos (Carroll et al., 1999). Esto fue usado por Carroll et al. (1999) para argumentar por su idea de un origen no monofilético de los Lissamphibia. No obstante esa posibilidad, existe una abrumadora cantidad de caracteres morfológicos y moleculares que sostienen la monofilia de Lissamphibia y la relación mayor entre Caudata y Anura respecto de los Gymnophiona (Trueb \& Cloutier, 1991; Frost et al., 2006; Zardoya \& Meyer, 2001; Haas, 2003). Lo más parsimonioso con esa cantidad de evidencia sería pensar que los anuros retienen el patrón de desarrollo de los Temnospondyli (aunque el producto final no sea una vértebra aspidospondila), mientas que en los restantes Lissamphibia y también en los Lepospondyli existiría una suerte de desarrollo abreviado.

Finalmente, el último aspecto del desarrollo postcraneano de anuros que resulta interesante para discutir es el desarrollo larvario del urostilo, en particular en referencia a la naturaleza del hipocordo. El urostilo es un rasgo único de los anuros, salvo formas básales como Triadobatrachus (Estes \& Reig, 1973). Al revisar la bibliografía existente, cuya mayoría fue mencionada al comenzar la presente sección de la discusión, se extrae la conclusión que en el desarrollo del urostilo interviene una estructura medial impar y subcordal, el hipocordo y una serie variable $(2-4)$ de arcos neurales postsacros reducidos (Rockova \& Rocek, 2006). Para todos los casos descritos se reporto que el hipocordo osifica autostósicamente (Rockova \& Rocek, 2006, y bibliografía citada al inicio de esta sección de la discusión), a excepción de Spea multiplicata para la cual Banbury \& Maglia (2006) describieron que osifica alostósicamente. La principal cuestión por resolver acerca del urostilo es resolver si el 
hipocor do es una neoformación o una estructura modificada a partir de otra preexistente. De derivar de estructuras preexistentes, las homologías para el hipocordo deben buscarse en estructuras subcordales, como pueden ser las porciones ventrales a la notocorda de los cuerpos vertebrales, o bien los arcos hemales. De hecho, Mookerjee (1936) y Mookerjee \& Das (1939) han sugerido que el hipocordo representa la fusión de una serie de arcos hemales postsacros para la cual se habrían perdido indicios de su segmentación. Para ello, los anuros deberían retener la capacidad de formar arcos hemales, dado que ellos se han perdido en los ancestros del grupo (ver Estes \& Reig, 1973), a diferencia de lo que ocurre en Caudata que los retienen a nivel caudal (Duellman \& Trueb, 1986). Normalmente, los arcos hemales encierran a la aorta dorsal independientemente de si forman o no una espina hemal (Goodrich, 1930, Duellman \& Trueb, 1986). En el caso del hipocordo, la aorta dorsal corre ventral a éste (obs. pers.), lo cual es un argume nto contrario a la interpretación del hipocordo como arcos hemales fusionados.

La restante estructura susceptible por su posición subcordal de ser homologada con el hipocordo es la región ventral de los cuerpos vertebrales. De hecho, Eaton (1959) ha sugerido la homologación del hipocordo con cuerpos vertebrales de vértebras postsacras. Como ya quedo establecido en la presente discusión, los cuerpos vertebrales de los anuros osifican en manera alostósica, y el hipocordo es autostósico, con lo cual no serían estrictamente lo mismo y en tanto no homologables con este criterio (Figura 67). Finalmente de las dos hipótesis de homología desarrolladas, la más plausible parece ser la segunda (cuerpos postsacros fusionados) dado que la osificación autostósica u alostósica de un elemento esta siendo últimamente dejada de lado en términos de establecer homologías (Kardong, 1998). De esa manera parece más probable que el hipocordo osifique autostósicamente a que la aorta dorsal se ubique ventral al arco hipocordo (en caso que este sea los arcos hemales fusionados). Futuros estudios empleando métodos modernos para el estudio del desarrollo (marcado de células, genética del desarrollo) deberían poder establecer si alguna de ambas hipótesis es correcta.

\section{IV.5. Musculatura axial postcraneana.}

En general, el patrón de músculos axiales es bastante constante entre los diferentes grupos de anuros (Duellman \& Trueb, 1986) y además, no conozco bibliografía que describa su desarrollo en las larvas con lo cual existen pocos aspectos para discutir en esta sección. Lo único que se discutirá es la presencia de m. 
transversoesophagicus. Al realizar las disecciones observe un músculo de aspecto ligeramente triangular que se ubica entre el proceso transverso III y la pared del esófago (Figura 68). Al principio pensé que se trataba de un nuevo elemento muscular propio de las especies de Batrachyla, pero al realizar las observaciones en los grupos externos empleados para el análisis, todos ellos lo presentaban. También lo presentaron los adultos de otras especies donde intente verificar su presencia (Leptodactylus ocellatus). Luego realicé una búsqueda bibliográfica a fin de verificar si realmente se trataba de un nuevo elemento muscular o si ya existía algo descrito al respecto para algún grupo de anuros. Dunlap (1960) describe un músculo similar pero evidentemente distinto, el m. pulmonum proprius para Pipa spp., el cual inserta en el fémur y se origina en el tejido conectivo dorsal al pulmón. Keith (1905) había descrito un "amphibian diaphragm" de características similares al músculo observado en las especies aquí estudiadas. La única diferencia es que el músculo en Xenopuscorre desde el vértice anterior del ileon hasta el esófago. Posteriormente a Keith (1905), Snapper et al. (1974) establecieron que el "amphibian diaphragm" era un músculo que intervenía en el mecanismo de ventilación pulmonar. Finalmente en un trabajo reciente, (Pickering et al., 2004) establecieron que la función respiratoria de este músculo es mínima, y que en realidad se trata de un músculo que tiene un rol gastrointestinal. También sugieren que el diafragma de Xenopus laevis sería homologo a la porción crural del diafragma mamaliano, que según De Troyer et al. (1981) tiene dos porciones de origen filogenético independiente, la costal y la crural, está última que actúa como un esfínter esofágico. Pickering et al. (2004) discuten además que dos posibles últimos roles de esté músculo serían: 1) actuar como un esfínter en el esófago y prevenir los riesgos que la aerofagia causaría sobre la flotabilidad, y 2) actuar en el reposicionamiento del estomago luego de la eversión del mismo (está última fue descrita por Naitoh et al., 1991 para Xenopus). Posiblemente ambas hipótesis sean ciertas, pero el hecho que exista este músculo en formas no acuáticas (ej., Eupsophus, Pleurodema, etc) restringe la hipótesis de flotabilidad solo para el caso de Xenopus. Por último, más allá de la función de este músculo, me parece importante remarcar que probablemente su presencia sea generalizada en el orden y que atendiendo a la falta de certeza acerca de su homología con el diafragma de mamíferos y con el "amphibian diaphragm" de Xenopus (el cual se origina en el extremo anterior del ileon) creo que corresponde darle un nuevo nombre ( $\mathrm{m}$. transversoesophagicus) sobre la base de su origen y su inserción. 
A
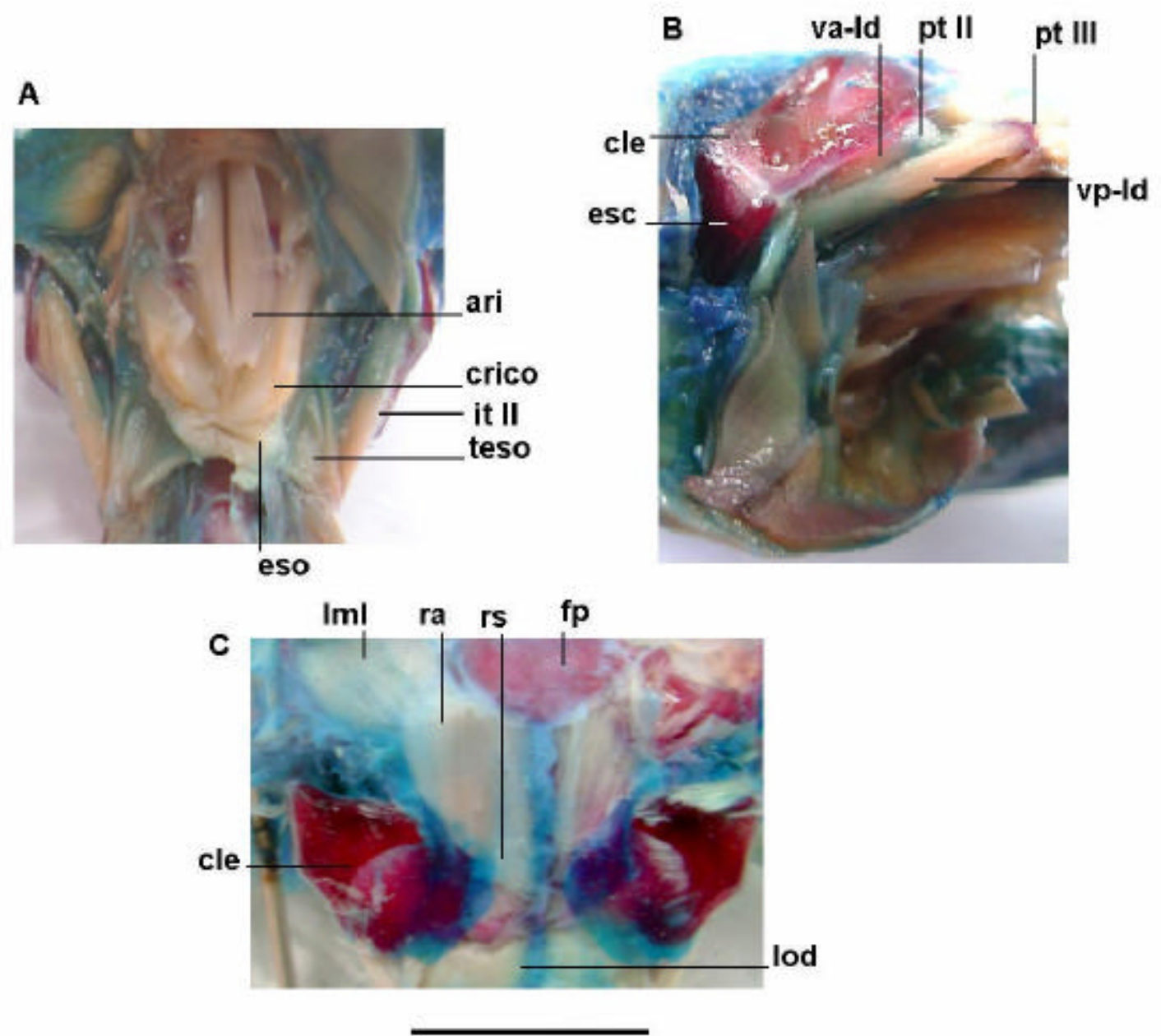

Figura 68. Vistas posteroventral (A), posterolateral (B) y dorsal (C) a nivel pectoral de una hembra adulta de Hylorina sylvatica. Escala $1 \mathrm{~cm}$. Referencias: ari: cartílago aritenoides; cle: cleitro; crico: cartílago cricoides; esc : escápula; eso: esófago; fp: frontoparietal; it Il: m. intertransversarius II; lod: m. longissimus dorsi; ImI: m. levator mandibulae longus; pt II: proceso transverso II; pt III: proceso transverso III; ra: m. rhomboideus anterior; rs: $\mathrm{m}$. rhomboideus superior; teso: $\mathrm{m}$. transversoesophagicus; va-dd: vientre anterior del m. latissimus dorsi ; vp-Id: vientre posterior del m. latissimus dorsi. 


\section{IV.6. Esqueleto y musculatura apendicular anterior.}

Existe una importante cantidad de bibliografía referida al desarrollo (Fabrezi, 1992; Fabrezi \& Alberch, 1996; Fabrezi, 2001; Fabrezi \& Barg, 2001) y la estructura adulta del esqueleto apendicular anterior (Trueb, 1973; Fabrezi, 1992, 1996; Fabrezi \& Alberch, 1996; Fabrezi, 2001; Kaplan, 2003), mientras que para los músculos asociados al miembro anterior se conocen muy bien las características adultas de los mismos para diversos grupos (Manzano \& Lavilla, 1995; Burton, 1996; Manzano, 1996, 1997; Burton, 1998).

Como resultado del análisis miológico realizado he encontrado que el patrón observado en las especies analizadas es mayormente consistente con el conocimiento publicado para el tema. Burton (1998) describió la musculatura de la mano de diversas especies, entre ellas muchas de las analizadas para esta tesis (Atelognathus patagonicus, Batrachyla taeniata, Ceratophrys ornata, Chacophrys pierottii e Hylorina sylvatica) o bien especies de géneros aquí estudiados (Alsodes, Eupsophus, Pleurodema) y describe ciertos estados de caracter que no he podido verificar en mi material. Entonces, Burton (1998) describe para Hylorina sylvatica la presencia de un tendón entre la aponeurosis palmaris y el epimísio del m. flexor indicis superficialis proprius. Ese tendón no fue observado en el material de Hylorina aquí estudiado. Burton (1998) resalta a su vez la naturaleza escandente del hábito locomotor de Hylorina, e indica que ese tendón es el único rasgo diferencial respecto de géneros como Alsodes, Batrachyla, y Eupsophus. Tampoco observe como indica Burton (1998) diferencias en 1) el desarrollo del $\mathrm{m}$. caput profundum para los géneros Ceratophrys y Eupsophus, 2) la composición del m. lumbricalis brevis digiti III para Ceratophrys, 3) el origen de los mm. flexores teretes para Eupsophus, 4) la naturaleza del m. lumbricalis longus digiti IV para los géneros Atelognathus, Ceratophrys y Pleurodema, 5) el grado de desarrollo del m. lumbricalis brevis digiti IV para los géneros Atelognathus y Ceratophrys, 6) la variación intraespecifíca de los mm. interphalangeales, 7) el origen del m. lumbricalis longus digiti $\mathrm{V}$ para los géneros Atelognathus y Ceratophrys, 8) el grado de desarrollo de los mm. transversi metacarporuml y II de Eupsophus, 9) el grado de desarrollo de los mm. transversus metacarpi III de Alsodes y Eupsophus, 10) la cantidad y tipo de inserciones del $\mathrm{m}$. digitorum communis longus para Ceratophrys ornata y Chacophrys, 11) el origen del m. abductor indicis longus para Alsodes, Batrachyla taeniata, Ceratophrys ornata e Hylorina, 12) el origen del m. extensor indicis brevis superficialis de Batrachyla, Eupsophus e Hylorina, 13) el origen de los $\mathrm{mm}$. extensor brevis medius II y e. b. profundi digiti III para Ceratophrys, y 14) el origen 
del m. extensor brevis superficialis digiti IV de Pleurodema. La mayoría de las diferencias citadas corresponden a especies estudiadas por Burton (1998) que no corresponden a las estudiadas por mi para los mismos géneros y probablemente se trate de diferencias interespecíficas. Respecto de las restantes divergencias entre ambos trabajos, algunas pueden deberse al desarrollo de los ejemplares (ej., los Chacophrys estudiados por Burton, 1998 eran juveniles).

En el contexto del conocimiento que se tiene de la musculatura pectoral de los anuros he hallado un músculo, que previamente no se había descrito para el orden. Este músculo se observó en todas las especies estudiadas y por su posición lo he asimilado al grupo de los $\mathrm{mm}$. rhomboideus. A este nuevo elemento lo he denominado m. rhomboideus superior y corre entre el margen dorsal de la supraescápula y una fascia del m. longissimus dorsi, en parte enmascarado por las fibras más dorsales del m. dorsalis scapulae (Figura 68). La presencia de elementos musculares no conocidos es un fenómeno que ha ocurrido escasas veces en el estudio de los anuros. Los mm. epicoracoideus, iliacus accesorius ventralisy femoralis, por ejemplo, se han descrito solo para Phyllomedusa hypocondrialis (Manzano \& Lavilla, 1994; Manzano, 1997) y a pesar de existir una importante literatura respecto de la musculatura de las regiones donde se encuentran esos elementos (ver reseña en Duellman \& Trueb, 1986), nunca se habían reportado. El caso del $\mathrm{m}$. rhomboideus superior es diferente al de los tres músculos mencionados porque no es propio de una sola especie ni de un género, sino que parece tener una distribución amplía en el orden ya que lo he observado en los géneros Alsodes, Atelognathus, Batrachyla, Ceratophrys, Chacophrys, Eupsophus, Hylorina, Leptodactylusy Pleurodema. La razón por la cual nunca fue observado es que puede haber sido confundido con las fibras más dorsales del m. dorsalis scapulae, que suelen enmascararlo.

Respecto del m. latissimus dorsi, no he encontrado en la literatura menciones acerca de su vientre anterior (Duellman \& Trueb, 1986; Manzano, 1997), el cual inserta en el proceso transverso II (Figura 68). Normalmente, en los trabajos específicos del tema se describe al $\mathrm{m}$. latissimus dorsi como compuesto por un solo vientre, el que aquí se denomina posterior y que presenta inserción en el proceso transverso III, o en una facia relacionada al $\mathrm{m}$. latissimus dorsi. Entonces, si bien el vientre anterior nunca se había descrito yo lo he observado en todas las especies analizadas para esta tesis.

Respecto del desarrollo del autopodio anterior, existen una serie de trabajos donde se estudia este aspecto (Fabrezi, 1992, Fabrezi \& Alberch, 1996; Fabrezi, 2001; Fabrezi \& Barg, 2001). Fabrezi (1992) sumarió la morfología carpiana de los anuros 
adultos de diferentes grupos en 12 morfologías posibles, y resaltó que una misma morfología adulta puede obtenerse mediante diferentes patrones de desarrollo. La morfología carpiana observada en los adultos de las especies de Batrachyla, así como en los de los grupos externos analizados corresponde al tipo C. La secuencia del desarrollo exacta de los carpianos de Batrachyla no pudo ser reconstruida dado que en el primer estadio observado ya se hallaban todos los elementos presentes. En cambio, sí pudo establecerse la presencia de los elementos radial' y ulnar' (intermedio) en la composición del radial y el ulnar del adulto. Del mismo modo pudo observarse la presencia de dos elementos cartilaginosos en la formación del elemento Y. Respecto de la homología de radial' y de los esbozos componentes del elemento Y, Fabrezi \& Alberch (1996) concluyeron que no es posible homologarlos con elementos carpianos de otros tetrápodos. Con la evidencia presentada en esta tesis doctoral no es posible proponer homologías para estos elementos, pero sin duda sería muy interesante establecer si tienen correlato en otros tetrápodos o si son elementos propios de los anuros.

Fabrezi (1996) estudió el desarrollo y la estructura adulta de las falanges terminales de una amplía muestra de anuros y concluyo que el caracter forma de la falange terminal es homoplásico y que no es útil para emplear en la reconstrucción filogenética de categorías superiores. De hecho, el caracter forma de la falange terminal ha sido empleado en la reconstrucción filogenética en esta tesis doctoral, aunque al mapear lo en diversas filogenias existentes es evidente su homoplásia para categorías superiores. Fabrezi (1993) observó que en la secuencia de Scinax fuscovaria, la reducción de los procesos laterales da lugar a la presencia de una escotadura distal y generalizó que la presencia de escotadura es producto de la reducción de los procesos laterales y no a su incipiente diferenciación. Mis observaciones sobre el desarrollo de Batrachyla e Hylorina muestran que los procesos laterales no se reducen durante el desarrollo y sin embargo conservan la escotadura distal, con lo cual, al menos para esos géneros no se cumple lo descrito para Scinax fuscovaria.

\section{IV.7. Esqueleto y musculatura apendicular posterior.}

Existe una importante cantidad de bibliografía referida al desarrollo (Fabrezi, 1993; Fabrezi, 2001) y la estructura adulta del esqueleto apendicular anterior (Trueb, 1973; Fabrezi, 1993, 1996; Fabrezi, 2001), mientras que para los músculos asociados al miembro anterior se conocen muy bien las características adultas de los mismos 
para diversos grupos (Dunlap, 1960; Limeses, 1963, 1964; Manzano \& Lavilla, 1995; Manzano, 1996; Burton, 2004). No se hallaron peculiaridades miológicas, respecto de la información existente para el orden. Los aspectos miológicos que fueron empleados en el análisis filogenético serán discutidos convenientemente en la correspondiente sección.

Respecto del desarrollo del autopodio posterior, en este caso no se evidencia tanta variación como en el caso del autopodio anterior. Aquí el elemento Y se forma a partir de un único esbozo y no existen elementos accesorios al tibial y el fibular equivalentes al radial' y ulnar'. Estas características del desarrollo de los tarsianos más las del patrón de diferenciación de los dígitos aquí observado son, en líneas generales, congruentes con el patrón descrito por Fabrezi (1993) para diversos neobatracios, fundamentalmente hylidos y leptodactylidos.

\section{IV.8. Relaciones Filogenéticas.}

Las relaciones interespecíficas de Batrachyla fueron reconstruidas por tres autores (Brieva Vasquez, 1988); Basso, 1994 y Vallejos Vallejos, 1994) empleando diferentes metodologías, diferentes grupos externos y en la mayoría de los casos caracteres diferentes. En ninguno de los tres trabajos, debido a que varias de las especies aun no habian sido descritas, se empleó a todas las especies del género. Del mismo modo, tampoco se emplearón en un mismo análisis caracteres larvarios y adultos. No obstante ello, las relaciones propuestas por esos autores son mayormente coincidentes entre si, no habiendo acuerdo en relación a cuales son las sinapomorfias que sostienen al género. Esto último es entendible si se comprende a las sinapomorfias como a un concepto dinámico que depende de los taxa y los caracteres empleados en los análisis. Los trabajos de Brieva Vasquez (1988) y Vallejos Vallejos (1994) recuperan un clado monofilético donde Batrachyla antartandicay B. leptopus son especies relacionadas entre si, quedando $B$. taeniata por fuera de ellas. En tanto Basso (1994), que empleó también a B. fitzroya, recupera a Batrachyla como monofilético, y dentro del clado hay un subclado formado por $B$. leptopus, $B$.antartandica y $B$. fitzroya (estas últimas más relacionadas entre si), quedando por fuera de ellas $B$. taeniata. Mis resultados coinciden en la existencia de dos clados dentro de Batrachyla, uno compuesto por Batrachyla taeniata, B. nibaldoi (clado taeniata) y el otro formado por B.antartandica, B. fitzroya y B. leptopus (clado leptopus). La mayor diferencia con las filogenias mencionadas es que en el presente análisis, Hylorina sylvatica queda anidada en el clado taeniata como hermana de 
Batrachyla taeniata y B. nibaldoi, haciendo a Batrachyla parafiletico respecto de Hylorina.

Lynch (1971), sobre la base de sus observaciones fundamentalmente osteológicas, postuló que los géneros más relacionados a Batrachyla eran Eusophus (incluía las especies de Alsodes en aquel entonces), Hylorina y Thoropa (tribu Alsodini de Lynch, 1971). En un trabajo casi inmediato y sin variar demasiado los caracteres, Lynch (1973) rompió en dos a la tribu Alsodini, quedando los Alsodini (Eupsophus incluyendo Alsodes e Hylorina) y Batrachylini (Batrachyla y Thoropa). Luego, Heyer (1975) separa Thoropa de su posición cercana a Batrachyla. Finalmente Lynch (1978) continúa con siderando a Thoropa como el género más próximo a Batrachyla. Las filogenias publicadas que analizan ambos géneros indican en todos los casos falta de relación entre ellos (Frost et al., 2006; Grant et al., 2006; Basso et al., en revisión). Por tal razón no he incluido a Thoropa en el análisis y la relación con Batrachyla no fue puesta a prueba aquí. Respecto de los restantes grupos externos algunos ya fueron sugeridos por Lynch (1971) y revalidados por muchos de los autores posteriores (Basso, 1991, 1994) (Alsodes, Eupsophus, Hylorina), mientras que otros (Atelognathus, Ceratophrys y Chacophrys) se escogieron a partir de los trabajos de Faivovich et al. (2005), Frost et al (2006), Grant et al. (2006) y Basso et al. (en revisión).

Algunas de esas filogénias, sobre datos fundamentalmente osteológicos, ubican a Hylorina en un mismo rango que Eupsophus como géneros hermanos de Batrachyla (Basso, 1994). En tanto, otras filogenias realizadas sobre datos moleculares ubican Atelognathus como hermano de Batrachyla, sin considerar a Hylorina en el análisis (Faivovich et al., 2005).

Finalmente, otras filogenias, fundamentalmente moleculares, pero con algunos datos morfológicos de Haas (2003) ubican a Atelognathus hermano de Batrachyla, mientras que Hylorina se ubica en otro clado bastante alejado (Frost et al., 2006; Grant et al., 2006). Los autores de estos últimos dos trabajos proponen que Batrachyla y Atelognathus forman la familia Ceratophryidae (junto con Ceratophrys, Chacophrys y Lepidobatrachus), mientras que Hylorina queda en otro clado denominado Cyclorhampidae. En este contexto resultan sorprendentes mis resultados respecto de la inclusión de Hylorina en la composición de Batrachyla. Sin embargo, en la filogenia molecular de Basso et al (en revisión), Hylorina cae dentro de Batrachyla, aunque los autores no formalizan esa topología proponiendo un cambio taxonómico al respecto. 
Frost et al. (2006) proponen como posibles sinapomorfias de los Ceratophryidae a: 1) mm. levatorae arcuum branchialium I y II angostos y separados por un amplío espacio, 2) ausencia de m. diaphragmatopraecordialis, 3) ausencia de m. suspensoriohyoideus, 4) la rama mandibular del nervio trigémino atraviesa a los $\mathrm{mm}$. levatorae mandibulae externus, 5) espículas reducidas o ausentes, 6) proyección anterior del proceso muscular ausente, 7 ) techo de la bóveda craneana casi completamente condrificado, 8) ausencia de trampas de alimento branquiales (del ingles branchial food traps). De esa lista, no he observado a ninguna en los géneros Atelognathus y Batrachyla, que según Frost et al. (2006) y Grant et al. (2006) integran Ceratophryidae. A su vez dentro de Ceratophryidae, Frost et al. (2006) ubican a dos subfamilias, una de ellas Ceratophryininae donde ubican a los clásicos géneros de escuerzos más Atelognathus y Batrachyla. Según esos autores la única sinapomorfia morfológica para ese clado es la presencia de una hilera de papilas marginales completa, incluso al nivel del claro rostral. Ese rasgo tampoco se cumple en Atelognathus y Batrachyla.

Por otro lado Frost et al. (2006) proponen como sinapomorfia de Cyclorhampidae (donde ubican a Hylorina, Alsodes y Eupsophusentre otros) la inserción del m. subarcualis obliquus II-IV en el ceratobranquial I. Ese estado está presente en Hylorina pero no en Alsodes y Eupsophus (Vera Candioti, 2005). Curiosamente, una de las sinapomorfias que sostienen Hylorina y Batrachyla en el análisis que he realizado es la inserción en el ceratobranquial I del m. subarcualis rectus II-IV.

Los resultados del análisis filogenéfico de la presente tesis no sirven para discutir las diferentes taxonomías que surgen de los cladogramas de Frost et al. (2006) y Grant et al. (2006) por un lado y de Basso et al. (en revisión) por el otro. Sin embargo es interesante la congruencia entre los cladogramas de Basso et al. (en revisión) y el mío respecto de la relación de Hylorina y Batrachyla. Un próximo análisis de evidencia total empleando los caracteres de ambos cladogramas, más una serie de caracteres de biología reproductiva que sería interesante verificar, podrían terminar de afirmar esa relación. Hasta tanto se realicen esos trabajos, la evidencia lleva a considerar a Hylorina sylvatica como a una especie de Batrachyla (Batrachyla sylvatica). 


\section{CONCLUSIONES.}

Las observaciones realizadas en la presente tesis, y la comparación de las mismas con la información publicada sobre los diversos temas tratados han permitido el tratamiento en la discusión de diferentes temas entre los que se destacan:

Proceso pseudopterigoideo. Se propone unafunción para este proceso en las larvas que lo tienen fusionado a la base del cráneo (Limnomedusa, Alsodes, algunos Telmatobius). En estas larvas recibe la inserción del ligamento inferior del techo dando lugar a una mayor estabilidad del proceso muscular como sitio de inserción para el m. orbitohyoideus y como área de articulación para el ceratohial.

Desarrollo larval del aparato hiobranquial y la homología de sus partes con el cuerpo hioideo del adulto. Se confirman las observaciones realizadas en trabajos previos (Alcalde, 2005) sobre la homología de las partes del aparato hiobranquial y del cuerpo hioideo. La única estructura adulta que no tiene correlato en la larva es el proceso anterolateral.

\section{Homología de los centros de osificación de los huesos que tienen origen}

complejo. Varios huesos del cráneo de anuros presentan origen a partir de más de un centro de osificación. Aquí se trataron solo los casos del escamoso, pterigoides y exoccipital. Para el caso del escamoso se proponen las siguientes hipótesis de homología: 1) el centro de la rama ventral es homólogo al escamoso de los restantes tetrápodos, 2) el centro de la rama anterior es homólogo al postorbital de los restantes tetrápodos, y 3) el centro de la rama ótica podría corresponder tanto al supratemporal como al tabular, aunque con mayor probabilidad sea homólogo a este último.

Para el caso del pterigoides se propone como hipótesis de homología que. 1) el centro de la rama zigomática corresponde al ectopterigoides de los restantes tetrápodos, y 2) de los restantes centros del pterigoides (ramas ótica y anterior) al menos uno de ellos corresponde al endopterigoides de los restantes tetrápodos.

Para el caso del centro accesorio del exoccipital, por su ubicación en la pared posterior de la cápsula ótica propongo como hipótesis de homología que corresponde al opistótico de los restantes tetrápodos.

M. rectus cervicis. Se discute la homología de este músculo con el $\mathrm{m}$. rectus abdominis sostenida por diversos autores (ej., Perotti \& Manzano, 1999). En la 
presente tesis sobre la base de la inervación y las relaciones topográficas de ambos durante el desarrollo se discute ese aspecto y se reconoce lo siguiente: 1) no puede descartarse ni afirmarse concluyentemente la homología entre ambos, y 2) el m. rectus cervicis de la larva es homológo al m. sternohyoideus del adulto.

Osificación de los cuerpos vertebrales. Se discute la evidencia existente sobre el mecanismo de osificación (alostósico versus autotósico) y la cantidad de centros de osificación que intervienen en la formación del cuerpo vertebral de los anuros. Sobre esa información más las observaciones aquí realizadas se concluye que: el cuerpo vertebral de los anuros osifica de manera alostósica a partir de un par de centros ventrolaterales a la not ocorda que rápidamente se fusiona entre si y es incorporado a los centros dorsolaterales que crecen ventralmente.

Homologías del hipocordo. Se discute si el hipocordo es una neoformación o es una estructura modificada de otras persistentes. De derivar de estructuras preexistentes, se ha propuesto que las homologías para el hipocordo deben buscarse en estructuras subcordales, como pueden ser las porciones ventrales a la notocorda de los cuerpos vertebrales (Eaton, 1959), o bien los arcos hemales (Mookerjee, 1936). A partir de la discusión de la evidencia de cada caso y la contrastación con mis observaciones, concluyo que la hipótesis más plausible parece ser la segunda (cuerpos postsacros fusionados).

M. transversoesophagicus. Se describe un músculo que está presente en todas las especies analizadas y que posiblemente sea homólogo al "amphibian diaphragm" de Xenopus (Keith, 1905), pero que no había sido descrito para otros anuros.

M. rhomboideus superior. Se describe un músculo que fue observado en todas las especies analizadas y que sin embargo no se había descrito previamente para el orden. A este nuevo elemento lo he denominado m. rhomboideus superior y corre entre el margen dorsal de la supraescápula y una fascia del $\mathrm{m}$. longissimus dorsi, en parte enma scarado por las fibras más dorsales del m. dorsalis scapulae.

Vientre anterior del $\mathbf{m}$. latissimus dorsi. Se describe, para todas las especies aquí analizadas, la presencia de un vientre anterior para el $\mathrm{m}$. latissimus dorsi. Este vientre se diferencia del vientre posterior por su inserción en el proceso transverso II. 
Ubicación familiar de Batrachyla. El presente análisis no fue diseñado para análizar las relaciones intrafamiliares y establecer recortes taxonómicos a ese nivel. Sin embargo, respecto de las propuestas taxonómicas dadas por Frost et al. (2006), Grant et al. (2006) y Basso et al. (en revisión), la topología obtenida aquí es más congruente con la propuesta por Basso et al. (en revisión). La mayor congruencia es justamente al nivel del grupo de estudio, donde en ambos casos Hylorina cae anidada en Batrachyla.

La monofilia de Batrachyla. Batrachyla es monofiletico e incluye a Hylorina en su composición. Se reconocen dos clados dentro del género: el clado taeniata (Hylorina, B. nibaldoi y B. taeniata) y el clado leptopus (B. antartandica, B. fitzroya y B. leptopus). Dentro del clado leptopus, $B$. fitzroya y $B$. leptopusforman un subclado. Dentro del clado taeniata, B. taeniata y B. nibaldoi forman un subclado. Por lo expuesto, debe considerarse a Hylorina sylvatica como a una especie más del género Batrachyla, cuyo nombre sería $B$. sylvatica. 


\section{LITERATURA CITADA}

ALBERCH, P. 1980. Ontogenesis and morphological diversification. American Zoologist 20: 653-667.

ALCALDE, L. 2002. ¿Cuáles son los estadios tipicamente larvales en anuros? XVI Reunión de Comunicaciones Herpetológicas de la Sociedad Herpetológica Argentina, La Plata, 17-19/11/2002.

ALCALDE, L. 2005a. Desarrollo del hioides y los cartílagos nasales en dos especies de anuros neotropicales. Ciencias Morfológicas 7 (1): 7-15.

ALCALDE, L. 2005b. Descripción de la musculatura craneana en larvas de anuros de las familias Hylidae y Leptodactylidae. Revista del Museo de La Plata, zoología (168): 1-12.

ALCALDE, L. \& BARG, M. 2006. Chondrocranium and cranial muscle morphology in Lysapsus and Pseudis tadpoles (Anura: Hylidae: Hylinae). Acta Zoologica (Stockholm) 87: 91-100.

ALCALDE, L. \& BLOTTO, B. 2006. Chondrocranium, cranial muscles and buccopharyngeal morphology on tadpoles of the controversial leptodactylid frog Limnomedusa macroglossa (Anura: Leptodactylidae). Amphibia Reptilia 27: 241-253.

ALTIG, R. \& R. W. Mc DIARMID. 1999. Body Plan. Development and Morphology, pp. 24-51. En: Tadpoles, The Biology of Anuran Larvae. Edited by R. W. Mc Diarmid \& R. Altig, The University of Chicago Press, Chicago London.

ANDERSEN, M. 1978. The comparative miology and osteology of the carpus and tarsus of selected anurans. PhD dissertation-University of Kansas.

BANBURY, B. \& A. M. MAGLIA. 2006. Skeletal development of the Mexican Spadefoot Toad Spea multiplicata (Anura: Pelobatidae). Journal of Morphology 267 (7): 803-821.

BARRIO, A. 1967a. Batrachyla antartandica n. sp. (Anura, Leptodactylidae), descripción y estudio comparativo con la especie genotípica, B. leptopus Bell. Physis XXVII (74): 101-109.

BARRIO, A. 1967b. Observaciones etoecologicas sobre Hylorina sylvatica Bell (Anura, Leptodactylidae). Physis XXVII (74): 153-157.

BARRIO, A. \& P. RINALDI DE CHIERI. 1970. Relaciones cariosistemáticas de los Ceratophryidae de la Argentina (Amphibia, Anura). Physis XXX (80): 321-329. 
BARRIO, A. \& P. RINALDI DE CHIERI. 1971. Contribución al esclarecimiento de la posición taxofilética de algunos batracios patagónicos de la familia Leptodactylidae mediante el análisis cariotípico. Physis XXX (81): 673-685.

BASSO, N. G. 1991. Proposal of a new classification of Telmatobiinae. Abs. Joint Ann. Meting. SSAR and_Herpetol. League (Pensilvania, USA): 42.

BASSO, N. G. 1994. Una nueva especie de Batrachyla (Anura: Leptodactylidae: Telmatobiinae). Relaciones filogenéticas interespecificas. Cuadernos de Herpetología 8: 51-56.

BASSO, N. G. \& D. C. CANNATELLA. 2001. The phylogeny of leptodactylid frogs based on 12S and 16S mtDNA. Joint Annual Meetings, Herpetologists's League and The Society for the Study of Amphibians and Reptiles, Indianapolis, 2001: 46.

BASSO, N. G., D. M. HILLIS \& D. C. CANNATELLA. Phylogeny of the frog family "Leptodactylidae" based on 12s and 16s mtDNA (Anura: Neobatrachia). Molecular Phylogenetics and Evolution (en revisión).

BLANCO, M. J. \& B. SANCHIZ, 2000. Evolutionary mechanisms of rib loos in anurans: a comparative developmental approach. Journal of Morphology 244: 57-67.

BREMER, K. 1988. The limits of aminoacid sequence data in angiosperm phylogenetic reconstruction. Evolution 42: 795-803.

BREMER, K. 1994. Branch support and tree stability. Cladistics 10: 295-304.

BRIEVA VASQUEZ, L. M. del P. 1988. Análisis morfológico y comparativo de las larvas de las especies del género Batrachyla (Anura: Leptodactylidae). Tesis presentada para optar al grado de Magíster en Ciencias con mención en Zoología, Univ. Austral de Chile, Valdivia, Chile, 42 pp.

BURTON, T. 1996. Adaptation and evolution in the hand muscles of Australo-Papuan hylid frogs (Anura: Hylidae: Pelodryadinae). Australian Journal of Zoology 44: 611-623.

BURTON, T. 1998. Variation in the hand and superficial throat musculature of neotropical leptodactylid frogs. Herpetologica 54 (1): 53-72.

BURTON, T. 2004. Muscles of the pes of hylid frogs. Journal of Morphology 260: 209233.

BUSSE, K. 1971. Desarrollo de Batrachyla leptopus Bell con observaciones sobre su ecología y comportamiento (Amphibia, Leptodactylidae). Investigaciones Zoológicas Chilenas 15: 5-64. 
CANNATELLA, D. 1985. A phylogeny of primitive frogs (Archaeobatrachians). Ph.D. Dissertation, The University of Kansas, Lawrence, Kansas.

CANNATELLA, D. 1999. Architecture. Cranial and Axial Musculoskeleton, 52-91. En: Tadpoles, The Biology of Anuran Larvae. Edited by R. W. Mc Diarmid \& R. Altig, The University of Chicago Press, Chicago London.

CAPURRO, L. 1958. Nota sobre la ovipostura y desarrollo de Eusophus taeniatus (Girard). Investigaciones Zoológicas Chilenas 4: 208.

CARROLL, R. L., A. KUNTZ \& K. ALBRIGHT. 1999. Vertebral development and amphibian evolution. Evolution and development 1 (1): 36-48.

CEI, J. M. 1960. A survey of the leptodactylid frogs genus Eupsophus in Chile. Breviora Museum of Comparative Zoology 24 (118): 1-13.

CEI, J. M. 1962a. El género Eupsophus en Chile. Investigaciones Zoológicas Chilenas 8 (enero 1962): 7-41.

CEI, J. M. 1962b. Batracios de Chile. 83 pp. Editorial Universidad de Chile, Santiago, Chile.

CEI, J. M. 1965. The tadpole of Batrachophrynus patagonicus Gallado. Herpetologica 20 (4): 242-245.

CEI, J. M. 1980. Amphibians of Argentina. Monitore Zoologico Italiano (N.S.) Monogr. 2, $609 \mathrm{pp}$.

CEI, J. M. \& L. CAPURRO. 1958. Biología y desarrollo de Eupsophus taeniatus Girard. Investigaciones Zoológicas Chilenas IV: 159-182.

CIHAK, R., K. KRALOVEC \& Z. ROCEK. 2003. Developmental origin of the frontoparietal bone in Bombina variegata (Anura: Discoglossidae). Journal of Morphology 255: 122-129.

DARST, C. R. \& D. C. CANNATELLA. 2004. Novel relationships among hyloid frogs inferred from $12 S$ and $16 S$ mitochondrial DNA sequences. Molecular Phylogenetics and Evolution 31 (2004): 462-475.

DE BEER, G. R. 1937. The development of the vertebrate skull. The University of Chicago Press, Chicago and London, 554 pp, 143 figs.

DE JONGH, H. S. 1968. Functional morphology of the jaw apparatus of larval and metamorphosing Rana temporaria L. Netherland Journal of Zoology 18 (1): 1103.

DE SA, R. O. 1988. Chondrocranium and ossification sequence of Hyla lanciformis. Journal of Morphology 195: 345-355. 
DE SA, R. O. \& S. HILL. 1998. Chondrocranial anatomy and skeletogenesis in Dendrobates auratus. Journal of Herpetology 32 (2): 205-210.

DE SA, R. O. \& L. TRUEB. 1991. Osteology, skeletal development, and chondrocranial structure of Hamptophryne boliviana (Anura: Microhylidae). Journal of Morphology 209 : 311-330.

DE TROYER, A., M. SAMPSON, S. SIGRIST \& P. T. MACKLEM. 1981. The diaphragm: two muscles. Science $213:$ 237-238.

DIAZ, N. E. \& A. VELOSO. 1979. Sistemática y evolución de los anfibios de Chile. Archivos de Biología y Medicina Experimental 12: 59-70.

DÍAZ PÁEZ, H. \& H. CARREÑO. 2002. Geographic distribution. Batrachyla nibaldoi. Herpetological Review 33 (2): 218.

DIAZ PEREZ, N. F. 1984. Biosistemática y relaciones filogenéticas de las especies Chilenas de Leptodactylidae (Amphibia; Salientia), enfoque multidisciplinario. Tesis, Facultad de Ciencias Básicas y Farmacéuticas, Universidad de Chile, Chile, $174 \mathrm{pp}$.

DIAZ PEREZ, N. F., SALABERRY, M. \& J. VALENCIA. 1987. Microhabitat and reproductive traits in populations of the frog Batrachyla taeniata. Joumal of Herpetology 21 (4): 317-323.

DUELLMAN, W. E., \& L. TRUEB. 1986. Biology of Amphibians. The Johns Hopkins University Press, pp: 1-610.

DUNLAP, D. 1960. The comparative miology of the pelvic appendages in the Salientia. Journal of Morphology 102: 1-76.

DUNLAP, K. D. \& B. SANCHIZ. 1996. Temporal dissociation between the development of the cranial and appendicular skeletons in Bufo Bufo (Amphibi: Bufonidae). Journal of Morphology 30 (4): 506-513.

EATON, T. H. Jr. 1959. The ancestry of modern amphibia: A review of the evidence. University of Kansas Publications, Museum of Natural History 12 (2): 153-180.

ECHEVERRIA, D. D., C. A. ALONSO, M. S. PILLADO, \& C. A. UBEDA. 2001. Microanatomía del aparato bucal y cavidad bucofaríngea de la larva de Alsodes gargola Gallardo, 1970 (Leptodactylidae, Telmatobiinae). Alytes 18 (3-4): 187-200.

EDGEWORTH, F. H. 1920. On the development of the hypobranchial and laryngeal muscles in Amphibia. Journal of Anatomy 44: 125-162.

ESTES, R. \& O. A. REIG. 1973. The earlier fossil record of frogs. A review of the evidence, pags. 11-63. En: Evolutionary Biology of the Anurans. 
Contemporary Research on Major Problems, edited by J. L. Vial. Columbia: University of Missouri Press.

FABREZI, M. 1992. El carpo de los anuros. Alytes 10: 1-29.

FABREZI, M. 1993. The anuran tarsus. Alytes 11 (2): 47-63.

FABREZI, M. 1996. Las falanges terminales y la clasificación de los anuros. Cuadernos de Herpetología 10 (1-2): 1-9.

FABREZI, M. 2001. A survey of prepollex and prehallux variation in anuran limbs. Zoological Journal of the Linnean Society 131: 227-248.

FABREZI, M. \& P. ALBERCH. 1996. The carpal elements of anurans. Herpetologica 52 (29. 188-204.

FABREZI, M. \& M. BARG. 2001. Patterns of Carpal development among anuran amphibians. Journal of Morphology 249: 210-220.

FABREZI, M. \& G. GARCIA, 1993. Metamorfosis del aparato hiobranquial en Pleurodema borelli y Ceratophrys cranwelli (Anura: Leptodactylidae). Acta Zoológica Lilloana XLII (2): 189-195.

FABREZI, M. \& E. O. LAVILLA, 1993. Anatomia del condrocráneo en larvas de tres especies de Telmatobius del grupo meridional (Anura: Leptodactylidae). Physis (Buenos Aires), secc. B, 48 (114-115): 39-36.

FABREZI, M., \& R. VERA. 1997. Caracterización morfológica de larvas de anuros del noroeste argentino. Cuadernos de Herpetología 11 (1-2): 37-49.

FAIVOVICH, J. 2002. A cladistic analysis of Scinax(Anura: Hylidae). Cladistics 18: 367-393.

FAIVOVICH, J., \& G. R. CARRIZO. 1992. Descripción de la larva de Chacophrys pierottii (Vellard, 1948) (Leptodactylidae, Ceratophryinae). Alytes 19 (3):81-89.

FARRIS, J. S. 1970. Methods for computing Wagner trees. Systematics zoology 19: 83-92.

FARRIS, J. S. 1989. The retention index and the rescaled consistency index. Cladistics 5: 417-419.

FARRIS, J. S. 1990. The retention index and homoplasy excess. Systematics zoology 38: 406-407.

FARRIS, J. S., V. A. ALBERT, M. KALLERSJO, D. LIPSCOMB, \& A. G. KLUGE. 1996. Parsimony Jackknifing outperforms neighbor-joining. Cladistics 12 (2): 99-124.

FELSENSTEIN, J. 1985. Confidence limits on phylogenies: An approach using the bootstrap. Evolution 39: 783-791. 
FERNANDEZ, K, \& M. FERNANDEZ. 1921. Sobre la biología y reproducción de algunos batracios argentinos. I. Cystignathidae. Anales de la Sociedad Científica Argentina 91: 97-145.

FITZINGER, L. J. F. J. 1843. Systema reptilium. Vienna, 106 pp.

FOREY, P. L., I. L. HUMPHRIES, R. W. KITCHING, D. J. SCOTLAND \& D. M. WILLIAMS. 1994. Cladistics. A practical course in systematics. The systematics association publication number 10, 187 pp, Oxford University Press, New York.

FORD, L. S. 1989. The phylogenetic position of poison-dart frogs (Dendrobatidae): reassessment of the neobatrachian phylogeny with commentary on complex character systems. Ph.D. Dissetation. The University of Kansas, Lawrence.

FORD, L. S \& D. C. CANNATELLA. 1993. The major clades of frogs. Herpetological Monographs 7: 94-117.

FORMAS, J. R. 1971. Reproducción y desarrollo de Batrachyla antartandica Barrio (Anura: Leptodactylidae). Boletín Museo Nacional Historia Natural de Chile 32: 201-213.

FORMAS, J. R. 1976. Descriptions of Batrachyla (Amphibia, Anura, Leptodactylidae) tadpoles. Journal of Herpetology 10 (3): 221-225.

FORMAS, J. R. 1979. Los anfibios del bosque temperado del sur de Chile: una aproximación sobre su origen. Archivos de Biología y Medicina Experimental 12: 191-196.

FORMAS, J. R. 1980. The chromosomes of E. calcaratus and the cariological evolution of the genus Eupsophus (Anura: Leptodactylidae). Experientia 36 (1980): 1163-1165.

FORMAS, J. R 1981. Adaptaciones larvarias de los anuros del bosque temperado austral de Sudamérica. Medio Ambiente 51(1-2): 15-21.

FORMAS, J. R. 1989. The tadpole of Eupsophus calcaratus in Southern Chile. Journal of Herpetology 23 (2): 195-197.

FORMAS, J. R. 1997. A new species of Batrachyla (Anura: Leptodactylidae) from Southern Chile. Herpetologica 53 (1): 6-13.

FORMAS, J. R, \& PUGIN. 1978. Tadpoles of Hylorina sylvatica, Eupsophus vittatus, and Bufo rubropunctactus in Southern Chile. Herpetologica 34 (4): 355-358.

FORMAS, J. R, \& L. M. BRIEVA. 2000. Population genetics of the Chilean frog Batrachyla leptopus (Leptodactylidae). Genetics and Molecular Biology 23 (1). 43-48. 
FORMAS, J. R. \& L. M. BRIEVA. 2004. The tadpole of Alsodes vanzolinii and A. verrucosus (Anura: Leptodactylidae) with descriptions of their internal oral and chondrocranial morphology. Amphibia-Reptilia 25: 151-164.

FROST, D. R. 2004. Amphibians Species of the World: An Online Reference. Base de datos electrónica disponible en http://research.amnh.org/herpetology/ amphibia/index.html.

FROST, D. R., T. GRANT, J. FAIVOVICH, R. H. BAIN, A. HAAS, C. F. B. HADDAD, R. O. DE SA, A. CHANNING, M. WILKINSON, S. C. DONNELLAN, C. J. RAXWORTHY, J. A. CAMPBELL, B. L. BLOTTO, P. MOLER, R. C. DREWES, R. A. NUSSBAUM, J. D. LYNCH, D. M. GREEN, \& W. C. WHEELER. 2006. The amphibian tree of life. Bulletin of the American Museum of Natural History 297: 1-370.

GALIS, F. 1999. On the homology of structures and Hoxgenes: the vertebral column. Pags, 80-94. En: Homology. Novartis foundation symposium 222. John Wiley and soons eds, $257 \mathrm{pp}$.

GARRIDO, O., PUGIN, E. \& B. JORQUERA. 1989. Sperm morphology of Batrachyla (Anura: Leptodactylidae). Amphibia- Reptilia 10: 141-149.

GOLOBOFF, P. A. 1993. Estimating character weigths during tree search. Cladistics 9: 83-91.

GOLOBOFF, P. A., J. S. FARRIS \& K. C. NIXON. 2003. T.N.T: Tree Analysis Using New Technology. Version 1.0. Program and documentation available from the authors, and at www.zmuc.dk/public/phylogeny.

GOODRICH, E. S. 1930. Studies on the structure and development of vertebrates, The University of Chicago Press, 837 pp.

GOSNER, K. L. 1960. A simplified table for staining anuran embryos and larvae with notes on identification. Herpetologica 16: 183-190.

GRANDISON, A. G. C. 1961. Chilean species of the genus Eupsophus (Anura: Leptodactylidae). Bulletin of the British Museum (Natural History), Zoology 8 (3): 111-149.

GRANDWELL, N. 1972. Gill irrigation in Rana catesbeiana Part. II. On the musculoskeletal mechanism. Canadian Journal of Zoology 50: 501-521.

GRANT, T., D. R. FROST, J. P. CALDWELL, R. GAGLIARDO, C. F. B. HADDAD, P. J. R. KOK, D. B. MEANS, B. P. NOONAN, W. E. SCHARGEL, \& W. C. WHEELER. 2006. Phylogenetic systematics of Dart-Poison Frogs and their 
relatives (Amphibia: Athesphatanura: Dendrobatidae). Bulletin of the American Museum of Natural History 299: 1-262.

GRIFFITHS, I. 1954. On the otic element in the Amphibia Salientia. Proccedings of the Zooloogical Society of London CXXIV: 35-50.

GUZMAN POO, J. 1970. Desarrollo larvario de Eusophus taeniatus (Girard). Tesis, Facultad de Filosofía y Letras, Universidad Austral de Chile, 42 pp.

HAAS, A. 1995. Cranial features of dendrobatid larvae (Amphibia: Anura: Dendrobatidae). Journal of Morphology 224: 241-264.

HAAS, A. 1996. Das larvale canium von Gastrotheca riobambae und seine metamorphose (Amphibia, Anura, Hylidae). Verh. Naturwiss. Ver. Hamburg. 36: 33-162.

HAAS, A 1997. The larval hyobranchial apparatus of discoglossoid frogs: its structure and bearing on the systematics of the Anura (Amphibia: Anura). Journal of Zoology, Systematics and Evolution Research 35: 179-197.

HAAS, A. 1999. Larval and metamorphic skeletal development in the fast-developing frog Pyxicephalus adspersus (Anura, Ranidae). Zoomorphology 119: 23-35.

HAAS, A. 2001. Mandibular arch musculature of anuran tadpoles with comments on homologies of amphibian jaw muscles. Journal of Morphology 247: 1-33.

HAAS, A 2003. Phylogeny of frogs as inferred from primarily larval characters (Amphibia: Anura). Cladistics 19: 23-89.

HAAS, A. \& J. RICHARDS. 1998. Correlations of cranial morphology, ecology, and evolution in Australian suctorial tadpoles of the genera Litoria and Nyctimystes (Amphibia: Anura: Hylidae: Pelodryadinae). Journal of Morphology 238: 109141.

HALL, B. 1984. Developmental processes underlaing heterocrony as an evolutionary mechanism. Canadian Journal of Zoology 62: 1-6.

HALL, B. K. 1999. Summary. Pags, 243-245. En: Homology. Novartis foundation symposium 222. John Wiley and soons eds, $257 \mathrm{pp}$.

HALL, B. K. \& T. MIYAKE. 2000. All for one and one for all: condensations and the iniciation of skeletal development. Bioessays 22: 138-147.

HANKEN, J. \& J. B. GROSS, 2005. Evolution of cranial development and the rol of neural crest: insights from amphibians. Journal of Anatomy 207: 437-446. 
HANKEN, J. \& B. K. HALL. 1988. Skull development during anuran metamorphosis: $1^{\circ}$ Early development of the first three bones to form the exoccipital, the parasphenoid, and the frontoparietal. Journal of Morphology 195: 247-256.

HEYER, W. R. 1975. A preliminary analysis of the intergeneric relationships of the frogs family Leptodactylidae. Smithsonian Contributions to Zoology 199: 1-55.

HILLIS, D. M. \& J. J. BULL. 1993. An empirical test of bootstrapping as a method for assessing confidence in phylogenetic analysis. Systematics biology 42: $182-$ 192.

JORQUERA, B \& E. MOLINARI. 1979. Estados de desarrollo normal de Batrachyla taeniata (Girard). Medio Ambiente 4 (1): 89-102.

KAPLAN, M. 2003. The "pseudofirmisternial" pectoral girdle of anurans. Alytes 21 (12): 77-99.

KARDONG, K. V. 1998. Vertebrates: comparative anatomy, function, evolution. Second edition, 1998. Mc Graw Hill, ed., 747 pp.

KEITH, A. 1905. The nature of the mammalian diaphragm and pleural cavities. Journal of Anatomy and Physiology 39: 243-284.

KEMP, N. E. \& J. A. HOYT. 1969. Sequence of ossification in the skeleton of growing and metamorphosing tadpoles of Rana pipiens. Journal of Morphology 129: 415-444.

KLUGE, A. G. \& J. S. FARRIS. 1969. Quantitative phyletics and the evolution of anurans. Systematics zoology 18: 1-32.

LARSON, P. M. \& R. O. DE SÁ. 1998. Chondrocranial morphology of Leptodactylus larvae (Leptodactylidae: Leptodactylinae): its utility in phylogenetic reconstruction. Journal of Morphology 238: 287-305.

LAURENT, R. F. 1979. Evolutionary esquisse dùne phylogenese des anoures. Bulletin de la Société Zoologique de France 104 (4): 397-422.

LAURENT, R. F. 1986. La souss-classe des Lissamphibiens (Lissamphibia). En P. P. Grassé y M. Delsol (eds.). Traité de Zoologie, XIV B, Amphibiens: 594 - 797.

LAURIN, M. 1998. A reevaluation of the origin of pentadactyly. Evolution 52 (5): 14761482.

LAURIN, M. \& R. R. REISZ, 1997. A new perspective on tetrapod phylogeny. Pp. 959. En: S. Sumida \& K. Martin eds. Amniote origins: completing the transition to land. Academic press, London. 
LAVILLA, E. O. 1983. Sistemática de larvas de Telmatobiinae (Anura: Leptodactylidae). Tesis Doctoral, Facultad de Ciencias Naturales, Universidad de Tucumán, Argentina, 354 pp.

LAVILLA, E. O. 1987. La larva de Rhinoderma darwinii D \& B (Anura: Rhinodermatidae). Acta Zoológica Lilloana XXXIX (1): 81-88.

LAVILLA, E. O. 1988. Lower Telmatobiinae (Anura: Leptodactylidae): generic diagnoses based on larval characters. Occasional Papers of the Museum of Natural History, University of Kansas, 124: 1-19.

LAVILLA, E. O. 1992. Estructura del condrocráneo y esqueléto visceral de larvas de Alsodes barrioi (Anura: Leptodactylidae). Acta Zoológica lilloana XLII (1): 1318.

LAVILLA, E. O. \& M. FABREZI. 1987. Anatomia de larvas de Hyla pulchella andina (Anura: Hylidae). Physis (Buenos Aires), secc. B 45 (109): 77-82.

LAVILLA, E. O. \& F. LOBO. 1992. Osteological notes on Hylorina sylvatica (Anura: Leptodactylidae). Estratto dal Bollettino del Museo Regionale di Scienze Naturali - Torino 10 (1): 209-216.

LIMESES, C. E. 1963. La musculatura del muslo en las especies del género Lepidobatrachus (Anura: Ceratophrynidae). Physis XXIV (67): 205-218.

LIMESES, C. E. 1964. La musculatura del muslo en los ceratofrinidos y formas afines. Con un análisis crítico sobre la significación de los caracteres miológicos en la sistemática de los anuros superiores. Contribuciones Científicas, Serie Zoología, Universidad de Buenos Aires 4: 193-245.

LIMESES, C. E. 1965. La musculatura mandibular en ceratofrinidos y formas afines (Anura : Ceratophrynidae). Physis XXV (69): 41-58.

LYNCH, J. D. 1971. Evolutionary relationships, osteology, and zoogeography of leptodactyloid frogs. Miscellaneous Publications University Kansas Museum Natural History 53: 1-238.

LYNCH, J. D. 1973. The transition from archaic to advanced frogs. Paginas 133-182 en: Vial, J. L. ed. Evolutionary Biology of the Anura, Contemporary Research on Major Problems, 470 pp., Columbia: University of Missouri press.

LYNCH, J. D. 1978. A re-assessment of the telmatobiinae leptodactylid frogs of Patagonia. Occasional Papers Museum Natural History University Kansas 72: $1-57$.

LYNCH, J. D. 1984. Growth and metamorphosis of the rectus abdominis muscle un Rana pipiens. Journal of Morphology 182: 317-337. 
LYNCH, J. D. 1993. The value of the muscle depressor mandibulae in phylogenetic hypotheses for Eleutherodactylus and its allies (Amphibia: Leptodactylidae). Herpetologica 49 (1): 32-41.

LYNCH, J. D. \& C. D. HARRIS. 1984. Metamorphosis of the rectus abdominis muscle in Rana pipiens. Anatomical Records 208: $106 \mathrm{~A}$.

MAGLIA, A. M. \& L. A. PUGENER, 1998. Skeletal development and adult osteology of Bombina orientalis (Anura: Bombinatoridae). Herpetologica 54 (3): 344-363.

MANZANO, A. S. 1996. Análisis de la musculatura de la familia Pseudidae (Amphibia: Anura). Tesis Doctoral, Facultad de Ciencias Naturales e Instituto Miguel Lillo, Universidad Nacional de Tucumán, 206 pp. 33 figs.

MANZANO, A. S. 1997. Estudio comparativo de la miología de la cintura pectoral de algunos Phyllomedusinos (Anura: Hylidae). Bolletino Museo Regionale Scientia Naturale Torino 15 (2): 255-277.

MANZANO, A. S. \& E. O. LAVILLA. 1995. Myological peculiarities in Rhinoderma darwinii (Anura: Rhinodermatidae). Journal of Morphology 224: 125-129.

MANZANO, A. S. \& M. G. PEROTTI. 1999. Muscle development in the abdominal region of larval hylidae (Amphibia: Anura). Journal of Morphology 241 (3): 275282.

MARCUS, H., E. STIMMELMAYR \& G. PORSCH. 1935. Die ossifikation des Hypogeophisschadels. Beitrag zur Kenntnis der Gymnophionen XXV. Gegenbaurs morphol Jb 76: 375-420.

MILNER, A. R. 1988. The relationships and origins of living amphibians. En: The phylogeny and classification of tetrapods. I. Amphibians, reptiles, birds. (Benton ed.). Systematics Association Spec. 35 (A): 59-103.

MILNER, A. R. 1993. The paleozoic relatives of Lissamphibians. Herpetological Monographs 7: 8-27.

MIRANDA - RIBEIRO, A. 1926. Notas para servirem ao estao dos Gymnobatrachios (Anura) Brasileiros. Arquivos do Museu Nacional 27: 1-227.

MOOKERJEE, H. K. 1936. The development of the vertebral column and its bearing on the study of organic evolution. Proccedings Indi. Science Congress 23: 307-343.

MOOKERJEE, H. K. \& S. K. DAS. 1939. Further investigation on the development of the vertebral column in Salientia (Anura). Journal of Morphology 3: 167-209. 
MUELLER, H. 2006. Ontogeny of the skull, lower jaw, and hyobranchial skeleton of Hypogeophis rostratus (Amphibia: Gymnophiona: Caecilidae) revisited. Journal of Morphology 267: 968-986.

MUELLER, H., O. V. OOMMEN \& P. BARTSCH. 2005. Skeletal development of the direct development caecilian Gegeneophis ramaswamii Taylor, 1964 (Amphibia: Gymnophiona: Caeciliidae). Zoomorphology 124: 171-188.

MULSOW FLORES, S. G. 1984. Mecanismos etológicos acústicos de aislamiento reproductivo entre las especies del género Batrachyla Bell, 1843. Tesis, Facultad de Ciencias, Universidad Austral de Chile, Valdivia, Chile, 76 pp.

NAITOH, T., M. INAMURA \& R. J. WASSERSUG. 1991. Interspecific variation in the emetic response of the anurans. Comp. Biochem. Physiol. C. Comp. Pharmacol. Toxicol. 100: 353-359.

NOBLE, G. K. 1922. The phylogeny of Salientia. I. The osteology and thigh musculature; their bearing on classification and phylogeny. Bulletin of American Museum of Natural History 46: 1-86.

ORTON, G. L. 1957. The bearing of larval evolution on some problems in frogs classification. Systematycs Zoology 6: 79-86.

PALAVECINO, P. 1999. Musculatura asociada al primer y segundo arco visceral de algunos anuros leptodactílidos. Cuadernos de Herpetología 13 (1-2): 37-46.

PALAVECINO, P. 2000. Desarrollo de la musculatura mandibular e hioidea en Leptodactylinae del noroeste argentino. Tésis doctoral, Facultad de Ciencias Naturales e Instituto Miguel Lillo, Universidad Nacional de Tucuman.

PARSONS, T. S. \& E. E. WILLIAMS. 1963. The relationships of the modern amphibia: a re-examination. Quarterly Review of Biology 38: 26-53.

PEROTTI, M. G. 2001. Skeletal development of Leptodactylus chaquensis (Anura: Leptodactylidae). Herpetologica 57 (3): 318-335.

PICKERING, M., D. CAMPION \& J. F. X. JONES. 2004. A gastrointestinal role for the amphibian 'diaphragm' of Xenopus laevis. Journal of Zoology, London 264:4551.

PILLADO, M. S., C. A., ALONSO, \& C. A. UBEDA. 2000. La larva de Alsodes gargola Gallardo, 1970 (Leptodactylidae, Telmatobiinae). Alytes 18 (1-2): 62-72.

PINCHEIRADONOSO, D. \& H. DIAZ-PAEZ. 2003. New geographic record of Batrachyla nibaldoi. Herpetological Review34 (3): 256. 
PUGENER, A. L. \& A. M. MAGLIA. 1997. Osteology and skeletal development of Discoglossus sardus (Anura: Discoglossidae). Journal of Morphology 233: 267-286.

PUGENER, L. A, A. N. MAGLIA, \& L. TRUEB. 2003. Revisiting the contribution of larval characters to an analysis of phylogenetic relationships of basal anurans. Zoological Journal of the Linnean Society 139: 129-155.

RAFF, A. R. 2000. Evo-devo: the evolution of a new discipline. Nature 1 (october 2000): 74-79.

REIG, O. A. 1958. Proposiciones para una nueva macrosistemática de los anuros. Nota preliminar. Physis 21: 109-118.

REINBACH, W. 1939. Untersuchungen ueber die Entwicklung des Kopskeletts von Calyptocephalus gayi (mit einem Anhang ueber das Os supratemporale der anuren Amphibien). Jena Z. Naturw. 72: 211-362.

ROCKOVA, H. \& Z. ROCEK. 2006. Development of the pelvis and posterior part of the vertebral column in the Anura. Journal of Anatomy 206: 17-35.

SEDRA, S. 1951. The metamorphosis of the jaw and their muscles in the toad Bufo regularis, correlates with changes in the animals feeding habits. Proceddings Zoology Society London 120: 405-449.

SHUBIN, N., \& P. ALBERCH. 1986. A morphogenetic approach on the origin and basic organization of the tetrapod limb, pp 319-387. En: M. Hecht, B. Wallace, and G. Prance (Eds.), Evolutionary Biology. Plenum Press, New York, New York.

SNAPPER, J. R., S. M. TENNEY \& F. V. McCANN. 1974. Observations on the amphibian "diaphragm". Comp. Biochem. Physiol. A Comp. Physiol. 49: 223230.

SOKOL, O. M. 1975. The phylogeny of anuran larvae: A new look. Copeia 1975: 1-23.

SOKOL, O. M. 1981. The larval chondrocranium of Pelodytes punctatus, with a review of tadpole chondrocrania. Journal of Morphology 169: 161-183.

STARRET, P. 1968. The phylogenetic significance of the jaw musculature in anuran amphibians. Dissertation, University of Michigan.

STARRET, P. 1973. Evolutionary patterns in larval morphology. pp 251-271. En: Evolutionary Biology of the Anurans. Contemporary Research on Major Problems, edited by J. L. Vial. Columbia: University of Missouri Press.

SZARSKI, H. 1962. The origin of the Amphibia. Quarterly Review of Biology 37: 189241. 
TAYLOR, W. R. \& G. C. VAN DYKE. 1985. Revised procedures for staining and clearing small fishes and other vertebrates for bone and cartilage study. Cybium 9 (2): 107-109.

TRUEB, L. 1973. Bones, frogs and evolution. En: J. L.Vial (red), Evolutionary biology of the anurans, Columbia, Univ. Missouri Press. 65-132.

TRUEB, L. 1985. A summary of the osteocranial development in anurans with notes on the sequence of cranial ossification in Rhinophrynus dorsalis (Anura: Pipoidea: Rhinophrynidae). South African Journal of Science 81: 181-185.

TRUEB, L. \& R. CLOUTIER, 1991. A phylogenetic investigation of the inter-and intrarelationships of the Lissamphibia (Amphibia: Temnospondyli). In: Origins of the higher groups of tetrapods (H. P. Schulze \& L.. Trueb eds.). Cornell University Press, Ithaca, pp. 223.313.

TRUEB, L. \& J HANKEN. 1992. Skeletal development in Xenopus laevis (Anura: Pipidae). Journal of Morphology 214: 1-41.

TRUEB, L., L. A. PUGENER \& A. M. MAGLIA. 2000. Ontogeny on the bizarre: an osteological description of Pipa pipa (Anura: Pipidae), with an account of skeletal development in the species. Journal of Morphology 243: 75-104.

TYLER, M. J. 1972. Superficial mandibular musculature, vocal sacs and the phylogeny of the Australo-Papuan leptodactylid frogs. Records of the South Australian Museum 16 (9): 1-20.

TYLER, M. J. \& W. E. DUELLMAN. 1995. Superficial mandibular musculature and vocal sac structure in Hemiphractine hylid frogs. Journal of Morphology 224 : 65-71.

UBEDA C. A. 1998. Batracofauna de los bosques templados patagónicos. Un enfoque ecobiogeográfico. Tesis, Biblioteca Central de la Facultad de Ciencias Exactas y Naturales, Universidad Nacional de Buenos Aires: 1134.

UBEDA C. A. 2000. Geographic distribution. Batrachyla antartandica. Herpetological Review31 (2): 109.

UBEDA C. A. \& J. NUÑEZ. 2006. New parental care bahaviours in two telmatobiine genera from temperate Patagonian forests: Batrachyla and Eupsophus (Anura: Leptodactylidae). Amphibia-Reptilia 27: 441-444.

VALLEJOS VALLEJOS, P. del C. 1994. Sistemática, morfología externa y osteología de los a dultos del género Batrachyla (Anura: Leptodactylidae). Tesis de Magíster en Ciencias con mención en Zoología, Universidad Austral de Chile, Valdivia, Chile, pp: 108. 
VELLARD, J. 1951. Estudios sobre batracios andinos. I. El grupo Telmatobius y formas afines. Memorias del Museo de Historia Natural "Javier Prado" 1: 1-89.

VERA CANDIOTI, M. F. 2005. Morphology and feeding in tadpoles of Ceratophrys cranwelli (Anura: Leptodactylidae). Acta Zoologica (Stockholm) 86: 1-11.

VERA CANDIOTI, M. F., E. O. LAVILLA \& D. D. ECHEVERRIA. 2004. Feeding mechanisms in two treefrogs, Hyla nana and Scinax nasicus (Anura: Hylidae). Journal of Morphology 261: 206-224.

VERA CANDIOTI, M. F., C. UBEDA \& E. O. LAVILLA. 2005. Morphology and metamorphosis of Eupsophus calcaratus tadpoles (Anura: Leptodactylidae). Journal of Morphology 262: 161-177.

VICKARYOUS, M. K. \& B. K.HALL. 2006. Homology of the reptilian coracoid and a reappraisal of the evolution and development of the amniote pectoral apparatus. Journal of Anatomy 208: 263-285.

WAKE, D. B. 1970. Aspects of vertebral evolution in the modern Amphibia. Forma et Functio 3: 33-60.

WASSERSUG, R. J. 1980. Internal oral features of larvae from eight anuran families: functional, systematic, evolutionary and ecological considerations. University of Kansas Museum of Natural History, Miscellaneous Publication 68: 1-46.

WIENS, J. J. 1989. Ontogeny of the skeleton of Spea bombifrons (Anura: Pelobatidae). Journal of Morphology 202: 29-51.

WILD, E. R. 1997. Desription of the adult skeleton and developmental osteology of the hyperossified horned frog, Ceratophrys cornuta (Anura: Leptodactylidae). Journal of Morphology 232: 169-206.

WILD, E. R. 1999. Description of the chondrocranium and osteogenesis of the Chacoan Burrowing Frog, Chacophrys pierotti (Anura: Leptodactylidae). Journal of Morphology 242: 229-246.

ZARDOYA, R. \& A. MEYER. 2001. On the origin and phylogenetic relationships among living amphibians. PNAS 98 (13): 7380-7383. 
APENDICE I. Material empleado para el grupo interno perteneciente a las especies de Batrachyla. Acronimos: CHINM: Colección Herpetológica Instituto Nacional Malbran (Colección Barrio depositada en el MACN), MACN: Museo Argentino de Ciencias Naturales Bernardino Rivadavia, MLP: Museo de La Plata.

\section{Batrachyla antartandica.}

Material empleado para morfología externa: El Alerzal, Parque Nacional Los Alerces, Chubut, Agentina, I/1980: 1 H (MACN 36642). Puerto Blest, PN Nahuel Huapi, Rio Negro, Argentina, I/1967: 13 H (CHINM 2534-47); s/f: 2 H (CHINM 4507-08). Puiyehue, Chile, V1970: $1 \mathrm{H}$ (CHINM 3964), $1 \mathrm{M}$ (CHINM 4348). El Correntoso, Chile, I/1970: 2 H (CHINM 3904, 4298). Localidad y fecha desconocidas: 4 H (CHINM 376567, 4353). Puerto Murta, XI Región, Chile, I/2004: 1 L (estadio 30) (MLP 4781). Lago Bayo, XI Region, Chile, I/2004: 1 L (estadio 33) (MLP 4770). Lago Queñi, PN Nahuel Huapi, Neuquen, Argentina, XII/1995: 2 L (estadios 40-41) (MLP 3543).

Material empleado para morfología externa, analisis miologico y osteologico: Localidad y fecha desconocidas: 2 H (CHINM 2542, 2547). Pucatrihue, X Región, Chile, I/1992: $27 \mathrm{~L}$ en estadios $36(\mathrm{~N}=3), 37(\mathrm{~N}=3), 38(\mathrm{~N}=1), 39(\mathrm{~N}=3), 40(\mathrm{~N}=3), 41$ $(\mathrm{N}=11), 42(\mathrm{~N}=1), 43(\mathrm{~N}=1), 44(\mathrm{~N}=1)$ (MLP 4774). Puerto Murta, XI Región, Chile, I/2004. 3 L (MLP 4776). Turbera, Puerto Blest, PN Nahuel Huapi, Rio Negro, Argentina, IX/2001: 2 J y $6 \mathrm{~L}$ en estadios $26(\mathrm{~N}=1), 28(\mathrm{~N}=1), 31(\mathrm{~N}=1), 34(\mathrm{~N}=1), 36$ ( $N=1$ ), 43 ( $N=1$ ) ( MLP 4768). Lago Queñi, PN Nahuel Huapi, Neuquen, Argentina, XII/1995: $17 \mathrm{~L}$ en estadios $35(\mathrm{~N}=1), 37(\mathrm{~N}=4), 38(1), 39(\mathrm{~N}=2), 40(\mathrm{~N}=3), 41(\mathrm{~N}=3), 42$ $(\mathrm{N}=1), 43(\mathrm{~N}=2)$ y $45(\mathrm{~N}=1)$ (MLP 4782). Entre lagos La Plata y La Plata Chico, Chubut, Argentina, I/2000: $1 \mathrm{~L}$ (estadio 29) (MLP 4769).

\section{Batrachyla fitzroya.}

Material empleado para morfología externa: Isla Grande, PN Los Alerces, Chubut, Argentina, I/1988: 2 H y 2 M (MLP 859-862).

Material empleado para morfología externa, analisis miologico y osteologico: Isla Grande, PN Los Alerces, Chubut, Argentina, XII/2003: 1 M (MLP 4771) y 1 H (MLP 4772).

Material empleado para analisis osteologico: Isla Grande, PN Los Alerces, Chubut, Argentina, I/1988: 1 H (MLP 854). 


\section{Batrachyla leptopus.}

Material empleado para morfología externa: Puerto Blest, Parque Nacional Nahuel Huapi, San Carlos de Bariloche, Rio Negro, Argentina, I/1967: 9 M (CHINM 1785, 1789, 1791, 1793, 1829, 1833, 1839, 1842, 1844), 5 INDET (CHINM 1830, 1842-3, 1847-8), 1 H (CHINM 1812); I/1971: 1 M (CHINM 4627), 8 H (CHINM 4626, 4682-5, 4701, 4706-7); XII/1972: 1 H (CHINM 6869); XI/1970: 8 H (CHINM 6303-10); XI/1966: 1 H (CHINM 1306); s/f: 3 H (CHINM 4393, 5775, 6855); III/1971: 3 H (CHINM 4613, 5719, 5882); I/1967: 16 H (CHINM 1786, 1788, 1790, 1792, 1826-7, 1830-2, 1834-7, 1841, 1845-6); X/1967: 1 H (CHINM 2548); I/1972: 4 H (CHINM s/n, 5907, 6098-9); I/1975: 2 H (CHINM 5875-6); III/1967: 4 H (CHINM 2180, 2183-4, 2310). Pichi Traful, I/1967: 5 H (CHINM 1810, 1825, 1811, 1849, 1853), 3 M (CHINM 1850-52). Cascada Los Alerces cerca de Lago Hess, XI/1966: 2 M (CHINM 1311-12), 3 H (CHINM 996, 1302, 1304). Rio Negro, Argentina, s/f: 1 H (CHINM 4693 ). El Correntoso, I/1967: 3 M (CHINM 1794-5, 1807). Minetue, ruta Pucón-Curarrehué, IX Región, Chile, I/1967: 1 M (CHINM 1808). Puyehue, Chile, I/1970: 3 H (CHINM 3848, 3772, 3906), 1 M (CHINM 3849); II/1970: 1 H (CHINM 3976). Mehuin, Chile, III/1973. 1 M (CHINM 6863). Quellon, Chiloe, X Región, Chile, I/1954: 1 M (CHINM B), 1 H (CHINM A). P. N. Lago Puelo, Chubut, Argentina, I/2005: 3 M (MLP 3999, 4017, 4067). Pampa Linda, PN Nahuel Huapi, Rio Negro, Argentina, I/2005: 1 M (MLP 3994), 1 H (MLP 3995).

Material empleado para morfología externa, analisis miologico y osteologico: Pampa Linda, P. N. Nahuel Huapi, San Carlos de Bariloche, Rio Negro, Argentina: 1 M (MLP 3994). Pichi Traful, I/1967: 2 H (CHINM 1830, 1837). Entre Hua-Hum y Lago Queñi, Parque Nacional Lanin, Neuquen, Agentina, I/1988: 1 H (MLP 4780). Pichi Traful, I/1967: 2 J (CHINM 1810). Carretera Austral entre Villa Amengual y Villa Mañiguales, XI Región, Chile,: $68 \mathrm{~L}$ en estadios $26(\mathrm{~N}=5), 27(\mathrm{~N}=2), 28(\mathrm{~N}=2), 30$ $(\mathrm{N}=1), 31(\mathrm{~N}=4), 32(\mathrm{~N}=1), 33(\mathrm{~N}=3), 34(\mathrm{~N}=2), 35(\mathrm{~N}=2), 36(\mathrm{~N}=3), 37(\mathrm{~N}=1), 38(\mathrm{~N}=1)$, $39(\mathrm{~N}=3), 40(\mathrm{~N}=8), 41(\mathrm{~N}=7), 42(\mathrm{~N}=4), 43$ ( $\mathrm{N}=12)$ (MLP 4783). Turbera, Puerto Blest, Parque Nacional Nahuel Huapi, San Carlos de Bariloche, Rio Negro, Argentina, X/2000: 3 J, 7 L en estadios $29(\mathrm{~N}=2), 41(\mathrm{~N}=1), 42(\mathrm{~N}=1), 43(\mathrm{~N}=2), 44(\mathrm{~N}=1)$ (MLP 4784).

Material empleado para analisis osteologico: Puerto Blest, Parque Nacional Nahuel Huapi, San Carlos de Bariloche, Rio Negro, Argentina, I/1967: 1 INDET (CHINM 1828). Lago Felipe, Parque Nacional Nahuel Huapi, Rio Negro, Argentina, II/1966: 1 INDET (CHINM 1309). 


\section{Batrachyla nibaldoi.}

Material empleado para morfología externa: Carretera Austral en la entrada de Puerto Murta, XI Región, Chile, I/2004: 1 M (grabado y ADN, MLP 4788). Material empleado para morfología externa, analisis miologico y osteologico: Carretera Austral en la entrada de Puerto Murta, XI Región, Chile, I/2004: 1 M (MLP 4789).

\section{Batrachyla taeniata.}

Material empleado para morfología externa: El Correntoso, Chamiza, Puerto Montt, X Región, Chile, I/1967: 1M (CHINM 1932), 3H (CHINM 1903, 1930-31). Vegas Blancas, Chile, I/1967: 1 M (CHINM 1901), 1 H (CHINM 1898). Bosque de Quinteros, Valparaiso, V Región, Chile, XII/1963: 1 H (CHINM 1616). Lago Puyehue, X Región, Chile, I/1970: 3 M (CHINM 3836-37, 3839), 3 H (CHINM 3838, 3907, 4070).

Concepción, VIII Región, Chile, s/f: 2 H (CHINM 4292-95). Mehuin, Valdivia, X Región, Chile, I/1970: 1 H (CHINM 3850), III/1973: 4 H (CHINM 6864-67). Lago Espejo, Chile?, I/1970: 2 H (CHINM 3962, 3967). Los Yeulles, Chile, s/f: 1 H (CHINM 1917). Lago Espejo Chico, Chile?. I/1970: 1 H (CHINM 4110); X/1970: 1 H (CHINM 4080). Sin localidad, s/f: 1 H (CHINM 1895), 2 M (CHINM 1893-4). Lago Hess, Parque Nacional Nahuel Huapi, Rio Negro, Argentina, XI/1965: 2 M (CHINM 894-5). Arroyo Las Ranas, Villa La Angostura, Neuquen, Argentina, III/1973: 12 M (CHINM 6922-26, 6928-31, 6934-35, 6938), 2 H (CHINM 6936-37); XI/1965: 2 H (CHINM 896-7). Termas de Epulafquen, Dpto. Huilinches, Neuquen, Argentina, I/1999: 1 H (MACN 38018); III/2000: 3 H (MACN 38024-26). Rio Negro, Argentina, s/f: 1 H (MLP 538). Pichi Traful, Parque Nacional Nahuel Huapi, Rio Negro, Argentina, XI/1965: 2 H (CHINM 913-14), 2 M (CHINM 929-30). Puerto Blest, Parque Nacional Nahuel Huapi, San Carlos de Bariloche, Rio Negro, Argentina, s/f: 5 M (MLP 939-43); IV/1969: 1 H (CHINM 3337); XII/1961: 6 M (CHINM 1557, 1561-62, 1564-65, 1569); I/1972: 1 M (CHINM 5917); III/1967: 1 M (CHINM 1990), 1 H (CHINM 1988); I/1970: 4 H (CHINM 4059-60, 4064, 6718); XII/1961: 1 H (CHINM 1567); V/1970: 1 H (CHINM 4325); IV/1965: 1 H (CHINM 3371); I/1971: 1 H (CHINM 4660). Isla Victoria, Parque Nacional Nahuel Huapi, Rio Negro, Argentina, HIII/1970: 5 H (CHINM 4073, 4076, 4100, 4297, 6937). Puerto Aysen, XI Región, Chile, s/f: 1 H (MLP 776). Puerto Tranquilo, XI Región, Chile, I/2004: $1 \mathrm{M}$ (grabado y ADN) (MLP 4785). Termas de Epulafquen, Dpto. Huilinches, Neuquen, Argentina, I/1999: 3 J (MACN 38019-21); XII/1999: 1 J (MACN 38023). Lago Espejo, 
Dpto. Los Lagos, Neuquen, Argentina, I/1999: (MACN 38022). Cir cuito Chico, San Carlos de Bariloche, Rio Negro, Argentina, X/2000: 1 L (estadio 36) (MLP 4773). Material empleado para morfología externa, analisis miologico y osteologico: Arroyo Las Ranas, Villa La Angostura, Neuquen, Argentina, III/1973: 2 M (CHINM 6921, 6932). Puerto Blest, Parque Nacional Nahuel Huapi, San Carlos de Bariloche, Rio Negro, Argentina, XI/1966: 2 J (CHINM s/n). Rio Negro, s/f: sexo indet. (MLP 2899). Puerto Aysen, XI Región, Chile, s/f: 1 H (MLP 775). Circuito Chico,

San Carlos de Bariloche, Rio Negro, Argentina, X/2000: 5 J y 172 L en estadios 29 $(\mathrm{N}=2), 31(\mathrm{~N}=6), 32(\mathrm{~N}=4), 33(\mathrm{~N}=14), 34(\mathrm{~N}=6), 35(\mathrm{~N}=20), 36(\mathrm{~N}=21), 37(\mathrm{~N}=12), 38$ $(\mathrm{N}=5), 39(\mathrm{~N}=2), 40(\mathrm{~N}=8), 41(\mathrm{~N}=28), 42(\mathrm{~N}=7), 43(\mathrm{~N}=35), 44(\mathrm{~N}=4)$ (MLP 4787). Material empleado para analisis osteologico: Puerto Blest, Parque Nacional Nahuel Huapi, San Carlos de Bariloche, Rio Negro, Argentina, XI/1966: 1 INDET (CHINM 1559). 
APENDICE II. Material de larvas y adultos empleado para los grupos externos perteneciente a los géneros Alsodes, Atelognathus, Ceratophrys, Chacophrys, Eupsophus, Hylorina y Pleurodema. Acronimos: CHINM: Colección Herpetológica Instituto Nacional Malbran (Colección Barrio depositada en el Museo Argentino de Ciencias Naturales Bernardino Rivadavia), FCCEN: Facultad de Ciencias Exactas y Naturales (Universidad de Buenos Aires), ILPLA: Instituto de Limnología Dr. R. A. Ringuelet, MLP: Museo de La Plata.

\section{Alsodes gargola.}

Material empleado para morfología externa, analisis miologico y osteologico: Laguna Atravezada, Cerro Atravezado, Primeros Pinos, Neuquen, Argentina, I/2000: 1 M (MLP 2874), 1 H (MLP 2891), 2 larvas (estadios 31 y 32) (MLP 2903).

\section{Atelognathus patagonicus.}

Material empleado para morfología externa, analisis miologico y osteologico: Laguna Teru, Laguna Blanca, Neuquen, Argentina, I/2000: 1 M (MLP 2796), 1 H (MLP 3432). Laguna del Burro, Neuquén, Argentina, s/f: 3 L (estadios 36, 38 y 41) (MLP 1222).

\section{Ceratophrys ornata.}

Material empleado para morfología externa: Alrededores de La Plata: Machos y hembras adultas (MLP 3624-3699)

Material empleado para morfología externa, analisis miologico y osteologico: Alrededores de La Plata, s/ fecha: 1 M (MLP 4925). 7L (estadios 31, 33, 34, 37, 40, 41, 43) (MLP 4849)

\section{Chacophrys pierottii.}

Material empleado para morfología externa, analisis miologico y osteologico: Laguna Seca, San Luis, año 1914: 1 J (ILPLA 350 ) y 1 J (MLP 1650). Hickman, Salta, s/f: 1 M? (FCEEN 314).

\section{Eupsophus calcaratus.}

Material empleado para morfología externa: Lago Queñi, PN Nahuel Huapi, Neuquén, Argentina, II/1997: 4 H (MLP 2780-83). 
Material empleado para morfología externa, analisis miologico y osteologico: Rio Negro, s/f: 1 H (MLP 2901). Departamento Cushamen, P. N. Lago Puelo, Chubut, Argentina: 1 M (MLP 4011).

\section{Hylorina sylvatica.}

Material empleado para morfología externa: Puerto Blest, PN Nahuel Huapi, Rio Negro, Argentina, s/f: IV/1983: 1 H (MLP 537). Puerto Murta, XI Región, Chile, I /2004: $1 \mathrm{~L}$ (estadio 29) ( MLP 4786). Circuito Chico, Bariloche, Rio Negro, Argentina, X/2001: $1 \mathrm{~L}$ (estadio 28) (MLP 4779).

Material empleado para morfología externa, analisis miologico y osteologico: PN Nahuel Huapi, Rio Negro, Argentina, s/f: 1 M (MLP 2536). El Correntoso, Chamiza, cerca Puerto Montt, Chile, s/f: 1 H (CHINM 1870). Puerto Murta, XI Región, Chile, I /2004: 1 L (estadio 33) (MLP 4777). Circuito Chico, Bariloche, Rio Negro, Argentina, $X / 2001: 16 L$ en estadios $31(\mathrm{~N}=2), 33(\mathrm{~N}=1), 35(\mathrm{~N}=1), 41(\mathrm{~N}=5), 42(\mathrm{~N}=1), 43(\mathrm{~N}=1)$, $44(\mathrm{~N}=4), 45(\mathrm{~N}=1)$ (MLP 4778).

\section{Pleurodema borelli.}

Material empleado para morfología externa: Yerba Buena, Tucumán, Argentina, XII/2003: 1 M ( MLP 3909). Catamarca, s/f: 1 H (MLP3759). Material empleado para morfología externa, analisis miologico y osteologico: Sin localidad, s/f: 2 M (MLP 4791, 4792). Salta Capital, Salta, Argentina, XI/2001: 19 L en estadios $37(\mathrm{~N}=1), 38(\mathrm{~N}=2), 40(\mathrm{~N}=4), 41(\mathrm{~N}=3), 42(\mathrm{~N}=2), 43(\mathrm{~N}=4), 44(\mathrm{~N}=3)(\mathrm{MLP}$ 4850). 
APENDICE III. Material de larvas empleado para comparación perteneciente a los géneros Alsodes, Atelognathus, Caudiverbera, Hypsiboas, Leptodactylus,

Limnomedusa, Odontophrynus, Physalaemus, Pleurodema y Telmatobius. Acronimos:

MACN: Museo Argentino de Ciencias Naturales Bernardino Rivadavia, MLP: Museo de La Plata.

\section{Alsodes monticola.}

Material empleado para morfología externa, analisis mi ologico y osteologico: Puerto Murta, XI Región, Chile, I/ 2004: 2 L (estadios 30 y 31) (MLP 4793).

\section{Atelognathus nitoi.}

Material empleado para morfología externa, analisis miologico y osteologico: Laguna Verde, Cerro Challuaco, PN Nahuel Huapi, Rio Negro, Argentina: 4 L en estadios $38(\mathrm{~N}=1)$ y $40(\mathrm{~N}=3)(\mathrm{MLP} 4794)$.

\section{Caudiverbera caudiverbera.}

Material empleado para morfología externa, analisis miologico y osteologico:

Puerto Montt, X Región, Chile, s/f: 1 L (estadio 36, LT 105 mm) (MLP 885).

Hypsiboas pulchellus. Isla Carabajal, Río Paraná, Santa Fe, Argentina: 32 larvas (estadios 27-46) (MLP 3322).

\section{Leptodactylus chaquensis.}

Material empleado para analisis miologico: Simóca, Tucumán, Argentina: 2 L (estadios 34 y 36) (MLP 3319).

\section{Leptodactylus gracilis.}

Material empleado para analisis miologico: Parque Sicárdi, La Plata, Buenos Aires, Argentina: 2 L (estadios 34 y 35) (MLP 3429).

\section{Leptodactylus latinasus.}

Material empleado para analisis miologico: Los Porteños, La Plata, Buenos Aires, Argentina: 1 L (estadio 35) (MLP 3427). 
Leptodactylus ocellatus.

Material empleado para morfología externa, analisis miologico yosteologico:

Punta Lara, Ensenada, Buenos Aires, Argentina, XI/2000: 46 L (estadios 38 a 46) y $4 \mathrm{~J}$

(MLP 3798).

Material empleado para analisis miologico: Tánti, Córdoba, Argentina: $4 \mathrm{~L}$ (estadio

35) (MLP 3424). Colón, Entre Ríos, Argentina: 5 L (estadios 30 a 34) (MLP 3425).

\section{Limnomedusa macroglossa.}

Material empleado para morfología externa, analisis miologico y osteologico:

Salto del Río Kozac, INTA San Antonio, Dpto. General Belgrano, Misiones province, Argentina, V1994: $4 \mathrm{~L}$ en estadios $36(\mathrm{~N}=2)$ y $38(\mathrm{~N}=2)$ (MACN 34996).

\section{Physalaemus fernandezae.}

Material empleado para morfología externa: Punta Lara, Buenos Aires, Argentina, V/2001: 7 L (estadios 32, 35, 36, 37 y 38) (MLP 3333).

Material empleado para morfología externa, analisis miologico y osteologico:

Punta Lara, Buenos Aires, Argentina, V/2001: 2 L (estadio 35) (MLP 3334) y 3 L (estadio 40) (MLP 3335).

\section{Pleurodema thaul.}

Material empleado para morfología externa, analisis miologico y osteologico:

Cascada Cantaros, P. N. Nahuel, Huapi, San Carlos de Bariloche, Río negro,

Argentina, s/fecha: 2 L (estadios 43 y 46) (MLP 4848).

Telmatobius schreiteri.

Material empleado para morfología externa, anal isis miologico y osteologico:

Famatina, La Rioja, Argentina, s/f: 1 L (estadio 36) (MLP 2425).

\section{Telmatobius spp.}

Material empleado para morfología externa, analisis miologico y osteologico: PN

Calilegua, Jujuy, Argentina, s/f: 1 L (estadio 35) (MLP 4847). 
APENDICE IV. Matriz de 110 caracteres por 12 taxa empleada para el análisis

filogenético.(-) indica datos inaplicables. (?) indica datos faltantes.

alsode $1010003011100010120100-1101000000000000011101100100110000110$ $000030000000[01] 11100000000020000010000000011000100 ? 0$

atelog 001000201010001111001101101110000001000000011001110201120110 $101030010100000100000011012000000[01] 00011001 ? ? ? 100 ? 0$

antart 00100020000000000201011010110000000100001000000110 ???1020111 11100010010100011002110111010000130200000112110200

fitzro ?????????? ????000201 $0110101110000 ? ? ? ? ? 001000 ? ? ? ? 100201020111$ 101100100101000110021101000100 ?0120????? ??????????

leptop 001000200000000002010110101100000001000010000001100201020111 11100010010100011002110100010000120100000110110201

nibald ?????????? ????001201 $0110101110000 ? ? ? ? ? 001100 ? ? ? ? 10$ ?1?1020110

$1111200000010001100000011100[01] 0001[01] 1 ? ? ? ? ?$ ??????????

taenia $0001002000000000120101101011[01] 000000110001100000110$

$11010201101111200000010001100000011100[01] 0001[01] 1200000110110211$

cerato 120-311100 $001010101100-01120[01] 110101001110000110020$

0[01]0011010- -013501011 100000200100001401111010001003 00???11000

chacop 00102011111110101011 10-0012011 101?????01 0100????11 ?0?012000-014511111 11010020110200120111 ?0000010?[02] 00???11???

eupsop $0100111000000110020000-010001000010100000100101011$ ?1?102020-001401001 11100001020000220000 00[12][012]101001 00???0-1?1

hylori 000000200000000012011120101010000001000011100001110201020010 11111000100100011000000113100010100100000121110010

pleuro 00102000100100101200110000011001000000100100110000 ?1?10212000241011010100001100002220000 10[12]0001100 001012-0?0 ; 
APÉNDICE V. Secuencia de condrificacion del cráneo de Batrachyla antartandica. A los estadios $35(N=1), 39(N=5), 41(N=14), 42(N=2), 43(N=2)$ y $44(N=1)$ no se registraron cambios.Referencias: AA: apendicular anterior, AH: Aparato hiobranquial, AN: arco neural, AO: arco occipital, AP: apendicular p osterior, AT: aritenoides, BP: basal del prepollex, BPH: basal del prehallux, C: carpianos, CA: cartílago alar, CCO: comisura cuadrado-orbitaria, $\mathbf{C l}$ : comisura intramandibular, CIM: cresta intermedia, CM: cartílago de Meckel, CO: cartílago oblicuo, COL: columella, CP: cintura pélvica, CPR: cartílagos procoracoideos, CR: cricoides, CS: cartílago suprarrostral, CSU: cresta subnasal, CT: cuernos trabeculares, DP: distales del prehallux, E: esternón, EP: epicoracoides, EPE: epiesternón, ES: escápula, EY: elemento Y, F: fémur, $\mathrm{F}(\mathrm{D})$ : falange (digíto), $\mathrm{FC}$ : foramenes carotídeos, FCO: foramenes cápsula ótica, FCP: forámen craneopalatino, H: húmero, HP: hipocordo, I: infrarrostral, LO: lamina orbitonasal, MC: metacarpiano, MT: metatarsianos, O: opérculo, OM: omoesternón, P: palatocuadrado, PA: pila antótica, PACP: proceso anterolateral de la cresta parótica, PIE: pila etmóidea, PL: proceso lateral de los cuernos trabeculares, PLE: placa etmóidea, PM: pila metóptica, PPC: proceso posterolateral de la cresta parótica, PPI: proceso prenasal inferior, PPR: pila preóptica, PPS: proceso prenasal superior, $\mathbf{P T}$ : proceso transverso, PX: prepollex, R-R': radial-radial', $\mathbf{R U :}$ radio-ulna, SDP: segmento dístal prepollex, SES: supraescápula, SN: septo nasal, T: tarsianos, TE: techo etmóideo, TF: tibia-fíbula, TFr: tibial-fibular, TN: techo nasal, TP: techo parietal, TS: techo sinótico, TTM: taenia tecti medial, TTMA: taenia tecti marginal anterior, TTMP: taenia tecti marginal posterior, TTT: taenia tecti transversal, U-U': ulnar-ulnar', X: xifiesternón, ZP: zigapofisis.

\begin{tabular}{|c|c|c|c|c|}
\hline Estadio & Cráneo & Axial & AA & AP \\
\hline $31(\mathrm{~N}=3)$ & $\begin{array}{l}\text { FC-PA-SN-AO-CCO-LO-TS-FCO } \\
\text { PACP-PLE-CT-PL-CS-P-CM-I-AH }\end{array}$ & PT I-II & & \\
\hline $34(N=1)$ & $\begin{array}{l}\text { FCP-TTM-TTT-PIE-PPR-PM-TE } \\
\text { TTMA }\end{array}$ & $\begin{array}{l}\text { AN X } \\
\text { PT III } \\
\text { ZP }\end{array}$ & $\begin{array}{l}\mathrm{ES} \\
\mathrm{H} \\
\mathrm{RU}\end{array}$ & $\begin{array}{l}\mathrm{F} \\
\mathrm{TF}\end{array}$ \\
\hline $36(\mathrm{~N}=1)$ & O-TTMP - TP & $\begin{array}{l}\text { HP } \\
\text { PT IV }\end{array}$ & $\begin{array}{l}\text { SES-CPR-MC II-V } \\
1^{\circ} \mathrm{F}(\mathrm{III}-\mathrm{V})-2^{\circ} \mathrm{F}(\mathrm{IV}-\mathrm{V}) \\
\mathrm{C} \text { II, III, IV-V-R-R' } \\
\text { U-U'-BP-EY }\end{array}$ & $\begin{array}{l}\text { CP-TFr-MT (I-V) } \\
1^{\circ} \mathrm{F}(\mathrm{IIIV})-2^{\circ} \mathrm{F}(\mathrm{IV}) \\
\mathrm{T} \text { I, II, III-BPH }\end{array}$ \\
\hline $37(\mathrm{~N}=7)$ & & $\begin{array}{l}\text { AN XI } \\
\text { PT V-IX }\end{array}$ & $\begin{array}{l}\mathrm{EP}-1^{\circ} \mathrm{F}(\mathrm{II})-^{\circ} \mathrm{F}(\mathrm{III}) \\
3^{\circ} \mathrm{F}(\mathrm{IV} \text { y V)-SDP }\end{array}$ & $\begin{array}{l}\mathrm{FP}(\mathrm{D} \mathrm{I}-\mathrm{II})-^{\circ} \mathrm{F}(\mathrm{D} \mathrm{I}-\mathrm{V}) \\
3^{\circ} \mathrm{F}(\mathrm{D} \mathrm{IIIV}) \\
4^{\circ} \mathrm{F}(\mathrm{D} \mathrm{IV})-\mathrm{DP}\end{array}$ \\
\hline $38(N=2)$ & Cl- CO-TN-CA-PPS-CIM-AT & & & \\
\hline $40(N=6)$ & $\mathrm{CSU}$ & & & \\
\hline $45(\mathrm{~N}=2)$ & & & $E$ & \\
\hline $46(N=2)$ & PPI-CR & & & \\
\hline $\mathrm{PM}(\mathrm{N}=2)$ & & & OM -EPE-X & \\
\hline
\end{tabular}


APÉNDICE VI. Secuencia de condrificacion del cráneo de Batrachyla leptopus. A los estadios $27(\mathrm{~N}=2), 29(\mathrm{~N}=1), 30(\mathrm{~N}=2), 33(\mathrm{~N}=2), 39(\mathrm{~N}=3), 43$ (15), 44 (1) y 46 (3) no se registraron cambios. Referencias: AA: apendicular anterior, AH: Aparato hiobranquial, AN: arco neural, AO: arco occipital, AP: apendicular posterior, AT: aritenoides, BP: basal del prepollex, BPH: basal del prehallux, C: carpianos, CA: cartílago alar, CCO: comisur a cuadrado-orbitaria, CE: cintura escapular, $\mathbf{C l}$ : comisura intramandibular, CIM: cresta intermedia, CM: cartílago de Meckel, CO: cartílago oblicuo, COL: columella, CP: cintura pélvica, CPR: cartílagos procoracoideos, CR: cricoides, CS: cartílago suprarrostral, CSU: cresta subnasal, CT: cuernos trabeculares, DP: distales del prehallux, E: esternón, EP: epicoracoides, EPE: epiesternón, ES: escápula, EY: elemento Y, F: fémur, F(D): falange (digíto), FC: foramenes carotídeos, FCO: foramenes cápsula ótica, FCP: forámen craneopalatino, FPS: foramen perilinfático superior, H: húmero, HP: hipocordo, I: infrarrostral, LO: lamina orbitonasal, MC: metacarpiano, MT: metatarsianos, O: opérculo, OM: omoesternón, P: palatocuadrado, PA: pila antótica, PACP: proceso anterolateral de la cresta parótica,PIE: pila etmóidea, PL: proceso lateral de los cuernos trabeculares, PLE: placa etmóidea, PM: pila metóptica, PPC: proceso posterolateral de la cresta parótica, PPI: proceso prenasal inferior, PPR: pila preóptica, PPS: proceso prenasal superior, PT: proceso transverso, PX: prepollex, R-R': radial-radial', RU: radio-ulna, SDP: segmento dístal prepollex, SES: supraescápula, SN: septo nasal, T: tarsianos: TE: techo etmóideo, TF: tibia-fíbula, TFr: tibial-fibular, TN: techo nasal, TP: techo parietal, TS: techo sinótico, TTM: taenia tecti medial, TTMA: taenia tecti marginal anterior, TTMP: taenia tecti marginal posterior, TTT: taenia tecti transversal, U-U': ulnar-ulnar', X: xifiesternón, ZP: zigapofisis.

\begin{tabular}{|c|c|c|c|c|}
\hline Estadio & Cráneo & Axial & $\mathbf{A A}$ & $\mathbf{A P}$ \\
\hline $26(N=6)$ & $\begin{array}{l}\text { CS-CT-PL-PLE-CM-I-P-CCO-AH } \\
\text { PA-PM PPR-PIE-FPS-AO-SN- } \\
\text { LO-TS-TE }\end{array}$ & AN I-IX & & \\
\hline $28(N=1)$ & FC -FCO-PACP & PTI -II & & \\
\hline $31(N=5)$ & TTM-TTT-TTMA-FCP & PTIII-AN X & & F-TF-CP \\
\hline $32(\mathrm{~N}=1)$ & & ZP & & \\
\hline $34(N=4)$ & $\mathrm{O}$ & $\mathrm{HP}$ & $\begin{array}{l}\text { H-RU-CE } \\
\text { MC (III-V) } \\
\text { C III y C IV-V } \\
\text { R-R' y U-U' }\end{array}$ & $\begin{array}{l}\text { TFr } \\
\text { MT (IV-V) }\end{array}$ \\
\hline $\begin{array}{l}35(\mathrm{~N}=3) \\
36(\mathrm{~N}=5)\end{array}$ & TTMP-TP & $\begin{array}{l}\text { PT IV-IX } \\
\text { AN II }\end{array}$ & \begin{tabular}{|l}
$\mathrm{EP}$ \\
$1^{\circ}, 2^{\circ} \mathrm{F}(\mathrm{II}-\mathrm{V})$ \\
$3^{\circ} \mathrm{F}(\mathrm{IV}-\mathrm{V})-\mathrm{EY}$ \\
$\mathrm{MC}(\mathrm{II})-\mathrm{CII}-\mathrm{BP}$
\end{tabular} & $\begin{array}{l}\mathrm{MT}(\mathrm{II} I \mathrm{III})-1^{\circ} \mathrm{F}(\mathrm{IIIV}) \\
3^{\circ} \mathrm{F}(\mathrm{III}-\mathrm{IV})-\mathrm{T} \mathrm{I}, \mathrm{II}, \mathrm{III} \\
1^{\circ} \mathrm{F}(\mathrm{I})-\mathrm{EY}-\mathrm{BPH} \\
2^{\circ} \mathrm{F}(\mathrm{I}-\mathrm{II}) \\
3^{\circ} \mathrm{F}(\mathrm{IV})\end{array}$ \\
\hline $37(\mathrm{~N}=1)$ & & & SDP & \\
\hline $38(N=1)$ & & & & $4^{\circ} \mathrm{F}(\mathrm{IV})$ \\
\hline $40(N=7)$ & CO-CA-PPS-CIM-YN & & & DP \\
\hline $41(N=8)$ & $\mathrm{Cl}$ & & & \\
\hline $42(\mathrm{~N}=5)$ & AT-PPI & & & \\
\hline PM & $\mathrm{CR}$ & & OM-E-EPE-X & \\
\hline
\end{tabular}


APÉNDICE VII. Secuencia de osificación de Batrachyla antartandica. En negrita se indican las autostosis. A los estadios $31(\mathrm{~N}=3), 35(\mathrm{~N}=1), 39(5)$ y $45(2)$ no se registraron novedades. Referencias: AA: apendicular anterior, AN: arcos neurales, AP: apendicular posterior, C: cuerpos vertebrales, FP: falanges proximales, HP: hipocordo, MC: metacarpianos, MT: metatarsianos, PT: procesos transversos, ra: rama anterior, ro: rama ótica, rv: rama ventral.

\begin{tabular}{|c|c|c|c|c|}
\hline Estadio & Cráneo & Axial & AA & AP \\
\hline $34(\mathrm{~N}=1)$ & Exoccipital & $\begin{array}{l}\text { AN I-X } \\
\text { C I-III } \\
\text { PT I-III }\end{array}$ & & \\
\hline $36(N=1)$ & & & $\begin{array}{l}\text { Escápula } \\
\text { Estilopodio } \\
\text { Zeugopodio } \\
\text { MC (III-V) } \\
\text { FP (III-V) } \\
2^{\circ} \text { F (IV-V) }\end{array}$ & $\begin{array}{l}\text { lleon } \\
\text { Estilopodio } \\
\text { Zeugopodio } \\
\text { Tibial } \\
\text { Fibular } \\
\text { MT (I-V) } \\
\text { FP (III-V) } \\
2^{\circ} \mathrm{F} \text { (IV) } \\
\end{array}$ \\
\hline $\begin{array}{l}37(N=7) \\
38(N=2)\end{array}$ & $\begin{array}{l}\text { 1. Paraesfenoides } \\
\text { 2. Frontoparietal }\end{array}$ & C IV-IX & $\begin{array}{l}\text { Coracoides } \\
\text { Clavícula } \\
\text { Cleitro }\end{array}$ & \\
\hline $40(N=6)$ & & & $\begin{array}{l}M C \text { (II) } \\
\text { FP (II) } \\
2^{\circ} F \text { (III) } \\
\end{array}$ & $\begin{array}{l}\text { FP (I-II) } \\
2^{\circ} \mathrm{F} \text { (III y V) } \\
3^{\circ} \mathrm{F} \text { (IV) } \\
\end{array}$ \\
\hline $41(\mathrm{~N}=14)$ & Proótico-Opistótico & $\begin{array}{l}\text { HP } \\
\text { PT IV } \\
\text { AN XI } \\
\end{array}$ & & \\
\hline $42(N=2)$ & & PT V-IX & $\begin{array}{l}\text { Falanges } \\
\text { restantes }\end{array}$ & $\begin{array}{l}\text { Falanges } \\
\text { restantes }\end{array}$ \\
\hline $43(N=2)$ & $\begin{array}{l}\text { 1.Premaxilar } \\
\text { 2. Maxilar-Nasal- } \\
\text { Septomaxilar } \\
\text { 3. Vomer }\end{array}$ & & & Isquion \\
\hline $44(N=1)$ & $\begin{array}{l}\text { Dentario } \\
\text { Anguloesplenial } \\
\text { Escamoso (rv) } \\
\text { Pterigoides } \\
\end{array}$ & & & \\
\hline $46(N=2)$ & $\begin{array}{l}\text { 1. Escamoso (ro) } \\
\text { 2. Palatino-columela- } \\
\text { Tirohial } \\
\text { 3.Escamoso (ra) }\end{array}$ & & $\begin{array}{l}\text { Carpianos } \\
\text { Prepollex }\end{array}$ & $\begin{array}{l}\text { Tarsianos } \\
\text { Prehallux }\end{array}$ \\
\hline PM & $\begin{array}{l}\text { Articular-Cuadrado - } \\
\text { Esfenoetmoides } \\
\text { Mentomeckeliano }\end{array}$ & & Esternón & \\
\hline
\end{tabular}


APÉNDICE VIII. Secuencia de osificación de Batrachyla leptopus. En negrita se indican las autostosis. A los estadios $38(\mathrm{~N}=1)$ y $44(\mathrm{~N}=1)$ no se registraron novedades. Referencias: AA: apendicular anterior, AN: arcos neurales, AP: apendicular posterior, C: cuerpos vertebrales, CL: centro lateral, CM: centro medial, FP: falanges proximales, HP: hipocordo, MC: metacarpianos, MT: metatarsianos, PT: procesos transversos, ra: rama anterior, ro: rama ótica, rv: rama ventral. Entre los estadios 26 y 33 no se registraron osificaciones.

\begin{tabular}{|c|c|c|c|c|}
\hline Estadio & Cráneo & Axial & AA & AP \\
\hline $34(\mathrm{~N}=4)$ & $\begin{array}{l}\text { Paraesfenoides } \\
\text { Exoccipital }\end{array}$ & $\begin{array}{l}\text { AN I-IV } \\
\text { PT I-III }\end{array}$ & $\begin{array}{l}\text { Escápula } \\
\text { Estilopodio } \\
\text { Zeugopodio }\end{array}$ & $\begin{array}{l}\text { Estilopodio } \\
\text { Zeugopodio } \\
\text { Ileon } \\
\text { Tibial-fibular }\end{array}$ \\
\hline $35(N=3)$ & & $\begin{array}{l}\text { AN V-VIII } \\
\text { C I-VIII }\end{array}$ & & MT(III-V) \\
\hline $36(N=5)$ & Frontoparietal & $\begin{array}{l}\text { PT IV } \\
C \text { IX }\end{array}$ & $\begin{array}{l}\text { Coracoides } \\
\text { Clavícula } \\
\text { Cleitro } \\
\text { MC (IV-V) } \\
1^{\circ} \mathrm{F} \text { (IV-V) } \\
\mathbf{2}^{\circ} \text { (IV) } \\
\end{array}$ & $\begin{array}{l}\text { MT(II) } \\
1^{\circ} \mathrm{F} \text { (IIIV) } \\
2^{\circ} \mathrm{F} \text { (IV-V) } \\
3^{\circ} \mathrm{F} \text { (IV) }\end{array}$ \\
\hline $37(\mathrm{~N}=1)$ & & HP-AN XI & $\begin{array}{l}\mathrm{MC}(\mathrm{II}-\mathrm{III}) \\
1^{\circ} \mathrm{F}(\mathrm{II}-\mathrm{III}) \\
2 \mathrm{~F}^{\circ} \text { (III) }\end{array}$ & MT(D I) \\
\hline $39(N=3)$ & Opistótico & PT 5०-90 & & \\
\hline $40(N=7)$ & & & $\begin{array}{l}\text { Falanges } \\
\text { restantes }\end{array}$ & $\begin{array}{l}\text { Falanges } \\
\text { restantes }\end{array}$ \\
\hline $41(N=8)$ & Proótico & & & \\
\hline $42(\mathrm{~N}=2)$ & $\begin{array}{l}\text { Premaxilar } \\
\text { Septomaxilar } \\
\text { Dentario-Maxilar } \\
\text { Anguloesplenial } \\
\text { Tirohial } \\
\end{array}$ & & & \\
\hline $43(\mathrm{~N}=15)$ & & & & Isquion (cl) \\
\hline $46(N=3)$ & $\begin{array}{l}\text { Nasal- Vomer } \\
\text { Escamoso (rv y ro) } \\
\text { Pterigoides - Palatino }\end{array}$ & & & Isquion (cm) \\
\hline PM & $\begin{array}{l}\text { Mentomeckeliano } \\
\text { Escamoso (ra) } \\
\text { Articular- } \\
\text { Cuadrado } \\
\text { Columela } \\
\text { Esfenoetmoides }\end{array}$ & & $\begin{array}{l}\text { Carpianos } \\
\text { Esternón }\end{array}$ & Tarsianos \\
\hline
\end{tabular}

